Karin Bickel

Familienbezogene Elemente im System der gesetzlichen Rentenversicherung 
Karin Bickel

\section{Familienbezogene Elemente im System der gesetzlichen Rentenversicherung}

Die Arbeit analysiert das System der gesetzlichen Rentenversicherung in Deutschland hinsichtlich der langfristigen Funktionsfähigkeit bei sinkender Geburtenrate. Dabei werden in erster Linie die verschiedenen Familienformen (vollständige, unvollständige Familien, nichteheliche Lebensgemeinschaften) und ihre rentenversicherungsrechtliche Stellung im gegenwärtigen System der umlagefinanzierten Alterssicherung betrachtet. Es zeigt sich, daß ein demographisch bedingter Verteilungskonflikt annähernd unausweichlich erscheint, wenn nicht alsbald innerhalb des auf intergenerativer Solidarität ausgelegten sozialen Systems Umbaumaßnahmen vorgenommen werden, die unter anderem das Subsidiaritätsprinzip wieder stärker in den Vordergrund rücken lassen. Ohne gravierende strukturelle Korrekturen wird die Finanzierbarkeit des Rentenversicherungssystems in Zukunft vermutlich gefährdet sein.

Karin Bickel wurde 1957 in Bothkamp/Schleswig-Holstein geboren. Sie studierte Volkswirtschaftslehre an der Universität Kiel (1978-1984). Von 1985 bis 1991 arbeitete sie als wissenschaftliche Mitarbeiterin am Institut für Finanzwissenschaft und Sozialpolitik der Universität Kiel und promovierte zum Dr. sc. pol. Seit 1991 ist sie als Dozentin für Volkswirtschafts- und Betriebswirtschaftslehre an verschiedenen Bildungseinrichtungen tätig, unter anderem an der Fachhochschule Kiel, der Hochschule für Kunst und Gestaltung, Muthesius-Hochschule, in Kiel, sowie der Wirtschaftsakademie Schleswig-Holstein. 
Familienbezogene Elemente im System der gesetzlichen Rentenversicherung 


\section{FINANZWISSENSCHAFTLICHE SCHRIFTEN}

Herausgegeben von den Professoren

Albers, Krause-Junk, Littmann, Oberhauser, Pohmer, Schmidt

Band 89

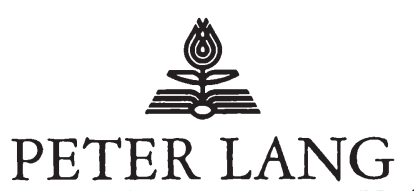

Frankfurt am Main · Berlin · Bern · New York · Paris · Wien 


\section{Karin Bickel}

\section{Familienbezogene Elemente im System der gesetzlichen Rentenversicherung}

Unter besonderer Berücksichtigung von Ein-Eltern-Familien



Europäischer Verlag der Wissenschaften 
Die Deutsche Bibliothek - CIP-Einheitsaufnahme

Bickel, Karin:

Familienbezogene Elemente im System der gesetzlichen

Rentenversicherung : unter besonderer Berücksichtigung von Ein-Eltern-Familien / Karin Bickel. - Frankfurt am Main ;

Berlin ; Bern ; New York ; Paris ; Wien : Lang, 1999

(Finanzwissenschaftliche Schriften ; Bd. 89)

Zugl.: Kiel, Univ., Diss., 1997

ISBN 3-631-33577-6

Open Access: The online version of this publication is published on www.peterlang.com and www.econstor.eu under the international Creative Commons License CC-BY 4.0. Learn more on how you can use and share this work: http://creativecommons. org/licenses/by/4.0.

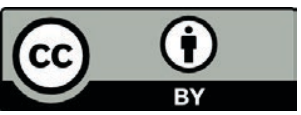

This book is available Open Access thanks to the kind support of ZBW - Leibniz-Informationszentrum Wirtschaft.

Gedruckt auf alterungsbeständigem, säurefreiem Papier.

\author{
D 8 \\ ISSN 0170-8252 \\ ISBN 3-631-33577-6 \\ ISBN 978-3-631-75221-0 (eBook) \\ (C) Peter Lang GmbH \\ Europäischer Verlag der Wissenschaften \\ Frankfurt am Main 1999 \\ Alle Rechte vorbehalten.
}

Das Werk einschließlich aller seiner Teile ist urheberrechtlich geschützt. Jede Verwertung außerhalb der engen Grenzen des

Urheberrechtsgesetzes ist ohne Zustimmung des Verlages unzulässig und strafbar. Das gilt insbesondere für Vervielfältigungen, Übersetzungen, Mikroverfilmungen und die Einspeicherung und Verarbeitung in elektronischen Systemen.

Printed in Germany 134567 
Für meinen Vater 



\section{Vorwort}

Die vorliegende Arbeit ist Ende 1996 an der Wirtschafts- und Sozialwissenschaftlichen Fakultät der Christian-Albrechts-Universität zu Kiel eingereicht und als Dissertation angenommen worden.

Besonderen Dank schulde ich Herrn Prof. Dr. Dr. h.c. Willi Albers, der nicht nur den AnstoB zur Bearbeitung des Themas gab, sondern auch durch ständige Diskussionsbereitschaft und langjährige Geduld das Entstehen dieser Arbeit förderte.

Ich danke ebenso dem Koreferenten der Arbeit, Herrn Prof. Dr. Lars Clausen für die Erstellung des Zweitgutachtens.

Von unschätzbarem Wert für mich waren die Unterstützung und die kaum endende Geduld meines Ehemannes Kai Marcus, der Ansporn für mich war, auch in schwierigen Situationen das einmal gesteckte Ziel nicht aus den Augen zu verlieren.

Für wertvolle Anregungen und konstruktive Kritiken danke ich den Professoren, allen wissenschaftlichen Assistenten und Hilfskräften des Instituts für Finanzwissenschaft und Sozialpolitik der Christian-Albrechts-Universität zu Kiel.

Zur Überprüfung des formalen Apparates und für die umfangreichen Schreibarbeiten, die durch den Einsatz elektronischer Datenverarbeitung manchmal ungeahnte Probleme auftauchen ließ, danke ich ganz herzlich Frau Marion Bielawa. 

Inhaltsverzeichnis

TEIL A: $\quad$ Einführung und Grundlagen

I: Die Entwicklung der Sozialen

Sicherung in Deutschland

1. Gründerjahre - Bismarcksche Sozialpolitik im Dienst von Volk und Monarchie

2. Sozialpolitik in der Weimarer Republik und im

Dritten Reich - Fortentwicklung unter widrigen

Umständen

3. Gründung der Bundesrepublik Deutschland -

Neuorientierung und Aufbau der sozialen

Marktwirtschaft

II: Die vollståndige Familie und ihre

Funktion im System der sozialen

Sicherung

$\begin{array}{ll}\text { 1. } & \text { Definition } \\ \text { 2. } & \text { Funktionen der Familie und soziale Sicherung }\end{array}$

III: Die unvollstãndige Familie

1. Definition

2. Ledige Mutterschaft - altes oder neues

Phänomen? 
1. Versicherungs-, Versorgungs-, Fürsorgeprinzip 26

2. Final- und Kausalprinzip $\quad 30$

3. Individual- und Familienprinzip 32

4. Vereinbarkeit der Prinzipien untereinander 34

V: Grundtatbestände des Systems der Alterssicherung in Deutschland 38

1. Die Struktur des Alterssicherungssystems $\quad 38$

2. Leistungsbegründende Tatbestände 41

2.1. Alter $\quad 42$

2.2. Minderung der Erwerbsfähigkeit 43

$\begin{array}{lll}\text { 2.3. } & \text { Tod } & 47\end{array}$

2.4. Kindererziehung $\quad 50$

2.5. Pflege eines Angehörigen 51

3. Grundlage der Leistungsbemessung in der gesetzlichen Rentenversicherung:

Die Rentenformel 52

4. Leistungen im System der Alterssicherung $\quad 72$

4.1. Höhe der eigenen Leistungen $\quad 72$

4.1.1. Gesetzliche Rentenversicherung 72

4.1.2. Betriebliche Altersversorgung 76

4.1.3. Altersversorgung im öffentlichen Dienst $\quad 78$

4.2. Höhe der abgeleiteten Leistungen 82

$\begin{array}{lll}\text { 4.3. Kumulation von Einkommen } & 84\end{array}$

5. Finanzierung der gesetzlichen

6. Rentenversicherung 95

$\begin{array}{lll}\text { 5.1. } & \text { Beiträge } & 97\end{array}$

$\begin{array}{lll}\text { 5.2. } & 104\end{array}$

$\begin{array}{lll}\text { 5.3. } & \text { Finanzausgleich } & 110\end{array}$ 
TEIL B: Die Stellung der Frau in der gesetzlichen Rentenversicherung

1. Erwerbstätigkeit als grundsätzliche Voraussetzung einer eigenständigen Sicherung

2. Die freiwillige Versicherung der nicht erwerbstätigen Frau

3. Ursachen für die schlechtere materielle Sicherung der Frau

3.1. Der geschlechtsspezifische Arbeitsmarkt

3.2. Erwerbsverhalten

3.3. Gesetzliche Schutzbestimmungen für Frauen

4. Berücksichtigung von Zeiten der Kindererziehung in der GRV

5. Bundesverfassungsgerichtsurteil vom 7. Juli 1992

6. Die Rentenreform 1992 - Auswirkungen auf die soziale Sicherung der Frau

TEIL C: Die rentenversicherungsrechtliche Stellung der verschiedenen Gruppen alleinerziehender Frauen

I: Quantitative Bedeutung der EinEItern-Familien

II: Kinder in Familien

III:

Wirtschaftliche Lage von alleinerziehenden Müttern 

2. Kosten von Kindern
3. Familienlastenausgleich in der BRD
4. Unterhaltsvorschußkassen
IV:
Nichteheliche Lebensgemeinschaften
als alternative Form des familialen
Zusammenlebens

V:

\author{
Die Rechtsstellung geschiedener \\ Mütter in der gesetzlichen \\ Rentenversicherung
}

1. Zur Situation vor dem Scheidungsgesetz vom 1.7.1977

1.1. Voraussetzungen für den Bezug einer

Rente zu Lebzeiten des geschiedenen Ehegatten

1.2. Die Geschiedenenwitwenrente

2. Zur Situation nach Inkrafttreten des neuen

Scheidungsgesetzes

2.1. Voraussetzung für eine Scheidung 282

2.2. Unterhaltspflichten 289

2.3. Versorgungsausgleich 303

2.3.1. Grundsatz und Zielsetzung 303

2.3.2. Ermittlung und Bewertung der auszugleichenden Anwartschaften 305

2.3.3.

Öffentlich-rechtlicher Versorgungsausgleich 
2.3.3.5. Höchstgrenze, Härteklausel und Auswirkungen des öffentlich-rechtlichen

Versorgungsausgleich

2.3.3.6.

Die Erziehungsrente

2.3.4.

Schuldrechtlicher Versorgungsausgleich

VI: Die Stellung der verwitweten Frau in der gesetzlichen Rentenversicherung

1. Die Entwicklung der Witwen-, bzw. Witwerrenten bis zur Entscheidung des Bundesverfassungsgerichts 1975

2. Überlegungen der '84er Kommission zur Reform der Hinterbliebenenrenten

3. Das „Anrechnungsmodell“ im Gesetz zur Neuordnung der Hinterbliebenenversorgung (HEZG)

VII:

Ũberlegungen zur systemkonformen Eingliederung Alleinerziehender in die gesetzliche Rentenversicherung

1.

Allgemeines, Zielsetzungen

2.

Konzeption

2.1 .

Ledige

Verheiratet getrennt Lebende

Geschiedene

2.4.

Witwen/Witwer

3.

SchluBbemerkung

378 


\section{Abkürzungsverzeichnis}

a.a.O.

Abs.

AFG

AnV

Art.

ArV

ArVNG

AVG

BGB

BeamtVG

BErzGG

BR-Drucks.

BSG

BSHG

BT-Drucks.

BVerfG

BVersG

bzw.

ca.

CDU

d.h.

EStG

ff.

GG am angegebenen Ort

Absatz

Arbeitsförderungsgesetz

Angestelltenversicherung

Artikel

Arbeiterrentenversicherung

Arbeiterrentenversicherungs-Neuregelungsgesetz

Angestelltenversicherung

Bürgerliches Gesetzbuch

Beamtenversorgung

Bundeserziehungsgeldgesetz

Bundesrats-Drucksache

Bundessozialgericht

Bundessozialhilfegesetz

Bundestags-Drucksache

Bundesverfassungsgericht

Bundesversorgungsgesetz

beziehungsweise

circa

Christlich Demokratische Union

das heibt

Einkommenssteuergesetz

folgende

Grundgesetz für die Bundesrepublik

Deutschland 
GKV

GRV

HEZG

i.d.R.

i.V.m.

Jg.

Ksvg

MuSchG

Nr.

o.a.

RGBI

RRG

RV Änd G

RVO

SGB I

SGB VI

SGB V

SGB VI
Gesetzliche Krankenversicherung

Gesetzliche Rentenversicherung

Gesetz zur Neuordnung der Hinterbliebenenrenten sowie zur Anerkennung von Kindererziehungszeiten in der gesetzlichen Rentenversicherung

in der Regel

in Verbindung mit

Jahrgang

Künstlersozialversicherungsgesetz

Gesetz zum Schutz der erwerbstätigen Mutter = Mutterschutzgesetz

Nummer

oben angeführt

Reichsgesetzblatt

Rentenreformgesetz 1992

Rentenversicherungs-Änderungsgesetz

Reichsversicherungsordnung

Sozialgesetzbuch, Erstes Buch - Allg. Teil

Sozialgesetzbuch, Viertes Buch - Gemeinsame

Vorschriften für die Sozialversicherung

Sozialgesetzbuch, Fünftes Buch - Gesetzliche Krankenversicherung

Sozialgesetzbuch, Sechstes Buch - Gesetzliche Rentenversicherung 
sog.

u.a.

u.a. 0 .

u.s.w.

VAHRG

VDR

vgl.

z.B.

Ziff.

z.T.

z.Zt. sogenannte

unter anderem

und anderen Orten

und so weiter

Gesetz zur Regelung von Härten im Versorgungsausgleich

Verband Deutscher Rentenversicherungsträger

vergleiche

zum Beispiel

Ziffer

zum Teil

zur Zeit 


\section{Tabellenverzeichnis}

Tabelle 1: Versicherte in der Rentenversicherung ( $\mathrm{ArV}$ und AnV) und der knappschaftlichen Rentenversicherung (KnV) nach dem Versicherungsverhältnis und dem Geschlecht

Tabelle 2: Die Struktur der Versicherten der Rentenversicherung der Arbeiter und der Angestellten in den alten und neuen Bundesländern in den Jahren 1991 bis 1994

Tabelle 3: Anzahl und Höhe der Leistungen der GRV (ArV/AnV) nach Geschlecht und Rentenart am 1.7.1994

Tabelle 4: Verteilung der Rentenzahlbeträge nach GröBenklasse, Rentenart und Geschlecht

Tabelle 5: Höhe der betrieblichen Altersversorgung, Personen ab 55 Jahre - Alte Bundesländer -

Tabelle 6: Anzahl und Höhe der Leistungen der Zusatzversorgung im öffentlichen Dienst - Alte Bundesländer -

Tabelle 7: Anzahl und Höhe der Leistungen aus der Beamtenversorgung - Alte Bundesländer -

Tabelle 8: Höhe und Verbreitung abgeleiteter Renten in der GRV nach Alter des Leistungsempfängers - Alte und Neue Bundesländer im Jahre 1992 -

Tabelle 9:

Anzahl der Rentner (ArV/AnV) und durchschnittliches Renteneinkommen am 1.7.1994

Tabelle 10: Anzahl und Struktur der Renten und der Rentner (ArV/AnV) nach Geschlecht und Rentenart am 1.7.1994 
Tabelle 11: Das durchschnittliche Renteneinkommen von Rentnerinnen (ArV/AnV) nach Altersgruppen am 1.7.1994 - Alte Bundesländer -

Tabelle 12: Das durchschnittliche Renteneinkommen von Rentnerinnen (ArV/AnV) nach Altersgruppen am 1.7.1994 - Neue Bundesländer -

Tabelle 13: Anzahl der Renten und der Rentner (ArV/AnV) sowie durchschnittlicher Rentenbetrag bzw. durchschnittliches Renteneinkommen nach Geschlecht und Rentenart am 1.7.1994

Tabelle 14: Schichtung des monatlichen Renteneinkommens von Rentnerinnen (ArV/AnV) am 1.7.1994 - Alte Bundesländer -

Tabelle 15: Schichtung des monatlichen Renteneinkommens von Rentnerinnen (ArV/AnV) am 1.7.1994 - Alte Bundesländer -

Tabelle 16: Witwenzugang 1994 - Alte Bundesländer - Höhe der Rentenleistungen nach Kinderzahl

Tabelle 17: Die Entwicklung der Beitragssätze in der Rentenversicherung der Arbeiter und der Angestellten 1980-1999

Tabelle 18: $\quad$ Allgemeiner Bundeszuschuß in \% der Rentenausgaben

Tabelle 19: Finanzausgleich der Angestelltenrentenversicherung an die Arbeiterrentenversicherung 1974 - 1995 in Mrd. DM

Tabelle 20: Die Entwicklung der Einnahmen, der Ausgaben und des Vermögens in der Rentenversicherung der Arbeiter und der Angestellten von 1995 bis 1999 
Tabelle 21: Die Entwicklung der Einnahmen und der Ausgaben in der Rentenversicherung der Arbeiter und der Angestellten von 1995 bis 1999 - Alte Bundesländer -

Tabelle 22: Die Entwicklung der Einnahmen und der Ausgaben in der Rentenversicherung der Arbeiter und der Angestellten von 1995 bis 1999 - Neue Bundesländer -

Tabelle 23: Anteil weiblicher Manager der 1. bis 3. Führungsebene im Unternehmen mit einer Mitarbeiterzahl von 501-5000 (nach ausgewählten Branchen/in Prozent)

Tabelle 24: Anteil weiblicher Manager der 1. bis 3. Führungsebene (nach Unternehmensgrößen/in Prozent)

Tabelle 25: $\quad$ Erwerbsbeteiligung von Frauen mit Kindern nach Familienstand, Anzahl der Kinder und Alter der Kinder im Jahre 1992

Tabelle 26: Ehepaare nach Familientyp und Beteiligung der Partner am Erwerbsleben (Alter des Ehemannes < 65 Jahre) im Jahre 1992

Tabelle 27: Nichteheliche Lebensgemeinschaften nach Familientyp und Beteiligung der Partner am Erwerbsleben (Alter des Partners < 65 Jahre) im Jahre 1992

Tabelle 28: $\quad$ Wichtigster Grund für die Berufstätigkeit von erwerbstätigen Frauen nach Familientyp Verteilung in \%

Tabelle 29: $\quad$ Ehepaare mit Kindern und Alleinerziehende nach Betei-ligung am Erwerbsleben (Vollzeittätigkeit, Teilzeittätigkeit) und Alter des jüngsten Kindes im Jahre 1992 
Tabelle 30: Auswirkungen der verschiedenen Rentenregelungen nach Mindesteinkommen auf den durchschnittlichen Rentenbetrag der Frauen

Tabelle 31: Alleinerziehende, Ehepaare und nichteheliche Lebensgemeinschaften im früheren Bundesgebiet

Tabelle 32: Ehepaare mit minderjährigen Kindern sowie Alleinerziehende

Tabelle 33: $\quad$ Alleinerziehende nach dem Familienstand in \%

Tabelle 34: $\quad$ Familien Alleinerziehender mit minderjährigen Kindern nach Geschlecht und Familienstand seit 1961

Tabelle 35: Kinderzahl bei Alleinerziehenden im Vergleich zur Kinderzahl bei Ehepaaren für Kinder unter $18 \mathrm{Jahren}$ in \%

Tabelle 36: Mütter mit minderjährigen Kindern 1992 nach Altersgruppen

Tabelle 37: Kinder von Ehepaaren, Alleinerziehenden und nichtehelichen Lebensgemeinschaften 1992 nach Altersgruppen

Tabelle 38: Minderjährige Kinder von Ehepaaren und Alleinerziehenden 1992 nach dem Familienstand

Tabelle 39: $\quad$ Ehepaare und Alleinerziehende 1992 nach Erwerbstätigkeit und monatlichem Haushaltsnettoeinkommen

Tabelle 40: Alleinerziehende 1992 nach monatlichem Haushaltsnettoeinkommen und Kinderzahl 
Tabelle 41: Alleinerziehende Frauen 1992 nach monatlichem Haushaltsnettoeinkommen und Alter des jüngsten Kindes

Tabelle 42: $\quad$ Ehepaare und Alleinerziehende 1992 nach überwiegendem Lebensunterhalt der Bezugsperson und monatlichem Haushaltsnettoeinkommen

Tabelle 43: Kinderkosten in Durchschnittswerten nach Berechnungszeiten

Tabelle 44: $\quad$ Ermittlung der Lebenshaltungskosten eines Kindes 1987

Tabelle 45: $\quad$ Familienpolitik in der BRD

Tabelle 46: Zeittafel der wichtigsten familienpolitischen Gesetze und Leistungen in der Bundesrepublik Deutschland 1949 1996

Tabelle 47: Höhe des Kindergeldes nach dem Bundeskindergeldgesetz in DM/Monat 1955 - 1997

Tabelle 48: $\quad$ Kinderfreibeträge 1949 - 1997 (Jahresbeiträge in DM)

Tabelle 49: Bevölkerung in Privathaushalten im Alter von 18 und mehr Jahren nach Zusammenleben mit einem Ehepartner bzw. Partner in Nichtehelicher Lebensgemeinschaft

Tabelle 50: Bevölkerung in Privathaushalten im Alter von 18 und mehr Jahren im Mai 1992 nach Altersgruppen und Zusammenleben mit einem Ehepartner bzw. Partner in Nichtehelicher Lebensgemeinschaft 
XXII

Tabelle 51: $\quad$ Ehepaare und Nichteheliche Lebensgemeinschaften im Mai 1992 nach Alter des weiblichen Partners und Zahl der Kinder

Tabelle 52: Überwiegender Lebensunterhalt von Alleinerziehenden mit Kindern unter 18 Jahren

Tabelle 53: Überwiegender Lebensunterhalt von Alleinerziehenden Müttern mit Kindern unter 18 Jahren nach Altersstufen

Tabelle 54: Unterhaltszahlungen an Kinder aus geschiedener Ehe (Düsseldorfer Tabelle)

Tabelle 55: Anrechenbares Einkommen auf die Hinterbliebenenrente

Tabelle 56: $\quad$ Ehescheidungen 1950 - 1988

Tabelle 57: Ehescheidungen nach dem Antragsteller

Tabelle 58: Geschiedene Ehen nach Art der „Entscheidung in der Ehesache $^{\text {6 }}$

Tabelle 59: Geschiedene Ehen nach der Zahl der minderjährigen Kindern in der Familie 


\section{Abbildungsverzeichnis}

Abbildung 1:

Beiträge und Leistungen in der gesetzlichen Krankenversicherung

Abbildung 2:

Erwerbsquoten von Personen im Alter von 15 bis unter 65 Jahren

Abbildung 3:

Ehefrauen unter 35 Jahren nach Beteiligung am Erwerbsleben $^{*}$ ) (Früheres Bundesgebiet)

Abbildung 4:

Minderjährige Kinder in Eltern-Kind-Gemeinschaften 1992*)

Abbildung 5:

Familienpolitische Transferströme

Abbildung 6:

Formen nichtehelicher Lebensgemeinschaften

Abbildung 7:

Nichteheliche Lebensgemeinschaften $1992^{*}$ ) 



\section{TEIL A: EINFÜHRUNG UND GRUNDLAGEN}

\section{Die Entwicklung der sozialen Sicherung in Deutschland}

1. Gründerjahre - Bismarcksche Sozialpolitik im Dienst von Volk und Monarchie

Darstellungen von Entstehung und Entwicklung staatlicher Sozialversicherungspolitik in Deutschland beginnen in aller Regel mit der Bismarckschen Sozialgesetzgebung in den achtziger Jahren des vergangenen Jahrhunderts. Dies erscheint legitim, auch wenn selten der Hinweis auf zahlreiche Sozialfürsorge- und Versicherungseinrichtungen fehlt, die schon vor den Sozialreformen des 1871 wiedergegründeten Kaiserreiches bestanden haben. So verweist Fischer $^{1}$ darauf, daß allein in Preußen zehn Jahre vor Beginn der reichsweiten Krankenversicherung (1883) rund eine Million Arbeitnehmer gegen Krankheit und teilweise auch gegen Unfall und Invalidität versichert waren, während sich erste gesetzliche Regelungen zur Armenhilfe bis auf das Jahr 1842 zurückverfolgen lassen. Der eigentliche Durchbruch von der eher dezentralisierten privaten, genossenschaftlichen oder kommunalen Hilfe hin zu einer gesamtstaatlichen Sozialpolitik mit einem "dauerhaften, institutionalisierten und durch Rechtsansprüche abgesicherten effektiveren Schutz gegen die Risiken einer arbeitsteiligen Industriegesellschaft" ${ }^{2}$ gelang aber tatsächlich erst unter der Ägide des "Eisernen Kanzlers". Seither läBt sich "die weitere sozialpolitische Entwicklung und damit die Entwicklung der deutschen Sozialordnung vornehmlich als ein sukzessiver Prozeß der Angliederung weiterer Institutionen an den Kernbereich der Sozialen Sicherung und die Aufnahme weiterer sozial schwacher und gefährdeter Gruppen in diese Ordnung"' beschreiben. Der schrittweise Ausbau des sozialen Si-

\footnotetext{
${ }^{1}$ Fischer, W., Deutschland 1815-1914, in: W. Fischer (Hrsg.), Europäische Wirtschaftsund Sozialgeschichte von der Mitte des 19. Jahrhunderts bis zum Ersten Weltkrieg. Stuttgart 1985, S. 357-442, hier: S. 435f.

${ }^{2}$ Schmidt, M.G., Sozialpolitik - Historische Entwicklung und internationaler Vergleich, Opladen 1988, S. 22.

3 Neumann, L.F., K. Schaper, Die Sozialordnung der Bundesrepublik Deutschland. Frankfurt, New York 1990, S. 24.
} 
cherungssystems, der bis in die heutige Zeit die politische Diskussion bestimmt und politische, wirtschaftliche und demographische Entwicklungen widerspiegelt (man denke an die Überlegungen, die angesichts steigender Lebenserwartung der Menschen und immenser Fortschritte in der Medizintechnik zur Einführung einer Pflegepflichtversicherung angestellt werden), steht im Mittelpunkt der folgenden Ausführungen.

Die Bismarcksche Sozialgesetzgebung entsprang keineswegs dem reformpolitischen Eifer ihrer Initiatoren, sondern vielmehr einem machtpolitischen Kalkül. Nicht das im Zuge der Industrialisierungswelle seit etwa 1850 wachsende soziale Elend, eher die (vermeintliche oder reale) Bedrohung des gesellschaftlichen Systems durch ein zahlenmäßig und organisatorisch erstarkendes Industrieproletariat bewog Bismarck, die Sozialpolitik als "ein Instrument zur Sicherung des Staates"4 einzusetzen. Sie war Teil einer Doppelstrategie, die zum einen sozialpolitische Zugeständnisse an die Arbeiterschaft vorsah, zum anderen jedoch mit dem "Gesetz wider die gemeingefährlichen Bestrebungen der Sozialdemokratie" von 1878 (Sozialistengesetz) deren Organisationen aufzulösen und in die Illegalität abzudrängen trachtete. Es sei vorweggenommen, daß das Unterfangen, die Sozialpolitik für politische Zwecke zu instrumentalisieren, gründlich fehlschlug. Ihre Einführung war nicht nur nicht geeignet, die Arbeiterbewegung zu schwächen und den gefürchteten "Vierten Stand" zu domestizieren; das Gegenteil sollte eintreten. Überdies zog Bismarcks Sozialpolitik die Kritik der Besitzbürger auf sich, die den Unternehmergeist durch den Staat bevormundet und eingeengt sahen und die Ausbreitung eines "Pensionsspekulantentums" bei weiten Teilen der Arbeiterschaft befürchteten5. Schon in den Gründerjahren also stand die Sozialpolitik im Spannungsfeld von egalitären Umverteilungsansprüchen und der liberalen Furcht vor einer Lähmung der individuellen Leistungsbereitschaft.

\footnotetext{
4 Saul, K., Industrialisierung, Systemstabilisierung und Sozialversicherung. Zur Entstehung, politischen Funktion und soziale Realität der Sozialversicherung des kaiserlichen Deutschland, in: Zeitschrift für die gesamte Versicherungswirtschaft 69 (1980), S. 177198, hier: S. 183.

5 Tennstedt, F., Sozialgeschichte der Sozialversicherung, in: Maria Blohmke u.a. (Hrsg.), Handbuch der Sozialmedizin, Bd. 3, Stuttgart 1976, S. 385-492, hier: S. 449.
} 
Neben der politischen Destabilisierung, die vom Prozeß der Industrialisierung ausging und maßgeblich zum Entstehen der staatlichen Sozialpolitik beitrug, brachte die Industrielle Revolution auch zunehmend das bis dahin vorherrschenden Gefüge der sozialen Sicherung - vornehmlich auf familiärer, lokaler, zünftiger und genossenschaftlicher Ebene - ins Wanken. Der enorme Arbeitskräftebedarf der Fabriken wurde zum überwiegenden Teil aus der verarmten Landbevölkerung rekrutiert; das traditionelle Übergewicht des agrarischen Bereiches schwand. Der Wandel in der Sozialstruktur aber lieB erst das Bedürfnis nach besonderen Sicherungseinrichtungen aufkommen: "Während innerhalb der gemeinsam arbeitenden und gemeinsam wohnenden agrarischen Großfamilie kranke, invalide und alte Familienmitglieder miternährt und mitverpflegt wurden, war der neue Typus des Fabrikarbeiters in der Regel auf sich allein gestellt; er lebte allein oder allenfalls im Rahmen der Kleinfamilie modernen Typs und war auf laufende Arbeitseinkommen angewiesen, die bei allen Formen der Leistungsunfähigkeit wegfielen"6. Hinzuzufügen ist, daß angesichts der generell niedrigen Löhne an eine auch nur annähernd ausreichende Eigenvorsorge nicht zu denken war. Somit bereitete die Industrielle Revolution nicht nur dem Angebot von staatlicher Sozialpolitik, sondern auch der Nachfrage nach kollektiven Sicherungseinrichtungen den Boden.

Die Sozialpolitik unter Reichskanzler Otto von Bismarck schuf Fundamente, auf denen das heutige System sozialer Sicherung noch aufbaut. Die Alters- und Invaliditätsversicherung', im Jahre 1889 eingeführt, war das letzte Element einer bis dahin einzigartigen Sozialreform, die nach kaiserlicher Ankündigung 1881 mit der Verabschiedung des Krankenversicherungsgesetzes 1883 und des Unfallversicherungsgesetzes 1884 eingeleitet

${ }^{6}$ Döring, D., Das System der gesetzlichen Rentenversicherung, Eine sozialpolitische Einführung, Frankfurt/M., New York 1980, S. 12.

${ }^{7}$ Das entsprechende Gesetz vom 22. Juni 1889 machte alle Personen, die das 16. Lebensjahr vollendet hatten und deren Verdienst unter einer jährlichen Einkommensgrenze von zunächst 2000 Mark blieb, versicherungspflichtig. Wie schon im Falle der Krankenund der Unfallversicherung, handelte es sich bei dieser ersten Rentenversicherung um eine "selektive Arbeitnehmer-Versicherung". Adressat der Sozialpolitik war in erster Linie die Arbeiterschaft; zur wichtigsten Zielgruppe zählten folglich nicht die Bedürftigen schlechthin, sondern jene Industriearbeiter, die als politisch "bedrohliche Bedürftige" galten. Vgl. dazu Hentschel, V., Geschichte der Sozialpolitik in Deutschland von 1880-1980, Frankfurt/M., 1983, S. 12. 
worden war. Das staatliche Bekenntnis und Engagement in der Sozialpolitik kann in seiner historischen Bedeutung und in seiner "Fernwirkung" kaum überschätzt werden, wenngleich die Zahl der Anspruchsberechtigten wie auch die Höhe der Sozialleistungen aus heutiger Sicht geradezu ärmlich erscheinen. Die Alterssicherung etwa verdiente diese Bezeichnung nicht, wenn man berücksichtigt, daB die Altersrenten im Regelfall nicht mehr als ein Sechstel bis ein Fünftel des durchschnittlichen Jahresverdienstes eines Arbeitnehmers in Industrie, Handel und Verkehr ausmachten ${ }^{8}$ und eine Altersgrenze von 70 Jahren dafür sorgte, daß im Jahre 1891 gerade 120.000 Personen überhaupt in den Genuß dieses Sicherungssystems gelangten?.

Die Jahre nach dem Rücktritt Bismarcks (20.3.1890) und der Außerkraftsetzung des Sozialistengesetzes (30.9.1890) waren geprägt von dem Bemühen, das in seinen Kinderschuhen steckende soziale Sicherungssystem durch Ausdehnung des Versichertenkreises, der Leistungen und des Versichertenschutzes weiterzuentwickeln. Ein bemerkenswerter Fortschritt in der Entwicklung der Sozialversicherung gelang 1911 mit der Reichsversicherungsordnung (RVO). Mit ihr wurde - in Abgrenzung von der ArbeiterRentenversicherung - nicht nur ein Versicherungsgesetz für Angestellte institutionalisiert. Die RVO von 1911 ergänzte überdies die Bismarcksche Alters- und Invaliditätsversicherung um eine Hinterbliebenenrente. Ihre Notwendigkeit hatten schon die Bismarckschen Reformer erkannt, ohne jedoch daraus die nötigen Konsequenzen zu ziehen. Die Sicherstellung der Hinterbliebenenversorgung - naturgemäß ein Bereich der sozialen Sicherung, von dem zu damaliger Zeit vorrangig Frauen betroffen waren - bedurfte schließlich eines politischen Tauschgeschäftes ${ }^{10}$. Schon im Jahre 1902 ließen sich die Abgeordneten des Zentrums, der Freisinnigen und der Sozialdemokratie ihre Zustimmung zur Anhebung der Agrar- und Industriezölle nur mit der Zusage abringen, daß die den Durchschnitt der Jahre 1898 bis 1903 übersteigenden Erträge bestimmter Agrarzölle zur Finanzierung einer Hin-

\footnotetext{
${ }^{8}$ Vgl. Ritter, G.A., Die Sozialversicherung in Deutschland 1881-1914, in: Aus Politik und Zeitgeschichte (Beilage zur Wochenzeitung Das Parlament) Nr. B 34/1983, S. 30-38, hier: S. 33.

${ }^{9}$ Vgl. Fischer, W., a.a.O., S. 436.

${ }^{10}$ Vgl. dazu Zöllner, D., Ein Jahrhundert Sozialversicherung in Deutschland, Berlin 1981, S. 33ff; ferner Döring, D., a.a.O., S. 24ff. sowie Schmidt, M.G., a.a.O., S. 35ff.
} 
terbliebenenversicherung angesammelt werden, die bis zum Anfang des Jahres 1910 geschaffen werden sollte.

Das der Sozialversicherung immanente ständische Prinzip, das in der Aufteilung der Arbeiternehmerschaft in Arbeiter, Angestellte und Beamte aufscheint, kam auch bei der institutionellen Ausgestaltung der Hinterbliebenenversorgung zum Tragen: "Arbeiter-Witwen wurde in der Regel eine Erwerbstätigkeit zugemutet, selbst wenn sie Kinder zu erziehen hatten und vorher nicht beruflich tätig waren. Von Angestellten-Witwen wurde das nicht erwartet" ". Die praktischen Auswirkungen dieser Regelung waren eklatant: Witwenrente wurde nur an erwerbsunfähige Arbeiterwitwen gezahlt; dabei galt die sogenannte Ein-Drittel-Invaliditätsgrenze, die "nur von 'völlig hilflosen Frauen' erreicht [wurde]"'. Die angeblich häufig unzureichende Ausbildung der Angestelltenwitwen und die hier vorgeblich höheren Aufwendungen bei der Ausbildung und Erziehung der Kinder fanden als Begründung für die Ungleichbehandlung bei der Mehrheit der Reichstagsabgeordneten Gehör. Endgültig beseitigt wurde dieser konzeptionelle Mangel - von Invalidität abhängige, bedingte Witwenrente für Arbeiterfrauen, unbedingte Witwenrente für die Hinterbliebenen von Angestellten - erst nach dem zweiten Weltkrieg mit dem Sozialversicherungsanpassungsgesetz vom 17.6.1949, als man dazu überging, die Witwenrente einheitlich nach dem Tode des versicherten Ehemannes zu zahlen. Eine erste Abmilderung der Benachteiligung der Arbeiterwitwen war allerdings schon 1927 erfolgt: Seither wurde die Witwenrente nach Vollendung des 65. Lebensjahres zumindest automatisch gewährt. Zuvor mußten selbst Frauen in weit höheren Altersjahren Überprüfungen ihrer Arbeitsfähigkeit hinnehmen ${ }^{13}$.

Das herannahende Ende des Kaiserreichs brachte trotz (oder gerade wegen) des Krieges eine Reihe weiterer Verbesserungen des sozialen Sicherungsnetzes. Erstmals übernahm das Reich 1914 mit einem Finanztransfer von 200 Millionen Mark an die Kommunen "Mitverantwortung für die Beseitigung der Not der Arbeitslosen"14. Familienpolitisch bedeutsamer noch

\footnotetext{
${ }^{11}$ Schmidt, M.G., a.a.O., S. 36.

${ }^{12}$ Döring, D., a.a.O., S. 26.

${ }^{13}$ Dreher, W., Die Entstehung der Arbeiterwitwenversicherung in Deutschland, Berlin 1978, S. 82.

${ }^{14}$ Bogs, W., Die Sozialversicherung in der Weimarer Demokratie, München 1981, S. 39.
} 
war die Einführung der sogenannten Wochenhilfe 1914 und 1915 innerhalb der gesetzlichen Krankenversicherung, mit der die "Grundlage eines systematischen Mutterschaftsschutzes und einer familienfreundlichen Politik"15 geschaffen wurde. Die Wochenhilfe sah eine bessere Mutterschaftshilfe für Ehefrauen von Kriegsteilnehmern vor, die krankenversichert waren und für nichtkrankenversicherte Ehefrauen, die Kriegsunterstützung bezogen ${ }^{16} .1916$ schließlich wurde die Altersgrenze in der Arbeiterrentenversicherung von 70 auf 65 Jahre herabgesetzt "und damit auf ein Niveau gedrückt, das dem der Angestelltenversicherung rechnerisch gleichkam"17.

\section{Sozialpolitik in der Weimarer Republik und im Dritten Reich - Fortentwicklung unter widrigen Umständen}

Der Zusammenbruch des Kaiserreiches und die Gründung der Weimarer Republik schufen für den weiteren Ausbau des Systems der sozialen Sicherung tendenziell günstige Voraussetzungen. Zum einen fand die junge Republik bereits entwickelte institutionelle Strukturen vor, zum anderen fungierten die politisch gestärkte Gewerkschaftsbewegung wie auch die Links-Parteien als Promotoren der sozialreformerischen Bewegung. Weniger günstig gestalteten sich die wirtschaftlichen Rahmenbedingungen, die den Spielraum für eine aktive Sozialpolitik erheblich einengten ${ }^{18}$. Demobilisierung, Arbeitslosigkeit, Reparationsforderungen der Siegermächte, vor allem aber die letztlich in die Hyperinflation von 1923 mündende Geldentwertung erschütterten die Sozialversicherung in ihren Grundfesten. Allein die Arbeiterrentenversicherung verlor in diesem Jahr ein aus den Beitragszahlungen gebildetes Vermögen von 2 Milliarden Mark ${ }^{19}$, während auf der anderen Seite die Zahl der Anspruchsberechtigten stark angestiegen war ${ }^{20}$. Dennoch ermöglichten die wenigen Jahre der wirtschaftlichen Erholung und

\footnotetext{
${ }^{15}$ Schmidt, M.G., a.a.O., S. 38.

${ }^{16}$ Ebenda, S. 38.

${ }^{17}$ Ebenda, S. 38.

${ }^{18}$ So auch Abelshauser, W. (Hrsg.), Die Weimarer Republik als Wohlfahrtsstaat, Wiesbaden 1987 .

19 Vgl. Petersen, H.-G., Sicherheit der Renten? Die Zukunft der Altersversorgung, Würzburg, Wien 1981, S. 25.

${ }^{20}$ Vgl. Schmidt, M.G., a.a.O., S. 41.
} 
der relativen Prosperität bis zum Ausbruch der Weltwirtschaftskrise einen expansiven sozialpolitischen Kurs. Zu den wichtigsten Maßnahmen ${ }^{21}$ zählten die Sozialleistungen für 1,5 Millionen Kriegsgeschädigte und 2,5 Millionen Kriegs-Waisen und Kriegs-Witwen (1920), der Ausbau der Wochenhilfe und -fürsorge (1919), Leistungsverbesserungen bei den bis dahin auf einen $\mathrm{Zu}$ verdienst angelegten Altersrenten (1922), der Einstieg in die berufliche Rehabilitation durch Einführung der Berufsfürsorge in der Unfallversicherung (1925) und ferner der schon erwähnte Abbau der Benachteiligung von Arbeiter- gegenüber Angestelltenwitwen in der Hinterbliebenenversorgung (1927). In die Zeit der Weimarer Republik fällt auch die Errichtung eines vierten Sozialversicherungssystems. Das Gesetz über die Arbeitsvermittlung und Arbeitslosenversicherung von 1927 schloB endgültig die bis dahin bestehende größte Lücke im Netz der sozialen Sicherung.

Ob die Sozialpolitik von der Weltwirtschaftskrise mitgerissen wurde oder ob das hohe Sozialstaatsniveau mit der Überforderung der öffentlichen Haushalte gar einen eigenständigen Beitrag zum Untergang der Weimarer Republik geleistet hat, wie dies einige Historiker zu erkennen glauben ${ }^{22}$, kann an dieser Stelle nicht näher erörtert werden. Es spricht jedoch einiges für die Analyse von Schmidt, daß dem kräftigen Tempo der Sozialpolitik in den 20er Jahren insofern Tribut gezollt wurde, als ihr Anfang der 30er Jahre eine "hausgemachte restriktive Sozial- und Wirtschaftspolitik [folgte], die orthodoxer und härter als in allen anderen westeuropäischen Ländern aus-

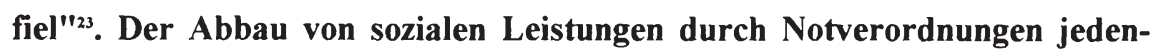
falls bildete den idealen Nährboden für politische Extremisten und Demagogen.

Nach der nationalsozialistischen Machtergreifung entging auch das Sozialversicherungssystem nicht der Gleichschaltung, die alle gesellschaftlichen Bereiche erfaßte. Die Selbstverwaltung der Sicherungsträger wurde beseitigt, das "Führerprinzip" eingeführt. Sozialpolitische Kontinuität oder gar Expansion (neue Sozialleistungen gab es in Form von Kinderbeihilfen

\footnotetext{
${ }^{21}$ Vgl. ebenda, S. 42.

${ }^{22}$ Die These von der "Krise vor der Krise" vertritt zum Beispiel der Historiker Knut Borchardt. Vgl. Borchardt, K., Wachstum, Krise, Handlungsspielräume der Wirtschaftspolitik, Göttingen 1982.

${ }^{23}$ Schmidt, M.G., a.a.O., S. 53, Hervorhebungen im Original.
} 
und Mutterschaftsgeld) scheinen weitgehend politisch-ideologisch motiviert gewesen zu sein. Das Gesamtbild der Sozialpolitik im NS-Staat weist keine einheitliche Linie auf, es gab "Leistungsverbesserungen und Freiheitsbeschränkungen, knauserige und großzügige Sozialleistungen, repressivreaktionäre und progressive Sozialpolitik, Ausbau des sozialen Schutzes und Entzug des sozial Schutzschildes, effizienz-orientierte Sozialpolitik und effizienz-vermindernde Personalpolitik im Bereich der sozialen Sicherung"24. Sozialleistungen auf niedrigem Niveau bei steigenden Beitragseinnahmen erlaubten nicht nur die finanzielle Konsolidierung; Überschüsse des Sozialversicherungssystems finanzierten zum Teil wiederum die exorbitanten Rüstungsausgaben. Daß die temporäre Verbesserung der sozialen Lage vieler Menschen mit Repression, Verfolgung, Terror, Krieg und Zerstörung "erkauft" wurde, bedarf keiner expliziten Erwähnung.

\section{Gründung der Bundesrepublik Deutschland - Neuorientierung und} Aufbau der sozialen Marktwirtschaft

Mit der Gründung der Bundesrepublik Deutschland in den alliierten Westzonen und der Entscheidung für die soziale Marktwirtschaft, die mit den Namen von Walter Eucken, Alfred Müller-Armack und Ludwig Erhard auf das engste verknüpft war, blieb die Sozialpolitik integraler Bestandteil der neuen politischen und wirtschaftlichen Ordnung. Ihr hoher Stellenwert mag an einem Beispiel illustriert werden: Während im Rahmen der Währungsreform alle anderen privaten Versicherungsansprüche praktisch wertlos wurden (Forderungen gegenüber privaten Lebensversicherungen wurden im Verhältnis 10:1 - in bestimmten Fällen 5:1 - von Reichsmark auf DM umgestellt), blieben die Ansprüche an die Sozialversicherung durch eine Umstellung um Verhältnis 1:1 vollständig erhalten ${ }^{25}$. Kontinuität auch im Bereich der Organisationsstruktur: Anders als in der sowjetischen Besatzungszone, in der ein radikaler Bruch mit dem aus der Kaiserzeit überlieferten, gegliederten Sozialversicherungssystem vollzogen und eine Einheitsver-

\footnotetext{
${ }^{24}$ Ebenda, S. 65. Vgl. auch dort zu einer ausführlichen Analyse der Sozialpolitik in der NS-Zeit, S. 55-65.

${ }^{25}$ Vgl. Petersen, H.-G., a.a.O., S. 26.
} 
sicherung installiert wurde ${ }^{26}$, hatten die westlichen Militärbehörden die organisatorische Struktur des Systems unangetastet gelassen - was freilich für zahlreiche kennzeichnende Elemente des nationalsozialistischen Sozialversicherungsrechtes nicht galt.

Die Sozialpolitik der ersten beiden Legislaturperioden (1949-1957) hatte sich auf die Linderung der dringlichsten Kriegsfolgen und Notlagen zu konzentrieren. Dazu gehörte an vorderster Stelle die Aufnahme und Eingliederung von mehr als zehn Millionen Flüchtlingen und Vertriebenen aus den Ostgebieten des ehemaligen Deutschen Reiches. Grundlagen für die Bewältigung dieser innenpolitischen "Jahrhundertaufgabe" waren das Gesetz zur Versorgung der Kriegsopfer (Bundesversorgungsgesetz von 1950), das Lastenausgleichsgesetz von 1952 und nicht zuletzt ein massives Wohnungsbauprogramm, mit dem der soziale Wohnungsbau ins Leben gerufen wurde und das seine institutionelle Fixierung im Ersten Wohnungsbaugesetz von 1950 fand.

Zu den Marksteinen in der Entwicklung des sozialen Sicherungssystems in der Bundesrepublik Deutschland zählt fraglos die Rentenreform des Jahres 1957 , mit der

- die laufenden Renten in der Arbeiterrentenversicherung um 65 vH., in der Angestelltenversicherung sogar um $72 \mathrm{vH}$. erhöht und damit die Lebenslage vieler Rentner entscheidend verbessert wurde;

- der Gesetzgeber die Beitragsäquivalenz und die Einkommensbezogenheit der Rente verankerte;

- die Dynamisierung der Renten und damit die "Entpolitisierung" der Rentenanpassungen erreicht werden konnte.

Die Sozialpolitik der 50er und frühen 60er Jahre hat sich indes bei weitem nicht in der Rentenpolitik erschöpft. Schon 1952 war das Mutterschutzgesetz in Kraft getreten. Mit der Kindergeld-Reform von 1961 wurde der Kindergeld-Anspruch, der bis dahin erst ab dem dritten Kind bestand, für Bezieher kleiner Einkommen auch auf das zweite Kind ausgedehnt (die heutige Kindergeld-Regelung besteht erst seit 1975). Ebenfalls 1961 verabschiedete die Regierung Adenauer das Bundessozialhilfegesetz, mit dem das Sozialrecht der Bundesrepublik neben dem Versicherungs- und dem Versor-

${ }^{26}$ Vgl. Schmidt, M.G., a.a.O., S. 67. 
gungsprinzip durch das Fürsorgeprinzip komplettiert wurde. Es bildet noch heute die Grundlage für das letzte, das unterste soziale Sicherungsnetz, die Sozialhilfe. Schließlich geht auch die Einführung der Subjektförderung in der Wohnungspolitik, i.e. das Wohngeldgesetz (1964), auf die erste Hälfte der 60er Jahre zurück.

Die Liste sozialpolitischer Errungenschaften läßt sich bis in die heutige Zeit fortführen. Sie reicht von der Einführung der sechswöchigen Lohnfortzahlung im Krankheitsfall (1969) auch für Arbeitnehmer über eine nochmalige Reform der Rentenversicherung 1972 (Stichworte: Flexible Altersgrenze, Rente nach Mindesteinkommen, Öffnung der Rentenversicherung auch für nicht-abhängig beschäftigte Gruppen) bis zur Einführung eines Erziehungsgeldes (1985). Gerade die 80er Jahre standen aber auch im Zeichen erheblicher Korrekturen und Reparaturen an bedeutenden Säulen des Sozialversicherungssystems, namentlich bei der gesetzlichen Krankenversicherung (Gesundheitsreformgesetz von 1988/89) und der gesetzlichen Rentenversicherung. Schmerzhafte Einschnitte in das Gefüge der sozialen Sicherung sind in der 40 jährigen Geschichte der Bundesrepublik Deutschland zwar nicht ausgeblieben - im Zuge der ersten Nachkriegs-Rezession 1966/67 etwa, weiters mit dem Haushaltsstrukturgesetz von 1975 und im Gefolge der haushaltspolitischen Konsolidierungsphase nach dem Regierungswechsel 1982. Ein Vergleich aber, der die hier in einem kurzen Abriß dargestellte historische Entwicklung des Sicherungssystems als Maßstab heranzieht, muß zu einer insgesamt positiven Würdigung gelangen. Die Leistungsfähigkeit des bundesrepublikanischen Sozialversicherungssystems ist um so wichtiger, als mit der Vollendung der deutschen Einheit im Jahre 1990 und der Sozialunion mit den fünf neuen Bundesländern gerade in der Anfangsphase eine neue Bewährungsprobe auf das Sozialsystem zugekommen ist. 


\section{Die vollståndige Familie und ihre Funktion im System der sozialen Sicherung}

\section{Definition}

Kaum ein anderer Begriff in der wissenschaftlichen Diskussion ist so vieldeutig wie der Terminus der "Familie", weil es die "Familie" schlechthin nicht gibt, einerseits ist sie kleinste Lebensgemeinschaft von Erwachsenen und Kindern, andererseits wird sie häufig sehr viel weiter definiert als Gemeinschaft, die auch die Verwandtschaft einbezieht.

Auch dem täglichen Sprachgebrauch liegen ganz unterschiedliche Vorstellungen zugrunde, wenn von Familie die Rede ist. Der Familienbegriff ist in hohem Maße abhängig von ethnischen, gesellschaftlichen und strukturellen Bedingungen. So haben längerfristige Beobachtungen gezeigt, "daß sich mit gesellschaftlichem Wandel auch Bedeutung, Funktion und damit der Begriffsinhalt der Familie"27 verändert hat. Dies zwingt zu einer jeweiligen begrifflichen Abgrenzung, je nach der Aussage, die im Hinblick auf die Familienforschung getroffen werden soll ${ }^{28}$.

Schon im Altertum gab es den Begriff "familia", womit jedoch das sogenannte "ganze Haus" gemeint war, dem nicht nur Eltern und Kinder, sondern auch sämtliche Seitenverwandte und ebenso das Gesinde angehörten $^{29}$.

Mit den gesellschaftlichen Wandlungen wurde auch der Familienbegriff immer wieder anders definiert. Die vorindustrielle Familie war beispielsweise durch die Gesamtheit von Produktion, Konsumtion und Normvermittlung gekennzeichnet ${ }^{30}$, diese Totalität löste sich mit Entstehung von Heimindustrie und Manufaktur auf und machte damit neuen Haushaltsformen Platz, die zunehmend vom Markt abhängig waren.

\footnotetext{
${ }^{27}$ Familie und Arbeitswelt, Gutachten des wissenschaftlichen Beirats für Familienfragen beim BMJFG. Stuttgart, Berlin, Köln, Mainz 1984, S. 26.

${ }^{28}$ Familie und Arbeitswelt, a.a.O., S. 27.

${ }^{29}$ Vgl. Bethusy-Huc von, Viola Gräfin, Familienpolitik, Tübingen 1987, S. 1.

${ }^{30}$ Vgl. Cramer, Alfons, Familie und Familienpolitik in der Bundesrepublik Deutschland, Opladen 1982, S. 12ff.
} 
Neben der bis dahin auffälligen Großfamilie trat die Kleinfamilie heutiger Form in den Vordergrund, bestehend aus zwei zusammenlebenden Generationen, den Eltern und deren ledige Kinder. Sie wird auch als "Kern-

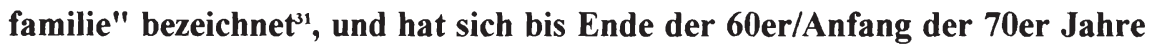
als relativ stabil erwiesen. Konstitutiv für die Familie als Kleingruppe war in dieser Zeit die eheliche Verbindung der Eltern ${ }^{32}$.

Die Familie ist in jeder Epoche ein Spiegelbild von Gestalt und Struktur der Wirtschaftsverhältnisse, sowie der in ihr bestehenden gesellschaftlichen Verhältnisse. ${ }^{33}$

Das typische Kennzeichen der vorindustriellen Zeit bis Mitte des 18. Jahrhunderts war eine vorwiegend agrarisch strukturierte Gesellschaft, in der die Familie Träger des Wirtschaftslebens sowohl hinsichtlich der Produktion als auch der Konsumption war. ${ }^{34}$

Der ländliche Haushalt umfaßte in der Regel mehrere Generationen blutsverwandter und blutsfremder Personen und war streng hierarchisch geordnet; der städtische Handwerkerhaushalt unterschied sich von ihm nur dadurch, daß er auf anderen wirtschaftlichen Voraussetzungen aufbaute. ${ }^{35}$ Denn war der Bauer ökonomisch durch Geld- oder Naturalabgaben mit einer Grundherrschaft, die ihm jedoch Militär- und Rechtsschutz gewährte, verbunden, ${ }^{36}$ so bestand beim Handwerker eine Abhängigkeit von einem gewerblichen oder händlerischen Erwerb, was darauf zurückzuführen ist, daß das Wirtschaftsgeschehen stärker auf den Geld- und Markterwerb abgestellt war als auf dem Lande. ${ }^{37}$

\footnotetext{
${ }^{31}$ Vgl. Bundesministerium für Jugend, Familie und Gesundheit (Hrsg.), Bericht über die Lage der Familie in der Bundesrepublik Deutschland, Dritter Familienbericht, Bundestagsdrucksache 8/3120, 8/3121, Bonn 1979, S. 14. Im folgenden zitiert als "Dritter Familienbericht".

${ }^{32}$ Vgl. Bundesministerium für Jugend, Familie und Gesundheit (Hrsg.), Bericht über die Lage der Familien, Erster Familienbericht, Bundestagsdrucksache V/2532, Bonn 1969, S. 7 f.

33 Vgl. E. Egner, Epochen im Wandel des Familienhaushalts, in: Familie und Gesellschaft, Tübingen 1966, S. 59.

34 Vgl. W. Dreier, Das Familienprinzip - Ein Strukturelement der modernen Wirtschaftsgesellschaft, Münster 1960, S. 72.

35 Vgl. E. Egner, a.a.O., S. 59f.

${ }^{36}$ Vgl. F. Oeter, Familienpolitik, Stuttgart 1954, S. 20.

${ }^{37}$ Vgl. E. Egner, a.a.O., S. 64 f.
} 
Aus ökonomischer Sicht betrachtet, stellt die Grobfamilie dieser Zeit ein geschlossenes Kreislaufsystem dar, in dem jeder Mensch als Kind die Fürsorge der anderen in Anspruch nimmt, und als Erwachsener für das Aufziehen von Kindern ebenso aufkommt, wie für die Versorgung der Alten, um sich damit wiederum einen eigenen Anspruch auf Versorgung im Alter zu sichern. ${ }^{38}$

Eine Familie gründen konnte jedoch nur derjenige, der eine gesicherte Lebens- und Nahrungsgrundlage vorweisen konnte, d.h. die EheschlieBung war unmittelbar mit der Erbfolge, bzw. mit der Erlangung einer Meisterstelle im Handwerk verbunden, ${ }^{39}$ so daB der Kreis der Heiratsfähigen auf die ältesten Söhne der Grundherren, Bauern und Handwerksmeister beschränkt blieb.

Der zu Beginn des 19. Jahrhunderts einsetzende Industrialisierungsprozeß war ausschlaggebend für die Änderung der Wirtschafts- und Gesellschaftsstruktur in Deutschland.

Den Hintergrund für die Auflösung der alten Familienordung bildete im wesentlichen die Französische Revolution, da von ihr u.a. die Entfaltung der Persönlichkeit für jeden Menschen angestrebt wurde, wozu ohne Zweifel auch das Recht auf Eheschließung und Familiengründung zählt. ${ }^{+0}$ Die $\mathrm{Zu}$ nahme der Eheschließungen führte jedoch auch zu einer Bevölkerungszunahme, „die für das beginnende kapitalistische Zeitalter ... bezeichnend ist". .1

Da diese Menschen auf dem Land keine Lebensgrundlage mehr hatten, zogen sie in die Städte, um sich dort eine Existenz aufzubauen; Beschäftigung fanden sie in den durch die Industrialisierung entstandenen Fabriken. Damit vollzog sich in den Familien eine Trennung von Wohn- und Arbeitsstätte. $^{\star 2}$

\footnotetext{
${ }^{38}$ Vgl. F. Oeter, a.a.O., S. 21.

${ }^{39}$ Vgl. ebenda, S. 20.

to Vgl. F. Oeter, a.a.O., S. 24.

${ }^{41}$ F. Oeter, a.a.O., S. 25.

$\$ 2$ Vgl. M. Wingen, Familienpolitik - Ziele, Wege und Wirkungen, Paderborn 1964, S. 29.
} 
Der Lebensunterhalt der Familie wurde in der Regel aus dem Arbeitseinkommen des Familienvaters bestritten, ${ }^{43}$ fiel dieser infolge Krankheit oder Unfall aus, stand die Familie meistens vor dem wirtschaftlichen Nichts. ${ }^{44}$ Dieser Existenzkampf in den Familien führte daher zu einer $\mathbf{Z u}$ nahme der außerhäuslichen Erwerbstätigkeit der Frau, zumal sie als Arbeitskraft in der Industrie beliebter war, da ihr Lohn geringer war und damit die Produktionskosten gesenkt werden konnten. ${ }^{45}$

Da Kinderarbeit inzwischen verboten wurde, sind Kinder wirtschaftlich gesehen, nur noch eine finanzielle Belastung für die Eltern. ${ }^{46}$ Außerdem führte eine große Zahl Kinder zu einer erheblichen Einschränkung der sozialen Mobilität. ${ }^{47}$

Diese, für die Familie negative Entwicklung hatte schließlich zur Folge, daß die eheliche Fruchtbarkeit vermehrt rationalem Verhalten unterlag.

Der durch die Industrialisierung beginnende Strukturwandel der Familie wurde angesichts zweier Weltkriege erheblich beschleunigt. Dabei waren als Folge des Zweiten Weltkriegs soziale Notlagen besonders gravierend.

Dazu gehören:

- die Vertreibung von zahlreichen Menschen aus ihrer Heimat, die mit dem Verlust der Existenzgrundlage verbunden war,

- der Verlust von Wohnung und Besitz durch Ausbombung,

- der Tod bzw. eine schwere Kriegsverletzung des Familienvaters, und

- die lange Kriegsgefangenschaft einer großen Zahl von Männern, aus. ${ }^{48}$

Die Notlagen stärkten den Zusammenhalt in den Familien, führten andererseits aber auch zur sozialen Ausgliederung und Isolierung des familiären Lebens, sowie ein wachsendes Desinteresse am gesellschaftlichen $\mathbf{G e}$ schehen. ${ }^{49}$ Ihre Aufmerksamkeit konzentrierte sich fast ausschließlich auf

\footnotetext{
${ }^{43}$ Vgl. E. Egner, a.a.O., S. 86.

${ }^{44}$ Vgl. F. Oeter, a.a.O., S. 27.

${ }^{45}$ Vgl. G. Bäumer, Familienpolitik, Berlin 1933, S. $22 f$.

46 Vgl. W. Dreier, a.a.O., S. 60.

${ }^{47}$ Vgl. M. Wingen, a.a.O., S. 44.

48 Vgl. H. Schelsky, Wandlungen der deutschen Familie in der Gegenwart, Dortmund 1953, S. 47.

${ }^{49} \mathrm{Vgl}$. ebenda, S. 122.
} 
den Aufbau einer eigenen Existenz und des sozialen Wiederaufstiegs. ${ }^{50}$ Als Folge davon war eine verstärkte Ausrichtung auf die Befriedigung materieller Bedürfnisse zu beobachten.

Die nach dem Kriege eingeführte marktwirtschaftlich orientierte Wirtschaftsordnung mit dem Prinzip des Leistungslohnes, ermöglichte jedem, der eine entsprechende Leistung erbringt, ein Leben, das durch zunehmenden Wohlstand gekennzeichnet ist. Da sich ein solches Einkommen aber nur an der Arbeitsleistung und nicht an der Familiengröße orientiert, sinkt mit zunehmender Kinderzahl das Pro-Kopf-Einkommen der Familienmitglieder. ${ }^{51}$ Die Folge davon ist häufig eine Verringerung der Kinderzahl in den Familien. ${ }^{52}$ Die Tendenz zur Verkleinerung der Familiengröße ist bei allen sozialen Schichten zu beobachten, ${ }^{53}$ und stellt ein wesentliches Charakteristikum der heutigen Gesellschaft dar. Als weitere bedeutsame Kennzeichen sind zu nennen:

- Die Trennung von Familie und Beruf, womit ein wesentliches Bindeelement der alten Familie fortgefallen ist. ${ }^{54}$

- Die veränderte Besitzgrundlage der Familie, die sich u.a. auch in den Wohnverhältnissen ausdrückt. Das Wohnen in einer Mietwohnung ist die für eine Familie typische Wohnform. ${ }^{55}$

- Die weitgehende Individualisierung des einzelnen, und die damit abnehmende Stabilität der Familie. ${ }^{56}$

- Die auf einem partnerschaftlichen Verhältnis beruhende Ehe, in der Mann und Frau gleichberechtigt die in der Familie anfallenden Entscheidungen treffen. ${ }^{57}$

- Die Anpassung der Leitgedanken der Erziehung an die außerfamiliären gesellschaftlichen Gegebenheiten, ${ }^{58}$ d.h. die Zuwendung zu einer Er-

\footnotetext{
50 Vgl. ebenda, S. 178.

${ }^{51}$ Vgl. R. Mayntz, Die moderne Familie, Stuttgart 1955, S. 72.

52 Vgl. ebenda, S. 15.

53 Vgl. ebenda.

54 Vgl. ebenda, S. 19.

55 Vgl. ebenda, S. 20.

56 Vgl. ebenda, S. 21.

57 Vgl. R. Mayntz, a.a.O., S. 50.

58 Vgl. R. Mayntz, a.a.O., S. 70.
} 
ziehung, die Selbständigkeit, Mündigkeit und Kritikfähigkeit des Kindes in den Vordergrund stellt.

Mit den 70er Jahren begannen sich neue Probleme der Familie abzuzeichnen, deutlich erkennbar an steigenden Ziffern unehelicher Kinder, steigenden Scheidungszahlen, Tendenzen hin zu Kommune-Bewegungen und alternativen Lebensformen, sowie der Problematisierung der Frauenrolle in der Familie ${ }^{59}$. Der Familienbegriff erfuhr in dieser Zeit insoweit eine Änderung als von nun an unterschieden wurde zwischen vollständigen und unvollständigen Familien (siehe III. 2.). Flankierend dazu gab es einige Gesetzesänderungen, von denen die Reform des Ehe- und Familienrechts vom 15.6.1976 ${ }^{60}$ sicherlich die einschneidendste war. Die Verantwortung für die Familie wurde beiden Elternteilen - bis dahin oblag sie allein dem Familienvater - übertragen, darüber hinaus wurde das Recht der Frau auf eigene Erwerbstätigkeit ausdrücklich anerkannt.

Diesem neuen Verständnis von Ehe und Familie folgt dann auch der Dritte Familienbericht, der von "Familie" spricht, "wenn durch Geburt oder Adoption von Kindern aus der Ehe eine biologisch-soziale Kleingruppe zusammenlebender Menschen entsteht"61. Abweichungen von dieser als "Normalfamilien" bezeichneten Kleingruppen werden ausdrücklich erwähnt und zugelassen, so z.B. Familien, die aus alleinerziehenden Müttern und Vätern und ihren Kindern bestehen ${ }^{62}$, sowie Lebensgemeinschaften unverheirateter Paare, den sogenannten "nichtehelichen Lebensgemeinschaften". Eine nichteheliche Lebensgemeinschaft ist "eine wenigstens auf eine gewisse Dauer angelegte Verbindung eines verschiedengeschlechtlichen Paares, das in einer Wohn- und Wirtschaftsgemeinschaft (Haushalt) in umfassender Lebens- und Geschlechtsgemeinschaft zusammenlebt, ohne daß die Beziehung durch eine Eheschließung offiziell bestätigt (legitimiert) ist" ${ }^{\prime \prime}$.

Es wird anhand der verschiedenen Definitionen sehr deutlich klargestellt, daß das Vorhandensein von Kindern für eine Familie maßgeblich ist.

\footnotetext{
${ }^{59}$ Vgl. Bethusy-Huc von, Viola Gräfin, a.a.O., S. 2.

${ }^{60}$ Vgl. Erstes Gesetz zur Reform des Ehe- und Familienrechts, BGBL 1976, S. 1421.

${ }^{61}$ Dritter Familienbericht, a.a.O., S. 14.

${ }^{62}$ Vgl. Dritter Familienbericht, a.a.O., S. 13.

${ }^{63}$ Wingen, Max, Nichteheliche Lebensgemeinschaften, Formen - Motive - Folgen, Zürich 1984, S. 13.
} 
So führt ein kinderloses Ehepaar zwar einen Haushalt, ist aber damit noch keine Familie ${ }^{64}$.

\section{Funktionen der Familie und soziale Sicherung}

Die Bestandserhaltung einer Gesellschaft wird durch Kinder gesichert $^{65}$, insofern muß jede Gesellschaft ein Interesse daran haben, "daB Kinder in gewünschter Zahl geboren ... gepflegt, aufgezogen und erzogen werden"66. Nach wie vor ist die Familie die Institution, die diese Leistung primär erbringt und damit ihre Reproduktionsfunktion erfüllt ${ }^{6}$.

Kinder werden zwar auch außerhalb von Familien geboren, sie stellen jedoch in Relation zur Gesamtzahl aller Geburten nur eine kleine Minderheit dar ${ }^{68}$.

Eine weitere Aufgabe der Familie ist die Daseinsvorsorge oder $R \boldsymbol{e}$ generationsfunktion. Die Familie erfüllt gegenüber allen Familienmitgliedern - jungen als auch alten - eine regenerative Funktion ${ }^{69}$. Dazu gehört neben der Versorgung mit lebenswichtigen Gütern wie Nahrung, Wohnung, Kleidung auch das Schaffen einer Atmosphäre, in der sich einerseits Kinder geborgen fühlen können, andererseits die im Erwerbsleben stehenden Familienmitglieder die Möglichkeit "für einen Ausgleich der Entpersönlichung oder ... der Entfremdung im Arbeitsleben"70 haben.

Die Aufgabe der Familie geht weit über die Daseinsvorsorge hinaus, die sich lediglich auf die Befriedigung physischer Lebensbedürfnisse beschränkt: Zusätzlich wird die heranwachsende Generation durch die im Elternhaus herrschenden Wertvorstellungen geprägt ${ }^{71}$, die Familie übt ihre sogenannte Sozialisationsfunktion aus.

\footnotetext{
${ }^{64}$ Vgl. Albers, Willi, Auf die Familie kommt es an, Stuttgart 1986, S. 7.

${ }^{65}$ Vgl. Dritter Familienbericht, a.a.O., S. 17.

${ }^{66}$ Neidhard, F., Die Familie in Deutschland, Gesellschaftliche Stellung, Struktur und Funktion, Opladen 1975, S. 69.

${ }^{67}$ Vgl. Neidhart, F., a.a.O., S. 69.

${ }^{68}$ Vgl. Albers, W., Auf die Familie kommt es an, a.a.O., S. 7.

${ }^{69}$ Vgl. Dritter Familienbericht, a.a.O., S. 17.

${ }^{70}$ Albers, W., Auf die Familie kommt es an, S. 8.

${ }^{71}$ Vgl. Albers, W., Auf die Familie kommt es an, S. 10.
} 
Sozialisation kann definiert werden als "das durch die soziale Umwelt vermittelte Lernen von Verhaltensweisen, von Denkstilen, Gefühlen, Kenntnissen, Motivationen und Werthaltungen"r?

Die elementare Bedeutung der Familie für die Sozialisation des Kindes gilt, angesichts der tiefgreifenden und häufig irreparablen psychischen Schäden von Heimkindern, als unbestritten ${ }^{73}$. Dabei wird besonders die Rolle der Mutter im frühkindlichen Sozialisationsprozeß hervorgehoben, da sie "in verstärktem Maße für Stimulation des Kindes sorgt"

Die Erfüllung der Sozialisationsaufgabe hängt von einer nicht quantifizierbaren Anzahl von Faktoren ab. Augenscheinlich beeinflussen aber die materielle Versorgung, sowie die damit verbundene ausreichende Wohnungsversorgung diesen Sozialisationsprozeß genauso wie der Bildungsstand der Eltern und deren soziale Zufriedenheit mit ihrer Lebenssituation.

Die Familie hat aufgrund ihrer konstitutiven Merkmale die Kraft, sich inneren und äuBeren Einflüsse wirkungsvoll zu widersetzen ${ }^{75}$. Im Hinblick auf die Sozialisation bedeutet diese Stabilität eine Grundvoraussetzung für eine optimale kindliche Entwicklungsmöglichkeit. Die relative Kleinheit der Familie läbt intensive Kontakte zwischen den einzelnen Mitgliedern zu, und schafft so die Voraussetzungen für eine positive emotionale Mutter-KindBeziehung ${ }^{76}$.

Die Sozialisation wird vom schichtenspezifischen Verhalten der Eltern wesentlich beeinfluBt ${ }^{7}$. Dies hat zur Folge, daB besonders Kinder aus Unterschichtenfamilien diskriminiert sind. Deshalb erscheint es sinnvoll, die Sozialisationsfunktion zwar grundsätzlich den Familien zu überlassen, innerhalb der Familienpolitik jedoch staatliche Maßnahmen zu konzipieren, die die Familie in Problemlagen unterstützen.

Die Plazierungsfunktion, also die Vermittlung sozialer Positionen in Familie, Schule, Freizeit, Beruf und Politik, ist eine Aufgabe, die sich Fami-

\footnotetext{
72 Bundesminister für Jugend, Familie und Gesundheit (Hrsg.), Zweiter Familienbericht, Familie und Sozialisation, Bonn-Bad Godesberg 1975, S. 13. Im folgenden zitiert als "Zweiter Familienbericht".

${ }^{73}$ Vgl. Zweiter Familienbericht, a.a.O., S. 43.

${ }^{74}$ Zweiter Familienbericht, a.a.O., S. 45.

${ }^{75}$ Vgl. Zweiter Familienbericht, a.a.O., S. 58.

${ }^{76}$ Vgl. Neidhardt, F., a.a.O., S. 84.

${ }^{77}$ Vgl. Neidhardt, F., a.a.O., S. 93.
} 
lie und Staat teilen. Schon der familiale SozialisationsprozeB bewirkt Effekte, die auf die soziale Plazierung des Kindes begünstigend oder hemmend einwirken ${ }^{78}$, insofern besteht zwischen Sozialisation und Plazierung ein enger Zusammenhang ${ }^{79}$.

Wesentliche Voraussetzung für jedwede soziale Plazierung ist eine entsprechende Bildung, die in der Regel an Schul- bzw. Berufsausbildungsabschlüssen gemessen wird $^{80}$. Und obwohl eine derartige Bildung fast ausschließlich von außerfamilialen Instanzen vermittelt wird, liegt die Entscheidung über Schullaufbahn und Ausbildungsgang im wesentlichen bei den Eltern eines Kindes ${ }^{81}$, so daß sie von ausschlaggebender Bedeutung für die Plazierung der vorhandenen Kinder sind. Die Plazierungsvorstellungen und das Plazierungsverhalten der Eltern sind nicht unabhängig von den familialen Lebensbedingungen, so wirken sich die schulische und berufliche Ausbildung, die berufliche Stellung, sowie die auBerfamilialen Kontakte der Eltern entscheidend auf den Plazierungsvorgang aus ${ }^{82}$. Zwar halten Eltern aller Schichten eine qualifizierte Schul- und Berufsausbildung für wünschenswert $^{33}$, die Realisierung dieses $W$ unsches wird aber nicht unerheblich von der jeweiligen Schichtenzugehörigkeit bestimmt. Die Chance von Unterschichtenkindern durch eine qualifizierte Ausbildung einen höheren sozialen Status zu erlangen, ist relativ gering, weil erwiesenermaßen "der Schulerfolg der Kinder mit dem sozio-ökonomischen Status des Elternhauses variiert"84. Die verhältnismäßig geringen Kenntnisse der Arbeiterfamilie erschweren die Mithilfe bei den Hausaufgaben, zudem ist bei auftretenden Schulschwierigkeiten meistens nicht das Geld für notwendige Nachhilfestunden vorhanden. Die Konsequenz ist häufig ein Zurücknehmen der Kinder aus den weiterführenden Schulen, was als Zurückstellen der ursprünglichen Bildungswünsche gedeutet werden kann".

\footnotetext{
${ }^{78}$ Vgl. Neidhard, a.a.O., S. 73.

${ }^{79}$ Vgl. Dritter Familienbericht, a.a.O., S. 67.

${ }^{80}$ Vgl. Dritter Familienbericht, a.a.O., S. 68.

${ }^{81}$ Vgl. Dritter Familienbericht, a.a.O., S. 68.

${ }^{82}$ Vgl. Dritter Familienbericht, a.a.O., S. 68.

${ }^{23}$ Vgl. Dritter Familienbericht, a.a.O., S. 69.

${ }^{84}$ Vgl. Dritter Familienbericht, a.a.O., S. 84.

${ }^{85}$ Vgl. Dritter Familienbericht, a.a.O., S. 71.
} 
Die bestehende Arbeitsteilung zwischen Familie und Staat im Bildungswesen ist durch Abgrenzungs- und Koordinationsprobleme gekennzeichnet $^{86}$. Einerseits wird von den Eltern erwartet, daß sie an der Erfüllung der schulischen Aufgaben unmittelbar mitwirken, andererseits wird ihnen dieses Mitwirken angesichts eines bestehenden komplexen Bildungssystems erheblich erschwert. Dabei ist das Bildungswesen, wenn es um die Verwirklichung von Reformen geht, in hohem Maße auf die Zustimmung und Unterstützung der Eltern angewiesen ${ }^{87}$.

Die Haushaltsgemeinschaft ist der wichtigste Ort familialer Aufgabenerfüllung. Hier vereint sich Tag für Tag die Familie, sei es zur Befriedigung physiologischer Grundbedürfnisse (wie Schlafen, Essen, u.s.w.), oder zum gemeinsamen Freizeitleben ${ }^{88}$, sie bildet somit die wesentlichste Rahmenbedingung für die Familienfunktion ${ }^{89}$. Elementares Lebensbedürfnis jedes Menschen ist und bleibt die Gestaltung der Hauswirtschaft ${ }^{90}$, häufig ist sie angesichts einer monotonen beruflichen Tätigkeit der einzige Ort, an dem noch Kreativität entwickelt werden kann.

Die haushälterischen Ressourcen und die für ein eigenverantwortliches Handeln erforderlichen Handlungsspielräume des einzelnen werden jedoch entscheidend von dem gesellschaftlichen Umfeld bestimmt, so wirken u.a. das Einkommen, die Wohnsituation und das Konsumniveau auf das familiale Haushaltsführungssystem ein ${ }^{91}$.

Während die Haushaltsführung mit ihren vielfachen Arbeitsaufgaben von der jungen Familie häufig als erhebliche Belastung angesehen wird, ist sie für die ältere Familie oft noch der einzige verbleibende Pflichtenbereich $^{22}$. Trotzdem geht die Entwicklung dahin, daß junge genauso wie alte Menschen die haushälterische Selbständigkeit wünschen³

Obwohl die Familie bzw. der Haushalt generell als Privatbereich anerkannt und geschützt wird, haben gesellschaftliche Änderungen Rückwirkun-

\footnotetext{
${ }^{86}$ Vgl. Dritter Familienbericht, a.a.O., S. 69.

${ }^{87}$ Vgl. Dritter Familienbericht, a.a.O., S. 83.

${ }^{88}$ Vgl. Neidhardt, F., a.a.O., S. 76.

${ }^{89}$ Vgl. Dritter Familienbericht, a.a.O., S. 53.

${ }^{90}$ Vgl. Dritter Familienbericht, a.a.O., S. 64.

${ }^{91}$ Vgl. Dritter Familienbericht, a.a.O., S. 53.

${ }^{92}$ Vgl. Dritter Familienbericht, a.a.O., S. 61.

${ }^{93}$ Vgl. Dritter Familienbericht, a.a.O., S. 61.
} 
gen auf das Haushaltsführungssystem ${ }^{94}$. Im folgenden sollen die wesentlichsten Veränderungen kurz angeführt werden"s:

- Die erhöhte Lebenserwartung verlängert den Zeitraum der Haushaltsführung.

- Durch eine verminderte Anzahl von Kindern bleibt der Haushalt relativ klein und verengt sich schließlich wieder auf eine Generation, wenn die Kinder sich vom elterlichen Haushalt trennen. Die Trennung erfolgt in der Regel schon sehr früh.

- Das System der sozialen Sicherung nimmt dem einzelnen einen großen Teil der Daseinsvorsorge ab, jedenfalls soweit es um die Finanzierung des Lebensunterhalts geht.

- Die allgemeine Wohlstandssteigerung, die durch Zunahme des frei verfügbaren Einkommens und der frei verfügbaren Zeit, sowie durch steigende Ansprüche, gekennzeichnet ist, konfrontiert die Familie mit neuen Problemen bezüglich ihrer Haushaltsführung.

- Die zunehmende Komplexität des Wirtschaftslebens einerseits und der staatlichen Bürokratie andererseits verlangen vom einzelnen wachsende Kenntnisse und ein hohes $\mathrm{Maß}$ an Eigenständigkeit.

Da diese Veränderungen auf unterschiedliche Familienverhältnisse stoBen, können keine eindeutigen Schlußfolgerungen bezüglich der Wirkungen auf die Haushalte gezogen werden $\%$.

Häufig wird auch die Tatsache unterschätzt, daß die Aufgabe des Wirtschaftens ein "vielseitiges fachliches Können, Umsichtigkeit und ein hohes Maß an Verantwortung"'97 erfordert.

Ein von außen oktroyiertes soziales Sicherungssystem war so lange nicht notwendig, wie jedes Familienmitglied „seinen Platz“, seine Aufgabe in der Familie erfüllte und dadurch als Gegenleistung von der Gemeinschaft eine Versorgung erhielt. Die einem Familienmitglied zugewiesene Aufgabe

\footnotetext{
${ }^{94}$ Vgl. Dritter Familienbericht, a.a.O., S. 62.

95 Vgl. Dritter Familienbericht, a.a.O., S. 62.

${ }^{96}$ Vgl. Dritter Familienbericht, a.a.O., S. 62.

${ }^{97}$ Jacobsen Ch., Familiengerechte Frauenarbeit, ein gesamtwirtschaftliches Zeitproblem, Berlin 1961, S. 92.
} 
wechselte im Laufe des Lebens und orientierte sich unter anderem an der altersspezifischen Leistungsfähigkeit der Person, so daß die heute übliche starre Trennung zwischen einer aktiven, erwerbstätigen Phase und einer Ruhestandsphase, die zudem auch noch abrupt einsetzt, völlig unbekannt war. Verteilungskonflikte wurden dadurch gemindert, daß die sinkende Leistungsfähigkeit im Alter mit sinkenden Versorgungsansprüchen korrespondierte. Bei Eintritt individueller Notlagen wie Krankheit oder vollkommener Arbeitsunfähigkeit im Alter konnte das ,ganze Haus ${ }^{\text {(988 }}$ zumeist die Existenz seiner Mitglieder im Kern gewährleisten, allerdings sollte auch nicht vergessen werden, daß eine altersbedingte Erwerbsunfähigkeit im vorindustriellen Deutschland aufgrund der geringen Lebenserwartung der Menschen kein großes gesellschaftliches Problem werden konnte. Statistiken zufolge waren um 1800 nur 3\% der Menschen älter als 65 Jahren und noch 1871 betrug ihr Anteil an der Gesamtbevölkerung des Deutschen Reiches lediglich 4,6 \%.

Erst die Auflösung des sogenannten „Ganzen Haus“ schuf die Voraussetzungen für ein zentralisiertes soziales Sicherungssystem, das jedoch nicht von vornherein für die Familie konzipiert wurde, sondern vielmehr die einzelnen Personen und ihre Fähigkeit, mittels Erwerbstätigkeit Einkommen zu erzielen, in den Vordergrund der Betrachtung stellte. Damit schloß die vorgenommene Selektion des Versichertenkreises ausnahmslos alle nicht direkt im Lohnarbeitsverhältnis stehenden, aber materiell bedürftigen Familienmitglieder, von der sozialen Sicherung aus. ${ }^{99}$ Dieser gesamtgesellschaft und sozialpolitisch unbefriedigende Zustand führte schließlich zur Ausweitung des Kreises der in die Sozialversicherung einbezogener Personen und zu einem System, daß sowohl Elemente des Individual- als auch des Familienprinzips enthält.

98 Das Wort „Familie“ im heutigen Verständnis findet erst im 18. Jahrhundert Eingang in die deutsche Umgangssprache.

99 Vgl. Ch. Hermann, Gleichstellung der Frau und Rentenrecht, Sozialpolitische Schriften, Heft 51, Berlin 1984, S. 40. 


\section{Die unvollständige Familie}

\section{Definition}

Die unvollständige Familie besteht ebenfalls aus zwei Generationen, jedoch umfaßt diese Gruppe nur einen EIternteil ${ }^{100}$.

Obwohl unvollständige Familien bzw. Ein-Elternteil-Familien im allgemeinen als Ergebnis neuer Lebensformen gesehen werden, sind sie kein neues Phänomen. Auch in den Personenstandsregistern vorindustrieller Zeit finden sich derartige Gruppierungen, sowohl Witwen als auch ledige Frauen mit Kindern ${ }^{101}$. Für den deutschsprachigen Raum kann im 19. Jahrhundert von ca. $10 \%$ nichtehelicher Geburten ausgegangen werden ${ }^{102}$, wovon jedoch i.d.R. ein Drittel noch im Säuglingsalter starb ${ }^{103}$.

Aufgrund des Fehlens einer staatlichen Sozialversicherung mußten Witwen ebenso wie die ledigen Mütter für sich und ihre Kinder den Lebensunterhalt durch eigene Arbeit bestreiten. In den Landgebieten lebten sie als Gesinde oder mithelfende Familienangehörige in einer größeren Hausgemeinschaft, in den Städten taten sich häufig alleinstehende mit anderen alleinstehenden Eltern zusammen oder lebten in untermietähnlichen Verhältnissen zusammen. Sie arbeiteten zumeist im Taglohn als Wäscherin, Spinnerin oder Näherin oder waren als Dienstboten tätig ${ }^{104}$. Diese Möglichkeit individueller Lohnarbeit schuf trotz Armut und Wohnungsnot die Voraussetzungen für eine selbständige familiale Existenz alleinstehender Mütter mit ihren Kindern, natürlich nicht mit heutigen Maßstäben gemessen.

Ein-Eltern-Familien sind keine homogene Gruppe, sie setzen sich zusammen aus ledigen Müttern, verwitweten Müttern und geschiedenen Frauen mit Kindern, letztere nehmen seit Inkrafttreten des neuen Scheidungsge-

\footnotetext{
${ }^{100}$ Vgl. Dritter Familienbericht, a.a.O., S. 14.

${ }^{101}$ Vgl. Napp-Peters, Anneke, Ein-Elternteil-Familien, Weinheim, München 1985, S. 10.

${ }^{102}$ Vgl. Gärtner, H., Das nichteheliche Kind in Schule, Lehre und Beruf, Tübingen 1978, S. 24f.

${ }^{103}$ Vgl. Petersen, J. Die öffentliche Fürsorge für die hilfsbedürftige Jugend, Leipzig 1907, S. 38.

${ }^{104}$ Vgl. Napp-Peters, Anneke, a.a.O., S. 10.
} 
setzes von 1977 ständig zu. Erwähnt werden müssen der Vollständigkeit halber auch alleinstehende Väter, deren Anzahl allerdings, trotz Zunahme in den letzten Jahren, immer noch so gering ist, daB Aussagen aufgrund erhobener Daten kaum möglich sind.

Unvollständige Familien als neue private Lebensform sind das Ergebnis der sich seit einiger Zeit abzeichnenden Entdifferenzierungstendenzen zwischen dem Ehe- und dem Familiensystem. ${ }^{105}$ Alleinerziehende Mütter und Väter hat es auch in früheren Zeiten gegeben, sie stellten jedoch kein geschlossenes auf die familiale Leistung spezialisiertes System dar. Erst in jüngster Zeit konnten sie sich als gesellschaftliches System ausdifferenzieren, bedingt durch den Wandel

- des sozial-politischen bzw. wohlfahrtsstaatlichen Systems,

- des Rechtssystems,

- des Bildungs- und Erwerbssystems. ${ }^{106}$

Dabei können sie den Sozialsystemen zugeordnet werden, die sich überwiegend auf die Nachwuchssicherung spezialisiert haben. ${ }^{107}$

Neben den ledigen, verwitweten und geschiedenen Frauen und Männern, "die alleinsorgeberechtigt für ein oder mehrere minderjährige Kinder sind und mit diesen Kindern allein in einem Haushalt wohnen"108, gehören darüber hinaus auch verheiratete aber getrenntlebende Männer und Frauen in die Kategorie unvollständiger Familien.

\section{Ledige Mutterschaft - altes oder neues Phänomen?}

Die ledige Mutterschaft war von jeher mit einem mehr oder weniger großem Stigma behaftet, wobei in den ärmeren Bevölkerungsschichten eine

\footnotetext{
${ }^{105}$ Vgl. Nave-Herz, Rosemarie, Zeitgeschichtliche Differenzierungsprozesse privater Lebensformen - am Beispiel des veränderten Verhältnisses von Ehe und Familie -, in: Gesellschaften im Umbruch, Verhandlungen des 27. Kongresses der Deutschen Gesellschaft für Soziologie in Halle an der Saale 1995, Hrsg.: Lars Clausen, Frankfurt/Main, S. 61.

${ }^{106}$ Vgl. ebenda S. 66.

107 Vgl. ebenda S. 68.

${ }^{108}$ Behr, Sophie, Familien "zweiter Klasse", in: Kühn, E. und Ingrid Tourneau (Hrsg.), Familienrechtsreform - Chance einer besseren Wirklichkeit, Bielefeld 1978, S. 251-263, hier 251.
} 
höhere Toleranz ledigen Müttern gegenüber zu verzeichnen war als im Bürgertum. Hier mußte bei vorliegender Schwangerschaft möglichst schnell geheiratet werden, um der Frau ein Leben außerhalb der Gesellschaft zu ersparen. Diese starke Ablehnung gegen "uneheliche" Geburten, die in allen bekannten Gesellschaften zu beobachten war und teilweise noch ist, scheint auch aus der erschwerten Plazierung des Kindes im gegebenen Verwandtschaftssystem zu resultieren. Erst in neuerer Zeit zeigen sich langsame Veränderungen, 1970 wurde die rechtliche Diskriminierung mit dem Inkrafttreten des Gesetzes zur Neuregelung der nicht-ehelichen Kinder aufgehoben, seither wird die ledige Mutterschaft auch als neue alternative Lebensform zur traditionellen Elternfamilie anerkannt. Der zunehmende medizinische Fortschritt, die Verbreitung von Antikonzeptiva, der höhere Grad an $\mathrm{Zu}$ verlässigkeit in der Empfängnisverhütung, das gestiegene SelbstbewuBtsein der Frauen und nicht zuletzt die Leistungen des hoch entwickelten Sozialstaates in Deutschland machen eine bewubte Entscheidung für oder gegen Kinder möglich, mit der Folge, daß es eine Gruppe von ledigen Frauen gibt, die ihre Schwangerschaft bewußt geplant und den Vater des Kindes gezielt ausgesucht haben, um eine neue Lebensform zu praktizieren. Sozioökonomische Erhebungen zeigen, daß diese bislang noch kleine Gruppe lediger Mütter sich aus Angehörigen eines bestimmten kulturellen Milieus - vorwiegend aus dem alternativen und akademischen Umfeld - zusammensetzt. ${ }^{109} \mathbf{R}$. Nave-Herz ging in einem Forschungsprojekt der Frage nach, ob die Ein-ElternFamilie inzwischen als eine subjektiv bejahte und bewußt geplante Lebensform im Zuge des allgemeinen Modernisierungsprozesses gelten kann, und kam zu ähnlichen Ergebnissen. ${ }^{110}$ Die Entscheidung zum Kind wird von den ledigen Müttern überwiegend allein $(55,5 \%)$ und häufig sogar gegen den Willen des Vaters $(20,6 \%)$ getroffen. Nur bei 33,1\% aller Befragten hatte der Vater die Entscheidung für das Kind mitgetragen. ${ }^{111}$ De facto scheint sich also eine neue Lebensform herauszubilden, die sich in ihrem Grün-

\footnotetext{
109 Vgl. G. Burkart/M. Kohli, Liebe, Ehe, Elternschaft: die Zukunft der Familie, München/Zürich 1992.

${ }^{110}$ Vgl. R. Nave-Herz, Ledige Mutterschaft: eine alternative Lebensform?, in: Einblicke, Wissenschaft und Forschung an der Carl-von-Ossietzky Universität Oldenburg, Nr. 17, April 1993, S. 4.

${ }^{111}$ Vgl. ebenda, S. 6.
} 
dungsanlaß von anderen dadurch unterscheidet, daß eine bewußte und bejahte Familienbildung ohne Ehesubsystem erfolgt, die Ehe scheint für bestimmte Frauen augenscheinlich keine Attraktivität mehr zu besitzen. ${ }^{112}$

\section{Ausgestaltungsprinzipien im System der sozialen Siche- rung}

Neben den Aufgaben eines Systems kollektiver Sicherung, der Regelung der Frage also, welche sozialen Tatbestände in ihm überhaupt aufgenommen werden sollen, muß die Ausgestaltung des Systems entweder im Sinne einer Grund- oder einer Vollsicherung geklärt werden, wobei gleichzeitig über den Umfang freiwilliger Vorsorge und über Versicherungszwang entschieden wird.

Im Spannungsverhältnis von Freiheit und Sicherheit stellt die Sozialversicherung ein Mischsystem zwischen Versicherungs- und SteuerTransfersystem dar. Im Gegensatz zum Versicherungsprinzip hat in einem Steuer-Transfersystem die Leistungs-Gegenleistungs-Beziehung keine oder allenfalls eine untergeordnete Bedeutung. Unter Berücksichtigung der Wirkungen auf die verschiedenen Aspekte des wirtschafts- und sozialpolitischen Zielsystems ist die normative Fragestellung darauf gerichtet, wo sich das Sozialversicherungssystem befinden sollte und welche Wirkungen jeweils auftreten $^{113}$.

Als Prinzipien staatlicher Sicherungspolitik kommen drei Grundprinzipien in Betracht, die die Art und Weise, wie die Leistungsseite des Sicherungssystems mit der Finanzierungsseite verknüpft ist, regeln.

\section{Versicherungs-, Versorgungs-, Fürsorgeprinzip}

Das Versicherungsprinzip ist zunächst als Selbsthilfemaßnahme beim privaten Risikoschutz (Individualversicherung) entstanden und regelt die

\footnotetext{
112 Vgl. ebenda, S. 6.

${ }^{113}$ Vgl. Schmähl, Winfried, Versicherungsgedanke und Sozialversicherung - Konzept und politische Bedeutung, in: Schmähl, Winfried (Hrsg.), Versicherungsprinzip und soziale Sicherung, Tübingen 1985, S. 1-12, hier: S. 2 f.
} 
Leistungs-Gegenleistungs-Beziehung nach dem Prinzip der versicherungstechnischen Äquivalenz, d.h. einer strengen Orientierung der beanspruchten Leistungen an den Beiträgen, und der Höhe der Beiträge an der Wahrscheinlichkeit des Risikoeintritts. Es kennzeichnet ein Entsprechungsverhältnis von Leistung und Gegenleistung bei Wirksamwerden eines Risikoausgleichs zwischen den Mitgliedern einer Versicherung ${ }^{114}$.

Grundgedanke ist somit die gemeinsame Selbsthilfe durch den freiwilligen Zusammenschluß von gleichartig Gefährdeten und den Risikoausgleich innerhalb dieser Gefahrengemeinschaft. Der bei Eintritt eines Schadens entstandene Bedarf beim einzelnen Geschädigten wird von der Gesamtheit der Gemeinschaft gedeckt ${ }^{115}$.

Die Versicherung muß in der Lage sein, zu jeder Zeit die Leistung erbringen zu können, dies impliziert, daß die Beiträge so bemessen sein müssen, daß sie unter Berücksichtigung bestimmter Faktoren insgesamt ausreichen, um die eintretenden Schadensfälle und den daraus resultierenden Leistungsbedarf zu decken. Es wird also die sogenannte Globaläquivalenz gefordert, "weil zunächst auf den gesamten Versichertenbestand abgestellt und die Gleichwertigkeit von Leistung und Gegenleistung unter den an der Versicherung insgesamt Beteiligten verlangt wird"116. Darüber hinaus besteht z.B. in der Alterssicherung Gruppenäquivalenz, d.h. es existiert eine Gruppe von Personen mit gleichartigen Risiken, denen nach den Gesetzen der Wahrscheinlichkeitsrechnung die gleiche mittlere Lebenserwartung zuzurechnen ist ${ }^{117}$.

Der Beitrag in einem nach dem Versicherungsgedanken konzipierten System ist eine fixe, versicherungsmathematisch festgelegte Größe aufgrund von Wahrscheinlichkeiten über Sterblichkeit, Zinsertrag und Verwaltungskosten. In einem System, das diese Anforderungen erfüllt, herrscht gemeinhin Beitragsäquivalenz, d.h. es besteht ein enger Zusammenhang zwischen

\footnotetext{
${ }^{114}$ Vgl. Schmähl, W., Versicherungsgedanke und Sozialversicherung - Konzept und politische Bedeutung, a.a.O., S. 2.

${ }_{115}$ Vgl. Kolb, Rudolf, Die Bedeutung des Versicherungsprinzips für die gesetzliche Rentenversicherung, in: Schmähl, W. (Hrsg.), Versicherungsprinzip und soziale Sicherung, Tübingen 1985, S. 120-140, hier: S. 123.

${ }^{116}$ Kolb, Rudolf, a.a.O., S. 123.

${ }^{117}$ Kolb, Rudolf, a.a.O., S. 125.
} 
den vom Versicherten aufgebrachten Beiträgen und der Höhe des Anspruches auf Leistungen.

Der Sozialversicherung liegt ein abgewandeltes Versicherungsprinzip zugrunde, insofern als es sich zusätzlich an der Idee des sozialen Ausgleichs orientiert (Solidarprinzip). Der freiwillige Beitritt wird durch eine Versicherungspflicht, die sich auf Mitglieder bestimmter sozialer Gruppen beschränkt, ersetzt. Die Beiträge zur Deckung der bei einer Schadensregulierung entstandenen Kosten sind nicht ausschließlich an der individuellen Risikowahrscheinlichkeit ausgerichtet (Äquivalenzprinzip), sondern bemessen sich nach sozialen Kriterien. Die nach Art und Höhe differenzierten Versicherungsleistungen sind nicht streng beitragsorientiert, sondern bei jedem Mitglied für den gleichen Risikofall gleich (Bsp. Krankenversicherung). Durch Teilübernahme der Kosten für Versicherungsleistungen durch den Staat aus dem Steueraufkommen findet ein Budgetausgleich zwischen Beitragsleistung und Leistungsfinanzierung im engeren Sinn nicht statt.

In einem nach dem Versicherungsprinzip zu konstruierenden System der sozialen Sicherung müssen folgende Grundprobleme geklärt werden ${ }^{118}$ :

(1) Der schutzwürdige und damit zu versichernde Personenkreis

(2) Die Bemessungsgrundlage für die Beiträge

(3) Die Tatbestände, die Voraussetzung für die Gewährung der Leistung sein sollen

(4) Die Höhe der für die Leistungsgewährung notwendigen Vorleistungen.

Nach dem Versorgungsprinzip wird den zu sichernden Personen ein nach Art und Höhe normierter Rechtsanspruch auf Sicherungsleistungen durch den Versicherungsträger (Staat) eingeräumt, ohne unmittelbaren Bezug zu einer eigenen Beitragsleistung oder Bedürftigkeit, aufgrund bestimmter Voraussetzungen, insbesondere von Leistungen für den Staat ${ }^{119}$. Da es entgegen dem Prinzip der Freiheit respektive der Selbstverantwortung auch diejenigen von der Finanzierung ihrer sozialen Sicherung freistellt, die in der Lage sind, eigene Beiträge zu leisten, gleichzeitig die private Initiative

\footnotetext{
${ }^{118}$ Vgl. Albers, W., Freiheit und Sicherheit in der Sozialpolitik, in: Die Sozialversicherung, 42. Jg. 1987, Heft 1, S. 5.

${ }^{119}$ Vgl. Musgrave/Musgrave/Kullmer, Die öffentlichen Finanzen in Theorie und Praxis, Bd. 1, 5. überarbeitete Auflage, Tübingen 1990, S. $250 \mathrm{ff}$.
} 
zu eigenen zusätzlichen Versorgungs- und Vorsorgemaßnahmen einschränkt und die Finanzierung aus dem öffentlichen Haushalt, d.h. aus Steuereinnahmen und anderen allgemeinen Haushaltsmitteln, erfolgt, ist es als Instrument zur vollen Absicherung von Normalrisiken ungebräuchlich, auch wenn es in einigen Ländern mit hohem Wohlstand Grundlage für das System sozialer Sicherung ist (Staatsbürgerversorgung).

Nach dem Fürsorgeprinzip wird unabhängig von irgendwelchen Vorleistungen und Opfern Beiträge jedem Staatsbürger aufgrund einer im Einzelfall nachzuweisenden speziellen Bedürftigkeit eine Unterhaltshilfe gewährt, die dazu dient, demjenigen, der in eine Notlage geraten ist, ein menschenwürdiges Dasein auch dann zu ermöglichen, wenn er seine Situation selbst verschuldet hat. Sie leiten sich eigentlich aus der traditionellen Armenfürsorge ab und orientieren sich ausschließlich am jeweiligen Einzelfall nach Maßgabe der individuellen Notlage; finanziert werden diese Leistungen aus allgemeinen Haushaltsmitteln. Eine Verpflichtung zur Rückzahlung besteht beim Bezug dieser Leistungen nicht, allerdings kann in manchen Fällen vom Bezieher dieser Leistung eine Gegenleistung in Form einer eingeschränkten Erwerbstätigkeit im öffentlichen Sektor verlangt werden. AuBerdem werden im Rahmen der Bedürftigkeitsprüfung die Vermögensverhältnisse der antragstellenden Person und deren Angehöriger überprüft, da gemäß dem Subsidiaritätsprinzip erst auf die zur Verfügung stehenden eigenen Mittel zurückgegriffen werden soll bzw. private Unterhaltspflichten Vorrang gegenüber der Hilfe der Solidargemeinschaft haben sollen.

Das Eindringen der Sozialbürokratie in die Privatsphäre der Bedürftigen zur Offenlegung ihrer privaten Lebensumstände - ein Vorgang, der heute oft als entwürdigend und tendenziell diskriminierend empfunden wird - ist auch aufgrund der Subsidiarität ${ }^{120}$ der gewährten Leistung notwendig und führt zu erheblichen Kosteneinsparungen.

\footnotetext{
${ }^{120}$ Das Prinzip der Subsidiarität geht von dem Grundgedanken aus, daß eine Hilfe zu Lasten der Gemeinschaft für den einzelnen nur dann wirksam werden soll, wenn er hilfsbedürftig wird, d.h. wenn er selbst vorab erfolglos den Versuch unternommen hat, sich selbst zu helfen. Dies impliziert, daß alles, was der einzelne selbst tun kann, ihm nicht durch die Gemeinschaft abgenommen werden soll. Der Staat soll also als letzter, quasi als Ausfallbürge, eingreifen, wenn in den kleineren sozialen Einheiten (= Familie) keine Hilfe mehr erfolgen kann.
} 
Die so konzipierte Sozialhilfe eignet sich besonders gut, Lücken, die die anderen Sicherungssysteme offen lassen, zu schließen; sie ist damit sozusagen letztes Auffangnetz für Notfälle, die anderweitig nicht berücksichtigt werden ${ }^{121}$. Die Leistung nach dem Fürsorgeprinzip soll keine Dauerhilfe sein, sondern zielt darauf ab, den Bedürftigen so weit wie möglich zu befähigen, "unabhängig von der Hilfe selbständig handelnd und wirtschaftend wieder am Leben der Gemeinschaft teilzunehmen"122.

Nach neuester Rechtsprechung hat der Leistungsempfänger auf den überwiegenden Teil der Hilfe einen Rechtsanspruch, der gerichtlich geltend gemacht werden kann, allerdings nur dem Grunde nach (lediglich bei der Hilfe zum Lebensunterhalt auch der Höhe nach), über die Art und Ausgestaltung entscheiden letztlich die Träger der Sozialhilfe nach pflichtmäßigem Ermessen $^{123}$.

\section{Final- und Kausalprinzip}

Gibt es hinsichtlich der Definition der unter 1 genannten Ausgestaltungsprinzipien kaum Differenzen in der Wissenschaft, stellt sich die Spezifizierung des Final- und Kausalprinzips als kontrovers diskutiertes Problem dar. So stellt beispielsweise Rohwer-Kahlmann fest: „Jede Sozialleistung ist sowohl kausal als final bedingt; das gilt auch für die Leistung der Sozialhilfe aus staatsbürgerlicher Solidarität; die Staatsbürgergemeinschaft fragt zwar nicht nach der Ursache des Hilfsbedarfs, wenn sie entscheidet, ob sie helfen will, aber sie ist nur zur Leistung verpflichtet, wenn der Rechtsgrund der staatsbürgerlichen Solidarität dies gebietet. Und auch die kausal bedingte Leistung der sozialen Entschädigung ist final ausgerichtet, ist auf ein bestimmtes zu erreichendes Ziel konkretisiert. “"124

Nach Liefmann-Keil besagt das Finalprinzip, "daß bei gleichem Ausgangstatbestand gleiche Bewertung und damit gleiche Behandlung erfolgen

\footnotetext{
${ }^{121}$ Vgl. Winterstein, Helmut, Prinzipien der sozialen Sicherung, in: WIST Heft 9, September 1976, S. 433-437, hier: S. 430.

${ }^{122}$ Winterstein, Helmut, a.a.O., S. 435.

${ }^{123}$ Winterstein, Helmut, a.a.O., S. 435.

${ }^{124}$ Rohwer-Kahlmann, H., Das Sozialgesetzbuch, Kritik an Stiers Kritik, in: Zeitschrift für Sozialreform, 19. Jg. 1973, S. 342.
} 
soll"125, und nach Molitor ist "mit der finalen Ausrichtung des Sicherungssystems eine qualitative Angleichung der Leistungen der Einzelträger für das gleiche Risiko, den gleichen Schaden und Notstand verbunden" ${ }^{126}$.

Die wohl umfassendste Auseinandersetzung mit dem Final- und Kausalprinzip im System der Sozialen Sicherung liegt von Albers vor, der den wesentlichen Unterschied zwischen beiden Prinzipien darin sieht, daß beim Finalprinzip Transferzahlungen auf die Neutralisierung der Folgen eines sozialen Tatbestandes abzustellen sind, während beim Kausalprinzip nach den in der Vergangenheit liegenden Ursachen des Einkommensausfalls und der Schädigung differenziert wird ${ }^{127}$. $\mathrm{Zu}$ beachten ist, daB nicht jede Beziehung zur Vergangenheit als Kriterium für das Kausalprinzip angesehen werden kann, konstitutiv ist in diesem Fall, daß ein leistungsfähiger "Schädiger" oder "Haftpflichtiger" vorhanden ist ${ }^{128}$. Besonders deutlich wird der Unterschied am Beispiel der sozialen Sicherung bei Tod oder Ausfall des Ernährers der Familie ${ }^{129}$. Leistungsbegründeter Tatbestand beim Kausalprinzip ist der Tod (Ausfall), "so daß ein Anspruch auf Sozialleistungen ohne Rücksicht darauf anerkannt wird, ob bei den Angehörigen eine soziale Notlage besteht" ${ }^{130}$. Nach dem Finalprinzip ist die soziale Lage der Angehörigen Grundlage der Leistungsgewährung. So ist in der Person der Witwe mit Kindern einerseits, der geschiedenen Alleinerziehenden und ledigen Mütter andererseits ein sozialer Tatbestand - das Aufziehen kleiner Kinder gegeben, der einen Unterhaltsanspruch durch die Allgemeinheit rechtfertigt.

Die konsequente Anwendung des Finalprinzips bedeutet jedoch nicht, daß eine Bedürftigkeitsprüfung vorzunehmen ist, "final bedeutet lediglich, daß bei dem Anspruchsberechtigten der vom Gesetzgeber für den Anspruch auf Transferzahlung festgelegte Tatbestand (Alter, Invalidität u.s.w.) erfüllt sein muß, bei dem unterstellt wird, daß der Betreffende seine Existenz nicht

\footnotetext{
${ }^{125}$ Liefmann-Keil, Elisabeth, Ökonomische Theorie der Sozialpolitik, Berlin u.a.O., S. 176.

${ }^{126}$ Molitor, Bruno, Kausal- und Finalprinzip, in: Böttcher, E. (Hrsg.), Sozialpolitik und Sozialreform, Tübingen 1957, S. 249.

127 Vgl. Albers, W., Möglichkeiten einer stärker final orientierten Sozialpolitik, Kommission für wirtschaftlichen und sozialen Wandel, Bd. 119, Göttingen 1976, S. 2.

${ }^{128}$ Vgl. ebenda, S. 2 f.

${ }^{129}$ Vgl. ebenda, S. 4.

${ }^{130}$ Ebenda, S. 4.
} 
mehr durch eigene Arbeit sichern kann"131. Das Vorhandensein von ausreichendem Vermögen oder finanzkräftiger Angehöriger ist für das Finalprinzip unerheblich, wenn die Leistungen auf einer Versicherung beruhen.

\section{Individual- und Familienprinzip}

Beim Individualprinzip steht die personenbezogene Betrachtung im Vordergrund, d.h. Beiträge und Leistungen knüpfen an individuelle Tatbestände an. Eine solche Konzeption findet sich prinzipiell im Versicherungsgedanken der Privatversicherungen. Die Prämie respektive der Beitrag wird festgesetzt, indem das individuelle Risiko der Person ermittelt und bewertet wird, so daß über den gesamten Versicherungsverlauf ein Entsprechungsverhältnis von Leistung und Gegenleistung bei Wirksamwerden eines Risikoausgleichs zwischen den Mitgliedern der Versicherung. Die Maßstäbe für Leistung und Gegenleistung können in den jeweiligen Sachzusammenhängen unterschiedlich sein.

Das Familien- oder Haushaltsprinzip stellt auf die Familie bzw. Haushaltsgemeinschaft ab, d.h. Beiträge und Leistungen knüpfen an die spezifischen Gegebenheiten der betrachteten Gruppe an. Konkret bedeutet dies im Falle der gesetzlichen Rentenversicherung, daß die Beiträge und daran anknüpfend die Leistungen nach dem Einkommen beider Ehegatten bemessen werden.

Die Ausgestaltung eines Systems der Sozialen Sicherung nach dem Individualprinzip wäre aus sozialen Erwägungen heraus dann sinnvoll, wenn es sich bei dem betrachteten Personenkreis um eine homogene Gruppe in dem Sinne handelte, daß sämtliche Gruppenmitglieder zu jeder Zeit die Voraussetzungen für ein Funktionieren des Systems erfüllen könnten. D.h. konkret, jeder müßte zu jedem Zeitpunkt entweder erwerbstätig und deshalb in der Lage sein, Beiträge zu leisten, oder es gäbe eine andere Person, die bereit wäre, die Beitragszahlung zu leisten. Individuelle Entscheidungen gleich welcher Art würden individuell zu tragende Konsequenzen nach sich ziehen. Bezogen auf das System der Sozialen Sicherung in Deutschland stünde danach im Bereich der Rentenversicherung jedem Ehepartner die Rente

\footnotetext{
${ }^{131}$ Ebenda, S. 3.
} 
zu, "die sich aus den für seine Person eingezahlten Beiträgen ergäbe"132. Solange beide Ehegatten erwerbstätig sind - dies ist zumeist bis zur Geburt des ersten Kindes der Fall - könnten beide Beiträge von dem jeweils von ihnen erzielten Einkommen leisten. Scheidet die Frau wegen der Geburt und anschließender Erziehung eines Kindes aus dem Erwerbsleben aus, führt ein konsequent angewandtes Individualprinzip nicht zu befriedigenden Ergebnissen, denn werden während dieser Zeit keine Beiträge gezahlt, führt dies zu einer verminderten Leistung bei Eintritt des sozialen Tatbestandes. D.h. die Rente einer Frau mit einem oder mehreren Kindern reicht dann in der Regel nicht aus, um den im Alter angemessenen Lebensstandard fortführen zu können.

Bei Anwendung des Familienprinzips wird davon ausgegangen, daß die Ehepartner sozialpolitisch eine Einheit sind, so daß das Eintreten des Rentenfalls und die Rentenhöhe von der sozialen Lage beider Ehepartner abhängt ${ }^{133}$. "Da in der Regel die Voraussetzungen für die Gewährung einer Rente (Alter, Zumutbarkeit einer Erwerbstätigkeit) nicht gleichzeitig bei beiden Ehepartnern gegeben sind, bedarf es besonderer Bestimmungen, die festlegen, bei dem Zusammentreffen welcher Kriterien bei beiden Ehepartnern Rente in welcher Höhe zu gewähren ist"134.

Im System der Sozialversicherung schlechthin, aber auch in einzelnen Zweigen, findet sich sowohl das Individual- als auch das Familienprinzip. Die Regelungen des Versorgungsausgleiches im Scheidungsfall beziehen sich auf den Grundgedanken der Zugewinngemeinschaft in der Ehe und entsprechen insofern dem Familienprinzip: Die Rentenansprüche der Ehegatten werden als Einheit gesehen, die im Bedarfsfall zu gleichen Teilen auf die Personen aufgeteilt werden. Nach erfolgter Aufteilung kann ohne Probleme, dem Individualprinzip folgend, eine weitere Aufstockung der Rentenansprüche bezogen auf die Person erfolgen. Dieses Beispiel zeigt schon, daß auch eine Kombination beider Prinzipien im Ergebnis zu einer eigenständigen Sicherung von Versicherten führen kann. Die Entscheidung, welchem Prinzip gefolgt werden soll, wird einerseits von ökonomischen Kriterien, anderer-

\footnotetext{
${ }^{132}$ Albers, W., Möglichkeiten einer stärker final orientierten Sozialpolitik, a.a.O., S. 91.

${ }^{133}$ Vgl. ebenda, S. $91 f$.

${ }^{134}$ Ebenda, S. 92.
} 
seits aber auch von soziologischen Vorstellungen über die Beziehungen in der sozialen Gruppe beeinflußt. In mehr oder weniger losen Verbindungen, die jederzeit gelöst werden können, wäre das Individualprinzip praktikabler und insofern „gerechter“, als nicht Zufälligkeiten für die Anrechnung bzw. Nichtanrechnung von Rentenzeiten verantwortlich wären. Wird die Ehe jedoch als eine auf Dauer angelegte stabile Gemeinschaft gesehen, deren Ziel es ist, Kinder aufzuziehen und als Kernfamilie die ihr im Grundgesetz übertragenen Aufgaben wahrzunehmen ${ }^{135}$, dann wäre die Anwendung des Familienprinzips in der Sozialversicherung nur logisch und konsequent.

\section{Vereinbarkeit der Prinzipien untereinander}

Bei der praktischen Ausgestaltung des Systems der sozialen Sicherheit ist zu prüfen, ob die betrachteten Prinzipien theoretisch miteinander zu vereinbaren sind. Es steltt sich insbesondere die Frage, inwieweit Kausal- und Finalprinzip mit dem Versicherungs-, Versorgungs- und Fürsorgeprinzip korrespondieren.

Kausal- und Finalprinzip stellen im wesentlichen auf die Gewährung der Leistungen ab, Versicherungs-, Versorgungs- und Fürsorgeprinzip hingegen betrachten in erster Linie die Finanzierungsseite.

Leistungen nach dem Versicherungsprinzip orientieren sich an einem klaren Ursache-Wirkungszusammenhang und werden bei Eintritt eines vorher eindeutig definierten Schadens gewährt. Gleichzeitig wird der für einen Schaden Verantwortliche ermittelt und über die Schadensersatzpflicht ,zur Verantwortung" gezogen. In der Sozialversicherung findet sich die Idee des Kausalprinzips in der gesetzlichen Unfallversicherung wieder. Bei festgestellter Erwerbsunfähigkeit tritt die Versicherung nur dann ein, wenn die Erwerbsunfähigkeit durch einen Unfall am Arbeitsplatz verursacht wurde, ein vom Hergang vergleichbarer Unfall in der Freizeit (Urlaub) mit gleichen Schädigungen würde von dieser Versicherung rentenrechtlich nicht anerkannt werden. Anders ist dies in der gesetzlichen Rentenversicherung, dort wird die Rente unabhängig von der Ursache der Erwerbsunfähigkeit gezahlt. Obwohl als „Versicherung“ konzipiert, folgt die Leistungsgewährung

135 Vgl. ebenda, S. 91. 
in der gesetzlichen Rentenversicherung dem Finalprinzip. Allein der gegebene soziale Tatbestand, seinen Unterhalt wegen Alter, Krankheit oder andauernder Behinderung nicht mehr selbst bestreiten zu können, führt zur Zahlung der Rente. Hilfen werden gewährt, um soziale Härten zu vermeiden, einzige Voraussetzung ist es, Mitglied in diesem Versicherungszweig zu sein. Die Leistung als solche orientiert sich also am Finalprinzip, lediglich die Höhe der Leistung variiert je nach der meßbaren Vorleistung in Form von Beitragszahlungen, letzteres ist Grundlage einer Versicherung mit ihren konstitutiven Elementen. In der Rentenversicherung existiert gleichberechtigt sowohl das Äquivalenzprinzip als auch das Solidarprinzip, die beide mit dem Versicherungsgedanken vereinbar sind, es fließen jedoch auch fürsorgerische Elemente ein, die eindeutig final orientiert sind. Schreiber als Begründer der gesetzlichen Rentenversicherung im Umlageverfahren ging allerdings noch davon aus, daß die Rentenversicherung eine Selbstorganisation sein sollte, in der in aller Strenge das Prinzip der Äquivalenz von Leistung und Gegenleistung gelten sollte, ${ }^{136}$ der Einbau von Umverteilungselementen zum Schutz gegen soziale Härten war ursprünglich im Rentenversicherungssystem nicht vorgesehen.

Das Bundesverfassungsgericht betont schon sehr bald in seiner Rechtsprechung, daß die Rentenversicherung nicht vom individuumbezogenen Risikobegriff der Privatversicherung ausgehe, sondern auch Elemente soziale Fürsorge (= sozialen Ausgleichs) enthalte. ${ }^{137}$ Insbesondere sei die Hinterbliebenenrente eine vorwiegend fürsorgerische Leistung, weil sie ohne eigene Beitragsleistungen des Rentenempfängers und ohne eine erhöhte Beitragsleistung des Versicherten gewährt wird. ${ }^{138}$

Der Versicherte in der gesetzlichen Rentenversicherung ist in der Tat nicht mit einem Versicherten in einer Privatversicherung mit Anwendung eines reinen Versicherungsprinzips zu vergleichen, denn er trägt sozusagen ein dreifaches Einkommensschicksal: ${ }^{139}$

1. sein eigenes,

\footnotetext{
${ }^{136}$ Vgl. W. Schreiber, a.a.O., S. 130.

137 BVerfG 48, S. 358.

${ }^{138}$ BVerfG 48, S. 358f.

139 Vgl. R. Kolb, Die Bedeutung des Versicherungsprinzips für die gesetzliche Rentenversicherung, in: Versicherungsprinzip und soziale Sicherung, Tübingen 1985, S.128.
} 
2. das seiner Generation, die die Leistungen aufbringen muß,

3. und letztlich dasjenige der Generation, die die Leistungen, die er später erhält, finanzieren muß.

Es ist somit offensichtlich, daB das Umlageverfahren der gesetzlichen Rentenversicherung nur bedingt dem Versicherungsprinzip folgt, denn die Rente des einzelnen Versicherten ist nicht streng beitragsbezogen, sondern ist erwerbseinkommensbezogen, sie reflektiert periodisch den Einkommensverlauf sowohl des Versicherten als auch des Kollektivs aller jetzt und künftig Versicherten. ${ }^{140}$ Die Rente ist nicht nur nicht strikt beitragsbezogen, der allgemeine Beitragssatz ermittelt sich auch nicht nach dem „Prinzip der gerechten Prämie“, für die Bemessung der Beitragshöhe spielen persönliche oder spezielle Risiken des Versicherten (Eintrittsalter, Gesundheitszustand, Zugehörigkeit zu einer Risikogruppe) keine Rolle. Der Beitrag wird nach Maßgabe des erzielten Einkommens erhoben und ist Ausdruck einer Solidarverpflichtung zwischen den Generationen. Der Beitrag konkretisiert lediglich ein Teilhaberecht an einer Finanzmasse, die von der aktiven Generation erarbeitet wird. Ausschließlich die Zugehörigkeit zur Solidargemeinschaft der Aktiven reicht aus, um später einmal selbst eine Rentenleistung zu erhalten, und dieses in Form einer Teilhabe des Versicherten an der nach Eintritt des Versicherungsfalles zur Verfügung stehenden Finanzmasse.

Wie auch gerade wieder aktuell zu verfolgen, spielen bei der Festlegung des Beitragssatzes demographische und arbeitsmarktpolitische Faktoren eine zentrale Rolle. Wenn die individuelle Beitragsleistung nur mittelbar die zukünftige Leistung bestimmt und der Versicherte ein dreifaches Einkommensschicksal trägt, muß der Rentenversicherung ein Sicherungsziel zwingend vorgegeben werden. ${ }^{141}$ Ein solches Sicherungsziel ist von der Sachverständigenkommission Alterssicherungssysteme derart definiert worden, daß ein altersgemäßer Lebensstandard gesichert werden soll, d.h. nach einem etwa 45 Jahre dauernden Arbeitsleben soll der Lebensstandard im Alter nur wenig hinter demjenigen zurückbleiben, den der Versicherte während der Zeit der Erwerbstätigkeit hatte, die Sachverständigenkommission verstand darunter ein Nettoeinkommen, das zwischen $70 \%$ und $90 \%$ des Nettoar-

\footnotetext{
140 Vgl. ebenda.

$1+1$ Vgl. R. Kolb, a.a.O., S. 134.
} 
beitseinkommens lag. Der sogenannte „Eckrentner“, also der Bezieher der Standardrente nach 45 Beitragsjahren bei dem jeweiligen Durchschnittsverdienst, erreicht $70 \%$ des Durchschnittsnettolohns. Faktisch erreicht der Bezieher von Altersruhegeld gegenwärtig durchschnittlich $60 \%$ seines Nettoarbeitseinkommens, da nur ein kleiner Teil der Versicherten 45 Beitragsjahre nachweisen kann. Die Anwendung des Individualprinzips in der gesetzlichen Rentenversicherung wäre durchaus möglich, gegenwärtig würde es aber zu nicht befriedigenden Ergebnissen führen. Trotz gestiegener $\mathbf{E r}$ werbstätigkeit von Frauen und inzwischen weit gefaßter Anrechnung von Kindererziehungszeiten, sind Lücken in der sozialen Biografie von Frauen noch eher die Regel, denn die Ausnahme, und der sich erst langsam vollziehende Strukturwandel läßt vermuten, daß Frauen auf dem Arbeitsmarkt hinsichtlich ihrer Markteintrittschancen in absehbarer Zeit nicht besser gestellt sein werden.

Eindeutig dem Finalprinzip zuzuordnen sind die Leistungen im Rahmen des Fürsorgeprinzips. Einziger Leistungsgrund ist eine gegenwärtige Notlage und das Leistungsmaß wird in diesen Fällen am momentanen Bedarf orientiert, d.h. die vom Finalprinzip geforderte Gleichbehandlung gleicher Tatbestände bedeutet bei gleicher Lebenslage der Hilfeempfänger zwangsläufig gleiche Leistung.

Sollen Sozialleistungen "in einem bestimmten Verhältnis zum früheren Arbeitseinkommen stehen", entsteht die Notwendigkeit, die Vereinbarkeit von Finalprinzip und den leistungsbegründenden und leistungsbemessenden Tatbeständen bei Versicherungs- und Versorgungsprinzip zu überprüfen. Die Forderung einkommensabhängiger Leistungen bedeutet aber, daB die Lebenslage nicht wie beim Fürsorgeprinzip umfassend unter Betrachtung aller sonst zur Verfügung stehenden Einkommensquellen geprüft wird, sondern eine Relation der Sozialleistung zum früheren Einkommen politisch bestimmt wird.

Die dem Fürsorgeprinzip zuzuordnenden Leistungen im System der sozialen Sicherung werden i.d.R. aus allgemeinen Haushaltsmitteln finanziert und sind an die Überprüfung der Bedürftigkeit gekoppelt, wobei neben dem Einkommen und Vermögen des Berechtigten auch die soziale Lage seiner engen Anverwandten in die Betrachtung einbezogen wird (Bsp: Hilfe zum 
laufenden Lebensunterhalt $=$ Sozialhilfe). Die ideologische Legitimation erhält dieses Vorgehen durch das Subsidiaritätsprinzip, nachdem der Staat als letzter, quasi als Ausfallbürge, bei Notlagen eingreifen soll.

Auch das Versorgungsprinzip knüpft am Gedanken des Finalprinzips an, da sowohl die Existenz einer Schädigung, als auch der soziale Bedarf die Leistung determiniert (Bsp: Wohngeld, Kindergeld, Ausbildungsförderung), allerdings wird der höhere finanzielle Bedarf bei bestimmten Gruppen als gegeben angenommen (z.B. Familien mit Kindern) und Pauschalleistung führt zu einer Bedürftigkeitsprüfung im Einzelfall. Da schon die Aufzählung der Beispiele zeigt, daß diese Leistungen sowohl einzelnen Personen als auch Familien als ganzes gewährt wird, kann auf die Vereinbarkeit von Versorgungsprinzip und Individualprinzip/Familienprinzip geschlossen werden.

\section{Grundtatbestände des Systems der Alterssicherung in Deutschland}

\section{Die Struktur des Alterssicherungssystems}

Im System sozialer Sicherung nimmt die gesetzliche Rentenversicherung, gemessen an den Ausgaben, den breitesten Raum ein. Sie gliedert sich in die Rentenversicherung der Arbeiter, der Angestellten und in die knappschaftliche Rentenversicherung, insgesamt gehörten ihr im Jahre 1993 in den alten Bundesländern rd. 35,3 Millionen Versicherte an, davon waren 48 $\%$ Frauen. In den neuen Bundesländern betrug die Zahl der gesetzlich Versicherten im gleichen Untersuchungszeitraum rd. 9,2 Millionen, wovon ca. $47 \%$ Frauen waren. Für rd. $80 \%$ der Erwerbstätigen ist die gesetzliche Rentenversicherung die wichtigste Absicherung der sozialen Tatbestände Alter und Invalidität, die bei einem Teil von ihnen durch eine Zusatzsicherung aus der betrieblichen Altersversorgung oder einer Zusatzversorgung im öffentlichen Dienst ergänzt wird, so daß in diesen Fällen ein Lebensstan- 
dard wie zur Zeit der Erwerbstätigkeit annähernd aufrechterhalten werden kann. Die gesetzliche Rentenversicherung erfüllt damit die Funktion einer Regelsicherung, d.h. für vollversicherte Erwerbstätige wird nach 45 Versicherungsjahren bislang ein Nettorentenniveau von $68 \%$ des letzten Einkommens sichergestellt. Zum Ausgleich evtl. auftretender Lücken aufgrund individueller Gegebenheiten muß diese Regelsicherung aufgestockt werden, um den einmal erreichten Lebensstandard zu erhalten. Diese Zielsetzung wird in der Beamtenversorgung schon von vornherein erfüllt, sie gewährleistet nach 40 Dienstjahren eine Bruttopension von $75 \%$ der ruhegehaltsfähigen Dienstbezüge. Im Unterschied zu GRV-Renten und dem überwiegenden Teil der Betriebsrenten werden Pensionen dreizehnmal pro Jahr gezahlt. Besondere Regelungen gelten bei den Leistungen der berufsständischen Versorgungssysteme. $\mathrm{Zu}$ nennen ist in diesem Zusammenhang die knappschaftliche Rentenversicherung (zuständig im Bereich des Bergbaus), die im Recht der gesetzlichen Rentenversicherung eine Sonderstellung einnimmt. Da bei der knappschaftlichen Rentenversicherung das berufsständische Prinzip im Vordergrund steht, sind sowohl Arbeiter als auch Angestellte bei ihr versichert, sofern sie in einem knappschaftlichen Betrieb tätig sind. Die knappschaftliche Rentenversicherung ist so ausgestaltet, daß sie die Regelsicherung und die betriebliche Altersversorgung in einem System einschliebt. Dies bedeutet für die dort Beschäftigten, daß das Beitrags- und Leistungsniveau rd. ein Drittel über dem Niveau der Rentenversicherung der Arbeiter und Angestellten liegt. Die Bifunktionalität dieses Versicherungszweiges drückt sich in einem entsprechend höheren Rentenartfaktor bei der Berechnung der Rente aus.

Im Zuge der Öffnung der Rentenversicherung für Selbständige wurden durch das Künstlersozialversicherungsgesetz vom 27.7.1981 (KSVG - Gesetz über die Sozialversicherung der selbständigen Künstler und Publizisten) selbständige Künstler und Publizisten mit Wirkung vom 1.1.1983 in der Rentenversicherung der Angestellten versicherungspflichtig.

Als Künstler wird angesehen, ,wer Musik, darstellende oder bildende Kunst schafft, ausübt oder lehrt.“1+2 Publizist gemäß des Gesetzes ist, „wer

$142 \S 2$ KSVG. 
als Schriftsteller, Journalist oder in anderer Weise publizistisch tätig ist. " ${ }^{\text {143 }}$ Die Voraussetzungen für die Aufnahme in die gesetzliche Rentenversicherung gelten also erfüllt, wenn die betreffende Person

1. die künstlerische oder publizistische Tätigkeit dauerhaft erwerbsmäßig ausübt und

2. im Zusammenhang mit diesen Tätigkeiten nicht mehr als 1 Arbeitnehmer beschäftigt, es sei denn, die Beschäftigung erfolgt zur Berufsausbildung oder ist geringfügig im Sinne des $§ 8$ SGB IV. ${ }^{144}$

Ansatzpunkt für die Ausdehnung der Rentenversicherung auch auf diesen Personenkreis war die besondere Schutzwürdigkeit, die darin gesehen wurde, daß viele Künstler und Publizisten ihre Werke nur schwer vermarkten können. Aus diesem Grund sieht das Gesetz weiterhin vor, daß diese Personen - wie abhängig Beschäftigte - nur einen halben Beitrag zu zahlen haben, die andere Hälfte wird von den Vermarktern als sogenannte Künstlersozialabgabe aufgebracht und an die Künstlersozialkasse abgeführt. Beitragsbemessungsgrundlage ist das voraussichtliche Jahreseinkommen ${ }^{145}$, mindestens jedoch ein Siebtel der Bezugsgröße. ${ }^{146}$ Die Mittel für die Versicherung werden also durch Beitragsanteile der Versicherten, durch die Künstlersozialabgabe und, soweit das beitragspflichtige Arbeitseinkommen der Versicherten nicht auf Entgelten für künstlerische oder publizistische Werke oder Leistungen beruht, durch einen Zuschuß des Bundes zur anderen Hälfte aufgebracht, ${ }^{147}$ außerdem trägt der Bund die Verwaltungskosten der Künstlersozialkasse. ${ }^{148}$

Die landwirtschaftliche Altersversorgung kommt zwar dem überwiegenden Teil der ehemaligen Landwirte zugute, ist jedoch nicht als Regelsicherung, sondern eher als Teilsicherung in Ergänzung des Altenteils konzipiert und nimmt somit ebenfalls eine Sonderstellung im Alterssicherungssystem ein.

\footnotetext{
143 Ebenda.

144 Vgl. § 1 KSVG.

145 Vgl. § 12 KSVG.

146 Vgl. § 165 Abs. 1 Nr. 3 SGB VI.

147 Vgl. § 14 KSVG.

148 Vgl. § 34 Abs. 2 KSVG.
} 
Letztendlich soll noch die Kriegsopferversorgung erwähnt werden, die zwar nicht primär dem Ziel finanzieller Sicherung im Alter dient, jedoch in hohem Maße hinterbliebenen Kriegerwitwen zugute kommt und die soziale Lage dieses Personenkreises verbessert.

Zu den staatlich oder berufsständisch organisiserten Systemkomponenten der Alterssicherung kommen die vielfältigen Möglichkeiten privater Vorsorge über Bankinstitute, Versicherungen oder Immobilienankauf. Da sie i.d.R. sehr individuell gestaltet sind, wird im folgenden nicht näher auf sie eingegangen.

Die Anzahl, noch mehr aber die Struktur der Versicherten ist eine wesentliche Grundlage zur Berechnung, Darstellung und Beurteilung der finanziellen Entwicklung der Rentenversicherung und wird infolgedessen in den Tabellen 1 und 2 abgebildet.

Unterschiedliches Beschäftigungsverhalten und ein noch nicht völlig übereinstimmendes Rentenrecht lieB die Struktur der Versicherten in den ersten Jahren nach der Vereinigung in den alten und neuen Bundesländern noch stark divergieren. Bis zum Jahre 1993 hatte sich bedingt durch die Nivellierung der Verhältnisse die Versicherungsstruktur in den neuen Bundesländern derjenigen in den alten Bundesländern weitgehend angenähert. Lediglich bei den weiblichen Pflichtversicherten am Stichtag und den latent versicherten Frauen gab es noch große Abweichungen, die auf ein unterschiedliches Erwerbsverhalten der Frauen in den neuen Bundesländern zurückzuführen sind. Die gegenwärtige Situation auf dem Arbeitsmarkt läßt vermuten, daß in den nächsten Jahren eine weitere Annäherung auch bei den weiblichen Versicherten erfolgt.

\section{Leistungsbegründende Tatbestände}

Als leistungsbegründete Tatbestände sollen im folgenden die sozialen Tatbestände definiert werden, deren Eintreten zwar notwendige, aber nicht hinreichende Bedingung für die Leistungsgewährung der gesetzlichen Ren- 
tenversicherung ist, da zusätzliche versicherungsrechtliche Bedingungen erfüllt sein müssen.

Die Versicherten der gesetzlichen Rentenversicherung sind primär gegen die Tatbestände Alter, Invalidität und Tod geschützt, hinzu kommt seit Inkrafttreten des Hinterbliebenen- und Erziehungszeiten-Gesetz (HEZG) der Tatbestand Kindererziehung, d.h. allein durch die Erziehung von mehreren Kindern kann der Anspruch auf Zahlung einer Rente erworben werden.

\subsection{Alter}

Gemäß § 33 SGB VI wird beim Tatbestand Alter die Leistungsart Rente wegen Alters gewährt.

Rente wegen Alters erhält auf Antrag der Versicherte, der das 63. Lebensjahr vollendet hat oder das 60 . Lebensjahr, sofern er in diesem Zeitpunkt Schwerbehinderter im Sinne des § 1 Schwerbehindertengesetzes oder berufsunfähig (§ 36 SGB VI) oder erwerbsunfähig (§ 44 SGB VI) ist, wenn die Wartezeit von 35 anrechnungsfähigen Versicherungsjahren erfüllt ist, in denen mindestens eine Versicherungszeit von 15 Jahren enthalten ist ${ }^{149}$. Ein Anspruch auf ein Altersruhegeld bis zur Vollendung des 65. Lebensjahres besteht neben einer Beschäftigung gegen Entgelt oder neben einer Erwerbstätigkeit nur, wenn die Beschäftigung oder Erwerbstätigkeit nur gelegentlich, d.h. im Laufe eines Jahres nicht mehr als 50 Tage ausgeübt wird oder zwar laufend, aber nur gegen ein Entgelt, das durchschnittlich im Monat $1.000,--$ DM nicht überschreitet ${ }^{150}$.

Altersruhegeld erhält auf Antrag auch der Versicherte, der das 60. Lebensjahr vollendet, die Wartezeit von 5 Versicherungsjahren zurückgelegt hat und nach einer Arbeitslosigkeit von mindestens 52 Wochen innerhalb der letzten $1 \frac{1}{2}$ Jahre noch immer arbeitslos ist ${ }^{151}$.

Altersruhegeld erhält auf Antrag die Versicherte, die das 60. Lebensjahr vollendet und die Wartezeit von 5 Versicherungsjahren erfüllt hat,

\footnotetext{
${ }^{149}$ Vgl. § 33 SGB VI.

${ }^{150}$ Vgl. § 34 SGB VI.

${ }^{151}$ Vgl. § 38 SGB VI.
} 
wenn sie in den letzten 20 Jahren überwiegend eine rentenversicherungspflichtige Beschäftigung oder Tätigkeit ausgeübt hat ${ }^{152}$.

Altersruhegeld erhält der Versicherte, der das 65. Lebensjahr vollendet und die Wartezeit von 5 Versicherungsjahren erfüllt hat ${ }^{153}$. In diesem Fall ist neben dem Bezug des Altersruhegeldes ein unbegrenzter Hinzuverdienst möglich.

Der Versicherte kann bestimmen, daß ein späterer Zeitpunkt für die Erfüllung der Voraussetzungen für den Bezug des Altersruhegeldes maßgebend sein soll.

\subsection{Minderung der Erwerbsfähigkeit}

Bei Vorliegen des Tatbestandes Invalidität wird entweder Rente wegen Berufsunfähigkeit oder Rente wegen Erwerbsunfähigkeit gewährt, je nach dem Grad der Minderung der Erwerbsfähigkeit.

Rente wegen Berufsunfähigkeit erhält der Versicherte, der berufsunfähig ist und die Wartezeit erfüllt hat ${ }^{154}$. Die Wartezeit für die Berufsunfähigkeitsrente ist erfüllt, wenn vor Eintritt der Berufsunfähigkeit eine Versicherungszeit von 60 Kalendermonaten zurückgelegt ist. Berufsunfähig ist ein Versicherter, dessen Erwerbsfähigkeit infolge von Krankheit oder anderer Gebrechen oder Schwäche seiner körperlichen oder geistigen Kräfte auf weniger als die Hälfte derjenigen eines körperlich und geistig gesunden Versicherten mit ähnlicher Ausbildung und gleichwertigen Kenntnissen und Fähigkeiten herabgesunken ist. Der Kreis der Tätigkeiten, nach denen die Erwerbsfähigkeit eines Versicherten zu beurteilen ist, umfaßt alle Tätigkeiten, die seinen Kräften entsprechen und ihm unter Berücksichtigung der Dauer und des Umfangs seiner Ausbildung sowie seines bisherigen Berufs und der besonderen Anforderungen seiner bisherigen Berufstätigkeit zugemutet werden können. Zumutbar ist stets eine Tätigkeit, für die der Versicherte durch Maßnahmen zur Erhaltung, Besserung oder Wiederherstellung der Erwerbsfähigkeit mit Erfolg ausgebildet worden ist.

\footnotetext{
${ }^{152}$ Vgl. § 39 SGB VI.

${ }^{153}$ Vgl. § 34 SGB VI.

${ }^{154}$ Vgl. § 43 SGB VI.
} 
Tabelle 1: Versicherte in der Rentenversicherung (ArV und AnV) und der knappschaftlichen Rentenversicherung (KnV) nach dem Versicherungsverhältnis und dem Geschlecht

\begin{tabular}{|c|c|c|c|c|c|c|}
\hline \multicolumn{7}{|c|}{ Gesetzliche Rentenversicherung ( $\mathrm{ArV}$ und $\mathrm{AnV})^{1}$} \\
\hline \multirow{3}{*}{ Versicherte in Tsd } & \multicolumn{6}{|c|}{ Pflichtversicherte } \\
\hline & \multicolumn{3}{|c|}{ am Stichtag } & \multicolumn{3}{|c|}{ in den letzten 12 Monaten } \\
\hline & 1991 & 1992 & 1993 & 1991 & 1992 & 1993 \\
\hline \multirow{3}{*}{$\begin{array}{l}\text { Männer } \\
\text { Alte Bundesländer } \\
\text { Neue Bundesländer }\end{array}$} & & & & & & \\
\hline & 13710 & 14424 & 14587 & 585 & 571 & 559 \\
\hline & 3890 & 3856 & 3689 & 471 & 332 & 191 \\
\hline \multirow{3}{*}{$\begin{array}{l}\text { Frauen } \\
\text { Alte Bundesländer } \\
\text { Neue Bundesländer }\end{array}$} & & & & & & \\
\hline & 9535 & 10216 & 10340 & 684 & 633 & 539 \\
\hline & 3466 & 3684 & 3473 & 657 & 243 & 158 \\
\hline \multirow{3}{*}{$\begin{array}{l}\text { Insgesamt } \\
\text { Alte Bundesländer } \\
\text { Neue Bundeslănder }\end{array}$} & & & & & & \\
\hline & 23246 & 24640 & 24926 & 1270 & 1204 & 1097 \\
\hline & 7364 & 7540 & 7162 & 1127 & 575 & 349 \\
\hline \multicolumn{7}{|c|}{ Knappschaftliche Rentenversicherung $(\mathrm{KnV})^{3)}$} \\
\hline \multirow{3}{*}{$\begin{array}{l}\text { Männer und Frauen }{ }^{4} \\
\text { Alte Bundesländer } \\
\text { Neue Bundesländer }\end{array}$} & & & & & & \\
\hline & 204 & 203 & 187 & - & - & - \\
\hline & 223 & 208 & 167 & - & - & - \\
\hline \multicolumn{7}{|c|}{ Gesetzliche Rentenversicherung (ArV und AnV) ${ }^{1}$} \\
\hline \multirow{3}{*}{ Versicherte in Tsd } & \multicolumn{3}{|c|}{ freiwillig Versicherte ${ }^{2}$} & \multicolumn{3}{|c|}{ latent Versicherte } \\
\hline & \multicolumn{3}{|c|}{ am Stichtag } & \multicolumn{3}{|c|}{ in den letzten 12 Monaten } \\
\hline & 1991 & 1992 & 1993 & 1991 & 1992 & 1993 \\
\hline \multirow{3}{*}{$\begin{array}{l}\text { Männer } \\
\text { Alte Bundesländer } \\
\text { Neue Bundesländer }\end{array}$} & & & & & & \\
\hline & 519 & 563 & 519 & 2636 & 2419 & 2621 \\
\hline & 19 & 73 & 99 & 196 & 516 & 705 \\
\hline \multirow{3}{*}{$\begin{array}{l}\text { Frauen } \\
\text { Alte Bundesländer } \\
\text { Neue Bundeslănder }\end{array}$} & & & & & & \\
\hline & 201 & 177 & 191 & 5731 & 5932 & 5802 \\
\hline & 14 & 33 & 47 & 271 & 549 & 637 \\
\hline \multirow{3}{*}{$\begin{array}{l}\text { Insgesamt } \\
\text { Alte Bundesländer } \\
\text { Neue Bundesländer }\end{array}$} & & & & & & \\
\hline & 720 & 740 & 710 & 8367 & 8351 & 8423 \\
\hline & 33 & 105 & 146 & 468 & 1064 & 1341 \\
\hline \multicolumn{7}{|c|}{ Knappschaftliche Rentenversicherung $(\mathrm{KnV})^{3}$} \\
\hline \multirow{3}{*}{$\begin{array}{l}\text { Männer und Frauen } \\
\text { Alte Bundesländer } \\
\text { Neue Bundesländer }\end{array}$} & & & & & & \\
\hline & - & & & 二- & & - \\
\hline & - & & & - & & - \\
\hline
\end{tabular}

Quelle: Statistisches Bundesamt, Mikrozensus 1993, Bundesknappschaft
1) Erhebung im April des jeweiligen Jahres
2) in den letzten 12 Monaten
3) Erhebung im Janunar des jeweiligen Jahres
4) Arbeiter und Angestellte einschließlich Kranken-, Verletzten-, Versorgungskranken- und Übergangsgeldempfän- ger gem. § 3 (1) Nr. 3 SGB VI 
Tabelle 2: Struktur der Versicherten der Rentenversicherung der A rbeiter und Angestellten in den alten und neuen Bundesländern in den Jahren 1991 bis 1994

\begin{tabular}{|c|c|c|c|c|c|c|c|c|c|c|c|c|}
\hline \multirow[t]{2}{*}{$\begin{array}{l}\text { Anteil an den } \\
\text { Ver-sicherten } \\
\text { insgesamt in Pro- } \\
\text { zent }\end{array}$} & \multicolumn{3}{|c|}{$\begin{array}{l}\text { Pflichtversi- } \\
\text { cherte am } \\
\text { Stichtag }\end{array}$} & \multicolumn{3}{|c|}{$\begin{array}{c}\text { Pflichtversi- } \\
\text { cherte in den } \\
\text { letzten } 12 \text { Mo- } \\
\text { naten }\end{array}$} & \multicolumn{3}{|c|}{$\begin{array}{c}\text { Freiwillig Ver- } \\
\text { sicherte }\end{array}$} & \multicolumn{3}{|c|}{$\begin{array}{l}\text { Latent Versi- } \\
\text { cherte }\end{array}$} \\
\hline & 1991 & 1992 & 1993 & 1991 & 1992 & 1993 & 1991 & 1992 & 1993 & 1991 & 1992 & 1993 \\
\hline $\begin{array}{l}\text { Männer } \\
\text { Alte Bundeslānder }\end{array}$ & 78.6 & 80.2 & 79,8 & 3,4 & 3,2 & 3,1 & 3,0 & 3,1 & 28 & 15,1 & 135 & 14.3 \\
\hline Neue Bundesländer & 85,0 & 80,7 & 78,8 & 10,3 & 7,0 & 4,1 & 0,4 & 1,5 & 2,1 & 4,3 & 10,8 & 15,1 \\
\hline $\begin{array}{l}\text { Frauen } \\
\text { Alte Bundeslănder }\end{array}$ & 59,0 & 60,2 & 61,3 & 4,2 & 3,7 & 3,2 & 1,2 & 1,0 & 1,1 & 35,5 & 35,0 & 34,4 \\
\hline $\begin{array}{l}\text { Neue Bundesländer } \\
\text { Männer und Frauen }\end{array}$ & 78,6 & 81,7 & 80,5 & 14,9 & 5,4 & 3,7 & 0,3 & 0,7 & 1,1 & 6,1 & 12,2 & 14,8 \\
\hline Alte Bundeslānder & $\begin{array}{l}69,2 \\
819\end{array}$ & 70,5 & $\begin{array}{l}70,9 \\
79,6\end{array}$ & $\begin{array}{r}3,8 \\
125\end{array}$ & 3,4 & 3,1 & 2,1 & 2,1 & 2,0 & 24,9 & 23,9 & 24,0 \\
\hline
\end{tabular}

Quelle: Bundesarbeitsblatt 9/95, S. 15

1. Die Erwerbsfähigkeit des Rentenbewerbers muB einen bestimmten Mindestsatz unterschritten haben. Dieser Mindestsatz ist an dem Durchschnittsverdienst der Berufsgruppe, der ein Versicherter mit ähnlicher Ausbildung und gleichwertigen Kenntnissen und Fähigkeiten angehört und an der Dauer der noch möglichen täglichen Arbeitszeit, zu messen.

2. Der Versicherte darf durch die mögliche Tätigkeit gesundheitlich, wissens- und könnensmäßig nicht überfordert werden.

3. Die Tätigkeiten, zu deren Verrichtung der Versicherte objektiv fähig ist, müssen ihm auch subjektiv zugemutet werden können. Bei der Prüfung der Zumutbarkeit können neben den im Gesetz zwingend vorgeschriebenen Merkmalen (Dauer und Umfang der Ausbildung, bisheriger Beruf und besondere Anforderungen der bisherigen Berufstätigkeit) im Einzelfall weitere 
Gesichtspunkte berücksichtigt werden. Die Zumutbarkeitsprüfung dient in erster Linie der Verhinderung eines wesentlichen sozialen Abstiegs.

Als "bisheriger Beruf" ist bei Pflichtversicherten die versicherungspflichtige Beschäftigung oder Tätigkeit zugrunde zu legen, die vor Antragstellung ausgeübt wird.

Rente wegen Erwerbsunfähigkeit erhält der Versicherte, der erwerbsunfähig ist und die Wartezeit erfüllt hat ${ }^{155}$.

Als erwerbsunfähig ist der Versicherte anzusehen, der infolge Krankheit oder anderer Gebrechen oder von Schwäche seiner körperlichen oder geistigen Kräfte auf nicht absehbare Zeit eine Erwerbstätigkeit in gewisser Regelmäßigkeit nicht mehr ausüben oder nicht mehr als geringfügige Einkünfte durch Erwerbstätigkeit erzielen kann. Nicht erwerbsunfähig ist, wer eine selbständige Erwerbstätigkeit ausübt ${ }^{156}$. Die Wartezeit für die Erwerbsunfähigkeitsrente ist erfüllt, wenn vor Eintritt der Erwerbsunfähigkeit eine Versicherungszeit von 60 Kalendermonaten zurückgelegt ist $^{157}$.

Es stellt sich auch hier wieder die Frage, wann eine Erwerbstätigkeit "in gewisser Regelmäßigkeit" ausgeübt wird, gemeinhin ist dies der Fall, wenn der Versicherte noch in der Lage ist, täglich einige Stunden mit kürzeren Pausen zu arbeiten. Geringfügige Einkünfte sind monatliche Einkünfte in Höhe von höchstens einem Siebtel der monatlichen Bezugsgröße. Eine Erwerbstätigkeit in gewisser Regelmäßigkeit nicht mehr ausüben zu können oder nicht mehr als geringfügige Einkünfte durch Erwerbstätigkeit erzielen zu können, sind zwei Tatbestände, von denen nur einer für den Anspruch auf Erwerbsunfähigkeitsrente vorzuliegen braucht.

Wird der Empfänger einer Berufsunfähigkeitsrente erwerbsunfähig, so ist die bisherige Rente in eine Rente wegen Erwerbsunfähigkeit umzuwandeln ${ }^{158}$.

Die Rente wegen Erwerbsunfähigkeit wird in eine Rente wegen Berufsunfähigkeit umgewandelt, wenn der Berechtigte infolge einer Änderung

\footnotetext{
${ }^{155}$ Vgl. § 37 SGB VI.

${ }^{156}$ Vgl. § 44 SGB VI.

${ }^{157}$ Vgl. § 44 SGB VI.

${ }^{158}$ Vgl. § 44 SGB VI.
} 
in seinen Verhältnissen nicht mehr erwerbsunfähig, aber noch berufsunfähig ist.

Im Rahmen der geplanten Rentenreform 1999 sollen auch die Berufsund Erwerbsunfähigkeitsrenten neu geregelt werden, die mittlerweile bei den Rentenneuzugängen etwa $25 \%$ ausmachen. Der relativ hohe Prozentsatz ergibt sich daraus, daß aufgrund gegenwärtiger Rechtssprechung Arbeitnehmer auch dann eine Rente erhalten, wenn sie lediglich leistungsgemindert sind, jedoch auf dem Arbeitsmarkt nicht mehr vermittelt werden können. In Zukunft sollen die Risiken der Invalidität und der Arbeitslosigkeit getrennt werden, um die entstehenden Kosten eindeutig den jeweiligen Trägern der Sozialversicherung zuordnen zu können. D.h. die Höhe der Rente soll sich nur noch am konkreten Leistungsvermögen des Einzelnen orientieren, vorgesehen ist eine mehrstufige Regelung, die die derzeitige Aufteilung der Renten wegen verminderter Erwerbsfähigkeit in Berufs- und Erwerbsunfähigkeitsrenten ersetzt: ${ }^{159}$

1. Bei einer Erwerbsfähigkeit von bis zu drei Stunden täglich wird die volle Invaliditätsrente gezahlt.

2. Bei einem Restleistungsvermögen von drei Stunden bis unter sechs Stunden täglich wird die halbe Invaliditätsrente gezahlt.

3. Bei einer Erwerbsfähigkeit von sechs Stunden und mehr täglich wird keine Rente mehr gezahlt.

\subsection{Tod}

Der Tod des Versicherten löst einen Anspruch auf Hinterbliebenenrenten, also Witwen- bzw. Witwerrenten sowie Waisenrenten, aus.

Hinterbliebenenrenten werden gewährt, wenn dem Verstorbenen zur Zeit seines Todes Versichertenrente zustand oder zu diesem Zeitpunkt die Wartezeit für eine Rente wegen Berufsunfähigkeit erfüllt ist oder als erfüllt gilt $^{160}$.

\footnotetext{
159 Vgl. Bundesministerium für Arbeit und Sozialordnung (Hrsg.), Eckpunkte für die Gesetzgebung beschlossen, in: Sozialpolitische Informationen, 31. Jg., Heft 5, S. 32.

${ }^{160} \mathrm{Vgl}$. 46 SGB VI.
} 
Nach dem Tode des versicherten Ehemannes/der versicherten Ehefrau erhält der Hinterbliebene eine Witwen- bzw. Witwerrente ${ }^{161}$.

Die Witwen- und die Witwerrente fallen mit dem Ablauf des Monats weg, in dem der Berechtigte wieder heiratet. Hat eine Witwe oder ein Witwer sich wieder verheiratet und wird diese Ehe aufgelöst oder für nichtig erklärt, so lebt der Anspruch auf Witwen- oder Witwerrente vom Ablauf des Monats, in dem die Ehe aufgelöst oder für nichtig erklärt ist, wieder auf. Ein von der Witwe oder dem Witwer infolge der Auflösung der Ehe erworbener neuer Versorgungs-, Unterhalts- oder Rentenanspruch ist auf die Witwen- oder Witwerrente anzurechnen. Eine bei Wiederverheiratung gezahlte Abfindung ist in angemessenen Teilbeträgen einzubehalten, soweit sie für die Zeit nach Wiederaufleben des Anspruchs auf Rente gewährt ist ${ }^{162}$.

Einer Witwe oder einem Witwer, die wieder heiraten, wird eine Abfindung gezahlt, wobei die Witwen- bzw. Witwereigenschaft endgültig durch das Eingehen einer Zweitehe endet, so daB keine Abfindung bei Drittehe geleistet wird.

Einer früheren Ehefrau des Versicherten, deren Ehe mit dem Versicherten vor dem 1. Juli 1977 geschieden worden ist, wird nach dem Tode des Versicherten Rente gewährt (sogenannte Geschiedenenwitwenrenten, siehe auch Teil C, II, 1.2.), wenn ihr der Versicherte zur Zeit seines Todes Unterhalt nach den Vorschriften des Ehegesetzes oder aus sonstigen Gründen zu leisten hatte oder wenn er im letzten Jahr vor seinem Tod Unterhalt geleistet hat. Ist eine Witwenrente nicht zu gewähren, wird der früheren Ehefrau eine Rente auch dann gewährt,

1. wenn eine Unterhaltsverpflichtung wegen der Vermögens- oder Erwerbsverhältnisse des Versicherten oder wegen der Erträgnisse der früheren Ehefrau aus einer Erwerbstätigkeit nicht bestanden hat und

2. wenn die frühere Ehefrau im Zeitpunkt der Scheidung, Nichtigerklärung oder Aufhebung der Ehe mindestens ein waisenrentenberechtigtes Kind zu erziehen oder für ein Kind, das wegen körperlicher oder geistiger Ge-

\footnotetext{
${ }^{161}$ Vgl. § 46 Abs. 2 und 3 SGB VI.

${ }^{162}$ Vgl. $\$ 90$ Abs. 2 SGB VI.
} 
brechen Waisenrente erhielt, zu sorgen oder das 45. Lebensjahr vollendet hatte und

3. solange sie berufsunfähig oder erwerbsunfähig ist oder mindestens ein waisenrentenberechtigtes Kind erzieht oder für ein Kind, das wegen körperlicher oder geistiger Gebrechen Waisenrente erhält, sorgt oder wenn sie das 60. Lebensjahr vollendet hat.

Mit dem Begriff "zur Zeit seines Todes " wird der letzte wirtschaftliche Dauerzustand vor dem Tode des Versicherten bezeichnet, d.h. der Zustand von dem Zeitpunkt an, in dem letztmalig eine wesentliche Änderung in den Einkommensverhältnissen der Ehegatten mit Dauerwirkung eingetreten ist und der ohne den Tod des Versicherten wahrscheinlich fortbestanden hätte $^{163}$.

Im vorangegangenen Abschnitt wurden anhand von Gesetzestexten und unter Benutzung von Kommentaren die sozialen Tatbestände beschrieben, deren Vorliegen notwendige, aber nicht hinreichende Bedingung für die Entstehung eines Anspruchs waren. Ein Anspruch auf Leistung entsteht dem Grunde nach erst dann, wenn zusätzlich die je nach Tatbestand differierenden versicherungsrechtlichen Bedingungen erfüllt sind.

Eine Rentenleistung kann nur in Anspruch genommen werden, wenn die allgemeine "Wartezeit" von 5 Jahren erfüllt ist; Für den Bezug von Berufs- und Erwerbsunfähigkeitsrenten sowie den Hinterbliebenenrenten muB eine Wartezeit von fünf Jahren erfüllt sein sofern sie nicht auf einen Betriebsunfall zurückgeht. Neben der Erfüllung der Wartezeit von 15 Jahren muB für den Anspruch auf Rentenzahlung ab dem 62. oder 63. Lebensjahr eine Dauer von 35 Versicherungsjahren gegeben sein. Eine weibliche Versicherte erhält Altersruhegeld nur dann mit Erreichen des 60. Lebensjahres, wenn sie nach Vollendung des 40 . Lebensjahres mehr als zehn Pflichtbeitragszeiten und die Wartezeit von 15 Jahren erfüllt hat ${ }^{164}$.

Unter Wartezeit versteht man demnach die nach den einzelnen Rentenarten differierende Zeit, die mit Versicherungszeiten belegt sein muß, damit ein Rentenanspruch entsteht, wobei der Gesetzgeber die Versicherungszeiten

${ }^{163}$ Vgl. Knapp-Geiger, Ilse, unveröffentlichtes Manuskript.

${ }^{164}$ Vgl. § 39 SGB VI. 
festgelegt hat, die auf die Wartezeit angerechnet werden. Dazu gehören Zeiten, in denen Beiträge entrichtet wurden (Beitragszeiten), anrechenbare Zeiten und Kindererziehungszeiten.

\subsection{Kindererziehung ${ }^{165}$}

Das Hinterbliebenen- und Erziehungszeiten-Gesetz (HEZG) beinhaltet neben der Neuregelung der Hinterbliebenenrenten die Einführung von Kindererziehungszeiten bei der Rentenberechnung. Sie werden Müttern und auch Vätern angerechnet, die ihr Kind im Inland erziehen und sich mit ihm dort gewöhnlich aufhalten. Die Anrechnung von Kindererziehungszeiten in der gesetzlichen Rentenversicherung erfolgt nur bei Versicherungsfällen nach dem 30.12.1985, sofern der oder die Versicherte noch nicht 65 Jahre alt ist. Bezieht der/die Versicherte am 1.1.1986 bereits eine Rente, ist aber noch nicht 65 Jahre alt, können - sofern die persönlichen Voraussetzungen erfüllt sind - Kindererziehungszeiten angerechnet werden,

1. im Falle einer Berufsunfähigkeitsrente bei Umwandlung in eine Erwerbsunfähigkeitsrente oder in ein Altersruhegeld,

2. im Falle einer Erwerbsunfähigkeitsrente bei Umwandlung in ein Altersruhegeld,

3. im Falle eines Altersruhegeldes bei Vollendung des 65 . Lebensjahres auf Antrag, das bedeutet also eine Neufestsetzung des Altersruhegeldes.

Der Bezug einer Witwen- oder Witwerrente am 1.1.1986 berechtigt nicht zur Neuberechnung der Hinterbliebenenrente, auch wenn der Rentenbezieher noch nicht $65 \mathrm{Jahre}$ alt ist.

Werden in den ersten 12 Monaten nach Ablauf des Monats der Geburt des Kindes mehrere Kinder erzogen und wird die Zeit ihrer Erziehung auf die Wartezeit angerechnet, verlängert sich die Zeit für das zweite und jedes weitere Kind um die Anzahl an Kalendermonaten, in denen gleichzeitig mehrere Kinder erzogen worden sind.

${ }^{165}$ Näheres zur Berücksichtigung von Kindererziehungszeiten in der gesetzlichen Rentenversicherung in Teil $\mathrm{B}, 5$. 
Haben die Eltern ihr Kind gemeinsam erzogen, werden Erziehungszeiten ab 1.1.1986 der Mutter angerechnet, sofern die Eltern nicht übereinstimmmend erklären, daß der Vater das Kind überwiegend erzogen hat, in diesem Fall werden dann die gesamten Zeiten der Kindererziehung für dieses Kind dem Vater angerechnet ${ }^{166}$.

\subsection{Pflege eines Angehörigen}

Die Rentenreform 1992 brachte einen völlig neuen Tatbestand in die GRV, der besonders Familien bzw. Frauen zugute kommt und ein weiterer Schritt im Hinblick auf eine eigenständige soziale Sicherung der Frau ist. Zu nennen ist hier die Einführung der rentenrechlichen Berücksichtigung der Nichterwerbsarbeit in Form der Pflege von pflegebedürftigen Personen (i.d.R. dürfte es sich um Angehörige handeln, obwohl dies nicht ausdrücklich im Gesetz vorgeschrieben ist). Diese Pflegeberücksichtigungszeiten ${ }^{167}$ bewirken

- daß dort, wo erforderlich, die allgemeine Wartezeit erfüllt werden kann,

- die Erhaltung des Invaliditätsschutzes und

- das Schließen von Lücken im Rahmen des Gesamtleistungsmodells.

Eine zeitliche Begrenzung der Anrechnung derartiger Zeiten existiert nicht. In die Rentenberechnung geht jeder Kalendermonat an Berücksichtigungszeit mit 0,0625 Entgeltpunkten ein.

Die Voraussetzungen für die Inanspruchnahme von Pflegeberücksichtigungszeiten gelten natürlich gleichermaßen auch für Männer, dies kann verfassungsrechtlich gar nicht anders sein, faktisch wird diese MaBnahme jedoch vorwiegend Frauen zugute kommen und insofern wird ein weiteres familienpolitisches Element in der GRV sichtbar.

\footnotetext{
${ }^{166}$ Vgl. § 56 SGB VI.

${ }^{167} \S 57$ Abs. 2 SGB VI.
} 
3. Grundlage der Leistungsbemessung in der GRV: Die Rentenformel

Seit der Reform der Rentenversicherung der Arbeiter und Angestellten im Jahre 1957 wurde zur Berechnung der Höhe der Neu- oder Zugangsrenten (Jahresrenten) folgende Rentenformel herangezogen ${ }^{168}$ :

$$
\mathbf{R}_{t}=A_{t} \times P \times N \times S t
$$

$\mathbf{R}_{\mathbf{t}}$... Rente im Jahr $\mathbf{t}$

At ... Allgemeine Bemessungsgrundlage im Jahr $\mathbf{t}$

P ... Persönliche Bemessungsgrundlage

N ... Zahl der anrechnungsfähigen Versicherungsjahre

St ... Steigerungssatz je anrechnungsfähigen Versicherungsjahr

Die deutsche Rentenformel setzte sich demgemäß aus zwei allgemeinen $\left(A_{t}, S t\right)$ und zwei persönlichen Faktoren $(P, N)$ zusammen.

Die allgemeine Bemessungsgrundlage beruhte auf der Entwicklung der durchschnittlichen Bruttoarbeitsentgelte aller Arbeiter und Angestellten (ohne Auszubildende und Anlernlinge) der gesetzlichen Rentenversicherung. Die persönliche Bemessungsgrundlage gab an, in welchem Verhältnis das Bruttoarbeitsentgelt des Versicherten im Jahre $t, E_{t} \mathbf{b}$, zum durchschnittlichen Bruttoarbeitsentgelt aller Versicherten im Jahre $t, D E_{t}$ stand, wobei $Z$ das Jahr des Eintritts in den Ruhestand und $T$ die Beitragszeit des Versicherten bezeichnen.

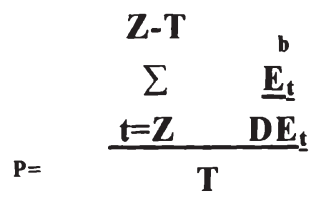

Dadurch wurde gewährleistet, daß Versicherte, die in den einzelnen Beitragsjahren überdurchschnittliche (unterdurchschnittliche) Beiträge be-

${ }^{168}$ Vgl. § 1255-1262 RVO. 
zahlt hatten, auch hinsichtlich der Rentenhöhe überdurchschnittliche (unterdurchschnittliche) Berücksichtigung erfuhren.

Die Zahl der anrechnungsfähigen Versicherungsjahre $N^{169}$ setzte sich aus den Beitragszeiten, den Ausfall-, Ersatz- und Zurechnungszeiten sowie den Zeiten der Kindererziehung zusammen.

Der Steigerungssatz ${ }^{170}$ (ST) war abhängig von der Art der Rente und betrug bei der Berufsunfähigkeitsrente 1,0 \%, der Erwerbsunfähigkeitsrente sowie dem Altersruhegeld 1,5\%. Dieser Faktor berücksichtigte die unterschiedlich langen Versicherungszeiten, indem pro Versicherungsjahr ein Rentenanspruch in Höhe von $1,5 \%$ oder $1 \%$ der beitragspflichtigen Einkommen erworben wurde. Je länger die Versicherungszeit war, desto höher war bei sonst gleicher Lage die Höhe des Altersruhegeldes. Bei einer Versicherungszeit von 40 Jahren betrug so das Altersruhegeld $60 \%$ der persönlichen Bemessungsgrundlage.

Der niedrigere Steigerungssatz im Falle der Berufsunfähigkeit beruhte auf dem Gedanken, daß die noch verbliebene Arbeitskraft anderweitig verwendet werden könnte.

Während die allgemeine Bemessungsgrundlage und der Steigerungssatz allgemeine Größen waren, die für alle Versicherten gleichermaßen galten, war die persönliche Bemessungsgrundlage und die Zahl der anrechnungsfähigen Versicherungsjahre Ausdruck des Äquivalenzprinzips in der Rentenversicherung. Je höher beide Komponenten ausfielen, desto höher war die sich ergebende Rente im Alter.

Mit dem Rentenreformgesetz 1992 wurde eine neue umgestaltete Rentenformel, die zu einer wesentlichen Vereinfachung beitragen soll und "selbst nicht zu einer anderen Rentenhöhe als das geltende Recht führt, aber leichter nachvollziehbar ist"111, wie es in der Begründung zum RRG 92 heibt, eingeführt.

\footnotetext{
${ }^{169} \mathrm{Vgl}$. § SGB VI.

${ }^{170}$ Vgl. § 1253-1259 RVO.

${ }^{171}$ BT-Drucksache 11/4124, S. 146.
} 
Mit Hilfe der neuen Rentenformel kann die Monatsrente eines RentnerNeuzuganges direkt errechnet werden, wobei folgende Kernelemente maßgeblich sind $^{17}$ :

- Wie schon vor 1992 richtet sich die Höhe eines Altersruhegeldes nach der Höhe der während des "Versicherungslebens" erbrachten Beiträge. Neu ist jedoch die Berücksichtigung in Form von Entgeltpunkten.

- Auch die Bewertung beitragsfreier Zeiten erfolgt durch die Zuordnung von Entgeltpunkten, deren Anrechnung sich nach der Höhe der in der übrigen Zeit versicherten Arbeitsentgelte richtet.

- Der Steigerungssatz wurde ersetzt durch den sogenannten "Rentenartfaktor", der das Sicherungsziel der jeweiligen Rentenart im Verhältnis zum Altersruhegeld festlegt.

- Erstmalig wird durch das Einfügen eines Zugangsfaktors die unterschiedliche Rentenbezugsdauer dadurch berücksichtigt, daß spürbare $\mathrm{Zu}$ - und Abschläge die Rentenhöhe beeinflussen.

- Die jährliche Fortschreibung des Rentenniveaus von Bestandsrenten erfolgt nach der Entwicklung der Nettolöhne aller versicherten Erwerbstätigen.

Die monatliche Rente ergibt sich durch Multiplikation der persönlichen Entgeltpunkte (Entgeltpunkte x Zugangsfaktor = persönliche Entgeltpunkte) mit dem Rentenartfaktor und dem aktuellen Rentenwert ${ }^{173}$ :

$$
M R=P E \times F A R
$$

PE .... Persönliche Entgeltpunkte (Entgeltpunkte x Zugangsfaktor)

F ... Rentenartfaktor

AR ... Aktueller Rentenwert

MR ... Monatsrente.

${ }^{172}$ Vgl. Bank/Brachmann/Kreikebohm/Schmidt, Rentenreform 1992, Stuttgart 1990, S. 195.

${ }^{173}$ Vgl. § 64 SGB VI. 
So sehr sich diese Rentenformel in formaler Hinsicht von der bis zum 31 . 12. 1991 geltenden Formel unterscheidet, führen die alte und neue Rentenformel von den materiellen Inhalten her grundsätzlich zu gleichen Ergebnissen hinsichtlich der Rentenhöhe, abgesehen davon, daß mit der neuen Formel nicht mehr die Jahresrente, sondern die Monatsrente ermittelt wird.

Die persönlichen Entgeltpunkte werden aus den Entgeltpunkten für Beitragszeiten und beitragsfreien Zeiten und dem Zugangsfaktor ${ }^{174}$ errechnet und bilden den individuellen Faktor der Rentenformel insofern als sie Ausdruck der individuellen Beitragsleistung des einzelnen Versicherten sind und sicherstellen, daß die Höhe der Rente vorwiegend von der Beitragsleistung abhängt. ${ }^{175}$ Entgeltpunkte treten an die Stelle der bisherigen Werteinheiten, wobei das Durchschnittsentgelt eines Kalenderjahres als Basis für die Beitragszahlung genommen wird, um einen vollen Entgeltpunkt zu definieren.

Die alte Rentenformel kannte noch zwei individuelle Bestandteile, die persönliche Bemessungsgrundlage, die angab, in welchem Verhältnis das Bruttoarbeitsentgelt eines Versicherten im betrachteten Jahr zum durchschnittlichen Bruttoarbeitsentgelt aller Versicherten des gleichen Jahres stand, die Berechnung gewährleistete somit, daß Versicherte, die in den einzelnen Beitragsjahren überdurchschnittliche (unterdurchschnittliche) Beiträge gezahlt haben, auch hinsichtlich der Rentenhöhe überdurchschnittliche (unterdurchschnittliche) Berücksichtigung erfahren; und die Zahl der anrechnungsfähigen Versicherungsjahre, bestehend aus Beitragszeiten (= Zeiten der Beitragsentrichtung an die GRV), Ersatzzeiten (= Zeiten, in denen der Versicherte keine Beiträge entrichten konnte, weil er staatlicherseits an der Ausübung einer Erwerbstätigkeit gehindert wurde, z.B. Wehr- und Zivildienst), Ausfallzeiten (= Zeiten, in denen der Versicherte aus persönlichen

${ }^{174}$ Der Zugangsfaktor bewirkt bei vorzeitigem Rentenbeginn einen Abschlag, bei hinausgeschobenem Rentenbeginn einen Zuschlag auf die Rente (§ 63 Abs. 5 SGB VI). Liegt der Rentenbeginn exakt auf der maßgeblichen Altersgrenze, beträgt der Zugangsfaktor 1,0 und verändert damit die Summe der Entgeltpunkte nicht. Ansonsten erhöht sich der Zugangsfaktor für jeden Monat des Verzichts auf die Altersrente um $0,5 \%$ und vermindert sich für jeden Monat um den die Rente vor erreichen der jeweiligen Altersgrenze in Anspruch genommen wird, um 0,3\%.

${ }^{175}$ Vgl. Michaelis, Klaus, a.a.O., S. 701. 
Gründen nicht erwerbstätig war, z.B. Ausbildung, Schwangerschaft, Rehabilitation), Zurechnungszeiten (= Zeit zwischen dem Eintritt des Versicherungsfalles und der Vollendung des 55. Lebensjahr des Versicherten) und schließlich der Kindererziehungszeiten.

Entgeltpunkte werden berücksichtigt für

- Beitragszeiten,

- beitragsfreie Zeiten,

- Zuschläge für beitragsgeminderte Zeiten,

- Zu- oder Abschläge aus einem durchgeführten Versorgungsausgleich $^{176}$.

Beitragszeiten sind Zeiten, in denen Pflichtbeiträge bzw. freiwillige Beiträge entrichtet werden ${ }^{177}$. Die Entgeltpunkte für diese Zeiten werden ermittelt, indem die Beitragsbemessungsgrundlage (Einkommensbetrag, von dem Rentenversicherungsbeiträge entrichtet werden) durch das Durchschnittsentgelt aller Versicherten desselben Kalenderjahres dividiert wird, ${ }^{178}$ d.h. die Entgeltpunkte berücksichtigen die Lohn/Gehaltsunterschiede und die daraus resultierenden unterschiedlichen Beiträge der Versicherten. Dieser Vorgehensweise liegt das "FÜR-PRINZIP" zugrunde, wonach die Beitragsbemessungsgrundlage durch das Durchschnittsentgelt dividiert wird, für das die Beiträge bestimmt sind. Deutlich wird, daB es nach diesem Prinzip völlig unerheblich wird, in welchem Jahr die Beitragszahlung tatsächlich erfolgte. Davon zu unterscheiden ist das "IN-PRINZIP", nachdem zur Ermittlung der Entgeltpunkte die Beitragsbemessungsgrundlage durch das Durchschnittsentgelt aller Versicherten des Jahres geteilt wird, in dem die Zahlung erfolgt. Dieses Prinzip gilt bei den verschiedenen Formen der Sondernachzahlungen ${ }^{179}$ und verfolgt den Zweck zu verhindern, daß durch Nachzahlungen höhere Rentenanwartschaften erzielt werden können als durch aktuelle Beitragszahlungen. ${ }^{180}$ Allerdings läßt der Gesetzgeber auch

\footnotetext{
${ }^{176}$ Vgl. § 66 SGB VI.

${ }^{177}$ Vgl. $§ 55$, Satz 1, 247 Abs. 3 SGB VI.

${ }^{178}$ Vgl. § 70 Abs. 1 SGB VI.

${ }^{179}$ Vgl. $§ \S 70$ Abs. 5, 256 Abs. 6 Satz 2 SGB VI.

${ }^{180}$ Vgl. BT-Drucksache 11/4124, S. 170.
} 
hier Ausnahmen zu, nach § 282 SGB VI galt für die Nachzahlung bei Heiratserstattung, die bis zum 31.12.1995 möglich war, noch das "FÜRPRINZIP". Für Frauen, die von dieser Regelung Gebrauch machten - und man beachte in diesem Zusammenhang, daß dafür ein entsprechend hohes Einkommen oder ausreichendes Vermögen vorhanden sein mußte - ließen sich also gemessen am Beitragsaufwand, äußerst hohe Rentenanwartschaften erzielen. Es stellt sich jedoch die Frage, ob diese Ausnahme, deren Zielsetzung es war, Frauen einen Anreiz zum Aufleben ihrer Rentenansprüche und damit ein Aufbau einer eigenständigen sozialen Sicherung zu geben, nicht gerade diejenigen Frauen begünstigte, die aufgrund ihrer finanziellen Lage gar keiner sozialen Sicherung mehr bedurften. Der GRV wurden damit Leistungsverpflichtungen zugewiesen, die die finanzielle Belastung vergrößern, wenn der Versicherungsfall eintritt und dies sozusagen auf dem "Rücken" der dann Beitrag zahlenden Personen.

Eine Schlechterstellung gegenüber dem geltenden Recht ergibt sich dadurch, daß für das Jahr des Rentenbeginns und das davorliegende Jahr auf die vorläufigen Durchschnittsentgelte dieser Jahre zurückgegriffen wird und nicht wie nach altem Recht die individuellen Arbeitsentgelte dieser Jahre mit dem letzten endgültigen Durchschnittseinkommen verglichen werden. Mit dieser neuen Vorgehensweise soll eine realitätsnähere Bewertung erreicht werden, wie es in der Gesetzesbegründung heißt ${ }^{181}$.

Kindererziehungszeiten sind nach neuem Recht ausnahmslos Pflichtbeitragszeiten ${ }^{182}$, dies gilt auch für Zeiten, die vor 1986 lagen und seinerzeit als beitragslose Zeiten galten. Sie erhalten für jeden Monat $0,0625(=1 / 16)$ Entgeltpunkte, dies sind $75 \%$ des Durchschnittsentgelts aller Versicherten. ${ }^{183}$

Als beitragsfreie Zeiten sind die Zeiten zu berücksichtigen, die ausschließlich mit Anrechnungszeiten, Ersatzzeiten oder einer Zurechnungszeit belegt sind.

Nach § 58 RRG haben Anrechnungszeiten die Funktion der bis zum Jahr 1992 geltenden Ausfallzeiten, allerdings mit erheblichen Änderungen. Der wesentliche Unterschied besteht in dem Verzicht auf die sogenannte

\footnotetext{
${ }^{181}$ Vgl. BT-Drucksache 11/4124, S. 170.

${ }^{182} \S \S 56$ Abs. 1 Satz 1 i.V.m. 55 SGB VI.

${ }^{183}$ Auf die Ausgestaltung der Kindererziehungszeit wird detailliert in Teil B, Punkt 5 eingegangen.
} 
Halbbelegung. ${ }^{184}$ Veränderungen sind schließlich auch bei den Anrechnungszeiten wegen einer Ausbildung zu verzeichnen, es entfällt die Einzelbegrenzung bezogen auf allgemeinbildende Schulen, Fachschulen und Hochschulen zugunsten der Anrechnung von Ausbildungszeiten (d.h. Zeiten, in denen nach dem vollendeten 17. Lebensjahr eine Schule besucht und/oder eine Fach- oder Hochschule besucht und abgeschlossen wurde $\left.{ }^{185}\right)$, die jedoch auf maximal 3 Jahre begrenzt sind, bislang konnten noch maximal 7 Jahre geltend gemacht werden. Für die Neurentner von 1997 bis 2000 wird eine stufenweise Reduktion vorgenommen.

Zu den Anrechnungszeiten zählen weiterhin Zeiten, in denen wegen Schwangerschaft oder Mutterschaft während der Schutzfristen nach dem Mutterschutzgesetz eine versicherte Beschäftigung oder selbständige Tätigkeit nicht ausgeübt oder unterbrochen wurde. ${ }^{186}$ Anrechnungszeiten sind auBerdem die Zeiten, in denen ein versicherungspflichtiges Beschäftigungsverhältnis wegen Krankheit, Rehabilitation oder Arbeitslosigkeit unterbrochen worden ist. ${ }^{187}$ Im Falle der Arbeitslosigkeit gilt darüber hinaus, daß der Versicherte als Arbeitssuchender bei einem deutschen Arbeitsamt gemeldet ist und eine öffentlich-rechtliche Leistung bezogen oder nur wegen des zu berücksichtigenden Einkommens oder Vermögens nicht bezogen hat. ${ }^{188} \mathrm{Zu}$ beachten sei, daß diese Formulierung eine Erweiterung gegenüber des Rechts vor der Rentenreform 1992 darstellt, denn eine öffentlich-rechtliche Leistung ist auch die Sozialhilfe oder das Wohngeld. Zahlt die Bundesanstalt für Arbeit für den Bezieher von Arbeitslosengeld, Arbeitslosenhilfe, Unterhaltsgeld oder Übergangsgeld Beiträge an eine Versicherungs- oder Versorgungseinrichtung, an ein Versicherungsunternehmen oder an den Betroffenen selbst, liegt keine Anrechnungszeit im Sinne des $§ 58$ SGB VI vor. Anrechnungszeit ist letztlich noch die Zeit, in denen Versicherte eine Rente be-

\footnotetext{
${ }^{184}$ Ausfallzeiten werden "nur dann angerechnet, wenn die Zeit vom Kalendermonat des Eintritts in die Versicherung bis zum Kalendermonat, in dem der Versicherungsfall eingetreten ist, mindestens zur Hälfte, jedoch nicht unter sechzig Monaten, mit Beiträgen für eine rentenversicherungspflichtige Beschäftigung oder Tätigkeit belegt ist" (§ 1259 Abs. 3 RVO).

${ }^{185}$ Vgl. $\$ 58$ Abs. 1 Nr. 4 SGB VI.

${ }^{186}$ Vgl. § 58 Abs. 2 Satz 1 i.V. m. § 58 Abs. 1 Nr. 2 SGB VI.

${ }^{187}$ Vgl. $\$ 58$ Abs. 1 Nr. 1 und 3 SGB VI.

${ }^{188}$ Vgl. § 58 Abs. 1 Nr. 3 SGB VI.
} 
zogen haben, soweit diese Zeiten auch als Zurechnungszeit in der Rente berücksichtigt waren (Bsp.: Erziehungsrente, Rente wegen Berufsunfähigkeit oder Erwerbsunfähigkeit), und die vor dem Beginn dieser Rente liegende Zurechnungszeit. ${ }^{189}$

Die Neukonzeption der Anrechnungszeiten veranlaßte den Gesetzgeber, zur Vermeidung nicht gewollter Härten im Einzelfall, eine Übergangsregelung zu verfassen. Diese gestattet es, neben den bereits behandelten Tatbeständen, übergangsweise folgende Anrechnungszeiten zu berücksichtigen: ${ }^{190}$ (1) Anrechnungszeiten sind danach Zeiten, in denen Versicherte

1. Anpassungsgeld für entlassene Arbeitnehmer des Bergbaus bezogen haben,

2. nach dem 31. Dezember 1991 eine Knappschaftsausgleichsleistung bezogen haben,

3. nach dem vollendeten 16. Lebensjahr als Lehrling nicht versicherungsfrei waren und die Lehrzeit abgeschlossen haben, längstens bis zum 28. Februar 1957,

4. vor dem vollendeten 55. Lebensjahr eine Rente wegen Berufsunfähigkeit oder Erwerbsunfähigkeit oder eine Erziehungsrente bezogen haben, in der eine Zurechnungszeit nicht enthalten war,

5. vor dem vollendeten 55. Lebensjahr eine Invalidenrente, ein Ruhegeld oder eine Knappschaftsvollrente bezogen haben, wenn diese Leistung vor dem 1. Januar 1957 weggefallen ist,

6. Schlechtwettergeld bezogen haben, wenn dadurch eine versicherte Beschäftigung oder selbständige Tätigkeit unterbrochen worden ist, längstens bis zum 31. Dezember 1978.

(2) Anrechnungszeiten sind auch Zeiten, für die

1. die Bundesanstalt für Arbeit in der Zeit vom 1. Januar 1983,

2. ein anderer Leistungsträger in der Zeit vom 1. Januar 1984

bis zum 31. Dezember 1997 wegen des Bezugs von Sozialleistungen

Pflichtbeiträge oder Beiträge für Anrechnungszeiten gezahlt hat.

${ }^{189}$ Vgl. § 58 Nr. 5 SGB VI.

${ }^{190} \S 252$ SGB VI. 
(3) Anrechnungszeiten wegen Arbeitsunfähigkeit oder Leistungen zur Rehabilitation liegen in der Zeit vom 1. Januar 1984 bis zum 31. Dezember 1997 bei Versicherten, die

1. nicht in der gesetzlichen Krankenversicherung versichert waren oder

2. in der gesetzlichen Krankenversicherung ohne Anspruch auf Krankengeld versichert waren,

nur vor, wenn für diese Zeiten, längstens jedoch für 18 Kalendermonate, Beiträge nach mindestens 70 vom Hundert, für die Zeit vom 1. Januar 1995 an 80 vom Hundert des zuletzt für einen vollen Kalendermonat versicherten Arbeitsentgelts oder Arbeitseinkommens gezahlt worden sind.

(4) Anrechnungszeit ist auch die Zeit, in denen Versicherte nach dem vollendeten 16. Lebensjahr vor dem 1. Januar 1992 eine Schule besucht oder eine Fachschule oder Hochschule besucht und abgeschlossen haben, jedoch die Zeit des Schulbesuchs oder Fachschulbesuchs höchstens bis zu vier Jahren und die Zeit des Hochschulbesuchs höchstens bis zu fünf Jahren, soweit die Höchstdauer für Anrechnungszeiten wegen des Besuchs einer Schule, Fachschule oder Hochschule von sieben Jahren überschritten ist. Die nach Satz 1 ermittelte Zeit wird bei Beginn der Rente

Im Jahre

voll,

1993

zu elf Zwölfteln,

1994

zu zehn Zwölfteln,

1995

zu neun Zwölfteln,

1996

zu acht Zwölfteln,

1997

zu sieben Zwölfteln, zu sechs Zwölfteln, zu fünf Zwölfteln, zu vier $Z$ wölfteln, zu drei Zwölfteln, zu zwei Zwölfteln, zu einem Zwölftel 
in vollen Monaten berücksichtigt, wobei die am weitesten zurückliegenden Kalendermonate vorrangig berücksichtigt werden.

(5) Zeiten einer Arbeitslosigkeit vor dem 1. Juli 1969 sind bei Handwerkern nur dann Anrechnungszeiten, wenn und solange sie in der Handwerksrolle gelöscht waren.

(6) Bei selbständig Tätigen, die auf Antrag versicherungspflichtig waren, und bei Handwerkern sind Zeiten vor dem 1. Januar 1992, in denen sie

1. wegen Krankheit arbeitsunfähig gewesen sind oder Leistungen zur Rehabilitation erhalten haben,

2. wegen Schwangerschaft oder Mutterschaft während der Schutzfristen nach dem Mutterschutzgesetz eine versicherte selbständige Tätigkeit nicht ausgeübt haben,

nur dann Anrechnungszeiten, wenn sie in ihrem Betrieb mit Ausnahme eines Lehrlings, des Ehegatten oder eines Verwandten ersten Grades Personen nicht beschäftigt haben, die wegen dieser Beschäftigung versicherungspflichtig waren. Anrechnungszeiten nach dem 30. April 1985 liegen auch vor, wenn die Versicherten mit Ausnahme von Lehrlingen und des Ehegatten oder eines Verwandten ersten Grades Personen nicht beschäftigt haben, die wegen dieser Beschäftigung versicherungspflichtig waren.

(7) Zeiten, in denen Versicherte

1. vor dem 1. Januar 1984 arbeitsunfähig geworden sind oder Leistungen zur Rehabilitation haben,

2. vor dem 1. Januar 1979 Schlechtwettergeld bezogen haben,

3. wegen Arbeitslosigkeit bei einem deutschen Arbeitsamt als Arbeitssuchende gemeldet waren und

a) vor dem 1. Juli 1978 eine öffentlich-rechtliche Leistung bezogen haben oder

b) vor dem 1. Januar 1992 eine öffentlich-rechtliche Leistung nur wegen des zu berücksichtigenden Einkommens oder Vermögens nicht bezogen haben, 
werden nur berücksichtigt, wenn sie mindestens einen Kalendermonat andauern. Folgen mehrere Zeiten unmittelbar aufeinander, werden sie zusammengerechnet.

Letztendlich wird für die Zeit vor dem 1. Januar 1957 entsprechend der bisherigen pauschalen Ausfallzeit eine pauschale Anrechnungszeit vorgesehen. ${ }^{191}$

Ersatzzeiten sind auch nach neuem Recht beitragslose Zeiten, in denen der Versicherte aufgrund staatlicher Eingriffe keine Beiträge leisten kann. Sie werden weiterhin auf die Wartezeit angerechnet, bisher erworbene Zeiten sind unter Wegfall der Halbbelegung und des Vor- und Anschlußbeitrages $^{122}$ anrechenbar. Die in $§ 250$ Abs. 1 Satz 1-6 SGB VI aufgeführten Ersatzzeittatbestände

1. Zeiten des militärischen und militärähnlichen Dienstes,

2. Zeiten der Internierung und Verschleppung,

3. Zeiten der Verhinderung der Rückkehr durch feindliche Maßnahmen,

4. Zeiten des Freiheitsentzugs oder Freiheitseinschränkung,

5. Zeiten des Gewahrsams,

6. Zeiten der Vertreibung, Aussiedlung oder Flucht und die sich daran anschließende Zeit der Arbeitsunfähigkeit

verliert an Relevanz, d.h. sie können nach dem 31.12.1991 nicht mehr erworben werden. Bis dahin erworbene Ersatzzeiten bleiben aber anrechenbar.

Letztlich zählt zu den beitragsfreien Zeiten die Zurechnungszeit ${ }^{193}$, d.h. die Zeit zwischen dem Eintritt des Versicherungsfalles und der Vollendung des 60. Lebensjahres durch den Versicherten. Wird der Versicherte vor Vollendung des 60. Lebensjahres berufs- oder erwerbsunfähig, wird bei der Rentenberechnung mit Hilfe der Zurechnungszeit die Fiktion geschaffen, er hätte bis zum 60. Lebensjahr seine Tätigkeit beitragspflichtig ausüben kön-

\footnotetext{
${ }^{191}$ Vgl. § 253 SGB VI.

${ }^{192}$ Vor der jeweiligen Ersatzzeit muß nach geltendem Recht mindestens ein Pflicht- oder freiwilliger Beitrag entrichtet worden sein, um diese Zeit bei der Rentenberechnung geltend machen zu können.

${ }^{193}$ Vgl. § 59 SGB VI.
} 
nen, um eine unzureichende Rentenhöhe zu vermeiden. Die Zurechnungszeit beginnt bei einer Berufs- oder Erwerbsunfähigkeitsrente mit dem Eintritt der maßgeblichen Minderung der Erwerbsfähigkeit, bei einer Erziehungsrente mit dem Tode des Versicherten, ebenso bei einer Witwen- oder Witwerrente und bei einer Waisenrente. Nach neuem Recht wird von der $\mathrm{Zu}$ rechnungszeit zwischen dem 55. und 60. Lebensjahr nur ein Drittel angerechnet, so daß sich im günstigsten Fall eine Zeit von 40 Jahren und 8 Monaten ergibt ${ }^{194}$. Auch hier bedarf es nicht mehr der Halbbelegung als Anspruchsvoraussetzung. Die Verlängerung des Berechnungszeitraums um 5 Jahre wird die Rentenversicherung voraussichtlich im Ausmaß von 0,1 Beitragsprozentpunkten belasten ${ }^{195}$.

Neu eingefügt ins Rentenrecht wurden mit der Rentenreform 1992 die Berücksichtigungszeiten, zu ihnen gehört die Kinderberücksichtigungszeit und Zeiten einer Pflegetätigkeit. Wie oben schon erwähnt, sind Zeiten der Erziehung von Kindern in den ersten drei Lebensjahren echte Beitragszeiten. Widmet sich die erziehende Person darüber hinaus der Erziehung eines Kindes, dann kann bis zu dessen vollendetem zehnten Lebensjahr eine Berücksichtigungszeit geltend gemacht ${ }^{196}$ werden, soweit die Voraussetzungen für die Anrechnung einer Kindererziehungszeit gemäß § 56 SGB VI vorliegen. Der Zeitpunkt der Geburt des Kindes ist für Berücksichtungszeiten unerheblich, so daß sie auch dem Elternteil zugute kommt, dessen Kind vor dem 1.1.1992 geboren wurde.

Erstmalig wird auch die Tätigkeit der nicht erwerbsmäßigen Pflege rentenrechtlich abgesichert, nach der Kindererziehung wird eine weitere familiäre Tätigkeit durch das Rentenrecht aufgewertet. Um die Pflegezeit als Berücksichtigungszeit anerkannt zu bekommen, müssen folgende Voraussetzungen erfüllt sein:

1. Berechtigung zur Beitragszahlung wegen Pflege gemäß § 177 SB VI. Die Berechtigung liegt vor, wenn für die Pflege regelmäßig wöchentlich mindestens 10 Stunden aufgewendet werden müssen, und der Pflegebedürftige nicht nur vorübergehend hilflos ist. Er muß dauerhaft für die gewöhnli-

\footnotetext{
${ }^{194}$ Vgl. Bank/Brachmann/Kreikebohm/Schmidt, a.a.O., S. 169.

${ }^{195}$ Vgl. Bank/Brachmann/Kreikebohm/Schmidt, a.a.O, S. 169.

${ }^{196}$ Vgl. § 57 SGB VI.
} 
chen und regelmäßig wiederkehrenden Verrichtungen im Ablauf des täglichen Lebens in erheblichem Umfang fremde Hilfe benötigen.

2. Die antragstellende Person darf nicht zu der Personengruppe gehören, die von der Anrechnung einer Kindererziehungszeit ausgeschlossen ist.

Berücksichtigungszeiten verlängern den 5-Jahreszeitraum bei den Berufs- und Erwerbsunfähigkeitsrenten, sie werden darüber hinaus auf die große Wartezeit von 35 Jahren angerechnet. Bei der Rentenberechnung werden sie in die Gesamtleistungsbewertung einbezogen, als ob für sie Beiträge nach einem Einkommen von 75 \% des Durchschnittsentgelts aller Versicherten gezahlt worden wäre. Für die Gesamtleistungsbewertung werden jedem Kalendermonat an Berücksichtigungszeit 0,0625 Entgeltspunkte zugeordnet, solange nicht durch eine Beitragszeit ein höherer Wert erreicht wird. ${ }^{197}$

Beitragsfreie Zeiten erhalten bei der Bewertung den Durchschnittswert an Entgeltpunkten, der sich aus der Gesamtleistung an Beiträgen im belegungsfähigen Zeitraum ergibt. Der belegungsfähige Zeitraum beginnt i.d.R. mit dem 16. Lebensjahr und endet mit dem Beginn des Rentenfalles, d.h. bei einer Altersrente mit dem Kalendermonat vor Beginn der zu berechnenden Rente. Nicht belegungsfähig sind Kalendermonate mit beitragsfreien Zeiten, die nicht auch zugleich Berücksichtigungszeiten sind und Rentenbezugszeiten aus eigener Versicherung, die nicht auch zugleich Beitrags- oder Berücksichtigungszeiten sind.

Um sicherzustellen, daß sich diese Zeiten nicht negativ auf die Grundbewertung auswirken können, werden sie vom belegungsfähigen Gesamtzeitraum subtrahiert ${ }^{198}$. Der Gesamtzeitraum wird bei Versichertenrenten mit Zurechnungszeit um einen sogenannten "Lückenausgleich" reduziert" Durch den "Lückenausgleich" sollen Anwartschaftsminderungen bei Versicherten begrenzt werden, die erhebliche Versicherungslücken aufweisen, aber die Halbbelegung nach dem bis zum 31.12.1991 geltenden Recht erfüllen und bei Fortbestand dieses Rechts besser gestellt wären. ${ }^{200}$

\footnotetext{
${ }^{197}$ Vgl. § 71 Abs. 3, Satz 1 SGB VI.

${ }^{198}$ Vgl. § 72 Abs. 3 RRG.

${ }^{199}$ Vgl. § 72 Abs. 4 RRG.

${ }^{200}$ BT-Drucksache 11/4124, S. 171.
} 
Um sicherzustellen, daß Zeiten, die nur deshalb nicht beitragsfrei sind, weil für sie gleichzeitig Beiträge gezahlt worden sind, nicht schlechter bewertet werden als ohne diese Beitragsleistung, werden zwei verschiedene Bewertungen durchgeführt ${ }^{201}$. Im Rahmen der sogenannten Grundbewertung erfolgt die Bewertung aus den vollwertigen Beiträgen, beitragsgeminderten Zeiten und Berücksichtigungszeiten, wobei für jeden Kalendermonat Entgeltpunkte in der Höhe zugrundegelegt werden, "die sich ergibt, wenn die Summe der Entgeltpunkte für Beitragszeiten und Berücksichtigungszeiten durch die Anzahl der belegungsfähigen Monate geteilt wird" ${ }^{202}$. Es ergibt sich somit folgende Formel:

$E=\frac{\text { E für } B Z+B \ddot{u} Z}{--------}$

E ........... Entgeltpunkte

BZ .......... Beitragszeiten

BüZ ........ Berücksichtigungszeiten

GZ ......... Belegungsfähiger Gesamtzeitraum (Monate)

Die Vergleichsbewertung erfolgt i.d.R. aus vollwertigen Beiträgen und Berücksichtigungszeiten; d.h. die Summe aller Entgeltpunkte aus der Grundbewertung wird um die Entgeltpunkte aus beitragsgeminderten Zeiten und Berücksichtigungszeiten, die gleichzeitig beitragsfrei sind oder mit Zeiten eigener Versichertenrente zusammentreffen, vermindert, entsprechend wird die Anzahl der belegungsfähigen Monate entsprechend verringert, so daß sich nach Division folgende Formel ergibt:

$$
E=\frac{E \text { aus GB-E(bgZ+BüZ1+BZ2+BüZ2) }}{-\mathrm{Gz}-\mathrm{Km}(\mathrm{bgZ}+\mathrm{BüZ1}+\mathrm{BZ1}+\mathrm{BüZ2})}
$$

\footnotetext{
${ }^{201}$ BT-Drucksache 11/4124, S. 171.

${ }^{202} \S 72$ Abs. 1 RRG.
} 
E ........... Entgeltpunkte

Gb ......... Grundbewertung

bgZ ....... beitragsgeminderte Zeiten

BüZ1 .... Berücksichtigungszeiten, die auch beitrags-

freie Zeiten sind

BZ1/BüZ2 ..... Beitrags- bzw. Berücksichtigungszeiten, die

mit einer eigenen Versichertenrente zu

sammentreffen

GZ ................ Belegungsfähiger Gesamtzeitraum (Monate)

Km ............... Kalendermonate

Beitragsgeminderte Zeiten sind Zeiten, in denen Anrechnungszeiten, Zurechnungszeiten oder Ersatzzeiten mit Beitragszeiten zusammentreffen. Sie erhalten bei der Rentenberechnung mindestens den Wert, den sie als beitragsfreie Zeit im Rahmen der Vergleichsbewertung hätten. Diese Mindestbewertung stellt sicher, daß Zeiten, die nur deshalb nicht beitragsfrei sind, weil für sie gleichzeitig Beiträge gezahlt worden sind, nicht schlechter bewertet werden als ohne diese Beitragsleistung. ${ }^{203} \mathrm{Im}$ wesentlichen handelt es sich hier um Zeiten des Bezugs von Lohnersatzleistungen (Arbeitslosenhilfe, Arbeitslosengeld, Unterhaltsgeld, Übergangsgeld, Krankengeld, Verletztengeld oder Versorgungskrankengeld), die nach geltendem Recht grundsätzlich als Pflichtbeitragszeiten behandelt werden, jedoch bis zum 31. 12. 1997 zugleich Anrechnungszeiten sind, ${ }^{204}$ und demzufolge in der Gesamtleistungsbewertung als beitragsgeminderte Zeiten zu berücksichtigen sind, ab dem Jahre 1998 werden diese Zeiten als vollwertige Beitragszeiten angerechnet, so daß die Gesamtleistungsbewertung entfällt.

Der Zugangsfaktor bestimmt, in welchem Umfang Entgeltpunkte bei der Ermittlung des Monatsbetrags der Rente zu berücksichtigen sind und

${ }^{203}$ Vgl. BT-Drucksache 11/4124, S. 171.

${ }^{204}$ Vgl. Rentenübergangsrecht $§ 252$ Abs. 1, 2, 6, 7. 
richtet sich nach dem Alter der Versicherten bei Rentenbeginn. ${ }^{205}$ Er beträgt 1,0

- bei Renten wegen verminderter Erwerbsfähigkeit,

- bei Renten wegen Todes,

- bei Renten wegen Alters, die mit Ablauf des Kalendermonats der Vollendung des 65. Lebensjahres oder eines für den Versicherten maßgebenden niedrigen Rentenalters beginnen.

Entgeltpunkte für Beitragszeiten, beitragsfreie Zeiten, Zuschläge für beitragsgeminderte Zeiten sowie für $\mathrm{Zu}$ - oder Abschläge aus einem Versorgungsausgleich gehen demzufolge mit $\mathbf{1 0 0} \%$ in die Rentenberechnung ein.

Will ein Versicherter seine Altersrente vorzeitig in Anspruch nehmen, verringert sich der Zugangsfaktor um 0,003 für jeden Monat des Vorziehens; wird der Rentenbezug hinausgeschoben, vergrößert sich der Faktor um $\mathbf{0 , 0 0 5}$ je Monat. Wer also vorzeitig "in Rente gehen" will, muß pro Jahr einen Abschlag von 3,6 \% hinnehmen, konsequenterweise erhöht sich allerdings auch die Rente, wenn der Versicherte über die Altersgrenze hinaus erwerbstätig bleibt. Nach neuestem Beschluß (Gesetz zur Umsetzung des Regierungsprogramms für mehr Wachstum und Beschäftigung) wird das Rentenzugangsalter für Frauen von derzeit 60 Jahren ab dem Jahre 2000 in jährlichen Schritten angehoben, so daß es ab dem Jahre 200565 Jahre beträgt. Für Männer steigt das Rentenzugangsalter von jetzt 63 stufenweise bis zum Jahre 2002 auf 65 Jahre. Interessanterweise wird in diesem Bereich auf die Gleichstellung von Mann und Frau verzichtet, obwohl es doch kaum noch stichhaltige Argumente für die Bevorzugung der Frauen gibt.

Mit Hilfe des Rentenartfaktors ${ }^{206}$ wird das vorgegebene Sicherungsziel der jeweiligen Rentenart festgelegt, er beträgt für jeden persönlichen Entgeltpunkt bei

- Renten wegen Alters

- Renten wegen Berufsunfähigkeit

- Renten wegen Erwerbsunfähigkeit
1,0

0,6667

1,0

${ }^{205}$ Vgl. § 77, Abs. 1 SGB VI.

${ }^{206}$ Vgl. § 67 SGB VI. 
- Erziehungsrenten $\quad 1,0$

- kleinen Witwen-/Witwerrenten bis zum Ende des dritten Kalendermonats nach Ablauf des Monats, in dem der Ehegatte verstorben ist, 1,0 anschließend 0,25

- großen Witwen-/Witwerrenten bis zum Ende des dritten Kalendermonats nach Ablauf des Monats, in dem der Ehegatte verstorben ist, anschließend 0,6

- Halbwaisenrenten 0,1

- Vollwaisenrenten 0,2

Das letzte Element der Rentenformel ist der aktuelle Rentenwert, ${ }^{207}$ der einerseits zur Eingliederung der Rente in das Einkommensgefüge und andererseits zur Anpassung der Rentenleistung im Zeitablauf dient. Der aktuelle Rentenwert löste die bis 1992 geltende allgemeine Bemessungsgrundlage ab, die auf der Entwicklung der durchschnittlichen Bruttoarbeitsentgelte aller Arbeiter und Angestellten (ohne Auszubildende und Anlernlinge) der gesetzlichen Rentenversicherung beruhte. Wie schon nach altem Recht werden die Bestandsrenten jeweils zum 1.07. eines Jahres angepaBt. Neu ist allerdings, daß sich die verfügbaren Renten im Gleichklang mit den verfügbaren Arbeitsentgelten entwickeln, der Gesetzgeber hat sich also für eine nettolohnbezogene Rentenanpassung entschieden. Der Übergang von der bruttolohn- zur nettolohnorientierten Anpassung der Renten wurde als notwendig erachtet, weil die Belastung der Arbeitnehmerentgelte durch Steuern und Sozialbeiträge ein derart hohes Niveau erreicht hat, daß es nicht mehr gerechtfertigt erschien, daß die Renten stärker stiegen als die Nettoverdienste. Allgemein wird die Auffassung vertreten, daß dadurch das Ziel der sozialen Gerechtigkeit verletzt wird. Mit der Reform sind die Einkommensentwicklungen der abhängig beschäftigten Bevölkerung und der Bezieher von Rentenleistungen gleichgerichtet, so daß ein sich anbahnender Verteilungskon-

${ }^{207}$ Vgl. § 68 SGB VI. 
flikt zwischen "Alt und Jung" entschärft wurde. Über die nettolohnbezogene Rentenformel werden politische Entscheidungen in der Steuer- und Sozialpolitik zunehmend auch rentenpolitisch bedeutsam, und angesichts der Tatsache, daB die Zahl der Rentenempfänger eine gewichtige Wählergruppe darstellt, die bei nicht zufriedenstellenden Rentenanpassungen einen erheblichen politischen Einfluß ausüben kann ${ }^{208}$, ist zu erwarten, daB die bisher allokations- und wachstumspolitisch ausgerichteten Entscheidungen zunehmend auch unter sozialpolitischen Aspekten getroffen werden. Die Rentenanpassung in Anlehnung an die Entwicklung der Nettolöhne zeigt nicht mehr allein die relative Einkommensposition einer Gruppe im Vergleich zu einer anderen, sondern spiegelt die gesamtgesellschaftliche Einkommensentwicklung wider.

Die Anpassungsformel für den aktuellen Rentenwert ${ }^{209}$ hat die Form

$$
\begin{aligned}
& B_{t-1} \quad Q_{t-1} \quad R_{t-2} \\
& \mathrm{AR}_{\mathrm{t}}=\mathbf{A R} \mathbf{R}_{\mathrm{t}-1} \\
& B_{t-2} \quad N_{t-2} \quad R_{t-1}
\end{aligned}
$$
$\mathbf{A R}_{\mathbf{t}}$
Aktueller Rentenwert ab 1. Juli des laufenden Kalenderjahres
ARt-1 ........ Aktueller Rentenwert vom 1. Juli des Vorjahres bis zum 30. Juni des laufenden Kalenderjahres
BE $_{t-1}$........ Durchschnittliches Bruttoarbeitsentgelt des vergangenen Kalenderjahres
BE $_{t-2}$........ Durchschnittliches Bruttoarbeitsentgelt des vorvergangenen Kalenderjahres
NQt-1 ....... Nettoquote für Arbeitsentgelt (Verhältnis von

\footnotetext{
${ }^{208}$ Vgl. Nullmeier, F./F.W. Rüb, Erschöpfung des Sozialversicherungsprinzips? Gesetzliche Rentenversicherung und sozialstaatlicher Repulikanismus, in: Barbara Riedmüller, Thomas Olk (Hrsg.), Grenzen des Sozialversicherungsstaates, Leviathan, Sonderheft 14/1994, Seite 65.

${ }^{209}$ Vgl. § 68 SGB VI.
} 
durchschnittlichem Nettoentgelt zu

durchschnittlichem Bruttoentgelt) nach der

Volkswirtschaftlichen Gesamtrechnung des

vergangenen Kalenderjahres

$N Q_{t-2}$....... Nettoquote für Arbeitsentgelt nach der

Volkswirtschaftlichen Gesamtrechnung des

vorvergangenen Kalenderjahres

$R Q_{t-1}$....... Rentennettoquote des vergangenen Kalenderjahres

$R_{\mathrm{t}-2}$....... Rentennettoquote des vorvergangenen

Kalenderjahres

Die Rentennettoquote ergibt sich aus dem Verhältnis der Standardrente und der Bruttostandardrente eines Versicherten. Die Standardrente wird ermittelt, indem von der Regelaltersrente eines Versicherten der Beitragsanteil zur Krankenversicherung und die auf die Regelaltersrente durchschnittlich entfallenden Steuern subtrahiert werden. Die Bruttostandardrente ist die Regelaltersrente aus der Rentenversicherung der Arbeiter und Angestellten mit 45 Entgeltpunkten. In der Anpassungsformel des aktuellen Rentenwertes hat der Kehrwert der Veränderung der Rentennettoquote eine Korrekturfunktion insofern, als durch die Berücksichtigung des Kehrwertes die doppelte Belastung der Renten verhindert werden soll. Da die Beiträge zur gesetzlichen Krankenversicherung schon bei der Ermittlung der Nettoarbeitsentgelte berücksichtigt werden, wird durch die Anwendung des Kehrwertes der Rentennettoquote die zweifache Anrechnung der Beitragssatzänderung vermieden. Gleiches gilt für die durchschnittlich auf die Rente entfallenden Steuern.

Der Übergang von der Bruttolohnorientierung der Renten zur Nettolohnorientierung, d.h. Anpassung sowohl der Neurenten als auch der Bestandsrenten an die Entwicklung der Nettoarbeitsentgelte trägt also dazu bei, die Finanzierung der Alterslast gleichmäßiger auf die erwerbstätige und nicht mehr erwerbstätige Generation zu verteilen. Nicht zu unterschätzen ist der sozialpsychologische Aspekt für den erwerbstätigen Beitragszahler; sieht er, daß auch der Rentner als Ausdruck der Generationensolidarität einen Teil der Last zu tragen hat, trägt er seine Belastung zweifellos leichter. 
Die Festlegung des aktuellen Rentenwerts erfolgt durch Rechtsverordnung, ${ }^{210}$ "indem der bisherige aktuelle Rentenwert durch den neuen Rentenwert ersetzt wird"211, im alten Recht erfolgte die Rentenanpassung per Gesetz. Diese diskretionäre Anpassung durch politischen Beschluß erfolgte i.d.R. einmal jährlich, obwohl der Gesetzgeber diesen Modus nicht explizit vorschrieb. Die gegenwärtige Regelung koppelt die Rentenanpassung an die Entwicklung der verfügbaren Einkommen, die diskretionäre Rentenanpassung bot nicht zuletzt den Politikern die Möglichkeit, die Tatsache der Rentenanpassung periodisch an die Öffentlichkeit zu bringen, sowie die Renten in einzelnen Jahren unterschiedlich anzupassen, wobei anstehende Wahltermine die politische Entscheidung beeinflussen konnten. Nur fünf Jahre nach der grundlegenden Rentenreform 1992 steht die Rentenformel wieder auf dem Prüfstand. Der Anteil der Älteren in der Bevölkerung nimmt stetig zu, während der Anteil der jüngeren Beitragszahler abnimmt. Gleichzeitig verändert sich auch die Rentenbezugsdauer, betrug sie noch im Jahr 1965 bei Männern 10 Jahre, 1 Monat und bei Frauen 11 Jahre, 7 Monate, so sind es im Jahr 1995 bei Männern 14 Jahre und bei Frauen 17 Jahre, 10 Monate. ${ }^{212}$ Ursächlich dafür sind die gestiegene Lebenserwartung und die Tendenz, immer früher aus dem Arbeitsleben auszuscheiden. Eine solche Situation bleibt nicht ohne Auswirkungen auf den Beitragssatz, der nach Schätzungen im nächsten Jahrtausend die $20 \%$ deutlich überschreiten müßte, um die Rentenkasse zu finanzieren. Da ein derartig hoher Beitragssatz der nachwachsenden Generation nicht zugemutet werden soll und angesichts eines sich verschärfenden internationalen Wettbewerbs ein weiterer Anstieg der Lohnkosten in Deutschland vermieden werden muB, sind Veränderungen der Rentenformel geplant. Kernpunkt ist die Ergänzung der Rentenanpassungsformel um einen demographischen Faktor, der die längere Rentenbezugsdauer als Folge der gestiegenen Lebenserwartung berücksichtigt. Dieser Faktor wird so gestaltet werden, daß das Netto-Rentenniveau bis zum Jahr 2030 auf $64 \%$ abgesenkt wird, wobei von Rentenkürzungen bei den Bestandsrenten abgesehen wird.

${ }^{210}$ Vgl. § 69 SGB VI.

${ }^{211} \S 65$ SGB VI.

212 Vgl. Bundesministerium für Arbeit und Sozialordnung (Hrsg.), Eckpunkte für die Gesetzgebung beschlossen, in: Sozialpolitische Informationen, 31. Jg., Heft 5, S. 2. 
4. Leistungen im System der Alterssicherung

\subsection{Höhe der eigenen Leistungen}

\subsubsection{Gesetzliche Rentenversicherung}

Die Renten aus der gesetzlichen Rentenversicherung basieren einerseits auf der eigenen Beitragsleistung während der aktiven Lebensphasen, andererseits auf Ansprüchen, die von Hinterbliebenen geltend gemacht werden können. Im letztgenannten Fall handelt es sich um sogenannte abgeleitete Renten. Die Auszahlung der jeweiligen Renten erfolgt in der gesetzlichen Rentenversicherung zwölfmal im Jahr. Der vom Leistungsträger ausgezahlte Betrag (= Zahlbetrag) ergibt sich nach Abzug einbehaltener Beiträge zur gesetzlichen Krankenversicherung und Steuern, oder ggf. zuzüglich der von den Leistungsträgern übernommenen Beitragsanteile zur Sozialversicherung (dies ist dann der Fall, wenn der Transferempfänger privat versichert ist).

Die auf die Rente zu zahlende Steuer bezieht sich ausschließlich auf den Ertragsanteil, der zudem noch um Freibeträge reduziert wird.

10,89 Mio. eigene und 4,04 Mio. abgeleitete GRV-Renten in den alten Bundesländern und 2,87 Mio. eigene sowie 0,96 Mio. abgeleitete GRVRenten in den neuen Bundesländern wurden im Juli 1994 ausgezahlt.

Die Rentenhöhe zwischen Männern und Frauen unterscheidet sich immer noch beträchtlich, die Versichertenrenten der Männer betragen im Durchschnitt 1.762,-- DM in den alten Bundesländern bzw. 1.584,-- DM in den neuen Bundesländern, bei Frauen dagegen belaufen sie sich auf 791,-DM bzw. 1.018,-- DM. Diese Differenzen zeigen immer noch deutlich die Konsequenz ,tradierter gesellschaftlich-rechtlicher Geschlechterrollendefinition“213 in der gesetzlichen Rentenversicherung, die sich in erheblich differierenden Rentenhöhen niederschlägt und damit die Qualität der materiellen Sicherung von Frauen im Alter nachhaltig verringert. Die bessere eigene Sicherung der Frauen in den neuen gegenüber den Frauen in den alten Bundesländern ist auf die höhere Erwerbsbeteiligung der Frauen in den neuen Bundesländern zurückzuführen. Gleichwohl wird deutlich, daB die Frauen

${ }^{213}$ Ch. Hermann, Gleichstellung der Frau und Rentenrecht, Zur bestehenden Reform der Alterssicherung, Sozialpolitische Schriften Heft 51, Berlin 1984, S. 222. 
insgesamt gegenwärtig auch mit eigener Versichertenrente nicht in der Lage sind, ausschließlich mit diesen Mitteln, ihren Lebensunterhalt zu bestreiten. Die gravierenden Unterschiede zwischen den Männer- und Frauenrenten sind hierbei sowohl auf erheblich höhere Einkommen während der Erwerbsphase als auch auf eine kontinuierliche Versicherungsbiografie der Männer zurückzuführen.

Tabelle 3: Anzahl und Höhe der Leistungen der GRV (ArV/AnV) nach Geschlecht und Rentenart am 1.7.1994

\begin{tabular}{|c|c|c|c|c|c|c|}
\hline & \multicolumn{3}{|c|}{ Alte Bundeslānder } & \multicolumn{3}{|c|}{ Neue Bundeslānder } \\
\hline & $\begin{array}{l}\text { Anzahl } \\
\text { (in 1000) }\end{array}$ & $\begin{array}{l}\text { Anteil } \\
\text { in \% }\end{array}$ & $\begin{array}{l}\text { Durch- } \\
\text { schnittsbe- } \\
\text { trag } \\
\text { (DM/Monat) }\end{array}$ & $\begin{array}{l}\text { Anzahl } \\
\text { (in 1000) }\end{array}$ & $\begin{array}{l}\text { Anteil } \\
\text { in \% }\end{array}$ & $\begin{array}{l}\text { Durch- } \\
\text { schnitts- } \\
\text { betrag } \\
\text { (DM/Monat) }\end{array}$ \\
\hline $\begin{array}{l}\text { Männer } \\
\text { insges. }\end{array}$ & 4860 & 100,0 & $1.725,-$ & 986 & 100,0 & $1.493,-$ \\
\hline \multicolumn{7}{|l|}{ Davon } \\
\hline $\begin{array}{l}\text {-Versicher- } \\
\text { ten- } \\
\text { renten } \\
\end{array}$ & 4735 & 97,4 & $1.762,-$ & 916 & 92,9 & $1.584,-$ \\
\hline $\begin{array}{l}\text {-Witwerren- } \\
\text { ten }\end{array}$ & 125 & 2,6 & - & 70 & 7,1 & - \\
\hline $\begin{array}{l}\begin{array}{l}\text { Frauen ins- } \\
\text { ges. }\end{array} \\
\end{array}$ & 10070 & 100,0 & 870,-- & 2845 & 100,0 & 917,-- \\
\hline \multicolumn{7}{|l|}{ Davon } \\
\hline $\begin{array}{l}\text {-Versicherten } \\
\text { renten }\end{array}$ & 6157 & 61,1 & 791,- & 1955 & 68,7 & $1.018,-$ \\
\hline $\begin{array}{l}\text {-Witwenren- } \\
\text { ten }\end{array}$ & 3914 & 38,9 & $995,-$ & 890 & 31,3 & 694,- \\
\hline $\begin{array}{l}\text { Renten ins- } \\
\text { ges. }\end{array}$ & 14930 & - & $1.148,-$ & 3831 & - & $1.065,-$ \\
\hline
\end{tabular}

Quelle: Bundesarbeitsblatt 9/95

Die unterschiedliche Rentenhöhe der Männer zwischen neuen und alten Bundesländern resultiert im wesentlichen nach wie vor aus der Anwendung unterschiedlichen Rentenrechts sowie teilweise aus niedrigeren Einkommen. 
Verzerrend wirkt sich insbesondere der in den neuen Bundesländern gezahlte Sozialzuschlag für Einzelpersonen, deren Netto-Gesamteinkommen unter 658,-- DM liegt, sowie für Ehepaare mit einem ebensolchen Einkommen unter 1.054,-- DM, aus.

In den Daten der Tabelle 3 sind nicht eingeschlossen die 1,12 Mio. Frauen der Geburtsjahrgänge 1920 oder früher, die eine sogenannte reine Kindererziehungsleistung in Höhe von 34,-- DM pro Kind (1996) erhalten, ohne daß sie einen Anspruch auf eine eigene Rente aus der GRV wegen Erwerbstätigkeit hätte. Betroffen sind davon $29 \%$ aller Frauen ab $72 \mathrm{Jahr}^{214}$ Die durchschnittliche Höhe dieser Leistung beträgt z.Zt. 85,-- DM/Monat. Von der Gesamtzahl der 1,116 Mio. Frauen haben 676.000 Witwen Anspruch auf eine abgeleitete Rente während 440.000 Frauen ausschließlich die Zahlung aus der Kindererziehungsleistung erhalten. Von diesen sind 223.000 Ehefrauen ohne eigene Einkünfte. ${ }^{215}$

Die Aussagekraft der Analyse soll im folgenden durch die Betrachtung der Verteilung der Renten auf einzelne Größenklassen verbessert werden.

Der schon erwähnte Sozialzuschlag in den neuen Bundesländern führt sowohl bei Männern als auch bei Frauen zu einer im Vergleich zu den alten Bundesländern geringen Besetzung der Größenklasse bis 600,-- DM (Neue Bundesländer: $20 \%$ bei Frauen, $1 \%$ bei Männern). Die Auffüllbeträge, die als sozialrechtliche Transferleistung viele Renten stützen, sind in erster Linie in Frauenrenten enthalten, wobei die niedrigen Renten einen durchschnittlich höheren Prozentsatz an Auffüll-Leistung enthalten. Von der Abschmelzung dieser Beträge sind demzufolge die niedrigen Renteneinkommen stärker betroffen, ${ }^{216}$ wodurch sich die Situation der Frauen tendenziell verschlechtern wird. Seltener besetzt sind in den neuen Bundesländern die oberen Größenklassen. 46 \% der Männer beziehen in den alten Bundesländern eine Rente von mehr als 2.000,-- DM, in den neuen Bundesländern sind es

\footnotetext{
${ }^{214}$ Vgl. Bundesministerium für Arbeit und Sozialordnung (Hrsg.), Alterssicherung in Deutschland 1992 (ASID '92), Bd. I Strukturdaten zur Einkommenssituation von Personen und Ehepaaren ab 55 Jahren, München 1994, S. 10.

${ }^{215}$ Vgl. ASID '92, a.a.O., S. 38.

216 Vgl. Brückner, Erika, Lebenslagen alleinstehender älterer Frauen in Brandenburg, in: Gesellschaften im Umbruch, Verhandlungen des 27. Kongresses der Deutschen Gesellschaft für Soziologie in Halle an der Saale 1995, Hrsg.: Lars Clausen, Frankfurt/Main 1995, S. $925 f$.
} 
lediglich $2 \%$. Die Situation der Frauen ist in beiden Gebieten gleichermaBen unbefriedigend, in Westdeutschland erhalten $4 \%$ der Frauen eine eigene Rente über 2.000,-- DM, in Ostdeutschland sind es weniger als $1 \%$. Da die Frauen der neuen Bundesländer in den meisten Fällen über eine lückenlose Versicherungsbiografie verfügen - ein längeres Ausscheiden aus der Erwerbstätigkeit wegen der Erziehung von Kindern war bedingt durch das flächendeckende Vorhandensein von Kinderbetreuungseinrichtungen unüblich - kann diese Situation nur bei einem niedrigen Einkommen in der Erwerbsphase entstehen. Ähnliches gilt in diesem Fall auch für die Männer in den neuen Bundesländern.

Deutlich zeigt sich die in vielen Fällen ungenügende soziale Sicherung der Frauen auch bei Vorhandensein eigener Renten. $71 \%$ aller Frauen mit einer eigenen Rente liegen betragsmäßig unter $1.000,--D M$ und nur $4 \%$ der Leistungen sind höher als 2.000,-- DM. Bei den Männern sind es demgegenüber $46 \%$. Leistungen unter 1.000,-- DM werden nur von $12 \%$ der Männer bezogen. Deutlich wird auch, daß die durchschnittlich höheren abgeleiteten Renten im Vergleich zu den eigenen Renten der Frauen aus der stärkeren Konzentration auf den mittleren Bereich zwischen 600,-- DM und 1.400,-DM resultieren.

Tabelle 4: Verteilung der Rentenzahlbeträge nach GröBenklasse, Rentenart und Geschlecht

\begin{tabular}{|c|c|c|c|c|}
\hline \multirow{3}{*}{ GrōBenklasse (DM) } & \multicolumn{4}{|c|}{ Alte Bundeslānder } \\
\hline & \multicolumn{2}{|c|}{ Eigene Renten } & \multirow{2}{*}{$\begin{array}{c}\text { Abgel. Renten } \\
\text { Frauen }\end{array}$} & \multirow[t]{2}{*}{ Reine KLG } \\
\hline & Männer & Frauen & & \\
\hline & \multicolumn{4}{|c|}{ in \% } \\
\hline \multirow{8}{*}{$\begin{array}{l}\text { bis unter } 200,- \\
200,-->400,- \\
400,-->600,- \\
600,-->1.000,- \\
1.000,->1.400,- \\
1.400,->2.000,- \\
2.000,->3.000,- \\
3.000,- \text { und mehr }\end{array}$} & $\left.0^{I}\right)$ & 8 & 1 & 98 \\
\hline & 2 & 23 & 5 & 2 \\
\hline & 3 & 17 & 9 & $-2)$ \\
\hline & 7 & 23 & 31 & - \\
\hline & 10 & 17 & 33 & - \\
\hline & 33 & 8 & 18 & - \\
\hline & 42 & 4 & 2 & - \\
\hline & 4 & $\mathbf{0}$ & 0 & - \\
\hline
\end{tabular}




\begin{tabular}{|c|c|c|c|}
\hline \multirow{4}{*}{ GrōBenklasse (DM) } & \multicolumn{3}{|c|}{ Neue Bundeslānder } \\
\hline & \multicolumn{2}{|c|}{ Eigene Renten } & \multirow{2}{*}{$\begin{array}{c}\text { Abgeleitete Renten } \\
\text { Frauen } \\
\end{array}$} \\
\hline & Männer & Frauen & \\
\hline & \multicolumn{3}{|c|}{ in $\%$} \\
\hline \multirow{8}{*}{$\begin{array}{l}\text { Bis unter } 200,- \\
200,->400,-- \\
400,-->600,- \\
600,-->1.000,- \\
1.000,->1.400,- \\
1.400,->2.000,-- \\
2.000,->3.000,-- \\
3.000,- \text { und mehr }\end{array}$} & 0 & 1 & 10 \\
\hline & 0 & 2 & 34 \\
\hline & 1 & 17 & 23 \\
\hline & 15 & 56 & 30 \\
\hline & 52 & 22 & 3 \\
\hline & 30 & 2 & 0 \\
\hline & 2 & 0 & - \\
\hline & - & - & - \\
\hline
\end{tabular}

Quelle: ASID ‘92

1) Wert liegt unter $1 \%$

2) Es existieren keinerlei Ansprüche

\subsubsection{Betriebliche Altersversorgung}

Die Existenz unterschiedlichster Formen betrieblicher Altersversorgung sowohl auf der Unternehmens- als auch der überbetrieblichen Ebene lassen eine differenzierte Betrachtung nicht zu. Dennoch ist es möglich für die alten Bundesländer aus Sekundärquellen Daten über die Anzahl und Höhe dieser Leistungen herauszufiltern. ${ }^{217}$ So bezogen 1992 rd. 1,4 Mio. Männer und ca. 0,5 Mio. Frauen eine Betriebsrente. Hinzu kommen noch knapp 0,5 Mio. Witwen, die eine abgeleitete Rente erhalten. Ein Vergleich mit der Untersuchung aus dem Jahre 1986 zeigt eine deutliche Zunahme dieser Leistungsempfänger. Bei den Männern betrug die Steigerungsrate 20 $\%$, bei den Frauen sogar $32 \%$. Die Zahl der Frauen, die eine abgeleitete Rente erhielt, stieg im gleichen Zeitraum um $22 \% .{ }^{218}$ Die Bedeutung dieses Sicherungszweiges steigt also kontinuierlich an.

Allerdings sind die einzelnen Zahlbeträge, gemessen an ihrer Höhe, nur als Ergänzung zur gesetzlichen Rentenversicherung, zu sehen. Zudem nimmt

\footnotetext{
${ }^{217}$ Vgl. ASID '92, a.a.O., S. 43.

${ }^{218}$ Vgl. ebenda, S. 44.
} 
die Bedeutung von Betriebsrenten ständig ab, immer mehr Betriebe haben diese Renten gekürzt oder für Neueinstellungen sogar abgeschafft. Der durchschnittliche Zahlbetrag der Männer lag im Jahre 1992 bei 652,-- DM, derjenige der Frauen bei 316,-- DM. Die abgeleiteten Renten lagen mit 306,- DM nur knapp darunter. Die Verteilung auf die einzelnen Größenklassen stützt die obige Argumentation, denn die Mehrzahl der Renten liegt zwischen 50,-- und 400,-- DM. Betriebsrenten über 1.000,-- DM beziehen $17 \%$ der Männer und $6 \%$ der Frauen. Da ein Anspruch auf betriebliche Leistungen erst nach langjähriger Erwerbstätigkeit erworben wird, läßt die positive Entwicklung dieser Leistung bei den Frauen bereits einen EinfluB veränderten Erwerbsverhaltens in der Vergangenheit erkennen.

Tabelle 5: Höhe der betrieblichen Altersversorgung, Personen ab 55 Jahre, alte Bundesländer

\begin{tabular}{|r|c|c|c|}
\hline \multirow{2}{*}{$\begin{array}{c}\text { Größenklasse } \\
(\text { DM) }\end{array}$} & \multicolumn{2}{|c|}{ Eigene Rente } & $\begin{array}{c}\text { Abgeleitete Rente } \\
\text { Männer }\end{array}$ \\
\cline { 2 - 4 } Frauen \\
\hline bis unter 50 & \multicolumn{2}{|c|}{ in \% } & in \% \\
$50>100$ & 11 & 8 & 10 \\
$100>200$ & 28 & 18 & 22 \\
$200>400$ & 20 & 30 & 27 \\
$400>600$ & 11 & 19 & 21 \\
$600>1.000$ & 9 & 12 & 8 \\
$1.000>1.400$ & 5 & 7 & 6 \\
$1.400>2.000$ & 4 & 4 & 4 \\
2.000 und & 8 & 1 & 2 \\
mehr & & 1 & 1 \\
\hline
\end{tabular}

Quelle: ASID '92 


\subsubsection{Altersversorgung im öffentlichen Dienst}

Die Altersversorgung im öffentlichen Dienst gliedert sich in die Zusatzversorgung der Arbeiter und Angestellten von Bund, Ländern und Gemeinden, Körperschaften und deren Verbände sowie der Arbeitnehmer sonstiger juristischer Personen des öffentlichen Rechts und die Beamtenversorgung.

Die Zusatzversorgung unterscheidet zwei Leistungsarten: Die Versorgungsrenten für Personen, die zeitlebens im öffentlichen Dienst tätig waren und aus ihrer Tätigkeit heraus in den Ruhestand treten und die Versicherungsrenten, bei denen ein unverfallbarer Anspruch erworben wurde (Voraussetzung sind fünf anrechnungsfähige Beschäftigungsjahre), jedoch das Beschäftigungsverhältnis vor Inanspruchnahme der Leistung endete, weil die Person in die Privatwirtschaft wechselte oder vollständig aus dem Erwerbsleben ausschied. Letzteres betrifft vor allem Frauen, die ihre Erwerbstätigkeit zugunsten der Kindererziehung aufgaben und nach der Zeit der Kindererziehung nicht wieder in den öffentlichen Dienst zurückkehrten bzw. keine Vollzeitbeschäftigung aufnahmen. Teilzeitbeschäftigte und kurzfristig Beschäftigte werden nicht generell in das Versorgungssystem eingebunden. Da der Anteil der Versicherungsrenten lediglich $8 \%$ aller Renten der $\mathbf{Z u}$ satzversorgung beträgt, wird im folgenden nicht zwischen Versorgungs- und Versicherungsrente unterschieden.

Insgesamt haben ca. 1,4 Mio. Personen eine Leistung aus der Zusatzversorgung des öffentlichen Dienstes erhalten, darunter waren 0,3 Mio. abgeleitete Renten im Rahmen der Hinterbliebenenversorgung. Der durchschnittliche Rentenbetrag liegt bei allen betrachteten Gruppen über dem Betrag aus der betrieblichen Altersvorsorge in der Privatwirtschaft. Da beide Leistungsarten die gleiche Zielsetzung verfolgen, wird ersichtlich, daß die Gesamtversorgung eines Bediensteten im öffentlichen Diesnt im Alter besser ist gegenüber einem Angestellten in der privaten Wirtschaft. Festzustellen ist außerdem, daß die Leistungsdifferenz zwischen den Leistungen der Männer und Frauen, verglichen mit den Leistungen aus der gesetzlichen Rentenversicherung und der betrieblichen Altersvorsorge, am geringsten ist (200,-- DM bzw. 35 \% Leistungsdifferenz). Die noch bestehende Differenz läßt sich auf das tendenziell höhere Einkommen und die längere Er- 
werbsphase der Männer zurückführen. Im Vergleich zur betrieblichen Altersversorgung sind deutlich weniger ausgeprägte geschlechtsspezifische Unterschiede erkennbar.

$41 \%$ der Leistungen an Frauen und $53 \%$ der Leistungen an Männer sind höher als 600,-- DM, bei den Betriebsrenten betragen die entsprechenden Anteile $13 \%$ bzw. $26 \%$. Auch hier wird noch einmal die relativ gute Versorgung im öffentlichen Dienst deutlich.

Abschließend sei noch auf die Versorgung der Beamten, Richter und Bundeswehrangehörige (mit Beamtenstatus) hingewiesen. Ein unmittelbarer Vergleich der Beamtenversorgung mit dem übrigen Alterssicherungssystem ist insofern problematisch als es sich beim Ruhegeld eines Beamten um eine Leistung handelt, die sich auf ein lebenslanges öffentlich-rechtliches Dienstund Treueverhältnis stützt und keinerlei Elemente des Versicherungsprinzips enthält.

Die gesetzliche Rentenversicherung enthält zwar auch versicherungsfremde Elemente, wie z.B. die Rente nach Mindesteinkommen oder die Kriegsopferversorgung, stützt sich in ihrer Konstruktion aber auf den Versicherungsgedanken, zwischen eingezahlten Beiträgen und ausgezahlten Renten eine nachvollziehbare Relation zu schaffen. Die Beamtenversorgung ist eine Vollversorgung basierend auf dem Versorgungsprinzip, wonach Leistungsansprüche nicht aufgrund von Beitragszahlung sondern wegen erbrachter Leistungen für den Staat entstehen. Es handelt sich also faktisch um eine Fortsetzung der Zahlung von Einkommen auf niedrigerem Niveau. Insofern ist es steuersystematisch korrekt, diese Pensionszahlungen wie Einkommen aus unselbständiger Arbeit zu versteuern, allerdings kann ein Versorgungsfreibetrag in Höhe von maximal 4.800,-- DM/Jahr geltend gemacht werden. Systemkonform ist auch die Kürzung der Pension bei einem $\mathbf{Z u}$ sammentreffen mit einer Rente der gesetzlichen Rentenversicherung aufgrund einer früheren Beschäftigung als pflichtversicherte Person (allerdings nur dann, wenn die Rente und die Pension für die gleiche Zeit gezahlt wird). 
Tabelle 6: Anzahl und Höhe der Leistungender Zusatzversorgung im öffentlichen Dienst, alte Bundesländer

\begin{tabular}{|l|c|c|c|}
\hline \multirow{2}{*}{$\begin{array}{c}\text { Größenklasse } \\
\text { (DM) }\end{array}$} & \multicolumn{2}{|c|}{ Eigene Renten } & Abgeleitete Renten \\
\cline { 2 - 4 } & \multicolumn{2}{|c|}{ in \% } & Frauen \\
\hline \multirow{2}{*}{ Bis unter 50 } & 2 & 9 & 10 \\
\hline $50>100$ & 5 & 8 & 11 \\
\hline $100>200$ & 7 & 11 & $! 8$ \\
\hline $200>400$ & 16 & 17 & 28 \\
\hline $400>600$ & 18 & 13 & 21 \\
\hline $600>1000$ & 27 & 24 & 10 \\
\hline $1000>1400$ & $! 4$ & 14 & 0 \\
\hline $1400>2000$ & 6 & 3 & - \\
\hline 2000 und mehr & 6 & 0 & 316 \\
\hline $\begin{array}{l}\text { Zahl der Emp- } \\
\text { fänger }{ }^{1} \text { (in Tsd.) }\end{array}$ & 572 & 529 & 314 \\
\hline $\begin{array}{l}\text { Durchschnitt- } \\
\text { licher Betrag pro } \\
\text { Monat in DM }\end{array}$ & 747 & 554 & \\
\hline
\end{tabular}

1 Personen ab 55 Jahre

Quelle: ASID ‘92

Weitaus problematischer ist das System der Besteuerung von Renten, da diese zur Zeit anders - und zudem noch günstiger - besteuert werden als Pensionen. Bereits 1980 erteilte das Bundesverfassungsgericht der Bundesregierung die Aufgabe, die Rentenbesteuerung dahingehend zu verändern, daß diese den Pensionen gleichgestellt werden. Rentner zahlen im Unterschied zu Pensionären in ihrer aktiven beruflichen Laufbahn Beiträge in die gesetzliche Rentenversicherung, steuerpflichtig ist deshalb nur der Ertragsanteil, der den erwirtschafteten Zinsen entspricht. Die Höhe des Ertragsanteils richtet sich nach dem Alter zu Beginn der Rentenzahlungen. Neben den Altersrenten unterliegen auch die abgeleiteten Renten und die Berufs-und 
Erwerbsunfähigkeitsrente der Besteuerung, allerdings gilt in diesen Fällen ein besonderer Ertragsanteil abhängig von der Laufzeit der Rente. Die gesetzliche Unfallrente ist steuerfrei ${ }^{219}$, ebenso die Zahlungen nach dem Bundeserziehungsleistungsgesetz an von 1921 geborene Mütter. Rentenerhöhungen durch Anrechnung von Kindererziehungszeiten werden wie die gesamte Rente mit dem normalen Ertragsanteil besteuert.

Tabelle 7: Anzahl und Höhe der Leistungen aus der Beamten-
versorgung, alte Bundesländer

\begin{tabular}{|l|c|c|c|}
\hline \multirow{2}{*}{$\begin{array}{c}\text { Größenklasse } \\
\text { (DM) }\end{array}$} & Männer & Frauen & Witwengeld \\
\cline { 2 - 4 } bis unter 1.000 & 0 & - & 8 \\
\hline $1.000>1.400$ & 1 & - & 29 \\
\hline $1.400>2.000$ & 10 & 10 & 27 \\
\hline $2.000>3.000$ & 33 & 36 & 26 \\
\hline $3.000>4.000$ & 25 & 35 & 8 \\
\hline $4.000>5.000$ & 19 & 18 & 2 \\
\hline $\begin{array}{l}5.000 \text { und mehr } \\
\text { Zahl der Emp- } \\
\text { fänger }{ }^{1} \text { (in Tsd.) }\end{array}$ & 11 & 1 & - \\
\hline $\begin{array}{l}\text { Durchschnittli- } \\
\text { cher Betrag pro } \\
\text { Monat in DM }\end{array}$ & 566 & 98 & 498 \\
\hline
\end{tabular}

1 Personen ab 55 Jahre

2 Zahlbetrag, d.h. eine eventuelle Kürzung infolge des Zusammentreffens mit einer Rente aus der GRV ist bereits berücksichtigt.

Quelle: ASID '92

In der Beamtenversorgung finden sich nicht nur die höchsten Leistungen je Empfänger, die geschlechtsspezifischen Unterschiede in der Höhe der 
Leistung sind in diesem System am geringsten. Die geringe Besetzung der Größenklassen bis 1.400,-- DM resultiert aus den Regelungen über Mindestpensionen. Immerhin beziehen $11 \%$ der männlichen Pensionäre eine Leistung von 5.000,-- DM und mehr, bei den Frauen sind es nur $1 \%$. Die stärkste Konzentration findet sich in den Größenklassen von 2.000 - 4.000,-DM, 58 \% der Männer und $71 \%$ der Frauen sind dieser Klasse zuzuordnen. Der relativ hohe Anteil von Frauen in dieser Größenklasse resultiert vermutlich auf einen im Vergleich zu den Männern größeren Anteil von Frauen im mittleren und gehobenen Dienst.

\subsection{Höhe der abgeleiteten Leistungen}

Neben eigenen Leistungen aus der GRV kann im Fall des Todes des Ehepartners eine abgeleitete Hinterbliebenenrente bezogen werden, die aus den Ansprüchen des Verstorbenen resultiert. Das praktizierte Anrechnungsmodell bewirkt zwar ein teilweises oder vollständiges Ruhen dieser Leistung, wenn ein dynamisierter Freibetrag von derzeit 1.220,-- DM überschritten wird, gleichwohl erhält die Mehrzahl von Hinterbliebenen eine Leistung aus der Hinterbliebenenversicherung. $84 \%$ der Witwen über 65 Jahre erhalten eine abgeleitete GRV-Rente, in der Altersgruppe zwischen 65 und 75 Jahren sind es sogar $87 \%$. ${ }^{220}$

Auch im System der betrieblichen Alterssicherung sind abgeleitete Renten verbreitet, allerdings auf weitaus geringerem Niveau als in der GRV. Lediglich $11 \%$ der Witwen über 65 Jahre beziehen eine abgeleitete Rente aus der betrieblichen Alterssicherung. Da die abgeleitete Rente nur 60 $\%$ der Rente des Verstorbenen beträgt, reicht sie in der Regel nicht aus, um den Lebensunterhalt zu bestreiten. Besonders betroffen sind Witwen, die wegen der Kindererziehung ihre Erwerbstätigkeit aufgaben und dadurch keine oder nur geringe eigene Ansprüche erwerben konnten. Dieser Personenkreis ist dann darauf angewiesen, zusätzlich zur Rentenzahlung aus der GRV, Leistungen aus der Sozialhilfe zu beziehen. Angesichts der Tatsache, daß gerade dieser Personenkreis durch das Aufziehen von Kindern die

${ }^{220}$ Vgl. ASID '92, a.a.O., S. 71. 
Funktionsfähigkeit des Sozialversicherungssystems ermöglicht, erscheint es nicht tolerierbar, daß diese Frauen im Alter auf Leistungen aus der Sozialhilfe verwiesen werden.

Tabelle 8: Höhe und Verbreitung abgeleiteter Renten in der GRV nach Alter des Leistungsempangers, alte und neue Bundesländer im Jahre 1992

\begin{tabular}{|c|c|c|c|c|c|c|c|c|}
\hline & \multicolumn{4}{|c|}{ Alte Bundesländer } & \multicolumn{4}{|c|}{ Neue Bundesländer } \\
\hline & $\begin{array}{l}65 \mathrm{u}, \\
\text { älter }\end{array}$ & $65<75$ & $75<85$ & 85 u. älter & $\begin{array}{l}65 \mathrm{u} . \\
\text { älter }\end{array}$ & $65<75$ & $75<85$ & $\begin{array}{l}85 \mathrm{u} \\
\text { älter }\end{array}$ \\
\hline & \multicolumn{4}{|c|}{ in \% der Altersgruppe } & \multicolumn{4}{|c|}{ in \% der Altersgruppe } \\
\hline & 84 & 87 & 83 & 78 & 93 & 92 & 93 & 94 \\
\hline $\begin{array}{l}\text { Durch- } \\
\text { schnittl. } \\
\text { Zahlbetrag } \\
\text { pro Monat in } \\
\text { DM }\end{array}$ & 1054 & 1016 & 1061 & 1122 & 489 & 499 & 496 & $4+3$ \\
\hline
\end{tabular}

Quelle: ASID ‘92

Die Höhe abgeleiteter Renten liegt in allen Alterskohorten bei ca. 1.000,-- DM, lediglich die Witwen im Alter von 85 und älter beziehen eine um etwa 100,-- DM, also 10 \%, höhere Rente. Dies dürfte darauf zurückzuführen sein, daß deren verstorbene Ehemänner erst nach Erreichen der Altersgrenze verstorben sind und somit in vollem Umfang Ansprüche erwerben konnten.

Gravierend ist der Unterschied in der Rentenhöhe zwischen den alten und den neuen Bundesländern. Die Rentenhöhe in den neuen Bundesländern ist in etwa 50 \% niedriger als in den alten Bundesländern. Zwei Gründe sind dafür verantwortlich: Zum einen wurde das Rentenrecht der alten Bundesländer 1992 noch nicht vollständig in den neuen Bundesländern angewendet und zum anderen war das für diese Berechnungen zugrundegelegte Ein- 
kommen in den neuen Bundesländern niedriger als das durchschnittliche Einkommensniveau in den alten Bundesländern. Im Gegensatz zu den alten Bundesländern beziehen die Witwen der ältesten Alterskohorte die niedrigste Rente. In diesen Fällen, so ist zu vermuten, spiegelt sich die geringe Einkommenshöhe der älteren Menschen (hier der Ehemänner der Witwen) wider.

\subsection{Kumulation von Einkommen}

Das Alterssicherungssystem in Deutschland stützt sich auf mehrere Säulen, die zum Teil völlig unabhängig voneinander Leistungen gewähren. Dies führt in zahlreichen Fällen zu Kumulationen bei den Leistungsempfängern. Das gegenwärtige Hinterbliebenenrecht in der gesetzlichen Rentenversicherung, das dem verwitweten Ehepartner einen abgeleiteten Anspruch von $60 \%$ des verstorbenen Mannes bzw. der verstorbenen Frau unter Berücksichtigung des eigenen Einkommens als Unterhaltsersatzleistung garantiert, hat bei zunehmenden eigenständigen Sicherungsansprüchen dieser Frauen im Zeitablauf versicherungsrechtlich einen ständigen Anstieg der Zahl der Bezieherinnen von zwei Rentenleistungen zur Folge, so übertraf erstmals in den siebziger Jahren die Gesamtzahl der Versichertenrenten an Frauen die der Witwenrente ${ }^{221}$. Diese Situation führt unweigerlich zu der Frage, inwieweit durch Kumulation von Sicherungsleistungen eine wiederum sozialpolitisch unerwünschte „Überversorgung“ entsteht.

Um eine Beurteilung der sozialen Lage von Transfereinkommensbeziehern vornehmen zu können, ist es daher notwendig, die Nettoeinkommen, d.h. die Einkommen unter Einbeziehung sämtlicher Einkommensarten und unter Berücksichtigung evtl. anfallender Steuern und Abgaben, heranzuziehen. Der Bezug von Mehrfachrenten kann seit kurzer Zeit nachgewiesen werden, da der Postrentendienst in der Lage ist, die Renten der Arbeiter- und Angestellten-Versicherung personenbezogen zusammenzuführen, so daß neben der Anzahl und Struktur der Renten auch diejenige der Rentner erfaßt wer-

221 Vgl. Hermann, Christopher, Gleichstellung der Frau und Beamtenrecht, a.a.O., S. 238. 
den kann. Über die Rentenleistungen hinausgehende Einkommen wurden in der ASID '92 erfaBt. Da die erhobenen Daten jedoch das Ergebnis einer Befragung zur Gesamthöhe des Nettoeinkommens sind, kann im einzelnen keine Aussage über die Struktur der aus privater Vorsorge resultierenden Einkommen getroffen werden.

Die folgende Tabelle zeigt das Resultat der personenbezogenen Zusammenführung des Postrentenbestands zum 1. Juli 1994.

Der Mehrfachbezug wird durch die verkleinerte Grundgesamtheit (von ca. 14,9 Millionen Renten auf ca. 12,8 Millionen Rentner) deutlich. Jeder sechste Rentner im Westen und jeder Vierte im Osten erhält also mehr als eine Rentenleistung. Die personenbezogene Auswertung läBt außerdem eine Nivellierung des Rentenniveaus zwischen Ost und West erkennen (ca. 1.340,-DM). Nicht überraschend ist, daß der Mehrfachrentenbezug üblicherweise bei Frauen vorkommt. Angesichts der Tatsache zunehmender Erwerbsbeteiligung von Frauen wird sich dieses bei unverändert beibehaltenem Rentenversicherungssystem - in Zukunft noch deutlicher herausprägen.

Da in dieser Arbeit in erster Linie die soziale Lage der Frau dargestellt werden soll, wird im folgenden die Situation der Rentnerinnen besonders intensiv analysiert.

Die Hälfte aller Rentnerinnen bezog 1994 ausschließlich eine Versichertenrente in Höhe von durchschnittlich 847,-- DM pro Monat. Ein Viertel bezog lediglich eine Witwenrente von 919,-- DM/Monat und das restliche Viertel konnte sowohl über eine eigene als auch eine abgeleitete Rente verfügen, die zusammen im Schnitt 1.745,-- DM ausmachten. Damit ist sie ähnlich gestellt den Männern mit einer Versichertenrente, die im Durchschnitt 1.764,-- betrug. 
Tabelle 9: Anzahl der Rentner (ArV/AnV) und durchschnittliches Renteneinkommen am 1.7.1994

\begin{tabular}{|c|c|c|c|c|c|}
\hline \multirow{2}{*}{ Geschlecht } & \multicolumn{2}{|c|}{ Alte Bundeslānder } & \multicolumn{2}{|c|}{ Neue Bundesländer } & \multirow{2}{*}{$\begin{array}{c}\text { Durchschnittsbe } \\
\text { trag NBL in Pro } \\
\text { zent von ABL }\end{array}$} \\
\hline & $\begin{array}{c}\text { Anzahl } \\
\text { (in Mio.) }\end{array}$ & $\begin{array}{c}\text { Durch- } \\
\text { schnittsbe- } \\
\text { trag } \\
\text { DM/Monat }\end{array}$ & $\begin{array}{c}\text { Anzahl } \\
\text { (in Mio.) }\end{array}$ & $\begin{array}{c}\text { Durch- } \\
\text { schnittsbe- } \\
\text { trag } \\
\text { DM/Monat }\end{array}$ & \\
\hline Männer & 4,8 & 1755 & 0,9 & 1555 & 88,6 \\
\hline Frauen & 8,0 & 1098 & 2,1 & 1241 & 113,0 \\
\hline Davon Frauen mit & & & & & \\
\hline $\begin{array}{l}\text { Nur einer Versicherten- } \\
\text { rente }\end{array}$ & 4,1 & 847 & 1,2 & 1057 & 124,8 \\
\hline Nur einer Witwenrente & 1,8 & 919 & 0,1 & 635 & 69,1 \\
\hline $\begin{array}{l}\text { Versicherten- und Wit- } \\
\text { wenrente }\end{array}$ & 2.1 & 1745 & 0,7 & 1660 & 95,1 \\
\hline Zusammen & 12.9 & 1344 & 3,0 & 1339 & 99,6 \\
\hline
\end{tabular}

Quelle: Dünnwald, Kuhn, Löffler, Statistische Aussagen verbessert, Bundesarbeitsblatt 9/1995, S. 24.

Die Versorgungssituation der Rentnerinnen in den alten und neuen Bundesländern kann weitaus präziser aufgezeigt werden, wenn das durchschnittliche Renteneinkommen differenziert nach dem Alter der Frauen und nach der Anzahl der von ihnen bezogenen Renten ermittelt wird. In der nachstehenden Tabelle zeigt sich, daß die Rentnerinnen in den neuen Bundesländern, die lediglich auf ihre Witwenrente angewiesen sind, über alle Altersgruppen hinweg, die am schlechtesten gestellte Gruppe von Rentenbeziehern ist. 
Tabelle 10: Anzahl und Struktur der Renten und der Rentner (ArV/AnV) nach Geschlecht und Rentenart am 1.7.1994

\begin{tabular}{|c|c|c|c|c|}
\hline & \multicolumn{2}{|c|}{ Alte Bundeslānder } & \multicolumn{2}{|c|}{ Neue Bundesländer } \\
\hline & $\begin{array}{c}\text { Anzahl (in } \\
1000)\end{array}$ & $\begin{array}{l}\text { Anteil in } \\
\text { Prozent }\end{array}$ & $\begin{array}{c}\text { Anzahl (in } \\
1000)\end{array}$ & $\begin{array}{c}\text { Anteil in } \\
\text { Prozent }\end{array}$ \\
\hline & \multicolumn{4}{|c|}{ Renten } \\
\hline Männer insgesamt & 4860 & 100,0 & 986 & 100,0 \\
\hline \multicolumn{5}{|l|}{ Davon: } \\
\hline - Versichertenrenten & 4735 & 97,4 & 916 & 92,9 \\
\hline - Witwerrenten & 125 & 2,6 & 70 & 7,1 \\
\hline Frauen insgesamt & 10070 & 100,0 & 2845 & 100,0 \\
\hline \multicolumn{5}{|l|}{ Davon: } \\
\hline - Versichertenrenten & 6157 & 61,1 & 1955 & 68,7 \\
\hline - Witwerrenten & 3914 & 38,9 & 890 & 31,3 \\
\hline \multirow{2}{*}{ Renten insgesamt } & 14930 & & 3831 & \\
\hline & \multicolumn{4}{|c|}{ Rentner } \\
\hline Männer insgesamt & 4777 & 100,0 & 945 & 100,0 \\
\hline \multicolumn{5}{|l|}{ Davon mit: } \\
\hline - nur einer Versichertenrenten & 4653 & 97,4 & 880 & 93,1 \\
\hline - nur einer Witwerrente & 42 & 0,9 & 29 & 3,0 \\
\hline - Versicherten- und Witwerrente & 82 & 1,7 & 36 & 3,8 \\
\hline Frauen insgesamt & 7980 & 100,0 & 2103 & 100,0 \\
\hline \multicolumn{5}{|l|}{ Davon mit: } \\
\hline - nur einer Versichertenrente & 4078 & 51,1 & 1210 & 57,5 \\
\hline - nur einer Witwenrente & 1819 & 22,8 & 148 & 7,1 \\
\hline - Versicherten- und Witwenrente & 2083 & 26,1 & 745 & 35,4 \\
\hline Renten insgesamt & 12757 & & 3049 & \\
\hline
\end{tabular}

Quelle: Dünnwald, Kuhn, Löffler, a.a.O., S. 25

Auch für die vergleichbare Gruppe in den alten Bundesländern sieht es nur unwesentlich besser aus, mit einem durchschnittlichen Rentenbetrag 
von unter 1.000,-- DM werden auch sie nicht in der Lage sein, ohne weitere finanzielle Hilfe, ihren Lebensunterhalt zu bestreiten. In der Mehrzahl wird es sich aber gerade bei dieser Personengruppe um Frauen handeln, die Kinder geboren und erzogen haben und aus diesem Grund auf eine eigene Erwerbstätigkeit verzichteten. Bis auf wenige Ausnahmefälle von ungewollter/gewollter Kinderlosigkeit war es für die betrachtete Generation der über 50jährigen üblich, eine Familie zu gründen. Die mit zunehmendem Alter der Frauen ansteigenden Renteneinkommen (Witwenrente) lassen sich auf die längere Versicherungszeit der verstorbenen Ehegatten und auf die nicht unerheblichen Leistungsverbesserungen bei den Beiträgen zurückführen, gleichwohl verbessern sie die finanzielle Lage der Witwen nur marginal. Rentnerinnen, die nur eine Versichertenrente beziehen, stehen im Vergleich zur vorherigen Gruppe von Rentnerinnen zwar besser dar, aber auch sie werden ohne weiteres Einkommen oder Vermögen nur schwerlich ihren Lebensunterhalt bestreiten können. Nicht überraschend ist es, daß Rentnerinnen in den neuen Bundesländern gleich oder sogar besser gestellt sind als die Rentnerinnen in den alten Bundesländern.

Da es für die Frauen in der DDR nicht nur möglich war, aufgrund einer umfassenden kollektiven Betreuung der Kinder, erwerbstätig zu sein, sondern es dazu noch gesellschaftlich erwünscht war, lagen die Erwerbsquoten der Frauen erheblich über denen der Frauen in den alten Bundesländern im vergleichbaren Alter. Durch die vollständige Übertragung des deutschen Rentenrechts auf die neuen Länder nach der Wiedervereinigung, schlugen sich die langen Versicherungszeiten der Frauen natürlich auf die aktuelle Rentenhöhe nieder, und führten zu diesen höheren Renten.

Die höheren Renten der jüngeren Frauen (unter 60 Jahre bezogen auf die alten und neuen Bundesländer) könnten auf den verbesserten beruflichen Positionen beruhen, da es für diese Frauen im Zuge der Emanzipationsbewegungen möglich und erstrebenswert war, Wissen und Bildung zu erwerben und diese auch beruflich einzusetzen. Da eine verbesserte berufliche Stellung zumeist auch mit höheren Einkommen einhergeht, könnte dies ursächlich für die höheren Renten sein. Erwartungsgemäß haben die Gruppen von Mehrfachrentnerinnen die höchsten durchschnittlichen Renteneinkommen. 
Tabelle 11: Das durchschnittliche Renteneinkommen von Rentnerinnen (ArV/AnV) nach Altersgruppen am 1.7.1994 - Alte Bundesländer -

\begin{tabular}{|c|c|c|c|c|c|c|}
\hline \multirow{3}{*}{$\begin{array}{c}\text { Alter in Jahren von } \\
\quad \ldots \text { bis unter ... }\end{array}$} & \multicolumn{4}{|c|}{ Einfachrentnerinnen } & \multirow{2}{*}{\multicolumn{2}{|c|}{$\begin{array}{l}\text { Mehrfach rentnerinnen } \\
\begin{array}{l}\text { Rentnerinnen mit Wit- } \\
\text { wen- und Versicherten- } \\
\text { rente }\end{array}\end{array}$}} \\
\hline & \multicolumn{2}{|c|}{$\begin{array}{l}\text { Rentnerinnen nur mit } \\
\text { Versichertenrente }\end{array}$} & \multicolumn{2}{|c|}{$\begin{array}{l}\text { Rentnerinnen nur mit } \\
\text { Witwenrente }\end{array}$} & & \\
\hline & Anzahl & $\begin{array}{c}\text { Durch- } \\
\text { schnittsbe- } \\
\text { trag } \\
\text { (DM/Monat) }\end{array}$ & Anzahl & $\begin{array}{c}\text { Durch- } \\
\text { schnittsbe- } \\
\text { trag } \\
\text { (DM/Monat) }\end{array}$ & Anzahl & $\begin{array}{c}\text { Durch- } \\
\text { schnittsbe- } \\
\text { trag } \\
\text { (DM/Monat } \\
\text { ) }\end{array}$ \\
\hline Unter 55 & 139018 & 1161,93 & 244088 & 800,45 & 5740 & 1821,95 \\
\hline $55-60$ & 131979 & 1021,22 & 209114 & 896,32 & 14891 & 1883,30 \\
\hline $60-65$ & 557629 & 1119,48 & 197254 & 895,05 & 105579 & 2068,08 \\
\hline $65-70$ & 1175243 & 786,28 & 135258 & 810,72 & 338682 & 1792,51 \\
\hline $70-75$ & 1094838 & 754,53 & 178057 & 832,14 & 542639 & 1740,91 \\
\hline $75-80$ & 401275 & 788,25 & 212968 & 928,21 & 333585 & 1712,99 \\
\hline $80-85$ & 348432 & 783,78 & 332871 & $\mathbf{9 8 6 , 9 8}$ & 419671 & 1677,15 \\
\hline $85-90$ & 166549 & 823,51 & 213024 & 1049,21 & 236686 & 1692,66 \\
\hline über 90 & 62998 & 920,08 & 91569 & 1105,34 & 85289 & 1757,65 \\
\hline ohne Altersangabe & 1 & 1060,63 & 4579 & 533,73 & 5 & 1635,19 \\
\hline insgesamt & 4077962 & 847,29 & 1818782 & 918,51 & 2082767 & $\begin{array}{r}1 \\
745,01\end{array}$ \\
\hline
\end{tabular}

Quelle: Dünnwald, Kuhn, Löfler, a.a.O., S. 23. 
Tabelle 12: Das durchschnittliche Renteneinkommen von Rentnerinnen (ArV/AnV) nach Altersgruppen am 1.7.1994 - Neue Bundesländer

\begin{tabular}{|c|c|c|c|c|c|c|}
\hline \multirow{3}{*}{$\begin{array}{l}\text { Alter in Jahren von } \\
\quad \ldots \text { bis unter ... }\end{array}$} & \multicolumn{4}{|c|}{ Einfachrentnerinnen } & \multirow{2}{*}{\multicolumn{2}{|c|}{$\begin{array}{l}\text { Mehrfachrentnerinnen } \\
\text { Rentnerinnen mit Wit- } \\
\text { wen- und Versicherten- } \\
\text { rente }\end{array}$}} \\
\hline & \multicolumn{2}{|c|}{$\begin{array}{l}\text { Rentnerinnen nur mit } \\
\text { Versichertenrente }\end{array}$} & \multicolumn{2}{|c|}{$\begin{array}{l}\text { Rentnerinnen nur mit } \\
\text { Witwenrente }\end{array}$} & & \\
\hline & Anzahl & $\begin{array}{c}\text { Durch- } \\
\text { schnittsbe- } \\
\text { trag } \\
\text { (DM/Monat) }\end{array}$ & Anzahl & $\begin{array}{c}\text { Durch- } \\
\text { schnittsbe- } \\
\text { trag } \\
\text { (DM/Monat) }\end{array}$ & Anzahl & $\begin{array}{c}\text { Durch- } \\
\text { schnittsbe- } \\
\text { trag } \\
\text { (DM/Monat) }\end{array}$ \\
\hline Unter 55 & 83152 & 1123,82 & 45177 & 504,46 & 2719 & 1700,06 \\
\hline $55-60$ & 62634 & 1089,00 & 42238 & 600,43 & 5959 & 1718,77 \\
\hline $60-65$ & 305028 & 1062,98 & 16576 & 645,50 & 53609 & 1776,04 \\
\hline $65-70$ & 319266 & 1087,07 & 4951 & 734,19 & 105283 & 1811,57 \\
\hline $70-75$ & 236776 & 1062,18 & 7092 & 767,77 & 160754 & 1753,82 \\
\hline $75-80$ & 85736 & 1002,14 & 5757 & 811,23 & 116390 & 1685,59 \\
\hline $80-85$ & 75571 & 929,97 & 10871 & 837,34 & 170048 & 1589,68 \\
\hline $85-90$ & 31569 & 922,30 & 9391 & 824,28 & 97112 & 1463,74 \\
\hline über 90 & 10062 & 926,04 & 5575 & $\mathbf{7 5 8 , 4 4}$ & 33416 & 1370,58 \\
\hline ohne Altersangabe & - & - & 740 & 727,63 & - & - \\
\hline insgesamt & 1209794 & 1057,28 & 148368 & 634,98 & 745290 & 1660,00 \\
\hline
\end{tabular}

Quelle: Dünnwald, Kuhn, Löffler, a.a.O., S. 23. 
Tabelle 13: Anzahl der Renten und der Rentner (ArV/AnV) sowie durchschnittlicher Rentenbetrag bzw. durchschnittliches Renteneinkommen nach Geschlecht und Rentenart am 1.7.1994

\begin{tabular}{|c|c|c|c|c|}
\hline & \multicolumn{2}{|c|}{ Alte Bundesländer } & \multicolumn{2}{|c|}{ Neue Bundeslānder } \\
\hline & $\begin{array}{l}\text { Anzah! } \\
\text { (in 1000) }\end{array}$ & $\begin{array}{l}\text { Anteil in } \\
\text { Prozent }\end{array}$ & $\begin{array}{l}\text { Anzahl } \\
\text { (in 1000) }\end{array}$ & $\begin{array}{c}\text { Anteil in } \\
\text { Prozent }\end{array}$ \\
\hline & \multicolumn{4}{|c|}{ Renten } \\
\hline Männer insgesamt & 4860 & 1725 & 986 & 1493 \\
\hline \multicolumn{5}{|l|}{ Davon: } \\
\hline - Versichertenrenten & 4735 & 1762 & 916 & 1584 \\
\hline Frauen insgesamt & 10070 & 870 & 2845 & 917 \\
\hline \multicolumn{5}{|l|}{ Davon: } \\
\hline - Versichertenrenten & 6157 & 791 & 1955 & 1018 \\
\hline - Witwerrenten & 3914 & 995 & 890 & 694 \\
\hline \multirow[t]{2}{*}{ Renten insgesamt } & 14930 & 1148 & 3831 & 1065 \\
\hline & \multicolumn{4}{|c|}{ Rentner } \\
\hline Männer insgesamt & 4777 & 1755 & 945 & 1555 \\
\hline \multicolumn{5}{|l|}{ Davon mit: } \\
\hline - nur einer Versichertenrenten & 4653 & 1764 & 880 & 1585 \\
\hline Frauen insgesamt & 7980 & 1098 & 2103 & 1241 \\
\hline \multicolumn{5}{|l|}{ Davon mit: } \\
\hline - nur einer Versichertenrente & 4078 & 847 & 1210 & 1057 \\
\hline - nur einer Witwenrente & 1819 & 919 & 148 & 635 \\
\hline - Versicherten- und Witwenrente & 2083 & 1745 & 745 & 1660 \\
\hline Renten insgesamt & 12757 & 1344 & 3049 & 1339 \\
\hline
\end{tabular}

Quelle: Dünnwald, Kuhn, Löffler, a.a.O., S. 25. 
Tabelle 14: Schichtung des monatlichen Renteneinkommens von Rentnerinnen (ArV/AnV) am 1.7.1994 - Alte Bundesländer

\begin{tabular}{|c|c|c|c|c|c|c|}
\hline \multirow{3}{*}{$\begin{array}{c}\begin{array}{c}\text { Rentenbetrag } \\
\text { (DM/Monat) }\end{array} \\
\text { Von ... bis unter ... }\end{array}$} & \multicolumn{4}{|c|}{ Einfachrentnerinnen } & \multirow{2}{*}{\multicolumn{2}{|c|}{$\begin{array}{c}\text { Mehrfachrentnerinnen } \\
\begin{array}{c}\text { Rentnerinnen mit Wit- } \\
\text { wen- und Versicherten- } \\
\text { rente }\end{array}\end{array}$}} \\
\hline & \multicolumn{2}{|c|}{$\begin{array}{l}\text { Rentnerinnen nur mit } \\
\text { Versichertenrente }\end{array}$} & \multicolumn{2}{|c|}{$\begin{array}{l}\text { Rentnerinnen nur mit } \\
\text { Witwenrente }\end{array}$} & & \\
\hline & Anzahl & $\begin{array}{l}\text { Anteil in } \\
\text { Prozent } \\
\text { kumuliert }\end{array}$ & Anzahl & $\begin{array}{l}\text { Anteil in } \\
\text { Prozent } \\
\text { kumuliert }\end{array}$ & Anzahl & $\begin{array}{l}\text { Anteil in } \\
\text { Prozent } \\
\text { kumuliert }\end{array}$ \\
\hline Unter 200 & 386551 & $\overline{9,5}$ & 145001 & 8,0 & 1948 & $\overline{0,1}$ \\
\hline $200-400$ & 785577 & 28,7 & 175931 & 17,6 & 14323 & 0,8 \\
\hline $400-600$ & 567492 & 42,7 & 211054 & 29,2 & 43317 & 2,9 \\
\hline $600-800$ & 389270 & 52,2 & 220754 & 41,4 & 84121 & 6,9 \\
\hline $800-1000$ & 435824 & 62,9 & 263762 & 55,9 & 122166 & 12,8 \\
\hline $1000-1200$ & 439639 & 73,7 & 281931 & 71,4 & 163858 & 20,6 \\
\hline $1200-1400$ & 395753 & 83,4 & 222638 & 83,6 & 213106 & 30,9 \\
\hline $1400-1600$ & 273042 & 90,1 & 140753 & 91,4 & 253580 & 43,0 \\
\hline $1600-1800$ & 137517 & 93,4 & 75532 & 95,5 & 260993 & 55,6 \\
\hline $1800-2000$ & 94101 & 95,8 & 40467 & 97,7 & 237770 & 67,0 \\
\hline $2000-2200$ & 66689 & 97,4 & 22694 & 99,0 & 203733 & 76,8 \\
\hline $2200-2400$ & 44857 & 98,5 & 11198 & 99,6 & 165768 & 84,7 \\
\hline $2400-2600$ & 27678 & 99,2 & 6041 & 99,9 & 121080 & 90,5 \\
\hline $2600-2800$ & 16559 & 99,6 & 768 & 99,9 & 76595 & 94,2 \\
\hline $2800-3000$ & 8669 & 99,8 & 206 & 99,9 & 46214 & 96,4 \\
\hline über 3000 & 8744 & 100,0 & 52 & 100,0 & 74195 & 100,0 \\
\hline insgesamt & 4077962 & & 1818782 & & 2082767 & \\
\hline
\end{tabular}

Quelle: Dünnwald, Kuhn, Löffler, a.a.O., S. 28. 
Sowohl in den alten, als auch in den neuen Bundesländern, wären sie durchaus in der Lage, ihren Lebensunterhalt zu finanzieren, da anzunehmen ist, daß größere Anschaffungen nicht mehr zu tätigen sind und beruflich bedingte Ausgaben wegfallen. Würde zu diesen Renten Einkommen aus weiteren Quellen bezogen werden, wäre die Versorgung der Frauen in ausreichendem Maße gesichert.

In einer abschließenden Betrachtung sei auf die Schichtung des monatlichen Renteneinkommens von Rentnerinnen verwiesen, die Kumulation zeigt noch einmal deutlich die schlechte Versorgungslage der Frauen, die lediglich auf die Hinterbliebenenversorgung angewiesen sind. Über $\mathbf{5 0}$ $\%(55,6 \%)$ der Frauen haben eine Rente, die unter 1.000,-- DM liegt (alte Bundesländer), in den neuen Bundesländern dieser Prozentsatz sogar bei annähernd $90 \%$. Es wird damit deutlich, daß die Hinterbliebenenversorgung allein nicht ausreicht, um den Frauen einen gesicherten Lebensabend zu ermöglichen. In der Kumulation mit anderen Einkommen wiederum, kann sie durchaus ,überflüssig“ sein, da sie nur den Zustand der Überversorgung verstärkt. Eine Lösung des Problems scheint in der momentanen Situation darin zu liegen, die Hinterbliebenenversorgung speziell und die soziale Sicherung der Frauen insgesamt auf eine neue Basis zu stellen. Tabelle 16 zeigt noch einmal deutlich die Situation von Frauen, die Kinder erzogen haben.

Mit zunehmender Kinderzahl sinkt die Höhe der eigenen Versichertenrente, auch die Anrechnung von Kindererziehungszeiten verbessert die Lage dieser Frauen nicht wesentlich. Gegenüber einer Frau, die ohne Unterbrechung erwerbstätig sein konnte, stehen die Witwen, die sich der Kindererziehung gewidmet haben, deutlich schlechter dar. 
Tabelle 15: Schichtung des monatlichen Renteneinkommens von Rentnerinnen (ArV/AnV) am 1.7.1994 - Neue Bundesländer

\begin{tabular}{|c|c|c|c|c|c|c|}
\hline \multirow{3}{*}{$\begin{array}{c}\begin{array}{c}\text { Rentenbetrag } \\
\text { (DM/Monat) }\end{array} \\
\text { Von ... bis unter ... }\end{array}$} & \multicolumn{4}{|c|}{ Einfachrentnerinnen } & \multirow{2}{*}{\multicolumn{2}{|c|}{$\begin{array}{l}\text { Mehrfach rentnerinnen } \\
\begin{array}{c}\text { Rentnerinnen mit Wit- } \\
\text { wen- und Versicherten- } \\
\text { rente }\end{array}\end{array}$}} \\
\hline & \multicolumn{2}{|c|}{$\begin{array}{l}\text { Rentnerinnen nur mit } \\
\text { Versichertenrente }\end{array}$} & \multicolumn{2}{|c|}{$\begin{array}{l}\text { Rentnerinnen nur mit } \\
\text { Witwenrente }\end{array}$} & & \\
\hline & Anzahl & $\begin{array}{c}\text { Anteil in } \\
\text { Prozent } \\
\text { kumuliert }\end{array}$ & Anzahl & $\begin{array}{l}\text { Anteil in } \\
\text { Prozent } \\
\text { kumuliert }\end{array}$ & Anzahl & $\begin{array}{l}\text { Anteil in } \\
\text { Prozent } \\
\text { kumuliert }\end{array}$ \\
\hline Unter 200 & 3290 & 0,3 & 8668 & 5,8 & 79 & 0,0 \\
\hline $200-400$ & 5220 & 0,7 & 26034 & 23,4 & 291 & $\mathbf{0 , 0}$ \\
\hline $400-600$ & 117045 & 10,4 & 33804 & 46,2 & 514 & 0,1 \\
\hline $600-800^{*}$ & 130658 & 21,2 & 39863 & 73,0 & 6718 & 1,0 \\
\hline $800-1000$ & 230803 & 40,3 & 23729 & 89,0 & 23478 & 4,2 \\
\hline $1000-1200$ & 324276 & 67,1 & 10748 & 96,3 & 64481 & 12,8 \\
\hline $1200-1400$ & 247624 & 87,5 & 4200 & 99,1 & 86169 & 24,4 \\
\hline $1400-1600$ & 101170 & 95,9 & 903 & 99,7 & 136310 & 42,7 \\
\hline $1600-1800$ & 32727 & 98,6 & 379 & 100,0 & 152726 & 63,2 \\
\hline $1800-2000$ & 12070 & 99,6 & 19 & 100,0 & 136258 & 81,4 \\
\hline $2000-2200$ & 3868 & 99,9 & 12 & 100,0 & 86101 & 93,0 \\
\hline $2200-2400$ & 704 & 100,0 & 5 & 100,0 & 35712 & 97,8 \\
\hline über $\mathbf{2 4 0 0}$ & 339 & 100,0 & 4 & 100,0 & 16453 & 100,0 \\
\hline insgesamt & 1209794 & & 148368 & & 745290 & \\
\hline
\end{tabular}

Quelle: Dünnwald, Kuhn, Löffler, a.a.O., S. 28. 
Tabelle 16: Witwenrentenzugang 1994, alte Bundesländer

- Höhe der Rentenleistungen nach Kinderzahl -

\begin{tabular}{|c|c|c|c|c|c|c|c|c|}
\hline & \multirow{3}{*}{$\begin{array}{l}\text { Witwen ohne } \\
\text { eigene Ver- } \\
\text { sicherten- } \\
\text { rente }\end{array}$} & \multicolumn{7}{|c|}{ Witwen mit eigener Versichertenrente } \\
\hline & & \multirow{2}{*}{$\begin{array}{c}\text { Insge- } \\
\text { samt }\end{array}$} & \multicolumn{6}{|c|}{ davon } \\
\hline & & & $\begin{array}{c}\text { Ohne } \\
\text { Kinder }\end{array}$ & $\begin{array}{l}\text { Mit } 1 \\
\text { Kind }\end{array}$ & $\begin{array}{l}\text { Mit } 2 \\
\text { Kin- } \\
\text { dern }\end{array}$ & $\begin{array}{l}\text { Mit } 3 \\
\text { Kin- } \\
\text { dern }\end{array}$ & $\begin{array}{c}\text { Mit } 4 \text { u. } \\
\text { mehr } \\
\text { Kin- } \\
\text { dern }\end{array}$ & $\begin{array}{c}\text { Mit Kin- } \\
\text { dern }\end{array}$ \\
\hline Anzahl & 6.024 & 41.943 & 5.675 & 18.073 & 7.279 & 4.945 & 5.971 & 36.268 \\
\hline $\begin{array}{l}\text { Durchschnittli- } \\
\text { che Höhe des } \\
\text { Renteneinkom- } \\
\text { mens in DM }\end{array}$ & 962 & 1.836 & 2.175 & 1.936 & 1.698 & 1.624 & 1.559 & 1.784 \\
\hline $\begin{array}{l}\text { Durchschnittli- } \\
\text { che Höhe der } \\
\text { eigenen Versi- } \\
\text { chertenrente } \\
\text { der Witwe in } \\
\text { DM }\end{array}$ & - & 728 & 1.027 & 782 & 598 & 567 & 575 & 682 \\
\hline $\begin{array}{l}\text { Durchschnittli- } \\
\text { che Höhe der } \\
\text { Witwenrente in } \\
\text { DM }\end{array}$ & 962 & 1.108 & 1.148 & 1.154 & 1.100 & 1.058 & 984 & 1.102 \\
\hline
\end{tabular}

Quelle: S. Ohsmann, U. Stolz, Renteneinkommen von Witwen, Vortrag anläßlich der Tagung der Gesellschaft für Sozialen Fortschritt und der Bundesversicherungsanstalt für Angestellte (BfA) am 30.10.1997 in Berlin zum Thema: Die Alterssicherung von Frauen.

\section{Finanzierung der gesetzlichen Rentenversicherung}

Während bis zur grundlegenden Rentenreform 1957 das Kapitaldeckungsverfahren galt, wird seit diesem Zeitpunkt das Umlageverfahren, also ein Finanzierungsverfahren, das auf die Bildung eines Kapitalstocks 
verzichtet und die jeweilige Generation der Erwerbstätigen zu Leistungen für die bereits aus dem Erwerbsleben Ausgeschiedenen heranzieht in der Erwartung, daß ihre Renten ebenfalls von der dann aktiven Generation gewährleistet werden, praktiziert. ${ }^{222} \mathrm{Um}$ etwaige Schwankungen von Einnahmen und Ausgaben ausgleichen zu können, haben die Rentenversicherungsträger zur Sicherung ihrer Zahlungsfähigkeit eine Rücklage zu bilden. Diese Rücklage muß mindestens eine Monatsauszahlung betragen, ist aber bereits mehrfach unterschritten worden. Zusammen mit den Betriebsmitteln, die zur Deckung der laufenden Ausgaben erforderlich sind und eine Monatsausgabe nicht überschreiten dürfen, stellt die Rücklage die sogenannte Schwankungsreserve dar.

Die Rücklage ist so anzulegen, daß ein Verlust weitgehend ausgeschlossen werden kann $^{223}$, darüber hinaus gilt die spezielle Vorschrift, "daB die Rücklage liquide anzulegen ist"224, wobei als liquide alle Vermögensanlagen mit einer Laufzeit, Kündigungsfrist oder Restlaufzeit bis zu 12 Monaten sowie Schatzwechsel und unverzinsliche Schatzanweisungen bezeichnet werden.

Die einmal jährlich vorzunehmenden langfristigen Vorausberechnungen der künftigen finanziellen Entwicklung der GRV gehen ebenfalls von einer Mindestschwankungsreserve in Höhe einer Monatsausgabe vor. Darüber hinaus hat der Bundesminister für Arbeit und Sozialordnung Vorausschätzungen der Einnahmen und Ausgaben, sowie des Vermögens des Rentenversicherungsträgers für die folgenden 15 Jahre vorzulegen. Ergeben diese Vorausberechnungen, daß die Schwankungsreserve für die Arbeiterund Angestelltenrentenversicherung zusammen jeweils am Ende von mindestens zwei aufeinanderfolgenden Kalenderjahren die durchschnittlichen Aufwendungen für einen Kalendermonat zu Lasten der Rentenversicherungsträger unterschreitet, dann ist der Beitragssatz so zu erhöhen, daß die Schwankungsreserve in ihrer vorgeschriebenen Höhe erhalten bleibt. Ein

222 Die Rentenreform 1957 brachte zunächst einmal ein modifiziertes Umlageverfahren (Abschnittsdeckungsverfahren), wonach für einen Zeitraum von 10 Jahren der Wert aller eingezahlten Beiträge und sonstigen Einnahmen die Aufwendungen decken mußte. Erst 1969 wurde das Umlageverfahren in heutiger Form eingeführt.

${ }^{223}$ Vgl. § 80 SGB IV.

${ }^{224}$ Müller-Heine, Karin, a.a.O., S. 93. 
entsprechender Vorschlag über die erforderliche Höhe des Beitragssatzes muß von der Bundesregierung eingebracht und dem Parlament vorgelegt werden. Eine Erhöhung des Beitragssatzes ist jedoch aufgrund dieses Verfahrens nicht zwingend notwendig, denn es besteht die Möglichkeit andere Maßnahmen zur Verbesserung der finanziellen Lage vorzunehmen, wie z.B. eine Aufstockung der finanziellen Mittel aus Bundesmitteln. Diese Gewährleistung der finanziellen Sicherung ergibt sich ohnehin aus der im Gesetz vorgesehenen Garantie des Staates, fehlende Mittel zur Ausgabenfinanzierung bereitzustellen ${ }^{225}$. Diese Liquiditätshilfe in Höhe der fehlenden Mittel ist jedoch zurückzuzahlen, wenn sie im laufenden Kalenderjahr zur Erfüllung der Zahlungsverpflichtungen nicht mehr benötigt werden. Die Rückzahlung muß spätestens bis zum 31.12. des auf die Vergabe folgenden Jahres erfolgen, Zinsen fallen für die gezahlte Summe jedoch nicht an. ${ }^{226}$

\subsection{Beiträge}

Die gesetzliche Rentenversicherung ist - wie im übrigen das soziale Sicherungssystem Deutschlands schlechthin - ein Zwangsversicherungssystem, in dem die erbrachten Sozialleistungen mit Zwangsabgaben (= Beiträgen) finanziert werden. Dem Grundgedanken des Versicherungsprinzips folgend, finanziert sich die GRV im wesentlichen aus den Beiträgen versicherungspflichtiger Arbeitnehmer zuzüglich der Arbeitgeberanteile, der versicherungspflichtigen Selbständigen sowie der freiwillig Versicherten.

Gemäß § 1 SGB VI sind pflichtversichert alle Personen, die als Arbeitnehmer gegen Entgelt beschäftigt sind, und zwar ohne Rücksicht auf die Verdiensthöhe sowie Bezieher von Vorruhestandsgeld, wenn sie vor Eintritt in den Vorruhestand rentenversicherungspflichtig waren, darüber hinaus Auszubildende oder sonst in einer Berufsausbildung beschäftigte Personen. Versichert sind auch Mütter und Väter, die ein Kind erziehen ${ }^{227}$, und zwar derzeit für die Dauer von 36 Monaten nach Ablauf des Monats der Geburt des Kindes.

\footnotetext{
225 Vgl. Gesetz Bundeszuschuß.

226 Vgl. § 214 SGB VI.

${ }^{227}$ Vgl. HEZG, diese Regelung gilt seit 1986.
} 
Werden in diesem Zeitraum mehrere Kinder erzogen, deren Erziehung die Versicherungspflicht begründet, so verlängert sich die Zeit der Versicherung für das zweite und jedes weitere Kind um die Anzahl von Kalendermonaten, in denen gleichzeitig mehrere Kinder erzogen worden sind. Erziehen die Eltern das/die Kind/er, so ist die Mutter versichert, wenn die Eltern nicht bis zum Ablauf des dritten Kalendermonats nach der Geburt des Kindes gegenüber dem zuständigen Rentenversicherungsträger erklären, daß der Vater versichert sein soll. Beiträge sind für die Kindererziehungszeit vom Versicherten nicht zu zahlen, es erfolgt im Zuge der Rentenberechnung eine rentenrechtliche Bewertung im Ausmaß von $75 \%$ des Durchschnittsentgelts aller Versicherten, was sich in 0,0625 Entgeltpunkte niederschlägt.

Die Beiträge in der gesetzlichen Rentenversicherung werden nach einem Beitragssatz von der Beitragsbemessungsgrundlage (= versicherungspflichtiges Einkommen) erhoben, die nur bis zur jeweiligen Beitragsbemessungsgrenze berücksichtigt wird. ${ }^{228}$ Der Beitragssatz beträgt $1996 \quad 19,2 \%$ und ist per Rechtsverordnung so festzusetzen, "daß die voraussichtlichen Beitragseinnahmen unter Berücksichtigung der voraussichtlichen Entwicklung der Bruttolohn- und -gehaltssumme je durchschnittlich beschäftigten Arbeitnehmer und der Zahl der Pflichtversicherten zusammen mit dem Bundeszuschuß und den sonstigen Einnahmen unter Berücksichtigung von Entnahmen aus der Schwankungsreserve ausreichen, um die voraussichtlichen Ausgabe des auf die Festsetzung folgenden Kalenderjahres zu decken und sicherzustellen, daß die liquiden Mittel der Schwankungsreserve am Ende dieses Kalenderjahres dem Betrag der durchschnittlichen Ausgaben für einen Kalendermonat zu eigenen Lasten der Tragen der Rentenversicherung der Arbeiter und der Angestellten entsprechen; der Beitragssatz ist auf eine Dezimalstelle aufzurunden." 229

Die Beitragsbemessungsgrenze ändert sich jeweils zum 1. Januar eines jeden Jahres in dem Verhältnis, in dem die Bruttolohn- und -gehaltssumme je durchschnittlich beschäftigten Arbeitnehmer im vergangenen zur entsprechenden Bruttolohn- und -gehaltssumme im vorvergangenen Kalender-

\footnotetext{
${ }^{228}$ Vgl. § 157 SGB VI.

${ }^{229} \S 158$ Abs. 1 SGB VI.
} 
jahr steht. ${ }^{230}$ Der veränderte Betrag wird dann für das jeweilige Kalenderjahr auf den nächsthöheren durch 1200 teilbaren Betrag aufgerundet, 1996 beträgt die Beitragsbemessungsgrenze 8.000,-- DM in den westlichen und 6.800,-- DM in den östlichen Bundesländern. Sie erhöht sich ab 1.1.1997 um 200,-- DM auf 8.200,-- DM im Monat in Westdeutschland, im Osten steigt die Grenze von 6.800,-- DM auf 7.100,-- DM. In der Knappschaftlichen Rentenversicherung erhöhen sich die Beträge von 9.800,-- DM auf 10.100,-- DM (West) und auf 8.700,-- DM (Ost). Die Geringfügigkeitsgrenze, bis zu der keine Sozialversicherungsbeiträge fällig werden, erhöht sich im Westen auf 610,-- DM, im Osten auf 520,-- DM. Rückwirkend zum 1. Juli 1996 werden die Grenzen für den Sozialzuschlag zu den Renten in Ostdeutschland angepaßt, für Alleinstehende gelten dann 688,-- DM, für Verheiratete 1.104,-DM. Beitragsbemessungsgrundlage für Versicherungspflichtige sind die beitragspflichtigen Einnahmen. ${ }^{231}$ Für Beschäftigte in Beschäftigungsverhältnissen ohne Besonderheiten ist dies das Arbeitsentgelt. ${ }^{232}$ einschließlich eines einmalig gezahlten Arbeitsentgelts ${ }^{233}$. Die Beiträge sind vom Versicherten und dem Arbeitgeber je zur Hälfte zu tragen, ausgenommen aus dieser Regelung sind die sogenannten "Geringverdiener", bei ihnen trägt der Arbeitgeber den gesamten Beitrag allein. Die Geringverdienergrenze beträgt 1/7 der monatlichen Bezugsgröße; solange 1/7 der Bezugsgröße den Betrag von 610 DM monatlich unterschreitet, ist dieser Betrag maßgebend. ${ }^{234}$ Soweit nichts anderes bestimmt ist, sind die Beiträge von demjenigen, der sie zu tragen hat (Beitragsschuldner), unmittelbar an die Träger der Rentenversicherung zu zahlen, ${ }^{235}$ im Falle des abhängig Beschäftigten erfolgt die Zahlung der Beiträge im Zuge des Quellenabzugsverfahrens vom Arbeitgeber.

Macht ein Selbständiger von der Möglichkeit der Pflichtversicherung auf Antrag Gebrauch oder versichert er sich freiwillig, muß er den vollen Beitrag allein tragen. Ausnahmen gelten lediglich für Künstler und Publizi-

\footnotetext{
${ }^{230}$ Vgl. § 159 SGB VI.

${ }^{231}$ Vgl. $\$ 161$ Abs. 1 SGB VI.

${ }^{232}$ Vgl. § 162 Abs. 1 SGB VI.

${ }^{233} \mathrm{Vgl}$. § 164 SGB VI.

${ }^{234}$ Vgl. $\$ 168$ Abs. 1 Nr. 1 SGB VI.

${ }^{235} \mathrm{Vgl}$. § 173 SGB VI.
} 
sten sowie Hausgewerbetreibende. ${ }^{236}$ Grundlage der Beitragsberechnung für die Selbständigen sind die beitragspflichtigen Einnahmen aus der selbständigen Tätigkeit. Beitragspflichtige Einnahmen werden entweder in Höhe einer Bezugsgröße festgesetzt oder ergeben sich aus dem mittels Einkommensteuerbescheid nachgewiesenen tatsächlichen Arbeitseinkommen. ${ }^{237}$

Wenn nicht ein niedrigeres oder höheres tatsächliches Arbeitseinkommen nachgewiesen wird, sind die Beiträge - abgesehen von Ausnahmefällen von diesem Betrag zu berechnen ${ }^{238}$. Damit wird die Problematik des Nachweises und der Kontrolle des tatsächlichen Arbeitseinkommens entschärft.

Für Wehr- und Zivildienstleistende trägt der Bund die Kosten der Beitragszahlung ${ }^{239}$, deren Bemessungsgrundlage jetzt 80 v.H. des durchschnittlichen Bruttoarbeitsentgelts aller Versicherten beträgt.

Neu ist ab 1992 die Berücksichtigung ehrenamtlicher und Pflegetätigkeit; so kann bei einer versicherungspflichtigen ehrenamtlichen Tätigkeit für eine Körperschaft des öffentlichen Rechts eine Aufstockung der Pflichtbeiträge vorgenommen werden ${ }^{240}$. Ebenso können Versicherte, die einen Pflegebedürftigen mindestens zehn Stunden in der Woche nicht erwerbsmäBig pflegen, ihre freiwilligen Beiträge in Pflichtbeiträge umwandeln lassen ${ }^{241}$.

Die Möglichkeit der Umwandlung von freiwilligen Beiträgen in Pflichtbeiträge stellt eine erhebliche Verbesserung der Stellung der Versicherten dar, denn auch nach den Regelungen des SGB VI sind freiwillige Beiträge Pflichtbeiträgen nicht in vollem Umfang gleichgestellt. So können Ansprüche auf Renten wegen verminderter Erwerbsfähigkeit nur durch Pflichtbeitragszeiten erworben werden, eine Umwandlung der Beiträge nach § 177 Abs. 1 SGB VI ermöglicht nun also auch Hausfrauen erneut den Aufbau eines Versicherungsschutzes gegen das Risiko der Berufs- und Erwerbsunfähigkeit. Soll eine Umwandlung erfolgen, muß dies beim Rentenversicherungsträger beantragt werden, der diese aber i.d.R. ohne weiteres vornimmt.

\footnotetext{
${ }^{236}$ Vgl. § 169 Abs. 2 und 3 SGB VI.

${ }^{237}$ Vgl. § 165 Abs. 1 Nr. 1 SGB VI in Verbindung mit $§ 18$ SGB IV.

${ }^{238}$ Vgl. $\$ 165$ Abs. 1 Nr. 1 SGB VI.

${ }^{239}$ Vgl. § 170 Abs. 1 Nr. 1 SGB VI.

${ }^{240}$ Vgl. § 163 Abs. 4 SGB VI.

${ }^{241}$ Vgl. § 177 Abs. 1 SGB VI.
} 
Tabelle 17: Die Entwicklung der Beitragssäte in der Rentenversicherung der Arbeiter und der Angestellten 1980-1999

\begin{tabular}{|l|c|}
\hline Jahr & Beitragssatz in \% \\
\hline 1980 & 18,0 \\
1981 & 18,5 \\
1982 & 18,0 \\
1983 & 18,5 \\
1984 & 18,5 \\
1985 & 18,7 \\
1986 & 19,2 \\
1987 & 19,2 \\
1988 & 18,7 \\
1989 & 18,7 \\
1990 & 18,7 \\
1991 & 17,7 \\
1992 & 17,7 \\
1993 & 17,5 \\
1994 & 19,2 \\
1995 & 18,6 \\
1996 & 19,2 \\
1997 & 20,3 \\
$1998{ }^{1}$ ) & 19,7 \\
$1999{ }^{1}$ ) & 19,9 \\
\hline & \\
\hline
\end{tabular}

1) Modellrechnungen der Rentenversicherungsträger über die weitere finanzielle Entwicklung der gesetzlichen Rentenversicherung im Februar 1996.

Grundsätzlich besteht für Personen nach Vollendung des 16. Lebensjahres, die nicht versicherungspflichtig sind, die Möglichkeit der freiwilligen Versicherung, dies gilt auch für Deutsche, die ihren gewöhnlichen Aufenthalt im Ausland haben. ${ }^{242}$ Versicherungsfreie oder von der Versicherung befreite Personen, mit Ausnahme der wegen Geringfügigkeit oder als Studenten versicherungsfreien, können sich nur dann freiwillig versichern, wenn sie 
die allgemeine Wartezeit von 5 Jahren erfüllt haben. ${ }^{243}$ Die Mindestbeitragsbemessungsgrundlage für freiwillig Versicherte beträgt ein Siebtel der Bezugsgröße. ${ }^{244}$

Personen, die für eine bestimmte Zeit versicherungsfrei waren oder von der Versicherungspflicht befreit worden sind, haben die Möglichkeit der Nachversicherung. ${ }^{245}$ Dazu gehören ${ }^{246}$

- Beamte, Richter, Berufssoldaten und Soldaten auf Zeit,

- sonstige Beschäftigte von Körperschaften, Anstalten oder Stiftungen des öffentlichen Rechts,

- satzungsmäßige Mitglieder geistlicher Genossenschaften und Angehörige ähnlicher Gemeinschaften,

- Lehrer oder Erzieher an nicht-öffentlichen Schulen oder Anstalten.

Die Berechnung der Beiträge erfolgt - anders als vor der Rentenreform 1992 - nach den Vorschriften, die im Zeitpunkt der Zahlung der Beiträge für versicherungspflichtige Beschäftigte gelten, ${ }^{247}$ ein Hinauszögern der Beitragszahlung bringt also dem Versicherten keine Vorteile mehr. Beitragsbemessungsgrundlage sind die beitragspflichtigen Einnahmen aus der Beschäftigung im Nachversicherungszeitraum bis zur jeweilig geltenden Beitragsbemessungsgrenze. ${ }^{248}$ Gemäß $\S 181$ Abs. 4 wird die Beitragsbemessungsgrundlage für die Berechnung der Beiträge um den Vomhundertsatz erhöht, um den das vorläufige Durchschnittsentgelt für das Kalenderjahr, in dem die Beiträge gezahlt werden, das Durchschnittsentgelt für das Kalenderjahr, für das die Beiträge gezahlt werden, übersteigt, somit findet also auch hier eine Dynamisierung, entsprechend dem Ansteigen des aktuellen Rentenwerts, statt. Die gezahlten Nachversicherungsbeiträge gelten als rechtzeitig gezahlte Pflichtbeiträge. In besonderen Fällen ist es möglich, unter bestimmten Voraussetzungen zusätzlich die Nachzahlung freiwilliger Beiträge für zurückliegende Zeiträume, sogenannte Sondernachzahlungen, vor-

\footnotetext{
${ }^{243}$ Vgl. § 7 Abs. 2 SGB VI.

${ }^{244}$ Vgl. § 167 SGB VI.

${ }^{245}$ Vgl. § 8 Abs. 1 SGB VI.

${ }^{246} \mathrm{Vgl}$. 8 Abs. 2 SGB VI.

${ }^{247} \mathrm{Vgl}$. § $181 \mathrm{Nr}$. 1 SGB VI.

${ }^{248}$ Vgl. § 181 Nr. 2 SGB VI.
} 
zunehmen. Beispielhaft soll hier die Nachzahlung wegen Heiratserstattung angeführt werden. Bis Ende des Jahres 1967 konnten sich weibliche Versicherte aus Anlaß einer Eheschließung die von ihnen bis dahin gezahlten Rentenversicherungsbeiträge erstatten lassen. Da mit der Heirat unmittelbar der Anspruch auf Hinterbliebenenversorgung entstand, wurde der von den Frauen erworbene eigene Rentenanspruch obsolet, zumal die Voraussetzungen des Rentenbezugs im Alter in den seltensten Fällen erworben und die Aufgabe der Erwerbstätigkeit bei Eheschließung üblich war, so daß die Rentenanspruche verloren gegangen wären. Zudem war die Heiratserstattung eine willkommene Starthilfe, um den neugegründeten Haushalt aufzubauen. Diese Heiratserstattung wurde dann jedoch abgeschafft, weil sie den Veränderungen bei der Erwerbstätigkeit verheirateter Frauen in den sechziger Jahren nicht mehr entsprach. Um den Frauen, die sich ihre Beiträge erstatten ließen, die Möglichkeit einer Korrektur ihrer Entscheidung einzuräumen, und ihnen damit die Wiederherstellung einer annähernd lückenlosen Versicherungsbiographie zu ermöglichen, konnten weibliche Versicherte zu verhältnismäßig günstigen Bedingungen für den Erstattungszeitraum Beiträge nachzahlen. Von 1992 bis zum 31.12.1995 entfielen sogar die bis dato geltenden Voraussetzungen einer versicherungspflichtigen Beschäftigung im Zeitpunkt der Nachzahlung sowie der Nachweis einer mindestens zweijährigen Pflichtbeitragszeit, so daß auch Hausfrauen von der Regelung Gebrauch machen konnten. Die Nachzahlung wegen Heiratserstattung ist ab 1.1.1996 abgeschafft worden. ${ }^{249}$ Die Nachzahlungsmöglichkeit war aber gerade in den letzten Jahren besonders attraktiv, weil die nachgezahlten Beträge nach den Maßstäben des Jahres bewertet wurden, für das die Beiträge gezahlt wurden (FÜR-PRINZIP). Diese aus sozialpolitischen Gründen geschaffene Privilegierung von Frauen widerspricht dem Versicherungsprinzip und belastete zudem die GRV in nicht unerheblichem Umfang.

Im Jahre 1995 betrugen die gesamten Beitragseinnahmen ${ }^{250}$ der ArV und AnV rd. 225,3 Mrd. DM, davon entfielen 126,7 Mrd. DM auf die AnV und 98,6 Mrd. DM auf die ArV. Das Beitragsaufkommen aus Pflichtbeiträgen betrug in beiden Versicherungszweigen 204,8 Mrd. DM (87,7 Mrd. ent-

\footnotetext{
${ }^{249}$ Vgl. § 282 SGB VI.

${ }^{250}$ Die folgenden Zahlen sind entnommen aus Genzke, J., a.a.O., S. 163.
} 
fielen auf die ArV, 117,1 Mrd. auf die AnV), die freiwilligen Beiträge lagen bei rd. 3,3 Mrd. DM. Hier ist interessant, daß ein Anstieg gegenüber dem Vorjahr von 0,2 Mrd. DM zu verzeichnen war. Dieser Anstieg wird im wesentlichen darauf zurückgeführt, daß von dem besonderen Angebot, früher erstattete Beiträge (Heiratserstattung) nachzuzahlen, in großem Umfang Gebrauch gemacht worden ist.

Die zunehmende Zahl von Arbeitslosen einerseits und eine neue Berechnungsgrundlage $^{2 s 1}$ andererseits führte zu einem Anstieg der Beitragszahlungen der Bundesanstalt für Arbeit um ca. $103 \%$ auf 13 Mrd. DM. Auch die Beiträge von Krankengeldzahlungen sind wegen einer geänderten Berechnungsbasis um rd. $30 \%$ auf 2,7 Mrd. DM gestiegen. Das Beitragsaufkommen für Pflegepersonen belief sich auf rd. 0,5 Mrd. DM. Insgesamt betrug der Anteil der Beitragseinnahmen an den Gesamteinnahmen der GRV rd. 81,8\%.

\subsection{BundeszuschuB}

Neben den Beiträgen der versicherungspflichtigen Mitglieder der GRV zählt der laufende Zuschuß aus dem allgemeinen Steueraufkommen zu den wesentlichen Finanzierungsmitteln dieses Sozialversicherungszweiges, denn einerseits hat er eine nicht unbeträchtliche Höhe (1995: 46,8 Mrd. DM), andererseits können durch Variationen der Höhe dieses Zuschusses Liquiditätsengpässe schneller und einfacher ausgeglichen werden. Rechtsgrundlage für die Zahlung des Bundeszuschusses ist Art. 120 I 4 GG, wonach der Bund einen Zuschuß zu den Ausgaben der Arbeiterrenten- und Angestelltenversicherung zu leisten hat, sofern diese nicht Leistungen der Alterssicherung sind.

Zu nennen wären beispielsweise die Berufs- und Erwerbsunfähigkeitsrenten, die Leistungen im Rahmen der Hinterbliebenenversorgung, sowie die Rehabilitationsmaßnahmen. Diese Aufwendungen sollten nicht allein der Versichertengemeinschaft aufgebürdet

\footnotetext{
${ }^{251}$ Die Beiträge werden auf Basis von $80 \%$ des der Leistung zugrundegelegten Bruttoentgelts gezahlt.
} 
werden, da die Leistungen zum Teil dem sozialen Ausgleich dienten und andererseits öffentliche Aufgaben erfüllten ${ }^{252}$.

In erster Linie wurde die Einführung des Bundeszuschusses allerdings mit der Abgeltung der der Versichertengemeinschaft aufgebürdeten Kriegsfolgelasten begründet, wozu vor allem Kriegsfolgerenten, die Anrechnung von Ersatzzeiten und die kriegsbedingten Beitragsausfälle gehören ${ }^{253}$. Infolgedessen stellen nach allgemeiner Auffassung die staatlichen Zahlungen keine echten Zuschüsse dar, sondern tragen eher den Charakter von Erstattungen für die versicherungsfremden Leistungen der Träger der GRV ${ }^{2 s 4}$.

Während die Begründung und die Festsetzung des Zuschusses für 1957 (es wurden 31,9 \% der Ausgaben der Arbeiter- und Angestelltenrentenversicherung gedeckt) kaum Probleme aufwarfen, erwies sich das eingeführte Verfahren der Dynamisierung des Zuschusses als problematisch, denn die gesetzliche Fixierung forderte eine jährliche Veränderung im Ausma B der Erhöhung der allgemeinen Bemessungsgrundlage ${ }^{255}$. Dies bedeutete, "daß die Steigerung des Bundeszuschusses in dem Maße erfolgt, in dem zugleich auch die Renten erhöht wurden." 256

Die Rentenerhöhungen aufgrund steigender allgemeiner Bemessungsgrundlage waren jedoch mit zunehmender Zeit nicht der Hauptfaktor, der die Ausgaben der Rentenversicherungsträger steigerte, vielmehr waren Leistungsausweitungen und die steigende Zahl der Rentner für erhebliche Ausgabensteigerungen verantwortlich und diese müssen dann ausschließlich durch die Masse der Beitragszahler finanziert werden, deren Anzahl zudem noch rückläufig ist ${ }^{257}$. Insofern wurde 1978 eine neue Regelung konzipiert, deren Kern darin bestand, daß für die jährliche Fortschreibung des Bundeszuschusses die im Jahre 1977 für die Ermittlung der allgemeinen Bemes-

${ }^{252}$ Vgl. Jantz, K. und H. Zweng, Kommentar zu den Gesetzen zur Neuregelung des Rechts der Rentenversicherung der Arbeiter und der Rentenversicherung der Angestellten, Stuttgart 1957, S. 221.

${ }^{253}$ Vgl. Hoffmann, K., Die Stabilität des Bundeszuschusses zur gesetzlichen Rentenversicherung, in: Die Angestelltenversicherung, 29. Jg. (1982), S. 403.

${ }^{254}$ Vgl. Sozialenquête-Kommission, Soziale Sicherung in der Bundesrepublik Deutschland, Stuttgart u.a.O. 1966, S. 94.

${ }^{255}$ Vgl. § 1389 RVO.

${ }^{256}$ Döring, Diether, Das System der gesetzlichen Rentenversicherung, Frankfurt/Main, New York 1980, S. 115.

${ }^{257}$ Vgl. Döring, D., a.a.O., S. 116. 
sungsgrundlage neu geregelte Veränderungsrate gültig war. Danach sollte sich der Zuschuß "jährlich um den Vomhundertsatz verändern, um den sich die Summe der durchschnittlichen Bruttoarbeitsentgelte in den drei Kalenderjahren vor dem Jahr, für das der Bundeszuschuß ermittelt wird, gegenüber der Summe dieser Entgelte in dem Dreijahreszeitraum, der ein Jahr vorher endet, verändert."258

Seit 1.1.1979 erstattet der Bund zudem dem Rentenversicherungsträger die Aufwendungen für die von ihnen gezahlten Kinderzuschüsse bis zur Höhe des allgemeinen Kindergeldes nach dem Bundeskindergeldgeset ${ }^{259}$.

Mit Inkrafttreten des RRG 1992 wurde diese Erstattungspflicht aufgehoben zugunsten einer Erhöhung des Bundeszuschusses "um die Aufwendungen, ... die den Trägern der Rentenversicherung der Arbeiter und der Angestellten im Jahre 1991 aus der Anrechnung von Zeiten der Kindererziehung ... entstehen ${ }^{260}$.

Ebenfalls seit 1992 gilt eine Neuregelung bei der Berechnung des Bundeszuschusses. Neben der Steigerung der Bruttoentgelte im vorvergangenen Jahr wird auch die Änderung beim Beitragssatz im laufenden Jahr berücksichtigt. Dies führte dazu, daß der Rückgang des Beitragssatzes von 19,2\% im Jahre 1994 auf 18,6 \% im Jahre 1995 bedeutete eine Minderung beim Bundeszuschuß um ca. 3,1\%. Die aufgrund der ungünstigen finanziellen Entwicklung im Verlauf des Jahres 1995 beschlossene Anhebung des Beitragssatzes auf 19,2\% für das Jahr 1996 läßt somit automatisch auch den Bundeszuschuß wieder ansteigen.

Von 31,9 \% der Rentenausgaben im Jahre 1957 hat sich der Bundeszuschuß um 42,9\% auf einen Anteil von 18,2 \% im Jahre 1995 verringert. Diese Zahlen lassen erkennen, daß sich der Bund in zunehmend stärkeren Maße aus der Finanzierung der Rentenversicherung zurückgezogen hat, bedingt dadurch, daß die Kriegsfolgelasten rückläufig waren. Zur Lösung der finanziellen Probleme wurden in der Vergangenheit in erster Linie die Beiträge erhöht und so die Arbeitnehmer und ihre Unternehmen verstärkt belastet.

\footnotetext{
${ }^{258}$ Müller-Heine, Karin, a.a.O., S. 100.

${ }^{259}$ Vgl. § 291 SGB VI i.V. mit der Kindererziehungszeiten-Erstattungsverordnung.

${ }^{260} \S 287$ Abs. 4 RRG.
} 
Der Rückzug des Bundes aus der Finanzierung der Rentenversicherung läßt vor dem Hintergrund der zu erwartenden weiter auswachsenden finanziellen Schwierigkeiten die Diskussion um die Rechtfertigung eines Bundeszuschusses immer wieder aufflammen. Insbesondere die Höhe des Bundeszuschusses in der Zukunft steht hier zur Debatte.

Argumente gegen eine Erhöhung des Bundeszuschusses verweisen auf das der Rentenversicherung zugrundeliegende Versicherungsprinzip und bestehen mehr oder weniger auf dessen Einhaltung. Die Zuführung von Finanzmitteln höhle das Versicherungsprinzip aus und gefährde die beitragsbezogene Rente. Außerdem verschleiere es nur die tatsächlichen Kosten des Systems und ändere nichts an der Gesamtlast, die von der jeweiligen erwerbstätigen Generation zu zahlen sei und insgesamt tragbar sein müsse. Letztlich wird die Frage gestellt, ob bei zunehmenden Zuschüssen aus Steuermitteln nicht die Gefahr wachse, daß schleichend ein steuerfinanziertes Grundsicherungssystem eingeführt werden könne.

Demgegenüber sprechen jedoch auch gewichtige Gründe dafür, den Bundeszuschuß zur Rentenversicherung zu erhöhen bzw. zumindest in der gegenwärtigen Höhe beizubehalten. Neben dem Ausgleich für die zumeist vom Bund konzipierten versicherungsfremden Leistungen, sei es auch eine Verpflichtung des Bundes, die Funktions- und Leistungsfähigkeit der Rentenversicherung aufrechtzuerhalten. ${ }^{261}$ Begründet wird dies gemeinhin mit der Haftung des Bundes als Organisator der gesetzlichen Rentenversicherung.

So stellte das Bundesverfassungsgericht fest, "daß die Bundeszuschüsse nicht etwa reine Subventionen des Staates für die Versichertengemeinschaft sind, sondern daß hierin zumindest auch ein Ausgleich für die der Versichertengemeinschaft aus Gründen des Allgemeinwohls auferlegten öffentlichen Last liegt"262, so daß dieser im gegenwärtigen System unverzichtbar sei.

\footnotetext{
${ }^{261}$ Vgl. Ruland, F., Die Verpflichtungen des Bundes gegenüber der Rentenversicherung, in: Wirtschaftsdienst 12/1987, S. 611 .

${ }^{262}$ BVerfGE 54, 11(30).
} 
Tabelle 18: Allgemeiner BundeszuschuB in \% der Rentenausgaben

\begin{tabular}{|c|c|}
\hline Jahr & ArV + AnV1 \\
\hline 1957 & 31,9 \\
\hline 1958 & 29,6 \\
\hline 1959 & 29,0 \\
\hline 1960 & 28,8 \\
\hline 1961 & 27,8 \\
\hline 1962 & 27,4 \\
\hline 1963 & 27,5 \\
\hline 1964 & 27,0 \\
\hline 1965 & 26,1 \\
\hline 1966 & 25,2 \\
\hline 1967 & 24,1 \\
\hline 1968 & 21,2 \\
\hline 1969 & 19,8 \\
\hline 1970 & 18,6 \\
\hline 1971 & 18,5 \\
\hline 1972 & 20,6 \\
\hline 1973 & 15,0 \\
\hline 1974 & 18,7 \\
\hline 1975 & 18,3 \\
\hline 1976 & 17,9 \\
\hline 1977 & 17,5 \\
\hline 1978 & 17,9 \\
\hline 1979 & 18,1 \\
\hline 1980 & 19,3 \\
\hline 1981 & 16,3 \\
\hline 1982 & 18,1 \\
\hline 1983 & 17,5 \\
\hline 1984 & 17,9 \\
\hline 1985 & 17,8 \\
\hline 1986 & 17,7 \\
\hline
\end{tabular}




\begin{tabular}{|c|c|}
\hline Jahr & ArV + AnV1 \\
\hline 1988 & 17,3 \\
1989 & 17,1 \\
1990 & 17,0 \\
1991 & 17,7 \\
1992 & 17,4 \\
1993 & 17,3 \\
1994 & 18,8 \\
1995 & 18,2 \\
\hline
\end{tabular}

1) ohne Zeiten der Kindererziehung

Auch das Bundessozialgericht kommt zu dem SchluB, daB die Zuschüsse des Bundes über die Frage einer finanzverfassungsrechtlichen Zuordnung einer Soziallast hinaus auch eine Verpflichtung aus dem Sozialstaatsprinzip sind, und sich als Konkretisierung der Sozialstaatsklausel in Art. 120 I GG widerspiegeln. Ein über den reinen Risikoausgleich hinausgehender sozialer Ausgleich innerhalb der Solidargemeinschaft kann nur gesamtgesellschaftlich vollzogen werden. Mit dem Sozialversicherungsbeitrag allein kann kein sozialer Ausgleich innerhalb der Versichertengemeinschaft finanziert werden, da dies ein klarer Verstoß gegen das Versicherungsprinzip wäre. Da die Sozialversicherung anders als die privat organisierte Versicherung auch die Aufgabe eines sozialen Ausgleichs zu erfüllen hat, ist die Beteiligung der Allgemeinheit daran sinnvoll. Nur so können auch Bezieher höherer Einkommen, die nicht Mitglied der Sozialversicherung sind, daran beteiligt werden. Andererseits kann innerhalb des Kreises der Versicherten eine soziale Umverteilung als Folge der bis zur Beitragsbemessungsgrenze einkommensproportionalen Beiträge besser als eine verstärkte Beteiligung am allgemeinen Steueraufkommen erreicht werden, weil wegen des hohen Anteils indirekter Steuern und der Aushöhlung der Steuerbemessungsgrundlage der Einkommen- und Körperschaftsteuer für Bezieher hoher Einkommen durch unangemessen hohe Steuervergünstigungen eine regressive Steuerlastverteilung besteht. Die ab 1998 vorgenommene Erhöhung der Mehrwertsteuer um einen Prozentpunkt, die die sonst notwendige Erhöhung des Beitragssatzes vermeiden soll, macht diesen Zusammenhang deutlich. 


\subsection{Finanzausgleich}

Während der Bund nach der Finanzverfassung an dem weitaus größten Teil der Gesetzgebung zumindest beteiligt ist, besitzen Länder und Gemeinden überwiegend die Verwaltungskompetenz. Das erfordert eine Aufteilung der Finanzierungsmittel auf die verschiedenen Ebenen, die im Finanzausgleich erfolgt.

In der Finanzwissenschaft wird zwischen einem Finanzausgleich im weiteren und engeren Sinn unterschieden. Der Finanzausgleich im weiteren Sinn regelt die Verteilung der Aufgaben, die sich daraus ergebenden Ausgaben und die Möglichkeiten der Einnahmenbeschaffung (Beschaffung eigener Einkommen der Gebietskörperschaften wie z.B. Steuern, Beiträge), während sich der Finanzausgleich im engeren Sinn auf die Betrachtung der Finanztransfers beschränkt. Auf letzteres wird in der Sozialversicherung das Hauptaugenmerk geworfen und dieses um so mehr, seitdem die finanzielle Lage der Sozialversicherungsträger sich von Jahr zu Jahr verschlechtert.

Angestrebte Allokations- und Distributionsziele werden möglicherweise dadurch verfehlt, dieses ist um so weniger tolerierbar, als eine schlechte Nutzung von Ressourcen einen unnötigen gesellschaftlichen Wohlstandsverlust bedeutet.

Finanzausgleichsmaßnahmen finden sich im System der Sozialen Sicherung immer dann, wenn die Aufgaben der Sicherung von mehreren zuständigen Trägern und Institutionen wahrgenommen werden. Im folgenden sollen lediglich die innerhalb der Rentenversicherung vorherrschenden Formen sowie das Ausmaß des gegenwärtig praktizierten Finanzausgleichs untersucht werden. $\mathrm{Zu}$ unterscheiden sind zwei Ebenen des Finanzausgleichs:

1. Der Finanzausgleich zwischen dem Bund und den Trägern der Sozialversicherung.

2. Der Finanzausgleich zwischen den Trägern der Sozialversicherung untereinander.

Der Finanzausgleich zwischen dem Bund und der gesetzlichen Rentenversicherung erfolgt in Form des Bundeszuschusses, der - wie oben ausgeführt - einen Ausgleich für die der Rentenversicherung vom Staat auferlegten versicherungsfremden Leistungen darstellt. Die zwischen den einzelnen 
Trägern der Rentenversicherung existierenden Finanzströme können in drei verschiedenen Arten unterteilt werden: ${ }^{263}$

1. Da die Arbeiterrentenversicherung in Landesversicherungsanstalten gegliedert ist, die jeweils aufgrund landesspezifischer Gegebenheiten eine Lücke zwischen Beitragsaufkommen und Auszahlungsbetrag aufweisen können, erfolgt im Rahmen eines Liquiditätsausgleichsverfahrens die vollkommene Angleichung von Beitragsaufkommen und Leistungsarten so, als ob es nur eine in sich homogene Bundesanstalt gäbe. Damit soll jeder Landesanstalt garantiert werden, daß Einnahmen und Ausgaben die gleiche Relation aufweisen.

2. Ein weiterer Liquiditätsausgleich wird zwischen der zentral organisierten Rentenversicherung der Angestellten (AnV) und den Arbeiterrentenversicherung (ArV) vorgenommen. Um der Tatsache Rechnung zu tragen, daß eine Veränderung in der Erwerbstätigenstruktur stattfindet - der Wechsel vom Arbeiter- zum Angestelltenstatus nimmt ständig zu - gibt es seit dem Jahre 1969 diesen direkten Finanzausgleich zwischen den beiden Versicherungszweigen. Theoretisch soll dieser Liquiditätsausgleich in beide Richtungen erfolgen, faktisch ist aber seit Bestehen dieser Einrichtung lediglich ein Finanzstrom von der AnV zur ArV zu verzeichnen, der ständig anwächst. Ursächlich dafür sind zum einen die sinkende Anzahl von Personen in der ArV, zum anderen die niedrigeren Einkommen der Arbeiter gegenüber den Angestellten, so daß insgesamt ein geringeres Beitragsaufkommen als in der AnV erzielt wird.

3. Eine Sonderstellung nimmt die Knappschaftliche Rentenversicherung (KnRV) ein, sie kann aufgrund anderer Beitragssatzmodalitäten, anderer Leistungsvoraussetzungen und nicht zuletzt wegen der großen strukturellen Probleme des Umbruchs in diesem Sektor, nur schwer in die Regelungen des Liquditätsausgleichs, der AnV und ArV eingebunden werden. Gleichwohl existiert auch in diesem Versicherungszweig ein Liquiditätsausgleich, der allerdings im Laufe der vergangenen Jahre unterschiedlich begründet wurde. Der sogenannte Wanderungsausgleich wurde eingeführt,

${ }^{263}$ Vgl. Mackscheidt, Klaus, Finanzausgleichsmaßnahmen zwischen dem Bund und den Träger der Sozialen Sicherung und zwischen den Trägern der Sozialen Sicherung untereinander, in: Schmidt, Kurt (Hrsg.), Finanzierungsprobleme der sozialen Sicherung I, Schriften des Vereins für Socialpolitik Band 194/I, Berlin 1990, S. 149. 
weil in der KnRV Beitragszahler ausfielen und demzufolge die Einnahmen zurückgingen, während in der $\mathrm{ArV}$ und $\mathrm{AnV}$ in den sechziger und siebziger Jahren die Zahl der Beitragszahler ständig zunahm, so daß sich die Beitragseinnahmen erhöhten, ohne daß zu diesem Zeitpunkt schon Leistungen eingefordert wurden. Daneben gibt es den Wanderversicherungsausgleich zwischen der KnRV und den beiden anderen Versicherungszweigen. Hat ein Versicherter Versicherungsbeiträge an zwei oder mehrere verschiedene Versicherungsträger geleistet, bekommt er üblicherweise von derjenigen Institution seine Rente ausbezahlt, bei der er zuletzt versichert war, selbstverständlich unter Anrechnung aller erworbenen Ansprüche. In der $\mathrm{KnRV}$ ist dies anders, bei ihr wird nach Erfüllen der kleinen Wartezeit von 60 Monaten, die gesamte Rentenauszahlung fällig, auch wenn der Versicherte zwischenzeitlich in der ArV oder AnV pflichtversichert ist, weil er nicht mehr im Bergbau tätig ist. Die Rentenansprüche, die diese ehemaligen Bergleute erworben haben, werden der KnRV im Rahmen des Wanderversicherungsausgleichs überwiesen.

Die AnV hatte gemäß der Finanzausgleichsregelung auch 1995 Zahlungen an die Träger der ArV zu leisten. Nach § 218 SGB VI hat die AnV die Schwankungsreserve der Träger der ArV insgesamt auf einen Betrag von 0,5 Monatsausgaben zu eigenen Lasten aufzufüllen, solange ihre eigene Schwankungsreserve einen entsprechend berechneten Wert von 0,5 Monatsausgaben überschreitet. Vor 1992 lag der entsprechende Grenzwert noch bei 1,5 Monatsausgaben bezogen auf das Vorjahr.

Die einzelnen Jahresbeträge ab 1974 können der folgenden Tabelle entnommen werden, dort wird auch ersichtlich, daß seit 1974 mehr als 215 Mrd. DM im Rahmen des Finanzverbundes zwischen den Rentenversicherungsträgern an die ArV in Form liquider Mittel geleistet wurden.

Neben dem rentenversicherungsinternen Finanzausgleich bestehen weitere Beziehungen zur Krankenversicherung und zur Arbeitslosenversicherung.

Anlaß für einen Finanzausgleich zwischen Rentenversicherung und gesetzlicher Krankenversicherung (GKV) war anfänglich die beitragsfreie Versicherung der Rentner in der GKV. 
Tabelle 19: Finanzausgleich der Angestelltenrentenversicherung an die Arbeiterrentenversicherung 1974 - 1995 in Mrd. D M

\begin{tabular}{|c|c|}
\hline Jahr & Ausgleichsbetrag in Mrd. DM \\
\hline 1974 & 2,2 \\
1975 & 10,1 \\
1976 & 13,2 \\
1977 & 13,1 \\
1978 & 10,9 \\
1979 & 7,1 \\
1980 & 5,1 \\
1981 & 6,5 \\
1982 & 7,7 \\
1983 & 10,0 \\
1984 & 5,6 \\
1985 & 9,0 \\
1986 & 9,4 \\
1987 & 6,6 \\
1988 & 8,2 \\
1989 & 8,1 \\
1990 & 5,3 \\
1991 & 5,3 \\
1992 & 6,1 \\
1993 & 21,5 \\
1994 & 20,4 \\
1995 & 24,1 \\
\hline
\end{tabular}

Quelle: Genzke, J., a.a.O., S. 166.

Um die Krankenversicherung zumindest teilweise von den hohen Kosten für einen Rentner zu entlasten, errechnete die Rentenversicherung einen ZuschuB pro Rentner, indem sie einen durchschnittlichen Beitragssatz von $11,7 \%$ (in 1980) zugrundelegte, den sie auf die Rentensumme anwendete. Eine volle Entlastung der GKV wurde damit jedoch keineswegs bewirkt, da der durchschnittliche Beitragssatz nicht ausreichte, um das höhere Krankheitsrisiko eines Rentners abzudecken. Seit dem 1. Juli 1983 gibt es 
einen eigenen Krankenversicherungsbeitrag für Rentner, der schrittweise eingeführt wurde, um die Rentenauszahlung nicht von einem Jahr auf das andere so kürzen zu müssen, daß effektive Rentenkürzungen dabei herauskämen, ${ }^{264}$ dieser Anpassungsprozeß war 1987 abgeschlossen. Die Rentenversicherungsträger erstatten außerdem der GKV für überlappende Zeiten Krankengeldzahlungen.

Der eigene Krankenversicherungsbeitrag für Rentner ist sicherlich im Zuge eines erhöhten Wohlstands der älteren Generation - ein erheblicher Anteil der Rentner verfügt noch über weitere Einkommensquellen - und der steigenden Kosten im Gesundheitswesen ein adäquates Mittel auch zur Stärkung der Solidarität zwischen den Generationen. Daß die aktiven Mitglieder der Krankenkassen dennoch in hohem Maße die Ausgaben der Kassen für die Rentner finanzieren, zeigt die folgende Abbildung. Vertreter der Krankenkassen befürchten sogar, daß sich dieser Trend in Zukunft noch verstärken werde, wenn nicht ein gravierender Umbau des Systems der Sozialversicherung schlechthin vorgenommen werde.

Zwischen der Bundesanstalt für Arbeit (BA) und den Trägern der Rentenversicherung besteht seit dem 1. Juli 1978 ein Finanzausgleich in Form der Beitragszahlung für die Leistungsempfänger der Bundesanstalt für Arbeit an die jeweilige Rentenversicherung, wobei die Beiträge so kalkuliert wurden als hätte der Arbeitslose seinen Arbeitslohn in voller Höhe weiterbezogen. Diese Bemessungsgrundlage wurde 1983 geändert, seitdem wurde nicht mehr der ausgefallene Arbeitslohn zur Berechnung herangezogen, sondern das ausgezahlte Arbeitslosengeld.

Die von 1978-1982 praktizierte Regelung des Finanzausgleichs zwischen der Bundesanstalt für Arbeit (BA) und den Trägern der Rentenversicherung belastete die Arbeitslosenversicherung angesichts steigender Arbeitslosigkeit in dieser Zeit zunehmend, so daß sie anfänglich ihr Vermögen abbaute und anschließend auf Bundeszuschüsse angewiesen war. Dies war dann auch Anlaß genug, die geltende Regelung per politischen Beschluß zu ändern. Durch das Haushaltsbegleitgesetz von 1983 wurde versicherungsrechtlich ein alter Zustand wiederhergestellt, denn die Zeiten des Leistungsbezuges wurden wieder Ausfallzeiten (dies waren sie schon vor 1978).

${ }^{264}$ Vgl. Mackscheidt, Klaus, a.a.O., S. 153. 
Abbildung 1:

Beiträge und Leistungen in der Gesetzlichen Krankenversicherung

(Angaben in DM)

ㅁost

\section{$\square$ West}



Ausgaben je aktives Mitglied

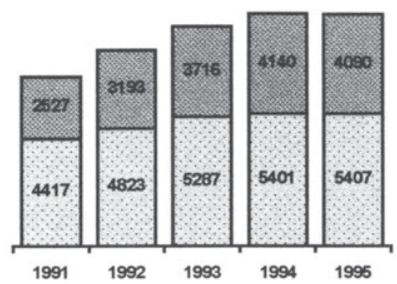

Beiträge je Rentner



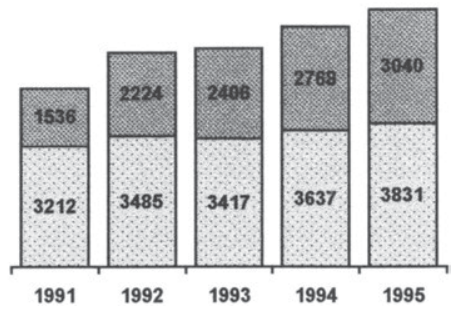

Quelle: Bundesministerium für Gesundheit

Für diese Ausfallzeiten hatte die Bundesanstalt für Arbeit zwar auch weiterhin Beiträge zu zahlen, allerdings lediglich auf der Grundlage der tatsächlich bezogenen Leistung (Arbeitslosengeld, Arbeitslosenhilfe, Unterhaltsgeld). Für den Versicherten bedeutete diese Regelung, daB die Zeiten der Arbeitslosigkeit sich nicht nur in der Erwerbsphase durch ein reduziertes Einkommen negativ auswirkten, sondern auch zu geringer bewerteten 
Zeiten für die Rentenansprüche führten, und somit auch die Höhe der Rente beeinflußten.

Tabelle 20: Die Entwicklung der Einnahmen, der Ausgaben und des Vermögens in der Rentenversicherung der Arbeiter und der Angestellten von 1995 bis 1999

\begin{tabular}{|c|c|c|c|c|c|}
\hline In Mio. DM & 1995 & 1996 & 1997 & 1998 & 1999 \\
\hline $\begin{array}{l}\text { Einnahmen } \\
\text { Darunter: } \\
\text { Beiträge } \\
\text { Bundeszuschuß }\end{array}$ & $\begin{array}{r}338272 \\
274420 \\
59673 \\
\end{array}$ & $\begin{array}{r}357548 \\
291443 \\
62556 \\
\end{array}$ & $\begin{array}{r}374777 \\
\\
305684 \\
65507 \\
\end{array}$ & $\begin{array}{r}393230 \\
321067 \\
68524 \\
\end{array}$ & $\begin{array}{r}415226 \\
\\
339390 \\
72133 \\
\end{array}$ \\
\hline $\begin{array}{l}\text { Ausgaben } \\
\text { Darunter: } \\
\text { Rentenausgaben } \\
\text { Krankenversicherung der } \\
\text { Rentner } \\
\text { Pflegeversicherung der Rentner }\end{array}$ & $\begin{array}{r}344517 \\
296025 \\
19021 \\
1474\end{array}$ & $\begin{array}{r}355003 \\
304916 \\
19280 \\
\\
2056\end{array}$ & $\begin{array}{r}372107 \\
319613 \\
19968 \\
2715\end{array}$ & $\begin{array}{r}392017 \\
337143 \\
21064 \\
2864 \\
\end{array}$ & $\begin{array}{r}411753 \\
354500 \\
22150 \\
3012 \\
\end{array}$ \\
\hline Einnahmen - Ausgaben & -6245 & 2544 & 2670 & 1213 & 3473 \\
\hline $\begin{array}{l}\text { Vermōgen } \\
\text { Schwankungsreserve Jahresen- } \\
\text { de } \\
\text { Änderung gegenüber Vorjahr } \\
\text { Liquide Schwankungsreserve } \\
\text { Schwankungsreservesoll } \\
\text { Schwankungsreserve in Mo- } \\
\text { natsausgaben } \\
\text { Liquide Schwankungsreserve in } \\
\text { Monatsausgaben }\end{array}$ & $\begin{array}{r}25897 \\
-7558 \\
23536 \\
23536 \\
1,10\end{array}$ & $\begin{array}{r}27633 \\
1736 \\
25462 \\
24187 \\
1,14\end{array}$ & $\begin{array}{r}29078 \\
1445 \\
27084 \\
25369 \\
1,15\end{array}$ & $\begin{array}{r}28831 \\
-247 \\
27001 \\
26776 \\
1,08\end{array}$ & $\begin{array}{r}30879 \\
2048 \\
29217 \\
28118 \\
1,10\end{array}$ \\
\hline
\end{tabular}

Quelle: Berntsen/Bloßfeld, a.a.0., S. 22.

Seit der Rentenreform am 1.1.1992 ist die beitragspflichtige Ausfallzeit wieder in eine "echte" Beitragszeit umgewandelt worden, allerdings auch wieder mit verminderter Beitragsbemessungsgrundlage. Während in der Zeit von 1978 bis 1982 das gesamte Bruttoarbeitsentgelt zur Berechnung der Beiträge herangezogen wurde, sind es gegenwärtig nur $80 \%$ des von dem Arbeitslosen vor Beginn der Arbeitslosigkeit bezogenen Bruttoarbeitsentgelts. 
Die Betrachtung der abschließenden Tabellen zeigen, wie sich die Einnahmen und Ausgaben bis 1999 voraussichtlich entwickeln werden, wenn nicht gravierende Veränderungen der konjunkturellen Lage oder externe Schocks auftreten.

Tabelle 21: Die Entwicklung der Einnahmen und der Ausgaben in der Rentenversicherung der Arbeiter und der Angestellten von 1995 bis 1999 - Alte Bundesländer -

\begin{tabular}{|c|c|c|c|c|c|}
\hline & \multicolumn{5}{|c|}{ In den alten Bundesländern } \\
\hline & 1995 & 1996 & 1997 & 1998 & 1999 \\
\hline $\begin{array}{l}\text { Entwicklung der Entgelte in Prozent } \\
\text { Entwicklung der Versichertenzahl } \\
\text { in Prozent } \\
\text { Anzahl der Arbeitslosen in } 1000 \\
\text { KVdR-Zuschuß in Prozent }\end{array}$ & $\begin{array}{r}3,5 \\
0,48 \\
2456 \\
6,6 \\
\end{array}$ & $\begin{array}{r}3,5 \\
0,95 \\
2256 \\
6,4 \\
\end{array}$ & $\begin{array}{r}3,5 \\
0,85 \\
2160 \\
6,4 \\
\end{array}$ & $\begin{array}{r}3,5 \\
0,84 \\
2060 \\
6,4 \\
\end{array}$ & $\begin{array}{r}3,5 \\
0,85 \\
1980 \\
6,4 \\
\end{array}$ \\
\hline \multicolumn{6}{|l|}{ Einnahmen in Mio. DM } \\
\hline Beitragseinnahmen insgesamt & 228490 & 242745 & 254728 & 267214 & 282106 \\
\hline Bundeszuschuß & 46771 & 48990 & 51236 & 53578 & 56306 \\
\hline $\begin{array}{l}\text { Erstattungen aus öffentlichen Mit- } \\
\text { teln }\end{array}$ & 1224 & 1213 & 1200 & 1200 & 1200 \\
\hline $\begin{array}{l}\text { Erstattungen in Wanderversiche- } \\
\text { rung von KnRV }\end{array}$ & 595 & 599 & 616 & 634 & 650 \\
\hline Vermōgensertrāge & 1550 & 1295 & 1372 & 1401 & 1444 \\
\hline Sonstige Einnahmen & 90 & 0 & 0 & 0 & 0 \\
\hline Einnahmen insgesamt & 278720 & 294841 & 309151 & 324028 & $3+1706$ \\
\hline \multicolumn{6}{|l|}{ Ausgaben in Mio. DM } \\
\hline $\begin{array}{l}\text { Zuschüsse zur Krankenversicherung } \\
\text { der Rentner }\end{array}$ & 14930 & 15028 & 15494 & 16342 & 17158 \\
\hline Beiträge zur Pflegeversicherung & 1157 & 1608 & 2120 & 2236 & 2349 \\
\hline Rehabilitationsmaßnahmen & 8050 & 8332 & 8623 & 8926 & 9238 \\
\hline $\begin{array}{l}\text { Erstattungen in Wanderversiche- } \\
\text { rung an KnRV }\end{array}$ & 5662 & 5705 & 5852 & 6032 & 6180 \\
\hline Wanderungsausgleich & 519 & 591 & 674 & 756 & 841 \\
\hline KLG-Leistungen & 2475 & 2312 & 2172 & 2043 & 1900 \\
\hline Beitragserstattungen & 445 & 425 & 425 & 425 & 425 \\
\hline Verwaltungs- und Verfahrenskosten & 4775 & 4980 & 5192 & 5414 & 5645 \\
\hline Sonstige Ausgaben & 48 & $\mathbf{0}$ & $\mathbf{0}$ & 0 & 0 \\
\hline Ausgaben insgesamt & 269596 & 277282 & 290074 & 305346 & 320049 \\
\hline Einnahmen - Ausgaben & 9124 & 17559 & 19078 & 18682 & 21658 \\
\hline
\end{tabular}

Quelle: Berntsen/Bloßfeld, a.a.O., S. 23. 
Tabelle 22: Die Entwicklung der Einnahmen und der Ausgaben in der Rentenversicherung der Arbeiter und der Angestellten von 1995 bis 1999 - Neue

Bundesländer -

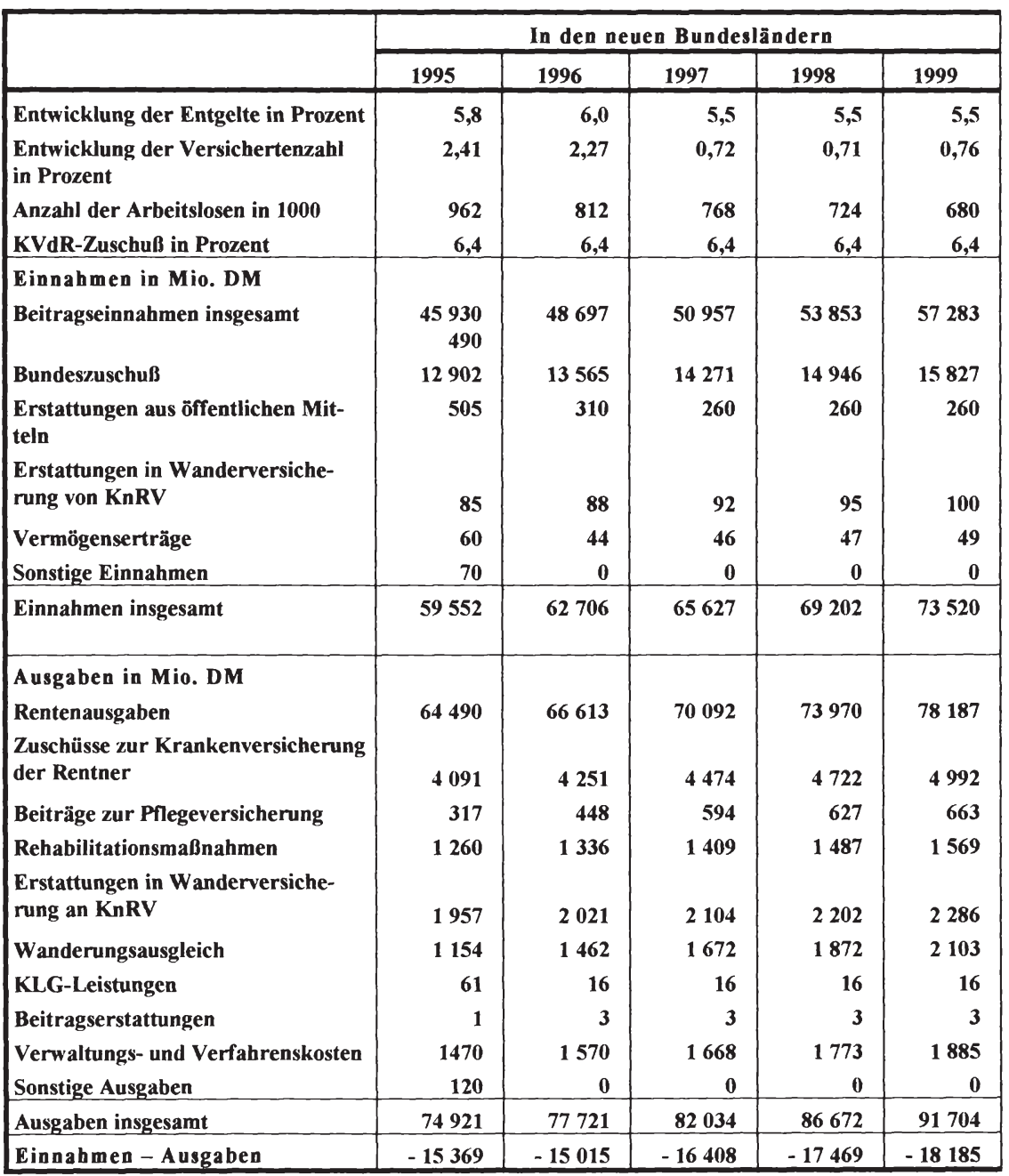

Quelle: Berntsen/Bloßfeld, a.a.O., S. 23. 


\section{Teil B: Die Stellung der Frau in der gesetzlichen Ren- tenversicherung}

1. Erwerbstätigkeit als grundsätzliche Voraussetzung einer eigenständigen Sicherung

Die Stellung der Frau im System der sozialen Sicherung und insbesondere im Bereich der Rentenversicherung hat sich spätestens seit dem Verfassungsgerichtsurteil vom 12. März $1975^{265}$ zu einem in Wissenschaft und Politik heftig diskutierten Dauerthema entwickelt. Die Ursachen realer Defizite in der sozialen Sicherung von Frauen liegen einerseits in der Ausgestaltung des sozialen Sicherungssystems, andererseits in veränderten individuellen Verhaltensweisen, wie z.B. einer vermehrten Scheidungshäufigkeit, die teilweise erst in den letzten Jahren an Bedeutung gewannen.

Die Sozialversicherung knüpft an ein Beschäftigtenverhältnis an, d.h. die erwerbstätige Frau kann unabhängig von ihrem Familienstand als abhängig Beschäftigte einen direkten, eigenständigen Rentenanspruch erwerben, sie ist damit gegen Arbeitsunfähigkeit gleich welcher Art gesichert, sei es wegen Invalidität oder Alter. Die soziale Sicherung der erwerbstätigen Frau erweist sich insofern als relativ unproblematisch, da sie rechtlich dem Manne gleichgestellt ist. Bezogen auf das System der GRV bedeutet dies nichts anderes als das Versicherungspflicht und Rentenberechtigung an eine ausgeübte Erwerbstätigkeit anknüpfen, die zudem noch entgeltlich betrieben werden muß. Es gelten für Männer und Frauen grundsätzlich die gleichen gesetzlichen Bestimmungen:

- es müssen Beiträge entrichtet worden sein,

- es muß eine Mindestwartezeit erfüllt sein, die je nach Art der beanspruchten Rente unterschiedlich ist,

- die jeweilige Höhe der Rente ergibt sich aus der Rentenformel,

- die Rente wird jährlich gemäß der Nettolohnentwicklung erhöht.

${ }^{265}$ Urteil des Bundesverfassungsgerichts zur Gleichbehandlung von Männern und Frauen in der Hinterbliebenenversorgung. 
Jeder unselbständige Erwerbstätige ist also in das System sozialer Sicherung eingebunden. Anders sieht es bei Nichterwerbstätigen und Selbständigen aus, sie sind entweder nicht in das soziale Sicherungssystem eingebunden oder als nichterwerbstätige Ehepartner eines abhängig Beschäftigten nur akzessorisch gesichert, d.h. sie sind nur gegen den Ausfall von Unterhaltsleistungen gesichert. Die Versichertenrente hat somit eine Lohnersatzfunktion, die Hinterbliebenenrente oder abgeleitete Rente demgegenüber eine Unterhaltsersatzfunktion, wobei sich die Höhe der Versichertenrente am im Lebenszyklus erzielten eigenen Einkommen orientiert, die Hinterbliebenenrente jedoch an dem Einkommen des verstorbenen Ehepartners.

Da der Gesetzgeber davon ausgegangen ist, daß unterschiedliche Ursachen für einen Einkommensausfall auch unterschiedliche Leistungen bedingen - insofern hat er sich am Kausalprinzip orientiert - ist es zu einem Nebeneinander von Versicherten- und Hinterbliebenenrenten gekommen (Rentenkumulation). Er hat allerdings erkannt, daß der gleichzeitige Bezug beider Renten teilweise zu unbefriedigenden Ergebnissen führt und deshalb wird ab 1. Januar 1986 ein Teil der Hinterbliebenenrente auf die Versichertenrente angerechnet. Im Grenzfall kann sie sogar vollständig gekürzt werden, was bei Männern häufig der Fall ist. Fällt das Einkommen weg, kommt erneut die Hinterbliebenenversorgung zum Tragen. ${ }^{266}$ Für die nichterwerbstätige Frau ergibt sich aus diesen Regelungen, daß sie keinen eigenen Rentenanspruch erwirbt.

\section{Die freiwillige Versicherung der nicht erwerbstätigen Frau}

Die freiwillige Versicherung in der gesetzlichen Rentenversicherung wurde bis zur Rentenreform 1972 in die "Selbstversicherung“ und die „freiwillige Weiterversicherung“ eingeteilt.

Die Selbstversicherung ermöglichte einer Person, in die gesetzliche Rentenversicherung einzutreten, ohne jemals versichert gewesen zu sein. Diese Öffnung der Rentenversicherung auch für Personenkreise, die nicht unselbständig beschäftigt und damit pflichtversichert waren, wurde erst

${ }^{266}$ Vgl. § 97 SGB VI i.V.m. § 18 d SGB IV und § 48 SGB X. 
durch das Gesetz über den Ausbau der Rentenversicherung vom 21.12.1937 (RGBI. 1937 I S. 1393) in erweitertem Maße möglich. Bis dahin waren die Möglichkeiten der Selbstversicherung sehr begrenzt, um die Rentenversicherung als Arbeitnehmerversicherung zu führen.

Als freiwillige Weiterversicherung wurde die Fortsetzung einer bisherigen Pflichtversicherung durch Entrichtung freiwilliger Beiträge verstanden. Mit der Rentenreform 1972 wurden beide Arten im § 7 SGB VI zusammengefabt und offiziell unter dem Begriff ,freiwillige Versicherung“ erfaBt.

GemäB derzeit gültiger Gesetzgebung können sich alle Personen (Deutsche und Ausländer) freiwillig versichern, die

- das 16. Lebensjahr vollendet haben,

- in keinem Zweig der gesetzlichen Rentenversicherung versicherungspflichtig sind, und

- ihren Wohnsitz oder gewöhnlichen Aufenthalt im Inland haben.

Freiwillig versichern können sich auch Personen, die versicherungsfrei oder von der Versicherungspflicht befreit sind, sofern sie die allgemeine Wartezeit von 5 Jahren erfüllt haben. Ausgenommen sind von dieser Regelung Personen, die wegen geringfügiger Beschäftigung oder als Student versicherungsfrei sind. ${ }^{267}$ Ebenfalls ausgeschlossen sind Rentner, wenn ihnen eine Altersvollrente bewilligt worden ist oder bereits von ihnen bezogen wird ${ }^{268}$ bei Bezug einer Teilaltersrente ist die freiwillige Versicherung zulässig. Um unerwünschte Härten für sogenannte „Altfälle“ $z u$ vermeiden, können auch Versicherte, die nicht pflichtversichert sind und vor dem 1.1.1992 vom Recht der Selbstversicherung, der Weiterversicherung oder der freiwilligen Versicherung Gebrauch gemacht haben, die freiwillige Versicherung weiterführen, auch wenn die Voraussetzungen des § 7 SGB VI nicht vorliegen. ${ }^{269}$

Im April 1994 betrug die Anzahl der freiwillig Versicherten insgesamt 1.962.000 Personen, wovon 1.199.000 männlich und 763.000 weiblich waren. Bezogen auf die Unterscheidung in Arbeiterrentenversicherung und Ange-

\footnotetext{
${ }^{267} \S 5$ Abs. 2 und 3 SGB VI.

${ }^{268} \S 7$ Abs. 3 SGB VI.

$269 \S 232$ SGB VI.
} 
stelltenrentenversicherung ergaben sich folgende Zahlen: Insgesamt waren in der ArV 917.000 Personen und in der AnV 1.035.000 Personen freiwillig versichert. 621.000 Personen waren in der ArV männliche Versicherte und 296.000 weibliche Versicherte, in der AnV waren 570.000 männlich und 465.000 weiblich. ${ }^{270}$

Nach geltendem Recht beträgt die Mindestbeitragsbemessungsgrundlage entsprechend der gültigen Geringfügigkeitsgrenze des $§ 8$ Abs. $1 \mathrm{Nr} .1$ SGB VI 1/7 der Bezugsgröße. Weiterhin gilt das Prinzip der stufenlosen Beitragsberechnung, d.h. Beitragsbemessungsgrundlage ist jeder mögliche Betrag zwischen der Mindestbeitragsbemessungsgrundlage und der Beitragsbemessungsgrenze. ${ }^{271}$ Hinsichtlich der Zahlung gilt, daß freiwillige Beiträge grundsätzlich nur dann wirksam entrichtet werden, wenn sie bis zum 31.3. des Jahres, das dem Jahr folgt, für das sie gelten sollen, gezahlt werden. ${ }^{27}$

In Sonderfällen können auch für zurückliegende Zeiträume freiwillige Beiträge wirksam nachentrichtet werden. Diese Regelung wurde für Personengruppen geschaffen, die als besonders schutzwürdig angesehen werden, wozu auch die Frauen gehören. Es soll ihnen dabei die Möglichkeit eingeräumt werden, nachträglich eine bereits bestehende Rentenanwartschaft zu verbessern bzw. eine noch nicht bestehende zu begründen. Im einzelnen sind für Frauen folgende Nachzahlungsmöglichkeiten relevant:

- Nachzahlung für Ausbildungszeiten (§ 207 SGB VI),

- Nachzahlung für mitarbeitende Familienangehörige (§ 208 Abs. 3 SGB VI),

- Nachzahlung wegen Heiratserstattung (§ 282 SGB VI), ${ }^{273}$

- Nachzahlung bei Heiratsabfindung früherer Beamtinnen (§ 283 SGB VI),

- Nachzahlung im Zuge der Nachversicherung beim Versorgungsausgleich (§ 8 Abs. 1 SGB VI).

\footnotetext{
270 Statistisches Bundesamt (Hrsg.), Statistisches Jahrbuch für die Bundesrepublik Deutschland 1996, Wiesbaden, S. 459.

${ }^{271} \S 167$ und § 159 SGB VI.

$27 \S 197$ Abs. 2 SGB VI.

${ }^{273}$ Galt nur noch bis 31.12.1995.
} 
3. Ursachen für die schlechtere materielle Sicherung der Frau

\subsection{Der geschlechtsspezifische Arbeitsmarkt}

Die Veröffentlichungen des Statistischen Bundesamtes der Bruttojahreseinkommen des Jahres 1996 zeigen - wie in allen Jahren zuvor - die Einkommensunterschiede zwischen Frauen und Männern, am stärksten sind diese bei den Angestellten in der westdeutschen Industrie. Der durchschnittliche Bruttojahresverdienst betrug in diesem Sektor 1996 82.699,-- DM, wobei das Durchschnittseinkommen der Frauen mit 60.049,-- DM um etwa ein Drittel unter dem ihrer männlichen Kollegen, die 90.304,-- DM verdienten, lag. Auch in Ostdeutschland liegen die Löhne und Gehälter der Frauen deutliche unter denen der Männer. Die Gehälter der weiblichen Angestellten bei Handel, Banken und Versicherungen haben sich dabei am weitesten den Westgehältern angenähert, mit durchschnittlich 48.159,-- DM erhielten Frauen bereits $\mathbf{9 0 , 4} \%$ des im Westen gezahlten Lohnes, die Männer erhalten im Durchschnitt jedoch 49.920,-- DM.

Auch die Detailbetrachtung der durchschnittlichen Bruttomonatsverdienste von Angestellten hinsichtlich unterschiedlicher Leistungsgruppen zeigt, daß die männlichen Arbeitnehmer i.d.R. eine höhere Entlohnung haben. Beispielsweise beziehen männliche Angestellte im Bekleidungsgewerbe (früheres Bundesgebiet im Jahre 1994) in der Leistungsgruppe II ein durchschnittliches Einkommen von 7 137,- DM monatlich, Frauen in vergleichbarer Stellung jedoch nur 5 449,- DM. Auch in den unteren Leistungs- und Lohngruppen bleiben diese Unterschiede bestehen (Leistungsgruppe $V$ : Männer 3 533,- DM, Frauen 2 871,- DM). ${ }^{274}$ Nicht ganz so ausgeprägt sind diese Unterschiede im Bereich Elektrizitäts-, Gas-, Fernwärme- und Wasserversorgung (Leistungsgruppe V: Männer 3 591,- DM, Frauen 3 361,DM), gleichwohl bestehen sie auch dort, und stellen sich in den oberen Leistungs- und Lohngruppierungen auch wieder eklatanter dar. Leistungsgruppe II: Männer 7 347,- DM, Frauen 6 388,- DM).

${ }^{274}$ Statistisches Jahrbuch 1995, S. 582f. 
Eine Umkehrung dieser Verhältnisse findet sich nur in wenigen Fällen, so z.B. bei den technischen Angestellten im Versicherungsgewerbe in den höheren Lohngruppen (Männer 6 598,- DM, Frauen 7 223,- DM). Diese statistisch ermittelten Einkommensunterschiede zwischen Frauen und Männern werden immer wieder zum Anlaß genommen, die These von der Diskriminierung der Frau im Erwerbsleben zu untermauern.

Die Existenz von Lohndifferenzen ist unumstritten und führt dann natürlich zu einer vergleichsweise schlechteren materiellen Lage, wenn die Frau in der Familie den Lebensunterhalt überwiegend bestreiten muß. Zudem setzt sich diese "Schlechterstellung" im System der sozialen Sicherung, besonders im Hinblick auf den Erwerb von Rentenansprüchen, fort.

Da Frauen bezüglich der formalen Ausbildung gerade in den letzten Jahren gegenüber den Männern stark aufgeholt haben, scheidet die unterschiedliche Qualifikation als Erklärungsansatz für die andauernde Lohndifferenz weitgehend aus. Um so mehr rückt die von verschiedenen Frauengruppen ständig geführte Diskriminierungsdebatte in den Vordergrund, mit dem Ziel, für Frauen eine besondere Förderung bzw. Bevorzugung auf dem Arbeitsmarkt zu erwirken. Dies ist ihnen teilweise schon gelungen, betrachtet man die Modalitäten einzelner Bundesländer bei der Einstellung von Personal des öffentlichen Dienstes. Dringend ist es also, diese Diskussion zu entemotionalisieren und zu untersuchen, ob tatsächlich eine Diskriminierung der Frauen auf dem Arbeitsmarkt zu erkennen ist und worauf diese dann beruht. Das Wort "Diskriminierung" stammt vom lateinischen "discriminare" ab und bedeutet so viel wie "trennen" und "absondern". Der Duden ${ }^{275}$ erläutert "diskriminieren" mit den Worten "herabsetzen, herabwürdigen, unterschiedlich behandeln". Bezogen auf die hier zu behandelnde Fragestellung läge also eine Diskriminierung vor, wenn Frauen für eine gleich produktive Tätigkeit weniger Lohn erhalten als Männer.

Die Diskussion über die ökonomische Diskriminierung von Frauen ist im übrigen keine Modeerscheinung neuerer Zeit, sondern setzte schon zum Ende des neunzehnten Jahrhunderts mit dem Essay John Stuart Mill's "Die Hörigkeit der Frau" (1869) ein. In dieser Arbeit setzte er sich ausdrücklich

${ }^{275}$ Vgl. Der große Duden, Fremdwörterbuch, Band 5, Mannheim/Wien/Zürich 1971, S. 164. 
für die Verwirklichung der Chancengleichheit beider Geschlechter ein. Frauen und Männer sollten bezüglich ihrer Berufs- und Lebenswege persönliche Wahlfreiheit sowie freien Zugang zu allen Ausbildungen und Berufen haben und unter gleichen Bedingungen frei um berufliche Positionen konkurrieren. Eine geschlechtsspezifische Bezahlung sei deshalb kategorisch abzulehnen, allerdings seien auch spezielle Schutzgesetze für Frauen nicht erforderlich. Die von ihm beobachtete Diskriminierung von Frauen führte Mill vor allem auf die unterschiedlichen gesellschaftlichen Rollen zurück, die in jener Zeit den Frauen und Männern zugewiesen wurden; im übrigen eine immer noch hochaktuelle These. Männer erhielten demzufolge lediglich deshalb eine höhere Entlohnung, weil sie als "Hauptverdiener" und Ernährer der Familie ein höheres Einkommen benötigten, während das Einkommen der Frauen eher den Charakter eines Zusatzverdienstes hätte und deshalb auch geringer ausfallen könne. Neben dieser direkten Ungleichbehandlung von Frauen und Männer sah Mill noch einen weiteren Grund für die ökonomische Diskriminierung der Frau. Da eine Vielzahl von Frauen um die wenigen mit ihrer Rolle zu vereinbarenden Arbeitsplätze konkurrierten, war es den Unternehmern - gemäB dem Gesetz von Angebot und Nachfrage - möglich, Frauen geringer zu bezahlen, ohne daB dies auf unterschiedlichen Arbeitsproduktivitäten beruhte.

In jüngerer Zeit hat der Wirtschaftswissenschaftler und Nobelpreisträger Gary S. Becker dieses Thema in seinem 1957 veröffentlichtem Buch "The Economics of Discrimination" aufgegriffen und Erklärungsansätze für dieses Phänomen erarbeitet. Ausgehend von der zu beobachtenden Rassendiskriminierung stellt er fest, daß ökonomische Benachteiligungen durchaus mit Rationalverhalten der Beteiligten begründet werden kann, wenn unterstellt wird, daß sich eine Mehrheit von Wirtschaftssubjekten ökonomisch besser stellt, wenn derartige Benachteiligungen existieren, als wenn sie fehlen.

Erklärungsansätze für die existierenden Lohndifferenzen sind also durchaus vorhanden und allgemein anerkannt, Probleme ergeben sich häufig erst dann, wenn es um Maßnahmen zur Beseitigung einer diskriminierenden Situation geht, da ideologische Vorstellungen eine sachliche Behandlung der Thematik nachhaltig behindern. 
Ein möglicher Erklärungsansatz für Lohndifferenzen ist die Differenzierung zwischen der horizontalen und vertikalen Segregation, womit die Verteilung von Frauen auf Hierarchiestufen und Berufe gemeint ist. ${ }^{276}$ Die Verteilung der Geschlechter auf die Berufe wird als horizontale Segregation und die Verteilung auf alle Führungsebenen innerhalb der Berufszweige als vertikale Segregation bezeichnet. Beide Arten der Segregation sind gegenwärtig in der BRD anzutreffen. Frauen sind auf den höheren Hierarchiestufen immer noch systematisch unterrepräsentiert, darüber hinaus ist festzustellen, daß es Berufe gibt, die fast ausschließlich von Männern ausgeübt werden, während auf der anderen Seite Frauen sich nur auf eine geringe Anzahl von Berufen konzentrieren.

Tabelle 23: Anteil weiblicher Manager der 1. bis 3. Führungsebene in Unternehmen mit einer Mitarbeiterzahl von 501 - 5000 (nach ausgewählten Branchen / in Prozent)

\begin{tabular}{|c|c|c|c|c|}
\hline & \multirow[b]{2}{*}{ insgesamt } & \multicolumn{3}{|c|}{$\begin{array}{c}\text { Unternehmen mit einer } \\
\text { Mitarbeiterzahl von } 501-5000 \\
\end{array}$} \\
\hline & & Handel & $\begin{array}{l}\text { Chemische } \\
\text { Industrie }\end{array}$ & $\begin{array}{l}\text { Elektro- } \\
\text { Industrie }\end{array}$ \\
\hline 1. Ebene & 2,7 & 5,1 & 0,8 & 3,5 \\
\hline 2. Ebene & 3,3 & 5,3 & 3,3 & 2,3 \\
\hline 3. Ebene & 6,9 & 10,5 & 5,5 & 5,9 \\
\hline
\end{tabular}

Quelle: Hadler, A../Michel E. Domsch, Frauen auf dem Weg in Spitzenpositionen der Wirtschaft? Eine Bestandsaufnahme für die Bundesrepublik Deutschland, in: Aus Politik und Zeitgeschichte, Beilage zur Wochenzeitung Das Parlament, Hrsg. Bundeszentrale für politische Bildung, Bonn 1994, S. 14.

Horizontale Segregation läßt sich auch bei der Wahl des Studienfaches der weiblichen Studenten feststellen, die vom Statistischen Bundesamt erhobenen Daten belegen, daß Mädchen eher geisteswissenschaftliche als naturwissenschaftliche Fächer bevorzugen.

${ }^{276}$ Vgl. M. Osterloh/K. Oberholzer, Der geschlechtsspezifische Arbeitsmarkt: Ökonomische und soziologische Erklärungsansätze, in: Aus Politik und Zeitgeschichte, Beilage 
Tabelle 24: Anteil weiblicher Manager der 1. bis 3. Führungsebene (nach Unternehmensgrößen / in Prozent)

\begin{tabular}{|l|c|c|c|c|}
\hline \multirow{2}{*}{} & \multicolumn{3}{c|}{$\begin{array}{c}\text { Unternehmen mit einer } \\
\text { Mitarbeiterzahl von }\end{array}$} \\
\cline { 2 - 5 } & insgesamt & bis zu 500 & $505-5000$ & $>5000$ \\
\hline 1. Ebene & 2,7 & 4,3 & 1,6 & 0,6 \\
\hline 2. Ebene & 3,3 & 5,4 & 2,5 & 1,1 \\
\hline 3. Ebene & 6,9 & 9,1 & 7,3 & 4,5 \\
\hline
\end{tabular}

Quelle: Hadler, A../Michel E. Domsch, Frauen auf dem Weg in Spitzenpositionen der Wirtschaft? Eine Bestandsaufnahme für die Bundesrepublik Deutschland, in: Aus Politik und Zeitgeschichte, Beilage zur Wochenzeitung Das Parlament, Hrsg. Bundeszentrale für politische Bildung, Bonn 1994, S. 14.

In der Literatur wird eine Unterscheidung in die Diskriminierung im und die Diskriminierung vor dem Arbeitsmarkt vorgenommen. ${ }^{27}$ Eine Diskriminierung im Arbeitsmarkt bzw. eine Diskriminierung im engeren Sinne liegt vor, wenn Frauen bei gleicher Produktivität weniger Lohn für ihre Arbeit erhalten als Männer. Diskriminierung vor dem Arbeitsmarkt bzw. Diskriminierung im weiteren Sinne knüpft an die Möglichkeiten der Berufswahl an, und fragt, ob und wie Frauen daran gehindert werden, in gleicher Weise wie Männer Berufe zu ergreifen, zu nennen sind hier Aspekte wie Vorurteile der Arbeitgeber, gesellschaftlich zugewiesene Rollenverteilung, ungeeignete Infrastruktur zur Betreuung von Kindern u.ä. In der Tat haben Unternehmen in einigen Bereichen bei der Einstellung von Personal starke Präferenzen für Männer. Dieses aber vorrangig wegen des möglicherweise zu erwartenden längeren Ausfalls von Frauen wegen der Geburt von Kindern und der damit verbundenen Kosten.

Eine Diskriminierung im Arbeitsmarkt dürfte es in Deutschland eigentlich nicht geben, da gemäß Artikel 3 des Grundgesetzes eine Benachteiligung wegen des Geschlechts unzulässig ist. Darüber hinaus verbietet das "Gesetz über die Gleichbehandlung von Frauen und Männern am Arbeits-

zur Wochenzeitung Das Parlament, Hrsg. Bundeszentrale für politische Bildung, Bonn 1994, S. 3.

${ }^{277}$ Vgl. M. Osterloh/K. Oberholzer, a.a.O., S. 3. 
platz" eine einkommensmäBige Schlechterstellung von Frauen. Gleichwohl sind Verdienstunterschiede zwischen Männern und Frauen existent, deren wissenschaftlicher Erklärungsansatz u.a. in der Theorie der statistischen Diskriminierung (Gruppendiskriminierung) zusammengefaßt ist.

Ansatzpunkt dieser Theorie ist der Informationsstand und das daraus resultierende Auswahlverfahren eines Unternehmers. Unternehmer kennen i.d.R. die individuellen Arbeitsproduktivitäten männlicher und weiblicher Anbieter nicht, sie können sich lediglich durch Zeugnisse, Biographien oder sonstiger Auswahlverfahren ein Bild von einem Bewerber für einen Arbeitsplatz machen. Unsicherheiten in der Interpretation dieser Auswahlkriterien läßt die Unternehmer häufig auf die durchschnittliche Produktivität homogener Bewerbergruppen zurückgreifen. Da diese statistisch gesehen bei Frauen niedriger ist, fallen sie im Entscheidungsprozeß zwangsläufig heraus. Gibt es nun Frauen, die genauso produktiv sind wie Männer, werden sie statistisch diskriminiert. Diese Diskriminierung kann sowohl eine Lohn- als auch eine Beschäftigungsdiskriminierung sein. Bezieht sich der eben beschriebene Auswahlprozeß auch auf die Vergabe von Ausbildungsplätzen, so können Frauen weniger in ihr Humankapital investieren, so daB ihre gruppenspezifische Durchschnittsproduktivität auch zukünftig nicht erhöht wird, und sich die Erwartung der Unternehmer, daß die Frauen geringer qualifiziert sind, auch erfüllt. ${ }^{278}$

In der Diskriminierungstheorie ${ }^{279}$ wird angenommen, daß Menschen eine Diskriminierungsneigung gegen einzelne Gruppen aufgrund ihrer Rasse, ihres Geschlechts etc. haben. Bezogen auf den Arbeitsmarkt kann zwischen folgenden Diskriminierungen unterschieden werden:

1. Unternehmen haben eine Präferenz für männliche Arbeitnehmer und sind erst zu einem geringeren Lohn als demjenigen der Männer bereit, Frauen einzustellen.

2. Schon in der Unternehmung beschäftigte Mitarbeiter lehnen eine Zusammenarbeit mit Frauen ab und sind nur zu einem höheren Lohn bereit, diese zu akzeptieren.

${ }^{278}$ Vgl. R. Schubert, Ökonomische Diskriminierung von Frauen, Frankfurt am Main 1993, S. 88.

${ }^{279}$ Vgl. Gary S. Becker, The Economics of Discrimination, Chicago/London 1957. 
3. Konsumenten schätzen eine von Frauen erbrachte Dienstleistung als minderwertig ein, weil sie Frauen als unzuverlässig ansehen. Die Unternehmen reagieren darauf mit einer geringeren Lohnzahlung an alle Arbeitnehmerinnen.

Jegliche Lohndiskriminierung kann jedoch - ökonomisches Verhalten der Wirtschaftssubjekte unterstellt - nur kurzfristiger Natur sein, denn die Existenz eines einzigen Unternehmers ohne Diskriminierungsneigung werde es diesem ermöglichen, mit den billigeren Frauenarbeitskräften relativ kostengünstiger zu produzieren, so daß es langfristig zu einer Verdrängung diskriminierender Unternehmen kommen würde, da diese relativ teurer produzieren. Empirisch konnte dieses bislang allerdings noch nicht nachgewiesen werden.

Die neoklassische Humankapitaltheorie beschäftigt sich in erster Linie mit dem Angebot an Arbeit. Der Begriff Humankapital steht dabei für das durch gut ausgebildete und hochqualifizierte Arbeitskräfte repräsentierte Leistungspotential der Bevölkerung. ${ }^{280}$ Lohnunterschiede resultieren nach dieser Theorie allein aus der unterschiedlichen Qualifikation (Humankapital) der Anbieter von Arbeit. Der Erwerb von Qualifikationen ist dabei Ausdruck der rationalen Entscheidungen der Arbeitskräfte über Investitionen in ihre Aus- und Weiterbildung, wobei sich diese Investition über eine entsprechende Höhe zukünftigen Einkommens amortisieren sollte. Einkommensunterschiede sind nach dieser Theorie also nicht diskriminierend, wenn sie auf einer unterschiedlichen Ausstattung mit Humankapital beruhen. Humankapital kann erstens über die Ausbildungsdauer und zweitens durch die Berufswahl gebildet werden. Eine kurze Ausbildungsdauer führt dazu, daß entsprechend früher über Einkommen verfügt wird. Nimmt die potentielle Arbeitskraft nach Beendigung der obligatorischen Schulzeit weitere Investitionen in Form einer Zusatzausbildung vor, entstehen zunächst einmal Kosten, da in dieser Zeit der Lebensunterhalt gesichert werden muß. Darüber hinaus fallen "Opportunitätskosten" durch das entgangene Einkommen während der Zeit der Ausbildung an. Allerdings kann auch damit gerechnet werden, daß das Einkommen über das gesamte Erwerbsleben be-

\footnotetext{
${ }^{280}$ Vgl. M. Osterloh/K. Oberholzer, a.a.O., S. 5.
} 
trachtet höher ist als ohne diese Zusatzausbildung. Frauen nehmen nachweislich weniger Investitionen in Aus- und Weiterbildung vor, haben damit i.d.R. auch ein niedrigeres Einkommen. Dieses niedrigere Lebenseinkommen haben Frauen jedoch auch, wenn sie über die gleiche Zusatzausbildung wie Männer verfügen. Dies ist immer dann der Fall, wenn die Frau eine Unterbrechung ihrer Erwerbstätigkeit vornimmt, was bei der Geburt von Kindern nicht nur gezwungenermaßen geschieht, sondern unter gesellschaftlichen und pädagogischen Erwägungen heraus auch überaus wünschenswert ist. Der Wiedereinstieg ins Berufsleben bedeutet für die Frau, einen geringeren Wiedereinstiegslohn in Kauf zu nehmen, da in der Zeit der Nichterwerbstätigkeit ein Wissensverfall eingetreten ist. Untersuchungen haben ergeben, daß selbst bei dann kontinuierlicher Erwerbstätigkeit bis zum Erreichen des Rentenalters ihr Einkommen deutlich unter demjenigen der Männer liegt. ${ }^{281}$ Unter diesem Aspekt lohnt sich eine Zusatzausbildung für eine Frau deutlich weniger als für einen Mann. $40 \%$ der beobachtbaren geschlechtsspezifischen Einkommensdifferenz werden auf diese Komponente zurückgeführt, ${ }^{282} 60 \%$ bleiben demnach weiterhin ungeklärt.

Im Gegensatz zu den soziologischen Erklärungsmustern leitet die Humankapitaltheorie auch die Berufswahl der Frauen aus den erwarteten Einkommensverläufen ab. Frauen wählen demnach häufiger einen Beruf, in dem das Wissen nicht so schnell veraltet und eine Weiterbildung deshalb auch nicht unbedingt notwendig wird. Allerdings werden in diesen Bereichen auch niedrigere Löhne gezahlt. Schließlich sei noch auf die Theorie des segmentierten Arbeitsmarktes als Erklärung für Diskriminierung verwiesen. Ansatzpunkt dieser Theorie ist die Überlegung, daß der Arbeitsmarkt nicht vollkommen homogen ist, sondern in einzelne Teilmärkte bzw. Marktsegmente eingeteilt werden kann. Diese Segmente sind in sich homogen, können aber mehr oder weniger stark voneinander abgeschottet werden. Unterschieden wird zwischen dem Segment des internen Arbeitsmarktes, bei dem freiwerdende Stellen mit Mitarbeitern aus dem Unternehmen besetzt werden, so daß dieser im Prinzip nur beim Berufseinstieg offen ist, und dem

\footnotetext{
${ }^{281}$ Vgl. Hannelore Weck-Hannemann/Bruno S. Frey, Die Frau in der Wirtschaft. Die Sicht der Nationalökonomie, in: Wirtschaft und Recht, 40. Jg. 1988, S. 295.

${ }^{282}$ Vgl. R. Schubert, Ökonomische Diskriminierung von Frauen, Frankfurt a. Main 1993, S. 37.
} 
Segment des externen Arbeitsmarktes, in dem Arbeitsplätze ohne hohe Qualitätsanforderungen und ohne wesentliche Aufstiegschancen gehandelt werden. Für Unternehmen stellen diese Arbeitskräfte eine Reserve für konjunkturelle Schwankungen dar. Die Arbeitsplätze des externen Arbeitsmarktes sind ohne hohe Qualifikationsanforderungen, Aufstiegschancen gibt es kaum. Die Löhne sind gegenüber denjenigen im internen Arbeitsmarkt niedriger. Ausbildungsinvestitionen lohnen sich im externen Arbeitsmarkt für die Anbieter wegen der zu erwartenden niedrigen Löhne nicht, für die Unternehmen rentieren sie sich nicht wegen der geringen Beschäftigungsdauer. Die Zuordnung zum internen bzw. externen Arbeitsmarkt erfolgt wie bei der statistischen Diskriminierung - über die Durchschnittsproduktivitäten, so daß der gleiche Effekt für Frauen eintritt: Sie werden von diesem Markt ausgeschlossen, weil die Unternehmen ihnen eine geringere Produktivität zuschreiben.

Von der Soziologin Elisabeth Beck-Gernsheim wurde die "Theorie des weiblichen Arbeitsvermögens" entwickelt. ${ }^{283}$ Nach dieser Theorie werden geschlechtsspezifische Verhaltensunterschiede mit der geschlechtsspezifischen Persönlichkeitsentwicklung im Sozialisationsprozeß erklärt, die wiederum geprägt ist von der gesellschaftlichen Aufteilung der Arbeit in berufliche Erwerbsarbeit und private Hausarbeit, die im wesentlichen den Frauen zugewiesen wird. In einer Gesellschaft existieren nun geschlechtsspezifische Rollenstereotype, wenn die Mitglieder einer solchen Gesellschaft einvernehmliche Vorstellungen von den Eigenschaften und Fähigkeiten einer typischen Frau bzw. eines typischen Mannes haben und diese Merkmale einzelnen Frauen und Männern zusprechen. ${ }^{2+}$ Begründet wird das Vorhandensein solcher Rollenmuster damit, daß sie komplexe Wahrnehmungsaufgaben erheblich vereinfachen, weil es sich für die beurteilenden Personen erübrigt, ein eigenständiges Beurteilungsraster aufzustellen. Männern werden danach Eigenschaften zugeschrieben wie z.B. fachliche Kompetenz, Rationalität, Logik, Führungswille, Leistungs- und Wettbewerbsorientierung, während Frauen eher Eigenschaften wie Ausdrucksstärke, Passivität, Geduld, Soli-

\footnotetext{
${ }^{283}$ Vgl. E. Beck-Gernsheim, Der geschlechtsspezifische Arbeitsmarkt. Zur Ideologie und Realität von Frauenberufen, Frankfurt a. Main 1976.

${ }^{284}$ Vgl. R. Schubert, a.a.O., S. 104.
} 
darität, ständige Verfügbarkeit zugeordnet werden. Frauen wählen nun vornehmlich Berufe, in denen Helfen, Pflegen, soziale Kontakte und Ästhetik eine große Rolle spielen, selten gibt es in diesen Bereichen harte Konkurrenzkämpfe, die bestanden werden müssen. ${ }^{285}$ Die vom Statistischen Bundesamt erhobenen Zahlen ${ }^{286}$ bekräftigen diese Hypothese: Überproportional vertreten sind Frauen gegenüber Männern in den sozialen Berufen, Frauen haben einen Anteil von $85 \%$ in diesem Sektor. Aber auch in den Berufen des Gesundheitsdienstes finden sich mit einem Anteil von 87\% überwiegend Frauen. Im Sektor Ärzte/Apotheker überwiegen jedoch wieder die Männer mit ca. 61\%. Die Anwendung der Fähigkeiten "Helfen und Beraten" spiegelt sich auch im hohen Anteil von Frauen beim Verkaufspersonal (81\%) wider. Im handwerklichen Bereich sind erwartungsgemäß vorwiegend Männer beschäftigt, lediglich Köchinnen gibt es mehr als Köche $(68 \%)$. Auch alle haus- und ernährungswirtschaftlichen Berufe sind mit 96\% Frauenanteil "fest in Frauenhand". Die Unternehmen stellen sich bei der $\mathrm{Zu}$ schneidung der Arbeitsplätze auf diese Gegebenheiten ein, was durchaus ökonomisch rational ist, den Frauen aber kaum die Chance gibt, aus dem althergebrachten Rollenmuster auszubrechen. Nach wie vor sind entscheidend für den beruflichen Erfolg die Fähigkeit und Bereitschaft zu Wettbewerbsverhalten und die strikte Abgrenzung zwischen Berufs- und Privatleben. Letzteres ist, zumindest für die kindererziehende Frau, ein besonders großes Problem. In diesem Zusammenhang wird in der Wissenschaft darauf verwiesen, daß empirisch beobachtbare Unterschiede im Ausbildungs- und Erwerbsverhalten von Männern und Frauen auf biologisch-genetisch bedingte Interessen und Eignungen zurückgeführt werden können. ${ }^{287}$ Diese biologisch-genetischen Unterschiede zwischen den Geschlechtern beruhen darauf, daß die parentale Investition bei Frauen und Männern unterschiedlich hoch ist, Frauen müssen sich angesichts der Einschränkungen bei der Zahl ihrer Nachkommen darauf konzentrieren, diese wenigen Nachkommen überlebensfähig zu machen, was sie veranlaßt, einerseits bei der Auswahl der in Frage kommenden Männer besonders restriktiv zu sein, andererseits

\footnotetext{
${ }^{285}$ Vgl. M. Osterloh/K. Oberholzer, a.a.O., S. 9.

${ }^{286}$ Statistisches Jahrbuch 1995, S. 113.

${ }^{287}$ Vgl. R. Schubert, a.a.O., S. 90.
} 
ihren Kindern ein besonderes MaB an Pflege und Zuwendung zukommen zu lassen. Männer wiederum müssen, wenn sie sich fortpflanzen wollen, in einen intensiven Konkurrenzkampf mit den Geschlechtsgenossen eintreten. Daraus entwickelt sich dann eine ausgeprägte Wettkampfmotivation, zu der neben einer erhöhten Risikobereitschaft auch das Akzeptieren von MiBerfolgen gehört. ${ }^{288}$ Die faktisch zu beobachtenden Verhaltensunterschiede sind also sowohl auf anlagebedingte als auch sozialisationsbedingte Faktoren zurückzuführen.

Es ist - auch nach Kenntnis arbeitsmarkttheoretischer Zusammenhänge - äuBerst schwierig, zwischen Diskriminierung und Nichtdiskriminierung von Frauen eine Abgrenzung zu finden, so wird gemeinhin auch ein überproportional hoher Frauenanteil an den Arbeitslosen als ökonomische Diskriminierung interpretiert. Erwähnt werden muß an dieser Stelle auch, daB der Anteil arbeitslos gemeldeter Frauen höher ist als derjenigen, die arbeitssuchend sind, da nur bei gemeldeter Arbeitslosigkeit Rentenansprüche erworben werden können. Sind aber Einstellungsvoraussetzungen und berufliches Engagement von Frauen und Männer gleich, wird die Beurteilung der Situation äußerst schwierig, wenn nicht völlig unmöglich.

Die beschriebenen Probleme auf dem Arbeitsmarkt wirken sich auf die soziale Sicherung von Frauen mehr oder weniger stark negativ aus, da das gegenwärtig praktizierte System der sozialen Sicherung fast durchgängig an der Ausübung einer Erwerbstätigkeit anknüpft. Insofern kann nicht davon gesprochen werden, daB das Sozialversicherungssystem als solches zu einer Diskriminierung führt, wenn der Systematik des Systems strikt gefolgt wird, vielmehr setzen sich existierende Diskriminierungen in diesem System fort. Werden Frauen bei Lohn- und Einkommenszahlungen benachteiligt, so ergibt sich daraus zwangsläufig eine Diskriminierung bezüglich ihrer sozialen Absicherung. ${ }^{289}$ Eine Betrachtung der einzelnen Zweige der Sozialversicherung mit besonderer Berücksichtigung der gesetzlichen Rentenversicherung soll im folgenden die Situation der Frauen aufzeigen.

Die gesetzliche Krankenversicherung erhebt ihre Beiträge vom Erwerbseinkommen eines unselbständigen Beschäftigten, unabhängig davon,

\footnotetext{
${ }^{288}$ Vgl. R. Schubert, a.a.O., S. 91.

${ }^{289}$ Vgl. R. Schubert, a.a.O., S. 27.
} 
welchen Geschlechts diese Person ist. Auch bei den Leistungen findet keine geschlechtsspezifische Differenzierung statt. Die nichterwerbstätige Person ist ebenfalls geschlechtsneutral in das System eingebunden: entweder im Rahmen einer beitragsfreien Familienversicherung oder als eigenständiges Mitglied mit freiwilligen Beiträgen bzw. Beitragszahlung von dritter Seite z.B. Zahlung durch das Arbeitsamt aufgrund von Arbeitslosigkeit.

Vielfach wird die Stellung von Frauen in der Arbeitslosenversicherung genannt, um eine Benachteiligung im System der sozialen Sicherung nachzuweisen. ${ }^{290}$ Eine geschlechtsspezifische Diskriminierungskomponente ist im Aufbau der Arbeitslosenversicherung nicht zu erkennen. Die Leistungen der Arbeitslosenversicherung haben die Funktion einer Lohnersatzleistung und gliedern sich in ein zweistufiges System von Arbeitslosengeld und Arbeitslosenhilfe. Die Zahlung von Arbeitslosengeld ist eine Versicherungsleistung aufgrund bestimmter Vorleistungen (Mindestversicherungszeit, beitragspflichtige Beschäftigung u.ä.), auf die der einzelne unter bestimmten Bedingungen einklagbare individuelle Rechtsansprüche hat. Ergeben sich wegen fehlender Versicherungszeit oder niedriger Erwerbseinkommen keine oder nur geringe Ansprüche, ist dies systemkonform und keineswegs eine Benachteiligung dieses Personenkreises, auch wenn davon in erster Linie Frauen betroffen sind. Die Arbeitslosenhilfe ist eine Leistung, die aus Bundesmitteln finanziert wird, und unmittelbar an die Bedürftigkeit der von Arbeitslosigkeit betroffenen Person anknüpft. Sie tritt i.d.R. dann ein, wenn der Bezug von Arbeitslosengeld ausläuft. Ergibt die Bedürftigkeitsprüfung, daß die arbeitslose Person Unterhaltsansprüche an einen Ehepartner oder einen Partner in einer nichtehelichen Lebensgemeinschaft hat, erfolgt der Ausschluß aus dem Leistungssystem. Auch hier sind in der Mehrzahl Frauen betroffen, was jedoch nicht daran liegt, daß es Ungleichbehandlungen von Männern und Frauen gibt. Und auch die Tatsache, daß bei einer Leistung, die von der Gesellschaft über Steuermittel finanziert wird, gemäß dem Subsidiaritätsprinzip erst einmal geprüft wird, ob Unterhaltspflichten von Angehörigen bestehen, die diesen dann nachzukommen haben, bevor die Soli-

\footnotetext{
${ }^{290}$ Vgl. S. Sell, Frauen in der Arbeitslosenversicherung und Arbeitsmarktpolitik, Theoretische und empirische Aspekte der Benachteiligung von Frauen, in: Sozialer Fortschritt, 43. Jg. Heft 5, S. 188.
} 
dargemeinschaft eintritt, entspricht der Grundidee des sozialen Sicherungssystems. Nicht zu leugnen ist, daß Frauen - und hier insbesondere die verheirateten Frauen - sowohl ein niedrigeres durchschnittliches Arbeitslosengeld als auch eine niedrigere durchschnittliche Leistung aus der Arbeitslosenhilfe beziehen (das monatliche Arbeitslosengeld betrug 1992 in den alten Bundesländern für verheiratete Männer durchschnittlich 1.708,-- DM, für verheiratete Frauen durchschnittlich 965,-- DM, an Arbeitslosenhilfe wurden an die Männer durchschnittlich 1.104,-- DM und an die Frauen durchschnittlich 708,-- DM gezahlt), dieses ergibt sich aber nicht aus dem System der Arbeitslosenversicherung, sondern ist die Folge eines unterschiedlichen Erwerbsverhaltens von Männern und Frauen. So üben Frauen häufiger eine Teilzeittätigkeit aus, um das Familieneinkommen und damit den Lebensstandard der Familie zu erhöhen, nicht aber, weil sie aus diesem Einkommen ihren Lebensunterhalt bestreiten müssen. In einem Versicherungssystem können derartige Verhaltensweisen nicht zu den gleichen Leistungen führen, wie für eine Person mit einer Vollzeittätigkeit.

Etwas anders stellt sich die Situation in der gesetzlichen Rentenversicherung dar: Das Versicherungsprinzip wird in diesem Zweig der Sozialversicherung bereits durch zahlreiche Umverteilungselemente durchbrochen, so daß eine Analyse hinsichtlich der Gleich- bzw. Ungleichbehandlung von Frauen und Männern sinnvoll erscheint. Da das Rentenversicherungssystem ebenfalls an der Ausübung einer Erwerbstätigkeit und dem dadurch erzielten Einkommen anknüpft, setzen sich eventuell bestehende Lohndiskriminierungen bei Frauen insofern fort, als die Rentenzahlungen im Alter gleichermaßen niedriger sind. Da, wie oben festgestellt, Frauen zudem Berufe bevorzugen, in denen die Löhne tendenziell niedriger sind, müssen sie auch niedrigere Renten im Alter in Kauf nehmen. Die Korrektur eines solchen unerwünschten Ergebnisses müßte dann allerdings dort ansetzen, wo die Ursache liegt und nicht im Rentenversicherungssystem. Mit den seit 1984 in Kraft getretenen Gesetzen (Haushaltsbegleitgesetz 1984, Gesetz über die Gewährung von Erziehungsgeld und Erziehungsurlaub vom 1.1.1986, Hinterbliebenen- und Erziehungszeitengesetz vom 1.1.1986 sowie Teilen des Gesundheitsreformgesetzes) wurde bereits erheblich dazu beigetragen, die Verringerung finanzieller Nachteile im Alter durch ein Engagement für 
Familienarbeit und hier insbesondere für die Erziehung von Kindern teilweise auszugleichen. Zu erwähnen sei allerdings auch, daß Frauen bis dato in der Rentenversicherung bevorzugt behandelt werden, sie erhalten unter bestimmten Voraussetzungen ${ }^{291}$ eine Regelaltersrente bereits mit Vollendung des 60. Lebensjahres, während Männer diese Leistung erst mit Vollendung des 65. Lebensjahres beziehen können. Begründet wurde diese Regelung damit, daß dadurch ein rentenrechtlicher Ausgleich für Frauen geschaffen werden sollte, die einer Mehrfachbelastung durch Haushalt, Schwangerschaft, Kindererziehung und Erwerbstätigkeit ausgesetzt waren. Da durch den früheren Rentenbezug und einer längeren statistischen Lebenserwartung der Frauen insgesamt eine höhere Rentenleistung gezahlt wird, als den Männern zugute kommt, kann an dieser Stelle eher von einer Bevorzugung als von einer Benachteiligung der Frauen gesprochen werden. Die im $\mathrm{Zu}$ sammenhang mit der zukünftigen Finanzierbarkeit des heutigen lohn- und beitragsbezogenen Rentenversicherungssystems geplanten Gesetzesänderungen sehen eine Anhebung der Altersgrenze für Frauen vor. ${ }^{292}$ In den vorgelegten Gesetzentwürfen der Bundesregierung ist vorgesehen, die Altersgrenze für Frauen ebenfalls auf 65 Jahre festzusetzen. Betroffen wären damit alle Frauen der Geburtsjahrgänge 1937 und später. ${ }^{293}$ Nach heftigen Protesten der Betroffenen wird die Anhebung erst ab dem Jahre 2000 und dann im Monatsschritten vorgenommen. ${ }^{294}$ Damit sind dann die Frauen mit Geburtsmonat Dezember 1944 die ersten, für die die Altersgrenze gilt.

\subsection{Erwerbsverhalten}

Die Erwerbsbeteiligung ist eine notwendige Voraussetzung, um in das System der GRV eingegliedert zu werden, alle Personen sind kraft Gesetzes versichert, die als Arbeitnehmer gegen Entgelt beschäftigt sind. Versicherungspflichtig sind darüber hinaus auch

${ }^{291}$ Neben der Erfüllung der Wartezeit von 15 Jahren gilt, daß die Frau das 40. Lebensjahr vollendet und mehr als 10 Jahre Pflichtbeiträge entrichtet hat.

${ }_{292}$ Vgl. Gesetz zur Förderung eines gleitenden Übergang in den Ruhestand.

${ }^{293}$ Vgl. G. Albrecht, Die geplanten Neuregelungen in der Rentenversicherung nach dem Sparpaket der Bundesregierung, in: Die Sozialversicherung, 51. Jg. 1996, Heft 8, S. 201. ${ }^{294}$ Vgl. ebenda. 
- Personen, für die eine Kindererziehungszeit

- anzurechnen ist,

- Wehr- und Zivildienstleistende,

- Bezieher von Lohnersatzleistungen und

- Vorruhestandsgeld.

Da diese Zeiten jedoch in der gesamten Versicherungsbiographie einer Person nicht den Regelfall darstellen, bleibt das Erwerbsverhalten die wesentliche Komponente zur Erlangung eines Rentenanspruches im Alter, der die Lebenshaltungskosten deckt.

Die Erwerbsbeteiligung von Männern und Frauen weist erhebliche Unterschiede auf, zudem muß gegenwärtig noch zwischen dem früheren Bundesgebiet und den neuen Ländern (einschließlich Berlin-Ost) unterschieden werden. Aufgrund differierender politischer und gesellschaftlicher Rahmenbedingungen hat es im östlichen Teil Deutschlands eine deutlich höhere Erwerbsbeteiligung - auch der weiblichen Bevölkerung - gegeben. Die arbeitsintensive Produktion führte zu einer relativ großen Nachfrage nach Arbeitskräften, darüber hinaus ermöglichte ein umfassendes Angebot an Einrichtungen zur Betreuung von Kindern die Beteiligung am Erwerbsleben. Obwohl die Erneuerung des Produktionsapparates in der ehemaligen DDR zu einer höheren Arbeitslosigkeit aller Bevölkerungsgruppen führte gibt es auch heute noch gravierende Unterschiede in der Erwerbsbeteiligung zwischen West und Ost.

Während die Erwerbsquoten ${ }^{295}$ der Männer seit 1972 kontinuierlich sinken, zeigt sich bei den Frauen ein gegenteiliges Bild.

Die rückläufigen Erwerbsquoten der Männer sind gröBtenteils auf die Inanspruchnahme der Möglichkeit einer Frühverrentung sowie einer verlängerter Ausbildung in jüngeren Lebensjahren zurückzuführen. Beide Aspekte treffen zwar auch auf Frauen zu, führen jedoch - bedingt durch den starken Zugang von Frauen zum Arbeitsmarkt - nicht zum Absinken der Erwerbsquoten.

${ }^{295}$ Prozentualer Anteil der Erwerbspersonen an der Bevölkerung. 
Abbildung 2:

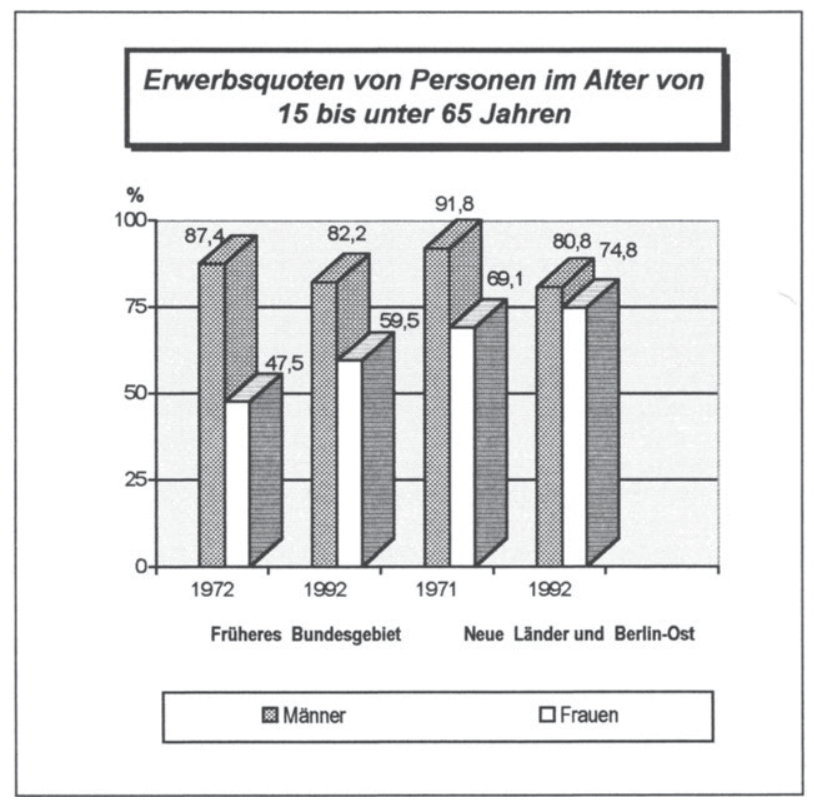

Quelle: Statistisches Bundesamt, Ergebnis der Volks- und Berufszăhlung vom 1.1.1971 sowie des Mikrozensus 1992

Um den Einfluß des Familienstandes und die Anzahl der Kinder auf die Erwerbsbeteiligung von Frauen zu analysieren, wird im folgenden das Augenmerk auf die Erwerbsbeteiligung von Ehefrauen mit und ohne Kinder sowie auf die Situation von Alleinerziehenden gerichtet. Die Erwerbsbeteiligung von Männern wird durch Eheschließung und Familiengründung in der Regel nicht beeinflußt, so daß von einer gesonderten Analyse dieser Personengruppen abgesehen wird.

Das Vorhandensein von Kindern in einer Ehe beeinfluBt das Erwerbsverhalten von Frauen. Während sich die Erwerbsquoten von Ehefrauen unter 35 Jahren ohne Kinder denen von Männern nahezu gleichen, sinkt die Erwerbsquote 
Abbildung 3:

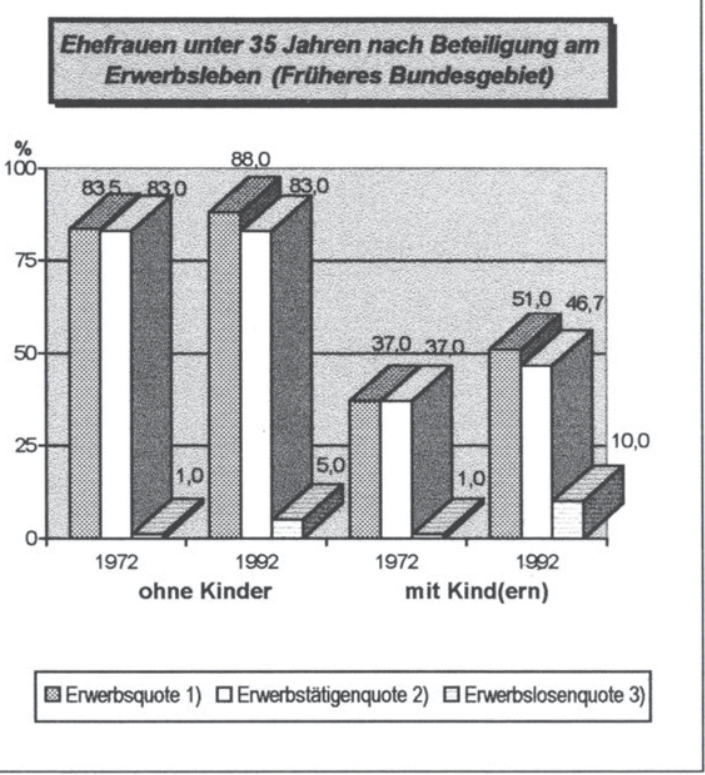

Ergebnis der Mikrozensen April 1972 und Mai 1992; Bevőlkerung am Familienwohnsitz.

1) Erwerbspersonen (Erwerbstätige und Erwerbslose) je 100 Personen-

2) Erwerbstätige je 100 Personen.-

3) Erwerbslose je 100 Erwerbspersonen.

Quelle: Statistisches Bundesamt.

junger Ehefrauen mit Kindern rapide (von $88 \%$ auf $51 \%$ im Jahre 1992) ab. Es ist jedoch zu einseitig, diesen Rückgang allein auf die schwierige Vereinbarkeit von Berufsausübung und Kindererziehung zurückzuführen. Sicherlich gestaltet sich die Arbeitswelt überwiegend noch nach herkömmlichen Mustern, in der Vollzeitarbeit die Regel ist und flexible Gestaltungen der Arbeitszeit, die während der Zeit der Kindererziehung notwendig wären, nur partiell eingeführt worden sind. Die rückläufigen Erwerbsquoten sind jedoch auch zunehmend Ausdruck einer bewuBten Entscheidung zu Mutterschaft und Kindererziehung in einer herkömmlichen Familienkonstellation. Die Möglichkeit, Erziehungsurlaub bis zu 3 Jahren in Anspruch 
zu nehmen, begünstigt eine derartige Entscheidung. Gleichwohl scheint es gegenüber dem Jahre 1972 eher möglich zu sein, die Doppelrolle einer Erwerbstätigen und Mutter auszuüben, da die Erwerbsquote von $37 \%$ auf 51 \% im Jahre 1992 gestiegen ist. Erhöhte Zahlen an Kindergartenplätzen und eine Verbesserung der sozialrechtlichen Stellung von Tagesmüttern begünstigen die Aufnahme einer Erwerbstätigkeit. Der inzwischen von der Bundesregierung geschaffene Rechtsanspruch auf einen Kindergartenplatz für alle Kinder ab dem 3. Lebensjahr vom 1.1.1996 an führt zu einer weiteren Verbesserung der Situation erwerbstätiger Frauen. Einschränkungen könnten sich eher dadurch ergeben, daß der Arbeitsmarkt ein vermehrtes Angebot an Arbeitskräften nur zum Teil verkraften kann. Schon im betrachteten Zeitraum 1972 - 1992 ist die Erwerbstätigenquote geringer gestiegen als die Erwerbsquote, die Erwerbslosenquote hat sogar stark zugenommen (von 1 $\%$ auf $10 \%$ ) und diese Entwicklung wird sich angesichts der gegenwärtigen und auch zukünftig zu erwartenden Arbeitsmarktprobleme zweifellos noch verschlechtern.

Das Ausmaß der Erwerbsbeteiligung wird wesentlich beeinflußt von der Anzahl und dem Alter der Kinder.

Bei alleinerziehenden Müttern liegen die Erwerbstätigenquoten, mit Ausnahme der verwitweten Alleinerziehenden, deutlich höher als bei verheirateten Müttern. Die niedrigere Quote der Verwitweten (48,6 \%) resultiert aus der besseren finanziellen Lage der kindererziehenden Witwen, die eine Hinterbliebenenrente aus der Gesetzlichen Rentenversicherung (Witwenrente, Waisenrente) erhält, die offenbar in vielen Fällen zur Versorgung der Familie ausreicht.

Die höchste Erwerbsbeteiligung weisen geschiedene Mütter auf (73,8 $\%$ ), sie haben selbst mit 3 Kindern eine höhere Erwerbstätigenquote (59,3 $\%)$ als die verheirateten Mütter insgesamt $(55,4 \%)$. Da zu vermuten ist, daß diese Frauen aufgrund ökonomischen Zwangs eine Erwerbstätigkeit aufgenommen haben, spiegelt sich hier die vielfach desolate finanzielle Lage der an einer Scheidung beteiligten Personen wider. Der im Falle des Vorhandenseins von Kindern zum Unterhalt verpflichtete Ehepartner (in den meisten Fällen ist dies der Ehemann) kann seiner Verpflichtung wegen eines zu geringen Einkommens nicht bzw. nicht vollständig nachkommen und 
zwingt dadurch die kindererziehende Mutter zur Aufnahme einer Erwerbstätigkeit.

Tabelle 25: Erwerbsbeteiligung von Frauen mit Kindern ach Familienstand, Anzahl der Kinder und Alter der Kinder im Jahre 1992

\begin{tabular}{|c|c|c|c|c|c|}
\hline & $\begin{array}{l}\text { Verheirate- } \\
\text { te } \\
\text { Mūtter }\end{array}$ & $\begin{array}{l}\text { ledig } \\
\% \\
\end{array}$ & \begin{tabular}{|} 
A l l e i n e r z i \\
$\begin{array}{c}\text { verheiratet } \\
\text { getrennt lebend } \\
\%\end{array}$
\end{tabular} & $\begin{array}{l}\text { n d e } M \text { ũ t t } \\
\text { geschieden } \\
\%\end{array}$ & $\begin{array}{c}\text { verwitwet } \\
\\
\%\end{array}$ \\
\hline $\begin{array}{l}\text { Erwerbstäti- } \\
\text { gen-quote }^{1} \text { in } \\
\%\end{array}$ & 55,4 & 66,6 & 62,7 & 73,8 & 48,6 \\
\hline \multicolumn{6}{|l|}{$\begin{array}{l}\text { nach der An- } \\
\text { zahl der Kin- } \\
\text { der }\end{array}$} \\
\hline 1 Kind & 57,4 & 69,3 & 68,6 & 76,5 & 46,4 \\
\hline 2 Kinder & 56,7 & 56,2 & 60,8 & 73,0 & 55,1 \\
\hline 3 Kinder & 47,2 & 1 & 42,2 & 59,3 & 47,2 \\
\hline 4 Kinder & 40,6 & 1 & 1 & 45,4 & 1 \\
\hline $\begin{array}{l}5 \text { u. mehr } \\
\text { Kinder } \\
\text { nach dem Al- } \\
\text { ter der Kinder }\end{array}$ & 28,4 & 1 & 1 & & 1 \\
\hline $\begin{array}{l}\text { Unter } 3 \text { Jah- } \\
\text { ren }\end{array}$ & 41,8 & 56,3 & 40,5 & 43,3 & 1 \\
\hline $\begin{array}{l}\text { Unter } 6 \text { Jah- } \\
\text { ren }\end{array}$ & 47,1 & 60,3 & 49,3 & 55,0 & 52,1 \\
\hline $\begin{array}{l}\text { Unter } 15 \\
\text { Jahren }\end{array}$ & 55,5 & 65,4 & 59,3 & 70,4 & 61,6 \\
\hline $\begin{array}{l}\text { Unter } 18 \\
\text { Jahren }\end{array}$ & 56,6 & 66,1 & 60,8 & 72,2 & 60,3 \\
\hline
\end{tabular}

/ Stichprobengrößen unter der Nachweisgrenze

${ }^{1}$ Anteil der Erwerbstätigen an 100 Frauen entsprechenden Familienstandes und entsprechender Zahl und Altersgruppe der Kinder insgesamt.

Quelle: Statistisches Bundesamt, Statistisches Jahrbuch 1994, Ergebnis des Mikrozensus (Deutschland) 
Eher vergleichbar ist die Situation der ledigen und verheiratet getrennt lebenden Mütter. Ihre Erwerbsbeteiligung ist überdurchschnittlich hoch und steigt mit zunehmendem Alter der Kinder weiter an. Bemerkenswerte Unterschiede ergeben sich bei der Betrachtung nach dem Alter der Kinder, mit Kindern bis unter 6 Jahren ist die Erwerbsbeteiligung der verheiratet getrenntlebenden Alleinerziehenden wesentlich geringer, was auf einen - im Vergleich zur ledigen Mütter - höheren Unterhaltsanspruch zurückzuführen ist. Die ledige alleinerziehende Frau hat lediglich einen Unterhaltsanspruch gegenüber dem Vater des Kindes für das Kind, sie selbst muß entweder erwerbstätig sein oder einen Anspruch auf Sozialhilfe geltend machen; die verheiratet getrennt lebende Frau kann vom Ehepartner Unterhalt für sich und vorhandene Kinder fordern.

Mit zunehmender Zahl von Kindern sinkt erwartungsgemäß die Erwerbstätigenquote der verheirateten Mütter. Bemerkenswert ist, daß die Geburt eines zweiten Kindes die Erwerbsbeteiligung nur wenig sinken läßt, erst mit der Geburt eines dritten Kindes ist ein deutliches Absinken zu erkennen (von 57,4\% mit einem Kind auf 47,2 \% mit drei Kindern bis auf 28,4\% mit 5 und mehr Kindern). Die Betreuungsmöglichkeiten einerseits und die organisatorischen Voraussetzungen für eine Ausübung des Berufes andererseits lassen augenscheinlich auch bei Vorhandensein von zwei Kindern eine Erwerbstätigkeit zu.

Ebenfalls nicht überraschend ist die Zunahme der Erwerbsbeteiligung mit zunehmendem Alter der Kinder (41,8\% mit Kindern unter 3 Jahren bis auf 56,6 \% der Ehefrauen mit Kindern unter 18 Jahren). Zu vermuten ist allerdings, daß die im Vergleich zu Ehefrauen ohne Kinder relativ geringe Erwerbsbeteiligung von 56,6 \% mit Kindern unter 18 Jahren auf eine erschwerte Wiedereingliederung in den Arbeitsmarkt zurückzuführen ist.

Die auf den ersten Blick aus dem Rahmen fallende hohe Erwerbsbeteiligung verwitweter Mütter mit einem Kind (46,4\%).

Ergänzend zur Analyse der Erwerbsbeteiligung von verheirateten Müttern soll im folgenden eine Gegenüberstellung der Erwerbsbeteiligung der Ehepartner erfolgen, um aufzuzeigen, wie beide Ehegatten oder nur ein Ehepartner durch Erwerbstätigkeit zum Familienunterhalt beitragen. 
Tabelle 26: Ehepaare nach Familientyp und Beteiligung der Partner am Erwerbsleben (Alter des Ehemannes <65 Jahre) im Jahre 1992

\begin{tabular}{|c|c|c|c|c|c|}
\hline \multirow{3}{*}{ Familientyp1 } & \multicolumn{5}{|c|}{ Frü heres } \\
\hline & \multirow{2}{*}{$\begin{array}{l}\text { zusammen } \\
\text { In } \mathbf{1 . 0 0 0} \\
\end{array}$} & \multirow[t]{2}{*}{$\begin{array}{l}\text { beide Ehepart- } \\
\text { ner erwerbstã- } \\
\text { tig }\end{array}$} & \multirow{2}{*}{\begin{tabular}{|c|}
$\begin{array}{c}\text { Ehemann allein } \\
\text { erwerbstätig }\end{array}$ \\
von Spalte 1 \\
\end{tabular}} & \multirow[t]{2}{*}{$\begin{array}{l}\text { Ehefrau allein } \\
\text { erwerbstätig }\end{array}$} & \multirow[t]{2}{*}{$\begin{array}{c}\text { beide Ehe- } \\
\text { partner } \\
\text { nicht er- } \\
\text { werbstätig2 } \\
\end{array}$} \\
\hline & & & & & \\
\hline $\begin{array}{l}\text { Ehepartner ohne } \\
\text { Kinder }\end{array}$ & 4.470 & 48,4 & 24,8 & 6,5 & 20,3 \\
\hline $\begin{array}{l}\text { Ehepaare mit } \\
\text { Kind(ern) }\end{array}$ & 8.490 & 48,8 & 42,1 & 3,1 & 6,0 \\
\hline $\begin{array}{l}\text { insgesamt } \\
\text { dar.: jüngstes Kind } \\
\text { ist }\end{array}$ & 12.960 & 48,7 & 36,1 & 4,3 & 11,0 \\
\hline unter 3 Jahre alt & 1.743 & 36,4 & 57,8 & 2,0 & 3,8 \\
\hline $3<6$ Jahre alt & 1.120 & 46,2 & 48,5 & 2,0 & 3,3 \\
\hline $6<15$ Jahre alt & 2.516 & 57,4 & 37,4 & 2,2 & 3,1 \\
\hline \multirow{3}{*}{ Familientyp $^{1}$} & \multicolumn{5}{|c|}{ Neue Lãnder und Berlin-Ost } \\
\hline & Zusammen & $\begin{array}{l}\text { beide Ehepart- } \\
\text { ner erwerbstä- } \\
\text { tig }\end{array}$ & $\begin{array}{c}\text { Ehemann allein } \\
\text { erwerbstātig }\end{array}$ & $\begin{array}{l}\text { Ehefrau allein } \\
\text { erwerbstätig }\end{array}$ & $\begin{array}{c}\text { beide Ehe- } \\
\text { partner } \\
\text { nicht er- } \\
\text { werbstätig }{ }^{2}\end{array}$ \\
\hline & In 1.000 & \multicolumn{4}{|c|}{$\%$ von Spalte 1} \\
\hline $\begin{array}{l}\text { Ehepartner ohne } \\
\text { Kinder }\end{array}$ & 1.201 & 34,3 & 19,2 & 10,8 & 35,8 \\
\hline \begin{tabular}{|l} 
Ehepaare mit \\
Kind(ern)
\end{tabular} & 2.174 & 65,2 & 21,8 & 6,3 & 6,7 \\
\hline $\begin{array}{l}\text { Insgesa m t } \\
\text { dar.: jüngstes Kind } \\
\text { ist }\end{array}$ & 3.375 & 54,2 & 20,9 & 7,9 & 17,0 \\
\hline alt Unter 3 Jahre & 280 & 57,6 & 32,1 & 5,0 & 5,3 \\
\hline $3<6$ Jahre alt & 368 & 67,5 & 23,9 & 5,7 & 2,9 \\
\hline $6<15$ Jahre alt & 870 & 72,4 & 19,2 & 5,3 & 3,2 \\
\hline
\end{tabular}

1 Kernfamilien im Sinne der Definition der Vereinten Nationen

2 Erwerbslose und Nichterwerbspersonen

Quelle: Statistisches Bundesamt, Im Blickpunkt: Familie heute, Ausgabe 1995. 
Auch hier zeigt sich noch einmal deutlich, daß das Ausmaß der Erwerbsbeteiligung der Ehepartner vom Alter der Kinder bestimmt wird: Je jünger das Kind ist, desto niedriger ist die Erwerbsbeteiligung der Ehefrau. Hervorzuheben ist in diesem Zusammenhang, daß zwischen dem früheren Bundesgebiet und den neuen Bundesländern bislang noch deutliche Unterschiede im Erwerbsverhalten bestehen. Die Erwerbstätigenquoten in den neuen Bundesländern sind wesentlich höher und selbst mit einem Kind unter 3 Jahren sind in 57,6 \% aller Fälle beide Partner erwerbstätig, im Westen sind es lediglich 36,4 \%. Der in den neuen Ländern höhere Anteil von Frauen mit Kindern, die allein erwerbstätig sind, dürfte auch auf die hohe Arbeitslosigkeit von Männern zurückzuführen sein.

Bevor auf die Situation der Alleinerziehenden näher eingegangen wird, soll eine Betrachtung der Erwerbsbeteiligung in nichtehelichen Lebensgemeinschaften einbezogen werden, da immer häufiger auch in dieser Lebensform Kinder aufgezogen werden.

Ein Vergleich des Erwerbsverhaltens der Partner in nichtehelichen Lebensgemeinschaften mit Ehepartnern läßt klare Unterschiede erkennen, soweit es sich um die alten Bundesländer handelt. Auch mit Kindern sind in 60,8 \% aller Fälle in nichtehelichen Lebensgemeinschaften beide Partner erwerbstätig, während es Ehepartner nur zu 48,8 \% sind. In den neuen Bundesländern sind die Quoten mit 65,2 \% bei Ehepaaren und 61,6 \% in nichtehelichen Lebensgemeinschaften etwa gleich hoch. Die im Vergleich zu Ehepaaren extrem hohe Erwerbsbeteiligung in Gemeinschaften ohne Kinder (70,2\% im früheren Bundesgebiet) ist auf das geringere Durchschnittsalter der Partner in diesen Lebensgemeinschaften zurückzuführen.

Um Aussagen zur sozialversicherungsrechtlichen Wirkung der Erwerbstätigkeit ableiten zu können, ist es in einer weitergehenden Betrachtung notwendig, die unterschiedlichen Erwerbsverläufe von Männern und Frauen zu analysieren.

Unterschiede im Erwerbsverlauf zwischen Frauen und Männern zeigen sich vor allem bei verheirateten Müttern und Alleinerziehenden. Dagegen entspricht die Entwicklung der Erwerbsquoten lediger und verheirateter Frauen ohne Kinder weitgehend der Entwicklung bei den Männern. 
Tabelle 27: Nichteheliche Lebensgemeinschaften nach Familientyp und Beteiligung der Partner am Erwerbsleben (Alter des Partners <65 Jahre) im Jahre 1992

\begin{tabular}{|c|c|c|c|c|c|}
\hline \multirow[b]{2}{*}{$\begin{array}{l}\text { Nichteheliche } \\
\text { Lebensgemeinschaf- } \\
\text { ten }\end{array}$} & \multicolumn{5}{|c|}{ Bundesge bie t } \\
\hline & zusammen & $\begin{array}{l}\text { beide Partner } \\
\text { erwerbstätig }\end{array}$ & $\begin{array}{c}\text { männlicher } \\
\text { Partner allein } \\
\text { erwerbstätig }\end{array}$ & $\begin{array}{c}\text { Weiblicher } \\
\text { Partner allein } \\
\text { erwerbstätig }\end{array}$ & $\begin{array}{c}\text { beide } \\
\text { Partner nicht } \\
\text { erwerbstätig1 }\end{array}$ \\
\hline & In 1.000 & \multicolumn{4}{|c|}{$\%$ von Spalte 1} \\
\hline \multirow{2}{*}{$\begin{array}{l}\text { Gemeinschaften } \\
\text { ohne Kinder } \\
\text { Gemeinschaften } \\
\text { mit Kindern }\end{array}$} & 925 & 70,2 & 10,1 & 7,7 & 12,0 \\
\hline & 222 & 60,8 & 23,9 & 7,7 & 7,7 \\
\hline Insgesa m t & 1.147 & 68,4 & 12,8 & 7,7 & 11,2 \\
\hline \multirow{3}{*}{$\begin{array}{l}\text { Nichteheliche } \\
\text { Lebensgemeinschaf- } \\
\text { ten }\end{array}$} & \multicolumn{5}{|c|}{ Ne ue Lānder und Berlin-Ost } \\
\hline & zusammen & $\begin{array}{c}\text { beide Partner } \\
\text { erwerbstätig }\end{array}$ & $\begin{array}{c}\text { männlicher } \\
\text { Partner allein } \\
\text { erwerbstätig }\end{array}$ & $\begin{array}{c}\text { weiblicher } \\
\text { Partner allein } \\
\text { erwerbstātig }\end{array}$ & $\begin{array}{c}\text { beide } \\
\text { Partner nicht } \\
\text { erwerbstätig }{ }^{1}\end{array}$ \\
\hline & In 1.000 & \multicolumn{4}{|c|}{$\%$ von Spalte 1} \\
\hline $\begin{array}{l}\text { Gemeinschaften } \\
\text { ohne Kinder }\end{array}$ & 151 & 46,7 & 16,5 & 10,1 & 26,6 \\
\hline $\begin{array}{l}\text { Gemeinschaften } \\
\text { mit Kindern }\end{array}$ & 188 & 61,6 & 22,9 & 8,9 & 6,7 \\
\hline Insgesamt & 338 & 54,9 & 20,1 & 9,4 & 15,5 \\
\hline
\end{tabular}

1 Erwerbslose und nicht Erwerbspersonen

Quelle: Statistisches Bundesamt, Im Blickpunkt: Familien heute, Ausgabe 1995.

Besonders gravierend im Hinblick auf die soziale Sicherung sind jedoch die wesentlich häufiger auftretenden Berufsunterbrechungen von Frauen. Selbst bei vergleichbaren Lebenseinkommen von Frau und Mann wirkt die lückenhafte Erwerbstätigkeitsbiographie von Frauen leistungsmindernd, führt also im Alter zu einer niedrigeren Rentenzahlung. So betrug die durchschnittliche Anzahl der Versicherungsjahre am 1.1.1992 der Männer in den alten Bundesländern 38,7, in den neuen Bundesländern 45,1, diejeni- 
gen der Frauen jeweils 21,6 (alte Bundesländer) und 30,4 (neue Bundesländer). ${ }^{296}$

Befragungen liefern das Ergebnis, daß Hauptgrund für Unterbrechungen die Geburt des ersten Kindes ist, gleichzeitig geben die befragten Frauen an, nach einer kindbedingten Pause wieder in die Berufstätigkeit zurückkehren zu wollen. Dieser Wiedereinstieg gestaltet sich nun zunehmend schwieriger und zwar um so mehr, je weiter er hinausgeschoben wird. Der fortschreitende Wandel der Arbeitswelt führt schon in kürzester Zeit zur Entwertung einmal erworbener Qualifikationen und stellt damit neben der Doppelbelastung Kindererziehung und Beruf aus der Sicht der befragten Personen eine der größten Hürden für den Wiedereinstieg ins Berufsleben dar. Damit wird auch deutlich, daß das sogenannte "Dreiphasenmodell"297 lediglich theoretisch Bedeutung hatte, da es für die Mehrzahl der Frauen nicht uneingeschränkt gilt. Nach diesem Modell wird das Leben in drei Phasen eingeteilt:

In die erste Phase der Berufsausbildung und daran anschließender Berufstätigkeit, in eine zweite Phase der Berufsunterbrechung wegen Heirat und Geburt von Kindern und schließlich in eine dritte Phase des Wiedereintritts in das Berufsleben ab dem 40. Lebensjahr.

Schon 1984 erkannte der Wissenschaftliche Beirat beim BMJG die Problematik der Wiedereingliederung. "Arbeitnehmer, die mehrere Jahre aus dem Erwerbsleben ausscheiden, um sich der Familientätigkeit zu widmen, werden mit schwer zu bewältigenden Problemen konfrontiert, wenn sie wieder erwerbstätig werden wollen. Diese Probleme werden um so größer und um so schwerer lösbar, je größer die Arbeitslosigkeit ist." ${ }^{298}$ Dieses Zitat ist bedauerlicherweise so aktuell wie nie zuvor angesichts einer Arbeitslosenquote von nahezu 10\%. Unternehmensbefragungen liefern das Ergebnis, daß Frauen in eine qualifizierte Tätigkeit sowohl im kaufmännischen und verwaltenden also auch im gewerblichen und technischen Bereich nach einer

\footnotetext{
${ }^{296}$ Vgl. Husmann, Jürgen, Die Lage der Rentner in den neuen Bundesländern, in: Aktuelles Presseseminar des VDR, 12./13. November 1992 in Würzburg.

${ }^{297}$ Vgl. Myrdal, A./Klein, V., Die Doppelrolle der Frau in Familie und Beruf, Köln/Berlin 1971, S. 16ff.

${ }^{298}$ Wissenschaftlicher Beirat für Familienfragen beim BMJG, Familie und Arbeitswelt 1984, S. 253.
} 
Unterbrechungszeit von 1-2 Jahren zurückkehren sollten. Bei der Rückkehr in eine einfache Tätigkeit in den genannten Bereichen sei nach Meinung der befragten Unternehmen eine Unterbrechungszeit von bis zu 5 Jahren tolerierbar. ${ }^{299}$

Das familienpolitische Engagement im Unternehmen nimmt in den letzten Jahren jedoch erfreulicherweise zu, insbesondere wenn es sich bei den relevanten Personen um qualifizierte Arbeitskräfte handelt, in deren Ausbildung hohe Investitionen getätigt wurden. Die Aktivitäten erstrecken sich von Programmen zur Weiterbildung in der Kindererziehungsphase bis zum Betreuungsangebot der Kinder bei Wiederaufnahme der Erwerbstätigkeit sowie darüber hinaus Einrichtung von Arbeitsplätzen mit flexibler Arbeitszeit.

Die im Rahmen des IAB-Projektes durchgeführte Befragung nach den Gründen für eine Erwerbstätigkeit sind in der folgenden Tabelle zusammengefaßt.

Von mehr als jeder zweiten Frau werden für deren Erwerbstätigkeit ökonomische Motive angegeben. Besonders eklatant ist die Situation für die alleinerziehenden Frauen ohne Partner, aber auch insgesamt scheint sich hier die sehr viel schlechtere finanzielle Situation der Alleinerziehenden gegenüber Verheirateten zu dokumentieren.

Die jeweils aktuelle ökonomische Lage steht bei allen befragten Personen sehr stark im Vordergrund, fast vernachlässigbar gering ist das Motiv der „Alterssorge“. Gerade die Alleinerziehenden scheinen derart von der Bewältigung akuter Finanznöte in Anspruch genommen zu sein, daß jeglicher Gedanke an die Versorgung im Alter in den Hintergrund tritt. Diese Tabelle läßt ebenfalls erkennen, daß die oft genannten Gründe für die Erwerbstätigkeit wie Selbstbestätigung, Selbstverwirklichung, Emanzipation augenscheinlich für die Mehrzahl der Personen dieser Kreise nur eine geringe bis gar keine Rolle spielen. Allerdings wird aus dieser Tabelle auch deutlich, daß diese Personengruppe mit ihren besonderen außergewöhnlichen Belastungen stärker in das Kalkül der Familienpolitik einbezogen wer-

${ }^{299}$ Vgl. Engelbrech, G./Kraft, H., Sind Frauen das zukünftige Innovationspotential? Gegenwärtige Hemmnisse und berufliche Möglichkeiten von Frauen - Ergebnisse einer Betriebsbefragung. In: Mitteilungen aus der Arbeitsmarkt- und Berufsforschung 1992, 1, S. 17 . 
den muß, wenn die in diesen Gemeinschaften aufwachsenden Kinder die gleichen Startchancen erfahren sollen, wie diejenigen, die in vollständigen Familien aufwachsen.

Abschließend stellt sich die Frage, inwieweit kindererziehende Frauen Ehefrauen und Alleinerziehende gleichermaßen - eine Vollzeitbeschäftigung oder einer Teilzeitbeschäftigung nachgehen, da unterschiedliche Beschäftigungszeiten über die Rentenformel Auswirkungen auf das Ausmaß der sozialen Sicherung im Alter haben.

Teilzeitarbeit spielt sowohl bei Ehemännern als auch bei alleinerziehenden Männern keine große Rolle. Die sich schon seit längerem in der Diskussion befindlichen Ansätze zur Umgestaltung der Arbeitssituation scheinen sich noch nicht durchzusetzen. 
Tabelle 28: Wichtigster Grund für die Berufstätigkeit von erwerbstätigen

Frauen nach Familientyp Verteilung in \%

\begin{tabular}{|c|c|c|c|c|c|c|c|c|c|c|c|}
\hline $\begin{array}{l}\text { Berufstātige } \\
\text { Frauen }\end{array}$ & 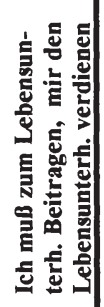 & 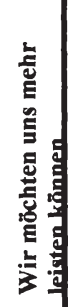 & 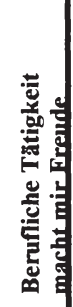 & 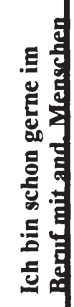 & 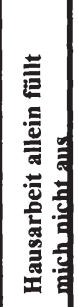 & 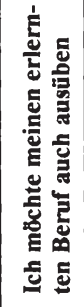 & 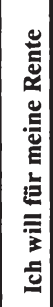 & 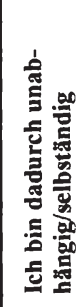 & 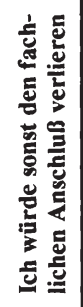 & 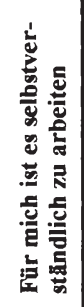 & z \\
\hline $\begin{array}{l}\text { Verheiratet ohne } \\
\text { Kinder unter } 16 \\
\text { Jahren }\end{array}$ & 33 & 12 & 17 & 10 & 3 & 3 & 7 & 3 & 1 & 11 & 991 \\
\hline $\begin{array}{l}\text { Verheiratet mit } \\
\text { Kindern unter } 16 \\
\text { Jahren }\end{array}$ & 37 & 13 & 15 & 10 & 5 & 4 & 3 & 4 & 1 & 8 & 1329 \\
\hline 1 Kind ... & 37 & 15 & 15 & 9 & 3 & 5 & 3 & 5 & $\mathbf{0}$ & 8 & 583 \\
\hline 2 Kinder ... & 39 & 12 & 16 & 10 & 6 & 4 & 2 & 3 & 1 & 7 & 617 \\
\hline $\begin{array}{l}3 \text { und mehr Kin- } \\
\text { der }\end{array}$ & 48 & 6 & 13 & 9 & 4 & 3 & 2 & 4 & 2 & 9 & 129 \\
\hline mit 1 Kind unter & 34 & 14 & 17 & 10 & 5 & 4 & 2 & 4 & 1 & 9 & 376 \\
\hline 6 Jahren... & & & & & & & & & & & \\
\hline $\begin{array}{l}2 \text { Kinder unter } \\
6 \text { Jahren... }\end{array}$ & 47 & 7 & 12 & 10 & 6 & 3 & 3 & 1 & 2 & 9 & 188 \\
\hline Alleinerziehend & & & & & & & & & & & \\
\hline $\begin{array}{l}1 \text { Kind unter } 16 \\
\text { Jahren }\end{array}$ & 74 & 3 & 5 & 4 & 1 & 2 & 1 & 5 & 1 & 4 & 271 \\
\hline $\begin{array}{l}2 \text { Kinder unter } 16 \\
\text { Jahren }\end{array}$ & 73 & 5 & 5 & 3 & 1 & 3 & $\mathbf{0}$ & 4 & $\mathbf{0}$ & 6 & 111 \\
\hline $\begin{array}{l}1 \text { Kind unter } 6 \\
\text { Jahren }\end{array}$ & 70 & 4 & 3 & 4 & 1 & 3 & 1 & 7 & 1 & 6 & 144 \\
\hline $\begin{array}{l}\text { Alleinerziehend } \\
\text { mit Partner... }\end{array}$ & 58 & 8 & 7 & 6 & 1 & 1 & 2 & 10 & 1 & 6 & 159 \\
\hline $\begin{array}{l}\text { Alleinerziehend } \\
\text { ohne Partner... }\end{array}$ & 87 & 1 & 3 & 2 & 0 & 2 & 0 & 1 & 0 & 4 & 249 \\
\hline $\begin{array}{l}\text { Ohne Kinder (16 } \\
\text { J.) mit Partner... }\end{array}$ & 48 & 11 & 11 & 1 & 2 & 4 & 2 & 11 & 1 & 9 & 168 \\
\hline $\begin{array}{l}\text { Ohne Kinder (16 } \\
\text { J.) ohne Partner }\end{array}$ & 66 & 2 & 6 & 5 & 2 & 2 & 3 & 9 & 1 & 4 & 479 \\
\hline Insgesamt... & 47 & 10 & 13 & 8 & 3 & 3 & 4 & 5 & 1 & 8 & - \\
\hline
\end{tabular}

Quelle: IAB-Projekt 3/2-399, 1991. 
Tabelle 29: Ehepaare mit Kindern und Alleinerziehende nach Beteiligung am Erwerbsleben (Vollzeittätigkeit, Teilzeittätigkeit) und Alter des jüngsten Kindes im Jahre 1992

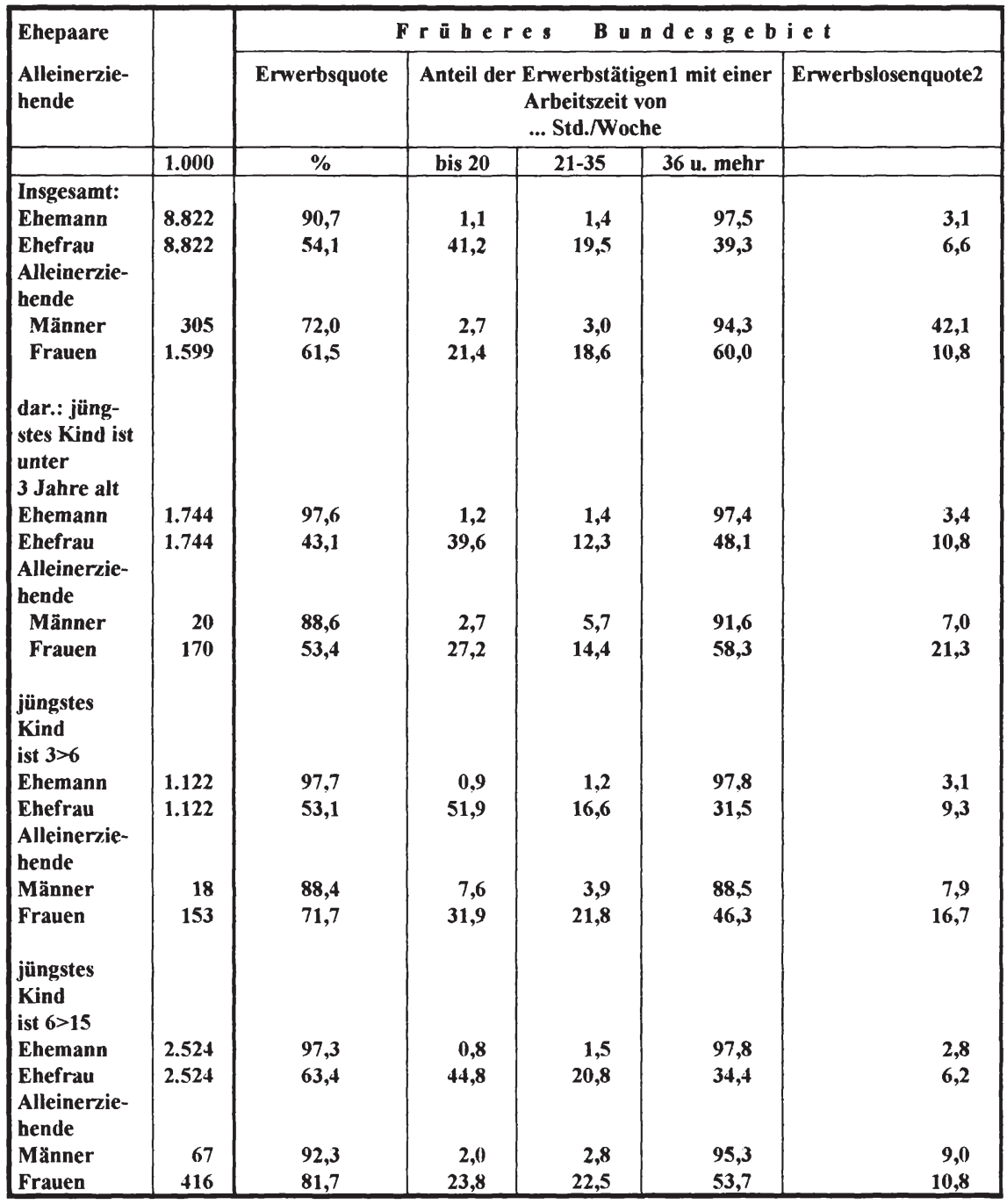




\begin{tabular}{|c|c|c|c|c|c|c|}
\hline \multirow{3}{*}{\begin{tabular}{|l} 
Ehepaare \\
Alleinerzie- \\
hende
\end{tabular}} & & \multicolumn{5}{|c|}{ Neue Lānder und Berlin-Ost } \\
\hline & & \multirow{2}{*}{$\begin{array}{c}\text { Erwerbsquote } \\
\%\end{array}$} & \multicolumn{3}{|c|}{$\begin{array}{l}\text { Anteil der Erwerbstätigen1 mit einer } \\
\text { Arbeitszeit von ... Std./Woche }\end{array}$} & \multirow[t]{2}{*}{ Erwerbslosenquote2 } \\
\hline & 1.000 & & bis 20 & $21-35$ & 36 u. mehr & \\
\hline \multicolumn{7}{|l|}{ insgesamt: } \\
\hline Ehemann & 2.210 & 92,8 & 0,4 & 0,6 & 99,1 & 7,7 \\
\hline Ehefrau & 2.210 & 91,7 & 3,8 & 14,7 & 81,5 & 23,1 \\
\hline $\begin{array}{l}\text { Alleinerzie- } \\
\text { hende }\end{array}$ & & & & & & \\
\hline Männer & 89 & 83,0 & 0,9 & 15,3 & 97,6 & 12,4 \\
\hline Frauen & 593 & 82,5 & 1,7 & 7,8 & 90,5 & 23,6 \\
\hline \multicolumn{7}{|l|}{ dar.: jüng- } \\
\hline \multicolumn{7}{|l|}{$\begin{array}{l}\text { stes Kind ist } \\
<3 \text { J } \text {. alt }\end{array}$} \\
\hline & & & & & & \\
\hline Ehemann & 280 & 98,6 & 0,3 & 0,4 & 99,4 & 8,9 \\
\hline Ehefrau & 280 & 92,2 & 5,1 & 12,7 & 82,2 & 32,0 \\
\hline \multicolumn{7}{|l|}{$\begin{array}{l}\text { Alleinerzie- } \\
\text { hende }\end{array}$} \\
\hline Männer & 20 & 97,9 & 1,3 & 1,9 & 96,8 & 12,2 \\
\hline Frauen & 111 & 90,7 & 1,6 & 6,1 & 92,3 & 27,1 \\
\hline \multicolumn{7}{|l|}{ Jüngstes } \\
\hline \\
\hline \multicolumn{7}{|l|}{ Ist $3>6$} \\
\hline Ehemann & 368 & 99,1 & 0,4 & 0,7 & 98,9 & 7,8 \\
\hline Ehefrau & 368 & 97,7 & 3,4 & 15,8 & 80,8 & 25,1 \\
\hline \multicolumn{7}{|l|}{ Alleinerzie- } \\
\hline hende & & & & & & \\
\hline Männer & 11 & 95,8 & - & 4,7 & 95,3 & 7,6 \\
\hline Frauen & 89 & 97,4 & 1,8 & 11,7 & 86,6 & 28,3 \\
\hline \multicolumn{7}{|l|}{ Jüngstes } \\
\hline \multicolumn{7}{|l|}{ Kind } \\
\hline \multicolumn{7}{|l|}{ Ist $6>15$} \\
\hline Ehemann & 871 & 98,2 & 0,3 & 0,5 & 99,2 & 6,8 \\
\hline Ehefrau & 871 & 97,4 & 3,4 & 14,5 & 82,1 & 20,3 \\
\hline Alleinerzie- & & & & & & \\
\hline hende & & & & & & \\
\hline Männer & 23 & 97,7 & 0,5 & 0,5 & 98,9 & 12,5 \\
\hline Frauen & 191 & 97,9 & 1,3 & 7,6 & 91,2 & 21,4 \\
\hline
\end{tabular}

1 Bezogen auf alle Erwerbstätigen der jeweiligen Zeile

2 Erwerbslose je 100 Erwerbspersonen der jeweiligen Zeile

Quelle: Statistisches Bundesamt, Im Blickpunkt: Familien heute, Ausgabe 1995. 
Auch zwei Jahre nach der Öffnung des Ostens (Berichtszeitpunkt) liegen die Erwerbsquoten der Ehefrauen in den neuen Bundesländern erheblich über den entsprechenden Quoten in den alten Bundesländern, gleiches gilt für alleinerziehende Frauen. Während Ehefrauen und alleinerziehende Frauen in den alten Bundesländern ihre wöchentliche Arbeitszeit reduzieren, bleiben vergleichbare Frauen in den neuen Bundesländern in einer Vollzeittätigkeit, auch wenn das jüngste Kind unter 3 Jahren alt ist. Ehefrauen mit Kindern zwischen 3 und 6 Jahren üben in überdurchschnittlichem Maße eine Teilzeitbeschäftigung aus, was darauf schließen läßt, das eine geeignete Betreuungsmöglichkeit (i.d.R. der Kindergartenplatz) eine teilweise Wiedereingliederung in den Arbeitsprozeß ermöglicht. Deutlich wird jedoch auch, daß vergleichbare alleinerziehende Frauen in annähernd gleichem Ausmaß einer Vollzeitbeschäftigung nachgehen $(46,3 \%$ in den alten Bundesländern), generell gehen alleinerziehende Frauen häufiger einer Vollzeitbeschäftigung nach als Ehefrauen. Zurückzuführen ist dies sicherlich auf den ökonomischen Zwang zur Erwerbstätigkeit, um den Lebensunterhalt bestreiten zu können, darüber hinaus aber auch auf die bevorzugte Behandlung bei der Vergabe von Kindergartenplätzen. Mit zunehmendem Alter des/der Kindes/Kinder steigt die Erwerbsquote der alleinerziehenden, ebenso wie die der Ehefrauen, an, jedoch auf höherem Niveau.

Um ein umfassendes Bild des Erwerbsverhaltens von Frauen zu erhalten, ist es notwendig, zusätzlich zu den Erwerbsquoten die Erwerbslosenquoten heranzuziehen. Und diese Betrachtung fördert deutliche Unterschiede zwischen Ost und West einerseits sowie Frauen und Männer andererseits zutage. Frauen sind ausnahmslos stärker von Erwerbslosigkeit betroffen als Männer, lediglich die alleinerziehenden Männer im früheren Bundesgebiet sind mit 42,1 \% außerordentlich häufig erwerbslos. Die Erwerbslosenquoten in den neuen Bundesländern liegen wesentlich höher als in den alten Bundesländern, sowohl bei Ehepaaren als auch bei den Alleinerziehenden, die mit Quoten zwischen 25 \% - 28 \% Spitzenwerte einnehmen. 


\subsection{Gesetzliche Schutzbestimmungen für Frauen}

Neben zahlreichen Arbeitsschutzgesetzen, die im Zuge des Gleichberechtigungsgrundsatzes inzwischen für Männer und Frauen gleichermaßen gelten, sind Beschäftigungsverbote speziell für Frauen noch in folgenden Gesetzen und Verordnungen enthalten:

- 64a Bundesberggesetz,

- Gefahrstoff VO vom 25.9.1991,

- Röntgen VO vom 8.1.1987,

- Strahlenschutz VO in der Fassung vom 30.6.1989.

Die wohl umfassendste, aber auch restriktivste noch geltende Schutzbestimmung ist das „Gesetz zum Schutz der erwerbstätigen Mutter“ kurz "Mutterschutzgesetz ${ }^{\text {". }}{ }^{300}$ Schon das Grundgesetz versichert jeder Mutter „den Schutz und die Fürsorge der Gemeinschaft ${ }^{6301}$, womit in erster Linie auf den Schutz der unselbständigen erwerbstätigen Mutter abgestellt wird, wenn die Bestimmungen des Mutterschutzgesetzes näher betrachtet werden. Im ursprünglichen Sinn beinhaltet der Mutterschutz die Vorsorge für die Gesundheit von Mutter und Kind sowie die wirtschaftliche Existenzsicherung der Mutter während der Schwangerschaft und der ersten Wochen nach der Entbindung. Nach einhelliger Auffassung der Juristen und entsprechenden Urteilen des Bundesverfassungsgerichtes verstößt der Mutterschutz nicht gegen den Grundsatz der Gleichberechtigung von Mann und Frau oder das Gebot der Gleichbehandlung aller Arbeitnehmer, da die Regelungen des Mutterschutzes auf objektiven biologischen und funktionalen Unterschieden von Mann und Frau beruhen.

SchutzmaBnahmen für Mütter gibt es seit 1878, es war verboten, gewerbliche Arbeiterinnen als Wöchnerinnen 3 Wochen nach der Niederkunft zu beschäftigen. Die Einführung der Krankenversicherung der Arbeiter im Jahre 1883 brachte eine Verbesserung der finanziellen Lage der Frauen, da

${ }^{300}$ Gesetz zum Schutz der erwerbstätigen Mutter in der Fassung der Bekanntmachung vom 18.4.1968 (BGBI 1 S. 315), zuletzt geändert durch „Erstes Gesetz zur Änderung des Mutterschutzgesetzes vom 3. Juli 1992 (BGBI. I S. 1191), in den neuen Ländern ab dem 1.1.1991 anzuwenden.

301 Art. 6 VI GG. 
für die 3wöchige Schutzfrist die Zahlung von Wochengeld in Höhe des Krankengeldes eingeführt wurde. Seither ist nicht nur die Zeit der Arbeitsfreistellung ständig ausgeweitet worden, auch die finanziellen Zuwendungen haben sich quantitativ und in der zeitlichen Ausdehnung erhöht.

In das Mutterschutzgesetz eingebunden sind alle Frauen, die in einem Arbeitsverhältnis stehen oder in Heimarbeit beschäftigt bzw. insoweit gleichgestellt sind ( 1 MuSchG). Mutterschaft einerseits und ein bestehendes Arbeitsverhältnis sind also die generellen Voraussetzungen zur Inanspruchnahme des gesetzlichen Mutterschutzes. Beamtinnen und Richterinnen werden vom MuSchG nicht erfaßt, da sie nicht in einem Arbeitsverhältnis im Sinne des Arbeitsrechts, sondern in einem öffentlich-rechtlichen Dienstverhältnis stehen. Für sie gelten jedoch entsprechende Verordnungen des Bundes und der Länder, die größtenteils die Bestimmungen des Mutterschutzgesetzes übernommen haben. In das Gesetz einbezogen sind jedoch arbeitslose Frauen im Sinne des Arbeitsförderungsgesetzes, die Leistungen von der Bundesanstalt für Arbeit beziehen.

Nach § 5 I MuSchG sollen werdende Mütter ihrem Arbeitgeber die Schwangerschaft und den voraussichtlichen Termin der Geburt mitteilen, sobald ihnen ihr Zustand bekannt ist. Es handelt sich hier aber ausdrücklich nicht um eine sanktionierte Rechtsverpflichtung, sondern lediglich um eine nachdrückliche Empfehlung. Die Vorschrift dient ausschließlich dem Zweck, die gesundheitsfürsorgerischen und sozialen Schutzbestimmungen im Interesse von Mutter und Kind, anwenden zu können. Der Arbeitgeber kann seinerseits verlangen, daß ihm das Zeugnis eines Arztes oder einer Hebamme über das Bestehen einer Schwangerschaft und den Geburtstermin, vorgelegt wird (§ 5 I 1 MuSchG), aber auch diese Vorschrift ist nur als Sollvorschrift ausgestaltet. Ist dem Arbeitgeber der Zustand der Frau offiziell bekanntgemacht worden, muß er die Aufsichtsbehörde unverzüglich über die vorliegende Schwangerschaft unterrichten (§ 5 I 3, 4 MuSchG), bei Versäumnis droht ihm eine Geldbuße gemäß $\$ 21$ I Nr. 6, II MuSchG.

Kern des Mutterschutzgesetzes bildet eine Reihe von schwangerschaftsund mutterschaftsbedingten Beschäftigungseinschränkungen. Wer eine werdende oder stillende Mutter beschäftigt, hat die zum Schutz ihrer Gesundheit und ihres Lebens erforderlichen Vorkehrungen bei der Einrichtung und 
der Unterhaltung des Arbeitsplatzes und bei der Regelung der Beschäftigung zu treffen (\$2 I MuSchG). Für werdende und stillende Mütter, die mit Arbeiten beschäftigt werden, bei denen sie ständig stehen oder gehen müssen, ist eine Sitzgelegenheit zum kurzen Ausruhen bereitzustellen (§ 2 II, III MuSchG).

Ein allgemeines Beschäftigungsverbot für werdende Mütter gilt in den letzten 6 Wochen vor der Entbindung und bis zum Ablauf von 8 Wochen nach der Entbindung, nach Früh- und Mehrlingsgeburten verlängert sich diese Frist auf 12 Wochen ( 6 I MuSchG). Während es der Schwangeren auf ihren Wunsch hin gestattet werden kann, in den 6 Wochen vor der Geburt ihre Arbeitsleistung zu erbringen (§ 3 II MuSchG), handelt es sich bei dem Beschäftigungsverbot nach der Entbindung um ein „absolutes Beschäftigungsverbot“" d.h. die Arbeitnehmerin kann darauf nicht verbindlich verzichten.

Für die Berechnung der 6-Wochen-Schutzfrist ist das Zeugnis des Arztes/der Hebamme maßgeblich. Wird der Schwangeren von ärztlicher Seite bescheinigt, daß das Leben oder die Gesundheit von ihr oder ihres Kindes bei Fortdauer der Beschäftigung gefährdet sind, kommen die sogenannten individuellen Beschäftigungsverbote zum Tragen. Insbesondere sie stellen eine hohe Belastung für den Arbeitgeber dar, weil außerhalb der allgemeinen Schutzfristen der Arbeitgeber das Arbeitsentgelt allein in voller Höhe weiterzuzahlen hat (§ 11 I 1 MuSchG). Gemäß § 4 MuSchG dürfen werdende Mütter nicht mit schweren körperlichen Arbeiten und darüber hinaus nicht mit Arbeiten beschäftigt werden, bei denen sie schädlichen Einwirkungen von gesundheitsgefährdenden Stoffen oder Strahlen, von Staub, Gasen oder Dämpfen, von Hitze, Kälte oder Nässe, von Erschütterungen oder Lärm ausgesetzt sind. Führen diese Beschäftigungsverbote dazu, daB die Arbeitnehmerin ihre bisherige Arbeit nicht weiter verrichten kann, so ist der Arbeitgeber berechtigt, ihr eine andere Beschäftigung zu übertragen, ohne daß ihre Entlohnung gekürzt wird. Werdende und stillende Mütter dürfen nicht mit Mehrarbeit, nicht in der Nacht zwischen 20.00 und 6.00 Uhr und nicht an Sonn- und Feiertagen ( $\$ 8$ I 1 MuSchG) beschäftigt werden. Der Arbeitgeber hat der schwangeren Frau zur Durchführung der Untersuchungen im Rahmen der Mutterschaftsvorsorge u.U. während der Ar- 
beitszeit ausreichend Freizeit zu gewähren ohne daB ein Entgeltausfall eintritt ( $\$ 16$ MuSchG). Von diesem Entgeltschutz sind lediglich diejenigen Frauen ausgenommen, die in einem Familienhaushalt mit hauswirtschaftlichen Arbeiten beschäftigt werden, aber nicht dauernd in einer ihre Arbeitskraft voll in Anspruch nehmenden Weise (§ 11 III MuSchG). Während der 6- bzw. 8wöchigen Schutzfrist tritt das Mutterschaftsgeld an die Stelle des Arbeitseinkommens der Frau. Die Zahlung von Mutterschaftsgeld differiert je nach Status in der Sozialversicherung ( $\$ 13$ I, II MuSchG), d.h. bei Ansprüchen auf laufendes Mutterschaftsgeld gilt folgende Unterscheidung:

1. Die werdende Mutter ist Mitglied in der gesetzlichen Krankenversicherung ( $\$ 200$ RVO).

Voraussetzung für den Bezug von Mutterschaftsgeld ist, daB die Frau bei Beginn der 6 wöchigen Schutzfrist vor der Entbindung entweder in einem Arbeitsverhältnis steht oder daß sie während der Schwangerschaft die ausnahmsweise zulässige Auflösung ihres Arbeitsverhältnisses durch den Arbeitgeber hat hinnehmen müssen. Darüber hinaus muß sie in der Zeit zwischen dem 10. und dem 4. Monat vor der Entbindung für mindestens 12 Wochen versicherungspflichtig gewesen sein. Die Höhe des Mutterschaftsgeldes bemißt sich nach dem durchschnittlichen Nettoarbeitsentgelt der letzten 3 abgerechneten Kalendermonate, bei wöchentlicher Abrechnung nach den letzten 13 Wochen vor Beginn der Schutzfrist (§ 200 II RVO).

Seit dem 1.1.1968 gilt, daß die Krankenkassen nur bis zur Höhe von 25,-- DM täglich Mutterschaftsgeld zu zahlen haben. Die Differenz zwischen diesem Betrag und einem darüber hinausgehenden durchschnittlichen Nettoarbeitsentgelt belastet den Arbeitgeber (§ 14 I MuSchG). Damit wurde im Laufe der Zeit bewirkt, daß der Arbeitgeber wegen des ständig steigenden Lohnes, tendenziell stärker belastet wird.

2. Die werdende Mutter ist Mitglied in einer privaten Krankenversicherung.

Gemäß § 13 II MuSchG erhalten diese Frauen kein laufendes Mutterschaftsgeld, sondern lediglich einen einmaligen Pauschalbetrag in Höhe von 400,-- DM. Dieser Betrag wird vom Bund auf Antrag gezahlt und entspricht dem Pauschalbetrag, den der Bund auch für jede in der gesetzlichen Krankenversicherung versicherte Frau mit regulärem Mutterschaftsgeld an die 
Kasse zu zahlen hat. Der Betrag von 400,-- DM wird jedoch auch nur dann gezahlt, wenn bei Beginn der Schutzfrist ein Arbeits- oder Heimarbeitsverhältnis besteht, sowie daB in der Zeit zwischen dem 10. und dem 4. Monat vor der Entbindung für mindestens 12 Wochen ein solches Verhältnis bestanden hat.

3. Die werdende Mutter ist Mitglied in der gesetzlichen Krankenversicherung, steht aber bei Beginn der Schutzfrist in keinem Arbeitsverhältnis.

Diese Regelung erfaBt im wesentlichen Frauen, die Arbeitslosengeld, Arbeitslosenhilfe oder Unterhaltsgeld nach dem Arbeitsförderungsgesetz beziehen. Die betroffenen Frauen erhalten in diesem Fall ein Mutterschaftsgeld in Höhe des Krankengeldes. Es gilt jedoch auch hier die Voraussetzung einer Vorversicherungszeit während der Rahmenfrist zwischen dem 10. und dem 4. Monat vor der Entbindung.

4. Die werdende Mutter ist Mitglied in der gesetzlichen Krankenversicherung, erfüllt aber in keiner Weise die Voraussetzungen für den Bezug von laufendem Mutterschaftsgeld.

Diese Frauen erhalten als einmalige Leistung bei der Entbindung ein Mutterschaftsgeld in Höhe von 150,-- DM (\$ 200 b RVO).

Letztlich regelt das MuSchG auch den Kündigungsschutz der erwerbstätigen Mutter während der Schwangerschaft und bis 4 Monate nach der Niederkunft ( 9 MuSchG). Das Kündigungsverbot umfaBt auch außerordentliche Kündigungen, sofern keine schwerwiegenden Gründe Ausnahmen zulassen. Lediglich ,in besonderen Fällen“ kann ausnahmsweise eine Kündigung von der für den Arbeitsschutz zuständigen obersten Behörde eines Bundeslandes für zulässig erklärt werden (§ 9 III MuSchG). Einen abgeschwächten Kündigungsschutz haben Arbeitnehmerinnen, die in einem Familienhaushalt voll beschäftigt sind ( $\$ 9$ MuSchG).

Im Gegensatz zu den äußerst restriktiven Kündigungsmöglichkeiten des Arbeitgebers im Falle einer Schwangerschaft, hat die Frau das Recht, von sich aus ihr Arbeitsverhältnis zu kündigen, $\$ 10$ I MuSchG räumt ihr zudem noch ein Sonderkündigungsrecht ein: Sie kann zum Ende der Schutzfrist ohne jegliche Fristwahrung kündigen. Zu bemerken sei in diesem Zusammenhang, daB jegliche Dispositionsbedürfnisse des Arbeitgebers hier auBer Acht gelassen werden. 
Die Forderung nach weiteren familien- und damit wohl in erster Linie frauenpolitischen Maßnahmen mag sicherlich ihre Berechtigung haben, allerdings sollte auch nicht verkannt werden, daß weitgehende Schutzbestimmungen bzw. Maßnahmen, die ausschließlich Frauen in hohem Maße begünstigen, als Markteintrittsschranke auf dem Arbeitsmarkt fungieren und damit im Extremfall den Ausschluß aus einigen Lebensbereichen zur Folgen haben können. Als Beispiel sei die zweifellos notwendige Mutterschutzgesetzgebung angeführt: Obwohl die entstehenden Kosten zwischen Bund (27 Mio. DM), Krankenkassen (2,83 Mrd. DM) und Arbeitgeber aufgeteilt werden, wird der Arbeitgeber in nicht unerheblichem Ausmaß, gemessen an seinem finanziellen Potential, zu Zahlungen herangezogen wird. Bei den Arbeitgebern spielen weitere Faktoren eine Rolle, die sich häufig nur unzureichend monetär bewerten lassen. Da die Arbeitgeber während der Zeit des Mutterschutzes das Mutterschaftsgeld auf die Höhe des letzten Durchschnittsverdienstes aufstocken müssen, trifft ihn dies umso härter, je mehr die Frau verdient. Er muß das Gehalt für die Zeit des Beschäftigungsverbotes weiterzahlen, auch wenn die Frau dafür keinerlei Leistungen erbringt. Es ist also zu vermuten, daß ein Arbeitgeber weniger geneigt sein wird, höher dotierte Positionen mit Frauen im gebärfähigen Alter zu besetzen. Für ihn gibt es zwar die Möglichkeit der Versetzung der schwangeren Frau auf einen anderen Arbeitsplatz, dies wird jedoch umso schwieriger, je kleiner der Betrieb ist, so daß er unter Umständen gezwungen ist, eine Ersatzkraft zu beschäftigen, die wiederum weitere Kosten verursacht, nicht nur durch die Entlohnung, sondern auch durch eine gewisse Einarbeitungszeit. Durch die Vielzahl der Beschäftigungsverbote über die eigentliche Schutzfrist hinaus können Arbeitgeber die Arbeitskraft von Frauen bei Schwangerschaft nur beschränkt nutzen. Jegliche Arbeitsausfälle belasten einen Betrieb in hohem Maße und erfordern auch organisatorisch eine hohe Bereitschaft und Fähigkeit zur Flexibilität. Geeignete Ersatzkräfte müssen zunächst einmal gefunden werden und weiterhin müssen sie bereit sein, ein Arbeitsverhältnis, das durch große Unsicherheit bzgl. langfristiger Beschäftigungsmöglichkeiten - selbst bei hervorragenden Leistungen - gekennzeichnet ist, einzugehen. Eine Mutter kann hingegen in Anspruch nehmen, fristlos zum Ende der Schutzfrist zu kündigen. Die Personalplanung wird dadurch für den Arbeit- 
geber sehr erschwert. Kündigt die Mutter, so hat der Arbeitgeber für einen längeren Zeitraum den Arbeitsplatz freihalten müssen. Eine für die Frauen negative Auswirkung besteht darin, daß ein Arbeitgeber eine Investition in kostenintensive Aus- und Fortbildungen bei Frauen als nicht lohnend erachtet. Die Konsequenzen liegen also auf der Hand: durch ein "Schutzgesetz" werden sie für Arbeitgeber zu einer Belastung und als Folge daraus nur in nachrangiger Priorität bei Einstellungen berücksichtigt. Werden Frauen eingestellt, so kommt es häufig dazu, daß sie weniger verdienen als ein Mann in gleicher Position (siehe die Ausführungen und Zahlen an anderer Stelle dieser Arbeit), weil der Arbeitgeber versucht, die ihm entstehenden Kosten bei Schwangerschaft auf die weiblichen Mitarbeiter abzuwälzen. Auch der Anspruch von Frauen, in den sogenannten "typischen" Männerberufen tätig zu sein, scheitert häufig nicht an fehlenden Fähigkeiten, sondern eher an dem zu erwartenden Aufwand für den Arbeitgeber, wenn der Tatbestand Schwangerschaft dann eintritt.

Die Ursache dieser unerwünschten Wirkungen dürfte jedoch nicht so sehr in dem Mutterschutz an sich liegen, sondern eher in der Art der Finanzierung, d.h. in der faktischen Kostenbelastung der Beteiligten. Die immer wieder betonte Diskriminierung der Frau auf dem Arbeitsmarkt ist m.E. auf diesen Tatbestand zurückzuführen. Dabei werden nicht nur potentielle Mütter benachteiligt, sondern alle Frauen, auch wenn bei ihnen eine Mutterschaft nicht zu erwarten ist. Die nachteiligen Wirkungen wirken sich natürlich umso stärker aus, je höher das Überangebot an Arbeitskräften ist, und je besser die Arbeitgeber bei ihrer Personalwahl selektieren können.

Angesichts der Tatsache, daß bereits Anfang des nächsten Jahrtausends aufgrund der bekannten Bevölkerungsentwicklung ein Defizit an jungen, qualifizierten Arbeitskräften auftreten wird, haben viele Großunternehmen schon seit geraumer Zeit Förderprogramme entwickelt und aufgelegt. Beispielsweise versuchen der Elektrokonzern Philips mit einem Konzept namens "Pfiff" (Philipsfrauen in Führungsfuntionen) und das Chemieunternehmen Hoechst mit einem Programm "HOECHSTweiblich" Frauen die Möglichkeit zu geben, leichter in leitende Positionen zu gelangen. Auch der Bankensektor engagiert sich auf dem Gebiet der Frauenförderung, was verständlich ist, da gerade in diesem Bereich der Frauenanteil überpropor- 
tional hoch ist, und darüber hinaus durch die zunehmende Technisierung hochqualifiziertes Personal benötigt wird. Im Durchschnitt gibt die Branche 50.000,-- DM für eine hoffnungsvolle Nachwuchskraft aus; eine Fehlinvestition, wenn die Frau nicht wieder an ihren Arbeitsplatz zurückkehrt, oder so viel Zeit bis zu ihrem Wiedereintritt verstreichen läBt, daB das einmal vorhandene Wissen schon völlig veraltet ist. Die aufgelegten Förderpläne erzielen momentan eher bescheidene Erfolgsquoten, der Stuttgarter Automobilhersteller Mercedes konnte seinen Frauenanteil im mittleren Management trotz frauenfördernder MaBnahmen - seit 1991 gerade mal von 2,6 \% auf 2,8\% steigern, und auch der Münchener Elektronikkonzern Siemens erzielte im gleichen Zeitraum nur eine Erhöhung von 2,6 \% auf 3,2 \%. Eine Umfrage bei Großunternehmen ergab, daß trotz bereits vieler Zugeständnisse nur wenige Frauen nach der Schwangerschaft an ihren Arbeitsplatz zurückkehren. Eine große Zahl der Frauen mit längerer Ausbildung und höherer Qualifikation legt ganz bewußt eine längere Babypause ein, um sich voll und ganz ihrem Kind widmen zu können. Auch dieses sollte einmal gesehen werden, wenn wieder einmal bestimmte gesellschaftliche Gruppen vehement die Beteiligung der Frau am Erwerbsleben fordern und damit automatisch die Kinder in die kollektiven Erziehungseinrichtungen "abschieben".

\section{Berücksichtigung von Zeiten der Kindererziehung in der GRV}

- Erziehungsgeld, Erziehungsurlaub und Anrechnung von Erziehungszeiten in der Rentenversicherung

Ende 1979 - in einer Zeit also, als die finanzielle Lage der GRV als äuBerst stabil bezeichnet werden konnte - erwog die Sachverständigenkommission für die soziale Sicherung der Frau und der Hinterbliebenen, 3 - 5 Jahre für ein Kind in der Rentenversicherung zu berücksichtigen. Getragen wurde diese Vorstellung von der Leitidee, daB Kindererziehung nicht zur bis dahin beobachtenden Altersarmut von Witwen führen dürfe, die geforderte "eigenständige" Sicherung der Frau allerdings auch nicht mit dem Ziel der Alterssicherung, zur Stabilität von Ehe und Familie beizutragen, kollidieren dürfe. Die Einbeziehung der Kindererziehung in die GRV erfordert also ein 
zweidimensionales Denken: im Hinblick auf das Grundgesetz, welches die Ehe unter besonderen Schutz stellt, ergibt sich die Frage, ob eine größere Eigenständigkeit der sozialen Sicherung der Frau zur Festlegung oder zur Auflösung der Ehe beitrage. Unter ökonomischen Gesichtspunkten und unter Berücksichtigung der zunehmenden Erwerbstätigkeit von Frauen ist zu untersuchen, ob eine Abkoppelung der Leistungen der GRV für Ehepartner - ohne daß hierfür eine besondere Beitragsleistung erbracht wurde - das Versicherungsprinzip nicht stärker in den Vordergrund rücken läßt, um somit letztlich die finanzielle Situation der GRV mittelfristig verbessert.

Die Überlegungen zur Einbeziehung der Kindererziehung als rentenbegründenden und rentensteigernden Tatbestand in der GRV gründeten sich in nicht unerheblichem Ausmaß auf der Idee einer Neugestaltung des $\mathrm{Zu}$ sammenlebens von Mann und Frau, in dem beide gleichermaßen in die Erziehungs- und Hausarbeit einbezogen werden und die Leistung der Kindererziehung aufgewertet wird. Neben der Aufwertung der Kindererziehungsarbeit ist im bestehenden System der sogenannte "Generationenvertrag" nur dann erfüllt, wenn ausreichend Kinder geboren werden, denn ohne Kinder - und damit zukünftige Beitragszahler - gibt es keine genügende Sicherung der künftigen Rentnergeneration. Auf die Notwendigkeit einer bestandserhaltenden Zahl von Geburten zur Aufrechterhaltung des Generationenvertrages hat neben Wilfried Schreiber auch der namhafte Vertreter der katholischen Soziallehre Oswald von Nell-Breuning hingewiesen, der ausdrücklich von einer Drei-Generationen-Solidarität ausging, die die Kindererziehung einschloB.

Seit dem 1. Januar 1986 zählen Erziehungsgeld, Erziehungsurlaub und die Anrechnung von Erziehungszeiten in der Rentenversicherung zu den anerkannten Instrumenten der Familienpolitik in der BRD, d.h. sie sind gesetzlich fixiert worden ${ }^{302}$ und damit gegen eine willkürliche Änderung aufgrund sich ändernder politischer Verhältnisse in gewissem Ausmaß gefeit. Der Gedanke, daB familienpolitische MaBnahmen im Rahmen einer Sozialpolitik in einer industriellen Wirtschaftsgesellschaft einen Platz haben müBten, wurde schon in den fünfziger Jahren heftig diskutiert.

\footnotetext{
${ }^{302}$ Gesetz über die Gewährung von Erziehungsgeld und Erziehungsurlaub (Bundeserziehungsgeldgesetz - BErzGG) vom 6. Dezember 1985, BGBL., Teil I, S. 2154 ff.
} 
Vor allem G. Mackenroth forderte, daß Sozialpolitik durch keine ihrer Einrichtungen und Maßnahmen die Familie gefährden dürfe. Hier sah er die aktive Aufgabe der Sozialpolitik. Ausgangspunkt seiner Überlegungen war die sich schon damals abzeichnende Entwicklung der permanenten Verbesserung der Einkommensposition kinderloser Familien, da nicht nur beide Elternteile einer Erwerbstätigkeit nachgehen konnten, sondern auch die Kosten für das Aufziehen der Kinder entfielen. Diese, zum Teil durch politische Entscheidungen (generell die Wirtschaftsordnung, speziell die Gesetzgebung, bei der die Leistung im Vordergrund steht) ausgelösten Prozesse des wirtschaftlichen und gesellschaftlichen Wandels würden die Verteilungsordnung nachhaltig ändern. Er postulierte in diesem Zusammenhang den Familienlastenausgleich als große sozialpolitische Aufgabe des 20. Jahrhunderts.

Übersehen hat Mackenroth nicht, daß die Erfüllung dieser Aufgabe, wollte man sie in das System der gesetzlichen Sozialversicherung einbetten, eine teilweise Abkehr vom Individualprinzip hin zum Familienprinzip bedeuten würde; dies mit seinen Vor- und Nachteilen, und mit Verteilungswirkungen, die unter Umständen nicht durchschaubar sind. Viel problematischer ist jedoch in der Realität die Veränderung einmal bestehender Verteilungsmuster.

Schon der Versuch, die Legitimität oder auch nur den Sinn bestehender Verteilungsmuster anzuzweifeln, weckt den Zorn der Verteidiger alter Positionen. Insofern war und ist die Durchsetzung eines zielgerichteten Familienlastenausgleichs oder nach neuerer Lesart Familienleistungsausgleich im sozialen System schwierig. Dies trifft auch deshalb zu, weil die Entscheidung für eines der beiden Prinzipien immer ein Werturteil beinhaltet, auch wenn für die stärkere Berücksichtigung des Familienprinzips ökonomische Gründe angeführt werden können.

Die Notwendigkeit familienpolitischer Maßnahmen zur Sicherung der Aufgabenerfüllung der Familie haben bisher sämtliche Familienminister/innen der Bundesrepublik ausdrücklich betont. Weitgehend Einigkeit herrscht auch darüber, daß es gezielter familienpolitischer Maßnahmen bedarf, um dem einzelnen die Chance zu geben, sich in bestimmten Lebensphasen für die Übernahme von Erziehungs- und Pflegeaufgaben ent- 
scheiden zu können. Das Problem besteht jedoch darin, wer die MaBnahmen bezahlen und wer in welchem AusmaB begünstigt werden soll.

Der Familienpolitik wird gemeinhin die Aufgabe zugewiesen, wirtschaftliche Nachteile, die durch das Aufziehen von Kindern entstehen, ${ }^{303}$ bis zu einem gewissen Grad auszugleichen.

Um im folgenden auf die einzelnen Bestimmungen eingehen und um eine sinnvolle Wirkungsanalyse durchführen zu können, sei erst einmal die Zielsetzung bzw. das Leitbild der Bundesregierung kurz dargestellt:

Leitbild ist ein Ausspruch des Bundeskanzlers vom 4. Mai 1983, in dem er erklärt:

"Beruf ist für uns nicht nur außerhäusliche Erwerbstätigkeit. Tätigkeit im Hause und für Kinder ist gleichwertig; sie muß wieder mehr Anerkennung finden."

Dieses Zitat läBt die familienpolitischen Ziele eindeutig erkennen:

(1) Die Familientätigkeit soll der Erwerbstätigkeit in gewissem AusmaB, nämlich in der Zeit der Kindererziehung, gleichgestellt sein, bzw. sie soll als eine der Erwerbstätigkeit gleichwertige Aufgabe anerkannt werden.

Daraus resultiert im übrigen, daB das Erziehungsgeld allen, also auch den nichterwerbstätigen Müttern und Vätern zu gewähren ist .

(2) Die Entwicklung des Kindes soll in der ersten Lebensphase nicht durch Ausfall einer festen Bezugsperson beeinträchtigt werden. Dafür ist es allerdings nicht notwendig, daß der Erziehende seine Erwerbstätigkeit vollkommen aufgeben muB; eine auf die Betreuungsaufgabe angepaBte Teilzeitarbeit wird akzeptiert. Dahinter steht die weitverbreitete, jedoch nicht unumstrittene These, daB Deprivationsschäden vermindert werden, wenn das Kind in seinem ersten Lebensjahr eine Bezugsperson hat.

Darüber hinaus verfolgt die heutige Familienpolitik folgende Zielsetzungen:

1. Die finanzielle Entlastung der Familien (besonders bei Alleinerziehenden) wird angestrebt.

${ }^{303}$ Vgl. 3. Familienbericht. 
2. Der Familie soll mehr Wahlfreiheit für die Entscheidung zwischen Tätigkeit in der Familie und außerhäuslicher Erwerbstätigkeit gegeben werden.

3. Das in der Ehe- und Familienrechtsreform von 1977 verankerte Partnerschaftsprinzip soll im "Prinzip der Elternschaft" fortgeführt werden. Ausdruck findet dies dadurch, daß bei der Gewährung familienpolitischer Maßnahmen nicht an der Geburt, sondern an der faktischen Erziehungsleistung angeknüpft wird. Die Elternteile sollen demzufolge die gleiche Verantwortung für die Betreuung und Erziehung der Kinder bei unterschiedlichen Formen des partnerschaftlichen Zusammenlebens erhalten.

4. Frauen sollen sich nicht aus wirtschaftlichen Gründen gegen ein Kind entscheiden.

Um Ansprüche auf Erziehungsgeld geltend machen zu können, müssen mehrere, vom Gesetzgeber formulierte, Anspruchsvoraussetzungen kumulativ erfüllt sein. Die relevanten Anspruchsvoraussetzungen können

1. nach der Art des anspruchsberechtigten Personenkreises,

2. nach der Art des Kindschaftsverhältnisses,

3. nach der Art der Betreuungssituation und

4. nach dem Umfang der Erwerbstätigkeit unterschieden werden.

Ad 1. Anspruchsberechtigt sind vier Personenkreise:

(1) Einen Anspruch auf Erziehungsgeld hat "wer einen Wohnsitz oder seinen gewöhnlichen Aufenthalt im Geltungsbereich dieses Gesetzes hat" ${ }^{\text {304 }}$.

(2) Anspruch auf Erziehungsgeld haben darüber hinaus Bedienstete, die ins Ausland entsandt, abgeordnet, versetzt oder kommandiert sind, weiterhin wer Versorgungsbezüge nach beamten- oder soldatenrechtlichen Vorschriften oder Grundsätzen oder eine Versorgungsrente von einer Zusatzversor-

${ }^{304}$ Vgl. $§ 1$ Abs. 1 Nr. 1 BErZGG. 
gungsanstalt für Arbeitnehmer des öffentlichen Dienstes erhält und letztlich Entwicklungshelfer im Sinne des § 1 Entwicklungshelfer-Gesetzes.

(3) Anspruch hat auch der Ehegatte, der unter (1) und (2) genannten Personen, wenn die Ehegatten in einem Haushalt leben ${ }^{305}$.

(4) Letztendlich ist anspruchsberechtigt, wer als Angehöriger eines Mitgliedstaates der Europäischen Gemeinschaft ein Arbeitsverhältnis im Geltungsbereich des Bundeserziehungsgeldgesetzes hat, allerdings in diesem Fall nur die betreffenden Arbeitnehmer selbst, Familienangehörige sind ausgeschlossen. Anspruchsberechtigt ist auch, wer als Grenzgänger in die BRD ein Arbeitsverhältnis im Geltungsbereich des Bundeserziehungsgeldgesetzes hat $t^{306}$.

Ad 2. Anspruch auf Erziehungsgeld hat eine Person, wenn sie mit einem nach dem 31. Dezember 1985 geborenen Kind, für das ihr die Personensorge zusteht, in einem Haushalt lebt ${ }^{307}$. Als "Kinder" gelten neben den leiblichen auch die Adoptivkinder ${ }^{308}$.

Das Zusammenleben "in einem Haushalt" stellt auf Personen ab, die in einer dauerhaften Beziehung zu dem Kind stehen, dazu können neben den leiblichen Eltern, Adoptiveltern, Stiefeltern, sowie diejenigen Eltern, die ein Kind in Obhut genommen haben, auch Großeltern und sonstige Personen, wenn ihnen das Sorgerecht zusteht, gehören ${ }^{309}$.

Ledige Mütter können ebenfalls einen Anspruch auf Erziehungsgeld geltend machen, sofern ihnen das Sorgerecht zusteht, hat der Vater des nichtehelich geborenen Kindes das Sorgerecht für dieses Kind, kann er einen Anspruch auf Erziehungsgeld geltend machen, in diesen Fällen kann stets nur einem Elternteil Anspruch auf Erziehungsgeld zugestanden werden.

\footnotetext{
${ }^{305}$ Vgl. § 1 Abs. 2 Satz 2 BErzGG.

${ }^{306}$ Vgl. § 1 Abs. 4, Nr. 1, Nr. 2 BErzGG.

${ }^{307}$ Vgl. $\$ 1$ Abs. 1, Nr. 2 BErzGG.

${ }^{308}$ Vgl. § 1 Abs. 3 BErzGG.

${ }^{309}$ Eingeschlossen sind hier auch minderjährige Eltern mit rechtlich eingeschränktem Sorgerecht, wenn sie das Kind tatsächlich betreuen.
} 
Ad. 3. Der Anspruchsberechtigte muß das Kind "selbst betreuen und erziehen" ${ }^{1310}$. Kürzere Verzögerungen oder Unterbrechungen, wie beispielsweise ein Krankenhausaufenthalt des Anspruchsberechtigten oder des Kindes, führen nicht zum Verlust des Anspruchs ${ }^{311}$.

Ad. 4. Innerhalb der Zeit, in der der Anspruchsberechtigte Erziehungsgeld erhält, wird vorausgesetzt, daß er keine oder zumindest keine volle Erwerbstätigkeit ausübt ${ }^{312}$.

Die Aufgabe oder zumindest die Teilaufgabe der Erwerbstätigkeit soll die selbständige Betreuung und Erziehung des Kindes in den ersten Lebensmonaten sichern, die Akzeptanz einer Teilzeitarbeit wird von der Bundesregierung damit begründet, daß sie "zur Ausgeglichenheit des Elternteils beitragen und damit auch dem Wohl des Kindes dienen (kann)", die "spätere Rückkehr in das Arbeits- und Berufsleben" erleichtert und "damit den Entschluß fördern (kann), sich in den für die Entwicklung des Kindes besonders wichtigen Jahren mit Vorrang dessen Pflege und Erziehung zu widmen" ${ }^{1313}$.

Als erwerbstätig gelten unselbständig beschäftigte Arbeitnehmer, Selbständige und mithelfende Familienangehörige; eine volle Erwerbstätigkeit im Sinne des Bundeserziehungsgeldgesetzes liegt vor, wenn die wöchentliche Arbeitszeit 19 Stunden übersteigt oder eine Beschäftigung ausgeübt wird, um eine Berufsausbildung zu begründen ${ }^{314}$. Wird eine volle Erwerbstätigkeit ausgeübt, schließt dies den Anspruch auf Erziehungsgeld aus, der gleichzeitige Bezug eines Erwerbseinkommens und des Erziehungsgeldes wird damit ausgeschlossen. Dies gilt ebenso für den Bezug von Arbeitslosengeld, Arbeitslosenhilfe, Eingliederungsgeld und sonstige einkommensabhängige Transferzahlungen sofern der Bemessung dieser Leistung ein Arbeitsentgelt

\footnotetext{
${ }^{310} \S 1$ Abs. 1, Nr. 3 BErzGG.

${ }^{311}$ Vgl. Erziehungsgeld, Erziehungsurlaub und Anrechnung von Erziehungszeiten in der Rentenversicherung, Gutachten des Wissenschaftlichen Beirats für Familienfragen beim Bundesminister für Jugend, Familie, Frauen und Gesundheit, Schriftenreihe des Bundesministers für Jugend, Familie, Frauen und Gesundheit, Bd. 243, Stuttgart u.a.O., 1989, S. 27.

${ }^{312}$ Vgl. § 1 Abs. 1, Nr.4 BErzGG.

${ }^{313}$ BR-Drs. 350/85, S. 15.

${ }^{314} \S 2$ Abs. 1, Nr. 1+3 BErzGG.
} 
für eine volle Erwerbstätigkeit zugrunde liegt. Damit wird deutlich, daB nicht die Doppelbelastung der erziehenden Person honoriert werden soll, sondern dem erziehenden Elternteil die Möglichkeit eröffnet wird, für einen bestimmten Zeitraum die Betreuungs- und Erziehungsaufgaben zu erfüllen.

Erziehungsgeld wird einer anspruchsberechtigten Betreuungsperson für die Erziehung eines oder mehrerer Kinder gewährt, wobei im letzteren Falle für jedes Kind Erziehungsgeld gezahlt wird ${ }^{315}$. Existieren mehrere Anspruchsberechtigte, d.h. erfüllen beide Ehegatten gleichzeitig die Voraussetzungen für den Bezug von Erziehungsgeld, können sie bestimmen, wem von ihnen das Erziehungsgeld gewährt werden soll ${ }^{316}$. Dies und die Tatsache, daB ein Wechsel in der Anspruchsberechtigung stattfinden darf, also jeder Anspruchsberechtigte für einen zusammenhängenden Teil des Zeitraumes, für den Erziehungsgeld gewährt wird, dieses beziehen kann ${ }^{317}$, stellen, nach Ansicht der Bundesregierung, einen erheblichen Schritt in Richtung auf mehr Gleichberechtigung dar und ermöglichen so das aktive Mitwirken bei der Erziehung der Kinder durch die Väter ${ }^{318}$. Es ist allerdings nicht möglich, den Bezugszeitraum in mehr als drei zusammenhängende Zeiträume aufzuteilen, d.h. es darf während des vorgesehenen Leistungszeitraumes nur ein zweimaliger Wechsel stattfinden. Der Grund für diese Regelung liegt darin, einen ständigen Wechsel in der Betreuungsperson zu vermeiden, lediglich in Ausnahmefällen kann nachträglich eine Änderung erfolgen, wenn aus wichtigem Grund die Erziehung des Kindes durch die Erziehungsgeld beziehende Person nicht mehr sichergestellt werden kann ${ }^{319}$.

Ein Anspruch auf Erziehungsgeld wird ab dem Tag der Geburt des Kindes erworben, wenn der Antrag spätestens sechs Monate nach der Geburt des Kindes gestellt wird, da Erziehungsgeld rückwirkend höchstens für sechs Monate vor Antragstellung gewährt wird ${ }^{320}$. Nach neuester Gesetzgebung wird Erziehungsgeld für die nach dem 31.12.1992 geborenen Kinder

\footnotetext{
${ }^{315} \S 3$ Abs. 1 Satz 1 BErzGG.

${ }^{316} \S 3$ Abs. 2 Satz 1+3 BErzGG.

${ }^{317}$ § 3 Abs. 2 Satz 2 BErzGG.

${ }^{318}$ BR-Drs. 350/85, S. 16.

${ }^{319}$ § 3 Abs. 3 BErzGG.

${ }^{320} \S 4$ Abs. 2 BErzGG.
} 
bis zur Vollendung des 24. Lebensmonats gewährt ${ }^{321}$. Die Höhe der Leistung beträgt 600,-- DM monatlich, seit dem 1.1.1994 ist diese Leistung vom ersten Monat einkommensabhängig, was nicht dem im Steuerrecht angewandten Leistungsfähigkeitsprinzip entspricht. In den ersten sechs Monaten nach der Geburt wird das Erziehungsgeld gemindert, wenn das Jahreseinkommen bei Verheirateten, die nicht dauernd getrennt leben 100000 DM und bei Alleinstehenden (verheiratet, aber dauernd getrennt lebende Ehepaare, Ledige und Verwitwete) 75000 DM nicht übersteigt. Vom Beginn des siebten Lebensmonats des Kindes erfolgt eine Minderung des Erziehungsgeldes, wenn das Einkommen bei Verheirateten, die von ihren Ehegatten nicht dauernd getrennt leben, $29400 \mathrm{DM}$ und bei den anderen Berechtigten (siehe oben) 23 700 DM übersteigt, die Minderung beträgt $1 / 2$ von $40 \%$ des die Grenze übersteigenden Einkommens. Vom zweiten Kind an erhöhen sich die Einkommensgrenzen je Kind um 4200 DM. Bei Mehrlingsgeburten oder bei Geburt eines weiteren Kindes während des Bezugs von Erziehungsgeld erhöht es sich je Kind um weitere 600 DM.

In die Berechnung einbezogen wird neben dem Einkommen des Erziehungsgeldberechtigten dasjenige seines nicht dauernd von ihm getrennt lebenden Ehepartners; nicht berücksichtigt wird das Einkommen eines in nichtehelicher Lebensgemeinschaft mit dem Berechtigten lebenden Partners, der nicht der Vater des Kindes ist, da der Erziehungsgeldberechtigte nicht davon ausgehen kann, daß er dauerhaft an diesem Einkommen teilhaben wird. Der Gesetzgeber geht davon aus, daß das Einkommen des Partners für den Betreuungsbedarf des Kindes nur bei der ehelichen Gemeinschaft, nicht aber bei der eheähnlichen Gemeinschaft durch zivilrechtliche Ansprüche sichergestellt wird. (BSG vom 10.3.1993, 14b REg 2/92) In der Begründung des Regierungsentwurfs, heißt es, daß die gesicherte Grundlage für die Entscheidung zwischen Erwerbstätigkeit und vorübergehendem Verzicht auf die Berufsausübung zugunsten der Kinderbetreuung in einer nichtehelichen und damit aufkündbaren Lebensgemeinschaft ausschließlich das Einkommen des erziehungsgeldberechtigten Elternteils sein kann ${ }^{322}$. Für die Berechnung des Erziehungsgeldes ist das Nettojahreseinkommen ausschlag-

\footnotetext{
${ }^{321}$ § 4 Abs. 1 BErzGG.

${ }^{322}$ BT-Drs. 10/3792, S. 17.
} 
gebend. Der Staat bestimmt damit den Wert der Erziehungsleistung unter Hinzuziehung des Einkommens des Mannes. Die sich ergebende Wirkung ist, daß bei einem Mann mit hohem Einkommen die Frau möglichst außerhäuslich tätig sein sollte, während bei einem niedrigen Einkommen der Anreiz für die Frau, die Kinder zu erziehen sehr viel größer ist. Bei gleichem Betrag ist der Anreiz für die Frauen einer Erwerbstätigkeit nachzugehen, unterschiedlich. Die Frau mit einem geringen hat die geringsten Opportunitätskosten. Sollen diese Wirkungen beseitigt werden, soll also für alle der gleiche Anreiz gelten, dann müßte ein mit steigendem Einkommen steigendes Erziehungsgeld gezahlt werden. Damit könnte die Honorierung der Erziehungsleistung als Gegenstück zur Besteuerung nach dem Leistungsfähigkeitsprinzip angesehen werden, das Bundessozialgericht betont jedoch in seinen Kommentaren, daß dies nicht die Intention der Bundesregierung sei.

Das Statistische Bundesamt weist für 1993 Zahlungen von Erziehungsgeld in Höhe von 6.835 Mill. DM und 1994 in Höhe von 6.681 Mill. DM aus, dies sind für 1994 ca. 0,6 \% des gesamten Sozialbudgets im Bundeshaushalt. Insgesamt verteilte sich diese Summe auf 788.562 Bezieher von Erziehungsgeld, wovon 16.920 Männer und 771.642 Frauen waren. Die vollständige Übernahme der Erziehungsaufgabe durch die Männer ist also eher die Ausnahme als die Regel.

Die differenzierte Betrachtung nach dem Familienstand zeigt, daß 10,2 $\%$ der Bezieher von Erziehungsgeld Alleinerziehend sind, der Anteil der Frauen beträgt dabei $10.06 \%$, der Anteil der Männer 0,14 \%. 672.081 Personen waren verheiratet (657.259 Frauen, 14.822 Männer), und 36.032 (4,6 $\%)$ lebten in nichtehelichen Lebensgemeinschaften (35.022 Frauen, 1010 Männer).

Die Möglichkeit, zeitweise ganz oder teilweise aus dem Erwerbsleben auszuscheiden und Erziehungsgeld in Anspruch zu nehmen, scheint für unselbständig Beschäftigte eher möglich zu sein als für Selbständige, wie folgende Zahlen vermuten lassen: 54,6 \% der Bezieher von Erziehungsgeld sind abhängig Beschäftigte, wogegen nur 1,27 \% in die Kategorie der Selbständigen eingeordnet werden kann. Sicherlich sind auch die niedrigen Einkommensgrenzen für diesen geringen Anteil mitverantwortlich, allerdings scheint es für einen Selbständigen auch nicht möglich zu sein, die Tätigkeit 
in der eigenen Unternehmung - und sei es auch nur für einen kurzen Zeitraum - gänzlich einzustellen. Besonders in mittelständischen Betrieben kann es sich der Betriebsinhaber nicht leisten, zeitweise aus dem Betrieb auszuscheiden und eine Vertretung zu beschäftigen. Lediglich 809 selbständige Männer beziehen Erziehungsgeld gegenüber immerhin noch 9.188 Frauen. 44,13\% aller Erziehungsgeldbezieher sind Nichterwerbstätige (338.897 Frauen, 9.121 Männer).

Angesichts des oben genannten Ausgabenbetrages, erscheint die Frage berechtigt, ob das Gesetz die angestrebten Ziele ganz oder doch zumindest teilweise erreicht? Ohne noch einmal im Detail auf die verkündeten Zielsetzungen eingehen zu wollen, seien im folgenden die Kernpunkte der Intention des Gesetzgebers kurz genannt:

1. Das Erziehungsgeld sollte eine elterliche Betreuung des Kindes in der ersten Lebensphase gewährleisten.

2. Es sollte mehr Wahlfreiheit bei der Entscheidung Kindererziehung oder Erwerbstätigkeit für Väter und Mütter geschaffen werden.

3. Die Erziehungskraft der Familie sollte gestärkt werden.

Schon bei Einführung des Gesetzes war der festgelegte Zeitraum für den Bezug von Erziehungsgeld zu kurz und zudem zu unflexibel geregelt. Inzwischen ist zwar der Bezugszeitraum ausgedehnt worden, die Einführung von außerordentlich niedrigen Einkommensgrenzen reduziert den Kreis der Anspruchsberechtigten aber auf ein Minimum. Verglichen mit den Einkommen aus einer Erwerbstätigkeit, stellt das Erziehungsgeld keine Alternative zu einem Erwerbseinkommen dar und ist insofern auch nicht geeignet, den oben genannten ersten Aspekt zu realisieren. Insofern ist auch die gewünschte Wahlfreiheit faktisch nicht gegeben: Ist das Haushaltseinkommen gering, führt zwar der Verzicht auf Erwerbstätigkeit zum Bezug von Erziehungsgeld, allerdings wird dieses nicht ausreichen, um die Lebensführung angemessen bestreiten zu können. Wird eine Teilzeitbeschäftigung ausgeübt, führt dieses wiederum zum Verlust des Erziehungsgeld, bei Vollzeitarbeit entfällt es sowieso gänzlich. Die theoretisch mögliche Wahlfreiheit führt also bestenfalls zu einer „Null-Eins“-Entscheidung Beruf oder Kind 
und wird der individuellen Bedarfslage der Familie in den meisten Fällen nicht annähernd gerecht. Vollends zur Farce wird die Regelung, wenn es um die Einbeziehung der Väter geht, da das Erziehungsgeld zum Unterhalt einer Familie selbst bei bescheidenster Lebensführung nicht ausreicht und das Einkommen der Frau das ausgefallene Einkommen des Mannes in den meisten Fällen nicht zu kompensieren vermag. Das Erziehungsgeld als Instrument zur Förderung des Drei-Phasen-Modells erscheint damit äußerst fragwürdig, nebulös wird es schließlich dann, wenn es um die Beurteilung der „Erziehungskraft“" der Familie geht, denn welches sind die Charakteristika einer qualitativen oder eher minderwertigen Erziehungskraft?

Flankierend zum Erziehungsgeld besteht eine Berechtigung zur Inanspruchnahme von Erziehungsurlaub ${ }^{323}$, dessen Vorteil für den Berechtigten darin besteht, daß während dieser Zeit das Arbeitsverhältnis quasi bestehen bleibt und der Arbeitnehmer lediglich der Hauptpflichten, die mit Aufnahme des Arbeitsverhältnisses übernommen wurden, entbunden wird; die arbeitsrechtlichen Nebenpflichten bleiben jedoch weiterhin bestehen ${ }^{324}$. Dazu gehört im wesentlichen, daß die Betriebszugehörigkeit nicht unterbrochen wird, der Arbeitnehmer Belegschaftsmitglied im Sinne des Betriebsverfassungsrechts und damit wahlberechtigt bleibt.

Gemäß $§ 16$ Abs. 1 BErzGG ist Erziehungsurlaub spätestens vier Wochen vor dem Zeitpunkt, ab dem er in Anspruch genommen werden soll, gegenüber dem Arbeitgeber geltend zu machen, gleichzeitig muß erklärt werden, für welchen Zeitraum oder für welche Zeiträume der Erziehungsurlaub beantragt wird, eine Inanspruchnahme von Erziehungsurlaub oder ein Wechsel unter den Berechtigten ist dreimal zulässig.

Um dem Arbeitgeber die Möglichkeit personeller Dispositionen zu ermöglichen, muß in der Erklärung über die Inanspruchnahme des Erziehungsurlaubs deutlich erkennbar sein, bis zu welchem Lebensmonat des Kindes der Erziehungsurlaub andauern soll. An diese Erklärung ist der Arbeitnehmer gebunden, er kann sie nicht mehr einseitig widerrufen, lediglich in Ausnahmefällen, wenn Arbeitgeber und Arbeitnehmer eine Einigung

\footnotetext{
${ }^{323} \S 15$ Abs. 1 BErzGG.

${ }^{324}$ Vgl. Winterfeld, Rosemarie, Mutterschutz und Erziehungsurlaub, Mutterschutzgesetz und Bundeserziehungsgeldgesetz mit Erläuterungen, München 1986, S. 47.
} 
darüber erzielen, daß der Erziehungsurlaub überhaupt nicht oder erst zu einem späteren Zeitpunkt angetreten werden soll, kann der Arbeitnehmer verlangen, weiter gegen Entgelt beschäftigt zu werden ${ }^{325}$.

Der Erziehungsurlaub beginnt frühestens nach Ablauf des Beschäftigungsverbotes für die leibliche Mutter und endet spätestens nach Vollendung des 36. Lebensmonats des Kindes ${ }^{326}$, soweit der Arbeitnehmer nicht einen früheren Termin gewünscht hat.

Da Erziehungsurlaub das Beschäftigungsverhältnis aus rechtlicher Sicht nicht verändert, sind auch die sozialversicherungsrechtlichen Auswirkungen eher gering. In der gesetzlichen Krankenversicherung bleibt die Mitgliedschaft Versicherungspflichtiger während der Zeit des Bezugs von Erziehungsgeld bestehen ${ }^{32}$. Der Versicherungsschutz, der beitragsfrei gewährt wird, umfaßt in dieser Zeit sämtliche Leistungen der Krankenversicherung mit Ausnahme des Anspruchs auf gesetzliches Krankengeld ${ }^{328}$. Voraussetzung für die Beitragsfreiheit ist, daß während des Bezugs von Erziehungsgeld kein Arbeitsentgelt bezogen wird, derjenige, der neben der Kindererziehung im gesetzlich zulässigen Rahmen teilzeitbeschäftigt ist, muß also weiterhin Beiträge entrichten. Ergibt sich für Mitglieder privater Krankenkassen, die aufgrund der Überschreitung der Verdienstgrenze bislang nicht krankenversicherungspflichtig waren, daß sie durch Reduzierung ihrer Beschäftigung auf eine Teilzeittätigkeit während des Erziehungsurlaubs krankenversicherungspflichtig werden, können sie sich zur Vermeidung doppelter Beitragszahlung für die Zeit des Erziehungsurlaubs von der Versicherungspflicht befreien lassen ${ }^{329}$. Auch die Arbeitslosenversicherung wird während des Bezugs von Erziehungsgeld beitragsfrei aufrechterhalten $^{330}$, im Unterschied zur Krankenversicherung auch dann, wenn wegen der Überschreitung der Einkommensgrenze kein Erziehungsgeld gezahlt wird. Für die Erziehungsurlaub in Anspruch nehmende Person besteht während dieser Zeit eine Beschäftigungsgarantie seitens der Unternehmung, soweit

\footnotetext{
${ }^{325}$ Vgl. Winterfeld, R., a.a.O., S. 50.

${ }^{326} \S 15$ Abs. 1, Satz 1, BErzGG.

${ }^{327} \S 22$ Nr. 4 BErzGG.

${ }^{328} \S 22$ Nr. 3 BErzGG.

${ }^{329} \$ 22$ Nr. 1 BErzGG.

${ }^{330}$ § 27 BErzGG, § 107 Satz 1, Nr. 5c AFG.
} 
sie mit dieser in einem sozialversicherungspflichten Beschäftigungsverhältnis stand.

So sehr diese Maßnahme aus familienpolitischer Sicht zu begrüßen ist, sollte nicht übersehen werden, daß die Garantie der Weiterbeschäftigung für Frauen nicht unbedingt vorteilhaft ist. Schon die bestehenden Gesetze zum Schutz der werdenden Mutter und der kindererziehenden Frau ${ }^{331}$ führen dazu, daß Unternehmen männliche Bewerber bei der Einstellung bevorzugen, um den Kosten, die sich zwangsläufig bei der Beschäftigung von Frauen, die ein oder mehrere Kinder bekommen, aus dem Weg zu gehen. Es handelt sich aus betriebswirtschaftlicher Sicht dabei im wesentlichen um folgende Kostenfaktoren: Regelmäßige Arztbesuche während der Schwangerschaft mindern die effektive Arbeitszeit, die gemäß tariflicher Vereinbarungen voll bezahlt werden muB, darüber hinaus ist der Arbeitgeber im Rahmen der Lohnfortzahlung verpflichtet, während des Mutterschaftsurlaubs den Lohn bzw. das Gehalt über den Betrag des Mutterschaftsgeldes, der von der Krankenkasse getragen wird, weiter zu entrichten einschlieBlich aller Arbeitgeberanteile zur Sozialversicherung. Unter Umständen kann die Schwangere während der Schwangerschaft wegen des Beschäftigungsverbots gemäß Mutterschutzgesetz nicht an ihrem eigentlichen Arbeitsplatz eingesetzt werden, so daß eine Ersatzkraft eingestellt werden muB. Nimmt die Frau die Möglichkeit des Erziehungsurlaubs nach der Geburt in Anspruch, ist aufgrund des bestehenden Kündigungsschutzes während dieser Zeit auch dieser Arbeitsplatz nur zeitweilig mit einer anderen Arbeitskraft besetzbar, was faktisch dazu führt, daß der Arbeitgeber lediglich einen zeitlich befristeten Arbeitsvertrag mit einer Aushilfskraft abschließen kann, deren Motivation und Produktivität, wie Untersuchungen bestätigen, deutlich geringer ist als im Falle eines dauerhaften Arbeitsverhältnisses. Für den Arbeitgeber fallen also neben den tatsächlich zu zahlenden Kosten weitere Opportunitätskosten aufgrund der oben beschriebenen Faktoren an. Aus Sicht der Unternehmen ist diese Verhaltensweise, die dem ökonomischen Prinzip der Kostenminimierung Rechnung trägt, durchaus begründet. Be-

${ }^{331}$ Gesetz zum Schutz der erwerbstätigen Mutter (Mutterschutzgesetz - MuSchG), BGBL. Ill 8052-1, sowie das Gesetz über die Gewährung von Erziehungsgeld und Erziehungsurlaub (Bundeserziehungsgeldgesetz - BErzGG), BGBL. I, S. 2154. 
sonders mittlere und kleine Betriebe werden noch zurückhaltender als bisher reagieren, wenn es um die Besetzung von Arbeitsplätzen mit Frauen im gebärfähigen Alter geht.

In der gesetzlichen Rentenversicherung wurden Kindererziehungszeiten mit dem "Gesetz zur Neuordnung der Hinterbliebenenrenten sowie zur Anerkennung von Kindererziehungszeiten in der gesetzlichen Rentenversicherung (Hinterbliebenen- und Erziehungszeitengesetz - HEZG)" vom 11. Juli 1985 eingeführt. Die Anrechnung der Erziehungszeiten beschränkt sich auf Personen, die nach dem 31. Dezember 1920 geboren sind und nach dem 31. Dezember 1985 rentenbezugsberechtigt wurden oder werden. Für die vor 1921 geborenen Mütter sichert das "Gesetz über Leistungen der gesetzlichen Rentenversicherung für Kindererziehung an Mütter der Geburtsjahrgänge vor 1921 (Kindererziehungsleistungsgesetz - KLG)" vom 12. Juli 1987 eine im Prinzip vergleichbare Leistung ${ }^{332}$.

Da das System der gesetzlichen Rentenversicherung an das Vorhandensein einer Erwerbstätigkeit anknüpft und Frauen, die Kinder aufzogen, nicht oder nur eingeschränkt eine Erwerbstätigkeit ausüben konnten, erwarben sie keine Anwartschaften und waren damit im Alter schlechtergestellt als die dauerhaft erwerbstätige kinderlose Frau. Zudem ergibt sich aufgrund der Anwendung des Umlageverfahrens, daß die kindererziehenden Frauen nicht nur Einschränkungen während der Zeit der Erwerbstätigkeit und im Alter auf sich nehmen, sondern sie finanzieren durch ihre Kinder auch noch die Renten der kinderlosen Ehepaare $^{333}$.

Die sozialpolitische Diskussion, die zur Einführung von Kindererziehungszeiten in der gesetzlichen Rentenversicherung geführt hat, erfolgte angesichts der sich ständig ergebenden Verschlechterung der demographi-

\footnotetext{
${ }^{332}$ Die Ergänzung des Erziehungszeiten-Gesetz wurde notwendig, nachdem aufs heftigste kritisiert wurde, daß gerade die Mütter, die in der Nachkriegszeit am Wiederaufbau maßgeblich beteiligt waren ("Trümmerfrauen") und darüber hinaus die Leistung der Kindererziehung allein erbringen mußten, da ihre Ehemänner im Krieg gefallen oder in Gefangenschaft waren, die Erziehungsleistung nicht honoriert bekamen.

${ }^{333}$ Vgl. Kaltenbach, Helmut, Clausing, Peter, Das neue Rentenrecht 1986, Rentenrecht für Hinterbliebene und Anrechnung von Kindererziehungszeiten nach dem HEZG, München 1985, S. 101.
} 
schen Entwicklung und der damit verbundenen Probleme bei Anwendung des Umlageverfahrens ${ }^{34}$ der Rentenversicherung.

Erste Überlegungen zur Anrechnung von Kindererziehungszeiten bei der Rente gab es bereits im Rahmen der Rentenreform 1972; für das sogenannte "Baby-Jahr" fand sich damals jedoch keine parlamentarische Mehrheit. Im weiteren wurde der Gedanke dann von der '84er Kommission $^{335}$ wieder aufgegriffen, deren Aufgabe unter anderem darin bestand, Vorschläge zur Neuordnung der sozialen Sicherung der Frau im Hinblick auf eine eigenständige Sicherung zu erarbeiten.

Mehrheitlich war die Kommission der Meinung, Kindererziehungszeiten als Beitragszeiten mindestens bis zum vollendeten dritten Lebensjahres des Kindes dem überwiegend erziehenden Elternteil zuzuschreiben.

Bewertet werden sollten diese Zeiten mit einem Prozentsatz von 75 des Durchschnittsverdienstes aller Versicherten. Hinsichtlich der Frage der Finanzierung sprach sich die Kommission dafür aus, daB der Bund die Anrechnung der Erziehungszeiten finanzieren sollte.

Das "Diktat der leeren Kassen" führte dann jedoch letztlich zur Berücksichtigung eines Kindererziehungsjahres, welches dann im Hinterbliebenen- und Erziehungszeitengesetz fixiert wurde. Die Gesetzesbegründung stützt sich im wesentlichen auf folgende Ziele:

1. Anerkennung der Leistung, die kindererziehende Frauen und Mütter erbringen,

2. Gleichbewertung der Tätigkeit in der Familie und der auBerhäuslichen Erwerbstätigkeit,

3. Verbesserung der eigenständigen sozialen Sicherung der Frau.

\footnotetext{
${ }^{334}$ Grundgedanke dieses Verfahrens ist, daß die jeweils im Erwerbsleben stehende Generation mit ihren Beiträgen zur Rentenversicherung die Renten der vorausgehenden Erwerbstätigengeneration finanziert und dadurch fïr sich selbst einen Anspruch auf Altersversorgung erwirbt, der von der nächsten aktiven Generation wieder eingelöst werden muß. Die Funktionsfähigkeit des Umlageverfahrens hängt damit offensichtlich davon ab, inwieweit die nachfolgende Generation in der Lage ist, die Alterssicherung der Vorgängergeneration mit Beiträgen aus ihrem Einkommen zu finanzieren, das bedeutet auch, daß die jeweils nachfolgende Generation zahlenmäßig nicht wesentlich kleiner sein darf als die vorausgegangene Erwerbsgeneration.

${ }^{335}$ Näheres dazu siehe P. III, 2.
} 
Nach der Neufassung dieses Gesetzes sind drei Gruppen von Versicherungsfällen zu unterscheiden:

1. Berechtigte mit Zeiten der Kindererziehung nach dem 31. Dezember 1985. Diese Zeiten sind Pflichtbeitragszeiten und begründen somit ein Versicherungsverhältnis in der gesetzlichen Rentenversicherung.

2. Berechtigte mit Zeiten der Kindererziehung vor dem 1. Januar 1986, die nach dem 31. Dezember 1920 geboren sind. Diese Erziehungszeiten werden als "Versicherungszeit eigener Art" angerechnet.

3. Berechtigte mit Zeiten der Kindererziehung nach dem 31. Dezember 1991. Auch diese Zeiten gelten als Pflichtbeitragszeiten und begründen eine Versicherungsverhältnis in der gesetzlichen Rentenversicherung (Wegfall von Ersatz-, Ausfall- und Zurechnungszeit).

Ad. 1: Diese Zeiten gelten als Zeiten der Pflichtversicherung und werden so bewertet, als hätte der Berechtigte $75 \%$ des Durchschnittsentgelts aller Versicherten der gesetzlichen Rentenversicherung verdient, wobei sich im speziellen vier Fälle unterscheiden lassen:

(1) Die Kindererziehungszeiten treffen nicht mit bewerteten Beitrags-, Ersatz-, Ausfall- und Zurechnungszeiten zusammen und fallen nicht in die ersten fünf Jahr nach Eintritt in die Versicherung. In diesem Fall erfolgt eine Bewertung der Erziehungszeit in Höhe von 75 \% des Durchschnittsverdienstes aller Versicherten ${ }^{336}$.

(2) Die Kindererziehungszeiten treffen nicht mit bewerteten Beitrags-, Ersatz-, Ausfall- und Zurechnungszeiten zusammen, fallen jedoch in die ersten fünf nach Eintritt in die Versicherung. Dann findet eine Bewertung in Höhe von $90 \%$ des Durchschnittsverdienstes aller Versicherten statt ${ }^{37}$.

(3) Kindererziehungszeiten treffen mit bewerteten Beitrags-, Ersatz-, Ausfall- und Zurechnungszeiten zusammen und fallen nicht in die ersten fünf Jahre nach Eintritt in die Versicherung. Die bewertete Zeit ist auf $75 \%$ des

\footnotetext{
${ }^{336}$ Vgl. § 56 SGB VI, § 112 Abs. 3 AVG.

${ }^{337}$ Vgl. § 56 SGB VI, § 32 Abs. 4 AVG.
} 
Durchschnittsverdienstes aller Versicherten aufzuwerten, wenn sie nicht $\mathbf{7 5}$ $\%$ oder mehr beträgt $t^{338}$.

(4) Die Kindererziehungszeiten treffen mit bewerteten Beitrags-, Ersatz-, Ausfall- und Zurechnungszeiten zusammen und fallen in die ersten fünf Jahre nach Eintritt in die Versicherung. In diesem Fall ist die bewertete Zeit auf $90 \%$ des Durchschnittsverdienstes aller Versicherten aufzuwerten, wenn sie nicht $90 \%$ oder mehr beträgt $t^{339}$.

Die Zeiten können sowohl bei der Mutter als auch beim Vater angerechnet werden, je nachdem, wem von beiden die alleinige Erziehung obliegt. Im Fall gemeinsamer Erziehung ist zunächst einmal die Mutter des Kindes versichert, soweit nicht bis zum Ablauf des dritten Kalendermonats nach der Geburt Mutter und Vater übereinstimmend erklären, daß der Vater für den gesamten Zeitraum versichert sein soll, wobei ein Widerruf dieser Erklärung nicht möglich is $\mathbf{t}^{340}$.

Anspruchsberechtigt sind "Mütter und Väter, die ihr Kind im Geltungsbereich dieses Gesetzes erziehen und sich mit ihm dort gewöhnlich aufhalten" ${ }^{341}$, in Ausnahmefällen werden auch im Ausland erbrachte Erziehungsleistungen berücksichtigt.

Im Zusammenhang mit den Erziehungszeiten ist Erziehung definiert als "Sorge für die sittliche, geistige und seelische Entwicklung des Kindes" ${ }^{3+2}$, d.h. der Erziehende muß sich um das Kind kümmern und einen erzieherischen Einfluß ausüben. Gemeinhin gelten diese Voraussetzungen als erfüllt, wenn der Erziehende und das Kind in einem gemeinsamen Haushalt leben.

Neben den leiblichen Eltern werden, sofern die Voraussetzungen erfüllt sind, Adoptiv- und Pflegeeltern Kindererziehungszeiten zuerkannt ${ }^{343}$. Ausnahmen von der Anspruchsberechtigung ergeben sich, wenn für die Personen ein

\footnotetext{
${ }^{338}$ Vgl. § 56 SGB VI, § 32 Abs. 6a AVG.

${ }^{339} \mathrm{Vgl}$. § 56 SGB VI, § 32 Abs. 4 AVG.

${ }^{340} \S 2$ a Abs. 2 AVG.

${ }^{341} \S 2$ a Abs. 1, Satz 1 AVG.

${ }^{342}$ Erziehungsgeld, Erziehungsurlaub und Anrechnung von Erziehungszeiten in der Rentenversicherung, a.a.O., S. 57.

${ }^{343}$ Vgl. § 56 SGB VI.
} 
entsprechender sozialer Schutz anderweitig gewährleistet ist. Dazu gehören $^{344}$

- Eltern, die nicht der Versicherungspflicht in der GRV unterliegen (Beamte, Zeitsoldaten, Berufssoldaten),

- Empfänger von Altersruhegeld,

- Personen, die nach beamtenrechtlichen Vorschriften eine Versorgung von nicht weniger als $65 \%$ der ruhegehaltsfähigen Dienstbezüge beziehen,

- Abgeordnete, Minister oder Parlamentarische Staatssekretäre, es sei denn, sie sind ohne Anspruch auf Versorgung ausgeschieden,

- Selbständige

Ad. 2: Die Erziehungszeiten vor dem 1. Januar 1986 sind "Versicherungszeiten eigener Art", weil eine nachträgliche Anerkennung dieser Zeiten als Versicherungszeit unterschiedliche, zufallsbedingte Auswirkungen auf die Versicherungsverläufe gehabt hätte ${ }^{345}$. Insbesondere durch die Regelung der sogenannten Halbbelegung, die bis zur Rentenreform 1992 maßgeblich war, wäre es bei sehr ähnlich gelagerten Fällen zu unterschiedlichen Rentenerhöhungsbeträgen gekommen, außerdem hätten alle Bestandsrenten von Müttern neu berechnet werden müssen.

Generell gilt auch für diese Zeiten, daß Mütter und Väter, die ihr Kind allein erzogen haben, die Erziehungszeit zuerkannt bekommen.

Bei gemeinsamer Erziehung werden im Unterschied zu den Kindererziehungszeiten nach 1985 die Zeiten der Mutter zugerechnet.

Den Anspruchsberechtigten werden dann jeweils für die Zeit der Kindererziehung die ersten 12 Monate nach dem Ablauf des Geburtsmonats des Kindes für die Erfüllung der Wartezeit angerechnet.

Bei Erziehung mehrerer Kinder verlängert sich die Anrechnungszeit um die Anzahl der Kalendermonate, in denen mehrere Kinder gleichzeitig erzogen wurden ${ }^{346}$, die Bewertung erfolgt mit $75 \%$ des Durchschnittsverdienstes aller Versicherten, treffen die Kindererziehungszeiten mit Ersatz-,

\footnotetext{
${ }^{344}$ Vgl. Art. 1, Ziff. 13 HEZG.

${ }^{345}$ Vgl. Erziehungsgeld, Erziehungsurlaub und Anrechnung von Erziehungszeiten in der Rentenversicherung, a.a.O., S. 59.

${ }^{346} \S 28$ a Abs. 1 AVG.
} 
Ausfall- oder Zurechnungszeiten zusammen, sind sie auf $75 \%$ des Durchschnittsverdienstes aller Versicherten anzuheben ${ }^{347}$.

Personen, die die kleine Wartezeit von 5 Jahren, die Voraussetzung für das Altersruhegeld mit 65 Jahren ist, auch unter Berücksichtigung der Erziehungszeiten noch nicht erfüllen und sie auch durch eine laufende Beitragsentrichtung in der Zeit vom 1. Januar 1987 bis zur Vollendung ihres 65. Lebensjahres nicht mehr erfüllen können, haben die Möglichkeit der Beitragsentrichtung, um die Erziehungszeiten effektiv werden zu lassen. In diesen Fällen können die betroffenen Personen auf Antrag freiwillig so viele Beiträge nachentrichten, wie zur Erfüllung der Wartezeit von fünf Jahren nötig sind.

Ad. 3: Für Geburten ab dem 1.1.1992 werden dem Berechtigten die ersten 36 Monate nach Ablauf des Geburtsmonats als Erziehungszeit, die dem Charakter einer Pflichtbeitragszeit entspricht, in der gesetzlichen Rentenversicherung gutgeschrieben. Die Kindererziehungszeit beginnt nach Ablauf des Monats der Geburt und endet i.d.R. nach 36 Kalendermonaten (der Monat der Geburt ist nicht mitzurechnen). ${ }^{3+8}$ Mit dieser Maßnahme wurde bei der Rentenreform 1992 ein weiterer Schritt zur eigenständigen sozialen Sicherung der Frau vollzogen. Werden in diesem Zeitraum mehrere Kinder gleichzeitig erzogen, deren Erziehung eine Versicherungspflicht nach dem HEZG begründet, verlängert sich die anzurechnende Zeit entsprechend. Dadurch wird erreicht, daß für jedes Kind drei Erziehungsjahre angerechnet werden können. Eine Frau bzw. ein Mann, die/der ohne jemals erwerbstätig gewesen zu sein, zwei Kinder erzieht, hat damit die Voraussetzungen für den Bezug einer Rente erfüllt. Bewertet werden die Kindererziehungszeiten weiterhin mit $75 \%$ des Durchschnittsentgelt aller Versicherten, d.h. nach neuem Rentenrecht mit 0,75 Entgeltpunkten. Dieser Wert wurde gewählt, weil er das durchschnittlich erzielte Arbeitseinkommen von Frauen widerspiegelt. Ebenso gilt nach wie vor, daß diese Zeiten entweder zusammen mit anderen rentenrechtlichen Zeiten oder allein anspruchsbegründend

\footnotetext{
${ }^{347}$ § 32a Abs. 5 A VG.

${ }^{348}$ Vgl. Grandi, Werner, Die rentenrechtlichen Zeiten und die Wartezeit, in: Handbuch der gesetzlichen Rentenversicherung, Hrsg.: F. Ruland, Frankfurt 1990, S. 653.
} 
wirken, allerdings werden Kindererziehungszeiten nicht additiv berücksichtigt, d.h. die rentensteigernde Wirkung einer Kindererziehungszeit ist geringer, wenn während dieser Zeit Beiträge -aufgrund einer Erwerbstätigkeit oder auf freiwilliger Basis- entrichtet werden. Als sogenannte beitragsgeminderte Zeit gilt die Kindererziehungszeit, wenn sie mit einer beitragsfreien Zeit zusammentrifft, d.h. sie wird mit den Entgeltpunkten bewertet, die sie als beitragsfreie Zeit nach der Vergleichsbewertung erhalten würde (dies bedeutet u.U. auch eine Anhebung der Bewertung). Im Extremfall bleiben Kindererziehungszeiten gänzlich unberücksichtigt, nämlich dann, wenn durch ständige Beitragsleistung im gleichen Zeitraum 0,75 Entgeltpunkte (oder mehr) erbracht worden sind.

Eine Begründung dieser Regelung sieht der Gesetzgeber in der Forderung des "Nachteilausgleichs". Besagter Nachteil ergibt sich, wenn wegen der Kindererziehung auf Erwerbsarbeit verzichtet wird und dadurch eine rentenmindernde Lücke in der Versicherungsbiografie der erziehenden Person entsteht. ${ }^{349}$ Die Kindererziehungszeit bekommt damit zwangsläufig den Charakter eines "Lückenfüllers", da die Erwerbstätigkeit faktisch weiterhin höher bewertet wird als die Zeit der Kindererziehung, was wiederum diametral zur Zielsetzung einer rentenrechtlichen Gleichstellung von Erwerbstätigkeit und Kindererziehung im Widerspruch steht. Benachteiligt wird die/der Erwerbstätige, der gleichzeitig Kinder erzieht, da Ansprüche aufgrund der Kindererziehungszeit gemindert werden -dies ist bei niedrigem Einkommen der Fall- oder bei hohem Einkommen ganz wegfallen; rentenrechtlich unberücksichtigt bleibt daneben die Doppelbelastung, die diese Person auf sich nimmt.

Eine Betrachtung der Ziele der Bundesregierung läßt weitere Inkonsistenzen erkennen. Erklärtes Ziel ist die Anerkennung der Erziehungsleistung im Rentenrecht. Mit den gegenwärtigen Maßnahmen wird dieses Ziel nur partiell erreicht, da bei gleichzeitiger Erwerbstätigkeit der Wert der Erziehungsleistung geschmälert wird. Lediglich dem Ziel des Aufbaus einer eigenen sozialen Sicherung bzw. einer eigenen Versicherungsbiografie der Frau werden die Maßnahmen dem Grunde nach gerecht, eine nähere Unter-

\footnotetext{
${ }^{349}$ Vgl. ebenda, S. 8.
} 
suchung der konkreten Höhe der Ansprüche lassen jedoch wieder Ungereimtheiten im System erkennen.

Die praktizierte Regelung der Berücksichtigung von Kindererziehungszeiten benachteiligt Bezieher niedriger Einkommen und vor allem Alleinerziehende, da diese aus wirtschaftlichen Gründen auf eine Fortführung der Erwerbstätigkeit in besonderem Maße angewiesen sind, ${ }^{350}$ gerade dies korrespondiert aber nicht mit den angestrebten Zielen der Familienpolitik.

Eine Benachteiligung erfahren auch die Frauen, die vor der Geburt des Kindes ein hohes Einkommen aus Erwerbstätigkeit erzielten, denn sie müssen bei Aufgabe der Erwerbstätigkeit eine niedrigere Bewertung (75\% des Durchschnittsentgelts aller Versicherten) ihrer Ansprüche akzeptieren als bei weitergeführter Erwerbstätigkeit. Der Anreiz zur Aufnahme einer Erwerbsarbeit ist für diese Personengruppe - zusätzlich noch durch den Wegfall des Erziehungsgeldes - ungleich größer als bei Frauen mit niedrigem Einkommen. Unter volkswirtschaftlichen Erwägungen kann diese Verhaltensweise durchaus sinnvoll und erwünscht sein, sozial- und frauenpolitisch sind derartige Wirkungen mit Skepsis zu betrachten. Die Verfechter einer konsequenten Frauenpolitik fordern einerseits die Anerkennung der Kindererziehung als gleichwertige Tätigkeit zur Erwerbsarbeit zur "Entschädigung für die Sinnkrise der traditionellen Hausfrauenexistenz" ${ }^{\text {"351 }}$, andererseits kristallisieren sich die Emanzipationsforderungen auf eine höhere Beteiligung der Frauen im Erwerbsleben (Frauenquote), um die sogenannte ökonomische Unabhängigkeit zu erreichen und die "Selbstverwirklichung" im Beruf zu finden. Es stellt sich in diesem Zusammenhang die Frage, ob diese Idealvorstellungen sich auch bei einer Arbeitnehmerin am Fließband verwirklichen lassen.

\footnotetext{
${ }^{350}$ Vgl. Engelen-Kefer, U., „Aktuelle Probleme der gesetzlichen Rentenversicherung Reform der Kindererziehungszeiten", in: Verband Deutscher Rentenversicherungsträger (Hrsg.), Aktuelles Presseseminar des VDR 12.13. November 1992 in Würzburg, S. 18.

${ }^{351}$ Ebert, Thomas, Frauen, Kinder, Renten, in: Soziale Sicherheit, 42. Jg. 1993, Heft 4, S. 98.
} 


\section{Das Bundesverfassungsgerichtsurteil vom 7. Juli 1992}

Konsequenz der Einführung des HEZG waren eine Reihe von Verfassungsbeschwerden, in denen sich die Beschwerdeführerinnen gegen Urteile des Bundessozialgerichtes, mehrerer Landessozialgerichte sowie gegen einen Rentenbescheid der Bundesversicherungsanstalt für Angestellte (BfA) wendeten, die die Anerkennung von Kindererziehungszeiten in der GRV betrafen.

Insofern war das Bundesverfassungsgericht aufgerufen, eine weitere familienpolitisch orientierte Entscheidung zu treffen, die sich im Urteil des 1. Senats des BVerfG vom 7. Juli 1992 manifestiert. Dabei hat sich das Bundesverfassungsgericht nicht nur auf den durch Vorlagen und Verfassungsbeschwerden gegebenen Verfahrensgegenstand beschränkt, sondern hat darüber hinaus grundsätzliche Ausführungen gemacht, die künftige sozialpolitische Entscheidungen erheblich beeinflussen dürften. Die Verfassungsbeschwerde wurde zwar generell abgewiesen, da die angeführten Tatbestände der Beschwerdeführerinnen als nicht verfassungswidrig angesehen wurden, gleichwohl hat das Bundesverfassungsgericht eine Position im Sinne der Beschwerdeführerinnen bezogen: "Der Gesetzgeber ist ... nach Art. 3 Abs. 1 GG in Verbindung mit Art. 6 Abs. 1 GG verpflichtet, den Mangel des Rentenversicherungssystems, der in den durch Kindererziehung bedingten Nachteilen bei der Altersversorgung liegt, in weiterem Umfang als bisher auszugleichen." 352 Wie ein solcher "weiter Umfang" im einzelnen ausgestaltet werden soll und wahrscheinlich politisch weitaus brisanter, wie dieser Gestaltungsauftrag finanziert werden soll, angesichts sowieso schon leerer Kassen in der GRV, darüber müssen sich nun die Politiker Gedanken machen. Eines aber wird wieder einmal sehr deutlich: die soziale Sicherung kindererziehender Personen paßt in die bisherige Sicherungssystematik nur schwer hinein und zwingt zu tiefgreifenden Reformüberlegungen. Denn obwohl seit der Rentenreform 1992 für jedes nach dem 31.12.1992 geborene Kind drei Kindererziehungsjahre bei der Rentenermittlung angerechnet werden, kommt das BVerfG zu dem Schluß, daß das bestehende Alterssicherungssystem zu einer Benachteiligung von Personen führt, die sich inner-

${ }^{352}$ BVerfG 7/92, Leitsatz 2. 
halb der Familie der Kindererziehung widmen, gegenüber kinderlosen Personen, die durchgängig einer Erwerbstätigkeit nachgehen können. ${ }^{363}$

Das HEZG sieht vor, daß beim Zusammentreffen von Beitragszeiten mit Kindererziehungszeiten letztere hinter ersteren zurücktreten. D.h. konkret, da B bei gleichzeitiger Erwerbstätigkeit und Kindererziehung die Kindererziehungszeiten wegfallen, wenn das Arbeitsentgelt so hoch ist, daß mit den Beiträgen mindestens Anwartschaften von $\mathbf{7 5 \%}$ des durchschnittlichen Entgelts aller Versicherten erworben werden. In dieser gesetzlich angeordneten Subsidiarität von Kindererziehungszeiten gegenüber Beitragszeiten sehen die Beschwerdeführerinnen einen Verstoß gegen den Art.3 Abs.1 und 2 GG (Gleichheitsgebot), gegen die Pflicht des Staates zum Schutz der Mütter (Art. 6 Abs. 4 GG) sowie gegen das Sozialstaatsprinzip und das Rechtsstaatprinzip (Art. 20 Abs.1 und 3 GG). In erster Linie beanstanden sie, daß die mit Einführung der rentenrechtlichen Berücksichtigung von Kindererziehungszeiten verfolgte familien- und frauenpolitische Zielsetzung der Anerkennung der Erziehungsleistung, die im Alter zu einer Verbesserung der finanziellen Lage der kindererziehenden Frauen führen soll, bei einigen Bevölkerungsgruppen nicht erreicht wird. So wären Familien, in denen die Frau aus wirtschaftlichen Gründen nach dem Auslaufen der Mutterschutzfrist ihre Erwerbstätigkeit wieder aufnehmen müßte und insbesondere Alleinerziehende insofern benachteiligt als sie nach geltendem Recht praktisch keine oder nur eine teilweise Anerkennung ihrer Kindererziehungszeit angerechnet bekommen.

Die Kindererziehungszeit rückte damit in den Vordergrund einer Diskussion, die auch nach dem "Erziehungszeitenurteil" nicht abgebrochen ist. Das Bundesverfassungsgericht stellte in seinem Urteil nicht nur die Verfassungsmäßigkeit der Kindererziehungszeiten in der Gesetzlichen Rentenversicherung sicher, es stellte darüber hinaus fest, daß das Hinterbliebenenrenten- und Erziehungszeiten-Gesetz und das Kindererziehungsleistungsgesetz nicht dadurch gegen das Grundgesetz verstoßen, daß sie Zeiten der Kindererziehung nicht generell mit Beitragszeiten in der Gesetzlichen Rentenversicherung gleichsetze. In der Urteilsbegründung wird zunächst darauf verwiesen, daB eine Pflichtverletzung des Staates gegenüber Ehe und Fami-

${ }^{353}$ Vgl. BVerfG 7/92, S. 56. 
lie, die sich aus Art. 6 Abs. 1 GG herleiten könnte, nicht vorliegt. Dem Gesetzgeber sei bei der Ausgestaltung eines Familienlastenausgleichs - besonders unter dem Aspekt finanzieller Leistungsfähigkeit - ein Gestaltungsspielraum einzuräumen. Erstmalig wird damit von höchster gerichtlicher Stelle die Gleichwertigkeit von Ehe und Familie, die in Art. 6 GG festgeschrieben ist, in Frage gestellt. Der Schutz der Ehe an sich ist jetzt nicht mehr verfassungsrechtlicher Schwerpunkt, der besondere Schutz wird lediglich den Familien zugestanden. Damit wird der allgemeine Gleichheitsgrundsatz des Art. 3 Abs. 1 GG in den Vordergrund der Betrachtung gestellt, der den Gesetzgeber bei steter Orientierung am Gerechtigkeitsgedanken verpflichtet, Gleiches gleich und Ungleiches seiner Eigenart entsprechend ungleich zu behandeln. Die kinderlose Ehe ist "anders" als die Familie und der Familie soll der Vorrang eingeräumt werden. Das bedeutet nicht, daß derjenige, der heirate bestraft werden soll, das kann und darf nicht sein, jedoch spricht nichts dagegen kinderlose Ehepaare an der Mitfinanzierung der Kinderkosten zu beteiligen, da Kinder zum Bestand unseres Rentenversicherungssystem zwingend notwendig sind und die Leistungen der GRV auch kinderlosen Personen zukommt. Eine differenzierte Behandlung zwischen mehreren Gruppen von Normaldressaten ist gerechtfertigt, wenn sachliche Unterschiede von solcher Art und Gewicht bestehen, daß sie eine Ungleichbehandlung rechtfertigen können (BVerfGE 83, 395, 401). Über die sachlichen Unterschiede hat im Einzelfall der Gesetzgeber zu entscheiden. Sein "Spielraum endet erst dort, wo die ungleiche Behandlung der geregelten Sachverhalte nicht mehr mit einer am Gerechtigkeitsgedanken orientierten Betrachtungsweise vereinbar ist, anders ausgedrückt: wo ein einleuchtender Grund für die gesetzliche Differenzierung fehlt" (BVerfGE 9, 334, 337). Für den praktizierten Anrechnungsmodus der Kindererziehungszeiten lassen sich sachliche Gründe finden:

1. Monetäre Beiträge und die Kindererziehungsleistung üben im System der Gesetzlichen Rentenversicherung unterschiedliche Funktionen aus, eine Ungleichbehandlung ist dadurch berechtigt. Monetäre Leistungen können an die ältere Generation ausgeschüttet werden, Leistungen der Kindererziehung wirken sich erst nach einiger Zeit aus. 
2. Eine Ungleichbehandlung, die sich aus der Stichtagsregelung ergibt Mütter der Geburtsjahrgänge vor 1921 erhalten für jedes von ihnen geborene Kind eine Honorierung ihrer Erziehungsleistung, unabhängig davon, ob sie in der Zeit der Erziehung Beiträge zur Rentenversicherung entrichtet haben oder sich gänzlich der Kindererziehung gewidmet haben - ist gerechtfertigt, auch wenn jede Stichtagsregelung gewisse Härten mit sich bringt. Allerdings muß sich die Wahl des Zeitpunktes am gegebenen Sachverhalt orientieren ${ }^{34.4}$. Praktikabilitätsüberlegungen zwingen den Gesetzgeber zur Durchführung von Stichtagsregelungen und auch die Rentenversicherungsträger hätten ohne diese Möglichkeit vor nahezu unüberwindlichen Schwierigkeiten gestanden. ${ }^{355}$

3. Eine Kollision mit dem in Art. 6 Abs. 4 GG verankerten Schutz- und Fürsorgeanspruch der Mütter gegenüber der staatlichen Gemeinschaft ist nicht festzustellen. In der Urteilsbegründung heißt es dazu, daß "für Sachverhalte, die nicht allein Mütter betreffen, keine besonderen Rechte hergeleitet werden" können. ${ }^{356}$

4. Auch der in Art. 14 GG verankerte Schutz der Rentenanwartschaften widerspricht nicht den Anrechnungsmodalitäten. Die Auffassung, gezahlte freiwillige Beiträge würden durch die Subsidiarität entwertet werden, ist nicht haltbar, da vor Erlaß des HEZG keine individuelle Rechtsposition hinsichtlich der Anrechnung von Kindererziehungszeiten vorhanden war, in die der Gesetzgeber hätte eingreifen können, da das HEZG diese Position erst geschaffen habe. Freiwillig geleistete Beiträge bleiben vielmehr vollständig erhalten und führen weiterhin zu entsprechenden Rentenleistungen. Ein Verstoß gegen das Rechtsstaatsprinzip (Art. 20 Abs. 1 GG) ist aus den gleichen Gründen nicht zu erkennen.

5. Das Sozialstaatsprinzip verpflichtet den Staat, durch den Ausgleich sozialer Gegensätze für eine gerechte Sozialordnung zu sorgen, um öffentliche Mittel jedoch dahin lenken zu können, wo im Einzelfall

\footnotetext{
${ }^{354}$ Vgl. BVerfG 7/92, S. 65.

${ }^{355}$ Vgl. BVerfG 7/92, S. 66.

${ }^{356}$ Vgl. BVerfG 7/92, S. 62.
} 
ein Bedarf besteht, ist eine "Differenzierung nach dem Grad der sozialen Schutzbedürftigkeit" zulässig (BVerfGE 23, 135, 145). Da das "Lückenschließungskonzept" des HEZG auf der Überlegung beruht, "daß im Falle eigener Beitragszeiten auch ohne zusätzliche Leistungen eine ausreichende rentenrechtliche Absicherung der Zeit der Kindererziehung gewährleistet ist", läßt sich eine kumulative Anrechnung der Kindererziehungszeiten zusätzlich zu Beitragszeiten aus dem Sozialstaatsprinzip nicht ableiten.

Die Diskussion um die Anrechnung von Erziehungszeiten wird von Albers um einen primär ökonomischen Gesichtspunkt erweitert: ${ }^{357}$ Die monetären Beiträge der aktiven Generation sichern die materielle Grundlage für die gegenwärtig alte Generation, die Kindererziehung als materielle Leistung sichert die zukünftige alte Generation gewährleistet damit den Fortbestand des Systems der gesetzlichen Alterssicherung schlechthin. Kindererziehung kann demnach nicht nur als beitragsäquivalente Leistung angesehen werden, sondern sie kann auch durchaus den monetären Beiträgen gleichgestellt werden und damit auch gleich bewertet werden. Albers weist außerdem darauf hin, daß das Aufziehen von Kindern einen Konsumverzicht erfordert, "der trotz der staatlichen Hilfen nicht kleiner als die Belastung durch Zwangsbeiträge zur Alterssicherung ist" ${ }^{1358}$, so daß auch deshalb kein Grund besteht, die Kindererziehungsleistung niedriger als die Zahlung von Beiträgen zu bewerten. Im übrigen streift auch das BVerfG diesen Aspekt in seiner Urteilsbegründung, wenn es heißt: "Die Familie, in der ein Elternteil zugunsten der Kindererziehung aus dem Erwerbsleben ausscheidet, nimmt im Vergleich zu Kinderlosen ... Einkommenseinbußen hin"359, dieser Hinweis wird allerdings dann nicht weiter verfolgt.

Die vom BVerfG bescheinigte Ungleichheit von Kindererziehung und Beitragszahlung hat für den Gesetzgeber aber zunächst einmal den Vorteil, daß er von einer Höherbewertung der Ansprüche absehen kann und somit eventuell auftretende Finanzierungsprobleme erst in der Zukunft relevant werden. Hinzu kommt, daß dem Gesetzgeber zwar der Abbau der Benach-

\footnotetext{
${ }^{357}$ Vgl. Albers, W., Kindererziehung und Alterssicherung, in: Wirtschaftsdienst, 72. Jg., Heft 10, S. 522.

${ }^{358}$ Ebenda.

${ }^{359}$ BVerfG 7/92, S. 56.
} 
teiligung auferlegt wurde, dies aber nicht notwendigerweise im Rentenrecht geschehen müsse: "Soweit sich die Benachteiligung gerade in der Alterssicherung der kindererziehenden Familienmitglieder niederschlägt, ist sie vornehmlich durch rentenrechtliche Regelungen auszugleichen." ${ }^{360}$ Das bedeutet aber nicht, daß der Gleichheitsgrundsatz nur eine Reform innerhalb der Rentenversicherung vorschreibt, vielmehr könnten auch andere Instrumente des Familienlastenausgleichs zum Tragen kommen, soweit sie Benachteiligungen effizient und systemkonform abbauen. ${ }^{361}$ Allerdings würde das Problem für die Politiker bei einer solchen Lösung nicht kleiner werden, da ohne eine konkrete verteilungspolitische Konzeption auch keine Konkretisierung im Rahmen des Familienlastenausgleichs möglich wäre. Das Bundesverfassungsgericht verweist in seinem Urteil unter anderem auf eine Stellungnahme des VDR, in der ausdrücklich darauf hingewiesen wird, daB ein Recht zur "beitragsäquivalenten" Berücksichtigung von Kindererziehungszeiten im Rahmen der gesetzlichen Rentenversicherung nicht herzuleiten ist, da die über die Zahlung von Beiträgen erworbenen Versichertenrenten Lohnersatzfunktion hätten, so daß ein Rentenbezug generell an das Erfordernis einer früheren Erwerbstätigkeit mit einem Erwerbseinkommen oberhalb der Sozialversicherungsgrenze geknüpft ist. Der Gleichbehandlungsgedanke lasse es unter diesem Gesichtspunkt nicht zu, Beitragszahler in der GRV zugunsten von Personen zu benachteiligen, die keine Beiträge entrichteten. Zudem kommt der VDR zu der Auffassung, daB die Beiträge der GRV allein der Finanzierung des Rentensystems dienen dürften und insofern allgemeine sozialpolitische Aufgaben des Staates auch in deren Finanzierungsverantwortung zugewiesen werden müßten.

Die mit einer Reform einhergehenden zu erwartenden Finanzierungsschwierigkeiten scheinen auch vom BVerfG berücksichtigt worden sein, denn es billigt dem Gesetzgeber einen erheblichen Spielraum in zeitlicher Hinsicht zu, wenn es um die Beseitigung der Benachteiligung geht. Dem Gesetzgeber wird eine ausreichende (allerdings vom BVerfG nicht näher spezifizierte) Anpassungszeit eingeräumt, zudem sei er befugt, die Reform in

\footnotetext{
${ }^{360}$ BVerfG 7/92, S. 59.

${ }^{361}$ Vgl. Netzler, A., Familie als Risiko? Zur Anerkennung von Erziehungszeiten in der gesetzlichen Rentenversicherung, Konsequenzen aus dem Lrteil des Bundesverfassungsgerichtes, Grafschaft 1993, S. 15.
} 
Teilschritten unter Berücksichtigung der jeweiligen Haushaltslage und der finanziellen Situation der gesetzlichen Rentenversicherung vorzunehmen. Allerdings sei bei diesem Vorgehen sicherzustellen, daß sich mit jedem Schritt die Benachteiligung der Familie verringere.

Interessanterweise eröffnet das Urteil erstmalig eine völlig neue Sichtweise, was unter dem Begriff der "Familie" subsumiert werden kann. Denn während sich bislang vom Gesetzgeber die Familie, wenn sie als solche die ihr nach dem Gesetz zugestandenen Rechte und Pflichten wahrnehmen wollte als sogenannte "Kernfamilie" (Eltern und Kinder) darstellen mußte, ist nach dem oben zitierten Urteil des Bundesverfassungsgerichtes eine Gleichstellung der Ehe respektive Familie mit der eheähnlichen Lebensgemeinschaft vereinbar, wenn der Rechtsstatus der in dieser Gemeinschaft befindlichen Kinder betroffen ist. Weiterhin wird in diese eher weite Definition von Familie auch ein alleinerziehender Elternteil einbezogen, so daß sich deren Rechtsstellung gegenüber früheren Zeiten verbessert hat.

Nicht immer konsistent ist das BVerfG, wenn es um die konkrete Abgrenzung der betrachteten benachteiligten Personenkreises geht, so erfolgt einerseits eine Eingrenzung auf denjenigen, der sich innerhalb der Familie auf die Kindererziehung konzentriert, wenn von einer "Benachteiligung von Personen, die sich innerhalb der Familie der Kindererziehung widmen, gegenüber kinderlosen Personen" ${ }^{1362}$ gesprochen wird, andererseits wird auf die gesamte Familie Bezug genommen, wenn festgestellt wird: "Die bisherige Ausgestaltung der Rentenversicherung führt im Ergebnis zu einer Benachteiligung der Familie" ${ }^{1363}$. An anderer Stelle werden dann beide Elternteile betrachtet: "Wenn die Kinder in das Erwerbsleben eingetreten sind..., haben die Eltern selbst eine geringere Rente zu erwarten"364. Eine klarere Unterscheidung, wer letztlich mit einer Reform begünstigt werden soll, müßte also auch von politischer Seite vorgenommen werden, was konkret bedeutet, daß eine grundlegende Entscheidung über die Anwendung des Individualoder des Familienprinzips in der GRV getroffen werden müßte.

\footnotetext{
${ }^{362}$ BVerfG 7/92, S. 55.

${ }^{363}$ Ebenda, S. 56.

${ }^{364}$ Ebenda, S. 56.
} 
Flankierend dazu stellt das Gericht in Frage, ob unter den sich momentan verändernden Rahmenbedingungen die abgeleitete Hinterbliebenenrente noch ihre Berechtigkeit habe. Diese Witwen-/Witwerrente habe ihre ursprüngliche Funktion als Lohnersatzleistung und damit eines "gewissen Ausgleichs" doch dadurch weitgehend eingebüßt, daß die Erwerbstätigkeit beider Ehegatten bzw. der Frauen zugenommen habe und zudem die Zahl der Kinder zurückgegangen sei. Auch diese Frage steht in engem Zusammenhang mit den Gestaltungsprinzipien der Sozialversicherung. Eine dem Individualprinzip folgende Systematik müßte in der Tat auf jegliche Formen abgeleiter Sicherung verzichten und für jeden Versicherten ein individuelles Versicherungskonto mit eigenen Ansprüchen einrichten. Die gegenwärtigen Erwerbsquoten von Frauen lassen jedoch eine Umstellung des Systems in diese Richtung sehr problematisch erscheinen, auch wenn dadurch der Aufbau einer eigenständigen sozialen Sicherung der Frau gewährleistet wäre.

Albers geht in seinem Vorschlag zum Abbau der Benachteiligung ${ }^{365}$ ebenfalls auf dieses Problem ein, er fordert, wie auch schon an früherer Stelle $^{366}$, neben der Höherbewertung der Kindererziehungszeit eine Staffelung von beitragsfreien Erziehungszeiten nach der Zahl der geborenen Kinder. Für das erste Kind sollten wie bisher drei Jahre, für das zweite Kind bereits vier Jahre und für das dritte und alle weiteren Kinder fünf Jahre angerechnet werden. Würde die Erziehungsaufgabe in dieser Weise rentenrechtlich anerkannt werden, könnte auf die Hinterbliebenenrente verzichtet werden, ohne das jedoch zwingend dem Individualprinzip gefolgt werden müßte. Im Rahmen des Familienprinzips könnte der Gedanke des Zugewinns in der Ehe auch auf das Rentenrecht übertragen werden, so daB zwar eine eigenständige, aber familienbezogene Rente für jeden Ehepartner entsteht. Der Tod eines Partners würde dann dazu führen, daB die gemeinsame Rente nicht mehr in voller Höhe gezahlt wird, jedoch immer noch in einer ausreichenden Höhe, um den Lebensunterhalt bestreiten zu können. Diese Regelung hätte zudem den Vorteil, daß Rentenkumulationen, die vielfach zu einer Überversorgung führen, beseitigt würden. Weitere Finanzierungsquellen für seinen Vorschlag sieht Albers in der Möglichkeit, nicht erwerbs-

\footnotetext{
${ }^{365}$ Vgl. Albers, W., Kindererziehung und Alterssicherung, a.a.O., S. 525.

${ }^{366}$ Vgl. Albers, W., Auf die Familie kommt es an, a.a.O., S. 108.
} 
tätige kinderlose Ehefrauen bis zu einer bestimmten Einkommenshöhe des Partners zur Zahlung von Versicherungsbeiträgen heranzuziehen, und darüber hinaus die Rentenansprüche über Differenzierungen beim Rentenartfaktor zu verringern. ${ }^{367}$

Letztlich hat das Bundesverfassungsgericht neben der grundlegend anderen Betrachtung bezüglich Ehe und Familie dem Gesetzgeber den Auftrag erteilt im Hinblick auf die bereits akzeptierte Zielsetzung, die Kindererziehungsleistung zu honorieren und eine eigenständige soziale Sicherung der Frau aufzubauen, um die durch die Kindererziehung entstehende Benachteiligung bei der Altersversorgung in weiterem Umfang als bisher auszugleichen.

Daraus kann gefolgert werden, daß eine maßvolle Umverteilung von kinderlosen zu kinderreichen Personen im System der GRV durchaus legitim ist. Allerdings besteht für den Gesetzgeber das Problem was er unter "maßvoll" verstehen soll. Hier wird man nicht umhin kommen, eine politische Entscheidung zu treffen, in welchem Ausmaß Kinderlose belastet werden sollen und können?

\section{Die Rentenreform 1992 - Auswirkungen auf die soziale Sicherung der Frau}

Nur drei Jahre nach der Reform der Hinterbliebenenversorgung verabschiedete der Deutsche Bundestag am 9. November 1989 das Gesetz zur Reform der gesetzlichen Rentenversicherung (Rentenreformgesetz 1992), das im Gegensatz zur Reform 1986 erhebliche Modifizierungen brachte, ohne jedoch das System der gesetzlichen Rentenversicherung in seiner Struktur zu verändern. Begleitet wurden die inhaltlichen Veränderungen davon, daß die bislang in besonderen Gesetzen für die Arbeiterrentenversicherung, die Angestelltenversicherung und die knappschaftliche Rentenversicherung sowie in zahlreichen Nebengesetzen enthaltenen Regelungen zusammenge-

\footnotetext{
${ }^{367}$ Näheres dazu bei Albers, W., Die Anpassung des Systems der gesetzlichen Rentenversicherung an demographische Änderungen, in: Finanzierungsprobleme der sozialen Sicherung I, Hrsg.: K. Schmidt, Schriften des Vereins für Socialpolitik, Neue Folge Bd. 194/I, S. 9-40.
} 
faßt und als Sechstes Buch in das Sozialgesetzbuch eingefügt wurden. Die Organisationsstrukturen und die Abgrenzung der Zuständigkeiten wurden durch diese Maßnahme nicht angetastet, so daß weiterhin die bisherigen Rentenversicherungsträger (Bundesversicherungsanstalt für Angestellte, Bundesknappschaft, Landesversicherungsanstalten, Seekasse und Bundesbahnversicherungsanstalt für die Abwicklung der organisatorischen Belange zuständig bleiben.

Von den rentensystematischen Neuerungen sollen im folgenden lediglich die im Detail behandelt werden, die die soziale Sicherung der Frau tangieren.

Eine Veränderung allgemeiner Art, die in der Öffentlichkeit jedoch wenig Beachtung gefunden hat, ist der Ersatz des Versicherungsfallprinzips durch das Prinzip des Leistungsbeginns. Das Versicherungsfallprinzip besagt, daß für eine Versicherungsleistung immer das Recht maßgebend ist, daß zum Zeitpunkt des Eintritts des Versicherungsfalles gilt. Im Rentenrecht wurde es als vorteilhaft angesehen, daß Personen, die zu demselben Zeitpunkt einen Versicherungsfall haben, unter ansonsten gleichen Verhältnissen, auch immer eine gleich hohe Rente erhalten, unabhängig davon, wann sie die Rente beantragen. Mit Aufgabe des Versicherungsfallprinzips ergibt sich für die Rentenversicherungsträger bei der Ermittlung und Berechnung der Rentenansprüche eine erhebliche Vereinfachung, da Rechenprogramme und Abwicklungsbestimmungen über zurückliegende Rechtszustände nicht mehr vorgehalten und in Einzelfällen angewendet werden müssen. Mit der Einführung des „Prinzips des Leistungsbeginns“ wird für den Antragsteller der Rente jeweils das Recht maßgebend, daß im Zeitpunkt der Antragstellung bzw. des Leistungsbeginns gilt.

Kernstück der Rentenreform 1992 ist sicherlich die neue Rentenformel mit ihren Modifikationen in der Rentenberechnung. Da die Rentenformel bereits an anderer Stelle dieser Arbeit ausführlich dargestellt wurde, sei zur Erinnerung nur kurz auf die wesentlichen Kennzeichen verwiesen:

1. Die Rentenanpassung erfolgt nach der Nettolohnentwicklung, d.h. daß sich die verfügbaren Renten und die Nettolöhne der Arbeitnehmer gleichgewichtig entwickeln. Diese Änderung war notwendig, weil die Belastung der Arbeitnehmereinkommen mit Steuern und Sozialabgaben ständig 
stieg, das verfügbare Einkommen damit geringer wurde, während die Rentner wegen der Rentenanpassung an der Bruttolohnentwicklung vollständig an Lohn- und Gehaltssteigerungen partizipierten. War dies noch in Zeiten erwünscht, in denen die Konsumnachfrage nicht sinken sollte, um die wirtschaftliche Entwicklung zu nennen, erscheint es jetzt aus verteilungspolitischen Erwägungen heraus nicht wünschenswert, die erwerbstäige Generation stärker zu belasten als die nicht mehr aktive Generation. Im Zuge der Anforderung einer gleichmäßigen und gerechten Verteilung der Lasten auf die Generationen konnte dieser Zustand nicht gebilligt werden. Berücksichtigung findet diese Veränderung in der neuen Rentenformel im aktuellen Rentenwert. Eher eine technische Veränderung ist die Umstellung der Rentenberechnung auf einen Monatsbetrag und nicht zunächst auf einen Jahresbetrag mit anschließender Ermittlung der Monatsrente.

Eine höhere Transparenz der Rentenzusammensetzung wird dadurch erreicht, daß einzelne Rententeile, die auf beitragsfreien- bzw. Beitragszeiten beruhen, getrennt ausgewiesen werden können. Damit wird es möglich, Maßnahmen des Solidarausgleichs von reinen Versicherungsleistungen zu trennen.

Jeder zusätzliche Beitrag und jede zusätzliche anrechenbare Zeit führt nun immer zu einer Erhöhung der maßgeblichen Faktoren und damit zu einer Steigerung der zukünftigen Rente. ${ }^{368}$

2. Versicherungssystematisch nur konsequent, jedoch in der Öffentlichkeit sehr negativ bewertet, ${ }^{369}$ wurde die Flexibilisierung der Altersgrenzen und gleichzeitige Verlängerung der Lebensarbeitszeit. Die Regelaltersrente von 65 Jahren wurde bei den Männern wieder eingeführt, bei den Frauen gab es 1992 noch eine Sonderregelung, die mittlerweile jedoch schon wieder aufgehoben worden ist. Es erscheint im Zuge der Gleichberechtigung und Gleichstellung von Mann und Frau auch nur konsistent, Benachteiligungen, oder wie in diesem Fall, Bevorzugungen von Frauen zu beseitigen. Die für die Sonderbehandlung der Frauen maßgebliche Begründung eines Ausgleichs der Doppelbelastung mit Erwerbstätigkeit und Kindererziehung

\footnotetext{
${ }^{368}$ Vgl. W. Niemeyer, Die Rentenversicherung nach der Reform - rechtlich, sozialpolitisch, finanziell, in: Sozialer Fortschritt, 39. Jg. 1990, Heft 5, S. 99.

369 Dieses ist jedoch insofern nachvollziehbar, als Leistungskürzungen immer schmerzlich sind und auf den Widerstand der Betroffenen stoßen.
} 
verliert an Bedeutung angesichts vermehrter Betreuung der Kinder in Kollektiveinrichtungen. Die generelle Heraufsetzung der Altersgrenzen erwies sich als unumgänglich, da mit zunehmender Zahl von Leistungsbeziehern im Verhältnis zu den Beitragszahlern eine nicht finanzierbare Erhöhung des Belastungsquotienten einherging, und die ständig erhöhende Lebenserwartung der älteren Generation zusätzlich verschärfend wirkte. Insofern war ein Heraufsetzen der Altersgrenzen als eine Maßnahme zur Aufrechterhaltung der Balance zwischen den Generationen unumgänglich. ${ }^{370}$

Die neu eingeführte Flexibilisierung ermöglicht erstmals einen Teilrentenbezug bzw. rechnet mit Ab- und Zuschlägen bei vorzeitigem bzw. hinausgeschobenem Rentenbezug.

3. Zur Stärkung des Versicherungsprinzips in der Rentenversicherung ist die Neuregelung der Anrechnung und Bewertung beitragsfreier und beitragsgeminderter Zeiten etabliert worden. Im alten Recht wurden Ausfallzeiten (= beitragslose Zeiten wegen Krankheit, Arbeitslosigkeit oder Schulausbildung) nur dann bei der Rentenberechnung berücksichtigt, wenn die sog. Halbbelegung erfüllt war. Das bedeutete, daß die Zeit vom Beginn der Versicherung bis zum Eintritt des Versicherungsfalles unter Ausklammerung der Ausfallzeiten mindestens zur Hälfte mit Pflichtbeiträgen belegt sein mußte. ${ }^{371}$ Schon das Fehlen eines Beitrages führte zur Nichtberücksichtigung sämtlicher Ausfallzeiten. Dieses „Alles-oder-Nichts-Prinzip“ war „auch nicht beitragsgerecht, weil bei gleichem Beitragswert die Halbbelegung - je nach Verteilung und Höhe der Beiträge - einmal erfüllt sein kann und ein anderes Mal nicht ${ }^{63 n}$. Diese stark restriktive Bedingung der Halbbelegung fällt mit dem RRG vollständig weg. Die Bewertung beitragsfreier Zeiten hängt nun von der ,individuellen Beitragsdichte“ ab, d.h. je mehr Lücken die gesamte Versicherungszeit aufweist, desto geringer ist der Wert, der diesen Zeiten zukommt. ${ }^{373}$ Der Wegfall der Halbbelegung als Anspruchsvoraussetzung wird vor allem Frauen zugute kommen, zum Zeitpunkt der Reform erfüllten $45 \%$ der Frauen nicht die Voraussetzung, bei-

${ }^{370}$ Vgl. W. Niemeyer, a.a.O., S. 100.

371 § 1259 Abs. 3 RVO.

${ }^{372}$ Deutscher Bundestag, BT-Drucksache 11/4124, S. 141.

${ }^{373}$ Vgl. Bank/Brachmann/Kreikebohm/Schmidt, a.a.O., S. 192. 
tragsfreie Zeiten angerechnet zu bekommen. ${ }^{374}$ Dabei war in erster Linie der kindbedingte Ausfall der Erwerbstätigkeit dafür verantwortlich, je mehr Kinder nun eine Frau aufzog, desto geringer waren ihre Chancen, beitragsfreie Zeiten angerechnet zu bekommen.

4. Die besonders den Frauen zugute kommenden Neuerungen finden sich weiterhin bei den familienbezogenen Elementen des neuen Rentenrechts. Dazu gehören die erweiterte Berücksichtigung von Zeiten der Kindererziehung, die Berücksichtigung von Zeiten der Pflege und die Fortführung der Rente nach Mindesteinkommen.

- Die Anrechnung von Kindererziehungszeiten wurde von einem Jahr auf drei Jahre für Geburten ab 1992 erweitert, wobei sich diese Zeiten sowohl rentenbegründend als auch rentensteigernd auswirken. Mit diesem Schritt sollte nicht nur die Gleichwertigkeit von Erwerbsarbeit und Kindererziehung betont werden, sondern auch der Weg für eine eigenständige soziale Sicherung der Frau beschritten werden. Bewertet werden diese Zeiten mit $75 \%$ des Durchschnittsentgelts aller Versicherten.

- Die neue Regelung der Berücksichtigungszeiten erfaßt die Erziehung eines Kindes bis zu seinem 10. Lebensjahr mit gleichzeitiger Funktionserweiterung: Zeiten einer nicht erwerbsmäßigen Pflege können unbegrenzt als Berücksichtigungszeit in der Rentenversicherung angerechnet werden. Vorteile ergeben sich in zweierlei Hinsicht: Mit der Anerkennung dieser Zeiten kann auch der Anspruch auf eine Berufs- oder Erwerbsunfähigkeitsrente aufrecht erhalten werden und sie werden auch bei der Erfüllung der für die Renten nach Mindesteinkommen oder für die Altersrente für langjährig Versicherte maßgeblichen Wartezeit von 35 Jahren angerechnet, allein haben diese Zeiten weder rentenbegründende noch rentensteigernde Wirkung, sie verhindern aber, daß sich aus diesen Zeiten rentenrechtliche Nachteile aus einer Nichtbewertung ergeben. ${ }^{375}$

Nicht neu eingeführt, aber erheblich modifiziert hat das Rentenreformgesetz 1992 die Rente nach Mindesteinkommen, ${ }^{376}$ die erweiterte Min-

\footnotetext{
374 Vgl. F. Ruland, a.a.O., S. 81.

375 Vgl. F. Ruland, Reform der sozialen Sicherung der Frau, Analyse des Ist-Zustandes und Bericht über die noch in der Diskussion befindlichen Lösungsvorschläge, in: Deutsche Rentenversicherung, Heft 2-3, 1992, S. 70.

${ }^{376}$ Altes Recht: Art. 2 §5a ArVNG, Art. 2 § 54b AnVNG. Neues Recht: Art. 82 RRG.
} 
destrentenregelung gilt zudem auch für Versicherungsfälle vor 1992. Die Mindestrentenregelung sah vor, daß Pflichtbeitragszeiten, die vor dem 1. Januar 1973 lagen, auf $75 \%$ des Durchschnittsentgelts aller Versicherten angehoben wurden, wenn der Versicherte unter Berücksichtigung von $\mathrm{Zu}$ rechnungs- und Ersatzzeiten mindestens 25 Jahre lang versicherungspflichtig war. Das RRG verlängerte diese Regelung bis zum 31. Dezember 1991 und erhöhte gleichzeitig die Beitragsbewertung auf das 1,5fache ihres Wertes, höchstens aber in Höhe von jährlich 0,75 Entgeltpunkten. „Die Anhebung auf das 1,5 fache ... wird bewirken, daB lange Beitragszeiten mit sehr niedrigen Pflichtbeiträgen aufgrund einer Teilzeitbeschäftigung im Verhältnis zu einer entsprechenden Vollzeitbeschäftigung nicht unverhältnismäßig angehoben werden". ${ }^{377}$ Voraussetzung für diese Wertverbesserung ist allerdings, daß anstatt der bisher geltenden 25 Versicherungsjahre künftig mindestens 35 Jahre mit rentenrechtlichen Zeiten zurückgelegt worden sind. Nachstehende Tabelle zeigt die Auswirkungen der neuen Regelung auf den durchschnittlichen Rentenbetrag.

Nach Berechnungen des VDR sollte die Rentenreform 1992 zu einer deutlichen Verbesserung der Renten an Frauen - besonders diejenigen, die Kinder aufgezogen haben - führen. Danach sollten Frauen mit weniger als 15 Versicherungsjahren eine Rentensteigerung von ca. 5,2\% erwarten können, Frauen, die zwischen 15 bis unter 35 Jahren versichert waren, können sogar eine 7\%ige Steigerung erwarten, während Frauen mit mehr als 35 Versicherungsjahren lediglich eine 4\%ige Rentensteigerung erwarten können. Bestätigen sich diese Zahlen in der Zukunft, ist das Ziel, Frauen zu begünstigen, die Kinder aufgezogen haben, zumindest teilweise realisiert worden.

377 Deutscher Bundestag, BT-Drucksache 11/4124, S. 144. 
Tabelle 30: Auswirkungen der verschiedenen Rentenregelungen nach Mindesteinkommen auf den durchschnittlichen Rentenbetrag der Frauen

\begin{tabular}{|c|c|c|c|c|c|c|}
\hline \multirow[t]{2}{*}{$\begin{array}{c}\text { Anspruch auf Rente } \\
\text { nach Mindesteinkom- } \\
\text { men }\end{array}$} & \multicolumn{3}{|c|}{$\begin{array}{c}\text { Rentenzugang } 1992 \\
\text { Durchschnittlicher Rentenbetrag ** }\end{array}$} & \multicolumn{3}{|c|}{$\begin{array}{c}\text { Rentenzugang } 2004 \\
\text { Durchschnittlicher Rentenbetrag ** }\end{array}$} \\
\hline & $\begin{array}{c}\text { Ohne Ren- } \\
\text { te nach } \\
\text { Mindes- } \\
\text { teinkom- } \\
\text { men }\end{array}$ & $\begin{array}{c}\text { Mit gel- } \\
\text { tender } \\
\text { Regelung } \\
\text { der Rente } \\
\text { nach Min- } \\
\text { destein- } \\
\text { kommen }\end{array}$ & $\begin{array}{c}\text { Mit RRG- } \\
\text { Regelung } \\
\text { nach Min- } \\
\text { destein- } \\
\text { kommen }\end{array}$ & $\begin{array}{c}\text { Ohne Ren- } \\
\text { te nach } \\
\text { Mindes- } \\
\text { teinkom- } \\
\text { men }\end{array}$ & $\begin{array}{c}\text { Mit gel- } \\
\text { tender } \\
\text { Regelung } \\
\text { der Rente } \\
\text { nach Min- } \\
\text { destein- } \\
\text { kommen }\end{array}$ & $\begin{array}{c}\text { Mit RRG- } \\
\text { Regelung } \\
\text { nach Min- } \\
\text { destein- } \\
\text { kommen }\end{array}$ \\
\hline 1 & 2 & 3 & 4 & 5 & 6 & 7 \\
\hline $\begin{array}{l}\text { Sowohl nach bislang } \\
\text { geltender als auch nach } \\
\text { RRG-Regelung }\end{array}$ & 856 DM & $927 \mathrm{DM}$ & $1029 \mathrm{DM}$ & $865 \mathrm{DM}$ & 892 DM & $986 \mathrm{DM}$ \\
\hline $\begin{array}{l}\text { Nur nach bislang gel- } \\
\text { tender Regelung }\end{array}$ & $1012 \mathrm{DM}$ & $1062 \mathrm{DM}$ & - & $1147 \mathrm{DM}$ & $1169 \mathrm{DM}$ & - \\
\hline $\begin{array}{l}\text { Nur nach RRG-Rege- } \\
\text { lung }\end{array}$ & $708 \mathrm{DM}$ & - & $815 \mathrm{DM}$ & 734 DM & - & $808 \mathrm{DM}$ \\
\hline
\end{tabular}

* Simulation auf der Basis des RRG 1992 (einschließlich der dortigen Höherbewertung der ersten Berufsjahre). Variiert wird allein die Regelung der Rente nach Mindesteinkommen.

** DM-Beträge auf der Basis der allgemeinen Bemessungsgrundlage vom 1.7.1989.

Quelle: Auswertungen der Rentenzugangsstichprobe 1988; in: Reimann/Tenbusch 1990, S. 100. 


\section{Teil C: Die rentenversicherungsrechtliche Stellung der verschiedenen Gruppen alleinerziehender Frauen}

\section{Quantitative Bedeutung der Ein-Eltern-Familien}

Die Zahl der Ein-Eltern-Familien ist seit Anfang der siebziger Jahre kontinuierlich gestiegen, wobei 1972 das niedrigste Niveau seit der Gründung der Bundesrepublik erreicht worden war.

Tabelle 31: Alleinerziehende, Ehepare und nichteheliche Lebensgemeinschaften im früheren Bundesgebiet*)

\begin{tabular}{|c|c|c|c|c|}
\hline \multirow[t]{2}{*}{ Familienform } & 1972 & 1982 & 1992 & $\begin{array}{l}\text { Verănderung } \\
1992 \text { gegenūber } \\
1972\end{array}$ \\
\hline & \multicolumn{3}{|c|}{1000} & $\%$ \\
\hline \multirow{4}{*}{$\begin{array}{l}\text { Alleinerziehende1) } \\
\text { Ehepaare ohne Kin- } \\
\text { der2) } \\
\text { Ehepaare mit Kin- } \\
\text { dern3) } \\
\text { Nichteheliche Le- } \\
\text { bens-Gemeinsch. 4) }\end{array}$} & 1462 & 1658 & 1904 & $\begin{array}{r}+30,3 \\
\end{array}$ \\
\hline & 5674 & 5924 & 6890 & $+21,4$ \\
\hline & 9634 & 9193 & 8822 & $-8,4$ \\
\hline & 137 & 516 & 1147 & $+740,1$ \\
\hline
\end{tabular}

*) Ergebnis des Mikrozensus. - 1) Einschl. der Alleinerziehenden, die Lebenspartner in einer nichtehelichen Lebensgemeinschaft sind. - 2) Ohne im Haushalt lebende Kinder. - 3) Im Haushalt lebende ledige Kinder ohne Altersbegrenzung. - 4) Schătzung aus Ergebnissen des Mikrozensus.

Quelle: Statistisches Bundesamt, Im Blickpunkt: Familien heute, Wiesbaden 1995, S. 23

Während die Zahl der Ehepaare mit im Haushalt lebenden Kinder von ca. 9,6 Millionen im Jahr 1972 auf ca. 8,8 Millionen im Jahr 1992 um 8,4 \% zurückgegangen ist, sind bei Ehepaaren ohne im Haushalt lebende Kinder und Alleinerziehenden deutliche Zuwächse erkennbar. Es ist zu vermuten, daB die Zunahme der Zahl der Alleinerziehenden von 30,3 \% sogar noch stärker ausfallen würde, wenn sich die Betrachtung auf das gesamte Bundesgebiet erstrecken würde. 
Tabelle 32: Ehepaare mit minderjährigen Kindern sowie Alleinerziehende ${ }^{*}$ )

\begin{tabular}{|c|c|c|c|c|c|c|}
\hline \multirow{2}{*}{$\begin{array}{l}\text { Eltern-Kind- } \\
\text { Gemeinschaft }\end{array}$} & \multicolumn{2}{|c|}{1972} & \multicolumn{2}{|c|}{1982} & \multicolumn{2}{|c|}{1992} \\
\hline & 1000 & $\%$ & 1000 & $\%$ & 1000 & $\%$ \\
\hline \multicolumn{7}{|c|}{ Früheres Bundesgebiet } \\
\hline Ehepaare & 8114 & 92,0 & 7240 & 88,6 & 6192 & 85,9 \\
\hline $\begin{array}{l}\text { Alleinerziehen- } \\
\text { de1) }\end{array}$ & 701 & 8,0 & 927 & 11,4 & 1016 & 14,1 \\
\hline Insgesamt & 8815 & 100 & 8167 & 100 & 7207 & 100 \\
\hline \multicolumn{7}{|c|}{ Neue Länder und Berlin-Ost2) } \\
\hline Ehepaare & - & - & 2117 & 85,5 & 1732 & 77,9 \\
\hline $\begin{array}{l}\text { Alleinerziehen- } \\
\text { de1) }\end{array}$ & - & - & 358 & 14,5 & 493 & 22,1 \\
\hline Insgesamt & - & - & 2475 & 100 & 2225 & 100 \\
\hline
\end{tabular}

*) Ergebnis des Mikrozensus. - Bevölkerung am Familienwohnsitz. - Im Haushalt der Eltern(teile) lebende ledige Kinder unter 18 Jahren. - 1) Einschl. der Alleinerziehenden, die Lebenspartner in einer nichtehelichen Gemeinschaft sind. - 2) Für 1982: Ergebnis der Volkszählung am 31.12. 1981 in der ehem. DDR; ledige Kinder bis unter 17 Jahren.

Quelle: Statistisches Bundesamt, Im Blickpunkt heute, Wiesbaden 1995, S. 36.

Der prozentuale Anteil von Ein-Eltern-Familien an der Gesamtzahl der Familien ist seit 1972 von $8 \%$ auf $14 \%$ gestiegen, in den neuen Bundesländern einschließlich Berlin-Ost ist die Zahl im Zeitraum 1982-1992 sogar noch stärker von $14,5 \%$ auf $22,1 \%$ gestiegen. Offenbar verläuft der Trend $\mathrm{zu}$ neuen Lebensformen auch in unterschiedlichen politischen und wirtschaftlichen Lebensverhältnissen in die gleiche Richtung. Der hohe Anteil von Alleinerziehenden an allen Familien mit Kindern in den neuen Ländern spiegelt allerdings auch Unterschiede der demographischen Entwicklung zwischen Ost und West wider, die sich in einer höheren Scheidungshäufigkeit und einem höheren Anteil nichtehelich geborener Kinder im Osten niederschlagen. ${ }^{361}$ Das staatliche Angebot an außerfamiliärer Kinderbetreuung erleichterte es zudem, Kindererziehung und Erwerbstätigkeit auch ohne Partner zu bewältigen.

${ }^{361}$ Vgl. Statistisches Bundesamt, Im Blickpunkt: Familien heute, a.a.O., S. 37. 
Tabelle 33: Alleinerziehende nach dem Familienstand in \%

\begin{tabular}{|c|c|c|c|c|}
\hline \multirow[t]{2}{*}{ Familienstand } & \multicolumn{2}{|c|}{ früheres Bundesgebiet } & \multirow{2}{*}{$\begin{array}{l}\text { neue Bundes- } \\
\text { länder } 1991\end{array}$} & \multirow{2}{*}{$\begin{array}{c}\text { Deutschland } \\
1991\end{array}$} \\
\hline & 1970 & 1991 & & \\
\hline ledig & 9,0 & 16,7 & 33,6 & 21,2 \\
\hline $\begin{array}{l}\text { verheiratet, } \\
\text { getrennt lebend }\end{array}$ & 10,4 & 11,3 & 3,1 & 9,1 \\
\hline verwitwet & $\mathbf{5 9 , 7}$ & 35,3 & 19,3 & 31,0 \\
\hline Geschieden & 20,9 & 36,6 & 44,0 & 38,6 \\
\hline Insgesamt & 100,0 & 100,0 & 100,0 & 100,0 \\
\hline
\end{tabular}

Quelle: StBA, Mikrozensus 1991

Alleinerziehende sind keine homogene Gruppe, insofern ist es für die weitere Betrachtung zwingend notwendig, eine Unterscheidung hinsichtlich des Familienstandes vorzunehmen.

Die Zunahme der Zahl der Alleinerziehenden ist danach im wesentlichen eine Folge zunehmender Scheidungshäufigkeit. Deutlich zurückgegangen sind die Ein-Eltern-Familien mit einem verwitweten Elternteil, sie betragen jedoch im früheren Bundesgebiet immer noch gut ein Drittel (35,3 $\%)$. In den neuen Bundesländern dominieren die Ledigen $(33,6 \%)$ und die Geschiedenen (44,0 \%).

Obwohl sich der Anteil alleinerziehender Väter im betrachteten Zeitraum verdoppelt hat, so sind sie doch im Vergleich zu der Zahl alleinerziehender Mütter in der Minderheit. Allerdings könnte der beobachtete Anstieg auch als ein Indiz für die häufigere Übernahme von Erziehungsleistungen durch Väter gedeutet werden. Der vergleichsweise hohe Anteil Alleinerziehender 1961 ist auf die hohe Zahl von kriegsbedingten Verwitweten zurückzuführen, die von einer Wiederverheiratung abgesehen haben, weil dies zu einem Verlust der Witwenrente geführt hätte. Der relativ hohe Anteil verwitweter Mütter (46,5\%), aber auch Väter $(62,5 \%)$ scheint diese Behauptung zu stiutzen.

Die Betrachtung der Entwicklung nach dem Familienstand läbt deutlich erkennen, daß der Anteil Verwitweter fortwährend gesunken, während der 
von Geschiedenen und ledigen Müttern und Vätern gestiegen ist, insbesondere ist hier der sprunghafte Anstieg der Geschiedenen zu sehen. Die Entwicklung des Anteils der Getrenntlebenden ist von der Änderung des Scheidungsrechts geprägt (Kap. II) und insofern diskontinuierlich.

Geschiedene alleinerziehende Väter und Mütter haben sich annähernd parallel entwickelt. Absolut gesehen hat sich die Anzahl alleinerziehender geschiedener Mütter und Väter von 236.000 im Jahre 1970 auf 426.000 im Jahre 1985 erhöht. Es kann momentan davon ausgegangen werden, daß etwa jede dritte Ehe mit einer Scheidung endet.

Wie die vorangegangene Analyse deutlich erkennen läßt, sind zwei Faktoren ursächlich für den quantitativen Anstieg der Ein-Eltern-Familien:

1. Zunahme der Zahl nichtehelicher Geburten,

2. Anstieg der Ehescheidungen, wobei letzterer als Hauptfaktor anzusehen ist.

Angesichts der steigenden Zahl von Ein-Eltern-Familien taucht die Frage auf, ob dies ein Indiz für eine veränderte Einstellung zu Ehe und Familie sein kann.

Befragungen haben ergeben, daß eine grundsätzliche Abkehr von der Ehe nicht eindeutig festzustellen ist, jedoch der Verpflichtungscharakter sowie die Dauerhaftigkeit der Ehe deutlich an Bedeutung verloren haben. ${ }^{378} \mathrm{Da}$ der Anteil alleinerziehender Väter an allen Alleinerziehenden relativ gering ist, werden im folgenden lediglich alleinerziehende Mütter betrachtet.

Eine Aussage über die soziale Lage der betrachteten Personengruppen ist nur dann substantiell, wenn das Alter und die Anzahl der in diesen Haushalten lebenden Kindern in die Betrachtung einbezogen werden, da die Existenz von besonders kleinen und mehreren Kindern ein bedeutendes Hemmnis für die Aufnahme einer Erwerbstätigkeit ist. Der Verzicht auf eine Erwerbstätigkeit bedeutet jedoch ein niedrigeres Einkommensniveau und in dessen Folge eine schlechtere Sozialversicherungsposition. Aber auch für erwerbstätige Alleinerziehende mit Kleinkindern ergeben sich Probleme. Sie haben zwar ein höheres Einkommen und sind sozial abgesichert, demgegen-

${ }^{378}$ Vgl. Köcher, R., Einstellungen zu Ehe und Familie im Wandel der Zeit, hrsg. vom Ministerium für Arbeit, Gesundheit, Familie und Sozialordnung Baden-Württemberg, Stuttgart 1985, S. 146. 
über steigen bei ihnen die Kosten der Lebenshaltung an, da sie aus Zeitgründen verstärkt auf fertige und damit teurere Produkte zurückgreifen müssen und darüber hinaus Kosten für die Kinderbetreuung entstehen. Zusätzlich zu den entstehenden Kosten für die Fremdbetreuung der Kinder ergibt sich aus der Doppelbelastung durch Familien- und Erwerbstätigkeit eine ständige zeitliche und psychische Belastung des erziehenden Elternteils, die auch für die Kinder eine nicht unerhebliche Beeinträchtigung ihres seelischen Wohlbefindens bedeuten kann. ${ }^{379}$

Tabelle 34: Familien Alleinerziehender mit minderjāhrigen Kindern nach Geschlecht und Familienstand $1961-1985$

\begin{tabular}{|c|c|c|c|c|c|c|c|c|c|c|c|}
\hline \multirow[t]{2}{*}{ Jahr } & \multirow{2}{*}{$\begin{array}{l}\text { Anteil der } \\
\text { Alleiner- } \\
\text { ziehenden an } \\
\text { allen Famili- } \\
\text { en mit min- } \\
\text { derjährigen } \\
\text { Kindern in } \\
\%\end{array}$} & \multicolumn{2}{|c|}{$\begin{array}{l}\text { Anteil der Alleiner- } \\
\text { ziehenden .. an allen } \\
\text { Alleinerziehenden in } \\
\%\end{array}$} & \multicolumn{4}{|c|}{$\begin{array}{l}\text { Anteil der alleinerziehenden } \\
\text {... Mütter an allen alleiner- } \\
\text { ziehenden Müttern in \% }\end{array}$} & \multicolumn{4}{|c|}{$\begin{array}{l}\text { Anteil der alleinerziehen- } \\
\text { den ... Väter an allen } \\
\text { alleinerziehenden Vätern } \\
\text { in } \%\end{array}$} \\
\hline & & Vãter & Mũtter & ledig & $\begin{array}{l}\text { getr.- } \\
\text { le- } \\
\text { bend }\end{array}$ & $\begin{array}{l}\text { ge- } \\
\text { schie- } \\
\text { den }\end{array}$ & $\begin{array}{c}\text { verwit- } \\
\text { wet }\end{array}$ & ledig & $\begin{array}{c}\text { getr.- } \\
\text { le- } \\
\text { bend }\end{array}$ & $\begin{array}{l}\text { ge- } \\
\text { schie } \\
\text {-den }\end{array}$ & $\begin{array}{l}\text { ver- } \\
\text { wit- } \\
\text { wet }\end{array}$ \\
\hline 1961 & 10,5 & 7,8 & 92,2 & 19,5 & 9,7 & 24,1 & 46,5 & - & 12,5 & 26,6 & 62,5 \\
\hline 1970 & 8,7 & 16,4 & 83,7 & 15,5 & 11,9 & 33,0 & 39,6 & 7,4 & 36,1 & 24,6 & 32,0 \\
\hline 1974 & 8,3 & 12,7 & 87,3 & 15,1 & 8,3 & 41,4 & 35,2 & 4,3 & 18,3 & 36,6 & 40,9 \\
\hline 1978 & 9,7 & 13,6 & 86,4 & 13,9 & 10,8 & 45,1 & 30,1 & 5,4 & 20,5 & 37,5 & 36,6 \\
\hline 1982 & 11,4 & 15,6 & 84,4 & 15,5 & 15,7 & 45,0 & 23,8 & 6,9 & 26,2 & 35,2 & 31,7 \\
\hline 1985 & 12,8 & 14,7 & 85,3 & 19,6 & 15,8 & 46,0 & 18,7 & 13,8 & 20,3 & 41,3 & 24,6 \\
\hline
\end{tabular}

Quelle: Stutzer, W., Wingen, M., Alleinerziehende in der Bundesrepublik Deutschland, Eine datenorientierte Analyse demographischer und sozioökonomischer Strukturen, Stuttgart 1989, S. 10.

${ }^{379}$ Vgl. Napp-Peters, A., Ein-Elternteil-Familien, Weinheim 1985, S. $76 f$. 
Tabelle 35 zeigt den hohen Anteil von Alleinerziehenden mit nur einem Kind von 72,3 \% bzw. 68,7\%, lediglich $22 \%$ bzw. $25,5 \%$ haben 2 Kinder und nur ca. 5,8 \% haben 3 und mehr Kinder. Ein Vergleich mit den Ehepaaren mit minderjährigen Kindern, von denen 48,1 \% bzw. 46,1 \% ein Kind, $39 \%$ bzw. $45 \%$ zwei Kinder und $13 \%$ bzw. 8,9\% drei und mehr Kinder haben, läbt den Schluß zu, daß die Belastung für Alleinerziehende durch das Vorhandensein von Kindern so stark ist, daB auf eine größere Kinderzahl verzichtet wird. Dies belegt auch die durchschnittliche Kinderzahl pro Familie, die in Ein-Eltern-Familien bei 1,3\% und in Ehepaar-Familien bei 1,7 liegt. Weiterhin kann beobachtet werden, daß in Ein-Eltern-Familien jüngere Kinder relativ häufiger bei den Müttern, ältere Kinder häufiger bei den Vätern zu finden sind.

Tabelle 35: Kinderzahl bei Alleinerziehenden im Vergleich zur Kinderzahl bei Ehepaaren für Kinder unter $18 \mathrm{Jahren}$ in \%

\begin{tabular}{|l|c|c|c|c|}
\hline \multirow{2}{*}{$\begin{array}{l}\text { Zahl der } \\
\text { Kinder }\end{array}$} & \multicolumn{2}{|c|}{ früheres Bundesgebiet } & \multicolumn{2}{c|}{ neue Bundeslănder } \\
\cline { 2 - 5 } & $\begin{array}{l}\text { Alleinerziehen- } \\
\text { de }\end{array}$ & $\begin{array}{l}\text { Ehepaare mit Kin- } \\
\text { dern }\end{array}$ & Alleinerziehende & $\begin{array}{l}\text { Ehepaare mit Kin- } \\
\text { dern }\end{array}$ \\
\hline 1 & 72,3 & 48,1 & 68,7 & 46,1 \\
\hline 2 & 22,0 & 39,0 & 25,5 & 45,0 \\
\hline $3+$ mehr & 5,8 & 13,0 & 5,8 & 8,9 \\
\hline Insgesamt & 100,0 & 100,0 & 100,0 & 100,0 \\
\hline
\end{tabular}

Quelle: StBA, Mikrozensus 1991.

Wie aus Tabelle 36 ersichtlich, ist ein großer Anteil der alleinerziehenden Mütter relativ jung, besonders besorgniserregend ist der hohe Anteil von annähernd 21,7 \% lediger Mütter im Alter von unter 25 Jahren, da in diesen Fällen nicht nur die soziale Lage von wirtschaftlichen Engpässen geprägt sein wird, sondern auch die rentenversicherungsrechtlichen Auswirkungen auf den Lebensstandard im Alter erheblich sind. 
Tabelle 36: Mütter mit minderjährigen Kindern 1992 nach Altersgruppen*)

\begin{tabular}{|c|c|c|c|c|c|c|c|}
\hline \multirow{2}{*}{$\begin{array}{l}\text { Alter } \\
\text { der } \\
\text { Mutter } \\
\text { von... } \\
\text { bis unter } \\
\text {... Jah- } \\
\text { ren }\end{array}$} & Insge- & Ehe- & \multicolumn{5}{|c|}{ Alleinerziehende Frauen } \\
\hline & 1000 & & $\begin{array}{c}\begin{array}{c}\text { zusam- } \\
\text { men }\end{array} \\
\% \\
\%\end{array}$ & $\begin{array}{l}\text { Ledig } \\
\qquad \%\end{array}$ & $\begin{array}{c}\text { verheiratet } \\
\text { getrennt le- } \\
\text { bend } \\
\%\end{array}$ & $\begin{array}{c}\text { geschieden } \\
\%\end{array}$ & $\begin{array}{c}\text { verwitwet } \\
\quad \%\end{array}$ \\
\hline & & & & Frūheres & $\begin{array}{r}\text { Bundesge- } \\
\text { biet }\end{array}$ & & \\
\hline unter 25 & 367 & 81,2 & 18,8 & 13,8 & 2,8 & - & 2,1 \\
\hline $25-35$ & 2826 & 87,7 & 12,3 & 5,0 & 2,1 & 0,4 & 4,9 \\
\hline $35-55$ & 3772 & 88,4 & 11,6 & 1,7 & 1,8 & 1,8 & 6,4 \\
\hline $55-65$ & 93 & 81,8 & 18,2 & Neue & Länder und & $\begin{array}{r}11,6 \\
\text { Berlin-0st }\end{array}$ & - \\
\hline unter 25 & 170 & 57,3 & 42,7 & 38,7 & - & - & - \\
\hline $25-35$ & 1021 & 79,9 & 20,1 & 9,9 & 1,0 & 0,6 & 8,6 \\
\hline $35-55$ & 955 & 84,4 & 15,6 & 2,9 & 0,7 & 1,7 & 10,2 \\
\hline $55-65$ & 16 & 78,6 & - & - & $\begin{array}{r}\text { Deutsch- } \\
\text { land }\end{array}$ & - & \\
\hline unter 25 & 536 & 73,6 & 26,4 & 21,7 & 2,4 & - & 2,2 \\
\hline $25-35$ & 3847 & 85,6 & 14,4 & 6,3 & 1,8 & 0,4 & 5,9 \\
\hline $35-55$ & 4727 & 87,6 & 12,4 & 2,0 & 1,5 & 1,8 & 7,1 \\
\hline $55-65$ & 109 & 81,4 & 18,6 & - & - & 11,3 & 5,8 \\
\hline
\end{tabular}

*) Ergebnis des Mikrozensus. - Bevölkerung am Familienwohnsitz. - 1) Einschl. der Alleinerziehenden, die Lebenspartner in einer nichtehelichen Lebensgemeinschaft sind. - keine Angabe, da Zahlenwert nicht sicher genug

Quelle: Statistisches Bundesamt, Familien heute, a.a.0., S. 35. 


\section{Kinder in Familien}

Der überwiegende Teil aller Kinder wächst in einer vollständigen Familie auf, unter Einbeziehung der nichtehelichen Lebensgemeinschaften leben rund $90 \%$ aller minderjährigen Kinder in einer Paargemeinschaft.

Analog zum höheren Anteil Alleinerziehender in den neuen Bundesländern ist die Zahl derjenigen Kinder, die bei ihren verheiratet zusammenlebenden Eltern leben, geringer (80,6 \%). Unter Einbeziehung des Alters der Kinder zeigt sich, daß 90,1 \% der unter 6jährigen und 88,3\% der unter 18jährigen in den früheren Bundesländern bei ihren verheirateten und zusammenlebenden Eltern leben.

In den neuen Bundesländern werden diese Zahlen deutlich unterschritten,

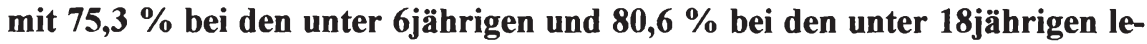
ben annähernd ein Viertel der Kinder in unvollständigen Familien. Wie die folgende Tabelle zeigt, leben in Deutschland $2 \%$ aller minderjährigen Kinder bei alleinerziehenden Vätern und $12 \%$ bei alleinerziehenden Müttern, so daß diese Arbeit vorwiegend auf die alleinerziehenden Mütter bezug nimmt.

Der Anteil minderjähriger Kinder, die bei alleinerziehenden Frauen aufwachsen, ist mit $11,8 \%$ deutlich größer als der entsprechende Anteil bei alleinerziehenden Männern (1,7\%). Auch hier zeigt sich erneut, daß eine Scheidung ursächlich für die unbefriedigende Situation von Alleinerziehenden und ihren Kindern ist. Bei geschiedenen Frauen leben 5,6 \% aller Kinder von alleinerziehenden Frauen. Mögen die 13,5 \% Kinder von Alleinerziehenden im Vergleich zu den 86,5 \% Kindern bei Ehepaaren in der Anzahl noch relativ gering erscheinen, so gibt sie doch Anlaß genug, ein Augenmerk auf diese Gruppe zu lenken, um zu verhindern, daß diese Kinder schlechtere Chancen in der Gesellschaft haben als Kinder aus vollständigen Familien. Darüber hinaus ist zu erwarten, daß die Zahl dieser Kinder weiter steigen wird, da auch die Scheidungsraten immer noch im Steigen begriffen sind. 
Abbildung 4:

Minderjährige Kinder in Eltern - Kind - Gemeinschaften 1992 ")

Früheres Bundesgebiet

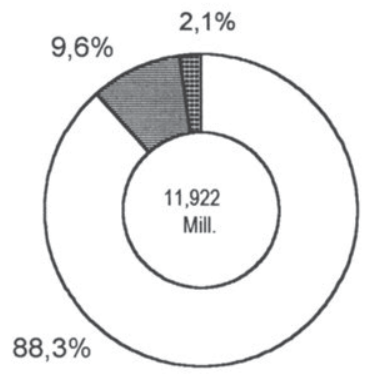

Kind(er) ${ }^{1)}$ unter 18 Jahren von ...

\section{口Ehepaaren}

口Alleinerziehenden 2)

田Nichteheliche Lebensgemeinschaften 3)
Neue Länder und Berlin - Ost

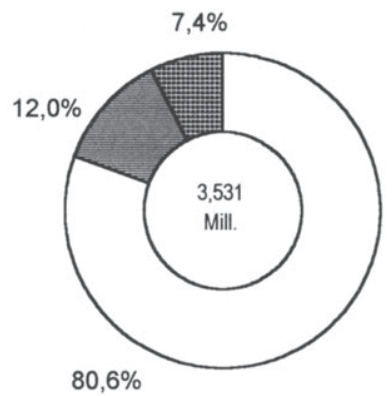

Kind(er) ${ }^{1)}$ unter 18 Jahren von ...

\section{口Ehepaaren}

口Alleinerziehenden 2)

田 Nichteheliche Lebensgemeinschaften 3)

") Ergebnis Mikrozensus. - Bevölkerung am Familienwohnsitz. ") Im Haushalt der Eltern(teile) lebende ledige Kinder. ${ }^{2)}$ Ohne Kinder, die in nichtehelichen Lebensgemeinschaften leben (Schätzung). - ${ }^{3)}$ Schätzung aus Ergebnissen des Mikrozensus.

Quelle: Statistisches Landesamt, Familien heute, a.a.O., S. 41. 
Tabelle 37: Kinder von Ehepaaren, Alleinerziehenden und nichtehelichen Lebensgemeinschaften 1992 nach Altersgruppen*)

\begin{tabular}{|c|c|c|c|c|c|c|c|}
\hline \multirow{3}{*}{$\begin{array}{c}\text { Kinder von } \\
\ldots\end{array}$} & \multirow{2}{*}{\multicolumn{2}{|c|}{ Insgesamt }} & \multicolumn{4}{|c|}{ Darunter } & \multirow{3}{*}{$\begin{array}{c}\text { Kinder je Familie } \\
\text { Anzahl } \\
\end{array}$} \\
\hline & & & \multicolumn{2}{|c|}{$\begin{array}{l}\text { bis unter } \\
6 \mathrm{Jahren}\end{array}$} & \multicolumn{2}{|c|}{$\begin{array}{l}\text { bis unter } \\
18 \mathrm{Jahren}\end{array}$} & \\
\hline & 1000 & $\%$ & 1000 & $\%$ & 1000 & $\%$ & \\
\hline \multicolumn{8}{|c|}{ Früheres Bundesgebiet } \\
\hline Ehepaaren & 15167 & 85,4 & 3768 & 90,1 & 10523 & 88,3 & 1,72 \\
\hline $\begin{array}{l}\text { Alleinerzie- } \\
\text { henden') }\end{array}$ & 2271 & 12,8 & 304 & 7,3 & 1145 & 9,6 & 1,35 \\
\hline $\begin{array}{l}\text { Nichteheli- } \\
\text { chen Le- } \\
\text { bensgemein- } \\
\text { schaften }^{2} \text { ) }\end{array}$ & 321 & 1,8 & 109 & 2,6 & 254 & 2,1 & 1,45 \\
\hline Zusammen & 17758 & 100 & 4181 & 100 & 11922 & 100 & 1,66 \\
\hline \multicolumn{8}{|c|}{ Neue Lănder und Berlin-Ost } \\
\hline Ehepaaren & 3624 & 79,5 & 774 & 75,3 & 2848 & 80,6 & 1,64 \\
\hline $\begin{array}{l}\text { Alleinerzie- } \\
\text { henden }{ }^{1} \text { ) }\end{array}$ & 653 & 14,6 & 126 & 12,3 & 423 & 12,0 & 1,32 \\
\hline $\begin{array}{l}\text { Nichteheli- } \\
\text { chen Le- } \\
\text { bensgemein- } \\
\text { schaften }^{2} \text { ) }\end{array}$ & 281 & 6,3 & 127 & 12,4 & 260 & 7,4 & 1,50 \\
\hline Zusammen & 4558 & 100 & 1027 & 100 & 3531 & 100 & 1,58 \\
\hline \multicolumn{8}{|c|}{ Deutschland } \\
\hline Ehepaaren & 18790 & 84,2 & 4542 & 87,2 & 13370 & 86,5 & 1,70 \\
\hline $\begin{array}{l}\text { Alleinerzie- } \\
\text { henden }^{1} \text { ) }\end{array}$ & 2924 & 13,1 & 430 & 8,3 & 1568 & 10,1 & 1,34 \\
\hline $\begin{array}{l}\text { Nichteheli- } \\
\text { chen Le- } \\
\text { bensgemein- } \\
\text { schaften }^{2} \text { ) }\end{array}$ & 602 & 2,7 & 236 & 4,5 & 514 & 3,3 & 1,47 \\
\hline Zusammen & 22316 & 100 & 5208 & 100 & 15453 & 100 & 1,65 \\
\hline
\end{tabular}

*) Ergebnis des Mikrozensus. - Bevőlkerung am Familienwohnsitz. - Im Haushalt der Eltern(teile) lebende ledige Kinder. - 1) Ohne Kinder, die in nichtehelichen Lebensgemeinschaften leben (Schätzung). - 2) Schätzung aus Ergebnissen des Mikrozensus.

Quelle: Statistisches Bundesamt, Im Blickpunkt, a.a.O., S. 40. 
Tabelle 38: Minderjährige Kinder von Ehepaaren und Alleinerziehenden 1992

\begin{tabular}{|l|c|c|c|}
\hline \multirow{2}{*}{ K i n d e r v o n } & \multicolumn{3}{|c|}{ F u u e re s B u d e s g b i e t } \\
\cline { 2 - 4 } & Insgesamt & \multicolumn{3}{|c|}{ Anteil an allen Kindern ${ }^{2}$} \\
\hline & 1000 & \multicolumn{3}{|c|}{$\%$} \\
\hline Ehepaaren & 10523 & 88,3 & 69,4 \\
\hline Alleinerziehenden1) & 1399 & 11,7 & 54,0 \\
\hline Männern & 179 & 1,5 & 44,8 \\
\hline Frauen & 1221 & 10,2 & 55,7 \\
\hline & 11922 & 100 & 67,1 \\
\hline
\end{tabular}

\begin{tabular}{|c|c|c|c|c|}
\hline \multirow[t]{2}{*}{ Kinder von } & \multicolumn{4}{|c|}{ Neue Lãnder und Berlin-Ost } \\
\hline & Insgesamt & \multicolumn{3}{|c|}{ Anteil an allen Kindern ${ }^{2}$} \\
\hline & 1000 & \multicolumn{3}{|c|}{$\%$} \\
\hline Ehepaaren & 2848 & 80,6 & & 78,6 \\
\hline Alleinerziehenden') & 683 & 19,4 & & 73,1 \\
\hline Männern & 79 & 2,2 & & 68,5 \\
\hline Frauen & 604 & 17,1 & & 73,8 \\
\hline$\because$ & 3531 & 100 & & 7,5 \\
\hline \multirow[t]{2}{*}{ Kinder von } & \multicolumn{4}{|c|}{ De u t s c b I a nd } \\
\hline & insgesam t & \multicolumn{3}{|c|}{ Anteil an allen Kindern ${ }^{2}$} \\
\hline & 1000 & \multicolumn{3}{|c|}{$\%$} \\
\hline Ehepaaren & 13370 & 86,5 & & 71,2 \\
\hline Alleinerziehenden ${ }^{1}$ ) & 2082 & 13,5 & & 59,1 \\
\hline Männern & 258 & 1,7 & & 50,1 \\
\hline Frauen & 1825 & 11,8 & & 60,6 \\
\hline$\Pi$ & 15453 & 100 & & 9,2 \\
\hline
\end{tabular}

1) Einschließlich der Kinder in nichtehelichen Lebensgemeinschaften.

2) Anteil an allen Kindern der Personengruppe der Vorspalte.

Quelle: Statistisches Bundesamt, Ergebnis des Mikrozensus 


\section{Wirtschaftliche Lage von alleinerziehenden Müttern}

\section{Einkommen und Einkommensstrukturen}

Die i.d.R. schlechte ökonomische Situation, der sich Alleinerziehende ausgesetzt sehen, bestimmt nachhaltig das AusmaB der Erwerbsbeteiligung $^{380}$ dieser Personengruppen. Wie aus Tabelle 25 zu ersehen, war 1992 die Erwerbstätigenquote der verheirateten Mütter mit minderjährigen Kindern von ca. 55,4\% deutlich niedriger als die der Alleinerziehende. Hier zeigt sich ganz deutlich die Notwendigkeit, eigenes Einkommen zu erzielen, um den Lebensunterhalt bestreiten zu können. Nicht unerhebliche Unterschiede in der Erwerbsbeteiligung ergeben sich bei der Betrachtung der verschiedenen Gruppen von Alleinerziehenden nach dem Familienstand. Die höchste Erwerbsbeteiligung weisen geschiedene Mütter auf $\mathbf{( 7 3 , 8 \% )}$. Neben der wirtschaftlichen Notlage stellt sicherlich auch das höhere Alter der Kinder eine mögliche Begründung für diese Situation dar. Die niedrigste Er-

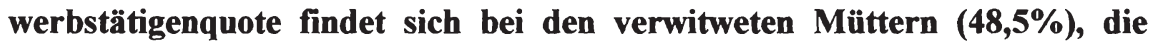
wirtschaftliche Lage dieses Personenkreis scheint durch das soziale Sicherungssystem mit den Witwen- und Waisenrenten gesichert zu sein.

Da die Möglichkeit zur Erwerbstätigkeit wesentlich vom Alter der zu betreuenden Kinder abhängt, ist dieses Merkmal bei der Betrachtung hinzuzuziehen. Wie zu erwarten, verzichten vor allem Mütter mit Kleinkinder auf eine Beteiligung am Erwerbsleben. Von den ledigen alleinerziehenden Müttern waren $56,3 \%$, von den verheiratet getrennt lebenden Müttern $40,5 \%$, von den geschiedenen Müttern $\mathbf{4 3 , 3} \%$ und von den verheirateten Müttern mit Kindern unter 3 Jahren $41,8 \%$ erwerbstätig. Der gravierende Anstieg der Quote für alleinerziehende Mütter, deren Kinder bereits im Kindergartenalter sind, belegt sicherlich wieder die Hypothese, daB in diesen Fällen hauptsächlich aus ökonomischen Zwängen heraus eine Erwerbstätigkeit aufgenommen wird. Das Vorhandensein von Kindergärten respektive einer Fremdbetreuung schafft also augenscheinlich mehr Freiräume für eine Be-

\footnotetext{
${ }^{380}$ Vgl. Stutzer, Erich, Wingen, Max, Alleinerziehende in der Bundesrepublik Deutschland, Eine datenorientierte Analyse demographischer und sozioökonomischer Strukturen, "Materialien und Berichte" der Familienwissenschaftlichen Forschungsstelle, Heft 21, Stuttgart 1989, S. 26.
} 
rufstätigkeit. Relativ bedeutsam im Hinblick auf das Ausüben einer Erwerbstätigkeit scheint dann wieder das höhere Alter von Kindern zu sein, bei Müttern mit 10-15jährigen Kindern tritt eine spürbare Erhöhung der Erwerbstätigenquote ein. Mit dem Begriff "wirtschaftliche Lage" wird anhand des objektiven Kriteriums Einkommen die Lebenssituation sozialer Schichten beschrieben. Herangezogen wird dazu i.d.R. das sogenannte Haushaltsnettoeinkommen pro Monat. Dieses Nettoeinkommen ergibt sich aus der Summe aller Einkommensarten und ist das Ergebnis der Mikrozensusbefragung aus dem Jahre 1991. Bei unregelmäBigem Einkommensbezug ist im Rahmen der Mikrozensusbefragung der Nettodurchschnitt im Jahr anzugeben. Selbständige und mithelfende Familienangehörige in der Landwirtschaft sind bei der Befragung nicht berücksichtigt worden.

Das Haushaltsnettoeinkommen wird primär von der Art und Anzahl der Unterhaltsquellen, vom Umfang der Erwerbsbeteiligung, der von der jeweiligen Phase der Familienbildung abhängt, und von der mit dem Lebensalter einhergehenden beruflichen Karriere bestimmt. Letztlich sind auch die mit dem Familienlastenausgleich zusammenhängenden Transferzahlungen und Steuererleichterungen in die Analyse einzubeziehen, da sie gerade bei Alleinerziehenden einen gewichtigen Anteil am Gesamtnettoeinkommen ausmachen. Um zu zeigen, wie die Einkommensverhältnisse von der Familienform beeinflubt werden, werden die Einkommen von Ehepaaren mit und ohne Kindern und Alleinerziehenden gegenübergestellt.

Die wirtschaftliche Lage eines Haushalts verbessert sich nachhaltig, wenn beide Ehepartner einer Erwerbstätigkeit nachgehen, dies zeigt sich besonders deutlich im früheren Bundesgebiet, nahezu zwei Drittel der Ehepaare verfügt über ein Einkommen von mindestens 4.000,-- DM. In den Neuen Ländern einschlieBlich Berlin-Ost ist diese Situation aufgrund niedrigerer Einkommen noch nicht so deutlich ausgeprägt, aber auch hier stehen sich Ehepaare, in denen beide erwerbstätig sind im Vergleich zu den anderen Gruppen deutlich besser. Geht nur ein Ehepartner einer Erwerbstätigkeit nach, liegt der Einkommensschwerpunkt im früheren Bundesgebiet bei etwa vier Fünfteln der Paare zwischen 1.800,-- und 5.000,-- DM, wenn keine Kinder im Haushalt leben. Wie die Tabelle zeigt, ist die Einkommenssituation mit Kindern etwas besser, mehr als $50 \%$ dieser Ehepaare haben ein 
Nettoeinkommen von wenigstens 4.000,-- DM (im neuen Bundesgebiet allerdings erst knapp $20 \%$ ). Dies dürfte einerseits auf eine zusätzliche Erwerbsbeteiligung der Kinder, andererseits auf die altersbedingte berufliche Karriere des verdienenden Ehepartners zurückzuführen sein. Allerdings gilt auch die umgekehrte Kausalität: Weil ein höheres Einkommen vorhanden ist, kann man sich eher Kinder leisten. Gehen beide Ehepartner, auch bei Vorhandensein von Kindern, einer Erwerbstätigkeit nach, stellt sich eine noch günstigere Situation ein. Der Einkommensschwerpunkt verlagert sich nach oben, und etwa zwei Drittel haben ein Nettoeinkommen von mindestens 4.000,-- DM.

Erwartungsgemäß befinden sich die Alleinerziehenden schwerpunktmäßig in den unteren Einkommensgruppen. Über ein Haushaltsnettoeinkommen bis $2.500,--$ DM verfügen fast $40 \%$ in den alten Bundesländern und sogar annähernd $67 \%$ in den neuen Bundesländern. Allerdings verfügen - zumindest im früheren Bundesgebiet - immerhin knapp $18 \%$ auch über ein Nettoeinkommen von über 4.000,-- DM, in den neuen Bundesländern sind es nur knapp $7 \%$. Die geschlechtsspezifische Betrachtung zeigt aber auch, daß dieser relativ hohe Anteil auf die günstige soziale Lage der alleinerziehenden Männer zurückzuführen ist. Selbst die nichterwerbstätigen alleinerziehenden Männer stehen noch besser da als die alleinerziehenden Frauen, auch wenn diese einer Erwerbstätigkeit nachgehen. In den neuen Bundesländern sieht die Situation etwas anders aus, hier ist die Zahl alleinerziehender Männer deutlich kleiner und in den oberen Einkommensgruppen sind sie kaum vertreten. Von den erwerbstätigen Frauen verfügen aber immerhin noch gut $8 \%$ über ein Nettoeinkommen von mehr als 4.000,- DM. Es überrascht auch nicht, daß sich nichterwerbstätige Frauen - in den alten sowie neuen Bundesländern - in der schlechtesten sozialen Lage befinden. Fast 50 \% aller Befragten in den alten Bundesländern und 76,5 \% der Befragten in den neuen Bundesländern verfügen lediglich über ein Haushaltsnettoeinkommen von unter $2.500,--$ DM. Um so interessanter erscheint es im folgenden, zu analysieren, welches die Haupteinkommensquellen dieses Personenkreises sind und auf welche Haushaltsgröße sich diese Einkommenswerte beziehen. Die Auswertung der Mikrozensusdaten unter diesem Aspekt ergibt folgendes Bild: 
Tabelle 39: Ehepaare und Alleinerziehende 1992 nach Erwerbstătigkeit und monatlichem Haushaltsnettoeinkommen*)

\begin{tabular}{|c|c|c|c|c|c|c|c|c|}
\hline \multirow{2}{*}{$\begin{array}{l}\text { Ehepaare/ } \\
\text { Alleinerziehende } \\
\begin{array}{c}\text { Erwerbstätig- } \\
\text { keit }\end{array} \\
\end{array}$} & \multirow[b]{2}{*}{$\begin{array}{l}\text { Insge- } \\
\text { samt }\end{array}$} & \multicolumn{7}{|c|}{$\begin{array}{l}\text { Davon mit einem monatlichen Haushaltsnettoeinkommen } \\
\text { von ... bis unter ... DM }\end{array}$} \\
\hline & & $\begin{array}{c}\text { unter } \\
1800\end{array}$ & $\begin{array}{l}1800- \\
2500\end{array}$ & $\begin{array}{l}2500- \\
3000\end{array}$ & $\begin{array}{l}3000- \\
3500\end{array}$ & $\begin{array}{l}3500- \\
4000\end{array}$ & $\begin{array}{l}4000- \\
5000\end{array}$ & $\begin{array}{l}5000 \\
\text { und } \\
\text { mehr }\end{array}$ \\
\hline & 1000 & \multicolumn{7}{|c|}{$\%$ von Spalte „Insgesamt ${ }^{*}$} \\
\hline & & \multicolumn{7}{|c|}{ Früheres Bundesgebiet } \\
\hline $\begin{array}{l}\text { Ehepaare ohne } \\
\text { Kinder }\end{array}$ & 6106 & 8,1 & 18,9 & 14,5 & 13,0 & 11,0 & 15,8 & 18,6 \\
\hline $\begin{array}{l}\text { Beide Ehepart- } \\
\text { ner erwerbstätig }\end{array}$ & 1923 & 0,5 & 2,2 & 5,9 & 10,9 & 15,3 & 28,0 & 37,3 \\
\hline $\begin{array}{l}\text { Ehemann allein } \\
\text { erwerbstätig }\end{array}$ & 1055 & 3,5 & 21,8 & 18,0 & 14,5 & 10,2 & 13,6 & 18,3 \\
\hline $\begin{array}{l}\text { Ehefrau allein } \\
\text { erwerbstātig }\end{array}$ & 326 & 6,6 & 17,6 & 17,3 & 16,6 & 13,5 & 15,6 & 12,9 \\
\hline $\begin{array}{l}\text { Beide Ehepart- } \\
\text { ner nicht er- } \\
\text { werbstätig') }\end{array}$ & 2802 & 15,2 & 29,4 & 18,8 & 13,5 & 8,1 & 8,3 & 6,6 \\
\hline $\begin{array}{l}\text { Ehepaare mit } \\
\text { Kindern }\end{array}$ & 7652 & 2,1 & 7,6 & 10,7 & 12,6 & 12,3 & 20,5 & 34,2 \\
\hline $\begin{array}{l}\text { Beide Ehepart- } \\
\text { ner erwerbstătig }\end{array}$ & 3460 & 0,3 & 1,8 & 5,6 & 10,4 & 13,1 & 23,9 & 44,9 \\
\hline $\begin{array}{l}\text { Ehemann allein } \\
\text { erwerbstätig }\end{array}$ & 3289 & 1,3 & 12,2 & 16,4 & 15,5 & 11,8 & 17,5 & 25,3 \\
\hline $\begin{array}{l}\text { Ehefrau allein } \\
\text { erwerbstätig }\end{array}$ & 252 & 5,2 & 11,8 & 11,8 & 11,8 & 12,2 & 19,9 & 27,3 \\
\hline $\begin{array}{l}\text { Beide Ehepart- } \\
\text { ner nicht er- } \\
\text { werbstätig ') }\end{array}$ & 651 & 14,4 & 13,1 & 8,9 & 10,3 & 10,7 & 18,1 & 24,5 \\
\hline $\begin{array}{l}\text { Alleinerzie- } \\
\text { hende }\end{array}$ & 1674 & 20,5 & 18,8 & 12,3 & 11,7 & 9,3 & 13,0 & 14,4 \\
\hline $\begin{array}{l}\text { Erwerbstätige } \\
\text { Männer }\end{array}$ & 177 & 2,9 & 14,0 & 10,7 & 13,5 & 10,6 & 18,9 & 29,2 \\
\hline $\begin{array}{l}\text { Nichterwerbstä- } \\
\text { tige Männer') }\end{array}$ & 87 & 14,8 & 13,9 & 11,1 & 11,1 & 13,6 & 17,2 & 18,2 \\
\hline $\begin{array}{l}\text { Erwerbstätige } \\
\text { Frauen }\end{array}$ & 785 & 17,1 & 22,2 & 13,9 & 11,5 & 8,8 & 12,6 & 13,8 \\
\hline $\begin{array}{l}\text { Nichterwerbstä- } \\
\text { tige Frauen }{ }^{1} \text { ) }\end{array}$ & 626 & 30,6 & 16,5 & 10,9 & 11,4 & 8,9 & 11,1 & 10,4 \\
\hline
\end{tabular}

*) Ergebnis des Mikrozensus. - Bevölkerung am Familienwohnsitz. - Ohne Selbständige in der Landwirtschaft, mithelfende Familienangehörige und sonstige Fälle ohne Angabe des Einkommens.-

1) Erwerbslos oder Nichterwerbspersonen. 


\begin{tabular}{|c|c|c|c|c|c|c|c|c|}
\hline 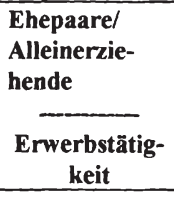 & $\begin{array}{l}\text { Insge- } \\
\text { samt }\end{array}$ & \multicolumn{5}{|c|}{$\begin{array}{c}\text { Davon mit einem monatlichen Haushaltsnettoeinkommen } \\
\text { von ... bis unter ... DM }\end{array}$} & & $\begin{array}{l}5000 \\
\text { und } \\
\text { mehr }\end{array}$ \\
\hline & 1000 & \multicolumn{7}{|c|}{$\%$ von Spalte "Insgesamt“ } \\
\hline & & \multicolumn{7}{|c|}{ Neue Länder und Berlin-Ost } \\
\hline $\begin{array}{l}\text { Ehepaare } \\
\text { ohne Kinder }\end{array}$ & 1646 & 30,2 & 40,2 & 13,2 & 7,8 & 3,9 & 3,2 & 1,4 \\
\hline $\begin{array}{l}\text { Beide Ehe- } \\
\text { partner er- } \\
\text { werbstätig }\end{array}$ & 395 & 5,2 & 25,4 & 22,8 & 20,6 & 11,9 & 9,6 & 4,5 \\
\hline $\begin{array}{l}\text { Ehem. allein } \\
\text { erwerbstätig }\end{array}$ & 223 & 21,1 & 43,5 & 17,6 & 9,0 & 3,7 & 3,4 & - \\
\hline $\begin{array}{l}\text { Ehefrau allein } \\
\text { erwerbstätig }\end{array}$ & 134 & 19,5 & 41,2 & 20,4 & 11,6 & 4,5 & - & - \\
\hline $\begin{array}{l}\text { Beide Ehe- } \\
\text { partner nicht } \\
\text { erwerbstătig }^{1} \text { ) }\end{array}$ & 895 & 45,1 & 45,7 & 6,9 & 1,4 & - & - & - \\
\hline $\begin{array}{l}\text { Ehepaare mit } \\
\text { Kindern }\end{array}$ & 2082 & 7,3 & 21,1 & 19,7 & 19,2 & 13,0 & 13,0 & 6,6 \\
\hline $\begin{array}{l}\text { Beide Ehe- } \\
\text { partner er- } \\
\text { werbstātig }\end{array}$ & 1341 & 2,8 & 15,8 & 19,1 & 21,8 & 15,4 & 16,4 & 8,6 \\
\hline $\begin{array}{l}\text { Ehem. allein } \\
\text { erwerbstätig }\end{array}$ & 442 & 13,1 & 33,5 & 21,8 & 13,9 & 8,4 & 6,2 & 3,1 \\
\hline $\begin{array}{l}\text { Ehefrau allein } \\
\text { erwerbstătig }\end{array}$ & 131 & 13,3 & 27,7 & 21,1 & 15,8 & 9,0 & 9,9 & - \\
\hline $\begin{array}{l}\text { Beide Ehe- } \\
\text { partner nicht } \\
\text { er werbstätig } \\
\text { 1) }\end{array}$ & 167 & 23,7 & 25,2 & 17,4 & 15,5 & 9,3 & 6,4 & - \\
\hline $\begin{array}{l}\text { Alleinerzie- } \\
\text { hende }\end{array}$ & 645 & 38,4 & 28,5 & 13,2 & 8,4 & 4,9 & 4,6 & 2,0 \\
\hline $\begin{array}{l}\text { Erwerbstätige } \\
\text { Männer }\end{array}$ & 60 & 19,9 & 30,2 & 17,6 & 14,1 & - & 8,5 & - \\
\hline $\begin{array}{l}\text { Nichterwerbs- } \\
\text { tätige Mãn- } \\
\text { ner' })\end{array}$ & 23 & 37,3 & 34,6 & - & - & - & - & - \\
\hline $\begin{array}{l}\text { Erwerbstätige } \\
\text { Frauen }\end{array}$ & 354 & 36,6 & 27,2 & 13,3 & 8,8 & 6,1 & 5,5 & 2,6 \\
\hline $\begin{array}{l}\text { Nichterwerbs- } \\
\text { tätige Frau- } \\
\text { en }^{1} \text { ) }\end{array}$ & 208 & 47,0 & 29,5 & 11,8 & 6,3 & - & - & - \\
\hline
\end{tabular}

*) Ergebnis des Mikrozensus. - Bevölkerung am Familienwohnsitz. - Ohne Selbståndige in der Landwirtschaft, mithelfende Familienangehörige und sonstige Fälle ohne Angabe des Einkommens.- 1) Erwerbslos oder Nichterwerbspersonen.

Quelle: Statistisches Bundesamt, Im Blickpunkt, a.a.O., S. 67. 
Tabelle 40: Alleinerziehende 1992 nach monatlichem Haushaltsnettoeinkommen und Kinderzah"*)

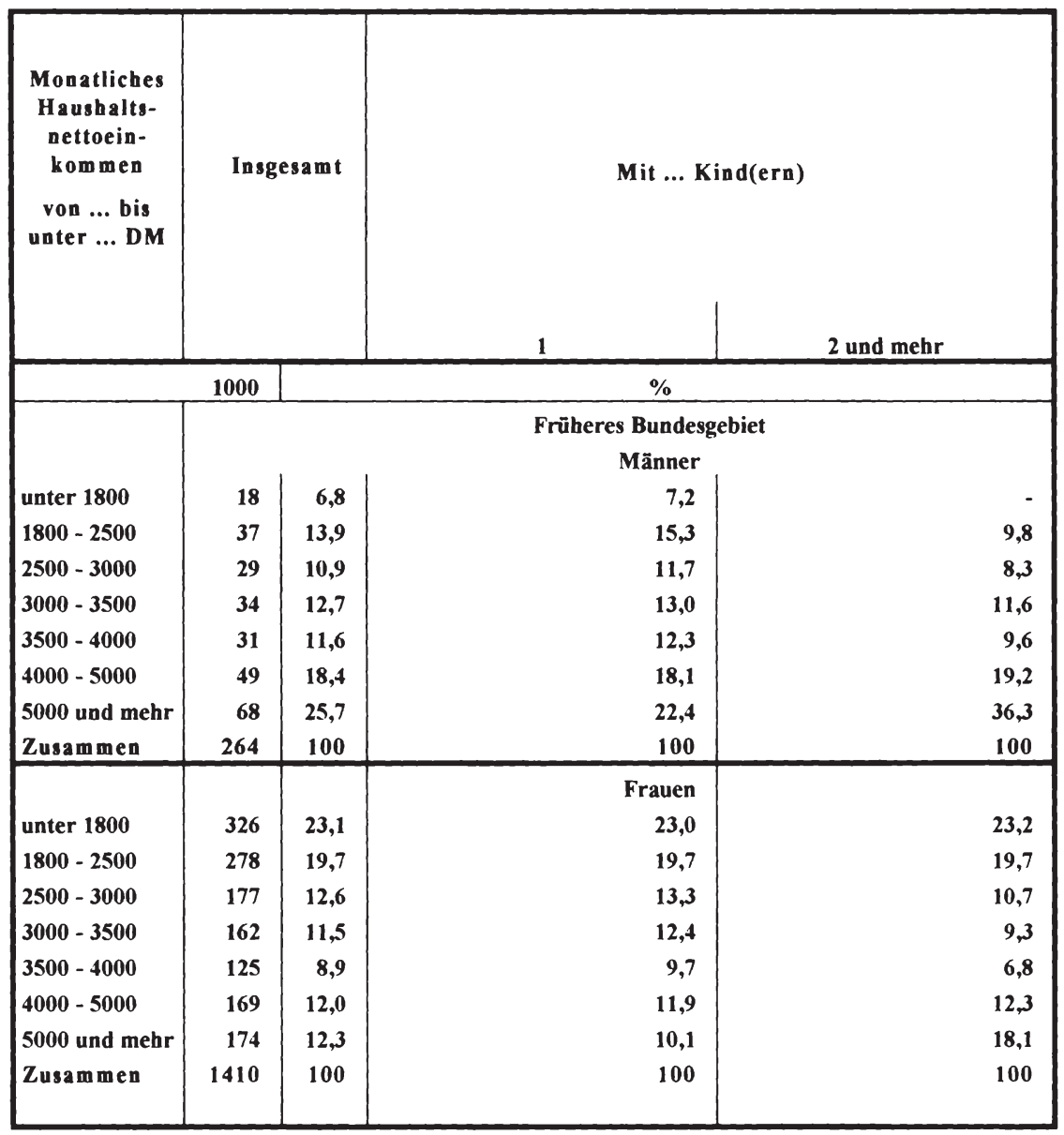

*) Ergebnis des Mikrozensus. - Bevōlkerung am Familienwohnsitz. - Ohne Selbständige in der Landwirtschaft, mithelfende Familienangehörige und sonstige Fälle ohne Angabe des Einkommens. 


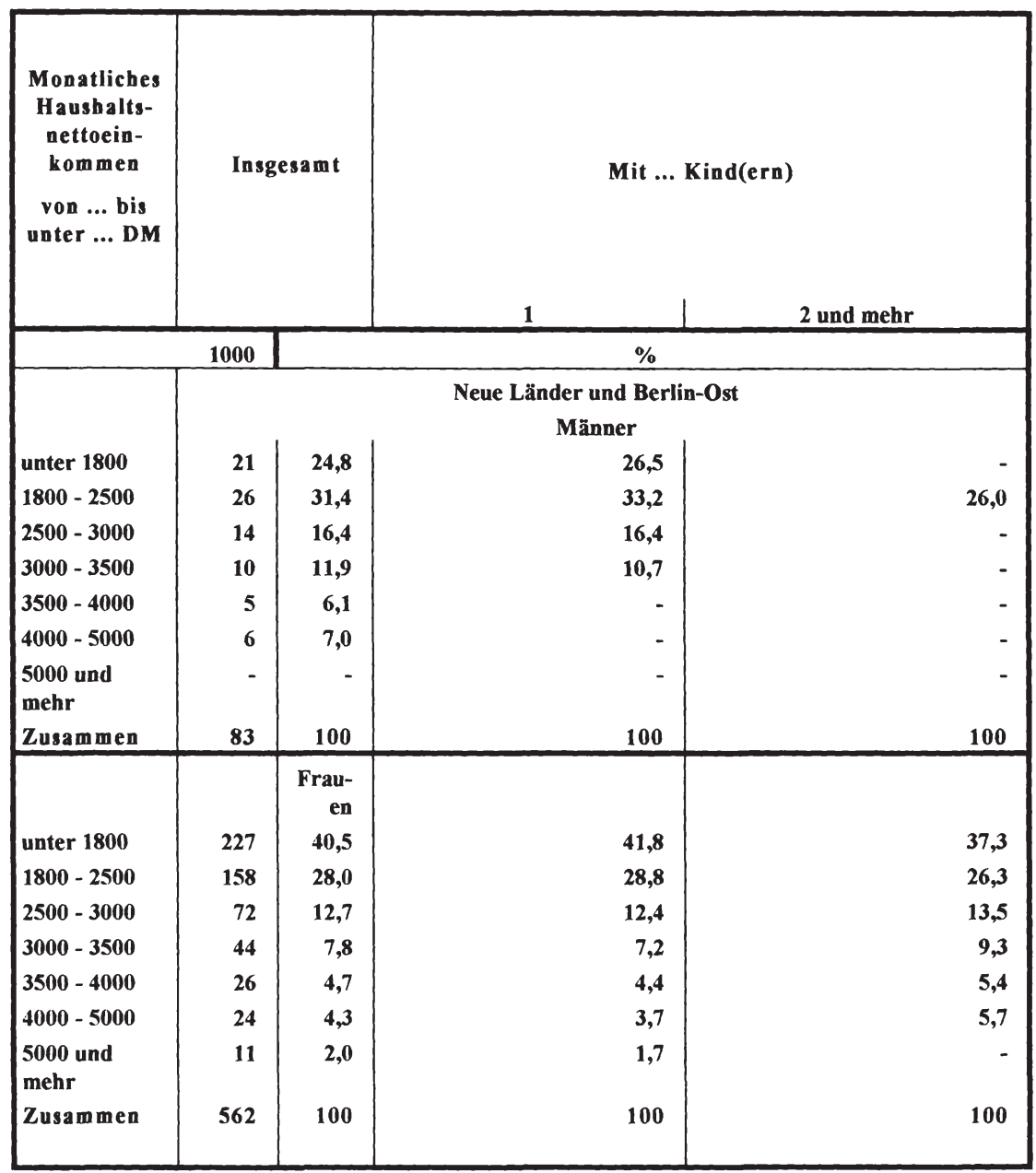

*) Ergebnis des Mikrozensus. - Bevōlkerung am Familienwohnsitz. - Ohne Selbstāndige in der Landwirtschaft, mithelfende Familienangehörige und sonstige Fälle ohne Angabe des Einkommens.

Quelle: Statistisches Bundesamt, Im Blickpunkt, a.a.O., S. 76.

Auch in Tabelle 40 wird noch einmal deutlich, daß die Einkommensverhältnisse alleinerziehender Männer und Frauen recht unterschiedlich ist. Während die Einkommensverteilung alleinerziehender Männer - zumindest im früheren Bundesgebiet - eine relativ gleichmäßige Besetzung der einzelnen Einkommensklassen mit Extremwerten im unteren und oberen Bereich 
aufweist, liegt der Schwerpunkt der Einkommenskurve alleinerziehender Frauen eindeutig im unteren Bereich. Dies ändert sich auch nicht mit zunehmender Kinderzahl. Die Besetzung der einzelnen Klassen bleibt annähernd gleich, da sich aber dieses Einkommen auf mehrere Personen verteilt, verschlechtert sich die Lage dieses Personenkreises noch einmal erheblich. Noch schlechter sieht es in den neuen Bundesländern aus, dort finden sich in den oberen Einkommensklassen (ab 3.000,-- DM) nur $17 \%$ (alte Bundesländer im Vergleich dazu 44,1\%) der Befragten mit einem Kind und 20,4\% (alte Bundesländer: 46,5 \%) zwei und mehr Kindern.

Bevor auf die verschiedenen Unterhaltsquellen näher eingegangen wird, soll mit Hilfe der folgenden Tabelle die besonders ungünstige Situation alleinerziehender Frauen mit Klein- und Schulkindern verdeutlicht werden.

Je jünger die zu erziehenden Kinder sind, desto schlechter ist die wirtschaftliche Lage dieser Frauen. Zurückzuführen ist dies sicherlich darauf, daß es den Frauen kaum möglich ist, mit Kindern unter drei Jahren erwerbstätig zu sein, da Unterbringungsmöglichkeiten für das Kind fehlen, und sie dann zwangsläufig zur Gänze auf Transferzahlungen angewiesen sind. Mit zunehmendem Alter der Kinder verbessert sich die Einkommenssituation der alleinerziehenden Mütter, besonders im früheren Bundesgebiet, hier erreichen immerhin $15 \%$ der Befragten mit Kindern zwischen 6 und 15 Jahren ein Einkommen von 4.000,-- DM und darüber. Eine nachhaltige Verbesserung der Situation des betrachteten Personenkreises kann über verschiedene Wege erfolgen, so können zum einen die finanziellen Leistungen an diese Personen erhöht werden, zum anderen können die Möglichkeiten zum Ausüben einer Erwerbstätigkeit verbessert werden (flexible Arbeitsplätze, bessere Betreuungsmöglichkeiten für Kinder u.s.w.). Auf die detaillierte Diskussion unterschiedlicher Ausgestaltungsformen und deren Wirkungen soll an anderer Stelle eingegangen werden (siehe Teil C, Punkt VIII dieser Arbeit).

Alleinerziehende bestreiten in hohem Maße ihren Lebensunterhalt aus Transferzahlungen bzw. aus einer Kombination von Erwerbseinkommen und Unterstützung von staatlicher Seite. Die folgende Tabelle gibt einen Hinweis auf das Ausma B der unterschiedlichen Einkommensquellen. 
Tabelle 41: Alleinerziehende Frauen 1992 nach monatlichem Haushaltsnettoeinkommen und Alter des jüngten Kindes*)

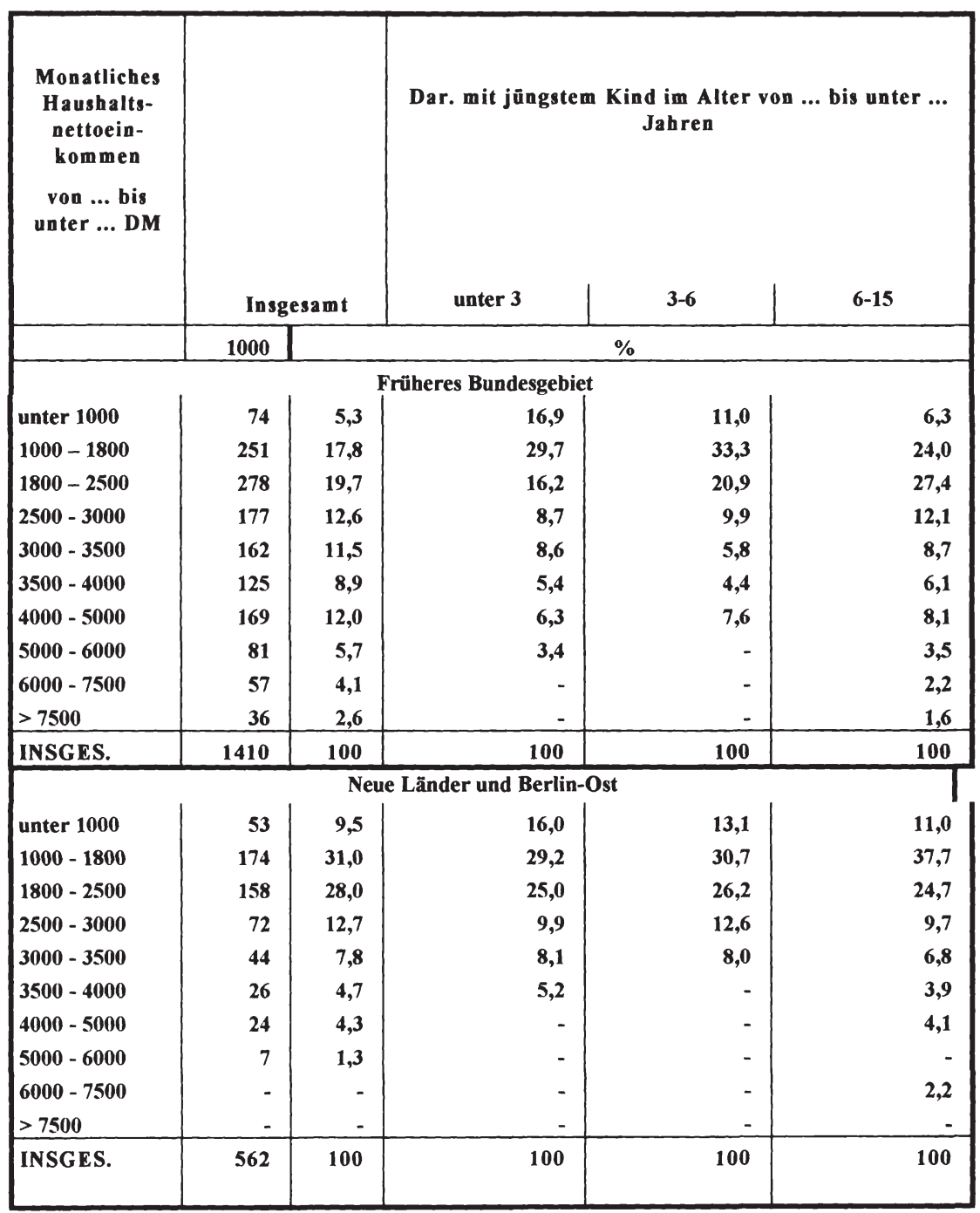

*) Ergebnis des Mikrozensus. - Bevölkerung am Familienwohnsitz. - Ohne Selbständige in der Landwirtschaft, mithelfende Familienangehörige und sonstige Fälle ohne Angabe des EInkommens.

Quelle: Statistisches Bundesamt, Im Blickpunkt, a.a.0., S. 180. 
Tabelle 42: Ehepaare und Alleinerziehende 1992 nach überwiegendem Lebensunterhalt der Bezugserson und monatlichem Haushaltsnettocinkommen *

\begin{tabular}{|c|c|c|c|c|c|c|c|c|}
\hline \multirow{3}{*}{$\begin{array}{l}\text { Ehepaare/ Al- } \\
\text { lein-erziehende } \\
\\
\text { Überwiegender } \\
\text { Lebensunterhalt } \\
\text { der Bezugsper- } \\
\text { son durch ... }\end{array}$} & \multirow{3}{*}{\begin{tabular}{|r} 
Ins- \\
gesamt \\
1000 \\
\end{tabular}} & \multicolumn{7}{|c|}{$\begin{array}{c}\text { Davon mit einem monatlichen Haushaltsnettoeinkommen } \\
\text { von ... bis unter ... DM }\end{array}$} \\
\hline & & $\begin{array}{l}\text { unter } \\
1800\end{array}$ & $\begin{array}{l}1800- \\
2500\end{array}$ & $\begin{array}{l}2500- \\
3000\end{array}$ & $3000-$ & $\begin{array}{l}3500- \\
4000\end{array}$ & $4000-$ & $\begin{array}{l}5000 \text { und } \\
\text { mehr }\end{array}$ \\
\hline & & \multicolumn{7}{|c|}{$\%$ von Spalte "Insgesamt } \\
\hline \multicolumn{9}{|c|}{ Früheres Bundesgebiet } \\
\hline $\begin{array}{l}\text { Ehepaare ohne } \\
\text { Kinder } \\
\text { darunter: }\end{array}$ & 6106 & 8,1 & 18,9 & 14,5 & 13,0 & 11,0 & 15,8 & 18,6 \\
\hline Erwerbstätigkeit & 2927 & 1,4 & 9,0 & 10,1 & 12,1 & 13,5 & 23,1 & 30,7 \\
\hline $\begin{array}{l}\text { Arbeitslosengeld/ } \\
\text {-hilfe }\end{array}$ & 102 & 33,8 & 26,6 & 13,6 & 9,8 & 6,9 & 6,1 & 1 \\
\hline Sozialhilfe & 17 & 77,2 & I & 1 & 1 & I & 1 & \\
\hline Angehörige & 84 & 22,9 & 29,1 & 13,9 & 10,9 & $\mathbf{8 , 7}$ & 7,0 & 7,5 \\
\hline Rente, Pension & 2902 & 12,8 & 28,2 & 19,1 & 14,1 & 8,8 & 9,3 & 7,5 \\
\hline $\begin{array}{l}\text { Ehepaare mit } \\
\text { Kind(ern) } \\
\text { darunter: }\end{array}$ & 7652 & 2,1 & 7,6 & 10,7 & 12,6 & 12,3 & 20,5 & 34,2 \\
\hline Erwerbstätigkeit & 6717 & 0,7 & 6,9 & 10,9 & 12,9 & 12,5 & 20,8 & 35,4 \\
\hline $\begin{array}{l}\text { Arbeitslosengeld/ } \\
\text {-hilfe }\end{array}$ & 152 & 26,9 & 20,4 & 12,6 & 10,6 & 9,5 & 12,5 & 7,6 \\
\hline Sozialhilfe & 47 & 55,2 & 24,4 & 1 & 1 & 1 & I & I \\
\hline Angehörige & 87 & 17,4 & 21,9 & 15,6 & 12,4 & 9,3 & 11,6 & 11,8 \\
\hline Rente, Pension & 599 & 3,1 & 7,9 & 8,2 & 10,8 & 12,5 & 23,0 & 34,5 \\
\hline $\begin{array}{l}\text { Alleinerziehende } \\
\text { darunter: }\end{array}$ & 1674 & 20,5 & 18,8 & 12,3 & 11,7 & 9,3 & 13,0 & 14,4 \\
\hline Erwerbstätigkeit & 895 & 13,2 & 21,0 & 13,4 & 11,8 & 9,3 & 14,1 & 17,1 \\
\hline $\begin{array}{l}\text { Arbeitslosengeld/ } \\
\text {-hilfe }\end{array}$ & 59 & 51,9 & 21,2 & 1 & 1 & 1 & 1 & 1 \\
\hline Sozialhilfe & 123 & 73,0 & 15,0 & 4,8 & 1 & 1 & 1 & 1 \\
\hline Angehörige & 112 & 38,2 & 20,3 & 10,8 & 9,0 & 6,4 & 7,5 & 7,7 \\
\hline Rente, Pension & 443 & 10,6 & 14,9 & 13,2 & 15,2 & 12,9 & 16,9 & 16,2 \\
\hline
\end{tabular}




\begin{tabular}{|c|c|c|c|c|c|c|c|c|}
\hline \multicolumn{9}{|c|}{ Neue Länder und Berlin-Ost } \\
\hline $\begin{array}{l}\text { Ehepaare ohne } \\
\text { Kinder }\end{array}$ & 1646 & 30,2 & 40,2 & 13,2 & 7,8 & 3,9 & 3,2 & 1,4 \\
\hline darunter: & & & & & & & & \\
\hline Erwerbstätigkeit & 612 & 10,9 & 31,8 & 21,0 & 16,4 & 9,0 & 7,4 & 3,6 \\
\hline $\begin{array}{l}\text { Arbeitslosengeld/ } \\
\text {-hilfe }\end{array}$ & 58 & 46,5 & 35,3 & 11,1 & I & I & 1 & -- \\
\hline Sozialhilfe & 1 & 1 & 1 & -- & I & -- & - & - \\
\hline Angehörige & 50 & 42,3 & 43,1 & 1 & I & 1 & 1 & I \\
\hline Rente, Pension & 627 & 40,5 & 48,0 & 7,8 & 2,1 & 1 & 1 & I \\
\hline $\begin{array}{l}\text { Ehepaare mit } \\
\text { Kind(ern) } \\
\text { darunter: }\end{array}$ & 2082 & 7,3 & 21,1 & 19,7 & 19,2 & 13,0 & 13,0 & 6,6 \\
\hline Erwerbstätigkeit & 1778 & 5,3 & 20,2 & 19,8 & 19,9 & 13,7 & 13,9 & 7,3 \\
\hline $\begin{array}{l}\text { Arbeitslosengeld/ } \\
\text {-hilfe }\end{array}$ & 126 & 29,1 & 32,0 & 17,1 & 10,6 & 4,7 & 4,8 & I \\
\hline Sozialhilfe & I & 1 & 1 & - & 1 & - & - & - \\
\hline Angehörige & 23 & 22,9 & 27,8 & 1 & 1 & 1 & 1 & 1 \\
\hline Rente, Pension & 68 & - & 19,7 & 19,7 & 23,2 & 14,2 & 11,8 & I \\
\hline $\begin{array}{l}\text { Alleinerziehende } \\
\text { darunter: }\end{array}$ & 645 & 38,4 & 28,5 & 13,2 & 8,4 & 4,9 & 4,6 & 2,0 \\
\hline Erwerbstätigkeit & 396 & 33,5 & 27,7 & 14,1 & 9,6 & 6,3 & 6,1 & 2,7 \\
\hline $\begin{array}{l}\text { Arbeitslosengeld/ } \\
\text {-hilfe }\end{array}$ & 98 & 58,8 & 23,2 & 8,9 & 5,1 & 1 & 1 & I \\
\hline Sozialhilfe & 10 & 77,0 & I & 1 & 1 & - & I & I \\
\hline Angehörige & 9 & 1 & 1 & 1 & I & 1 & I & I \\
\hline Rente, Pension & 85 & 28,5 & 40,7 & 15,5 & 8,3 & 1 & 1 & ' \\
\hline
\end{tabular}

*) Ergebnis des Mikrozensus. - Bevölkerung am Familienwohnsitz. - Ohne Selbständige in der Landwirtschaft, mithelfende Familienangehörige und sonstige Fälle ohne Angabe des Einkommens.- / Stichprobengröße unter der Nachweisgrenze - Es gibt keine Probanden.

Quelle: Statistisches Bundesamt, Im Blickpunkt, a.a.O., S. 64.

Unabhängig vom familialen Status werden die höchsten Einkommen mit einer Erwerbstätigkeit erzielt, jedoch knapp gefolgt von den Renten/Pensionen. Im früheren Bundesgebiet erzielen mehr als die Hälfte der Ehepaare mit erwerbstätiger Bezugsperson ein Haushaltsnettoeinkommen von 4.000,-- DM und mehr, unabhängig davon, ob Kinder im Haushalt vorhanden sind oder nicht. Auch in den neuen Bundesländern (einschließlich Berlin-Ost) sind die Bezieher von Erwerbseinkommen am besten gestellt, allerdings auf deutlich niedrigerem Einkommensniveau, lediglich $11 \%$ der 
Ehepaare ohne Kinder erzielen ein Haushaltsnettoeinkommen von mindestens 4.000,-- DM und auch nur $20 \%$ der Ehepaare mit Kindern erreichen diese Einkommenshöhe. Erwartungsgemäß ist auch die finanzielle Lage von Alleinerziehenden besser, wenn diese eine Erwerbstätigkeit ausüben. Im früheren Bundesgebiet haben immerhin 31,2 \% der erwerbstätigen Alleinerziehenden ein Haushaltsnettoeinkommen von über 4.000,-- DM, deutlich schlechter sieht es in den neuen Ländern aus, hier erreichen nur 8,8 \% der erwerbstätigen Alleinerziehenden diese Einkommenshöhe. Bemerkenswert ist auch, daB die Alleinerziehenden mit keiner anderen Einkommensquelle ein derart hohes Einkommen erzielen. Dies stellt sich im früheren Bundesgebiet deutlich anders dar, 33,1\% der Alleinerziehenden beziehen ein Einkommen über 4.000,-- DM in Form von Renten und Pensionen und immerhin noch 15,2 \% werden in dieser Einkommenshöhe von Angehörigen finanziert. Wie bereits an anderer Stelle ausgeführt, scheinen diese Zahlen zu bestätigen, daß Alleinerziehende - zumindest in den alten Bundesländern - im Falle der Verwitwung durch das System der sozialen Sicherung aufgefangen und gut abgesichert werden.

Beim Bezug von Renten spielt es auch für Ehepaare eine große Rolle, ob Kinder im Haushalt leben oder nicht, zu vermuten ist allerdings, daB diese Kinder schon wesentlich zum Unterhalt des Haushalts beitragen. Von den Rentnerehepaaren ohne Kinder haben in den alten Bundesländern 70,2 \% ein Haushaltsnettoeinkommen zwischen 1.800,-- und 4.000,-- DM, und nur $16,8 \%$ ein Einkommen von mehr als 4.000,-- DM. Mit Kindern liegt der Schwerpunkt in der Einkommensskala im oberen Bereich, zwischen 1.800,-und 4.000,-- DM beziehen 39,4\% und mehr als die Hälfte $(57,5 \%)$ überschreitet die Grenze von 4.000,-- DM. Auch hier sieht es in den neuen Bundesländern vergleichsweise schlechter aus, der Schwerpunkt liegt hier mit $\mathbf{7 6 , 8} \%$ im Einkommensbereich von $1.800,--$ bis $4.000,--$ DM. Allerdings haben $19,6 \%$ der Rentnerhaushalte ohne Kinder ein Nettoeinkommen von über 4.000,-- DM. Sind Kinder im Haushalt vorhanden, reduziert sich dieser Wert um $7,8 \%$ auf $11,8 \%$. In der Einkommensklasse von $1.800,--$ bis 4.000,-- DM befinden sich 57,9 \% aller Haushalte. Sowohl in den alten als auch in den neuen Bundesländern befinden sich die Haushalte mit überwiegenden Transfereinkommen eher im unteren Bereich der Einkommensskala. 
Einkommensmäßig am schlechtesten gestellt sind Sozialhilfeempfänger, obwohl es auch hier Unterschiede zwischen Ehepaaren mit und ohne im Haushalt lebende Kinder und Alleinerziehenden gibt. Von den Ehepaaren ohne Kinder haben $\mathbf{7 7 , 2} \%$ ein Nettoeinkommen, das geringer als $\mathbf{2 . 5 0 0 , - - ~ D M ~ i s t ; ~}$ 79,6 \% sind es in der Gruppe der Ehepaare mit Kindern und $88 \%$ der Alleinerziehenden befinden sich in dieser Einkommensklasse. 4,8 \% der Alleinerziehenden verfügen über ein Einkommen aus der Sozialhilfe, daß zwischen 2.500,-- und 3.000,-- DM liegt.

Ebenfalls überwiegend im unteren Einkommensbereich finden sich die Bezieher von Arbeitslosengeld/-hilfe, sowohl in den alten als auch in den neuen Bundesländern. Im früheren Bundesgebiet liegt ihr Haushaltsnettoeinkommen zu 74 \% unter 3.000,-- DM, wenn keine Kinder im Haushalt leben, und lediglich bei zwei Fünfteln von ihnen überschreitet es die Grenze von 2.500,-- DM. Mit Kindern im Haushalt verbessert sich die finanzielle Situation, $47,3 \%$ verfügen über mindestens $2.500,--$ DM und $45,2 \%$ haben ein Einkommen von 1.800,-- bis 5.000,-- DM. Auch die Alleinerziehenden mit Bezug von Arbeitslosengeld/-hilfe sind überwiegend im unteren Einkommensbereich zu finden. Interessanterweise ist die Lage dieser Personengruppe in den neuen Bundesländern etwas besser als in den alten Bundesländern. 73,1 \% haben dort ein Nettoeinkommen von unter 2.500,-- DM, in den neuen Bundesländern befinden sich zwar 82,0\% der Befragten in dieser Einkommensklasse, allerdings haben auch $14,0 \%$ ein Einkommen aus dieser Quelle in Höhe von 2.500,-- bis 3.500,-- DM. Dies läßt sich sicherlich zum einen auf die höhere Erwerbsquote der Alleinerziehenden in der früheren DDR zurückführen, zum anderen befanden sich die Alleinerziehenden in den Zeiten ihrer Erwerbstätigkeit in geringem Maße auch in höher dotierten Arbeitsplätzen. Von den befragten Alleinerziehenden waren in den neuen Bundesländern noch ca. $61 \%$ in der Lage durch Erwerbstätigkeit den Unterhalt zu sichern, im früheren Bundesgebiet waren es lediglich 53,1 \%. Bezogen auf das gesamte Bundesgebiet läßt sich abschließend feststellen, daß der überwiegende Teil der Alleinerziehenden ihren Lebensunterhalt über eine Erwerbstätigkeit sichert, eine nicht unerhebliche Zahl jedoch auf Transferzahlungen staatlicherseits angewiesen ist. 


\section{Kosten von Kindern}

Die durch das Vorhandensein von Kindern in einer Familie verursachten Kosten und ihre exakte Ermittlung standen zwar auch in der Vergangenheit immer wieder im Mittelpunkt wissenschaftlicher Untersuchungen, ${ }^{381}$ eine gröBere Beachtung finden sie jedoch erst in neuerer Zeit, seitdem die Vermutung an Gewicht gewinnt, daB eine wesentliche Ursache des zu beobachtenden Geburtenrückgangs die deutliche Verringerung des Lebensstandards von Familien mit Kindern gegenüber Kinderlosen ist. Da rückläufige Geburtenraten nicht nur den Bestand einer Gesellschaft gefährden, sondern in langfristiger Perspektive auch das gegenwärtige System sozialer Sicherung in seinen Grundfesten erschüttern, haben sich seit den 70er Jahren neben den Bevölkerungswissenschaften auch die Sozialpolitiker mit diesem Problem beschäftigt. Die ökonomische Theorie der Familie identifiziert als Ursache der rückläufigen Geburtenentwicklung primär ökonomische Bestimmungsgründe und nimmt an, daß ökonomisches Rationalverhalten prinzipiell für den gesamten Lebensbereich der Familie gilt, d.h. auch für das Vorhandensein des Kinderwunsches. Die Existenz von Kindern stiftet einerseits Nutzen, andererseits ist das Kinderhaben bzw. Kindererziehen auch eine ressourcenverzehrende Aktivität, sowohl durch den benötigten Zeitaufwand als auch durch die Bereitstellung materieller Güter. Entstehende Kosten und zu erwartender Nutzen werden von potentiellen Eltern bewertet, wobei für den Zeitaufwand (=Zeitkosten) nach dem Opportunitätskostenprinzip die Marktlohnsätze herangezogen werden. ${ }^{322}$ Soweit die Frau einer Erwerbstätigkeit nachgeht, kann bei Verzicht auf diese Tätigkeit der Nutzenentgang in Form des erzielten Einkommens präzise bestimmt werden, mit zunehmendem Anstieg der Löhne und Gehälter haben sich damit die Zeitkosten der Haushaltsproduktion und die Kosten des Aufziehens von Kindern erhöht. Mit steigendem Lohnsatz steigt die Bereitschaft von Frauen, sich am Erwerbsleben zu beteiligen, so daB der starke Anstieg der Erwerbsbeteiligung verheirateter Frauen gegen Ende der sechziger Jahre auch

\footnotetext{
${ }^{381}$ Vgl. H. Schmucker, Das Kind als Kostenfaktor, in: Die ökonomische Lage der Familie in der Bundesrepublik Deutschland, Stuttgart 1961, S. 267-304.

${ }^{382}$ Vgl. K. Zimmermann, Grenzen einer Bevölkerungspolitik durch Familienpolitik, in: Wirtschaftsdienst, 64. Jg., Heft 4, S. 182.
} 
durch die Zunahme der Lohnsätze verursacht wurde. Dem monetär bewerteten Ressourceneinsatz steht im staatlich organisierten sozialen Sicherungssystem kein unmittelbarer monetärer Nutzen von Kindern gegenüber, so daß sich die Nutzenbewertung auf der Mikroebene Familie vorwiegend auf emotionale Determinanten stützt. Während also die Kosten von Kindern auch langfristig prognostizierbar sind, kann der erwartete Nutzen nur sehr schwer festgelegt werden. Die zu beobachtende Tendenz zur Kleinhaltung der Familie läßt zudem den Verdacht aufkommen, daß sich nach dem ersten Kind die Kosten-Nutzen-Relation verändert, so daß auf weitere Kinder verzichtet wird.

Die ökonomische Belastung mit Unterhaltskosten für das Aufziehen eines Kindes haben sich seit dem zweiten Weltkrieg infolge ständig steigender Konsumnormen und einer verlängerten Schulausbildung laufend erhöht. Diese Entwicklung wurde begleitet von einer ungleichmäßigen Verteilung der Kinder und damit der Unterhaltslasten für die nachwachsende Generation auf die erwerbstätige Bevölkerung, was zwangsläufig zu einer relativen Schlechterstellung der Familien mit Kindern führte. ${ }^{383}$ Übersehen wurde lange Zeit, daß die Kosten, die durch das Vorhandensein von Kinder entstehen, sowohl eine private wie auch eine öffentliche Angelegenheit sind. ${ }^{384}$ Wird letzteres akzeptiert, so stellt sich die Frage, in welchem Umfang eine Kostenübernahme durch die Gesellschaft erfolgen soll. Die Beantwortung dieser Frage hängt nun wiederum von der wirtschaftlichen Leistungsfähigkeit und Belastungsfähigkeit der privaten Haushalte, von den Vorstellungen über die horizontale und vertikale Einkommensverteilung, vom Finanzierungspotential der öffentlichen Hand und nicht zuletzt vom politischen Werturteil der Entscheidenden ab. Voraussetzung für die Übernahme von Kosten durch den Staat ist die Kenntnis über die Höhe dieser Kosten, danach erst kann entschieden werden, in welchem Ausmaß die Belastung bei den Familien ausgeglichen werden soll. Da die Ausgaben für Kinder in den Familien stark variieren, kann nur mit durchschnittlichen Werten gearbeitet werden. Zuletzt wurden die durchschnittlichen Lebenshaltungskosten von

\footnotetext{
${ }^{383}$ Vgl. H. Schmucker, a.a.O., S. 276.

${ }^{384}$ Vgl. F. Bertsch, Kinderkosten-Private Kosten-Öffentliche Kosten?!, in: Wie privat sind Kinder in unserer Gesellschaft?, Dokumentation der Tagung in Bad Honnef 26./27. November 1993, Hrsg. Bundesverband Neue Erziehung e.V., Grafschaft 1994, S. 47.
} 
Kindern vom Statistischen Bundesamt im Rahmen einer Sonderauswertung der Einkommens- und Verbrauchsstichprobe (EVS) 1988 ermittelt. Danach betrugen die durchschnittlichen monatlichen Lebenshaltungskosten eines Kindes unter 18 Jahren im früheren Bundesgebiet bei Ehepaaren mit 1 Kind 691,-- DM, bei Ehepaaren mit 2 Kindern 492,-- DM je Kind und bei Alleinerziehenden mit 1 Kind 544,-- DM, wobei die Lebenshaltungskosten der Kinder mit ihrem Alter, mit dem Haushaltseinkommen, mit der Familienphase und der sozialen Stellung der Eltern variierte. Es zeigt sich, daß die Kosten für ein Kind im allgemeinen mit steigendem Alter zunehmen, vor allem dann, wenn das Kind eine längere Schulausbildung und/oder ein Hochschulstudium durchläuft. Bei kleinen Kindern stehen die Ausgaben für Ernährung noch im Vordergrund, mit zunehmendem Alter gewinnen die Ausgaben für Bekleidung, Sport, Freizeitgestaltung an Bedeutung. Die Höhe der Ausgaben für Ausbildung wird in hohem Maße von dem Einkommensniveau und der sozialen Stellung des elterlichen Haushalts beeinflußt. ${ }^{385}$ Mit wachsender Kinderzahl erhöhen sich die Ausgaben der Familie für die Kinder, jedoch unterproportional zu der Kinderzahl, da gewisse Einsparungen bei den Anschaffungen an Babywäsche, Kinderwagen, Spielsachen u.s.w. möglich sind. Je nach Berechnungsart variieren die für Kinder angesetzten Kosten in den verschiedenen Statistiken von 430,- DM - 1.200,- DM.

${ }^{385}$ Vgl. H. Schmucker, a.a.O., S. 280. 
Tabelle 43: Kinderkosten in Durchschnittswerten nach Berechnungsarten

Berechnungsart

Kosten DM pro Kind/Monat

1. Als Existenzminimum bewertet nach Sozialhilfeleistungen - als

konstruierter Durchschnitt für das gesamte Bundesgebiet und von

4 Altersstufen, 1990

450 bzw. 430

2. In Analogie zur Höhe der Vergütung für die Versorgung von Pflegekindern: als Durchschnitt nach Alter der Kinder und ohne Berücksichtigung von Erziehungskosten, 1991

$628-719-875$

3. Nach Analysen im Rahmen der Laufenden Wirtschaftsberechnungen:

Als Durchschnittskosten bei Ehepaaren mittleren Einkommens mit zwei Kindern, nach unterschiedlichen Anteilen der Kinder an Gemeinkosten (25\%, $33 \%, 40 \%), 1990$

$483-363-633$

4. Nach Berechnungen mit amtsstatistischen Daten aus Sondererhebungen: als Durchschittskosten nach Haushaltsnettoeinkommen, Zahl, Alter und Altersrang der Kinder, 1988

$550-1200$

Quelle: Weidacher, Kritische Anmerkungen zum Familienlastenausgleich, Eine Bestandsaufnahme, in: Hauswirtschaft und Wissenschaft, 40. Jg. 1992, Heft 3, S. 132.

Eine sehr detaillierte Aufstellung der Aufwendungen für ein Kind findet sich in den Berechnungen des Statistischen Bundesamtes von 1990: 
Tabelle 44: Ermittlung der Lebenshaltungskosten eines Kindes 1987 *

Aufwendungen je Monat in DM

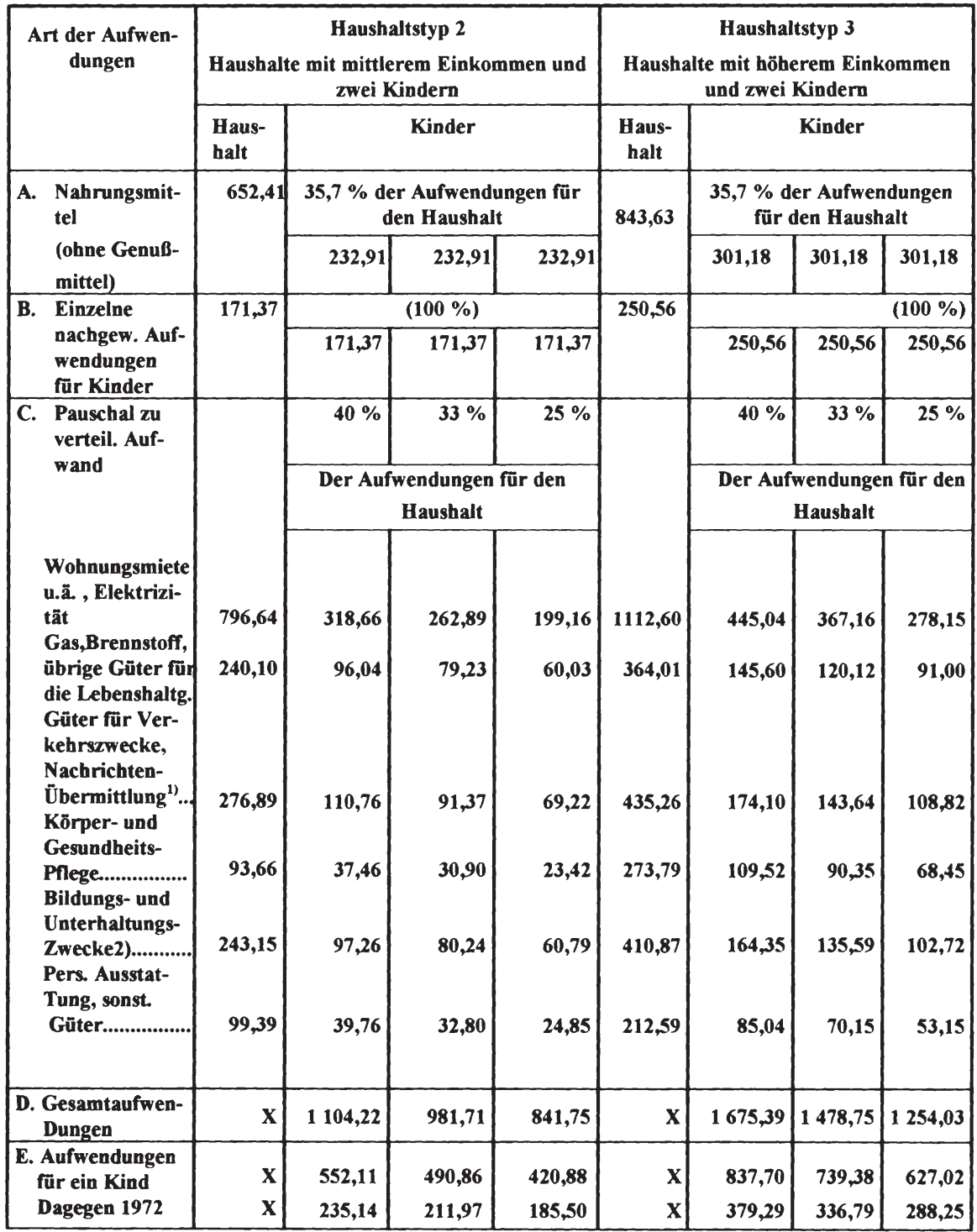

Quelle: Statistisches Bundesamt (Hrsg.), Familien heute, Ausgabe 1990, S. 76 
Unter Hinzunahme kostenrechnerischer Erkenntnisse werden zwei Kategorien des Aufwandes für Kinder unterschieden:

1. Einzelkosten, d.h. direkt zurechenbare und einzeln auszuweisende Kosten wie Kleidung, spezielle Baby- bzw. Kindernahrung, Spielzeug u.s.w.

2. Gemeinkosten, d.h. nicht unmittelbar dem Kind zurechenbare Kosten, die mittels eines Kostenverrechnungsschlüssels zu unterschiedlichen Anteilen Kindern zugeordnet werden, wie Wohnungsmiete, Haushaltsgeräte, Verkehr u.s.w.

Als mittleres Einkommen wird für 1987 vom Statistischen Bundesamtes ein Bruttoarbeitseinkommen von 2.800,-- DM bis unter 4.250,-- DM zugrunde gelegt, ein höheres Einkommen wird mit 5.050,-- DM bis unter 6.700,-- DM veranschlagt, weitere Einkommen bleiben in der Betrachtung unberücksichtigt. $^{386}$

Die doch erheblichen Differenzen der unterschiedlichen Schätzungen ergeben sich aus der Verteilung der Gemeinkosten. Da diese den größten Anteil an den Kosten für ein Kind ausmachen, wird die eingeschränkte Aussagekraft solcher Schätzungen deutlich. Eine etwas andere Rechnung hat $\mathbf{H}$. Lampert, Mitglied des wissenschaftlichen Beirats für Familienfragen, aufgestellt. Er hat die Einkommen und Kosten eines Doppelverdienerehepaares mit denen einer Familie verglichen, die zwei Kinder bis zum 18. Lebensjahr großzieht, wobei er von folgenden Annahmen ausgeht:

- Die Frau ist von der Geburt des ersten Kindes 1983 bis zum 6. Geburtstag des zweiten Kindes 1990 nicht erwerbstätig.

- Als Einnahmen werden die Durchschnittswerte für Angestellte angesetzt.

- Durch die achtjährige kindbedingte Unterbrechung der Erwerbstätigkeit hat die Frau nur noch geringere Karrierechancen und kann beim Wiedereinstieg auch nicht das übliche Durchschnittseinkommen erzielen.

Für 1990 errechnet Lampert dann folgende Einkommensunterschiede:

\footnotetext{
${ }^{386}$ Vgl. Statistisches Bundesamt (Hrsg.), Familien heute, Strukturen, Verläufe und Einstellungen, Ausgabe 1990, S. 75.
} 
$\begin{array}{ll}\text { Ehepaar } & \text { Ehepaar } \\ \text { keine Kinder } & \text { zwei Kinder } \\ \text { (zwei Verdiener) } & \text { (ein Verdiener) }\end{array}$

Brutto Ehemann

69.154,00

69.154,00

Brutto Ehefrau

$44.000,00$

Brutto Familie

$113.154,00$

69.154,00

Lohn- und Kirchensteuer

$\mathbf{- 2 4 . 6 1 1 , 0 4}$

- 10.704,96

$-19.256,11$

$-11.468,11$

Kindergeld

Netto-Jahreseinkommen

Einkommensnachteil durch

zwei Kinder im Jahr 1990:

Außerdem fehlen der Familie weitere 4.114 Mark Rentenversicherungsbeiträge, die der Arbeitgeber für die arbeitende Frau zahlt. In den acht Jahren, in denen die Mutter nicht arbeitet, betragen die

Einkommensausfälle

entgangenen Rentenbeiträge

GESAMT
$126.026,91$

$28.464,84$

$154.491,75$

Aber die Familie verdient nicht nur weniger, sie hat für ihre Kinder insgesamt 20 Jahre lang auch zusätzliche Ausgaben. Sie betragen in dieser Zeit*

$$
320.267,04
$$

Als Entlastung erhält die Familie aus Kindergeld und steuerlichen Kinderfreibeträgen in der Zeit, in der wieder beide Eltern berufstätig sind

$-54.420,00$

Vermögensunterschied zum Doppelverdienerehepaar nach 20 Jahren Kindererziehung

$420.338,79$ 
Sicherlich ist auch diese Schätzung nicht generell auf alle übertragbar, sie ist aber ohne Zweifel als eine realistische Größenordnung aufzufassen.

Die wirtschaftliche Leistungsfähigkeit privater Haushalte wird am Verhältnis von verfügbarem Haushaltseinkommen und den Lebenshaltungskosten der Haushaltsmitglieder gemessen. Wie schon im vorhergehenden analysiert, liegen die Einkommen von Alleinerziehenden am unteren Ende der Einkommensskala, so daß bei Kosten von inzwischen ca. 600,-- DM pro Kind die soziale Lage dieses Personenkreises als äußerst mangelhaft eingestuft werden kann. Um die Chancengleichheit von in unvollständigen Familien aufwachsenden Kindern gegenüber Kindern in vollständigen Familien zu gewährleisten, sollten im Rahmen des Familienlastenausgleichs Maßnahmen vorgesehen werden, die nach Bedarfsgesichtspunkten eine Zuordnung von Sozialleistungen gewähren.

\section{Familienlastenausgleich in der BRD}

Ebenso wie die Ermittlung der Kosten für das Aufziehen von Kindern, sind auch Maßnahmen des Familienlastenausgleichs in der Bundesrepublik Deutschland schon unmittelbar nach ihrer Gründung diskutiert worden. Allerdings erfolgte dies eher unsystematisch, weil ein einheitliches Zielsystem sogar noch bis in die sechziger Jahre hinein nicht existierte oder zumindest kontrovers war. ${ }^{387}$ Dies führte dazu, daß die Ausgestaltung und der Umfang der Leistungen umstritten waren und Finanzierungsmittel eher spärlich zur Verfügung gestellt wurden. Angesichts noch hoher Geburtenraten wurde die Notwendigkeit, einen Familienlastenausgleich durchzuführen, nicht beachtet oder schlichtweg vernachlässigt. Erst die nachhaltig sinkenden Geburtenraten seit den siebziger Jahren führten zu einer Beachtung der Situation der Familien, und hier insbesondere ihrer finanziellen Situation. Seither werden staatliche Maßnahmen zur Entlastung der Familien mit Kindern wieder stärker diskutiert, allerdings auch verstärkt kritisiert. Hauptkritikpunkt ist dabei das immer noch vorliegende unsystematische Nebeneinander verschiedener Leistungen, die zudem noch, je nach Finanz-

\footnotetext{
${ }^{387}$ Albers, W., Zur Reform des Familienlastenausgleichs in der Bundesrepublik Deutschland, in: Sozialer Fortschritt, 16.Jg.1967, S. 199.
} 
lage des Bundes und der Länder, erhöht oder gekürzt werden, ohne an die sozialpolitischen Wirkungen zu denken. Die desolate Finanzlage der gesetzlichen Rentenversicherung läßt die Familienpolitik jedoch wieder in den Vordergrund treten, denn das bestehende umlagefinanzierte Alterssicherungssystem hat langfristig nur dann Bestand, wenn eine ausreichend große Generation die zukünftige Finanzierung der jetzigen erwerbstätigen Generation übernimmt. Kinder und die damit verbundenen Kosten haben also einen Investitionscharakter, der allerdings im heutigen System der Alterssicherung für den einzelnen nicht unmittelbar erkennbar wird, da auch der Kinderlose Rentenzahlungen aus einem scheinbar vorhandenen "Rententopf" erhält. Der Nutzen von Kindern wird im bestehenden System sozialisiert, während die Kosten weitgehend privatisiert sind. Die im Alter zu erwartenden Rentenleistungen für Kinderlose entlasten diese vom Zwang, Vermögen zu bilden. In der Entstehungszeit des deutschen Rentenversicherungssystemsstellte diese Sozialisierung des Kindernutzens kein großes Problem dar, denn Ende des vorigen Jahrhunderts waren nur $8 \%$ aller geschlossenen Ehen kinderlos, heute sind es $\mathbf{2 0 \%}$ aller Ehen einer Kohorte. ${ }^{388}$ War Kinderlosigkeit zur Zeit der Jahrhundertwende ein bedauerliches Problem, welches eine Familie schicksalshaft traf, so wird gegenwärtig in vielen Fällen ganz bewuBt auf Kinder verzichtet, um die aktuellen Konsummöglichkeiten nicht zu vermindern. Die zu beobachtende starke Zunahme dieser freiwilligen Kinderlosigkeit und der erhebliche Ausbau des Alterssicherungssystems in den letzten Jahren lassen erkennen, daB das Alterssicherungssystem inzwischen "ein gewaltiger, in seinen Auswirkungen noch völlig unterschätzter Umverteilungsmechanismus zwischen Familien mit und ohne Kinder"1389 geworden ist, so daB es nicht verwundert, daB die Zahl der Reformvorschläge zur Beseitigung dieser unbefriedigenden Situation ständig zunehmen. Während also mehr oder weniger Einigkeit über die Notwendigkeit der Existenz eines Familienlastenausgleichs besteht, unterscheiden sich die einzelnen Konzeptionen jeweils durch die verfolgten Ziele und deren Gewichtung. Erschwert wird eine rationale Betrachtung der Thematik durch die unzulänglichen

\footnotetext{
${ }^{388}$ Vgl. R. Nave-Herz, Kinderlose Ehen, Weinheim 1988, S. 17.

${ }^{389}$ R. Dinkel, Kinder- und Alterslastenausgleich bei abnehmender Bevölkerung, in: Finanzarchiv N:F: Bd. 39, 1981, S. 137.
} 
Vorstellungen über die ökonomischen Wirkungen der eingesetzten Instrumente, Horizontale und vertikale Verteilungseffekte lassen sich nur schwer ermitteln und werden häufig falsch eingeschätzt. Zudem wird häufig übersehen, daß es sich bei Maßnahmen des Familienlastenausgleichs nicht um eine "Armenhilfe" handelt, sondern das er eine Maßnahme der gesellschaftlichen Strukturpolitik ist, " durch die die in dem Aufziehen der Kinder liegende Leistung der Familien für die Gesellschaft anerkannt wird, was bei dem am Markt erzielten Leistungseinkommen nicht möglich ist" ${ }^{390}$ Ökonomisch betrachtet gibt es also durch das Aufziehen von Kindern positive externe Effekte für die Gesellschaft, die vom Markt nicht honoriert werden und demzufolge durch staatliche Eingriffe ganz oder teilweise korrigiert werden müssen.

Kaum ein Begriff in der Familienpolitik scheint auf den ersten Blick so eindeutig, auf den zweiten Blick jedoch so vielschichtig zu sein wie der Begriff "Familienlastenausgleich", seit neuestem wird auch von einem "Familienleistungsausgleich" gesprochen. ${ }^{391}$ Erschwert wird eine präzise Definition auch noch dadurch, daB die Ausgestaltung des Familienlastenausgleichs, wie die Familienpolitik schlechthin, eine Querschnittsaufgabe ist, die zu einer vertikalen und horizontalen Kompetenzzersplitterung in der Politik führt. Insofern lassen sich mehrere Abgrenzungen eines Familienlastenausgleichs unterscheiden:

1. In einer sehr weiten Abgrenzung wird unter den Familienlastenausgleich alles subsumiert, was die Familie mit ihrer besonderen Funktion und ihrer besonderen Belastung fördert, so auch staatliche Realtransfers (Kindergärten, sozialer Wohnungsbau u.s.w.) sowie Leistungen nichtstaatlicher Institutionen (betriebliche Kinderkrippen).

2. In einer sehr engen Abgrenzung, die dem $§ 25$ SGB I in Verbindung mit § 6 SGB I zugrunde liegt, zählen zum Familienlastenausgleich lediglich staatliche Transferzahlungen wie das Kinder- und Erziehungsgeld.

3. In einer Abgrenzung, die irgendwo dazwischen liegt, werden darüber hinaus alle Maßnahmen in die Betrachtung einbezogen, die eine Erhö-

\footnotetext{
${ }^{390}$ Albers, W. Zur Reform des Familienlastenausgleichs, a.a.O., S. 199.

${ }^{391}$ Vgl. Freiheit in Verantwortung, Grundsatzprogramm der Christlich Demokratischen Union Deutschlands, Beschlossen vom 5. Parteitag, Hamburg, 20.-23. Februar 1994, S. 22.
} 
hung des verfügbaren Einkommens bewirken, so z.B. Arbeitgeberleistungen, Steuerbefreiungen und sonstige Sozialleistungen. ${ }^{392}$

Auf Basis von $\S 6$ des Sozialgesetzbuches I wiederum werden als Familienlastenausgleich diejenigen Leistungen verstanden, "die die wirtschaftlichen Belastungen von Familien aufgrund des laufend anfallenden, allgemein gleichbleibenden Grunderhaltungsbedarf der Kinder angemessen mindern. Dies geschieht durch Kindergeld einschlieBlich Kindergeldzuschlag (Anm. d. Verf.: dieser ist 1995 abgeschafft worden). Zusammen mit dem Kinderfreibetrag bilden diese Leistungen das duale System des Familienlastenausgleichs". ${ }^{393}$

Die ersten, dem Familienlastenausgleich zugeordneten, politischen Aktivitäten, knüpften an der Lohngestaltung der Arbeitnehmer an und bewirkten eine Korrektur des am Markt erzielten Leistungslohns insofern, als die Arbeitgeber gemäß dem Kindergeldgesetz vom 13.11.1954 ab dem 3. Kind Ausgleichszahlungen an die Familien zu leisten hatten. Ausgezahlt wurde das Kindergeld von sogenannten Familienausgleichskassen, die bei den Berufsgenossenschaften errichtet und allein über Arbeitgeberbeiträge finanziert wurden. Jedoch ging man bereits 1956 dazu über, die Kindergeldleistung als sozialpolitische Staatsaufgabe zu sehen, die konsequenterweise dann auch aus allgemeinen Steuermitteln zu finanzieren ist.

Dem Grundgedanken des Ausgleichs von Familienlasten liegt der Sachverhalt zugrunde, daB Familien durch den Unterhalt und das Aufziehen von Kindern eine erhebliche finanzielle Belastung zu tragen haben, die sie in vielen Fällen überfordert. Maßnahmen zur Entlastung der Familien können monetäre oder reale Leistungen sein. Monetäre Leistungen erhöhen unmittelbar das verfügbare Einkommen der Familien, reale Leistungen bedingen eine Inanspruchnahme bestimmter Güter oder staatlicher Dienstleistungen, im einzelnen können folgende Formen unterschieden werden: ${ }^{394}$

1. MaBnahmen, die das frei verfügbare Nettoeinkommen der Familien erhöhen, wie z.B. das Kindergeld.

\footnotetext{
392 Vgl. Karl-Jürgen Bieback, Familienleistungen und Familienlastenausgleich in der Sozialversicherung, in: Vierteljahresschrift für Sozialrecht, Heft 2, 1996, S. 74.

${ }^{393}$ Deutscher Bundestag, BT-Drucksache 12/5168, S. 9.

${ }^{394}$ Vgl. M. Wingen, Familienlastenausgleich, in: HdWW, Bd. 2, 1980, S. 584.
} 
2. Aufwendungen des Staates, die von Familien mit Kindern in Anspruch genommen werden, z.B. Realleistungen im Bildungssektor.

3. Einbeziehung von Kindern in das System der Sozialversicherung, ohne daß die Eltern entsprechend zur Finanzierung herangezogen werden, z.B. die beitragsfreie Mitversicherung von Familienangehörigen in der gesetzlichen Krankenversicherung.

4. MaBnahmen, die dem Ausgleich von Opportunitätskosten dienen, z. B. die beitragsfreie Gewährung von Versorgungsansprüchen. 
Tabelle 45: Familienpolitik in der BRD

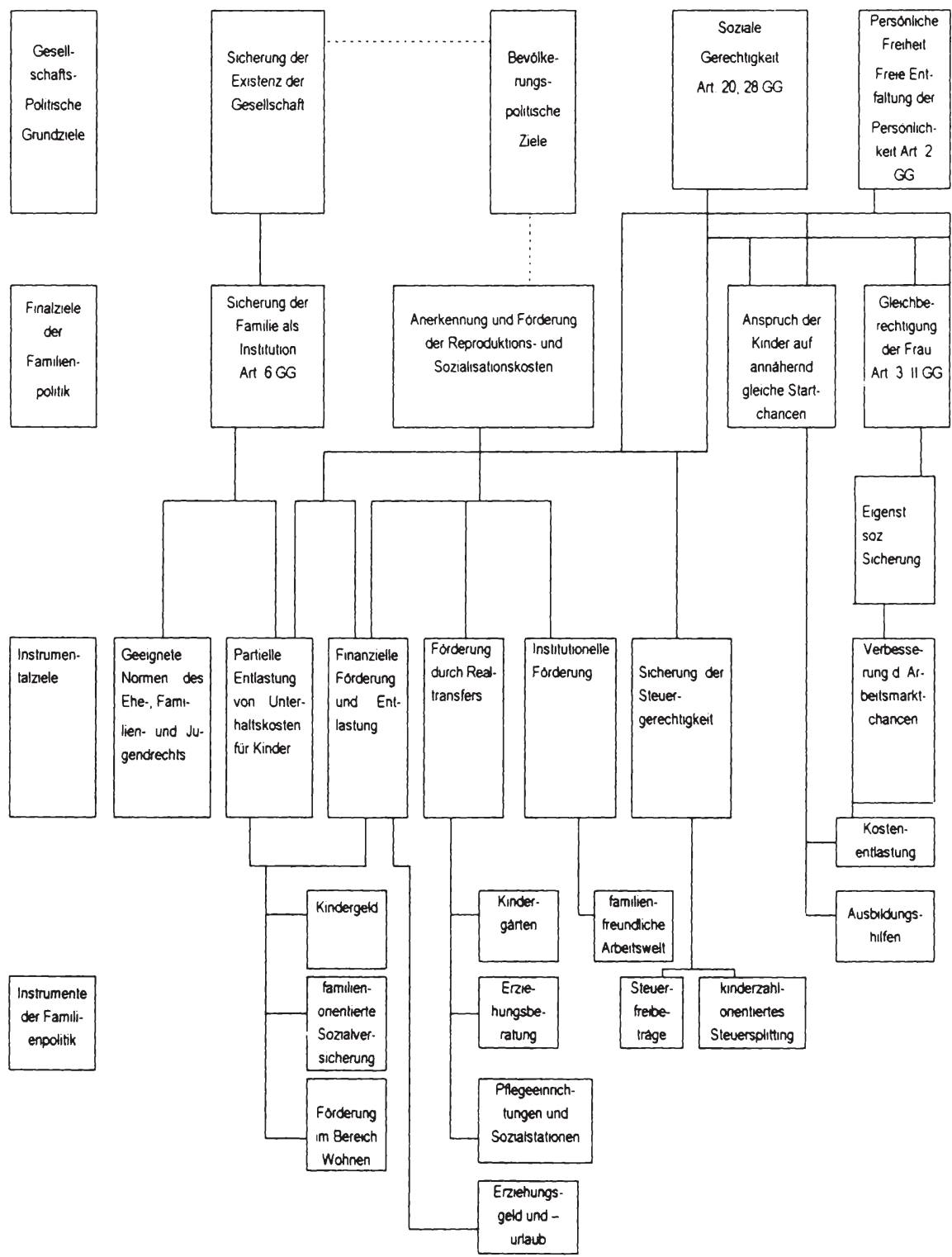

Quelle: Lampert, Ordnungspolitische und verteilungspolitische Aspekte der Familienpolitik, a.a.O., S. 17. 
5. Subventionierung von am Markt gehandelten Gütern, die dann zu niedrigen Preisen an Familien mit Kindern abgegeben werden, z.B. Maßnahmen im Rahmen der Wohnungsförderung.

6. Vermögenspolitische Maßnahmen, die an die Existenz von Kindern gebunden sind, z.B. Baukindergeld.

7. Staatliche Realleistungen und Gebührenermäßigungen, die eine Begünstigung von Familien mit Kindern bewirken, z.B. Fahrpreisermäßigungen bei öffentlichen Verkehrsunternehmen.

Bevor nun auf die Maßnahmen des Familienlastenausgleichs im einzelnen eingegangen wird, müssen die Zielsetzungen eines Familienlastenausgleichs näher untersucht werden, da nur dann auf die Wirkung familienpolitischer Maßnahmen sinnvoll eingegangen werden kann.

Obwohl jegliche, politisch festgesetzte Zielsetzung immer einen stark normativen Charakter hat, existiert über alle politischen Parteien hinweg ein Konsens, daß die positiven externen Effekte des Aufziehens der nächsten Generation durch Leistungen im Rahmen eines Familienlastenausgleichs internalisiert werden sollen, da die Kosten ansonsten allein von den Eltern getragen werden müßten, obgleich der Nutzen der Gesellschaft insgesamt zugute kommt. Dieser Sachverhalt ist in der ökonomischen Wissenschaft als Problem der optimalen Allokation bekannt, wonach dann - bezogen auf diese Thematik - erst nach umfassender Internalisierung externer Effekte von einer gesamtwirtschaftlich optimalen Kinderzahl im wohlfahrtstheoretischen Sinne gesprochen werden kann $^{395}$. Herrscht hinsichtlich dieser Zielsetzung noch weitgehend Übereinstimmung, so zeigen sich z.T. erhebliche Differenzen bei der Operationalisierung der externen Effekte einerseits und der Maßnahmen zur Internalisierung andererseits. Es sei an dieser Stelle der Vollständigkeit halber darauf hingewiesen, daß eine konsequente Anwendung der Theorie externer Effekte im Bereich der Bevölkerungsentwicklung natürlich auch den Fall negativer externer Effekte einbeziehen müßte. Wenn also durch zusätzliche Kinder nicht zu akzeptierende Agglomerationskosten entstehen würden, dann müßten staatlicherseits Maßnahmen zur Geburtenkontrolle und Geburtenregulierung ergriffen werden. Dies ist in Entwick-

\footnotetext{
${ }^{395}$ Vgl. H. Willgerodt, Der Familienlastenausgleich im Rahmen der Sozialreform, in: Ordo, Jahrbuch für die Ordnung von Wirtschaft und Gesellschaft, 8. Bd., 1956, S. 128.
} 
lungsländern und im asiatischen Raum eine durchaus gängige Praxis, die dort allerdings auch nicht auf die Vorbehalte stößt, wie sie gerade in Deutschland - aufgrund der unsäglichen Vergangenheit des Dritten Reiches - ständig geäußert werden. Für die dargestellte Problematik sind es jedoch die positiven externen Effekte, die relevant sind. Als Folge des starken Geburtenrückgangs und des hohen Zustromes ausländischer Menschen rücken jedoch auch bevölkerungspolitische Zielsetzungen jedoch wieder etwas mehr in den Vordergrund. Eine weitere Zielkomponente geht von den Kindern selbst aus. Ausgangspunkt ist die Vorstellung, daß die individuellen Entwicklungsmöglichkeiten nicht von vornherein durch ökonomische Restriktionen behindert werden sollten. Das einzelne Kind - so wird argumentiert habe aus humanitären und sozialen Erwägungen heraus Anspruch auf die Förderung durch die Gesellschaft, um eine Annäherung seiner Startchancen an die anderer Kinder zu erreichen. Dies impliziert nicht eine vollständige Kompensation aller entstehenden Kosten, sondern bedeutet im Kern, daß jedem Kind das Recht auf Sicherung eines Mindestbedarfs zugestanden wird, wobei als Maßgröße i.d.R. das sozio-ökonomische Existenzminimum herangezogen wird. Eine zumutbare Eigenbeteiligung der Eltern leitet sich aus der Selbstverantwortlichkeit der Eltern ab. Ein in diesem Sinne ausgestalteter Familienlastenausgleich folgt strikt dem Individualprinzip und wird nur deshalb "der Familie" gewährt, weil die Kinder nicht ohne die Einbindung in den Familienverband betrachtet werden können.

In die gleiche Richtung zielt eine Reihe von Argumenten, die als familienbezogen bezeichnet werden können, sie kennzeichnen eher die "klassische" sozialpolitische Begründung für die Existenz eines Familienlastenausgleichs. ${ }^{396}$ Anknüpfungspunkt ist die Familie als gesellschaftliche Institution gemäß Artikel 6 GG. Art. 6 GG in Verbindung mit dem Subsidiaritätsprinzip bedeutet zweierlei:

1. die Forderung nach einer privat-individuellen Primärverantwortung, ${ }^{397}$ und

\footnotetext{
${ }^{396}$ Vgl. R.H. Dinkel, Familienlastenausgleich: Reformen und kein Ende, in: Wirtschaftsdienst, 67. Jg. 1987, Heft 2, S. 92.

${ }^{397}$ Vgl. Friedhelm Hase, Sozialversicherung und Familie - verfassungsrechtliche Vorgaben für die Ausgestaltung der sozialen Sicherung?, in: Vierteljahresschrift für Sozialrecht, 1996, Heft 2, S. 82.
} 
2. die Forderung nach einer öffentlichen Verantwortung.

Auch hier wird erkennbar, daß nicht alle Lasten ausgeglichen werden sollen, sondern lediglich diejenigen, die die Familie nicht selbst tragen kann. Darauf aufbauend wird dem Familienlastenausgleich die Aufgabe zugewiesen, die Differenz zwischen dem familiengrößenunabhängigen Leistungseinkommen und dem familiengrößenabhängigen Bedarf zu verringern. ${ }^{398}$ Auch hier geht es nicht um die vollständige Kostenübernahme durch den Staat, allerdings setzt diese Zielsetzung am Familienprinzip an, so daß eine weitergehende Konkretisierung bezüglich des Ausmasses der Kostenübernahme notwendig wird. Soll Dem „Reichen“ die Übernahme der finanziellen Konsequenzen des Aufziehens eines Kindes eher als dem "Armen" zugemutet werden, so müßte der Entlastungsbetrag mit steigendem Einkommen absolut sinken, was einer zunehmenden Selbstbeteiligungsquote gleichkommt, und mit dem Gedanken der Subsidiarität staatlicher Transferleistungen korrespondieren würde. Wird allerdings der effektive Aufwand für Kinder von Eltern verschiedener sozialer Schichten als Maßstab herangezogen und es nicht wünschenswert ist, daß Eltern durch die mit Kindern verbundenen finanziellen Belastungen aus ihrer sozialen Schicht absinken, dann müßte konsequenterweise die Höhe des Entlastungsbetrages den schichtenspezifischen Ausgaben angepaßt werden, was zwangsläufig einen mit zunehmendem Einkommen steigenden Betrag bedeutet. Die ersten familienpolitischen Maßnahmen nach dem zweiten Weltkrieg in Form von Kinderfreibeträgen waren solche schichtspezifisch wirksamen Maßnahmen mit der klaren Zielsetzung Besserverdienende stärker zu entlasten. Der damalige Bundesfamilienminister Franz-Josef Wuermeling äußert sich in einem Bulletin 1962 folgendermaßen: "Gerade auch unseren weithin kulturtragenden Mittelstandsschichten darf nicht ausgerechnet da die Erfüllung ihrer wichtigen kulturellen Aufgabe unmöglich gemacht werden, wo sie diese an ihren Kindern und damit für die Zukunft aller wirksam werden lassen wollen ... Familienausgleich bedeutet: ... Kaufkraftausgleich innerhalb jeder sozialen Schicht ...". Augenscheinlich war es damals für einen Politiker noch möglich, sich öf-

\footnotetext{
${ }^{398}$ Vgl. H. Schmidt, U. Frank, I. Müller-Rohr, Kritische Bemerkungen zum System des Kinderlastenausgleichs - zugleich ein Vorschlag zur Neugestaltung der gesetzlichen Rentenversicherung, in: Finanzarchiv, N.F., Bd. 43, Heft 1, 1985, S. 31.
} 
fentlich zu schichtenspezifischen MaBnahmen zu bekennen, ohne daB eine sozialromantisch ausgerichtete Opposition diesem Politiker gleich jegliches soziales Denken absprach. Als jedoch 1961 das Kindergeld für das zweite Kind eingeführt wurde, beschränkte es sich auf Eltern mit niedrigem Einkommen.

Steuerliche Maßnahmen werden im wesentlichen mit dem Ziel der steuerlichen Gerechtigkeit begründet. Im Rahmen des deutschen Steuersystems erfolgt die Besteuerung des Einkommens i.d.R. nach dem Prinzip der individuellen Leistungsfähigkeit. Werden die Aufwendungen für Kinder nicht als private Konsumentscheidung angesehen, so folgt daraus zwangsläufig, Kinder und die damit verbundenen Kosten als Reduktion der Leistungsfähigkeit zu definieren, so daB ein Abzug dieser Ausgaben von der Steuerbemessungsgrundlage bzw. von der Steuerschuld nur konsequent erscheint. $^{399}$

Da der bundesdeutsche Einkommenssteuertarif progressiv gestaltet ist, folgt dann zwingend, daß aus gleichen Abzugsbeträgen je nach Einkommenshöhe unterschiedlich hohe Entlastungsbeträge resultieren. Sowohl steuersystematisch als auch unter allokationstheoretischen Erwägungen ist gegen eine derartige Regelung nichts einzuwenden, allerdings kann es unbestrittenermaßen Kollisionen mit anderen Umverteilungszielsetzungen geben. Es kann auch nicht bezweifelt werden, daB steuerliche MaBnahmen allein zu keinem zieladäquaten Ergebnis führen, da die Bezieher kleiner Einkommen, die keine oder nur geringe Steuern zu zahlen haben, aber am dringendsten von einem Teil der Kinderkosten entlastet werden müßten, keine oder nur eine minimale Begünstigung erfahren. Direkte Transferzahlungen haben in diesen Fällen den Vorteil, so ausgestaltet werden zu können, daß die gewünschte Einkommensdifferenzierung für alle Familien eintritt. AuBerdem kann ohne gravierende Wirkungsverzögerung jederzeit eine Änderung der

\footnotetext{
${ }^{399}$ Daß Familienpolitik auch Eingang ins Steuerrecht finden müsse, wurde schon in der Regierungserklärung vom 13. Oktober 1982 als zentrales Anliegen aufgeführt und am 3. November 1982 im Urteil zur Besteuerung der Alleinerziehenden vom Bundesverfassungsgericht bekräftigt, wenn es heißt: "Die wirtschaftliche Belastung durch Unterhaltsverpflichtungen gegenüber Kindern ist ein besonderer, die Leistungsfähigkeit der Eltern beeinträchtigender Umstand. Diese unabweisbare Sonderbelastung darf der Gesetzgeber ohne Verstoß gegen die Steuergerechtigkeit nicht außer acht lassen.
} 
Leistungshöhe vorgenommen werden und so die gewünschte Eigenbeteiligung der Leistungsfähigkeit der Eltern angepaßt werden.

Die Ausgestaltung und das Ausmaß eines Familienlastenausgleichs hinsichtlich eines konsistenten, zielgerichteten Systems erfordert eine Konkretisierung der Orientierungsgrößen.

1. Grundsätzlich kommt als Bemessungsgröße die durch den Unterhalt und das Aufziehen von Kindern verursachten Kosten in Frage, wobei ein vollständiger oder teilweiser Ausgleich dieser Kinderkosten erfolgen könnte. Der teilweise Ausgleich wiederum könnte sich auf einen Normaufwand, der näherungsweise mit dem sozialkulturellen Existenzminimum gleichgesetzt werden kann, beschränken oder von den schichtenspezifischen Ausgaben ausgehen. Wie schon ausgeführt, sind die gesellschaftlichen Ausgleichsleistungen nach herrschenden Vorstellungen auf einen Teilbetrag der Aufwendungen zu begrenzen, um die Selbstverantwortung der Eltern zu erhalten. Sinnvoll erscheint es, die Leistungen des Familienlastenausgleichs nach dem Alter und der Ordnungszahl der Kinder zu differenzieren, da die Ausgaben je Kind mit steigendem Alter zunehmen, demgegenüber mit steigender Kinderzahl sinken. ${ }^{400}$ Allerdings sei noch erwähnt, daß die mit steigender Kinderzahl abnehmenden Aufwendungen je Kind auch die Folge abnehmender Pro Kopf Einkommen sind.

2. Das veränderte Rollenverhalten der gegenwärtigen Frauengeneration führt dazu, daß über die tatsächlichen Aufwendungen für Kinder hinaus auch die wirtschaftliche Belastung durch den Wegfall des Erwerbseinkommens der Frau bei Aufgabe der Erwerbstätigkeit zu berücksichtigen ist, in der Wirtschaftswissenschaft als sogenannte "Opportunitätskosten" bekannt. In diesem Zusammenhang sind auch die Minderung der Versorgungsansprüche im Alter in die Überlegung zur Ausgestaltung des Familienlastenausgleichs einzubeziehen.

3. Schließlich könnte auch die monetär zu bewertende Beeinträchtigung der Erwerbsbiographie der Frau herangezogen werden. Nachweislich haben länger andauernde Unterbrechungen der Erwerbstätigkeit, die in den hier betrachteten Fällen kindbedingt sind, zur Folge, daß nach Wiederaufnahme der Beschäftigung Einkommenseinbußen gegenüber einer kontinuierlich

${ }^{400}$ Vgl. M. Wingen, Familienlastenausgleich, a.a.O., S. 587. 
ausgeübten Tätigkeit in Kauf genommen werden müssen, die dann ein Sinken des gesamten Lebenseinkommens bewirken. Die gestiegene Erwerbstätigkeit von verheirateten Frauen und die Geburtenentwicklung mit den zu beobachteten sinkendem Nettoreproduktionsraten haben diesen Aspekt verstärkt in den Vordergrund rücken lassen.

Multidimensionale Möglichkeiten zur Konkretisierung der Bemessungsgrundlage für einen Familienlastenausgleich lassen eine mannigfaltige Ausgestaltung zu. Stehen beispielsweise demographische Gesichtspunkte im Vordergrund, müßte sich die Förderung vorrangig auf die Phasen der Schwangerschaft und des frühen Kindesalters konzentrieren. Soll die Förderung der Humankapitalbildung forciert werden, müßte der Förderakzent bei der Erziehung und Ausbildung von Kindern liegen. Sollen die emanzipatorischen Bestrebungen der Frauen gefördert werden, so muß eine starke Akzentsetzung bei Maßnahmen stattfinden, die die Vereinbarkeit von Familie und Beruf erhöhen..$^{401}$ Es wird an diesen Beispielen schon deutlich, daB die hinter diesen Maßnahmen stehenden Ziele nicht komplementär zueinander sind, sondern sich in einzelnen Fällen sogar konkurrierend zueinander verhalten. Fatalerweise besteht nun - bedingt durch die Multidimensionalität der Ziele - die zwingende Notwendigkeit, ein Zielsystem mit klarer Zielhierarchie zu entwickeln. Diese Aufgabe ist bislang von politischer Seite nicht gelöst worden, so daß sich das heutige "System" des Familienlastenausgleichs kaum als solches bezeichnen läßt. Dies stellt im übrigen schon im Jahre 1971 der Wissenschaftliche Beirat für Wirtschaft und Finanzen fest, wenn es heißt, daß es "das ungeordnete Nebeneinander verbietet..., von einem System zu sprechen", ${ }^{402}$ und diese Aussage hat auch noch nach 25 Jahren nicht ihre Aktualität eingebüBt, angesichts der gestiegenen Zahl von Einzelregelungen initiiert von den verschiedensten Ministerien. Eine Begründung für diese unbefriedigende Situation ist sicherlich darin zu sehen, daß in der Vergangenheit vermehrt dem Kausal- und nicht dem Finanzprinzip gefolgt wurde, ${ }^{403}$ und diese Leistungen zudem auch noch ungenügend un-

\footnotetext{
${ }^{401}$ Vgl. F. Bertsch, a.a.O., S. 51.

${ }^{402}$ Finanzwissenschaftlicher Beirat beim Bundesministerium für Wirtschaft und Finanzen. Alterssicherung und Familienlastenausgleich. Gutachten zur Neugestaltung und Finanzierung, Bonn 1971, S. 51.

${ }^{403}$ Vgl. H. Schmidt, U. Frank, I. Müller-Rohr, a.a.O., S. 34.
} 
tereinander abgestimmt wurden. Sicherungslücken einerseits und Kumulation von kindbezogenen Leistungen andererseits sind die Folge und so existiert trotz materiell identischer Ausgangssituation von Familien ein Anspruch auf Transfers in unterschiedlicher Höhe. ${ }^{404}$

Die folgende Darstellung einiger relevanter Einzelregelungen soll die Problematik noch einmal konkret aufzeigen. Bevor jedoch auf den Familienlastenausgleich im einzelnen eingegangen wird, verdeutlicht die nachstehende Übersicht die Verflochtenheit familienpolitischer Leistungsströme mit den beteiligten Institutionen.

Den Kern des Familienlastenausgleichs im Sinne eines Kinderlastenausgleichs bildet das Kindergeld. Die Ausgaben für Kindergeldzahlungen betrugen im Jahre 1994 20,4 Mrd. DM und machten damit ca. 35 \% des Gesamtvolumens für Ausgaben und steuerliche Regelungen im Rahmen des Familienleistungsausgleichs der Bundesregierung aus. Das Kindergeld soll Eltern helfen, den kindbedingten Unterhalt tragen zu können.

${ }^{404}$ Vgl. ebenda. 
Abbildung 5: Familienpolitische Transferströme

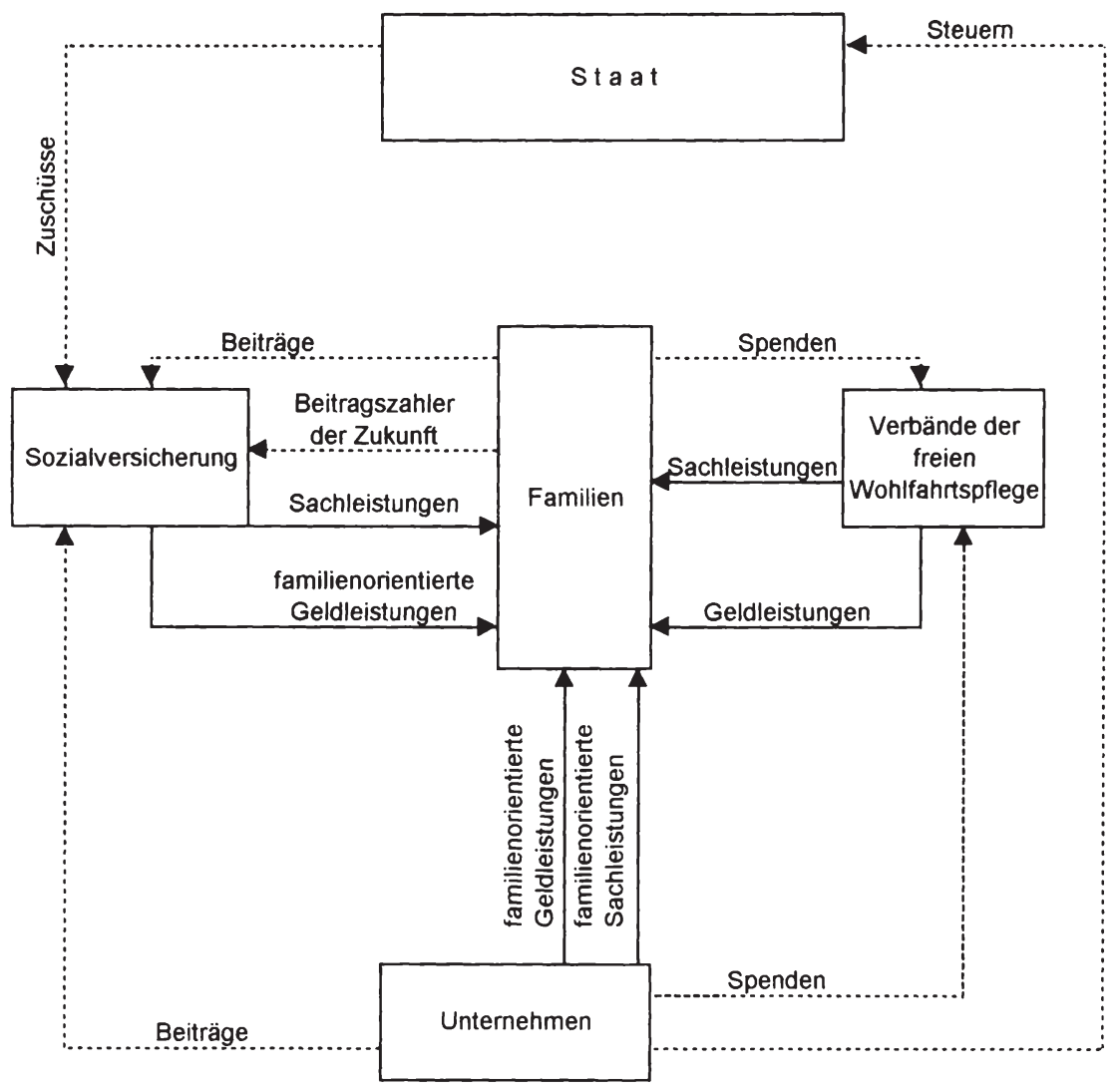

Quelle: H. Lampert, Ordnungspolitische und verteilungspolitische Aspekte der Familienpolitik in der Bundesrepublik Deutschland, in : H. Lampert, M. Wingen, Familie und Familienpolitik - Bestandsaufnahme und Perspektiven, Walter-Raymond-Stiftung, Kleine Reihe, Heft 41, S. 34, Köln 1986 
Tabelle 46: Zeittafel der wichtigsten familienpolitischen Gesetze und Leistungen in der Bundesrepublik Deutschland 1949 - 1996

\begin{tabular}{|c|c|c|}
\hline $\begin{array}{l}\text { Zeit/Mini- } \\
\text { ster(innen) }\end{array}$ & Gesetz/MaBnahme & Inhalt \\
\hline \multicolumn{3}{|c|}{ Christilich-liberale Koalition, CDU-Regierung und GroBe Koalition } \\
\hline $\begin{array}{l}1949 \text { (ohne } \\
\text { Ministeri- } \\
\text { um) }\end{array}$ & $\begin{array}{l}\text { Wiedereinführung } \\
\text { des steuerlichen } \\
\text { Kinderfreibetrages }\end{array}$ & 600,- DM Einkommensabzug für erste, zweite, dritte Kinder \\
\hline 1950 & $\begin{array}{l}\text { Erstes Wohnungs- } \\
\text { bauforderungsge- } \\
\text { setz }\end{array}$ & $\begin{array}{l}\text { Festlegung cines Bauvolumens von 1951-1956 auf } 2 \text { Mio. } \\
\text { Wohnungen, Förderung insbes. des sozialen Wohnungsbaus } \\
\text { und des Eigenheimbaus }\end{array}$ \\
\hline 1950 & $\begin{array}{l}\text { Gründung des } \\
\text { Müttergenesungs- } \\
\text { werkes }\end{array}$ & \\
\hline 1952 & $\begin{array}{l}\text { Gesetz zum Schutz } \\
\text { der erwerbstätigen } \\
\text { Mutter }\end{array}$ & $\begin{array}{l}\text { Kündigungsschutz für Frauen während der Schwangerschaft; } \\
\text { Verbot gesundheitsgefährdender Tätigkeiten für Schwange- } \\
\text { re; Beschäftigungsverbot sechs Wochen vor und acht Wochen } \\
\text { nach der Geburt }\end{array}$ \\
\hline \multicolumn{3}{|c|}{ 20. Okt. 1953 - 11. Dez. 1962 Franz-Josef Wuermeling (CDU) } \\
\hline 1954 & Kindergeldgesetz & $\begin{array}{l}\text { Zahlung eines Kindergeldes in Höhe von } 25,- \text { DM ab dem } \\
\text { dritten Kind durch die Arbeitgeber }\end{array}$ \\
\hline 1956 & $\begin{array}{l}\text { Zweites Woh- } \\
\text { nungsbauforde- } \\
\text { rungsgesetz }\end{array}$ & $\begin{array}{l}\text { Einführung von Mietbeihilfen; stärkere Förderung von } \\
\text { Wohnungseigentum }\end{array}$ \\
\hline 1957 & „Honnefer Modell“ & $\begin{array}{l}\text { Förderung des Studiums für Studenten aus einkommens- } \\
\text { schwachen Familien (Vorläufer des BAFöG) }\end{array}$ \\
\hline 1958 & $\begin{array}{l}\text { Einführung des } \\
\text { Ehegattensplittings }\end{array}$ & $\begin{array}{l}\text { Nach einem Urteil des Bundesverfassungsgerichtes Addition } \\
\text { der Einkommen beider Ehepartner und Division durch zwei; } \\
\text { zuvor Addition beider Einkommen und Versteuerung als Ge- } \\
\text { samteinkommen }\end{array}$ \\
\hline 1959 & $\begin{array}{l}\text { Erhöhung des Kin- } \\
\text { dergeldes }\end{array}$ & Zahlung von 40,-DM ab dem dritten Kind \\
\hline 1961 & \begin{tabular}{|l|} 
Einführung des \\
Zweitkindergeldes \\
aus Bundesmitteln
\end{tabular} & $\begin{array}{l}\text { 25,- DM für das zweite Kind aus Bundesmitteln; 40,-- DM } \\
\text { für weitere Kinder noch aus Familienausgleichskasse der Ar- } \\
\text { beitgeber }\end{array}$ \\
\hline \multicolumn{3}{|c|}{ 14. Dez. 1962 - 2. Okt. 1968 Bruno Heck (CDU) } \\
\hline 1963 & $\begin{array}{l}\text { Erhöhung der Kin- } \\
\text { derfreibeträge }\end{array}$ & $\begin{array}{l}\text { 1. Kind: } 1.200,- \text { DM } \\
\text { 2. Kind: } 1.680,-- \text { DM } \\
\text { 3. und weitere Kinder: } 1.800,-- \text { DM }\end{array}$ \\
\hline 1964 & $\begin{array}{l}\text { Erhöhung des Kin- } \\
\text { dergeldes und } \\
\text { Auflösung der Fa- } \\
\text { milienausgleichs- } \\
\text { kassen (Kinder- } \\
\text { geldkassen) der } \\
\text { Arbeitgeber } \\
\end{array}$ & $\begin{array}{l}\text { 25,-- DM für das zweite nur für Bezie-her niedriger Ein- } \\
\text { kommen, 50,-- DM für das dritte, } 60,-- \text { DM für das vierte, } \\
\text { 70,-- DM für das fünfte und weitere; Zahlung für alle aus } \\
\text { Bundesmitteln }\end{array}$ \\
\hline 1965 & Wohngeldgesetz & einkommens- und kinderzahlabhängige Zuschüsse zur Miete \\
\hline
\end{tabular}




\begin{tabular}{|c|c|c|}
\hline 1968 & $\begin{array}{l}\text { Erster Familienbe- } \\
\text { richt }\end{array}$ & \\
\hline 1968 & Mutterschutzgesetz & $\begin{array}{l}\text { Erweiterung des Beschäftigungsverbotes, Entgeltregelungen } \\
\text { bei Beschäftigungsverboten, Mutterschaftsgeld }\end{array}$ \\
\hline \multicolumn{3}{|c|}{ 16. Okt. 1968 - 20. Okt. 1969 Aenne Brauksiepe (CDU) } \\
\hline \multicolumn{3}{|r|}{ Sozialliberale Regierung } \\
\hline \multicolumn{3}{|c|}{ 22. Okt. 1969 - 14. Dez. 1972 Käthe Strobel (SPD) } \\
\hline 1969 & $\begin{array}{l}\text { Nicht-Ehelichen- } \\
\text { Gesetz }\end{array}$ & $\begin{array}{l}\text { weitgehende Gleichstellung ehelicher und nichtehelicher } \\
\text { Kinder im Gesetz }\end{array}$ \\
\hline 1969 & $\begin{array}{l}\text { Freistellungsmög- } \\
\text { lichkeit für Beam- } \\
\text { tinnen und Richte- } \\
\text { rinnen für Kin- } \\
\text { dererziehung }\end{array}$ & $\begin{array}{l}\text { Möglichkeit der Beurlaubung oder von Teilzeitarbeit für Be- } \\
\text { amtinnen und Richterinnen bei Freihalten der Stelle, wenn } \\
\text { Kinder unter } 16 \text { Jahren zu betreuen sind (nur für Frauen) }\end{array}$ \\
\hline 1971 & $\begin{array}{l}\text { Erhöhung des Kin- } \\
\text { dergeldes }\end{array}$ & $\begin{array}{l}\text { Anhebung des Kindergeldes für das zweite Kind auf 60,- } \\
\text { DM }\end{array}$ \\
\hline \multicolumn{3}{|c|}{ 15. Dez. 1972 - 15. Dez. 1976 Katharina Focke (SPD) } \\
\hline 1974 & $\begin{array}{l}\text { Ausweitung der } \\
\text { Freistellungsmög- } \\
\text { lichkeit im öffentli- } \\
\text { chen Dienst für Er- } \\
\text { ziehung auch für } \\
\text { Männer }\end{array}$ & $\begin{array}{l}\text { Ausweitung der } 1969 \text { für Beamtinnen und Richterinnen ge- } \\
\text { schaffenen Möglichkeit der Beurlaubung oder von Teilzeit- } \\
\text { arbeit für Kindererziehung auf Männer }\end{array}$ \\
\hline 1974 & $\begin{array}{l}\text { Einführung von } \\
\text { Pflegetagen für El- } \\
\text { tern }\end{array}$ & $\begin{array}{l}\text { Freistellung von der Arbeit von bis zu fünf Tagen für die } \\
\text { Pflege von erkrankten Kindern }\end{array}$ \\
\hline 1975 & $\begin{array}{l}\text { "Kindergeldre- } \\
\text { form" }\end{array}$ & $\begin{array}{l}\text { Abschaffung des steuerlichen Kinderfreibetrages; Einfüh- } \\
\text { rung des Kindergeldes für erste Kinder von 50,- DM; 70,-- } \\
\text { DM Kindergeld für das zweite Kind; 120,- DM für dritte } \\
\text { und weitere Kinder }\end{array}$ \\
\hline 1975 & $\begin{array}{l}\text { Zweiter Familien- } \\
\text { bericht }\end{array}$ & \\
\hline 1976 & Adoptionsgesetz & $\begin{array}{l}\text { Ausgestaltung der Rechtslage in Adoptionsfällen nach dem } \\
\text { Gesichtspunkt des größtmöglichen Kindeswohls, Gleichstel- } \\
\text { lung leiblicher und adoptierter Kinder }\end{array}$ \\
\hline \multicolumn{3}{|c|}{ 16. Dez. 1976 - 7. Apr. 1982 Antje Huber (SPD) } \\
\hline 1977 & $\begin{array}{l}\text { Reform des Ehe- } \\
\text { und Scheidungs- } \\
\text { rechtes }\end{array}$ & $\begin{array}{l}\text { Zerrüttungs- statt Schuldprinzip bei Scheidungen, Aufgabe } \\
\text { des Leitbildes der Hausfrauenehe im BGB }\end{array}$ \\
\hline 1978 & \begin{tabular}{|l|l} 
Anpassung des \\
Kindergeldes
\end{tabular} & $\begin{array}{l}\text { 50,- DM für das erste Kind, } 80,- \text { DM für das zweite Kind, } \\
150,-- \text { DM für das dritte und weitere Kinder }\end{array}$ \\
\hline 1979 & $\begin{array}{l}\text { Reform des elterli- } \\
\text { chen Sorgerechtes }\end{array}$ & $\begin{array}{l}\text { Wechsel vom Prinzip der elterlichen Gewalt zum Prinzip der } \\
\text { elterlichen Sorge, gesteigerte staatliche Eingriffsmöglichkei- } \\
\text { ten bei Erziehung in Konfliktfällen }\end{array}$ \\
\hline 1979 & $\begin{array}{l}\text { Anpassung des } \\
\text { Kindergeldes }\end{array}$ & $\begin{array}{l}\text { 50,-- DM für das erste Kind, } 80,- \text { DM für das zweite, } 200,- \\
\text { DM für das dritte und weitere Kinder }\end{array}$ \\
\hline
\end{tabular}




\begin{tabular}{|c|c|c|}
\hline 1979 & $\begin{array}{l}\text { Dritter Familien- } \\
\text { bericht }\end{array}$ & \\
\hline 1979 & $\begin{array}{l}\text { Gesetz zur Ein- } \\
\text { führung des Mut- } \\
\text { ter-schaftsurlaubs }\end{array}$ & $\begin{array}{l}\text { Einführung eines mit 750,- DM pro Monat bezahlten Mut- } \\
\text { terschaftsurlaubes für sechs Monate nach der Geburt eines } \\
\text { Kindes inkl. Kündigungsschutz und Aufrechterhaltung einer } \\
\text { beitragsfreien Versicherung (gilt nur für erwerbstätige Müt- } \\
\text { ter, nicht für Hausfrauen und Väter) }\end{array}$ \\
\hline 1979 & \begin{tabular}{|l|} 
Anpassung des \\
Kindergeldes
\end{tabular} & $\begin{array}{l}\text { 50,- DM für das erste Kind, 100, - DM für das dritte und } \\
\text { weitere Kinder }\end{array}$ \\
\hline 1980 & $\begin{array}{l}\text { Einführung des } \\
\text { staatl. Unterhalts- } \\
\text { vorschusses }\end{array}$ & $\begin{array}{l}\text { Zahlung des Mindestunterhaltes für max. } 36 \text { Monate bei } \\
\text { Kindern unter sechs Jahren, deren unterhaltspflichtiger El- } \\
\text { ternteil zahlungsunwillig oder zahlungsunfähig ist }\end{array}$ \\
\hline 1981 & $\begin{array}{l}\text { Anpassung des } \\
\text { Kindergeldes } \\
\end{array}$ & $\begin{array}{l}\text { 50,- DM für das erste Kind, } 120,- \text { DM für das zweite Kind, } \\
240,- \text { DM für das dritte und weitere Kinder }\end{array}$ \\
\hline \multicolumn{3}{|c|}{ 29. Apri. 1982 - 4. Okt. 1982 Anke Fuchs (SPD) } \\
\hline 1982 & $\begin{array}{l}\text { Anpassung des } \\
\text { Kindergeldes }\end{array}$ & $\begin{array}{l}\text { 50,-- DM für das erste Kind, } 100,-- \text { DM für das zweite Kind, } \\
220,-- \text { DM für das dritte Kind, } 240,-- \text { DM für das vierte und } \\
\text { weitere Kinder }\end{array}$ \\
\hline \multicolumn{3}{|r|}{ Christlich-liberale Koalition } \\
\hline \multicolumn{3}{|c|}{ 4. Okt. 1982 - 26. Sept. 1985 Heiner Geißler (CDU) } \\
\hline 1983 & $\begin{array}{l}\text { Wiedereinführung } \\
\text { des dualen Kin- } \\
\text { derlastenausgleichs }\end{array}$ & $\begin{array}{l}\text { Einführung von Kinderfreibeträgen von 432,- DM pro } \\
\text { Kind; einkommensabhängige Zahlung des Kindergeldes von } \\
\text { 50,- DM für das erste Kind, 70,-- DM - 100,- DM für das } \\
\text { zweite Kind, 140,-- DM - 220,- DM für das dritte und wei- } \\
\text { tere Kinder; Einführung eines Kindergeldzuschlages von } \\
\text { 48,- DM für Eltern, die die Kinderfreibeträge bei geringe- } \\
\text { rem Einkommen nicht ausschöpfen können. }\end{array}$ \\
\hline 1984 & $\begin{array}{l}\text { Gründung der } \\
\text { „Bundesstiftung } \\
\text { Mutter und Kind } \\
\text { zum Schutz des un- } \\
\text { geborenen Lebens“ }\end{array}$ & $\begin{array}{l}\text { Wirtschaftliche Unterstützung von schwangeren Frauen in } \\
\text { besonderen Notfällen, um Schwangerschaft auszutragen; } \\
\text { kein Rechtsanspruch; Gewährung, wenn Hilfe durch andere } \\
\text { Sozialleistungsträger nicht greift; Haushaltsmittel 1992: } 140 \\
\text { Mio. DM, Förderungsfälle } 1984 \text { - 1992: 500.000 }\end{array}$ \\
\hline \multicolumn{3}{|c|}{ 26. Sept. 1985 - 25. Nov. 1988 Rita Süssmuth (CDU) } \\
\hline 1985 & $\begin{array}{l}\text { Gesetz über die } \\
\text { Gewährung von } \\
\text { Erziehungsgeld } \\
\text { und Erziehungs- } \\
\text { urlaub }\end{array}$ & $\begin{array}{l}\text { ab 1.1.1986 Erziehungsgeld 600,- DM für alle Mütter und } \\
\text { Văter; } \\
\text { Erziehungsurlaub: } \\
\text { ab 1.1.1986: } 10 \text { Monate } \\
\text { ab 1.1.1988: } 12 \text { Monate } \\
\text { ab 1.1.1989: } 15 \text { Monate } \\
\text { ab 1.1.1990: } 18 \text { Monate } \\
\text { ab 1.1.1993: } 24 \text { Monate } \\
\text { (Erziehungsgeld, Ausweitung des Erziehungsurlaubs ohne } \\
\text { Bezahlung auf } 36 \text { Monate) }\end{array}$ \\
\hline
\end{tabular}




\begin{tabular}{|c|c|c|}
\hline 1986 & $\begin{array}{l}\text { Gesetz zur Aner- } \\
\text { kennung von Kin- } \\
\text { dererziehungszei- } \\
\text { ten in der Renten- } \\
\text { versicherung }\end{array}$ & $\begin{array}{l}\text { pro Kind wird zunächst ein Jahr in der Rentenversicherung } \\
\text { angerechnet; } \\
\text { ab } 1.10 .1987 \text { für alle Mütter ab Jg. } 1906 \\
\text { ab } 1.10 .1988 \text { für alle Mütter ab Jg. } 1911 \text { u. früher } \\
\text { ab } 1.10 .1989 \text { für alle Mütter ab Jg. } 1916 \text { u. früher } \\
\text { ab 1.10.1990 für alle Mütter oder Väter } \\
\end{array}$ \\
\hline 1986 & $\begin{array}{l}\text { Anpassung der } \\
\text { Kinderfreibeträge }\end{array}$ & Anhebung des Kinderfreibetrages auf $2.488,--\mathrm{DM}$ \\
\hline \multicolumn{3}{|c|}{ 9. Dez. 1988 - Okt. 1990 Ursula Lehr (CDU) } \\
\hline 1989 & $\begin{array}{l}\text { Anerkennung von } \\
\text { Pflegeleistungen } \\
\text { durch das Gesund- } \\
\text { heitsreformgesetz } \\
\end{array}$ & $\begin{array}{l}\text { Zahlung von Pflegegeldern und Urlaubskräften für pflegen- } \\
\text { de Angehörige (Erweiterungen 1991) }\end{array}$ \\
\hline 1990 & $\begin{array}{l}\text { Anpassung des } \\
\text { Kindergeldes }\end{array}$ & $\begin{array}{l}\text { 50,- DM für das erste Kind, } 100,- \text { DM }-130,- \text { DM für das } \\
\text { zweite Kind, 140,- DM - 220,- DM für das dritte und wei- } \\
\text { tere Kinder }\end{array}$ \\
\hline 1990 & \begin{tabular}{|l} 
Anhebung des \\
Kinderfreibetrages
\end{tabular} & $3.024,-\mathrm{DM}$ \\
\hline 1990 & $\begin{array}{l}\text { „Hilfsfonds für } \\
\text { schwangere Frauen } \\
\text { in Not" }\end{array}$ & $\begin{array}{l}\text { Gründung per Einigungsvertrag mit Dauer von Okt. } 1990 \text { - } \\
1992 \text { zur wirtschaftlichen Unterstützung von schwangeren } \\
\text { Frauen in Notlagen in den neuen Bundesländern; } 1990 \text { - } \\
\text { 1992: } 20.000 \text { Förderungsfälle; } 1993 \text { Überleitung in die } \\
\text { „Bundesstiftung Mutter und Kind - Schutz des ungeborenen } \\
\text { Lebens }{ }^{\omega}\end{array}$ \\
\hline \multicolumn{3}{|c|}{ Jan. 1991 - Okt. 1994 Hannelore Rönsch (CDU) } \\
\hline 1992 & $\begin{array}{l}\text { Einführung des } \\
\text { Pfle- } \\
\text { gepauschbetrages } \\
\end{array}$ & $1.800,-$ DM für Pflegepersonen \\
\hline 1992 & $\begin{array}{l}\text { Erhöhung der Kin- } \\
\text { dererziehungszei- } \\
\text { ten in der Renten- } \\
\text { versicherung }\end{array}$ & pro Kind werden drei Jahre anerkannt \\
\hline 1992 & $\begin{array}{l}\text { Freistellung für die } \\
\text { Pflege von er- } \\
\text { krankten Kindern } \\
\end{array}$ & Erhöhung auf 10 Tage pro Jahr \\
\hline 1992 & $\begin{array}{l}\text { Erhöhung des Kin- } \\
\text { dergeldzuschlages }\end{array}$ & Kindergeldzuschlag: $65,-$ DM \\
\hline 1992 & \begin{tabular}{|l|} 
Anpassung des \\
Erstkindergeldes
\end{tabular} & $\begin{array}{l}\text { 70,- DM für das erste Kind, in den neuen Bundesländern } \\
1991 \text { schon auf } 65,- \text { DM }\end{array}$ \\
\hline 1992 & \begin{tabular}{|l} 
Anhebung des \\
Kinderfreibetrages
\end{tabular} & Anhebung des Kinderfreibetrages auf 4.104,- DM \\
\hline 1993 & $\begin{array}{l}\text { Anpassung des Un- } \\
\text { terhaltsvor- } \\
\text { schußgesetzes }\end{array}$ & $\begin{array}{l}\text { Erweiterung der Zahlung des Mindestunterhaltes bei Kin- } \\
\text { dern zahlungsunfähiger oder -unfreiwilliger Elternteile auf } \\
\text { Kinder bis zu } 12 \text { Jahren; Verlängerung der Zahlungsdauer } \\
\text { von } 36 \text { auf } 72 \text { Monate } \\
\end{array}$ \\
\hline \multicolumn{3}{|c|}{ ab Nov. 1994 Claudia Nolte (CDU) } \\
\hline 1995 & $\begin{array}{l}\text { Anhebung des } \\
\text { Kindergeldes }\end{array}$ & $\begin{array}{l}\text { Anhebung des Kindergeldes für das erste und zweite Kind } \\
\text { auf } 200,- \text { DM, für das dritte auf } 300,- \text { DM und für jedes } \\
\text { weitere auf } 350,- \text { DM }\end{array}$ \\
\hline
\end{tabular}




\begin{tabular}{|l|l|l|}
\hline 1995 & $\begin{array}{l}\text { Wegfall des Kin- } \\
\text { dergeldzuschlages }\end{array}$ & Wegfall des Kindergeldzuschlags von 65,-- DM \\
\hline 1996 & $\begin{array}{l}\text { Heraufsetzung des } \\
\text { Kinderfreibetrages }\end{array}$ & Anhebung des Kinderfreibetrages auf 6.264,- DM \\
\hline 1997 & $\begin{array}{l}\text { Erhöhung des Kin- } \\
\text { dergeldes }\end{array}$ & $\begin{array}{l}\text { Anhebung des Kindergeldes auf 220,- DM für das erste und } \\
\text { zweite Kind }\end{array}$ \\
\hline 1997 & $\begin{array}{l}\text { Heraufsetzung des } \\
\text { Kinderfreibetrages }\end{array}$ & Anhebung des Kinderfreibetrages auf 6.912,-- DM \\
\hline
\end{tabular}

Quelle: Irene Gerlach, a.a.O., S. 205ff., eigene Ergänzungen.

Tabelle 47: Höhe des Kindergeldes nach dem Bundeskindergeldgesetz in DM/Monat

1955-1997

\begin{tabular}{|l|r|r|r|r|}
\hline \multicolumn{1}{|c|}{ Jahr } & 1. Kind & 2. Kind & 3. Kind & 4. und weiteres Kin \\
\hline $1955-1957$ & 0 & 0 & 25 & 25 \\
$1957-1959$ & 0 & 0 & 30 & 30 \\
$1959-1961$ & 0 & 0 & 40 & 40 \\
$1961-1964$ & 0 & 25 & 40 & 40 \\
$1964-1970^{1}$ & 0 & 25 & 50 & 60 \\
$1970-1974^{1}$ & 0 & 25 & 60 & 60 \\
$1975-1977$ & 50 & 70 & 120 & 120 \\
1978 & 50 & 80 & 150 & 150 \\
$1979-1980$ & 50 & 100 & 200 & 200 \\
1981 & 50 & 120 & 240 & 240 \\
1982 & 50 & 100 & 220 & 240 \\
$1983-06.1990^{2}$ & 50 & $100 / 70$ & $220 / 140$ & $240 / 140$ \\
$07.1990-1991^{2}$ & 50 & 130 & 220 & 240 \\
$1992-1995^{2}$ & 70 & 130 & 220 & 240 \\
1996 & 200 & 200 & 300 & 350 \\
1997 & 200 & 200 & 300 & 350 \\
& & & & \\
\hline
\end{tabular}

1) 25,-- DM für das zweite Kind nur für Bezieher niedriger Einkommen, 70,-- DM für das fünfte und alle weitere.

2) Das Kindergeld für das zweite und jedes weitere Kind wird bei Überschreiten bestimmter Einkommensgrenzen bis auf einen Sockelbetrag reduziert. 
Eingeführt wurde das Kindergeld ab 1. Januar 1955, allerdings wurden lediglich für das dritte und alle weiteren Kinder 25,-- DM pro Kind/pro Monat gezahlt, zudem war die Zahlung an Einkommensgrenzen gebunden. Die Finanzierung des Kindergeldes erfolgte im wesentlichen aus den sogenannten Familienausgleichskassen, in die Arbeitgeber und Selbständige Beiträge zu entrichten hatten, deren Höhe von der Lohnsumme des jeweiligen Betriebes abhing. Lediglich für Nicht-Erwerbstätige wurde das Kindergeld aus Bundesmitteln gezahlt. Erst 1961 wurde die Kindergeldzahlung auch auf das zweite Kind ausgedehnt, für die dritten und weiteren Kinder gab es inzwischen 40,-- DM. Aufgrund des Protestes der Arbeitgeber übernahm der Bund die Ausgaben der Kindergeldzahlung für das zweite Kind, für alle weiteren Kinder blieb alles beim alten System. 1964 wurden dann schließlich die Familienausgleichskassen vollständig abgeschafft, so daß der Bund für die Zahlung des gesamten Kindergeldes zuständig war, die Auszahlung erfolgte über die Bundesanstalt für Arbeit und damit über die Arbeitsämter. Eine grundlegende Neuordnung des Kindesgeldes erfolgte 1975, es gab jetzt bereits für das erste Kind eine Transferzahlung in Höhe von 50,-- DM, zugleich entfielen die bis dahin geltenden Einkommensgrenzen. Erstmals seit der Einführung des Kindergeldes erfolgte 1982 eine Kürzung der Kindergeldbeträge für das zweite Kind von 120,-- DM auf 100,-- DM und für das dritte Kind von 240,-- DM auf 220,-- DM, für das vierte und alle weiteren Kinder blieb es bei den alten Beträgen. Nach dem Regierungswechsel kam es dann in der Amtszeit Heiner Geißlers zu erneuten Kürzungen und zur Wiedereinführung eines steuerlichen Kinderfreibetrages. 1986 wurde mit dem "Gesetz zur leistungsfördernden Steuersenkung und zur Entlastung der Familie" der steuerliche Kinderfreibetrag von 432,-- DM auf 2.484,-- DM angehoben, verbunden mit Kinderzuschlägen für diejenigen Familien, denen durch die Kinderfreibeträge keine volle steuerliche Entlastung zukam. das Kindergeld wurde weiterhin einkommensabhängig gezahlt. Bis 1995 bleibt es bei der alten Regelung, zum einen steuerliche Kinderfreibeträge zu berücksichtigen, zum anderen Kindergeld zu zahlen, das - abgesehen von einem Mindestbetrag von 70,-- DM monatlich - nach der Anzahl der Kinder und der Höhe des Familieneinkommens gestaffelt war. $\mathrm{Zu}$ den Kindergeldbeträgen kam für kleine Einkommen noch ein Kindergeldzuschlag in Höhe 
von bis zu 65,-- DM/Monat hinzu. Ab 1996 erhalten Eltern für jedes zu berücksichtigende Kind entweder nur Kindergeld oder nur den Kinderfreibetrag. Im laufenden Jahr wird stets Kindergeld als Steuervergütung gezahlt. Bei der Veranlagung zur Einkommenssteuer prüft das Finanzamt von Amts wegen, ob statt des gezahlten Kindergeldes der Kinderfreibetrag abzuziehen ist. Die einkommensabhängige Kürzung des Kindergeldes entfällt somit, darüber hinaus auch der Kindergeldzuschlag.

Anspruch auf Kindergeld besteht für

- eheliche und für ehelich erklärte Kinder,

- nichteheliche Kinder,

- adoptierte Kinder,

- Stiefkinder, wenn sie im Haushalt des Berechtigten leben,

- Pflegekinder, wenn sie im Haushalt des Berechtigten leben, auf längere Dauer zur Familie gehören und ein Obhuts- und Pflegeverhältnis zu ihren Eltern nicht mehr besteht,

- Enkelkinder und Geschwister, wenn sie im Haushalt des Berechtigten leben oder überwiegend von diesem unterhalten werden,

soweit sie das 18. Lebensjahr noch nicht vollendet haben. Die Einkommensgrenze für die Zahlung von Kindergeld für Kinder über 18 Jahre beträgt ab 1996 12.000,-- DM/Jahr. Diese Grenze orientiert sich an dem Betrag, der einem erwachsenen Alleinstehenden als Existenzminimum steuerfrei belassen bleibt.

Grundsätzlich wird für jedes Kind, das einen Anspruch auf Kindergeld hat, nur an eine Person Kindergeld gezahlt. Wenn nichts anderes bestimmt wird, erhält der Elternteil das Kindergeld, der die Kinder überwiegend unterhält. Auch bei Trennung oder Scheidung erhält vorrangig die Person das Kindergeld, in deren Obhut sich das Kind befindet (Obhutsprinzip). Die Kinderfreibeträge können geschiedene Eltern unabhängig voneinander geltend machen, in diesem Fall wird dann jeweils das halbe Kindergeld verrechnet.

Neu ist seit dem 1. Januar 1996 auch die administrative Abwicklung der Auszahlung, sie erfolgt entweder vom Arbeitgeber, von den Familienkassen oder - wie bisher - von den Kindergeldstellen des öffentlichen Dien- 
stes als Steuervergütung, Arbeitnehmer erhalten das Kindergeld in der Regel vom Arbeitgeber.

Eher eine Maßnahme der steuerlichen Wohnungsbaugrundförderung als ein Ausgleich von Unterhaltskosten ist das sogenannte Baukindergeld. Es wird bis zu acht Jahre lang gewährt und beträgt für eine erstellte oder angeschaffte selbstgenutzte Wohnung 1.500,-- DM pro Kind und Jahr. Das Baukindergeld wird seit dem 1. Januar 1996 ohne jegliche Einkommensgrenzen an die Berechtigten ausgezahlt.

Bereits vor Einführung des Kindergeldes und vor der Schaffung eines Ministeriums für Familienfragen im Jahre 1953 wurde, sozusagen als erste familienpolitische Maßnahme nach dem 2. Weltkrieg und der Verabschiedung des Grundgesetzes, im Jahre 1949 der steuerliche Kinderfreibetrag wieder eingeführt. Kontrovers diskutiert wird seitdem die Frage, ob es sich bei dieser Maßnahme um aktive Familienpolitik handelt, oder ob das deutsche Einkommenssteuerrecht, das auf dem Grundkonzept der Besteuerung des Zensiten nach seiner wirtschaftlichen Leistungsfähigkeit basiert, aus Gründen der gerechten Besteuerung neben einem Freibetrag für den steuerpflichtigen (Grundfreibetrag) selbst, auch das Existenzminimum für zu versorgende Kinder von der Steuer befreien muB. Mehrere Bundesverfassungsgerichtsurteile stützten letzteres, zuletzt in einem BeschluB vom September 1992, wonach bei der Einkommensbesteuerung ein am Sozialhilferecht orientiertes Existenzminimum freigestellt werden muß und dies unter Berücksichtigung der im Haushalt lebenden Personen. Kinderfreibeträge stellen also keine besondere "Begünstigung" dar, ihr Effekt liegt vorrangig in der Beseitigung einer Strafsteuer, der Eltern bislang unterworfen werden. ${ }^{405}$ Wie die folgende Übersicht zeigt, folgt die Bundesregierung der Argumentation des Bundesverfassungsgerichtes, indem von 1990 bis dato der Kinderfreibetrag um nahezu $130 \%$ erhöht wurde.

Die Ausgaben bzw. die Mindereinnahmen an Steuern betrugen 1994 16,6 Mrd. DM, das waren nahezu $30 \%$ der Ausgaben des gesamten Familienlastenausgleichs. Berücksichtigt sind in dieser Summe noch nicht die weiteren Regelungen im Steuerrecht, die an der Ehe oder Familie anknüpfen.

${ }^{405}$ Vgl. F. Oeter, Die Familienpolitik in den Steuersenkungsgesetzen der Regierung Kohl, in: Zeitschrift für Sozialreform, 33. Jg., Heft 7, S. 435. 
Zu nennen sind die Haushalts- und Ausbildungsfreibeträge sowie das Ehegattensplitting, die Kinderbetreuungsfreibeträge und schließlich einkommensmindernde Unterhaltsleistungen. Das Ehegattensplitting kann einem Familienlastenausgleich im eigentlichen Sinne nicht zugerechnet werden, ${ }^{406}$ da auch kinderlose Ehepaare in den Genuß dieser Begünstigung gelangen. Die teilweise Entlastung durch das Splitting ist um so größer, je höher der Einkommensunterschied zwischen den Ehepartnern ist. Die höchste Entlastung wird erreicht, wenn ein Ehepartner nicht erwerbstätig ist bzw. kein Einkommen bezieht. In einer anderen Regelung im Einkommenssteuerrecht soll die besondere Lebenslage eines Personenkreises berücksichtigt werden.

Gemäß § 32 Abs. 3 EStG wird Alleinerziehenden als Ausgleich für die Leistungsfähigkeitsminderung durch Kinder ein besonderer Freibetrag gewährt. Begründet wird dieser damit, daß die Minderung der Leistungsfähigkeit bei diesem Personenkreis schwerer wiegt als bei einem kindererziehenden Ehepaar. Zusätzlich wird alleinerziehenden Berufstätigen pauschal und ohne Nachweis die Möglichkeit der steuerlichen Absetzbarkeit für Betreuungskosten gewährt. Es wird dabei offensichtlich übersehen, daß auch in einer Ehe die Problematik existiert, daß entweder ein Ehepartner auf eine Berufstätigkeit verzichtet, also Opportunitätskosten trägt oder vor dem gleichen Problem steht, zusätzlichen Aufwand für die Betreuung seines Kindes in Kauf zu nehmen. Insofern führt die Regelung also zu einem gravierenden Verstoß gegen das Prinzip der Gleichmäßigkeit der Besteuerung, so daß die Forderung, den Familienlastenausgleich als direkte Transferleistung zu gestalten, an Gewicht gewinnt.

\footnotetext{
${ }^{406}$ Dies war allerdings auch nicht das Anliegen des Bundesverfassungsgerichtes, wenn es in seinem Urteil vom 3. November 1982 heißt: "Das Ehegattensplitting entspricht dem Grundsatz der Besteuerung nach der Leistungsfähigkeit. Es geht davon aus, daß zusammenlebende Eheleute eine Gemeinschaft des Erwerbs und des Verbrauchs bilden, in der ein Ehegatte an den Einkünften und Lasten des anderen wirtschaftlich jeweils zur Hälfte teil hat... Damit knüpft das Splitting an die wirtschaftliche Realität der intakten Durchschnittsehe an, in der ein Transfer steuerlicher Leistungsfähigkeit zwischen den Partnern stattfindet."
} 
Tabelle 48: Kinderfreibeträge 1949 - 1997

(Jahresbeträge in DM)

\begin{tabular}{|c|c|c|c|}
\hline Zeitraum & 1. Kind & 2. Kind & 3. u. weitere Kinder \\
\hline $1949-1952$ & $600,-$ & $600,-$ & $600,-$ \\
\hline $1953-1954$ & $600,--$ & $600,-$ & $840,-$ \\
\hline $1955-1956$ & $720,-$ & $720,-$ & $1.680,-$ \\
\hline 1957 & $720,-$ & $1.440,-$ & $1.680,-$ \\
\hline $1958-1961$ & $900,-$ & $1.680,-$ & $1.800,-$ \\
\hline $1962-1974$ & $1.200,-$ & $1.680,--$ & $1.680,-$ \\
\hline $1975-1982$ & $\mathbf{0 , -}$ & $\mathbf{0},-$ & 0,- \\
\hline $1983-1985$ & $432,-{ }^{*}$ & $432,-$ & $432,-$ \\
\hline $1986-1989$ & $2.484,-$ & $2.484,-$ & $2.484,-$ \\
\hline $1990-1992$ & $3.024,--$ & $3.024,-$ & $3.024,-$ \\
\hline $1993-1995$ & $4.104,-$ & $4.104,-$ & $4.104,-$ \\
\hline 1996 & $6.264,-$ & $6.264,-$ & $6.264,-$ \\
\hline 1997 & $6.912,-$ & $6.912,-$ & $6.912,-$ \\
\hline
\end{tabular}

* der Kinderfreibetrag wurde in den Fällen, in denen aufgrund der Urteile des Bundesverfassungsgerichtes vom 29. Mai und 12. Juni 1990 nach Einspruch der Steuerbescheid revidiert wurde, auf 2.432,- DM angehoben.

Quelle: I. Gerlach, a.a.O., S. 219, eigene Ergänzungen.

Die Konzeptionslosigkeit im Steuerrecht erreicht ihren Höhepunkt, wenn folgende weitere Regelung dazukommt:

Im Falle des Getrenntlebens (Trennungsjahr, vollzogene Scheidung) der Eltern eines Kindes kann zusätzlich zu dem allgemeinen Freibetrag desjenigen Elternteils, dem das Kind zugeordnet ist, für den Unterhalt zahlenden Partner nochmals der halbe Freibetrag gewährt werden. ${ }^{407}$ Auch wenn die besonders schwierige Lebenslage Alleinerziehender in der Familienpolitik zu berücksichtigen ist, kann nicht geleugnet werden, daß die oben genannten Regelungen Alleinerziehende im Vergleich zu Eltern, die ihr Kind in einer Ehegemeinschaft erziehen, unangemessen begünstigen. Das kann doch aber nicht die Zielsetzung einer Partei sein, die in ihrem Grundsatzprogramm ${ }^{+08}$ schreibt: "Die Ehe ist das Leitbild der Gemeinschaft von Frau

\footnotetext{
${ }^{+07}$ Vgl. H. Schmidt, U. Frank, I. Müller-Rohr, a.a.O., S. 36.

${ }^{408}$ Grundsatzprogramm der CDU vom Februar 1994, a.a.O., S. 21.
} 
und Mann. Sie ist die beste Grundlage für die gemeinsame Verantwortung von Mutter und Vater in der Erziehung der Kinder ... Ehe und Familie brauchen unsere besondere Unterstützung, gerade weil Bindungen in unserer offenen Gesellschaft mehr denn je vom Scheitern bedroht sind."

Um der horizontalen Gleichbehandlung der Steuerpflichtigen im Steuersystem Rechnung tragen zu können, ist die Beibehaltung des Kinderfreibetrages in Höhe eines festgelegten Existenzminimums sinnvoll zu sein, allerdings sollten weitere sozialpolitisch motivierte Ziele nicht mittels Einzelregelungen im Steuerrecht verfolgt werden, sondern im Rahmen direkter Transfers Berücksichtigung finden. Eine gewünschte Entlastung kann auch durch ein Kindergeld in Höhe des Existenzminimums für ein Kind erreicht werden.

Da das Hauptanliegen dieser Arbeit darin besteht, die Familie und ihre Stellung im System sozialer Sicherung zu analysieren, sollen im folgenden einzelne Maßnahmen des Familienlastenausgleichs in der Sozialversicherung untersucht und kritisch beleuchtet werden. Die Sozialversicherung soll schutzbedürftigen und zugleich vorsorgefähigen Personen eine Risikovorsorge ermöglichen. ${ }^{409}$ Das als Zwangsversicherung gestaltete System gewährt einerseits Sachleistungen, die von jedem Versicherten unabhängig von seinen gezahlten Beiträgen in Anspruch genommen werden können, und andererseits Geldleistungen, die den Charakter von Einkommensersatzleistungen haben und deshalb in ihrer Höhe mit dem während der Erwerbsphase erzielten Einkommen variieren.

Sachleistungen finden sich vor allem in der Krankenversicherung, zu einem geringen Teil auch in der Rentenversicherung (Bsp.: Rehabilitationsmaßnahmen), Geldleistungen kommen in allen Sparten der Sozialversicherung, vornehmlich aber in der Rentenversicherung vor. Der Grundidee der Sozialversicherung folgend, wurden bei Entstehung des Systems lediglich unselbständig Beschäftigte einbezogen, da bei ihnen offensichtlich der Schutzbedarf am Größten war, denn sie mußten allein von den wirtschaftlichen Erträgen ihrer eigenen Arbeit leben. War der unselbständig Beschäftigte wegen Krankheit, Invalidität oder Alter nicht mehr in der Lage, seine Ar-

\footnotetext{
${ }^{409}$ Vgl. F. Hase, Sozialversicherung und Familie - verfassungsrechtliche Vorgaben für die Ausgestaltung der sozialen Sicherung?, a.a.O., S. 85.
} 
beitskraft am Markt anzubieten, gab es für ihn keinerlei Kompensation durch eventuell vorhandenes Vermögen, insofern lag es nahe, in erster Linie diesen Personenkreis in ein staatliches Sozialversicherungssystem einzubeziehen. Auch die im Laufe der Zeit erfolgte Ausweitung des Personenkreises täuscht nicht darüber hinweg, daß nur ein Ausschnitt aus der Gesamtbevölkerung von der Sozialversicherung erreicht wird. Darüber hinaus wird in der Sozialversicherung nicht die wirtschaftliche Gesamtsituation des einzelnen Versicherten, geschweige denn einer Familiengemeinschaft, abgebildet. ${ }^{410}$ Infolgedessen scheint das Sozialversicherungssystem eher ungeeignet für die Aufgaben eines Familienlastenausgleichs zu sein. Gleichwohl finden sich im Sozialversicherungsrecht zahlreiche familienbegünstigende Regelungen, die teilweise als versicherungsfremde Leistungen kritisiert werden. Als Beispiele werden die Hinterbliebenenversorgung der gesetzlichen Rentenund der Unfallversicherung ${ }^{411}$, die beitragsfreie Mitversicherung von Familienangehörigen im Krankenversicherungsrecht $\mathrm{t}^{412}$, die Möglichkeiten des Bezugs von Krankengeld bei Erkrankung eines Kindes ${ }^{43}$ sowie die höhere Bemessungsgrundlage des Arbeitslosengeldes für Leistungsbezieher mit Kindern, ${ }^{414}$ beispielhaft genannt. Die Frage, ob es systemkonform ist, diese Leistungen als versicherungsfremde Elemente anzusehen oder ob es sich um einen sozialen Ausgleich innerhalb der Versichertengemeinschaft handele, sei an dieser Stelle nicht weiter verfolgt. ${ }^{415}$ Eines ist aber unbestritten: Maßnahmen des Familienlastenausgleichs, die in der Sozialversicherung angesiedelt sind, führen dazu, daß es Personen gibt, die nicht an der Finanzierung beteiligt werden, jedoch irgendwann in ihrem Leben positive externe Effekte erfahren. Demgegenüber müssen steuerfinanzierte Staatszuschüsse auch von Nichtmitgliedern der Versicherung aufgebracht werden, die keine Versicherungsleistungen erhalten. Unerwünschte Verteilungswirkungen sind zwar meist nicht völlig zu eliminieren, treten aber bei der jetzigen Konstruktion in verstärktem Maße auf, so daB im Endeffekt die Familien mit Kin-

\footnotetext{
${ }^{410}$ Vgl. ebenda, S. 84.

${ }^{411} \S \S 46$ ff. SGB VI.

${ }^{412} \S 10$ SGB V.

${ }^{413} \S 45$ SGB V.

${ }^{414} \S 111$ Abs. 1 AFG.

${ }^{415}$ Näheres dazu in Teil A, IV 1 dieser Arbeit.
} 
dern ihre Leistungen selbst teilweise finanzieren. Wünschenswert wäre es, wenn Kinderlose in Ermangelung eines Realbeitrages zur Bevölkerungsentwicklung monetäre Leistungen erbringen würden, die eindeutig im Rahmen einer personellen Umverteilung Familien mit Kindern zugute kämen.

Die finanziell bedeutsamste Regelung ist mit Kosten von derzeit ca. $63 \mathrm{Mrd}$. DM die Hinterbliebenenversorgung, insofern wird sie in der momentanen Finanzsituation der Rentenversicherung sozusagen als erstes "zur Disposition gestellt". Ihren Ursprung hatten die Hinterbliebenenrenten in der Unfallversicherung (1884), wo sie mit dem Ziel angesiedelt wurde, zivilrechtliche Haftungsansprüche von Versicherten und deren Angehörigen gegenüber ihren Arbeitgebern abzulösen. Die Renten wurden aus den Beiträgen finanziert, die - wie auch heute noch üblich - vollständig von den Unternehmen gezahlt werden. ${ }^{416}$ Die in diesem Zweig der Sozialversicherung relevanten Prinzipien der Familienleistungen waren: ${ }^{417}$

1. Hinterbliebenenversorgung zur Ablösung zivilrechtlicher Haftung,

2. differierende Anspruchsvoraussetzungen für Männer und Frauen (Frauen mußten nachweislich zum Unterhalt der Familie beigetragen haben),

3. Schutz der Familie einschließlich der Großelterngeneration (auch die Eltern eines Getöteten konnten Ansprüche geltend machen, sofern sie zuvor von dem oder der Getöteten unterhalten worden waren),

4. Finanzierung aus dem Beitragsaufkommen (dem Versicherungsprinzip wurde damit vollständig entsprochen).

1912 wurde die Hinterbliebenenversorgung dann auch auf die gesetzliche Rentenversicherung ausgedehnt, sie war ausschließlich aus sozialpolitischen Erwägungen heraus eingeführt worden, bezog sich auf die Kernfamilie (Eltern-Kind-Familie) und sollte die Unterhaltslücke bei Ausfall des Ernährers der Familie schließen. Zusätzliche Beiträge wurden für diese Leistung nicht erhoben, eine besondere Begünstigung von Verheirateten wurde nicht gese-

\footnotetext{
${ }^{416}$ Die Beitragshöhe der Unternehmen orientiert sich an der Lohnsumme des Betriebes und ist nach Gefahrenklasse gestaffelt, zusätzlich beeinflussen Unfälle der Vergangenheit - ähnlich wie in der Kfz-Haftpflichtversicherung - die Beitragszahlung.

${ }^{417}$ Vgl. U. Rust, Historische Entwicklung und gegenwärtige Bedeutung von Familienleistungen in der Sozialversicherung, in: Vierteljahresschrift für Sozialrecht, Heft 2, 1996, S. 108.
} 
hen, da die Eheschließung bis auf wenige Ausnahmen die überwiegende Lebensform war und damit jeder die Möglichkeit hatte, diese Leistung in Anspruch zu nehmen. Probleme hätten sich zudem ohne diese Form der Hinterbliebenenversicherung ergeben, da die Frauen keine eigenständige Alterssicherung besaßen und in großem Umfang soziale Notlagen entstanden wären, die öffentliche Hilfen erfordert hätten. Theoretisch gilt dies auch heute noch, allerdings haben sich die praktizierten Lebensformen dahingehend gewandelt, daß neben der Ehe andere Formen des Zusammenlebens an Bedeutung gewonnen haben. Das System beruhte auf einer Situation in den Familien, in der durch einen männlichen, lebenslang Vollzeit beschäftigten Arbeitnehmer die Familie unterhalten wurde, die ihrerseits finanziell von ihm abhängig war. Das Sozialversicherungsrecht nahm in dieser Konstellation durch Hinzunahme des Tatbestandes "Versicherungsfall wegen Todes des Ernährers" dem Alleinverdiener den Vorsorgeunterhalt für die Familie ab, zu dem er zu Lebzeiten durch das Ehe- und Familienrecht verpflichtet war und derzeit auch noch ist. ${ }^{418}$ Familienleistungen dieser Art ergeben sich also zwangsläufig aus der Funktion eines Unterhaltsersatzes beim Tod des Versicherten. Solange es der Normalfall war, daß die nicht erwerbstätige Ehefrau Kinder aufzog, war damit sichergestellt, daß ihr auch im Alter eine Leistung zufloß, mit der sie ihren Lebensunterhalt bestreiten konnte. Auf diese Leistung war sie dann jedoch auch angewiesen. Veränderte Verhaltensweisen innerhalb des Familienverbundes, die wiederum eine Veränderung staatlich gesetzter Rahmenbedingungen zur Folge hatten, lassen eine Hinterbliebenenversorgung in heutiger Gestalt zunehmend obsolet erscheinen:

- 1977 erfuhr das Familienrecht eine Änderung, seither gibt es gemäB $\S 1356$ BGB keine gesetzliche Vorgabe mehr für die Arbeitsteilung von Ehegatten in Erwerbstätigkeit und Haushaltsführung.

- 1977 ist ebenfalls die Unterhaltspflicht nach einer Scheidung neu geregelt worden, indem das Schuldprinzip durch das Zerrüttungsprinzip ersetzt wurde und jeder Ehegatte prinzipiell nach der Trennung

\footnotetext{
${ }^{418}$ Vgl. R. Jaeger, Familienleistungen in der Rentenversicherung, in: Vierteljahresschrift für Sozialrecht, Heft 2, 1996, S. 126.
} 
erst einmal für sich selber sorgen muß, es sei denn, er hat Kinder zu erziehen.

- Frauen sind heute vielfach selbst sozialversichert, von familienbedingten Unterbrechungszeiten und Teilzeitarbeit einmal abgesehen.

- Der Versorgungsausgleich im Scheidungsfall läBt Frauen an den in der Ehe erworbenen Sozialversicherungsansprüche partizipieren.

- Die Kindererziehung führt - wenn auch noch nicht in voll befriedigendem Maße - zum Aufbau einer eigenständigen sozialen Sicherung.

Schon seit den 70er Jahren werden Modelle zur eigenständigen sozialen Sicherung der Frau diskutiert, die mehr oder weniger die herkömmliche Form der Hinterbliebenenversorgung in Frage stellen und deren Abschaffung anstreben. Auch die Rechtsprechung des Bundesverfassungsgerichts der letzten 20 Jahre betont die Notwendigkeit familienbegünstigender Komponenten im Sozialversicherungsrecht, wenn auch aus dem Art. 6 Abs. 1 GG keine eindeutige Aussage über die konkrete Ausgestaltung abgeleitet werden könne, der Gesetzgeber bestimme vielmehr im Rahmen seiner Gestaltungsfreiheit, wie er den Schutz von Ehe und Familie im Sozialversicherungsrecht verwirklichen wolle. Damit können Maßnahmen sowohl innerhalb als auch außerhalb des Sozialversicherungsrecht der Zielsetzung der Familienförderung gerecht werden. Das Bundesverfassungsgericht hat aber ausdrücklich festgestellt, daß sozialpolitisch begründeten Umverteilungsmaßnahmen innerhalb der Sozialversicherung zulässig sind, wenn deren Charakter als Versicherung nicht beseitigt wird. So heißt es in seinem Urteil, daß die Sozialversicherung nicht nach dem reinen Versicherungsprinzip zu gestalten ist, sondern von jeher ein Stück staatlicher Fürsorge enthalte, sie erfülle somit ihre sozialstaatliche Aufgabe im Interesse der Gemeinschaft als verlängerter Arm des Staates. ${ }^{419}$

Eine Argumentation, die nur auf Art. 3 und 6 GG, die als "wertentscheidende Grundsatznorm"420 aufbaut werden kann, klammert das Problem der Finanzierung aus. Auch wenn der in die Sozialversicherung einbezogene Per-

\footnotetext{
${ }^{419}$ Vgl. BVerfGE 21, 362, 378.

${ }^{420}$ Vgl. F. Hase, Sozialversicherung und Familie, a.a.O., S. 90.
} 
sonenkreis immer weiter ausgedehnt wurde, so ist sie doch in erster Linie eine Sicherung für Erwerbstätige und zwar mit Schwerpunkt auf nichtselbständig Tätige, auch wenn 1972 in einer Veröffentlichung des Bundesministers für Arbeit und Sozialordnung zu lesen ist, daß die Sozialversicherung, die bisher vorwiegend auf die Arbeitnehmer ausgerichtet ist, in Zukunft den einzelnen Staatsbürger in den Mittelpunkt ihrer Überlegungen rücken wird, gleichgültig ob er berufstätig ist oder nicht. ${ }^{421}$

Wenn die gesellschaftspolitisch wichtige Sicherung der Familie befriedigend verwirklicht werden soll, müBte entweder die Rentenversicherung zu einer Sicherung aller Staatsbürger umgebaut werden, oder der Familienlastenausgleich müBte auBerhalb der Rentenversicherung verwirklicht werden und alle Staatsbürger umfassen. Bei der ersten Lösung müßte die Erziehungsarbeit und die Erwerbstätigkeit für Ansprüche auf eine Alterssicherung als gleichwertig behandelt werden. Dann würde dafür die herkömmliche Hinterbliebenenrente überflüssig werden. In der Ehe erworbene Rentenansprüche könnten nach einem geeignet erscheinenden Modus auf die Ehepartner aufgeteilt werden - im Zusammenhang mit einer Scheidung geschieht dies inzwischen auch ohne irgendwelche verfassungsrechtlichen Bedenken - und jedem Ehepartner eine eigenständige Sicherung gewährleisten. Personen, die weder erwerbstätig sind noch Kinder aufziehen, müßten im Rahmen der Eigenvorsorge ihren Lebensunterhalt im Alter sichern. Dies könnte durchaus auch mit freiwilligen Beiträgen zum gesetzlichen Sozialversicherungssystem geschehen, wenn dieses im Vergleich zu privatwirtschaftlich organisierten Systemen attraktiver erscheint.

Die sozialpolitische Diskussion hat die Idee des Splitting von Rentenanwartschaften erneut aufgegriffen - nachdem schon die Vorschläge zur Rentenreform 1984 in diese Richtung liefen - und bietet mehrere Varianten an: ${ }^{22}$

1. Ein Splitting von Rentenanwartschaften könnte schon während der Ehe stattfinden. D.h. auf Basis des Individualprinzips hätte jeder ein "Rentenkonto", auf dem er die im Laufe seines Lebens erworbenen Rentenansprüche sammeln könnte. Damit würde das herkömmliche Familienleitbild, das

\footnotetext{
${ }^{421}$ Vgl. Bundesminister für Arbeit und Sozialordnung, Kennzeichen sozial, Bonn 1972, S. 153.

${ }^{422}$ Vgl. M. Schmidt, Verbessern Modelle der eigenständigen Sicherung wirklich die Altersvorsorge der Frauen?, in: Sozialer Fortschritt, 45. Jg. 1996, Heft 10, S. 251.
} 
auf der Rolle des Mannes als Ernährer der Familie basiert, zugunsten eines partnerschaftlich-orientierten Zusammenlebens mit eigener Identität in der Sozialversicherung aufgegeben. Die praktische Durchführung gestaltet sich dann so wie beim Versorgungsausgleich im Scheidungsfall. Diese Form des Splitting entspricht dann dem Zugewinnausgleich, durch den das während der Ehe erworbene Vermögen unter den Ehegatten aufgeteilt wird.

2. Ein Splitting findet erst nach dem ersten Leistungsfall statt. D.h. wird ein Ehegatte berufs- oder erwerbsunfähig bzw. erreicht er die zum Bezug von Altersrente notwendige Altersgrenze, bekommt er lediglich eine Rente im Ausmaß der ihm verbliebenen Anwartschaften nach Anwendung des Splitting. Verfügt der noch nicht rentenberechtigte Ehepartner über kein weiteres Einkommen, so wird die Höhe der Rente für den Lebensunterhalt beider Ehegatten oftmals unzureichend sein.

3. Um das in Punkt 2 beschriebene Problem zu beseitigen, wird vorgeschlagen, das Splitting erst nach dem zweiten Leistungsfall vorzunehmen, dies könnte jedoch dazu führen, daß eine bereits gezahlte Leistung nachträglich zu mindern ist.

4. Ein Splitting der Anwartschaften, die vor und während der Ehe erworben wurden unter Beibehaltung der abgeleiteten Hinterbliebenenrente mit Einkommensanrechnung, so wie sie derzeit praktiziert wird. Um Zeiten der Kindererziehung rentenrechtlich besser zu honorieren, soll der Umfang der Hinterbliebenensicherung von der Ehedauer und der Kinderzahl abhängig gemacht werden, d.h. bei der Einkommensanrechnung werden der Freibetrag und der Anrechnungsprozentsatz nach der Kinderzahl differenziert. Flankierend dazu sollten Hinterbliebenenrenten nur noch auf Zeit gezahlt werden, die Unterscheidung von "kleiner" und "großer" Witwenrente wegfallen, die anzurechnenden Kindererziehungszeiten mit der Ordnungszahl der Kinder steigen und Kindererziehungszeiten additiv angerechnet werden. So sehr jede einzelne vorgeschlagene Reformmaßnahme ihre Berechtigung hat, löst auch dieses Konzept nicht in befriedigendem Maße das Problem der Ermittlung und Bewertung entstehender Verteilungswirkungen, und letztlich beschränkt es sich auch nur wieder auf den Kreis der in die Sozialversicherung einbezogenen Personen, so daß die Finanzierungsfrage weiterhin offen bleibt. Zudem sollte jegliche Reform des Rentenversicherungssy- 
stems von der Zielsetzung geleitet sein, das System eher zu vereinfachen und es im Sinne des Äquivalenzprinzips für jeden durchschaubar zu machen, so daß eine eindeutige Beziehung von Leistung und Gegenleistung erkennbar und kalkulierbar bleibt. Ein Reformkonzept mit vielen detaillierten Einzelregelungen - mögen sie sozialpolitisch auch alle berechtigt sein - erfordert darüber hinaus einen hohen Verwaltungsaufwand und läuft trotzdem immer Gefahr, neue Ungerechtigkeiten zu produzieren.

Nahezu Einigkeit herrscht darüber, Kindererziehungszeiten, Kinderberücksichtigungszeiten und Pflegezeiten rentenrechtlich $\mathrm{zu}$ berücksichtigen, wie dies seit einiger Zeit auch geschieht. Damit werden diese familiären Tätigkeiten vom Prinzip her der Erwerbstätigkeit gleichgestellt. Diskrepanzen zeigen sich jedoch, wenn es um die Bewertung derartiger häuslich-familiärer Tätigkeiten geht, bzw. aus welchen Quellen die Finanzierung erfolgen sollte. Zwei unterschiedliche Sichtweisen werden zur Lösung des Problems derzeit herangezogen: ${ }^{423}$

1. Die sogenannte Leistungsthese stellt in den Vordergrund, daß die o.a. familiären Tätigkeiten einen besonderen Wert für die Allgemeinheit und die Vorsorgesysteme haben und deshalb honoriert werden müBten und da diese Tätigkeiten genauso ihren Wert haben wie eine ausgeübte Erwerbstätigkeit, sollte sich die Bewertung der rentenrechtlichen Zeit an der Bewertung nach dem Durchschnittsverdienst der Erwerbstätigkeit orientieren.

2. Die zweite Argumentation stützt sich darauf, daB diejenigen Personen, die die familiären Tätigkeiten ausüben, ein "Opfer" bringen und dafür in einem primär erwerbsarbeitsbezogenen System keine oder nur eine unzureichende soziale Absicherung erreichen. Es sei deshalb ureigenste Sache des Staates oder der sozialen Sicherungssysteme, diese Situation durch die Zuteilung eigener, am Sicherungsstandard Erwerbstätiger gemessener Sicherungsrechte zu kompensieren. Auch diese Argumentation impliziert die Gleichbewertung von Erwerbstätigkeit und Familienarbeit.

Mit Hinweis auf die positiven Folgen für die Gesellschaft kommt in beiden Fällen nur eine entsprechende Finanzierung durch die Allgemeinheit aus

${ }^{423}$ Vgl. F. Hase, Sozialversicherung und Familie, a.a.O., S. 97f. 
dem allgemeinen Steueraufkommen in Frage, das Rentenversicherungssystem kann und darf nicht weiter belastet werden, wenn seine Funktionsfähigkeit auch in Zukunft erhalten bleiben soll. Denkbar wäre z.B. eine staatliche Erstattung der Ausgaben der Rentenversicherung oder eine spezifische Erhöhung des Bundeszuschusses, wie derzeit schon zur Abgeltung der Anrechnung von Kindererziehungszeiten praktiziert wird. Interessanterweise hat sich W. Schreiber, der geistige Vater des Umlageverfahrens, gegen einen Familienlastenausgleich in der heutigen Form ausgesprochen. Schreibers Vorschlag ging von der Erkenntnis aus, daß das Individualeinkommen, das i.d.R. nur im mittleren Lebensalter erzielt werden könne, auf die drei Lebensabschnitte Kindheit und Jugend, Arbeitsalter und Lebensabend verteilt werden müsse. ${ }^{424}$ Schreiber konkretisierte dies, indem er den Arbeitnehmern empfahl, unter sich einen Solidarvertrag zu schließen, der dem Kind einen Vorgriff auf sein eigenes zukünftiges Einkommen gestattet. Diese „Kindheits- oder Jugendrente" sollte von der Gesamtheit der zur gleichen Zeit erwachsenen Arbeitnehmer finanziert und dem Erziehungsberechtigten ausgezahlt werden. Die spätere Rückzahlung sollte dann mit den Jugendrenten für die Enkelgeneration verrechnet werden. Allerdings gestaltet sich die Rückzahlung von Unterhaltsleistungen für Kinder durch die erwachsenen Kinder als äußerst schwierig und aufwendig. Die Kindererziehung wurde also schon von Schreiber selbst als grundlegende Basis für den Bestand Rentenversicherungssystem im Umlageverfahren gesehen: "Wer kinderlos oder kinderarm ins Rentenalter geht und, mit dem Pathos des Selbstgerechten, für gleiche Beitragsleistungen gleiche Rente verlangt und erhält, zehrt im Grunde parasitär an den Mehrleistungen der Kinderreichen, die seine Minderleistungen kompensiert haben. Es gibt, allen Spöttern zum Trotz, ein gesellschaftliches Soll der Kinderzahl..., damit die Gesellschaft am Leben bleibt und auch für den Unterhalt ihrer Alten aufkommen kann. Es ist nicht mehr als billig und gerecht, daß der wirtschaftliche Dienst, den der Kinderreiche der Gesellschaft leistet und der Kinderarme ihr schuldig bleibt, auch in den

\footnotetext{
${ }^{424}$ Vgl. W. Schreiber, Existenzsicherheit in der industriellen Gesellschaft, Vorschläge des Bundes katholischer Unternehmer zur Reform der Sozialversicherung, Köln 1955.
} 
wirtschaftlichen Parametern der Rentenordnung seinen Niederschlag findet. ${ }^{425}$

Trotz aller Logik dieses Systems, wurde es nur unvollkommen umgesetzt. Während Adenauer die "dynamische Rente" für die nicht mehr erwerbstätige Generation einführte und damit erheblich an Wählerschaft gewann, konnte er sich für das Konzept der Kindheits- und Jugendrente nicht begeistern und ließ diese kurzerhand "unter den Tisch fallen". Die Folgen dieser Entscheidung werden zunehmend offensichtlicher und tragen in nicht unerheblichem Umfang zu den gegenwärtigen Problemen des Rentenversicherungssystems bei.

\section{UnterhaltsvorschuBkassen}

Die oftmals prekäre wirtschaftliche Lage alleinerziehender Elternteile wird dadurch verschärft, daB Unterhaltsverpflichtete ihren Zahlungsverpflichtungen gegenüber dem unterhaltsberechtigten Elternteil nicht oder nicht regelmäßig nachkommen, bzw. trotz gesetzlicher Verpflichtung in praxi den Zahlvätern die Unterhaltspflichten gegenüber ihren Kindern erlassen wird. ${ }^{426}$ Der Ausfall von Unterhaltszahlungen für das Kind kann unterschiedliche Ursachen haben, so z.B. Leistungsunfähigkeit, Zahlungsverweigerung, Unauffindbarkeit oder Tod des unterhaltspflichtigen Elternteils. So wurde festgestellt ${ }^{227}$, daß nur $53 \%$ aller ledigen Mütter und $42 \%$ der geschiedenen Elternteile regelmäßige Unterhaltszahlungen für ihre Kinder erhalten, $19 \%$ (Ledige) bzw. $18 \%$ (Geschiedene) erhalten lediglich in unregelmäßigen Abständen Zahlungen und dies nur selten in der festgesetzten Höhe. Zu erwähnen sei in diesem Zusammenhang, daB ein geschiedener Partner, der erneut heiratet, in vielen Fällen nicht in der Lage ist, eine zweite „Familie“ zu unterhalten.

Seit dem 1.1.1980 können nach dem "Gesetz zur Sicherung des Unterhalts von Kindern alleinstehender Mütter und Väter durch Unterhaltsvor-

\footnotetext{
425 Vgl. ebenda.

${ }^{426}$ Vgl. Carola Schewe, Zur Zahlungsmoral von unterhaltspflichtigen Elternteilen, in: Sozialer Fortschritt, 45. Jg., Heft 9, S. 225.

${ }^{427}$ Vgl. Napp-Peters, A., a.a.O., S. $63 f f$.
} 
schüsse oder -ausfalleistungen (Unterhaltsvorschußgesetz)" beim zuständigen Jugendamt Unterhaltsvorschußleistungen beantragt werden.

Der Kreis der Anspruchsberechtigten umfaßt ${ }^{428}$

- Alleinerziehende mit Kindern bis zur Vollendung des zwölften Lebensjahres,

- die im Geltungsbereich des Gesetzes bei einem Elternteil leben, der ledig, verwitwet oder geschieden ist oder von seinem Ehegatten dauernd getrennt lebt, und

- nicht oder nicht regelmäßig Unterhalt von dem anderen Elternteil oder wenn dieser gestorben ist, Waisenrente erhält.

Ein Anspruch wird ausgeschlossen, wenn die Elternteile zusammenleben oder sich ein Elternteil weigert, die zur Durchführung des Gesetzes erforderlichen Auskünfte (Feststellen der Vaterschaft, evtl. Aufenthalt des anderen Elternteiles) zu erteilen.

Die Höhe der Unterhaltsleistungen orientiert sich an den von der Bundesregierung festgesetzten Regelbedarfssätzen für nichteheliche Kinder und beträgt 1996 291,-- DM in den alten Bundesländern (Ost: 219,-- DM) für jedes Kind unter sechs Jahren sowie 353,-- DM (Ost 264,-- DM) für jedes Kind bis zum 12. Lebensjahr pro Monat. Hierauf werden angerechnet:

1. Kindergeld oder kindergeldähnliche Leistungen nach dem Bundeskindergeldgesetz, die derjenige Elternteil erhält, bei dem das Kind lebt. Die Unterhaltsleistung vermindert sich um die Hälfte des für ein erstes Kind zu zahlenden Kindergeldes. ${ }^{429}$ (Bsp.: 291,-- DM - 35,-- DM = 256,-- DM bzw. 353,-- DM - 35,-- DM = 318,-- DM).

2. Regelmäßig eingehende Unterhaltszahlungen des Unterhaltsverpflichteten, ${ }^{430}$

3. Waisenbezüge, die nach dem verstorbenen Elternteil gezahlt werden. ${ }^{431}$

\footnotetext{
${ }^{428}$ Vgl. § 1 Unterhaltsvorschußgesetz.

${ }^{429}$ Vgl. § 2, Absatz 2, Satz 1, Unterhaltsvorschußgesetz.

${ }^{430}$ Vgl. § 2, Absatz 3, Satz 1 Unterhaltsvorschußgesetz.

${ }^{431}$ Vgl. § 2, Absatz 3, Satz 2 Unterhaltsvorschußgesetz.
} 
Das Einkommen des Unterhaltsberechtigten bleibt bei der Frage, ob und in welcher Höhe Leistungen nach dem Unterhaltsvorschußgesetz an das Kind gezahlt werden, unberücksichtigt.

Die Unterhaltsleistung wird derzeit für längstens 72 Monate gezahlt, ${ }^{432}$ wobei Bundesfamilienministerin Claudia Nolte in Erwägung zieht, den Zeitraum der Leistungsinanspruchnahme bis zum 16. Lebensjahr des Kindes auszudehnen. ${ }^{43}$ Die Zahlung endet spätestens, wenn das Kind das 12 . Lebensjahr vollendet. Das gilt auch dann, wenn die Unterhaltsleistung noch nicht volle 72 Monate gezahlt worden ist.

Die Finanzierung dieses Bundesgesetzes, daß im Auftrag des Bundes von den Ländern ausgeführt wird, erfolgt zu $50 \%$ aus Bundesmitteln und zu $50 \%$ aus Landesmitteln. Verwaltungskosten gehen vollständig zu Lasten der Länder, d.h. auch die Kosten, die im Zuge der Rückforderung der bezahlten Beträge an den Unterhaltsverpflichteten entstehen. Eingezogene Beträge müssen zu $50 \%$ an den Bund abgeführt werden. Die Ausgaben von Bund und Ländern nach dem Unterhaltsvorschußgesetz betrugen 1994 rund 1,3 Milliarden Mark und weisen steigende Tendenz auf. Der größte Teil dieses Betrages kann oder wird bei den Unterhaltsverpflichteten - zumeist sind es die Väter - nicht zurückgeholt, da entweder der Aufenthaltsort des Zahlungspflichtigen nicht ermittelt werden kann oder der Zahlungspflichtige selbst mittellos ist oder letztlich die Kosten des "Eintreibens" der Beträge den Nutzen - also die tatsächlich zurückerhaltenen Beträge - bei weitem übersteigen. So schwanken die "Rücklaufquoten" in den einzelnen Ländern sehr stark, einige Länder erreichen Quoten von $30 \%$, während andernorts keine einzige Mark zurückgeholt wird. Im Landesdurchschnitt kann bei etwa $12 \%$ der Väter der Vorschuß wieder eingetrieben werden, den größten Teil des Geldes müssen Bund und Länder jedoch als verloren abschreiben. Von der Bundesregierung genannte Gründe für die Nichtrückholbarkeit sind Leistungsunfähigkeit, Auslandsaufenthalt, nicht festgestellte Vaterschaft, nicht abschließbare Prüfung, unbekannter Aufenthalt u.a. ${ }^{34}$ Von 1982 bis 1991 stieg die absolute Zahl der Kinder, die UnterhaltsvorschuB

\footnotetext{
${ }^{432}$ Vgl. § 3 Unterhaltsvorschußgesetz.

${ }^{43}$ Süddeutsche Zeitung vom 13.3.1995, Seite 2.

${ }^{434}$ Vgl. Angaben der Bundesregierung in ihrer Antwort auf die Kleine Anfrage der SPDBundestagsfraktion vom 28.5.1993, Bundestagsdrucksache 12/5052.
} 
bezogen, um etwa vierzig Prozent auf $84.427 .^{435}$ Die Gründe für diesen raschen Anstieg dürften auf die deutsche Wiedervereinigung zurückzuführen sein, aber noch mehr auf die wachsende Zahl Alleinerziehender. Demzufolge erhöhten sich auch die Gesamtausgaben des Bundes und der Länder sehr stark, lagen sie 1982 noch bei 94.940.000,-- DM, so hatten sie sich zehn Jahre später annähernd verdoppelt (1991: 178.660.000,-- DM). Der Vergleich der Erhöhung der Ausgaben mit der Erhöhung der Fallzahlen läßt erkennen, daB etwa die Hälfte der Mehrausgaben auf finanziellen Ursachen beruht, wobei der wichtigste Faktor die fehlende Rückzahlung ist, da die Unterhaltsbeträge pro Kind nur gering gestiegen sind. ${ }^{436}$

Fazit ist, daB der Staat - hier der Steuerzahler - für immer mehr Väter finanziell geradestehen muB, die sich ihrer Unterhaltspflicht entziehen. Die 1993 erfolgte Verdoppelung des Höchstalters der berechtigten Kinder und die damit einhergehende Verdoppelung der Anspruchsdauer zog eine Vervierfachung der Fallzahlen nach sich, die Kosten haben sich seit dieser Gesetzesänderung sogar versechsfacht. ${ }^{47}$ Angesichts leerer Kassen in den Ländern und Gemeinden wird über verbesserte Methoden des "Geldeintreibens" nachgedacht. Vorgeschlagen wird unter anderem, die Auskunftsrechte für die Unterhaltsvorschußkassen zu verbessern, das Rückforderungsverfahren durch Zentralisierung effektiver zu gestalten und diverse Anreizbzw. Sanktionssysteme für besonders erfolgreiche/erfolglose Kommunalverwaltungen. In der verwaltungstechnischen Ausgestaltung liegt ein wesentlicher Mangel des UVG: Da die Gemeinden lediglich Ausführungsorgan von Bund und Ländern sind, und keinerlei finanzielle Vorteile durch ein besonders eifriges Eintreiben des Unterhaltsvorschusses für sich erwirken können, wird das ohnehin schon überlastete Personal nicht besonders gern für diese Zwecke eingesetzt. Auch die Regelung bzgl. des Selbstbehalts ist nicht unumstritten; ein Selbstbehalt steht nämlich nur dem barunterhaltenspflichtigen Elternteil zu. Der Selbstbehalt erhöht sich aber auch durch schuldhaft verursachte Belastungen. Beim unterhaltsberechtigten Elternteil wird dagegen sein gesamtes Einkommen und Vermögen als maßgeblich für

${ }^{435}$ Angaben des Bundesministeriums für Familie und Senioren, Unterhaltsvorschußgesetz, Statistik A und B.

${ }^{436}$ Vgl. Carola Schewe, a.a.O., S. 225.

${ }^{437}$ Vgl. Carola Schewe, a.a.O., S. 225. 
den Unterhalt des Kindes angesehen. Fallen Mutter und Kind einkommensmäBig in die Sozialhilfe, können sogar die Großeltern zur Zahlung von Unterhalt herangezogen werden, während sich der unterhaltsverpflichtete Vater des Kindes auf seinen Selbstbehalt berufen kann. ${ }^{438}$

So sehr es auch zu begrüßen ist, daß die wirtschaftliche Lage der Alleinerziehenden verbessert wird und die Kinder in diesen Familien durch das Unterhaltsvorschußgesetz keine materiellen Nachteile gegenüber Kindern in Kernfamilien erleiden sollen, stellt sich die grundlegende Frage nach den Anreizwirkungen eines solchen Gesetzes, zumal allerorts die rudimentäre Durchführung des Gesetzes bekannt ist. Während die Entscheidung für ein Kind in allen betrachteten Fällen (ledig, geschieden, verheiratet getrennt lebend, verwitwet) eine individuelle im Sinne der Maximierung des privaten Nutzens ist, werden die Kosten dieser Entscheidung in immer stärkerem Maße sozialisiert, also auf die Gesamtgesellschaft abgewälzt. Der alleinerziehende Elternteil wird aufgrund des bestehenden Gesetzes in die Lage versetzt, sein Einkommen nicht mehr für den Unterhalt der Kinder einzusetzen und der Unterhaltsverpflichtete hat nach herrschender Rechtslage gute Gründe anzunehmen, daB er sich seiner Verpflichtung - auch dauerhaft entziehen kann und sein Kind staatlicherseits materiell ebensogut versorgt wird wie mit seiner Unterhaltszahlung. Eine verantwortungsvolle langfristige Planung des Auf- und Erziehens von Kindern seitens der Eltern wird zugunsten einer kurzfristigen Betrachtung aufgegeben, letzteres ist umso wahrscheinlicher, je weniger risikobehaftet diese Verhaltensweise ist. Ein dicht geknüpftes soziales Netz begünstigt das kurzfristige Denken, da sichergestellt wird, daB in jedem Fall die Allgemeinheit die finanziellen Lasten übernimmt. Und so ist auch das Unterhaltsvorschußgesetz auf dem besten Wege ein Unterhaltsentlastungsgesetz zu werden.

Seit dem 1. Oktober 1995 hat der Gesetzgeber im Zuge des neuen Abtreibungsrechts den $§ 1615$ im Bürgerlichen Gesetzbuch (BGB) eigens geändert, um ledige Alleinerziehende besserzustellen. ${ }^{43}$ Danach kann eine ledige Mutter, zusätzlich zu den Unterhaltszahlungen für das Kind, während der ersten drei Lebensjahre einen Unterhaltsanspruch für sich selbst geltend

\footnotetext{
${ }^{438}$ Vgl. Carola Schewe, a.a.O., S. 226.

439 Schwangeren- und Familienhilfeänderungsgesetz.
} 
machen, um in dieser Zeit nicht erwerbstätig zu sein müssen. Nach dem Regierungsentwurf zum Kindschaftsrecht soll sich diese Frist in besonderen Fällen sogar noch verlängern. Bis 1995 konnte eine ledige Mutter vom Vater ihres Kindes zwar auch Unterhalt für sich verlangen, der Anspruch war jedoch maximal bis auf ein Jahr nach der Entbindung begrenzt (BGB § 1615 I). Nach dem Willen des Gesetzgebers sollen die Väter in die Verantwortung einbezogen werden, so daß ein nichteheliches Kind durch seine Mutter betreut werden kann. Flankierend dazu wird diskutiert, das Kindschaftsrecht völlig neu zu regeln, vor allem im Hinblick auf das gemeinsame Sorgerecht. Lange Zeit galt im Regelfall, daß die Mutter das Sorgerecht für ein uneheliches Kind erhält (BGB, § 1705). Ein Vater, der mit der Mutter seines Kindes nicht verheiratet war, hatte kaum Chancen, sein Kind zu sehen, wenn die Mutter ihm dies verwehrte (BGB § 1711). Das neue Gesetz soll nun unverheirateten Vätern ein regelmäßiges Besuchsrecht einräumen, verweigert die Mutter dieses, kann der Vater klagen. Begründet wird diese Entscheidung mit den veränderten gesellschaftlichen Verhältnissen und dem damit verbundenen Anstieg alleinerziehender Mütter. Väter sollen also nicht nur zum Zahlen von Unterhalt degradiert werden, sondern es soll durch regelmäßige Kontakte eine Bindung zwischen Vater und Kind ermöglicht werden, die für die Entwicklung des Kindes wichtig ist und nicht einfach unterbunden werden darf. Der Gesetzgeber argumentiert also in erster Linie mit dem "Wohl des Kindes". Allerdings beugt der Gesetzgeber einer sich in den Anfängen befindenden Entwicklung vor, die gesellschaftlich nicht gewünscht sein kann: Eine Frau, die ein Kind möchte, nicht aber den Mann dazu, wird es in Zukunft schwerer haben, diese Lebenseinstellung zu realisieren.

Abgeschafft werden soll dagegen die sogenannte Unterhaltsabfindung (BGB § 1615e), wonach ein Vater seinem unehelichen Kind eine einmalige Summe zahlen kann und sich damit von seiner Unterhaltspflicht befreit. 


\section{Nichteheliche Lebensgemeinschaften als alternative Form des familialen Zusammenlebens}

Das Phänomen nichtehelicher Lebensgemeinschaften gewann, initiiert unter anderem auch durch die Aufhebung des sogenannten "Kuppelparagraphen", Anfang der siebziger Jahre kontinuierlich an Bedeutung und ist spätestens seit den achtziger Jahren eine Form der Zweierbeziehung, die mit einer allgemeinen gesellschaftlichen Akzeptanz einhergeht. Es handelt sich hierbei "um eine wenigstens auf eine gewisse Dauer angelegte Verbindung eines verschiedengeschlechtlichen Paares, das in einer Wohn- und Wirtschaftsgemeinschaft (Haushalt) in umfassender Lebens- und Geschlechtsgemeinschaft zusammenlebt, ohne daB die Beziehung durch eine EheschlieBung offiziell bestätigt (legitimiert) ist" ${ }^{\prime 40}$.

Zu beobachten sind in der Bundesrepublik Deutschland verschiedene Formen von nichtehelichen Lebensgemeinschaften, die Ausdruck andersartiger Einstellungen und Absichten der jeweiligen Partner sind. Allerdings ist ebenfalls zu beobachten, daB diese nichtehelichen Lebensgemeinschaften häufig in einer Ehe münden, zumal dann, wenn Kinder aus dieser Verbindung erwachsen sollen.

- Es ist momentan festzustellen, daß sich die zahlenmäBig größte Gruppe aus jungen Leuten rekrutiert, die aus dem elterlichen Haushalt ausscheiden, um einen eigenen Haushalt zu gründen. Sie betrachten die Zeit des Zusammenlebens als "Probezeit" ihrer Beziehung, als "Prüfung" vor der Ehe, die wiederum spätestens dann in Erwägung gezogen wird, wenn Kinder geboren werden bzw. deren Geburt geplant wird. Hält die Partnerschaft der Prüfung nicht stand, wird sie in den meisten Fällen relativ problemlos beendet.

- In der Folge zunehmender Trennungs- und Scheidungshäufigkeiten von Partnern gewinnen auBereheliche und damit auch nichteheliche Lebensgemeinschaften an Bedeutung, in denen ein bereits geschiedener Ehepartner eine erneute Ehe scheut oder ein getrennt leben-

\footnotetext{
${ }^{\$ 40}$ M. Wingen, Nichteheliche Lebensgemeinschaften, Formen-Motive-Folgen, Osnabrück 1984, S. 13.
} 
der Ehepartner aus Angst vor dem Verlust zugestandener Unterhaltszahlungen keine legitimierte Beziehung eingehen will.

- Verwitwete Personen, die die Witwen/Witwerrente nicht verlieren wollen, es aber andererseits für erstrebenswert halten, sich einem neuen Lebensgefährten zuzuwenden.

- Personen, die die nichteheliche Lebensgemeinschaft als eigenständige Form des Zusammenlebens betrachten, sie auf Dauer anlegen und auch gemeinsam Kinder aufziehen. Eine Eheschließung wird von diesem Personenkreis nicht in Betracht gezogen, da tradierte Wertvorstellungen hinsichtlich Ehe und Familie, sittliche Werte und religiös motivierte Handlungsnormen von ihm abgelehnt oder doch zumindest sehr kritisch gesehen werden.

\section{Abbildung 6: Formen nichtehelicher Lebensgemeinschaften}

\begin{tabular}{|c|c|c|c|}
\hline $\begin{array}{l}\text { Beziehungsvielfalt im } \\
\text { Zusammenleben } \\
\text { Angestrebte Dauer des } \\
\text { Zusammenlebens }\end{array}$ & $\begin{array}{c}\text { Zweierbeziehung } \\
\text { - Ebene nur einer Ge- } \\
\text { neration - }\end{array}$ & $\begin{array}{l}\text { Paarbeziehung mit } \\
\text { Kind(ern) } \\
\text { - Ebene von zwei Ge- } \\
\text { nerationen - }\end{array}$ & $\begin{array}{c}\text { Paarbeziehung (mit oder } \\
\text { ohne Kind) im Kollektiv } \\
\text { - Ein- oder Mehrgenerati- } \\
\text { onsebene - }\end{array}$ \\
\hline Kurzfristig & $\begin{array}{l}\text { „BafoG-Ehe“ } \\
\text { „Cohabitation“ }\end{array}$ & $\begin{array}{l}\text { „freie Partner- } \\
\text { schaft" }\end{array}$ & in Wohngemeinschaft \\
\hline Mittel- bis langfristig & $\begin{array}{l}\text { „Probe-Ehe“ } \\
\text { „Ehe auf Widerruf“ } \\
\text { „Consensual union“ } \\
\text { „freie Lebensgemein- } \\
\text { schaft“ Geschiedener }\end{array}$ & "Onkelehe" & $\begin{array}{l}\text { "freie Partnerschaft" in } \\
\text { Wohngemeinschaft }\end{array}$ \\
\hline $\begin{array}{l}\text { Auf grundsätzlich } \\
\text { lebenslange Dauer }\end{array}$ & $\begin{array}{l}\text { "Langzeitkonkubi- } \\
\text { nat" } \\
\text { "Rentnerkonkubi- } \\
\text { nat" } \\
\text { "Lebensgefährten- } \\
\text { verhältnis" }\end{array}$ & $\begin{array}{l}\text { "nichteheliche Fa- } \\
\text { milie“ }\end{array}$ & \\
\hline
\end{tabular}

Quelle: Wingen, Nichteheliche Lebensgemeinschaften, a.a.0., S. 67 
Tabelle 49: Bevölkerung in Privathaushalten im Alter von 18 und mehr Jahren nach Zusammenleben mit einem Ehepartner bzw. Partner in Nichtehelicher Lebensgemeinschaft 1)

\begin{tabular}{|c|c|c|c|c|c|c|c|c|c|c|}
\hline \multirow[t]{3}{*}{ Jahr } & \multirow{2}{*}{\multicolumn{2}{|c|}{$\begin{array}{l}\text { Bevölkerung } \\
\text { in Privat- } \\
\text { haushalten } \\
\text { im Alter von } \\
18 \text { und mehr } \\
\text { Jahren ins- } \\
\text { gesamt }\end{array}$}} & \multicolumn{6}{|c|}{$\begin{array}{l}\text { Personen, die mit einem Partner verschiedenen } \\
\text { Geschlechts zusammenleben }\end{array}$} & \multirow{2}{*}{\multicolumn{2}{|c|}{ Sonstige Personen ${ }^{3}$ ) }} \\
\hline & & & \multicolumn{2}{|c|}{$\begin{array}{l}\text { zusam- } \\
\text { men }\end{array}$} & \multicolumn{2}{|c|}{ Ehepartner } & \multicolumn{2}{|c|}{$\begin{array}{l}\text { Partner in Nichtehe- } \\
\text { licher Lebensge- } \\
\text { meinschaft }{ }^{2} \text { ) }\end{array}$} & & \\
\hline & \multicolumn{2}{|c|}{1000} & & $\begin{array}{c}\% \text { von } \\
\text { Sp. } 1\end{array}$ & 1000 & $\begin{array}{c}\% \text { von } \\
\text { Sp. } 1\end{array}$ & 1000 & $\begin{array}{c}\text { \% von } \\
\text { Sp. } 1\end{array}$ & 1000 & $\%$ von Sp. 1 \\
\hline \multicolumn{11}{|c|}{ Früheres Bundesgebiet } \\
\hline 1972 & 44502 & 307 & & 69,0 & 30432 & 68,4 & 273 & 0,6 & 13797 & 31,0 \\
\hline 1982 & 47825 & 311 & & 65,2 & 30129 & 63,0 & 1031 & 2,2 & 16665 & 34,8 \\
\hline 1992 & 52977 & 339 & & 64,2 & 31694 & 59,8 & 2293 & 4,3 & 18990 & 35,8 \\
\hline \multicolumn{11}{|c|}{ Neue Lānder und Berlin-Ost } \\
\hline 1992 & 12161 & 85 & 37 & 70,2 & 7860 & 64,6 & 677 & 5,6 & 3624 & 29,8 \\
\hline \multicolumn{11}{|c|}{ Deutschland } \\
\hline 1992 & 65138 & 425 & & 65,3 & 39554 & 60,7 & 2970 & 4,6 & 22613 & 34,7 \\
\hline
\end{tabular}

1) Ergebnis des Mikrozensus Mai 1992 sowie April 1972 und 1972 für das frühere Bundesgebiet. -

2) Schätzung aus Ergebnissen des Mikrozensus. - Beide Partner 18 Jahre und älter. -

3) Alle übrigen Personen in Privathaushalten im Alter von 18 und mehr Jahren, d.h. Personen, die o h $n$ e Ehepartner bzw. o h n e Partner in Nichtehelicher Lebensgemeinschaft leben. Dazu zählen Alleinlebende, Alleinerziehende; Personen, die in Haushaltsgemeinschaften mit Verwandten sowie auch mit nicht verwandten Personen (x.B. in Wohngemeinschaften, Lebensgemeinschaften mit einem gleichgeschlechtlichen Partner) leben; volljährige ledige Kinder, die mit Eltern(teil) zusammenleben.

Quelle: Wirtschaft und Statistik 7/1994, S. 506.

Es handelt sich also in allen Fällen um eher pluralistische Formen von Beziehungen," die ihrerseits die Individualisierungstendenzen innerhalb der Gesellschaft zum Ausdruck bringen".4+1 Individualisierung und der Anspruch auf Selbstverwirklichung führen jedoch zu einer konfliktären Bezie-

${ }^{411}$ Niemeyer, Frank, Nichteheliche Lebensgemeinschaften und Ehepaare-Formen der Partnerschaft gestern und heute, in: Wirtschaft und Statistik, 7/1994, S. 504. 
hung, da einerseits Übereinstimmungen im Fühlen, Denken und Handeln verlangt werden, andererseits die Partnerschaft beiden Partnern einen größtmöglichen Freiraum gewähren soll. Zweifelsohne ist der Wunsch nach "Freiheit", der Möglichkeit, jederzeit gehen zu können so groß, daß davon abgesehen wird, eine offizielle Bindung einzugehen.

Begünstigt wurden die verschiedenen Formen nichtehelichen Zusammenlebens durch bestimmte Bedingungen wirtschaftlicher, institutioneller und geistiger Art, die in den siebziger Jahren geprägt wurden oder doch zumindest stärker in den Vordergrund rückten ${ }^{42}$. Änderungen des Ehe- und Familienrechts, der Umbruch in der Sexualmoral, ein steigendes Realeinkommensniveau gepaart mit einer Ausweitung öffentlicher Versorgungsleistungen, eine Lockerung religiös-kirchlicher Bindung seien hier beispielhaft genannt.

Insgesamt ist die Bedeutung der nichtehelichen Lebensgemeinschaften mit 4,6\% gemessen an der Gesamtzahl aller Haushalte relativ gering, allerdings ist die steigende Tendenz deutlich zu erkennen. Nichtsdestotrotz ist die dominierende Form der Partnerschaft nach wie vor die Ehe. Dieses resultiert sicherlich auch daraus, daß nichteheliche Lebensgemeinschaften nach der bisherigen verfassungsrechtlichen Sichtweise nicht unter den besonderen Schutz der staatlichen Ordnung fallen und keine weitergehenden Verpflichtungen bei einer Auflösung bestehen.

Kinder sind in nichtehelichen Lebensgemeinschaften am häufigsten in Partnerschaften anzutreffen, in denen der Mann noch ledig ist, die Frau aber bereits verheiratet war. Hier spiegelt sich die zunehmende Zahl von Scheidungen wider, die von Frauen eingereicht werden, die also mit bereits vorhandenen Kindern ihren Ehemann verlassen.

Die nichteheliche Lebensgemeinschaft ist der Ehe rechtlich nicht gleichgestellt, es besteht also kein besonderer Schutz durch das Grundgesetz (Art.6 GG). Die Partner sind weder unterhalts- noch erbberechtigt, steuerlich werden sie behandelt wie Einzelpersonen. Allerdings existieren seit kurzem in der Rechtsprechung (Bundesverfassungsgericht, Bundesgerichtshof)

\footnotetext{
${ }^{442}$ Vgl. Wingen, M., Nichteheliche Lebensgemeinschaften: Formen, Bedingungen und familienpolitische Forderungen, in: Wingen, M., Zur Theorie und Praxis der Familienpolitik, Stuttgart u.a.O. 1994, S. 353.
} 
Entscheidungen, die eine Gleichbehandlung von Ehepartnern und Partnern in nichtehelichen Lebensgemeinschaften verlangen.

Abbildung 7: Nichteheliche Lebensgemeinschaften 1992 *)

Früheres Bundesgebiet

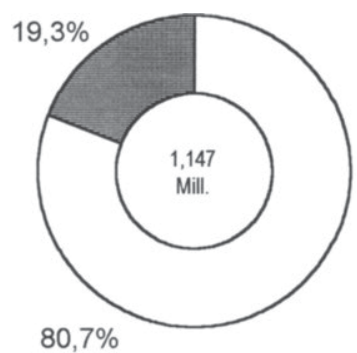

口Ohne Kinder

Mit Kind(ern)
Neue Länder und Berlin - Ost

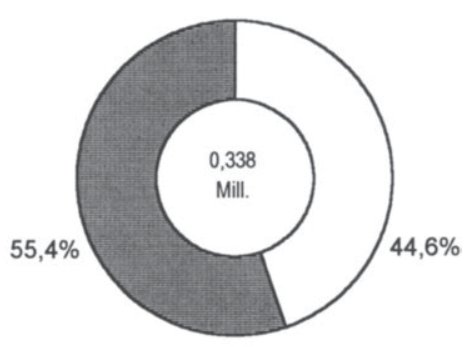

口Ohne Kinder

Mit Kind(ern)

\footnotetext{
•) Schätzung aus Ergebnissen Mikrozensus.
}

Quelle: Statistisches Landesamt, Familien heute, a.a.O., S. 41.

Nichteheliche Lebensgemeinschaften sind in den Altersgruppen der unter 35jährigen besonders häufig vertreten, hier finden sich vorwiegend die oben als erste charakterisierte Gruppe. Es ist zu vermuten, daß der überwiegende Teil dieser Personen seine Beziehung in einer Ehe enden läßt.

In der Diskussion befindet sich die Gleichstellung von unverheirateten Paaren mit Ehepaaren bei der Bestimmung des steuerlichen Existenzminimums. Sollte dieses realisiert werden, würde der Forderung Nachdruck verliehen, Ungereimtheiten im Steuer- und Sozialversicherungsrecht zu beseitigen. So wird vielfach kritisiert, daß die Gerichte, wenn es um Leistungen des Staates respektive der Sozialversicherungsträger geht, eine Gleichstellung der beschriebenen Partnerschaftsform als nicht verfassungswidrig 
ansehen, handelt es sich jedoch um Ansprüche und Begünstigungen, Ehe und nichteheliche Lebensgemeinschaft als Ungleiches behandelt werden. Genannt wird in diesem Zusammenhang häufig die Ungereimtheit den nichtehelichen Partner bei gemeinsamer Haushaltsführung zum teilweisen Unterhalt zu verpflichten -Einkommen des Partners werden bei Zahlung von Arbeitslosenhilfe und Sozialhilfe berücksichtigt- ihm jedoch nicht die steuerlichen Vorteile einer gemeinsamen Haushaltsführung (Ehegattensplitting) zu gewähren. Sicherlich liegt gerade in diesem Fall der Gedanke nahe, den Gesetzgeber gemäB Art. 3 Abs. 1 GG zu verpflichten, Gleiches gleich - augenscheinlich handelt es sich doch um Gleiches- und Ungleiches seiner Eigenart entsprechen ungleich zu behandeln. Angesichts eines natürlicherweise unvollkommenen Vollzuges der gesetzlichen Bestimmungen im Bereich der Sozialleistungen lassen sich ohne große Schwierigkeiten Fälle konstruieren, in denen die Familie mit Kindern über das System sozialer Sicherung schlechtergestellt wird als die nichteheliche Lebensgemeinschaft mit Kindern. Gemäß Art. 6 GG muß zusätzlich die Frage gestellt werden, inwieweit die Gleichstellung der auf Dauerhaftigkeit angelegten Lebensgemeinschaft Familie mit der eher instabilen nichtehelichen Lebensgemeinschaft vor allem im Hinblick auf die Erziehungsleistung (Sozialisation des Kindes) erwünscht und rechtlich zulässig ist?

Die momentan zahlenmäBig geringe Bedeutung nichtehelicher Lebensgemeinschaften sollte jedoch nicht dazu führen, diese Paarbeziehungen familienpolitisch unbeachtet zu lassen, da sie letztendlich Wandlungen gesellschaftlicher und sozialethischer Wertvorstellungen anzeigen und die Möglichkeit eröffnen, "überkommene Ehemodelle auf Elemente hin zu überprüfen, die inzwischen ideologischen Charakter angenommen haben". ${ }^{43}$ Scheinbar gibt es gute Gründe über neue Ehestrukturen nachzudenken und gegebenenfalls an neue Leitvorstellungen des Zusammenlebens anzupassen.

Die vielfältigen Formen des nichtehelichen Zusammenlebens lassen zwar generell keine Vereinheitlichung zu, gleichwohl ist festzustellen, daß die Partner in dieser Lebensform Pluralismus und Subjektivismus als wichtigstes Merkmal zur Entwicklung des Menschen herausheben. Subjektive und private Zielvorstellungen gelangen in den Vordergrund zu Lasten kollektiven

${ }^{443}$ Wingen, Max, Nichteheliche Lebensgemeinschaften, a.a.O., S. 360. 
und religiösen Denken und Handelns. Die scheinbare Befreiung von Zwängen erweist sich jedoch häufig als eine Erhöhung der Anforderungen an den einzelnen im Zusammenleben. ${ }^{\text {t4 }}$ Menschliches Zusammenleben - auch in kleinster Form - bedarf eines institutionellen Rahmens, um den Beteiligten Normen vorzugeben, die eine verhaltenssteuernde Wirkung auf den einzelnen ausüben, dieser wertbesetzte Orndungsrahmen muB jedoch allgemein akzeptiert sein. Nichteheliche Lebensgemeinschaften zeichnen sich jedoch gerade durch ein überzogenes Autonomiestreben des einzelnen aus, dessen individuelle Rationalität im Vordergrund steht. Wenn nun nichteheliche Lebensgemeinschaften als freie Entscheidung des Einzelnen toleriert werden, so sollten sie nicht das MaB sein, an dem sich die Familienpolitik orientiert. $^{445}$

${ }^{4+4}$ Ebenda, S. 358.

4t5 Vgl. Ebenda, S. 359. 
Tabelle 50: Bevölkerung in Privathaushalten im Alter von 18 und mehr Jahren im Mai 1992 nach Altersgruppen und Zusammenleben mit einem Ehepartner bzw. Partner in Nichtehelicher Lebensgemeinschaft

\begin{tabular}{|c|c|c|c|c|c|}
\hline \multirow{2}{*}{$\begin{array}{c}\text { Geschlecht } \\
\text { Alter von... } \\
\text { bis unter ... Jah- } \\
\text { ren }\end{array}$} & \multirow{2}{*}{\begin{tabular}{|l|} 
Bevölkerung \\
in Privat- \\
haushalten \\
im Alter von \\
18 und mehr \\
Jahren ins- \\
gesamt
\end{tabular}} & \multicolumn{3}{|c|}{$\begin{array}{l}\text { Personen, die mit einem Partner ver- } \\
\text { schiedenen Geschlechts zusammenle- } \\
\text { ben }\end{array}$} & \multirow[t]{2}{*}{ Sonstige Personen ${ }^{2}$} \\
\hline & & $\begin{array}{c}\text { zusam- } \\
\text { men }\end{array}$ & $\begin{array}{c}\text { Ehepart- } \\
\text { ner }\end{array}$ & $\begin{array}{c}\text { Partner in } \\
\text { Nichtehelicher } \\
\text { Lebens- } \\
\text { gemeinschaft }^{1} \text { ) }\end{array}$ & \\
\hline & 1000 & \multicolumn{4}{|c|}{$\%$ von Spalte 1} \\
\hline \multicolumn{6}{|c|}{ Frūheres Bundesgebiet } \\
\hline Insgesamt & 52977 & 64,2 & 59,8 & 4,3 & 35,8 \\
\hline Männer & 25273 & 67,2 & 62,7 & 4,5 & 32,8 \\
\hline $18-25$ & 3208 & 11,8 & 6,9 & 4,9 & 88,2 \\
\hline $25-35$ & 5463 & 54,8 & 45,8 & 8,9 & 45,2 \\
\hline $35-55$ & 9142 & 81,2 & 77,3 & 3,9 & 18,8 \\
\hline 55 und mehr & 7460 & 83,1 & 81,1 & 2,0 & 16,9 \\
\hline Frauen & 27704 & 61,3 & 57,2 & 4,1 & 38,7 \\
\hline $18-25$ & 3095 & 26,2 & 17,0 & 9,2 & 73,8 \\
\hline $25-35$ & 5236 & 69,6 & 61,1 & 8,5 & 30,4 \\
\hline $35-55$ & 9022 & 81,7 & 78,6 & 3,1 & 18,3 \\
\hline 55 und mehr & 10352 & 49,9 & 48,6 & 1,3 & 50,1 \\
\hline \multicolumn{6}{|c|}{ Neue Länder und Berlin-Ost } \\
\hline Insgesamt & 12161 & 70,2 & 64,6 & 5,6 & 29,8 \\
\hline Männer & 5690 & 75,0 & 69,1 & 5,9 & 25,0 \\
\hline $18-25$ & 677 & 18,9 & 9,3 & 9,6 & 81,1 \\
\hline $25-35$ & 1200 & 70,3 & 59,5 & 10,8 & 29,7 \\
\hline $35-55$ & 2193 & 86,7 & 81,9 & 4,7 & 13,3 \\
\hline 55 und mehr & 1619 & 86,2 & 83,7 & 2,5 & 13,8 \\
\hline Frauen & 6471 & 66,0 & 60,7 & 5,2 & 34,0 \\
\hline $18-25$ & 637 & 37,4 & 20,7 & 16,7 & 62,6 \\
\hline $25-35$ & 1219 & 81,1 & 71,6 & 9,5 & 18,9 \\
\hline $35-55$ & 2206 & 83,9 & 80,2 & 3,7 & 16,1 \\
\hline 55 und mehr & 2409 & 49,4 & 48,0 & 1,4 & 50,6 \\
\hline
\end{tabular}

1) Schätzung aus Ergebnissen des Mirkozensus. - Beide Partner 18 Jahre und älter. -

2) Alle übrigen Personen in Privathaushalten im Alter von 18 und mehr Jahren, d.h. Personen, die o h n e Ehepartner bzw. o h n e Partner in Nichtehelicher Lebensgemeinschaft leben. Dazu zählen Alleinlebende, Alleinerzichende; Personen, die in Haushaltsgemeinschaften mit Verwandten sowie auch mit nicht verwandten Personen (z.B. in Wohngemeinschaften, Lebensgemeinschaften mit einem gleichgeschlechtlichen Partner) leben; volljährige ledige Kinder, die mit Eltern(teil) zusammenleben. 
Tabelle 51: Ehepaare ") und Nichteheliche Lebensgemeinschaften $^{2)}$ im Mai 1992 nach Alter des weiblichen Partners und Zahl der Kinder

\begin{tabular}{|c|c|c|c|c|c|c|c|c|c|c|}
\hline \multirow{4}{*}{$\begin{array}{l}\text { Alter des weiblichen } \\
\text { Partners } \\
\text { von ... bis unter ... } \\
\text { Jahren }\end{array}$} & \multirow{2}{*}{\multicolumn{3}{|c|}{ Ehepaare }} & \multirow{2}{*}{\multicolumn{3}{|c|}{$\begin{array}{c}\text { Nichteheliche } \\
\text { Lebensgemeinschaf- } \\
\text { ten }\end{array}$}} & \multicolumn{4}{|c|}{ Kinder $^{3)}$ von } \\
\hline & & & & & & & \multicolumn{2}{|c|}{ Ehepaaren } & \multicolumn{2}{|c|}{\begin{tabular}{|c}
$\begin{array}{c}\text { Nichtehelichen } \\
\text { Lebensgemein- } \\
\text { schaften }\end{array}$ \\
\end{tabular}} \\
\hline & $\begin{array}{c}\text { insge- } \\
\text { samt }\end{array}$ & \multicolumn{2}{|c|}{$\underset{3)}{\text { Kind(ern) }}$} & $\begin{array}{l}\text { Insge- } \\
\text { samt }\end{array}$ & \multicolumn{2}{|c|}{$\underset{3)}{\operatorname{Kind}(\mathbf{e r n})}$} & $\begin{array}{l}\text { insge- } \\
\text { samt }\end{array}$ & $\begin{array}{c}\text { je } \\
\text { Ehe- } \\
\text { paar } \\
\text { Insge- } \\
\text { samt }\end{array}$ & $\begin{array}{l}\text { Insge- } \\
\text { samt }\end{array}$ & $\begin{array}{l}\text { je Ge- } \\
\text { mein- } \\
\text { Schaft } \\
\text { insge- } \\
\text { samt }\end{array}$ \\
\hline & 1000 & \multicolumn{2}{|c|}{$\%$ v. Sp. 1} & \multicolumn{3}{|c|}{ \% v. Sp. 4} & 1000 & Anzahl & 1000 & Anzahl \\
\hline & \multicolumn{10}{|c|}{ Früheres Bundesgebiet } \\
\hline 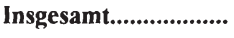 & 15712 & 43,8 & 56,2 & 1147 & 80,7 & 19,3 & 15167 & 0,97 & 321 & 0,28 \\
\hline Unter $25 \ldots . . . . . . . . . . .$. & 528 & 43,5 & 56,5 & 285 & 93,1 & 7,0 & 398 & 0,75 & 23 & 0,08 \\
\hline $25-30$ & 1409 & 29,6 & 70,4 & 296 & 85,3 & 14,7 & 1603 & 1,14 & 60 & 0,20 \\
\hline $30-35 \ldots \ldots \ldots \ldots . . . . . . . . . .$. & 1777 & 16,2 & $\mathbf{8 3 , 8}$ & 149 & 68,6 & 31,4 & 2810 & 1,58 & 70 & 0,47 \\
\hline $35-45$ & 3492 & 15,4 & 84,6 & 168 & 57,6 & 42,4 & 5713 & 1,64 & 113 & 0,67 \\
\hline $45-55$ & 3537 & 40,9 & 59,1 & 112 & 73,4 & 26,6 & 3344 & 0,95 & 41 & 0,37 \\
\hline 55 und mehr ............... & 4969 & 79,9 & 20,1 & 136 & 92,4 & 7,7 & 1299 & 0,26 & 14 & 0,10 \\
\hline & & & Ne u & e L $\mathbf{a}$ & der & u n d & B e r li & $\mathrm{n}-\mathrm{O} \mathbf{s t}$ & & \\
\hline Insgesamt........................ & 3921 & 43,6 & 56,4 & 33,8 & 44,6 & 55,4 & 3624 & 0,92 & 281 & 0,83 \\
\hline Unter $25 . . . . . . . . . . . . . . . . . . .$. & 132 & 26,2 & 73,8 & 10,6 & 56,3 & 43,7 & 122 & 0,93 & 53 & 0,50 \\
\hline $25-30$ & 389 & 9,5 & 90,5 & 73 & 26,7 & 73,3 & 572 & 1,47 & 76 & 1,05 \\
\hline $30-35$ & 483 & 3,9 & 96,1 & 43 & 11,7 & $\mathbf{8 8 , 3}$ & 886 & 1,83 & 67 & 1,57 \\
\hline $35-45 \ldots \ldots \ldots \ldots \ldots$ & 900 & 10,3 & 89,7 & 51 & 22,2 & 77,8 & 1426 & 1,58 & 71 & 1,39 \\
\hline $45-55$ & 864 & 59,3 & 40,7 & 31 & 73,5 & 26,5 & 457 & 0,53 & 12 & 0,39 \\
\hline 55 und mehr................ & 1154 & 88,1 & 11,9 & 35 & 94,0 & 1 & 162 & 0,14 & 1 & 1 \\
\hline
\end{tabular}

" Ergebnis Mikrozensus. - Bevōlkerung am Familienwohnsitz. Ehepartner verheiratet zusammenlebend. - ${ }^{2)}$ Schätzungen aus Ergebnissen des Mikrozensus. - Beide Partner 18 Jahre und älter. - ${ }^{3)}$ Ledige Kinder ohne Altersbegrenzung, die mit Eltern(teil) zusammenleben. - ") Durchschnittliche Kinderzahl bezogen auf alle Ehepaare bzw. Nichteheliche Lebensgemeinschaften (mit und ohne Kinder). 


\section{Die Rechtsstellung geschiedener Mütter in der GRV}

Die rentenversicherungsrechtliche Stellung der geschiedenen Frau und Mutter unterscheidet sich danach, ob die Scheidung nach altem oder nach neuem Recht durchgeführt wurde.

Für alle bis zum 30.6.1977 geschiedenen Ehen gelten die Bestimmungen über die abgeleitete Hinterbliebenenversorgung an frühere Ehegatten ${ }^{446}$.

Seit dem 1.7.1977 gilt das "Erste Gesetz zur Reform des Ehe- und Familienrechts"477, damit wird für alle von diesem Stichtag an geschiedenen Ehen der Versorgungsausgleich durchgeführ $\mathrm{t}^{48}$.

Diese Situation erfordert auch noch gegenwärtig in der Analyse der rentenrechtlichen Bestimmungen eine Trennung nach altem und neuem Recht.

\section{Zur Situation vor dem Scheidungsgesetz vom 1.7.1977}

\subsection{Voraussetzungen für den Bezug einer Rente zu Lebzeiten des ge- schiedenen Ehegatten}

Eine nach altem Recht geschiedene Frau erhält aus der Rentenversicherung ihres früheren Ehemannes keinerlei Leistungen, solange dieser noch lebt. In Ausübung der Normen des bürgerlichen Rechts werden der haushaltsführenden Ehefrau bei ständiger Erfüllung ihrer Ehe- und Familienpflichten auch nach einer vom Mann betriebenen Scheidung Unterhaltsansprüche zugesprochen ${ }^{44}$, diese Versorgungszusage erstreckt sich jedoch nicht auf sozialversicherungsrechtliche Unterhaltsersatzleistungen, auch wenn eine Frau nach der Scheidung wegen der Betreuung und Erziehung ihrer Kinder nicht erwerbstätig sein kann. D.h., die geschiedene Frau kann

\footnotetext{
446 § 42 AVG.

${ }^{447}$ BGBL. I, S. $1421 \mathrm{ff}$.

${ }^{448}$ Dies gilt allerdings nur insoweit, als nicht die Möglichkeiten des Ausschlusses oder der Modifikation des Versorgungsausgleichs in Anspruch genommen wurden. Ansonsten gelten die Vorschriften der $§ § 1587 f$. BGB neue Fassung.

${ }^{449} \S 1569$ BGB.
} 
keinen Anspruch geltend machen, daß ihr früherer Ehemann sich an den Kosten einer freiwilligen Mitgliedschaft in der gesetzlichen Rentenversicherung beteiligt, sie müßte also - will sie das Risiko einer einkommensmäBigen Unterversorgung im Alter aufgrund fehlender oder unzureichender Hinterbliebenenrentenansprüche aus eigener Erwerbstätigkeit abmildern - entsprechende Beiträge in vollem Umfang selbst tragen. Da die finanzielle Lage geschiedener Frauen ohnehin sehr angespannt ist, wird sie in der Regel dazu kaum in der Lage sein. Die geschiedene Frau wird also auf die eigene Erwerbstätigkeit ohne Rücksicht auf die Zumutbarkeit einer solchen oder auf Leistungen aus der Sozialhilfe verwiesen.

\subsection{Die Geschiedenenwitwenrente}

Ansprüche auf abgeleitete Rentenleistungen aus der Versicherung des früheren Ehegatten konnte eine geschiedene Witwe erstmals 1942 aufgrund des national-sozialistischen "2. Leistungsverbesserungsgesetz zur Rentenversicherung" 450 geltend machen. Allerdings wurde diese Witwenrente privatrechtlich an eine bestehende Unterhaltsverpflichtung des verstorbenen Ehemannes gebunden, darüber hinaus galten die novellierten Scheidungsnormen des Ehegesetzes G 1938, wonach neben der Erweiterung des Verschuldensprinzips des BGB eine Ehe auch dann geschieden werden konnte, wenn "objektive" konkret biologisch-rassistische Ehescheidungsgründe vorlagen. Dazu gehörte insbesondere die Verweigerung der Fortpflanzung und die Unfruchtbarkeit der Frau. Die Höhe der Rente bestimmte sich durch den abgeleiteten Prozentsatz der Witwenrente, durfte im weiteren aber den individuellen Unterhaltsanspruch nicht übersteigen, den die Frau zum Zeitpunkt des Todes ihres früheren Ehegatten gegen ihn realisiert hatte. Darüber hinaus unterlag die Gewährung einer Rentenzahlung der Kontrolle des Reichsarbeitsministers, so daß sie faktisch eine Kannleistung war.

Diese Regelung bestand bis zur Rentenreform 1957, die die Möglichkeit eines Bezugs von Geschiedenenwitwenrente eröffnete. Überflüssig wurde die Geschiedenenwitwenrente 1977 mit dem neuen Scheidungsgesetz, daB den

\footnotetext{
${ }^{450}$ § 3 des Zweiten Gesetzes über die Verbesserung der Leistungen in der Rentenversicherung vom 19.6.1942, RGBI.I, S. 407.
} 
Versorgungsausgleich zwischen geschiedenen Ehepartner einführte. Wurde eine Ehe vor dem 1. Juli 1977 geschieden, kommt bei Tod des geschiedenen Ehepartners eine Geschiedenen-Witwen- bzw. eine GeschiedenenWitwerrente in Betracht. ${ }^{451}$ In der Rentenbestandsstatistik des VDR ${ }^{452}$ wurden zum 31.12.1994 in der gesetzlichen Rentenversicherung immerhin noch 36.050 Witwenrenten mit einem durchschnittlichen Rentenzahlbetrag von 975,84 DM gezählt. Davon entfielen auf die Arbeiterrentenversicherung 27.667 Renten, auf die Angestelltenversicherung 5.382 Renten und auf die Knappschaftliche Rentenversicherung 3.001 Renten. Erwartungsgemäß weist die Statistik nur eine äußerst geringe Anzahl von Witwerrenten an frühere Ehegatten aus, insgesamt wurde in der gesetzlichen Rentenversicherung 46 registriert mit einem durchschnittlichen Rentenzahlbetrag von 560,20 DM. 30 Renten entfielen auf die Arbeiterrentenversicherung, 15 auf die Angestelltenversicherung und 1 Rente stammte aus der Knappschaftlichen Rentenversicherung. Obwohl es sich bei dieser Regelung um ein auslaufendes Institut handelt, sollen im folgenden die Grundzüge dieses Gesetzes aufgezeigt werden, zumal sie sich auch im neuen Gesetzeswerk nach der Rentenreform 1992 noch befindet (§ 243 SGB VI).

Gemäß § 1265 RVO, Abs. 1 wurde einer früheren Ehefrau bzw. einem früheren Ehemann eines Versicherten, deren Ehe mit dem Versicherten vor dem 1. Juli 1977 geschieden, für nichtig erklärt oder aufgehoben wurde, nach dem Tode des Versicherten Rente gewährt, wenn ihr der Versicherte zur Zeit seines Todes Unterhalt nach den Vorschriften des Ehegesetzes oder aus sonstigen Gründen zu leisten hatte oder wenn er im letzten Jahr vor seinem Tode Unterhalt geleistet hatte. Mit der Neuregelung der Witwen- und Witwerrenten ab 1.1.1986 wurde das Anrechnungsmodell auch auf die Geschiedenenwitwenrente ausgedehnt, was zu einer Einschränkung der Anspruchsvoraussetzungen führte. Denn war eine Witwe zwar vorhanden, ruhte die Witwenrente wegen der Einkommensanrechnung aber vollständig, dann kamen die weiteren im Gesetz aufgeführten Tatbestände für die Gewährung einer Geschiedenen-Hinterbliebenenrente nicht mehr zur Anwen-

\footnotetext{
${ }^{451}$ Vgl. § 1265 RVO, § 243 SGB VI.

${ }^{452}$ VDR Statistik Rentenbestand am 31. Dezember 1994, Frankfurt, April 1995.
} 
dung. ${ }^{453}$ Gleichzeitig wurde aber gemäß des Auftrags des Bundesverfassungsgerichtes die Gleichstellung von Mann und Frau auch bei den Geschiedenen-Hinterbliebenenrenten realisiert, indem die gleichen Voraussetzungen für den Bezug einer Geschiedenen-Hinterbliebenenrente geschaffen wurde: Starb bzw. stirbt die geschiedene Frau nach dem 31. Dezember 1985, so erhält der Mann eine Geschiedenen-Witwerrente ohne den Nachweis, daB die verstorbene Frau den Unterhalt des Mannes überwiegend bestritten hat. Auch die Möglichkeit, sich für die Anwendung des neuen oder alten Rechts zu entscheiden, galt für Geschiedene. ${ }^{\star 4}$ Eine Entscheidung zugunsten des neuen Rentenrechts bedeutete die Anerkennung des Ansatzes eines Versorgungsausgleichs. Verzichtet ein Ehepartner jedoch dann auf die ihm zustehenden Ansprüche aus dem Versorgungsausgleich könnte sich das später einmal nachteilig auswirken, da die Geschiedenenwitwenrentenregelung für alle nach dem 1. Juli 1977 geschiedenen Frauen/Männer nicht mehr gilt. Eine geschiedene nichterwerbstätige Frau, die zunächst nach der Scheidung durch einen Unterhaltsanspruch gesichert war, aber auf einen Versorgungsausgleich verzichtet hat, steht also nach dem Tod des Mannes im Alter völlig mittellos dar, sofern sie nicht über eigenes Vermögen verfügt oder der Mann ein Vermögen hinterläbt, aus dem ihr Unterhaltsanspruch von seinen Erben weiter gezahlt werden kann.455

Hinsichtlich der Berechnung der Geschiedenen-Hinterbliebenenrente galten und gelten die gleich Vorschriften wie für Witwen- und Witwerrenten, lediglich die Vorschrift über das Sterbevierteljahr findet keine Anwendung, es wird auch in den ersten drei Monaten nach dem Tod des geschiedenen Ehepartners nur $60 \%$ der Rente des Versicherten gezahlt.

Mit der Rentenreform 1992 wurde der alte Paragraph 1265 RVO durch $§ 243$ SGB VI ersetzt und gleichzeitig geringfügig modifiziert. Unklar und etwas verwirrend erscheint der in diesem Paragraphen neu verwendete Begriff der Witwe/des Witwers, da nach allgemeingültigem Sprachgebrauch die Verwitwung nur im Zusammenhang mit einer noch gültigen Ehe möglich ist. Der Gesetzgeber hat außerdem den Paragraphen außerhalb der Rege-

\footnotetext{
${ }^{453}$ Vgl. § 1265 Abs. 1 Satz 3 RVO.

454 Vgl. § 19 Abs. 4 ArVNG.

${ }^{455}$ Vgl. Eva Marie v. Münch, Die Scheidung nach neuem Recht, München 1988, S. 175.
} 
lungen zur sonstigen Hinterbliebenensicherung angesiedelt, so daB daraus geschlossen werden kann, daB es sich bei diesem Sachverhalt eher um eine Sonderregelung als um einen Normalfall handelt. In $₫ 243$ SGB VI heißt es:

"Witwenrente und Witwerrente an vor dem 1. Juli geschiedenen Ehegatten

(1) Anspruch auf kleine Witwenrente oder kleine Witwerrente besteht auch für geschiedene Ehegatten,

1. deren Ehe vor dem 1. Juli 1977 geschieden ist,

2. die nicht wieder geheiratet haben und

3. die im letzten Jahr vor dem Tode des geschiedenen Ehegatten (Versicherten) Unterhalt von diesem erhalten haben oder im letzten wirtschaftlichen Dauerzustand vor dessen Tode einen Anspruch hierauf hatten,

wenn der Versicherte die allgemeine Wartezeit erfüllt hat und nach dem 30. April 1942 gestorben ist.

(2) Anspruch auf große Witwenrente oder große Witwerrente besteht auch für geschiedene Ehegatten,

1. deren Ehe vor dem 1. Juli 1977 geschieden ist,

2. die nicht wieder geheiratet haben und

3. die im letzten Jahr vor dem Tode des Versicherten Unterhalt von diesem erhalten haben oder im letzten wirtschaftlichen Dauerzustand vor dessen Tode einen Anspruch hierauf hatten und

4. die entweder

a) ein eigenes Kind oder ein Kind des Versicherten erziehen (§ 46 Abs. 2),

b) das 45 . Lebensjahr vollendet haben oder

c) berufsunfähig oder erwerbsunfähig sind,

wenn der Versicherte die allgemeine Wartezeit erfüllt hat und nach dem 30. April 1942 gestorben ist.

(3) Anspruch auf große Witwenrente oder groBe Witwerrente besteht auch ohne Vorliegen der in Absatz 2 Nr. 3 genannten Unterhaltsvoraussetzungen für geschiedene Ehegatten, die

1. einen Unterhaltsanspruch nach Absatz 2 Nr. 3 wegen eines Arbeitsentgelts oder Arbeitseinkommens aus eigener Beschäftigung oder selbstän- 
diger Tätigkeit oder entsprechender Ersatzleistungen oder wegen des Gesamteinkommens des Versicherten nicht hatten und

2. im Zeitpunkt der Scheidung entweder

a) ein eigenes Kind oder ein Kind des Versicherten erzogen haben ( $\$ 46$ Abs. 2) oder

b) das 45 . Lebensjahr vollendet hatten und

3. entweder

a) ein eigenes Kind oder ein Kind des Versicherten erziehen ( $\$ 46$ Abs. 2),

b) berufsunfähig oder erwerbsunfähig sind oder

c) das 60 . Lebensjahr vollendet haben,

wenn auch vor Anwendung der Vorschriften über die Einkommensanrechnung auf Renten wegen Todes ein Anspruch auf Hinterbliebenenrente für eine Witwe oder einen Witwer des Versicherten aus dessen Rentenanwartschaften nicht besteht.

(4) Anspruch auf kleine oder große Witwenrente oder Witwerrente nach dem vorletzten Ehegatten besteht unter den sonstigen Voraussetzungen der Absätze 1 bis 3 auch für geschiedene Ehegatten, die wieder geheiratet haben, wenn die erneute Ehe aufgelöst oder für nichtig erklärt ist.

(5) Geschiedene Ehegatten stehen Ehegatten gleich, deren Ehe für nichtig erklärt oder aufgehoben ist."

Im neuen § 243 SGB wird in Absatz 3 ein Anspruch eines früheren Ehemannes auch auf den Fall ausgedehnt, daB er einen Unterhaltsanspruch gegenüber der Versicherten wegen seiner oder deren Einkünfte nicht gehabt hat. Da dies aber nur für Versicherungsfälle nach dem 1.1.1986 gilt, wird es künftig für denselben Sachverhalt zwei unterschiedliche Rentenarten geben, ${ }^{456}$ womit der Intention des Gesetzgebers, das Rentenrecht überschaubarer und klarer zu machen, kaum Rechnung getragen wird. Darüber hinaus verstößt diese Regelung gegen das - sozialpolitisch eher präferierte - Finalprinzip.

Neue Tatbestandsvoraussetzungen, die den Bezug der Rente erschweren würden, sind nicht eingeführt worden. Auch eine Wiederheirat der Ehe-

\footnotetext{
${ }^{456}$ Vgl. K. Wunderlich, Kein Anspruch auf Witwenrente, weil ein Anspruch auf Hinterbliebenenrente für eine Witwe besteht, in: Die Sozialversicherung, 45. Jg., Heft 7, S. 185.
} 
frau bzw. des Ehemannes führt nach wie vor nur dann zum Verlust der Rente, wenn sie noch zu Lebzeiten des Versicherten stattgefunden hat ${ }^{457}$ oder wenn die nach dem Tode des/der Versicherten geschlossene weitere Ehe noch besteht. Es kommt nach neuem Recht auch nicht mehr darauf an, daß zur Zeit der Wiederheirat ein Hinterbliebenenrentenanspruch bestanden haben muß.458 Davon profitieren vor allem Witwen und frühere Ehefrauen, die nach dem Tod des Versicherten vor dem 1.1.1957 wiedergeheiratet haben, die aber die bis zum 31.12.1956 geltenden Anspruchsvoraussetzungen des $§ 1256$ RVO nicht erfüllten. ${ }^{459}$

\section{Zur Situation nach Inkrafttreten des neuen Scheidungsgesetzes}

\subsection{Voraussetzungen für eine Scheidung}

Den größten Einschnitt in das bisherige Scheidungsrecht brachte das erste Eherechtsreformgesetz vom 14.06.1976 mit der Einführung des Zerrüttungsprinzips, daß das bis dahin gültige Verschuldungsprinzip ablöste. Grundgedanke dieser Veränderung war die Überlegung, daß in einer Ehe als kleinste soziologische Gruppierung niemals jeweils nur ein Partner am Scheitern dieser Beziehung "schuld" sein könne, sondern beide Partner i.d.R. durch Agieren und Reagieren auf Konfliktsituationen im Laufe der Zeit zu keinem Grundkonsens mehr gelangen können, was letztlich zu einer "Zerrüttung" der Beziehung führe.

Dieser neue Leitgedanke im Scheidungsrecht läßt die Frage entstehen, unter welchen Voraussetzungen nach neuem Recht eine Ehe geschieden werden kann.

Grundlage ist § 1565 BGB, der wie folgt lautet: "Eine Ehe kann geschieden werden, wenn sie gescheitert ist." Diese für den Gesetzgeber so typische allgemeine Behauptung ist wenig aussagekräftig, so lange nicht geklärt ist, was als "Scheitern" einer Ehe aufgefaßt wird. Auf diese Frage gibt $\S 1565$ BGB folgende Antwort: "Die Ehe ist gescheitert, wenn die Lebensgemeinschaft der Ehegatten nicht mehr besteht und nicht erwartet werden

\footnotetext{
${ }^{457}$ Beschluß des Bundesverfassungsgerichtes vom 8.7.1987, Az 1 BvR 568/87.

${ }^{458}$ Vgl. § 243 Abs. 4 SGB VI.

${ }^{459}$ Vgl. K. Wunderlich, a.a.O., S. 185.
} 
kann, daß die Ehegatten sie wiederherstellen". Der Ehe wird also grundsätzlich keine Zukunft mehr gegeben, das Aus ist somit endgültig.

Es ergibt sich an dieser Stelle zwangsläufig, nach den Kriterien zu fragen, die zwingend das Scheitern erkennen lassen und die zudem prognostischen Wert haben könnten. Denn selbst nach erfolgter Scheidung liegt das definitive Ende oft nicht vor, gibt es doch Paare, die auch nach längerer Trennungsphase wieder zusammenfinden. Das einzig objektive Kriterium für das Ende einer Ehe kann unter diesen Umständen konsequenterweise nur der Tod sein. In jeder anderen Situation handelt es sich um subjektive Kriterien, um Einschätzungen durch die Betroffenen, um Indizien für den Richter. Allein der Konsens der Partner selbst könnte noch Anhaltspunkt dafür sein, daß es sich um einen endgültigen Zusammenbruch der Ehe handelt. Dieser Fall ist, wie die einschlägige Literatur erkennen läBt, äuBerst selten, da die Entscheidung meistens von einem Partner isoliert getroffen wird. Der andere Partner ist in diesem Fall - auch bei objektiv gesehen katastrophaler Beziehung - der Verlassene und wird sich um so mehr gegen diese Trennung wehren, je ungünstiger ihm die Situation nach der Trennung erscheint.

Die Schwierigkeiten und Probleme für die über die Auflösung einer Ehe entscheidenden Richter liegen damit auf der Hand. Entweder sie verlassen sich auf ihr subjektives Gespür bezüglich des Endes einer Ehe, oder es muB ein Kriterienkatalog existieren, an dem dann jeweils gemessen wird, ob sich die Ehe in der Auflösungsphase befindet oder nicht.

Zentraler Bestandteil dieses Kriterienkataloges ist die vom Gesetzgeber geregelte Bestimmung, nach der angenommen werden kann, daB eine Ehe nach einer bestimmten Trennungsfrist gescheitert ist, nach $\S 1566$ BGB "wird unwiderlegbar vermutet, daB die Ehe gescheitert ist, wenn die Ehegatten seit einem Jahr getrennt leben". "Unwiderlegbare Vermutung" heißt in diesem Fall also ganz eindeutig, daß die einjährige Trennungszeit zum maBgeblichen Indiz für die Zerrüttung einer Ehe angesehen wird, so daB der Richter die Ehe auch dann scheiden muB, wenn er subjektiv noch nicht vom Ende dieser Beziehung überzeugt ist. Besteht bei beiden Partnern Übereinstimmung hinsichtlich des Wunsches geschieden zu werden, nimmt der Gesetzgeber an, daß eine Trennungsfrist von einem Jahr angemessen ist. 
Bei fehlender Übereinstimmung fordert das Gesetz eine dreijährige Trennungsfrist mit der Begründung, daß nach dieser Zeit mit einer Wiederherstellung der Ehe nicht mehr zu rechnen ist. Eine Verkürzung dieser dreijährigen Frist kann ein Partner nur dann erwirken, wenn er im einzelnen nachweisen kann, daB seine Ehe gescheitert ist, womit sich der Kreis wieder schließt, denn was heißt "Scheitern", wenn dieser Tatbestand nicht an der Trennungsfrist gemessen wird.

Die Verkürzung der einjährigen Trennungsfrist kann nur unter besonderen Umständen und ausnahmsweise erfolgen. Eine Verlängerung über die dreijährige Trennungsfrist hinaus kann trotz Anerkennung des Scheiterns der Ehe durch Berufung auf die Härteklausel erfolgen, wenn besondere Umstände vorliegen.

Es läßt sich mit Einschränkungen (vgl. Härteklausel) also feststellen, daß folgende Trennungsfristen gelten:

\section{Fall: Die Trennungsfrist ist kürzer als ein Jahr}

Eine Ehe kann bei noch nicht einjähriger Trennung nur dann geschieden werden, „wenn die Fortsetzung der Ehe für den Antragsteller aus Gründen, die in der Person des anderen Ehegatten liegen, eine unzumutbare Härte darstellen würden ${ }^{6460}$.

2. Fall: Die Trennungsfrist ist länger als ein Jahr, aber kürzer als drei Jahre

- Eine einvernehmliche Scheidung ist ohne weiteres möglich. ${ }^{461}$

- Eine Scheidung gegen den Willen eines Ehepartners ist nur dann möglich, wenn detailliert nachgewiesen werden kann, daB die Ehe gescheitert ist. ${ }^{462}$

- Ein Ehepartner kann sich der Scheidung widersetzen, indem er sich auf die Härteklausel beruft. ${ }^{403}$

3. Fall: Die Trennungsfrist überschreitet den Zeitraum von drei Jahren Eine Ehe kann auch gegen den Willen des anderen Ehepartners geschieden werden, der nicht Scheidungswillige kann sich jedoch auf die Härteklausel

\footnotetext{
${ }^{460} \S 1565$ Abs. II BGB.

$461 \S 1566$ Abs. I BGB.

$462 \S 1565$ Abs. II BGB.

$463 \S 1568$ BGB.
} 
berufen, d.h. schwerwiegende Gründe würden auch in diesem Fall nicht zu einer Scheidung führen.

\section{Fall: Die Trennungsfrist ist länger als fünf Jahre}

Die Ehe wird geschieden, auch dann, wenn einzelne Folgesachen noch nicht rechtskräftig geregelt sind (z.B. nacheheliche Unterhaltsansprüche). ${ }^{464}$

Schon an dieser Stelle sei vermerkt, daB die umstrittenste Regelung seit Einführung des neuen Scheidungsgesetzes die Härteklausel ist, so daB sie dann auch in einer am 23. März 1983 konzipierten Koalitionsvereinbarung geändert wurde, um so dem Ziel der Einzelfallgerechtigkeit einen höheren Stellenwert einzuräumen.

Da dem Begriff "Getrenntleben" nach neuem Recht eine besondere Bedeutung zukommt, definiert das BGB in $\S 1567$, was darunter verstanden werden soll: "Die Ehegatten leben getrennt, wenn zwischen ihnen keine häusliche Gemeinschaft besteht und ein Ehegatte sie erkennbar nicht herstellen will, weil er die eheliche Lebensgemeinschaft ablehnt."

Es müssen also deutlich erkennbar zwei Tatbestände zusammenkommen: Der objektive Tatbestand der Auflösung des ehelichen Haushaltes und darüber hinaus der subjektive Tatbestand der Ablehnung der ehelichen Lebensgemeinschaft durch mindestens einen Partner. Liegt nur ein Tatbestand vor, beispielsweise durch einen beruflich bedingten Ortswechsel lebt ein Partner in einer anderen Stadt, kann von "getrennt leben" im Sinne des Gesetzes nicht gesprochen werden.

Während zwingend notwendig beide oben genannten Tatbestände vorliegen müssen, erlaubt § 1567 Abs. I Satz 2 BGB die Trennung der häuslichen Gemeinschaft auch innerhalb der ehelichen Wohnung, wenn eine gemeinsame Haushaltsführung nicht mehr besteht, d.h. die vorhandenen Räume auf die Partner aufgeteilt sind und sich ein Zusammentreffen der Eheleute als ein bloBes Nebeneinandersein ohne persönliche Beziehung darstellt (siehe Urteil Bundesgerichtshof).

Die Schwierigkeit einer solchen Regelung besteht natürlich darin, daB eine vollkommmene Kontrolle der Zusammenlebenssituation nicht erfolgen kann, bzw. aus moralischen Gründen auch nicht erfolgen sollte. Letztlich obliegt

t64 $§ 1568$ Abs. II. BGB. 
also auch hier dem Familienrichter die Entscheidung ob aus objektiver Sicht in der Vergangenheit eine Trennung vorlag. Diffiziler wird diese Situation durch § 1567 Abs. II BGB, der besagt, daß "ein Zusammenleben über kürzere Zeit, das der Versöhnung der Ehegatten dienen soll", die in $\S 1566$ BGB bestimmten Fristen nicht unterbricht oder hemmt. Begründet wird diese Regelung mit dem Hinweis darauf, daß den Ehepartnern, deren Zerwürfnis lediglich kurzfristiger Art ist, die Chance zu einer Versöhnung gegeben wird, ohne die bereits laufenden Trennungsfristen zu berühren und dadurch eine eventuell doch nicht zu verhindernde Scheidung unnötig $\mathrm{zu}$ verzögern. Auch hier wird wieder die Intention des Gesetzgebers sehr deutlich, durch eine vage, allgemeine Formulierung bzw. durch Einfügen eines sehr interpretationsbedürftigen Paragraphen die endgültige Entscheidung über die zu verhandelnden Einzelfälle dem Familienrichter zu überlassen, denn er hat in diesem Fall abermals die Entscheidung zu treffen, was unter dem Gesetzesbegriff "über kürzere Zeit" konkret verstanden werden soll, zumal bislang kein verbindliches Urteil in der Rechtsprechung existiert. Lediglich das OLG Zweibrücken sah ein Zusammenleben von mehr als drei Monaten nicht mehr als "kurz" $\mathrm{an}^{465}$. Findet in dieser Zeit jedoch eine Versöhnung zwischen den Ehepartnern statt, sind sämtliche Trennungsfristen irrelevant geworden.

Das "Getrennt leben" als eindeutiges Bekenntnis zur potentiellen Auflösung der Ehe zieht zusätzliche Rechtsfolgen nach sich, wie z.B. die Aufhebung der Schlüsselgewalt (Jeder Ehepartner hat die Konsequenzen seiner Rechtsgeschäfte ab Trennungszeitpunkt wieder selbst zu tragen), die Klärung der Unterhaltsansprüche, die Hausratverteilung, den Zugewinnausgleich und eine Sorgerechtsregelung für evtl. vorhandene Kinder.

Grundsätzlich beträgt die Trennungsfrist bis zum Vollzug einer Ehescheidung ein Jahr. Kürzere Fristen gestattet der Gesetzgeber nur unter bestimmten Voraussetzungen, wie sie in $\S 1565$ Abs.II BGB zu finden sind. Es heißt dort: "Leben die Ehegatten noch nicht ein Jahr getrennt, so kann die Ehe nur geschieden werden, wenn die Fortsetzung der Ehe für den Antragsteller aus Gründen, die in der Person des anderen Ehegatten liegen, eine unzumutbare Härte darstellen würde". Deutlich erkennbar wird die Loslö-

${ }^{465}$ FamRZ 1981, S. 146. 
sung dieses Grundsatzes von der Dauer der Ehe, sie kann 20 Jahre, aber auch nur 2 Jahre gedauert haben, ausschlaggebend ist allein die Trennungsfrist und darüber hinaus eine individuelle Härtesituation.

Wie wird nun in der Judikatur der Fall der "unzumutbaren Härte" definiert? Eindeutig geht aus den zahlreichen Urteilen zu diesem Tatbestand hervor, daB schwere Eheverfehlungen von Seiten des scheidungsunwilligen Ehepartners vorliegen müssen, um eine Scheidung vor Ablauf der einjährigen Trennungsfrist rechtfertigen zu können. $\mathrm{Zu}$ den Fällen der schweren Eheverfehlungen gehören Schläge, Mordversuche oder der Zwang zu strafbaren Handlungen ebenso wie Drogensüchtigkeit oder eine ansteckende, nicht zu heilende Krankheit.

Auch der Begriff "Fortsetzung der Ehe" ist vom BGH ${ }^{466}$ (FamRZ 1981 S. 127) inzwischen nachhaltig definiert worden. Demnach ist darunter die rechtliche Tatsache des "Weitermiteinander-verheiratetseins" aus formaler Sicht zu verstehen. Eine Auflösung des formalen Ehebandes soll nur dann zumutbar sein, wenn ein "besonderer Härtefall" vorliegt. Dieser muB im Einzelfall besonders erläutert werden. Immerhin ist durch dieses Urteil der Rechtsprechung eine Scheidung während des ersten Trennungsjahres erheblich erschwert.

So wie eine einvernehmliche Scheidung relativ problemlos abgewickelt werden kann - es müssen neben den ausdrücklich erklärten Willen beider Ehepartner sich scheiden zu lassen, die Modalitäten des Unterhalts nach der Scheidung, die Verwendung der gemeinsamen Ehewohnung und des Hausrates sowie das Sorgerecht und die Besuchsregelung für gemeinsame Kinder geklärt werden - kann nach neuem Recht generell eine Ehe auch ohne die explizite Einwilligung des anderen Ehepartners geschieden werden, wenn die gesetzlich vorgeschriebene Trennungsfrist beachtet wird. An dieser Stelle wird der Unterschied zum Schuldprinzip des alten Rechts besonders deutlich: Wehrte sich der "nicht schuldige" Partner gegen eine Scheidung, verblieben dem "Schuldigen" nur die Alternativen einer unter Umständen lebenslangen Ehe mit einem dann ungewollten Ehepartner oder der Nachweis eines nach moralisch-sittlichen Grundsätzen abtrünnigen Lebens des/der Ehemannes/frau.

${ }^{466}$ FamRZ 1981, S. 127. 
Nach neuem Recht kann eine Ehe immer dann geschieden werden, wenn sie gescheitert ist, und dieses Scheitern wird in der Regel an der einjährigen Trennungsfrist gemessen, so daB auch eine nicht einvernehmliche Scheidung nach einem Jahr erfolgen kann. Völlig unerheblich ist in diesem Zusammenhang die Frage nach der Ursache des Scheiterns, denn jeder Ehepartner kann unabhängig von irgendeiner "Schuld" ohne Begründung die Scheidung beantragen. Nur die in besonderen Fällen zum Tragen kommende Härteklausel führt im Einzelfall zu abweichenden Lösungen. Ein Verstoß gegen die strikte Anwendung des Zerrüttungsprinzips hat das Unterhaltsrechtsänderungsgesetz gebracht, indem mit Wirkung vom 1.4.1986 die Möglichkeit geschaffen wurde, eine Ehe formal auch über eine Frist von fünf Jahren aufrechtzuerhalten (nur in besonderen Härtefällen, die natürlich ausdrücklich definiert werden müssen).

Da allem Anschein nach die sogenannte "Härteklausel" in vielen Fällen verantwortlich für Abweichungen vom eigentlichen Grundgedanken des neuen Rechts ist, soll im folgenden näher auf sie eingegangen werden.

Der erst im Jahre 1986 - also fast zehn Jahre nach in Kraft treten des neuen Scheidungsrechts - neu eingeführte $§ 1568$ BGB führt zwei wesentliche Gründe zur Durchbrechung des Zerrüttungsprinzips an. Es soll zum einen "das Interesse der aus der Ehe hervorgegangenen minderjährigen Kinder" gewahrt werden, darüber hinaus sollen "außergewöhnliche Umstände", die für den nicht scheidungswilligen Ehepartner eine "so schwere Härte darstellen, daß die Aufrechterhaltung der Ehe "ausnahmsweise geboten erscheint", berücksichtigt werden.

Zu erwähnen sei in diesem Zusammenhang, daß diese außergewöhnlichen Härten nicht der Ausdruck subjektiven Empfindens sein sollen, sondern Umstände", die nach objektiver Beurteilung außergewöhnlich sind". Neu ist auch, daB nicht nur physische und psychische Härten AnlaB zur Anwendung der Härteklausel sein können, vielmehr können auch wirtschaftliche Härten den Rückgriff auf die Härteklausel rechtfertigen. Da die finanzielle Situation eines geschiedenen Ehepartners durch Unterhaltsansprüche, Zugewinnausgleich und Versorgungsausgleich annähernd gesichert ist, wird die Anwendung des $§ 1565$ BGB auf einige wenige Einzelfälle beschränkt bleiben. 
Erschwerend für den entscheidenden Richter wirkt außerdem die Tatsache, daB der sich gegen die Scheidung wehrende Ehegatte die besondere Härte nachweisen muB ${ }^{467}$ ( $\$ 616$ Abs. III ZPO), denn er muß den Angaben des Scheidungsgegners zufolge zu einer für alle Beteiligten gerechten Entscheidung gelangen.

\subsection{Unterhaltspflichten}

Es sollen zunächst einmal die Unterhaltspflichten zwischen den Ehepartnern und darüber hinaus die Unterhaltsverpflichtungen eines Ehepartners gegenüber vorhandenen Kindern unterschieden werden. Weiterhin ergeben sich unterschiedliche rechtliche Situationen während der laufenden Trennungszeit und nach in Kraft treten eines Scheidungsurteiles.

Gemäß § 1361 BGB ist maßgeblich für den Anspruch auf Unterhaltsleistungen die Bedürftigkeit des einen und die Leistungsfähigkeit des anderen Ehepartners, § 1361 Abs. II BGB legt zwingend fest, daß der bisher nicht erwerbstätige Ehepartner für seinen Unterhalt nur dann selbst sorgen muB, "wenn dies von ihm nach seinen persönlichen Verhältnissen, insbesondere wegen einer früheren Erwerbstätigkeit unter Berücksichtigung der Dauer der Ehe, und nach den wirtschaftlichen Verhältnissen beider Ehepartner erwartet werden kann". Im wesentlichen sind dies die Kriterien, die auch für die Unterhaltszahlungen nach der Scheidung angesetzt werden. Während des Getrenntlebens können auch Kinder aus einer früheren Verbindung einen Unterhaltsanspruch begründen ${ }^{48}$, dies ist nach erfolgter Scheidung nicht mehr möglich. Der unterhaltsberechtigte Ehepartner kann unter bestimmten Voraussetzungen auch an Einkommenssteigerungen des Unterhaltspflichtigen partizipieren, wenn diese mit Sicherheit zu erwarten waren. Außergewöhnliche Einkommenszuwächse bleiben in jedem Fall unberücksichtigt. Zusätzlich zur Unterhaltsleistung ist der unterhaltsverpflichtete Ehegatte gezwungen, für eine angemessene Altersversorgung sowie für eine Versicherung für den Fall der Berufs- und Erwerbsunfähigkeit zu sorgen. Damit wird sichergestellt, daB die Trennungszeit keine Lücke in der

\footnotetext{
${ }^{467} § 616$ Abs. III ZPO.

${ }^{468}$ BGH FamRZ 1979, S. 569 und 571, FamRZ 1981, S. 17.
} 
"sozialen Biografie" des Unterhaltsberechtigten hinterläßt. Die Regelungen bezüglich des Trennungsunterhalts gelten nur für die Zeit der Trennung, erfolgt das Scheidungsurteil, muß auch ein Unterhaltsurteil über die Zeit nach der Scheidung erfolgen. Die Rechtsprechung des BGH besagt eindeutig, daß der Trennungsunterhalt und der nacheheliche Unterhalt nicht identisch sind ${ }^{469}$.

Die Abkehr vom Schuldprinzip im Scheidungsrecht mußte zwangsläufig eine Änderung im Bereich des Unterhaltsrechts nach sich ziehen. Nach alter Regelung konnte die nicht schuldig geschiedene Frau einen zeitlich unbegrenzten Unterhaltsanspruch durchsetzen oder sich gegen die Scheidung wehren, in beiden Fällen bedeutete es aber für sie, lebenslang finanziell gesichert zu sein, so lange die finanzielle Lage des Ehemannes dies zuließ. Konsequenterweise löst das neue Recht die Unterhaltsfrage von der Schuldfrage, da die alte Regelung sich keinesfalls mit dem Zerrüttungsprinzip vereinbaren ließe.

Eine mögliche Unterhaltszahlung an den früheren Ehepartner knüpft an die individuelle Situation der beiden Ehegatten an. Ein geschiedener Ehegatte kann von dem anderen Ehepartner Unterhalt verlangen, wenn - er wegen der Erziehung eines oder mehrerer gemeinsamer Kinder keiner Erwerbstätigkeit nachgehen kann ${ }^{470}$.

- wegen seines Alters die Aufnahme einer Erwerbstätigkeit nicht mehr erwartet werden kann ${ }^{471}$.

-wegen Krankheit oder anderer Gebrechen oder Schwächen seiner körperlichen oder geistigen Kräfte eine Erwerbstätigkeit nicht mehr ausgeübt werden kann ${ }^{472}$.

- er arbeitslos ist und eine "angemessene" Erwerbstätigkeit nicht findet. "Angemessen" ist eine Erwerbstätigkeit, die der Ausbildung, den Fähigkeiten, dem Lebensalter und dem Gesundheitszustand des geschiedenen Ehegatten sowie den ehelichen Lebensverhältnissen entspricht; bei den ehelichen Lebensverhältnissen sind die Dauer der Ehe und die Dauer der Pflege oder

\footnotetext{
${ }^{469}$ BGG FamRZ 1981, S. 242.

${ }^{470}$ Vgl. § 1570 BGB.

${ }^{471}$ Vgl. § 1571 BGB.

${ }^{472}$ Vgl. § 1572 BGB.
} 
Erziehung eines gemeinschaftlichen Kindes zu berücksichtigen"4?3 . Die Zahlungen können nach neuester Rechtsprechung ${ }^{74}$ zeitlich begrenzt sein, so daB nicht auszuschließen ist, daß der bis dahin unterhaltsberechtigte Ehegatte Sozialhilfeempfänger wird.

- er nach der Scheidung eine Erwerbstätigkeit in einer angemessenen beruflichen Position aufnimmt, die Einkünfte aus dieser Tätigkeit nicht die Höhe des vollen Unterhaltes erreichen. In diesem Fall kann der Unterschiedsbetrag zwischen den Einkünften aus der Erwerbstätigkeit und dem vollen Unterhalt vom unterhaltspflichtigen Ehepartner gefordert werden.

Auch dieser Anspruch ist zeitlich begrenzt ${ }^{45}$, wobei die Begrenzung zum Teil an den oben aufgeführten Kriterien Dauer der Ehe, Teilung von Haushaltsführung und Erwerbstätigkeit und Kinderbetreuung anknüpft.

- er eine Ausbildungs-, Fortbildungs- oder Umschulungsmaßnahme absolviert, auch wenn ein angemessener Arbeitsplatz zur Verfügung steht. Dieser Anspruch ist jedoch an folgende Bedingungen geknüpft: Es muß eine Berufsausbildung vor oder während der Ehe abgebrochen oder gar nicht erst aufgenommen worden sein und es sollen ehebedingte Nachteile ausgeglichen werden $^{476}$. Darüber hinaus ist auch dieser Anspruch zeitlich begrenzt, insofern als er für die Zeit besteht, "in der eine solche Ausbildung im allgemeinen abgeschlossen wird"+"?.

- wenn "von ihm aus sonstigen schwerwiegenden Gründen eine Erwerbstätigkeit nicht erwartet werden kann und die Versagung von Unterhalt unter Berücksichtigung der Belange beider Ehegatten grob unbillig wäre"478.

Dieser Paragraph soll sicherstellen, daB eine Ehefrau auch dann Unterhalt beziehen kann, wenn sie zwar nicht unter die oben genannten Bestimmungen fällt, auBergewöhnliche Leistungen und schwerwiegende Belastungen es aber nicht gerechtfertigt erscheinen lassen, sie auf die Sozialhilfe zu verweisen (positive Billigkeitsklausel).

\footnotetext{
${ }^{473}$ Vgl. § 1574 Abs. II BGB.

${ }^{474}$ Vgl. § 1573 Abs. V BGB Unterhaltsrechtsänderungsgesetz vom 1. April 1986.

${ }^{475}$ Vgl. Unterhaltsrechtsänderungsgesetz.

${ }^{476}$ Vgl. § 1575 BGB.

477 Vgl. § 1575 Abs. I BGB.

${ }^{478}$ Vgl. § 1576 BGB.
} 
Eine derartige Regelung knüpft sehr deutlich an die Situation im Einzelfall an, was wiederum bedeutet, daß dem über den Unterhaltsanspruch zu entscheidenden Richter ein nicht unerheblicher Spielraum für Entscheidungen verbleibt.

Der Gesetzgeber erklärt jedoch eindeutig, daß schwerwiegende Gründe nicht allein deswegen berücksichtigt werden dürfen, weil sie zum Scheitern der Ehe geführt haben ${ }^{479}$. Es soll damit also sichergestellt werden, daß das Schuldprinzip nicht "durch die Hintertür" wieder zum Tragen kommt.

Der Gesetzgeber hat es sich nicht nur zur Aufgabe gemacht, die Unterhaltsansprüche zu regeln, sondern er erachtet es als notwendig, auch den AusschluB des Unterhaltsanspruchs gesetzlich zu fixieren. Ein AusschluB ist im wesentlichen bei "grober Unbilligkeit" vorgesehen, wobei definiert werden muß, was der Gesetzgeber darunter versteht ${ }^{430}$.

Im Geset $z^{481}$ werden enumerativ Fälle definiert, die den Tatbestand der "groben Unbilligkeit" darlegen. Dazu gehört

1.) eine kurze Ehedauer ${ }^{482}$,

2.) das Begehen von Straftaten,

3.) das mutwillige Herbeiführen der Bedürftigkeit durch den Berechtigten,

4.) das Hinwegsetzen über schwerwiegende Vermögensinteressen des Partners $^{483}$,

5.) die Verletzung der Unterhaltspflicht, d.h. in diesem Fall die nicht strafbare Vernachlässigung der Haushaltsführung oder der Betreuungspflicht dem gemeinsamen Kind gegenüber,

\footnotetext{
${ }^{479}$ Vgl. § 1576 BGB.

${ }^{480}$ Vgl. § 1579 BGB, es handelt sich hier um die sogenannte "negative Billigkeitsklause".

${ }^{481}$ Vgl. § 1579 BGB.

${ }^{482}$ Eine Ehe ist nach der Rechtsprechung des Bundesgerichtshofes dann als kurz anzusehen, wenn sie 2 Jahre bestand, eine Ehedauer von 3,5 bis 4 Jahre wird als nicht mehr kurz angesehen; eine eindeutig definierte Grenze gibt es allerdings nicht.

${ }^{483}$ Dazu gehört beispielsweise das mutwillige Zerstören der Karriere oder ruinöse Verhaltensweisen zur geschäftlichen Schädigung des Ehepartners.
} 
6.) offensichtliches schwerwiegendes Fehlverhalten ${ }^{\text {es }}$,

7.) ein anderer Grund, der ebenso schwer wiegt, wie in den Nummern 1 bis 6 aufgeführten Gründe ${ }^{485}$.

Die Realisierung von Unterhaltsansprüchen orientiert sich an der Bedürftigkeit: Nur wer für sich selbst nicht sorgen kann, soll demzufolge Unterhalt erhalten. D.h. wer, ohne daB er durch die oben aufgezählten Tatbeständen an der Ausübung einer Erwerbstätigkeit gehindert wird, nicht erwerbstätig ist, kann nicht damit rechnen, von seinem geschiedenen Ehepartner Unterhalt zu bekommen, sondern wird auf die Sozialhilfe verwiesen. Wer die im Gesetz aufgeführten Voraussetzungen für einen Unterhaltsanspruch erfüllt, jedoch trotzdem arbeitet, muß in Kauf nehmen, dieses Einkommen angerechnet zu bekommen, allerdings nur dann, wenn der Unterhaltsverpflichtete nicht oder nicht voll zahlt.

Neben dem Einkommen wird das Vermögen des Unterhaltsberechtigten berücksichtigt. Ist er in der Lage, von den Einkünften seines Vermögens zu leben, kann er keinen Unterhalt beanspruchen. Dies gilt grundsätzlich auch für sämtliche andere Einkünfte, wie z.B. Transferleistungen des Staates.

Der Unterhaltsanspruch eines Berechtigten endet mit dem Tod oder mit der Wiederheirat des Berechtigten, Ansprüche aus der Vergangenheit bleiben jedoch bestehen. ${ }^{486}$ Wird die neue Ehe erneut aufgelöst, so kann der Unterhaltsanspruch gegen den früheren Ehegatten wieder aufleben, sofern der Unterhaltsberechtigte

\footnotetext{
484 Ein offensichtliches schwerwiegendes Fehlverhalten liegt vor, wenn ein Ehepartner grundlos aus einer durchschnittlich verlaufenen Ehe ausbricht und mit einem anderen Partner in einer nichtehelichen Lebensgemeinschaft zusammenlebt (vgl. BGH NJW 1980 S. 1686).Darüber hinaus führt auch ein über längere Zeit bestehendes intimes Verhältnis mit einem Dritten zum Unterhaltsausschluß, selbst wenn beide nicht zusammenleben (vgl. BGH NJW 1981 S.1214).

${ }^{485}$ Vgl. § 1579 Abs. I Ziffer 7 BGB. Hier wird deutlich erkennbar, daß es sich um eine Generalklausel handelt, die die Einzelfallentscheidung letztlich dem Urteilsvermögen des zu entscheidenden Familienrichters überläßt. Die Vermutung,es könne das alte Schuldprinzip wieder eingeführt werden, hat sich bislang mit Blick auf die Rechtsprechung nicht bestätigen können. Bis dato wurden eher objektive Gründe der Zumutbarkeit für die Zahlung von Unterhalt herangezogen. (Vgl. von Münch, E.M., a.a.O., S. 72). ${ }^{486} \S 1586$ BGB.
} 
- ein Kind aus der früheren Ehe zu pflegen oder zu

- erziehen hat, ${ }^{487}$

- wegen seines Alters keiner Erwerbstätigkeit

- nachgehen kann, ${ }^{488}$

- wegen Krankheit oder anderer Gebrechen nicht

- erwerbstätig sein kann, ${ }^{49}$

- sich in einer Ausbildungs-, Fortbildungs- oder

- Umschulungsmaßnahme befindet, ${ }^{40}$

- er noch auf der Suche nach einer angemessenen

- Erwerbstätigkeit ist; ${ }^{491}$

jedoch haftet der Ehegatte der später aufgelösten Ehe vor dem Ehegatten der früher aufgelösten Ehe. ${ }^{492}$

Stirbt der Unterhaltsverpflichtete, geht die Unterhaltspflicht nahezu uneingeschränkt auf den Erben als Nachlaßverbindlichkeit über. ${ }^{493}$

Maßgeblich für die Höhe des zu zahlenden Unterhalts sind nach § 1578 BGB die ehelichen Lebensverhältnisse zum Zeitpunkt der Scheidung ${ }^{494}$, wobei jedoch berücksichtigt werden soll, ob die Einkommensverhältnisse zu diesem Zeitpunkt "das Gesamtbild der ehelichen Lebensverhältnisse" ${ }^{495}$ widerspiegeln oder vorübergehend atypisch sind. Ergebnis dieser Bestimmung ist ein nach den individuellen Gegebenheiten berechneter Unterhalt. Um eine horizontale Gleichbehandlung der Unterhaltsberechtigten annähernd gewährleisten zu können, werden Unterhaltsrichtsätze herangezogen, die sich aus Prozeßurteilen der Vergangenheit und der Gesetzgebung des BGB herauskristallisiert haben. Für den Ehegattenunterhalt gelten dann folgende Regelungen:496

\footnotetext{
${ }^{487} \S 1570$ BGB.

${ }^{488} \S 1571$ BGB.

${ }^{489} \S 1574$ BGB.

490 § 1575 BGB.

${ }^{491} \S 1573$ BGB.

${ }^{492} \S 1586 a$, Absatz 2 BGB.

${ }^{493} \S 1586$ b, Absatz 1 BGB.

${ }^{494}$ Vgl. BGH NJW 1982, S. 1870.

${ }^{495}$ Vgl. BT-Drucks. 7/650, S. 136.

496 Vgl. E.M. von Münch, Die Scheidung nach neuem Recht, 9. Auflage, München 1996, S. $250 \mathrm{f}$.
} 
I. Monatliche Unterhaltsrichtsätze des berechtigten Ehegatten ohne gemeinsame unterhaltsberechtigte Kinder ( $\S 1361,1569,1578,1581$ BGB):

1. gegen einen erwerbstätigen Unterhaltspflichtigen:

a) wenn der Berechtigte kein Einkommen hat:

3/7 des anrechenbaren Erwerbseinkommens zuzüglich $1 / 2$ der anrechenbaren sonstigen Einkünfte des Pflichtigen, nach oben begrenzt durch den vollen Unterhalt, gemessen an den zu berücksichtigenden ehelichen Verhältnissen;

b) wenn der Berechtigte ebenfalls Einkommen hat:

aa) Doppelverdienerehe: 3/7 der Differenz zwischen den anrechenbaren Erwerbseinkommen der Ehegatten, insgesamt begrenzt durch den vollen ehelichen Bedarf; für sonstige anrechenbare Einkünfte gilt der Halbteilungsgrundsatz;

bb) Alleinverdienerehe: Unterschiedsbetrag zwischen dem vollen ehelichen Bedarf und dem anrechenbaren Einkommen des Berechtigten, wobei $1 / 7$ zu kürzen ist; der Unterhaltsanspruch darf jedoch nicht höher sein als bei einer Berechnung nach aa);

c) wenn der Berechtigte erwerbstätig ist, obwohl ihn keine Erwerbsobliegenheit trifft:

gemäß § 1577 II BGB;

2. gegen einen nicht erwerbstätigen Unterhaltspflichtigen (z.B. Rentner):

wie zu 1a, b oder c, jedoch $50 \%$.

II. Monatliche Unterhaltsrichtsätze bei Geltung des alten Scheidungsrechtes:

1. des nach dem Ehegesetz berechtigten Ehegatten ohne gemeinsame unterhaltsberechtigte Kinder:

a) $\$ \S 58,59$ EheG: in der Regel wie I,

b) $\$ 60$ EheG: in der Regel $1 / 2$ des Unterhalts zu I,

c) § 61 EheG: nach Billigkeit bis zu den Sätzen I.

2. Bei Ehegatten, die vor dem 3.10.1990 in der früheren DDR geschieden worden sind, ist das FGB/DDR i.V. mit dem Einigungsvertrag zu berücksichtigen (Art. 234 § 5 EGBGB). 
III. Monatliche Unterhaltsrichtsätze des berechtigten Ehegatten mit von ihm versorgten gemeinsamen unterhaltsberechtigten minderjährigen Kindern:

Wie zu I bzw. II 1, jedoch wird vorab der Kindesunterhalt (Tabellenbetrag ohne Abzug von Kindergeld) vom Nettoeinkommen des Pflichtigen abgezogen.

IV. Monatlicher notwendiger Eigenbedarf (Selbstbehalt) gegenüber dem getrenntlebenden und dem geschiedenen Berechtigten:

1. wenn der Unterhaltspflichtige erwerbstätig ist: $1.500,--D M$

2. wenn der Unterhaltspflichtige nicht erwerbstätig ist: $1.300,--D M$.

Dem geschiedenen Unterhaltspflichtigen ist nach MaBgabe des $§ 1581$ BGB u.U. ein höherer Betrag zu belassen.

V. Monatlicher notwendiger Eigenbedarf (Existenzminimum) des unterhaltsberechtigten Ehegatten einschließlich des trennungsbedingten Mehrbedarfs in der Regel:

1. falls erwerbstätig: $\quad 1.500,--\mathrm{DM}$

2. falls nicht erwerbstätig: $1.300,--D M$.

VI. Monatlicher notwendiger Eigenbedarf (Existensminimum) des Ehegatten, der in einem gemeinsamen Haushalt mit dem Unterhaltspflichtigen lebt

1. falls erwerbstätig: $\quad 1.100,--D M$

2. falls nicht erwerbstätig: $950,--D M$.

Der einmal festgelegte Unterhaltsanspruch kann nach Ablauf von zwei Jahren erneut zur Diskussion gestellt werden, d.h. das Einkommen und Vermögen des Unterhaltverpflichteten muß abermals überprüft werden.

Ist der Unterhaltsberechtigte nicht in der Lage, den vollen Unterhalt an seinen geschiedenen Ehepartner zu leisten, sieht $§ 1581$ BGB eine Reduzie- 
rung des Unterhaltsanspruchs vor, zu zahlen sei nur soviel, wie "mit Rücksicht auf die Bedürfnisse und die Erwerbs- und Vermögensverhältnisse der geschiedenen Ehegatten der Billigkeit entspricht".

Das mit Wirkung vom 1.4.1986 in Kraft getretene Unterhaltsrechtsänderungsgeset $z^{97}$ erlaubt ein Herabsetzen des Unterhaltsanspruchs nach einer gewissen Zeit, womit gewährleistet werden soll, daß ein Unterhaltsverpflichteter teilweise oder ganz von seiner Verpflichtung befreit werden kann, wenn der Unterhaltsberechtigte seinen "angemessenen Lebensbedarf" selbst decken kann. Sämtliche Unterhaltsansprüche können durch AbschluB eines entsprechenden Vertrages ausgeschlossen werden, der jederzeit, also auch während der Scheidung, verfabt werden kann. Voraussetzung ist allerdings, daß der verbleibende Ehepartner finanziell gesichert ist, da ein Unterhaltsverzicht zu Lasten der Sozialhife unwirksam ist, sofern die Bedürftigkeit vorhersehbar ist. Das Unterhaltsrechtsänderungsgesetz gestattet in seinen Übergangsvorschriften eine nachträgliche Revision der Unterhaltsverträge, jedoch nur, wenn diese vor dem 1.4.1986 und nach dem 30. 6. 1977 abgeschlossen wurden.

"Der laufende Unterhalt ist durch Zahlung einer Geldrente zu gewähren"498 und "monatlich im voraus zu entrichten" ${ }^{499}$. Der Unterhaltsberechtigte kann anstelle der monatlichen Rente auch eine Kapitalabfindung verlangen, "wenn ein wichtiger Grund vorliegt und der Verpflichtete dadurch nicht unbillig belastet wird" ${ }^{1500}$. Die Gestaltung des Unterhaltsanspruchs kann je nach den individuellen Gegebenheiten von den Ehegatten geregelt werden, wobei jedoch für die Zahlung einer Kapitalabfindung besondere Gründe vorliegen müssen.

Um die Bedeutung des Unterhalts für die einzelnen Personengruppen ermessen zu können, ist zu ermitteln, welchen Anteil die Unterhaltszahlungen am gesamten Nettoeinkommen haben.

\footnotetext{
${ }^{497}$ Vgl. § 1578 Abs. 1 BGB.

${ }^{498}$ Vgl. $\$ 1585$ Abs. 1 BGB.

${ }^{499}$ Vgl. § 1585 Abs. 1 Satz 2 BGB.

${ }^{500}$ Vgl. § 1585 Abs. 2 BGB.
} 
Tabelle 52: Zusammensetzung des Nettoeinkommens von Alleinerziehenden mit Kindern unter 18 Jahren

\begin{tabular}{|c|c|c|c|c|c|c|}
\hline & $\begin{array}{c}\text { zusammen } \\
\\
\%\end{array}$ & $\begin{array}{c}\text { ledig } \\
\%\end{array}$ & $\begin{array}{c}\text { verheiratet } \\
\text { getrennt } \\
\text { lebend } \\
\%\end{array}$ & $\begin{array}{c}\text { geschieden } \\
\% \\
\%\end{array}$ & $\begin{array}{c}\text { verwitwet } \\
\%\end{array}$ & $\begin{array}{c}\text { Alleinerziehen- } \\
\text { de } \\
\text { Vãter } \\
\\
\%\end{array}$ \\
\hline $\begin{array}{l}\text { Erwerbs- } \\
\text { einkommen }\end{array}$ & 53,9 & 54,2 & 49,8 & 62,6 & 35,6 & 77,7 \\
\hline Unterhalt & 14,6 & 14,7 & 28,1 & 15,4 & - & 4,9 \\
\hline $\begin{array}{l}\text { Rente, Pensi- } \\
\text { on }\end{array}$ & 12,4 & - & - & 1,7 & 60,5 & 6,2 \\
\hline $\begin{array}{l}\text { Arbeitslosen- } \\
\text { geld-,hilfe }\end{array}$ & 5,8 & 12,1 & 5,5 & 5,0 & - & 7,9 \\
\hline Sozialhilfe & 11,5 & 14,9 & 13,9 & 13,5 & - & - \\
\hline $\begin{array}{l}\text { Sonstige Un- } \\
\text { terstütz-ungen }\end{array}$ & 1,3 & - & -- & - & - & - \\
\hline Basis in 1000 & 803 & 157 & 127 & 369 & 150 & 138 \\
\hline
\end{tabular}

Quelle: Mikrozensus 1985, Sonderauswertung des statistischen Bundesamtes

Tabelle 52 zeigt, daß für alle Alleinerziehenden mit Ausnahme der Verwitweten das Erwerbseinkommen die überwiegende Einkommensquelle darstellt. Die Situation der Verwitweten überrascht insofern nicht, als sich der größte Anteil der verwitweten Alleinerziehenden im Alter von 55 Jahren und darüber befindet, so daß neben der Zahlung von Waisenrenten die groBe Witwenrente geleistet wird.

Da die Kinder von Witwen im Regelfall ein höheres Alter haben, besteht für diese Personen die Möglichkeit, neben der Betreuung und Erziehung des Kindes eine zumindest reduzierte Beschäftigung aufzunehmen; dies bestätigt auch Tabelle 53. Mit zunehmendem Alter der Kinder erhöht sich der Anteil derjenigen, die ein Erwerbseinkommen erzielen (von 32,2 \% mit Kindern von 6 bis unter 10 Jahren auf 36,6\% mit Kindern von 15 bis unter 18 Jahren).

Das Erwerbseinkommen ist besonders für alleinerziehende Väter (78 $\%)$ und geschiedene Mütter (63\%) die wichtigste Einkommensquelle. Un- 
terhaltsleistungen spielen bei den alleinerziehenden Vätern nur eine untergeordnete Rolle, dies ist darauf zurückzuführen, daß im Falle der Scheidung die finanzielle Lage der geschiedenen Frau eine Unterhaltszahlung an den geschiedenen Ehemann (der in dieser Situation das Sorgerecht der Kinder hat) nicht zuläBt.

Während von den ledigen und geschiedenen Müttern jeweils $15 \%$ Unterhaltsleistungen als überwiegende Lebensunterhaltsquelle angeben, sind es bei den verheiratet getrennt Lebenden nahezu die doppelte Anzahl (28\%). Hier spiegelt sich die unterschiedliche rechtliche Stellung der Personen während der Trennungszeit und nach in Kraft treten des Scheidungsurteiles wider.

Ledige Mütter leben überproportional häufig (12\%) von Arbeitslosengeld oder -hilfe, diese Anzahl geht einher mit einer überproportionalen Erwerbslosenquote dieses Personenkreises. Sie sind es auch, die in hohem MaBe ihren überwiegenden Lebensunterhalt aus Sozialhilfe bestreiten.

EItern sind verpflichtet, ihren Kindern Unterhalt bis zur wirtschaftlichen Selbständigkeit zu zahlen, ein minderjähriges Kind ist damit in der Regel unterhaltsbedürftig und hat einen gesetzlichen Anspruch auf Sicherung seines gesamten Lebensbedarfes.

Der laufende Unterhalt umfaßt in diesem Sinne die Kosten der Ernährung, Kleidung, des Wohnens, der Pflege und Erziehung, einschließlich angemessener Kosten für eine Krankenversicherung sowie den Kostenaufwand für eine Berufsausbildung. Die Lebensstellung eines Kindes richtet sich darüber hinaus nach der Lebensstellung seiner Eltern, die folglich maBgeblich die Höhe des Unterhaltsanspruchs im Falle der Trennung beeinflubt. 
Tabelle 53: Überwiegender Lebensunterhalt von Alleinerziehenden Müttern mit Kindern unter 18 Jahren nach Altersstufen

\begin{tabular}{|c|c|c|c|c|}
\hline \multirow[b]{2}{*}{ mit Kindern ... } & \multicolumn{4}{|c|}{ Alleinerziehende Mütter } \\
\hline & $\begin{array}{l}\text { ledig } \\
\% \\
\end{array}$ & $\begin{array}{c}\text { verheiratet } \\
\text { getrennt lebend } \\
\%\end{array}$ & $\begin{array}{c}\text { geschieden } \\
\\
\% \\
\end{array}$ & $\begin{array}{c}\text { Verwitwet } \\
\% \\
\end{array}$ \\
\hline \multicolumn{5}{|l|}{ Unter 3 Jahren } \\
\hline - Erwerbseinkommen & 39,4 & 32,6 & 36,1 & - \\
\hline - Rente, Pension & - & - & - & 76,9 \\
\hline - Unterhalt & 19,0 & 30,3 & 30,1 & - \\
\hline - Sozialhilfe & 20,3 & 25,3 & 27,1 & - \\
\hline \multicolumn{5}{|c|}{ von 3 bis unter 6 Jahren } \\
\hline - Erwerbseinkommen & 54,2 & 35,0 & 45,9 & - \\
\hline - Rente, Pension & - & - & - & 70,8 \\
\hline - Unterhalt & 15,0 & 38,8 & 24,1 & - \\
\hline - Sozialhilfe & 16,3 & 22,5 & 23,4 & - \\
\hline \multicolumn{5}{|c|}{$\begin{array}{l}\text { Von } 6 \text { bis unter } 10 \mathrm{Jah} \text { - } \\
\text { ren }\end{array}$} \\
\hline - Erwerbseinkommen & $\mathbf{5 8 , 5}$ & 36,7 & 52,0 & 32,2 \\
\hline - Rente, Pension & - & -- & - & 60,8 \\
\hline - Unterhalt & - & 35,8 & 21,1 & - \\
\hline - Sozialhilfe & - & 17,6 & 18,5 & - \\
\hline \multicolumn{5}{|c|}{$\begin{array}{l}\text { Von } 10 \text { bis unter } 15 \mathrm{Jah} \text { - } \\
\text { ren }\end{array}$} \\
\hline - Erwerbseinkommen & 59,6 & 52,5 & 61,9 & 34,1 \\
\hline - Rente, Pension & - & - & - & 62,3 \\
\hline - Unterhalt & - & 26,1 & 13,7 & - \\
\hline - Sozialhilfe & - & 14,1 & 15,5 & - \\
\hline \multicolumn{5}{|c|}{$\begin{array}{l}\text { von } 15 \text { bis unter } 18 \mathrm{Jah} \text { - } \\
\text { ren }\end{array}$} \\
\hline - Erwerbseinkommen & 82,8 & 61,0 & 70,0 & 36,6 \\
\hline - Rente, Pension & -- & - & - & 60,6 \\
\hline - Unterhalt & - & 25,7 & 11,2 & - \\
\hline - Sozialhilfe & - & -- & 11,0 & - \\
\hline
\end{tabular}

Quelle: Mikrozensus 1985, Sonderauswertung des statistischen Bundesamtes 
Für die Bemessung des Unterhalts an Kinder aus geschiedenen Ehen hat sich aus Gründen der Rechtssicherheit sowie der Gleichbehandlung gleichgelagerte Fälle eine Orientierungshilfe in Form der "Düsseldorfer Tabelle" herausgebildet.

Tabelle 54: Unterhaltsahlungen an Kinder aus geschiedener Ehe - DÜSSELDORFER TABELLE - (Stand 1.7.1998)

\begin{tabular}{|r|r|r|r|r|}
\hline $\begin{array}{r}\text { Nettoein- } \\
\text { kommen: }\end{array}$ & \multicolumn{2}{|c|}{} & \multicolumn{2}{|c|}{} \\
\hline bis 2.400 & unter 6 & Unter 12 & unter 18 & über 18 Jahre \\
\hline $2.400-2.700$ & $349,-$ & $424,-$ & $502,-$ & $580,-$ \\
$2.700-3.100$ & $374,-$ & $454,-$ & $538,-$ & $621,-$ \\
$3.100-3.500$ & $398,-$ & $484,-$ & $573,-$ & $662,-$ \\
$3.500-3.900$ & $423,-$ & $514,-$ & $608,-$ & $702,-$ \\
$3.900-4.300$ & $447,-$ & $543,-$ & $643,-$ & $743,-$ \\
$4.300-4.700$ & $471,-$ & $570,-$ & $677,-$ & $783,-$ \\
$4.700-5.100$ & $496,-$ & $603,-$ & $713,-$ & $824,-$ \\
$5.100-5.800$ & $524,-$ & $636,-$ & $753,-$ & $870,-$ \\
$5.800-6.500$ & $559,-$ & $679,-$ & $804,-$ & $928,-$ \\
$6.500-7.200$ & $594,-$ & $721,-$ & $854,-$ & $986,-$ \\
$7.200-8.000$ & $629,-$ & $764,-$ & $904,-$ & $1.044,-$ \\
& $664,-$ & $806,-$ & $954,-$ & $1.102,-$ \\
\hline
\end{tabular}

Grundlage für die Anwendung dieser Tabelle ist das sogenannt "bereinigte Netto-Einkommen", d.h. vor der Unterhaltsberechnung ist das Einkommen (netto) um solche Beträge zu bereinigen, die dem Unterhaltsverpflichteten nicht für die Deckung seines eigenen Unterhaltsbedarfs und zum Transfer auf die Unterhaltsberechtigten zur Verfügung stehen, z.B. Vorsorgeaufwendungen, Werbungskosten, sowie laufende Verbindlichkeiten, deren Erfüllung der Unterhaltsverpflichtete sich nicht entziehen kann. Die Be- 
rechnung erfolgte unter der Annahme, daß ein Unterhaltspflichtiger im Durchschnitt zwei Kinder zu versorgen hat. Abweichungen der Unterhaltsbeträge in Form von $\mathrm{Zu}$ - oder Abschlägen oder durch Einstufung in niedrigere/höhere Gruppen sind statthaft, wenn die Zahl der Unterhaltsberechtigten steigt/bzw. sinkt. Wird ein Unterhaltspflichtiger aufgrund der Anwendung der betrachteten Unterhaltssätze überdurchschnittlich belastet, so ist gegebenenfalls eine Herabstufung bis in die unterste Tabellengruppe möglich, um die Deckung des notwendigen Mindestbedarfs für alle Beteiligten zu gewährleisten. Ist auch dieses nicht möglich, weil das verfügbare Einkommen des Unterhaltspflichtigen zu gering ist, handelt es sich um einen sogenannten Mangelfall, greift folgendes Verfahren: Vom verfügbaren Einkommen wird der notwendige Eigenbedarf (Selbstbehalt) des Unterhaltspflichtigen abgezogen und danach die noch verbleibende Verteilungsmasse auf die Unterhaltsberechtigten im Verhältnis ihrer jeweiligen Bedarfssätze gleichmäßig verteilt, wobei das Kindergeld in die Verteilungsmasse einzubeziehen ist. Der Selbstbehalt beträgt z.Zt. 1.300,-- DM monatlich, wenn der Unterhaltspflichtige nicht erwerbstätig ist und 1.500,-- DM/Monat bei einem erwerbstätigen Unterhaltspflichtigen. In diesen Beträgen sind 650,-- DM Warmmiete enthalten. Vom notwendigen Eigenbedarf ist der angemessene Eigenbedarf zu unterscheiden, er beträgt mindestens $1.800,--$ DM/Monat, darin eingerechnet ist eine Warmmiete bis 800 ,-- DM, die Selbstbehaltssätze richten sich nach den für den Wohnort des Unterhaltspflichtigen maBgeblichen Verhältnissen. ${ }^{501}$ Ist das unterhaltsberechtigte Kind bereits volljährig, befindet sich aber noch in einer Ausbildung (= Studium), und wohnt nicht mehr bei einem Elternteil, so beträgt der angemessene Gesamtunterhaltsbedarf im Regelfall 1.050,-- DM/Monat. Eventuell zu leistende Beiträge zur Kranken- und Pflegeversicherung sind in den Untehaltsbeträgen nicht enthalten.

501 Vgl. von Münch, Eva Marie, a.a.O., S. 277. 


\subsection{Versorgungsausgleich}

\subsubsection{Grundsatz und Zielsetzung}

Neben der Einführung des Zerrüttungsprinzips ist der Versorgungsausgleich ein weiteres Kernstück des neuen Scheidungsrechts und darüber hinaus ein weiterer Schritt zu einer eigenständigen sozialen Sicherung der Frau. Der Versorgungsausgleich beruht auf dem Grundsatz der Halbierung der von beiden Ehegatten in der Ehezeit erworbenen Versorgungsansprüche. Die Grundidee ist, daB die Arbeitsleistungen der Ehepartner gleichwertige Beiträge zum Familienunterhalt darstellen und damit die Versorgungsanwartschaften das Resultat gemeinsamer gleichwertiger Leistungen sind. ${ }^{502}$ Es soll dabei vollkommen unerheblich sein, ob die Leistung durch eigene Erwerbstätigkeit, Haushaltsführung und Kindererziehung oder durch Vermögen erbracht wurde. Hauptzweck des Versorgungsausgleichs ist es, dem Ehepartner mit den niedrigeren Versorgungsansprüchen durch entsprechenden Ausgleich nach der Scheidung eine eigene Alters- bzw. Invaliditätsversorgung zu verschaffen. Es werden ausgeglichen: Rentenanwartschaften sowie Berufs-, Erwerbs- und Altersrenten aus der GRV, Pensionen, Anrechte auf Leistungen der betrieblichen Altersversorgung, sonstige Renten, z.B. aus berufsständischen Versorgungseinrichtungen, Altersrenten für Landwirte, Renten und Anwartschaften aus der Höherversicherung der GRV sowie Renten oder Rentenanwartschaften aus privaten Versicherungsträgern. ${ }^{503}$

Unter einer Anwartschaft versteht man "eine gesicherte Aussicht, aus der durch Eintritt des Versicherungs- bzw. Versorgungsfalls der Anspruch entsteht. Eine Aussicht ist eine Versorgungsposition, aus der sich nach gewöhnlichem Verlauf der Dinge einmal ein Anspruch entwickelt." ${ }^{504}$

GemäB § 1587 BGB findet ein Versorgungsausgleich statt, wenn von den geschiedenen Ehegatten "in der Ehezeit Anwartschaften oder Aussichten auf eine Versorgung wegen Alters oder Berufs- oder Erwerbsunfähigkeit

${ }^{502}$ Vgl. Gümpel, Udo, Versorgungsausgleich im Scheidungsfall, Frankfurt/Main 1988, S. 13.

${ }^{503}$ Vgl. Gümpel, U., a.a.O., S. 14.

${ }^{504}$ Gümpel, U., a.a.O., S. 15. 
... begründet oder aufrechterhalten worden sind". In der Regel kommt der Versorgungsausgleich der Ehefrau zugute, besonders dann, wenn sie ihre Erwerbstätigkeit zugunsten der Haushaltsführung und der Kindererziehung aufgegeben hat.

Aber auch im Falle der Erwerbstätigkeit profitiert i.d.R. die Frau, da sie im allgemeinen weniger verdient hat und deshalb nur geringere Beiträge zur Rentenversicherung leisten konnte. Der Versorgungsausgleich soll also die Ehepartner für den Zeitraum der Ehe versorgungsmäBig gleich stellen.

Wie fast jede Reform war und ist auch der Versorgungsausgleich umfangreicher Kritik ausgesetzt. Der Haupteinwand gegen dieses Konzept lief darauf hinaus, daß nun eine Vielzahl von Rentenbeziehern Renten unter dem Sozialhilfeniveau erhalten würden, da durch das Splitting, also der Übertragung von Anwartschaften in der GRV, eine früher noch ausreichende Rente unter Umständen erheblich gekürzt würde. Da ein großer Teil der geschiedenen Frauen wieder heiratet, kann dieses Argument entkräftet werden. E.M.v. Münch weist darauf hin ${ }^{505}$, daß dieser Kritikpunkt zwar richtig sei, jedoch die Frage gestellt werden müsse, weshalb denn ausgerechnet die geschiedene Hausfrau zum Sozialhilfeempfänger werden muß - wie es häufig nach altem Recht der Fall war - und nicht beiden eine Aufstockung ihrer Rente durch Sozialhilfe - auch mit den damit verbundenen Empfindungen, ein Almosemempfänger zu sein - zugemutet werden sollte. In hohem Maße inkonsistent ist das Rentenrecht im Falle aufgelöster Ehen: Wird eine Ehe geschieden, erhalten beide Ehepartner hälftig ihre Ansprüche, die durch den Tod eines Partners aufgelöste Ehe führt zu Ansprüchen des verwitweten Ehepartners von $60 \%$ der Versichertenrente des Verstorbenen.

Für v.Münch ist die Tatsache weit schwerwiegender, daB der Versorgungsausgleich auch auf alle schon bestehenden Ehen ausgedehnt wurde, für den Fall, daß sie nach dem 1. Juli 1977, also nach dem neuen Scheidungsgesetz geschieden wurden. Hier wendet sie nicht zu Unrecht ein, daB bei der EheschlieBung diese Paare nicht mit einer diesbezüglichen Gesetzesänderung rechnen konnten und insofern Fälle geschaffen wurden, die mit einem gesunden Rechtsempfinden als ungerecht angesehen werden können, bei-

${ }^{505}$ Vgl. Münch, E.M.v., Die Scheidung nach neuem Recht, München, 6. Auflage 1988, S. $112 \mathrm{ff}$. 
spielsweise der Fall des Ehegatten, der seit Jahren getrennt lebt, wegen des Widerspruchs des Partners nicht geschieden werden konnte und nun seine fällige Rente trotz fehlender gemeinsamer Lebensleistung mit dem Partner teilen muB. Selbst die nach Art. 12 Ziff. 3 EheRG geschaffene Übergangsregelung, nach der die Familienrichter die Möglichkeit haben, den Ausgleichsanspruch zu halbieren, sowie unter bestimmten Voraussetzungen ( 1587c, \$1587h BGB) den Ausschluß des Vesorgungsausgleichs zu erwirken, sieht v.Münch als unzureichend an, bzw. stellt die Frage nach der VerfassungsmäBigkeit einer derartigen Regelung.

Auf eine nach Inkrafttreten des neuen Rechts geschlossene Ehe werden die Regelungen des Versorgungsausgleichs voll angewendet, es besteht jedoch die Möglichkeit, diese Rechtsfolgen durch einen entsprechenden Vertrag auszuschließen, d.h. es besteht für jeden die Möglichkeit, nach Abschätzen der wirtschaftlichen Folgen des Versorgungsausgleichs diesen teilweise oder ganz zu entgehen.

\subsubsection{Ermittlung und Bewertung der auszugleichenden Anwartschaf- ten}

Die gesetzliche Rentenversicherung ist wesentlicher Träger des Versorgungsausgleichs, da die weitaus größte Anzahl der Versicherten diesem Zweig der Sozialvesicherung angehört. Für jeden rentenversicherungspflichtigen Arbeitnehmer wird ein Versicherungskonto geführt, das Ausdruck seines Versicherungslebens ist. Im Zuge von Übertragung von Anteilen von Versorgungsanwartschaften oder schon gezahlter Rententeile werden diese auf dem bereits bestehenden oder noch zu eröffnenden Versicherungskonto gutgeschrieben. Die Übertragung erfolgt mit Hilfe von spezifischen Werteinheiten, die für jede Beitragszahlung gesondert ermittelt werden können. Sie ergeben sich durch Anwendung der Rentenformel auf das erzielte Einkommen. Eine Übertragung findet auch dann statt, wenn der/die Ausgleichspflichtige bereits Rentner/in ist, es erfolgt dann eine effektive Kürzung der Rente.

Wie bereits oben erwähnt, sind für den Versorgungsausgleich die während der Ehe erworbenen Rentenanwartschaften relevant. 
Um den Versorgungsausgleich durchführen zu können, müssen sie ermittelt und bewertet werden. Was der Gesetzgeber unter "Ehezeit" versteht, wird in $§ 1587$ Abs. 2 BGB definiert: Danach gilt als Ehezeit "die Zeit vom Beginn des Monats, in dem die Ehe geschlossen worden ist, bis zum Ende des Monats, der dem Eintritt der Rechtshängigkeit des Scheidungsantrags vorausgeht". Die für diese Zeit festgestellten Anwartschaften werden nun dahingehend überprüft, ob sie "mit Hilfe des Vermögens oder durch Arbeit" ( $\$ 1587$ a Abs. 1 BGB) erworben wurden (§ 1587a BGB nennt enumerativ die wichtigsten Arten von Renten, die bei Durchführung des Versorgungsausgleichs berücksichtigt werden müssen), da nur diese in die Berechnung eingehen. Diese Prüfung erfolgt bei beiden Ehepartner um festzustellen, welcher von beiden der Ausgleichspflichtige bzw. der Ausgleichsberechtigte ist.

Anwartschaften werden ermittelt, indem zum Ende der Ehezeit ein Altersruhegeld fingiert, und darüber hinaus das Verhältnis zwischen den Werteinheiten aus allen Versicherungszeiten und den in der Ehezeit erworbenen Rentenanwartschaften, gebildet wird.

Eine Übertragung dieser Renten im Rahmen des Versorgungsausgleichs ist deshalb äußerst problematisch, weil sie nicht in gleicher Weise dynamisiert sind wie die Renten aus der GRV und der volldynamischen Beamtenversorgung, wobei eine Versorgung als "volldynamisch" angesehen wird, wenn über eine längere Zeit eine vergleichbare Anpassung wie in den oben erwähnten Versorgungssystemen erfolgt. Da die hier betrachteten Rentenleistungen eher privatwirtschaftlichen Charakter haben, wird entweder vom Barwert der Leistung ausgegangen oder respektive vom "Deckungskapital" oder einer "Deckungsrücklage".

\subsection{3. Öffentlich-rechtlicher Versorgungsausgleich}

Dem Grundgedanken des Versorgungsausgleichs folgend soll nach Feststellung und Bewertung aller während der Ehe von den Ehepartnern erworbenen Versorgungsansprüche derjenige Ehegatte, der die höheren Ansprüche erworben hat, demjenigen, der die niedrigeren erworben hat, die 
Hälfte der Ansprüche abgeben. ${ }^{506}$ Zur konkreten Durchführung dieser Handlungsanweisung bietet das Gesetz zwei Wege an: den öffentlichrechtlichen Versorgungsausgleich (Wertausgleich) und den schuldrechtlichen Versorgungsausgleich (siehe Kap. 2.3.4.). In erster Linie sollen möglichst alle Versorgungsrechte mit Hilfe des öffentlich-rechtlichen Wertausgleichs geteilt werden, erst sekundär und nur unter bestimmten Voraussetzungen oder wenn beide Ehegatten es ausdrücklich vereinbart haben, soll der schuldrechtliche Versorgungsausgleich durchgeführt werden.

Im Rahmen des öffentlich-rechtlichen Versorgungsausgleichs werden immer Anwartschaften oder Anrechte in die GRV übertragen oder dort neu begründet, wobei die Art der vom Ausgleichspflichtigen erworbenen Ansprüche die Form des Wertausgleichs determinieren. Hat der Ausgleichspflichtige Anwartschaften in der GRV erworben, erfolgt der Ausgleich durch Übertragung (Splitting), handelt es sich um einen beamtenrechtlichen Versorgungsanspruch, wird in Höhe des auszugleichenden Betrages eine Anwartschaft auf Kosten des beamtenrechtlichen Versorgungskontos in der GRV begründet (Quasi-Splitting). ${ }^{507}$ Sämtliche anderen Versorgungsrechte sollen durch konkrete Geldleistungen an einen Rentenversicherungsträger ausgeglichen werden (Beitragsentrichtung).

Ein Nebeneinander mehrerer Ausgleichsformen ist dabei vom Gesetzgeber durchaus zugelassen worden.

\subsubsection{Splitting}

Da annähernd $90 \%$ der Bevölkerung in der GRV versichert sind, ist der Wertausgleich von Rentenanwartschaften in dieser Versicherung die häufigste Form des Versorgungsausgleichs. Zudem erfolgt in der GRV auch die Begründung von auszugleichenden Beamtenversorgungen.

Jeder Versicherte erwirbt durch Beitragszahlung - egal ob es sich um Pflichtbeiträge oder freiwillige Beiträge handelt - Anteile (= Werteinheiten) an dem im Versorgungsfall zur Verfügung stehenden Beitragsaufkommen, der jeweilige Barwert der Werteinheiten kann mit Hilfe der Rentenformel

\footnotetext{
506 Vgl. § 1587a Abs. I BGB.

${ }^{507}$ Vgl. Münch, E.M.v., a.a.O., S. 147.
} 
errechnet werden. ${ }^{508}$ Im Falle der Scheidung erfolgt nun ein Wertausgleich, d.h. die in der Ehezeit jeweils von beiden Ehepartnern erworbenen Rentenanwartschaften werden ermittelt und in Werteinheiten umgerechnet. Der Ehegatte mit der größeren Anzahl von Werteinheiten muß dann die Hälfte des Differenzbetrages zum Partner an diesen abgeben.

Beispiel:

Ein Ehemann hat während der 10 Jahre dauernden Ehe eine in Werteinheiten umgerechnete Rentenanwartschaft.

\subsubsection{Quasi-Splitting}

Als Quasi-Splitting (§ 1587b Abs. 2 BGB) wird das Begründen von Rentenanwartschaften in der GRV bezeichnet, welches erfolgt, wenn ein oder beide Ehepartner Ansprüche im Rahmen der Beamtenversorgung erworben haben. D.h. bei Eintritt des Versicherungsfalles erhält der Ausgleichsberechtigte neben seiner Pension ein Altersruhegeld aus der GRV im AusmaB der ihm durch den Verrsorgungsausgleich zustehenden Werteinheiten. Mit Hilfe der Umrechnung in Werteinheiten erfolgt über die Anwendung der Rentenformel eine Dynamisierung der Rente.

\subsubsection{Realteilung}

Kann ein Wertausgleich weder durch Übertragung (GRV) noch durch Begründung von Rentenanwartschaften (Beamtenversorgung) herbeigeführt werden, bietet sich neben dem Quasi-Splitting als weitere bargeldlose Ausgleichsform die "Realteilung" an. Realteilung bedeutet, daB ein Anrecht in einem privaten Versorgungsträger z.B. bei Pensionskassen oder privaten Versicherungsunternehmen begründet wird.

Die Möglichkeit der Realteilung wurde geschaffen, um Nachteile des Versorgungsausgleichs zu beseitigen. So konnte es in Einzelfällen zu Zahlungsverpflichtungen kommen, die die Zahlungsfähigkeit des ausgleichspflichtigen Ehepartners überschritt. Darüber hinaus wurde ein Rentenanspruch des Ausgleichsberechtigten nur dann begründet, wenn die fälli-

${ }^{508}$ Vgl. Gümpel, U., a.a.O., S. 74. 
gen Beträge auch tatsächlich eingezahlt wurden, zahlte der ausgleichspflichtige Partner nicht, entstand auch kein eigenständiger Rentenanspruch für den Ausgleichsberechtigten, der wiederum die Aufgabe hatte, den säumigen Schuldner zu mahnen. Das Risiko der Zahlungsunfähigkeit bzw. unwilligkeit lag also jeweils beim ausgleichsberechtigten Ehepartner.

Im Rahmen der Realteilung sollten deshalb nach dem "Gesetz zur Regelung von Härten im Versorgungsausgleich" ${ }^{509}$ Versorgungsanrechte privater Natur beim Versorgungsträger geteilt und jedem Ehegatten jeweils sein Anteil übertragen werden. Dies setzt natürlich voraus, daB die privaten Versorgungsträger ihre Bedingungen entsprechend ändern; der Gesetzgeber erwartet, daB vor allem die Lebensversicherungen die Realteilung privater Versicherungen auf Rentenbasis ermöglichen und weiterhin die Rentendirektversicherungen der betrieblichen Altersversorgung eine entsprechende Gestaltung der Verträge vornehmen werden.

Der Gesetzgeber hat nicht geregelt, wie die Realteilung im einzelnen ausgestaltet sein soll, in der Begründung des Härteregelungsgeset ${ }^{510}$ sind allerdings drei mögliche Lösungen aufgezeigt worden:

1. die private Versicherung der halben Differenzrente für den Berechtigten.

2. aus dem vorhandenen Deckungskapital oder dem Barwert des auszugleichenden Anrechts werden gleich hohe Anrechte für beide Beteiligten gebildet,

3. die Halbierung des Deckungskapitals oder des Barwerts der Differenzrente.

\subsubsection{Verpflichtung zur Beitragszahlung}

Nach $§ 1587 b$ Abs. III BGB besteht neben Splitting und Quasi-Splitting eine weitere Form des Wertausgleichs, die vorgenommen wird, wenn der Ausgleichspflichtige keine Versorgungsanrechte erworben hat. In diesem Fall kann durch Beitragsentrichtung - also durch eine direkte Zahlung an den Sozialversicherungsträger - ein Versorgungsanrecht begründet werden.

\footnotetext{
${ }^{509}$ Vgl. BT-Drucksache 9/2296,11.

${ }^{510}$ Vgl. BT-Drucksache 9/2296,11.
} 
$\mathrm{Zu}$ beachten ist, daß es durchaus möglich ist, sämtliche Formen des Wertausgleichs zu kombinieren. So können beispielsweise Ansprüche aus der gesetzlichen Rentenversicherung übertragen werden und gleichzeitig kann eine Rente durch Beitragsentrichtung begründet werden. Letzteres ist jedoch nur dann zu realisieren, wenn der Ausgleichsberechtigte noch nicht die Voraussetzungen für den Bezug eines Altersruhegeldes aus der gesetzlichen Rentenversicherung erfüllt, denn in der GRV können Beiträge nur im Hinblick auf ein künftig entstehendes Risiko gezahlt werden.

Ist der Ausgleichsberechtigte also bereits Rentenempfänger, kann nur noch auf den schuldrechtlichen Versorgungsausgleich ausgewichen werden.

2.3.3.5. Höchstgrenze, Härteklausel und Auswirkungen des öffentlichrechtlichen Versorgungsausgleichs

Der Gesetzgeber hat, um besondere Härten zu vermeiden, den Versorgungsausgleich in der Form des Splitting oder Quasi-Splitting durch eine Höchstgrenze limitiert, ${ }^{511}$ danach darf ein Ehegatte durch den Wertausgleich keine höheren Anwartschaften erhalten, als er aufgrund eigener Erwerbstätigkeit im günstigsten Fall hätte selbst erwerben können. Zur Erleichterung der richterlichen Entscheidung ist in der Durchführungsverordnung des Versorgungsausgleichs in der GRV Errechnung des Höchstbetrages ein relativ einfaches Verfahren vorgesehen. ${ }^{512}$

Ist der Ausgleichsanspruch höher als der errechnete Höchstbetrag, kann der Restbetrag nur im schuldrechtlichen Versorgungsausgleich ausgeglichen werden.

\footnotetext{
511 Vgl. § 1587 Abs. V BGB.

${ }^{512}$ Vgl. "Rechengrößen zur Durchführung des Versorgungsausgleichs in der gesetzlichen Rentenversicherung vom 1.12.1976, BANZ Nr. 233, Nr. 6, S.
} 
Neben der Höchstbetragsregelung existiert eine Härteklausel ${ }^{513}$, die es dem Familienrichter gestattet, in Sonderfällen auf die Durchführung des ansonsten obligatorischen Wertausgleichs zu verzichten. Ein AusschluB kann vorgenommen werden, "soweit die Inanspruchnahme des Verpflichteten unter Berücksichtigung der beiderseitigen Verhältnisse, insbesondere des beiderseitigen Vermögenserwerbs während der Ehe oder im Zusammenhang mit der Scheidung, grob unbillig wäre". ${ }^{514}$ Die Konkretisierung dieser sehr allgemeinen Regelung obliegt dem jeweiligen Richter und führt damit zu Einzelfallentscheidungen: Eine Frau, die ihrem Mann durch eigene Erwerbstätigkeit eine Berufsausbildung ermöglicht, sollte nicht noch einen Teil ihres Rentenanspruchs abgeben müssen ${ }^{515}$; ein Ehepartner, der während der Ehezeit einen Pensionsanspruch erwirbt, sollte diesen nicht noch mit einem Partner teilen müssen, der als Unternehmer ein Vermögen, aber keine Altersversorgung erworben hat.

Die "grobe Unbilligkeit" ergibt sich - wie die oben genannten Fälle zeigen - im wesentlichen aus den wirtschaftlichen Verhältnissen, es können daneben aber auch Faktoren des persönlichen Bereichs zum AusschluB des Versorgungsausgleichs führen, allerdings "dürfen Umstände nicht allein deshalb berücksichtigt werden, weil sie zum Scheitern der Ehe geführt haben" ${ }^{516}$, d.h. nach Rechtsprechung des Bundesgerichtshofes muß es sich immer um ein besonders schwerwiegendes pflichtwidriges Verhalten handeln, welches sich auf einen längeren Zeitraum erstreckt und zudem auch die Zeit vor der Trennung der Ehepartner einschlieBt. Unter diesen Voraussetzungen kam es zu folgendem Urteil: Einer Frau, die nach langjähriger Ehe die Trennung erwirkte und daraufhin mit einem anderen Mann zusammenlebte, wurde zwar der Anspruch auf Unterhalt abgesprochen, nicht aber die Möglichkeit des Versorgungsausgleichs genommen, denn ihr Fehlverhalten betraf nicht die Zeit vor der Trennung. ${ }^{517}$ In der Begründung wurde darauf hingewiesen, daB die Frau in der langen Zeit der Aufrechterhaltung der Ehe

\footnotetext{
${ }^{513} \mathrm{Vgl}$ § 1587c BGB.

${ }^{514} \S 1587 \mathrm{c}$, Ziffer 1 BGB.

515 Vgl. BT-Drucksache 7/4361, S. 43 sowie OLG Celle, Fam RZ 1979, S. 595, dies gilt natürlich auch im umgekehrten Fall, vgl. dazu BGH Fam RZ 1983, S. 1217.

${ }^{516} \S 1587 \mathrm{c}$, Ziffer 1 BGB.

${ }^{517}$ Vgl. BGH Fam RZ 1983, S. 35.
} 
ihre Aufgaben als Hausfrau und Mutter erfüllt habe, sie somit zur Versorgungsgemeinschaft Ehe einen Beitrag geleistet habe und nicht allein deshalb vom Versorgungsausgleich ausgeschlossen werden könne, weil sie einen neuen Partner habe.

Der Versorgungsausgleich kann desweiteren ausgeschlossen werden, wenn "der Berechtigte in Erwartung der Scheidung oder nach der Scheidung durch Handeln oder Unterlassen bewirkt hat, daB ihm zustehende Anwartschaften oder Aussichten auf eine Versorgung, die nach § 1587 Abs. I auszugleichen wären, nicht entstanden oder entfallen sind" ${ }^{18}$. Wirkt einer der Ehepartner durch sein Verhalten also bewubt daraufhin, seine eigenen Versorgungsansprüche zu reduzieren oder zu eliminieren, um so einen Ausgleichsanspruch gegen den geschiedenen Ehegatten zu erwerben, muß er dieses Verhalten gegen sich gelten lassen. Einen Ausgleichsanspruch verliert beispielsweise derjenige, der im Hinblick auf die bevorstehende Trennung Ansprüche aus der ausgleichspflichtigen gesetzlichen Rentenversicherung in Ansprüche aus einer privaten nicht ausgleichspflichtigen Kapitalversicherung umwandelt.

Derartige Verhaltensweisen müssen immer in bewußtem Zusammenhang mit der Scheidung stehen, nicht jede Vermögensdisposition führt automatisch zu einer Verringerung oder einem Wegfall von Ansprüchen. Zudem darf $\S 1587$ c Ziffer 2 nur dann zur Anwendung kommen, wenn ein Ausgleichsanspruch an sich schon besteht, die Härteklausel ist kein Instrument zur Begründung eines Ausgleichsanspruchs.

Wie schon oben deutlich wurde, gründet sich der Versorgungsausgleich auf der Versorgungsgemeinschaft der Ehegatten, die Pflichtverletzung durch einen oder beide Ehepartner führt konsequenterweise zum Ausschluß des Versorgungsausgleichs. Die Härteklausel wird also auch dann angewendet, wenn "der Berechtigte während der Ehe längere Zeit hindurch seine Pflicht, zum Familienunterhalt beizutragen, gröblich (Hervorhebung durch den Verfasser) verletzt hat"sis.

Die Frage, wann eine grobe Pflichtverletzung vorliegt, wird ebenfalls wieder anhand von Einzelfallurteilen beantwortet. So hat das OLG Celle

\footnotetext{
${ }^{518} \S 1587 \mathrm{c}$, Ziffer 2 BGB.

${ }^{519} \S 1587$ c, Ziffer 2. BGB.
} 
entschieden, daB keine grobe Pflichtverletzung vorliegt, wenn eine Frau nach 28jähriger Ehe 10 Jahre lang jährlich 6 Wochen eine Entziehungskur infolge Alkoholismus durchführen muB. ${ }^{520}$

Hinsichtlich der Haushaltsführung sei noch erwähnt, daß nach neuem Recht diese einer partnerschaftlichen Aufteilung unterliegt und somit einer Ehefrau nicht mehr die alleinige Haushaltsführung obliegt, insbesondere wenn sie durch eigene Erwerbstätigkeit zum Familieneinkommen beiträgt.

Die Auswirkungen des Versorgungsausgleichs auf den Ausgleichsberechtigten einerseits und den Ausgleichspflichtigen andererseits lassen sich folgendermaßen zusammenfassen:

1. Der Wertausgleich durch Übertragung oder Begründung von Rentenanwartschaften führt beim Ausgleichsberechtigten entweder zu einer Erhöhung der zukünftigen Rente oder zum Aufbau einer eigenständigen sozialen Sicherung; beides trägt unmittelbar zur Verbesserung seiner Situation bei und war schließlich Hauptgrund für die Einführung des Versorgungsausgleichs.

2. Der Ausgleichsverpflichtete muB eine Minderung seiner Versorgungsrechte in Kauf nehmen (Wertausgleich durch Splitting, Quasi-Splitting oder Realteilung), oder muß durch erhebliche Geldleistungen Versorgungsanrechte direkt bei einem Sozialversicherungsträger "erkaufen", gerade letzteres führt aber auch häufig zu einer finanziellen Überforderung des Ausgleichsverpflichteten, die ihm i.d.R. - zumindest dann, wenn auch noch Unterhaltszahlungen geleistet werden müssen - eine weitere Familiengründung nicht mehr gestattet.

3. Die verminderten Versorgungsanrechte können durch entsprechende Beitragszahlungen sowohl in der gesetzlichen Rentenversicherung ${ }^{521}$ als auch im Zuge der Bildung von Pensionsanwartschaften der Beamten ${ }^{522}$ wieder ausgeglichen werden, beim Ausgleichsverpflichteten ergeben sich aber die glei-

\footnotetext{
${ }^{520}$ Vgl. OLG Celle, Fam RZ 1981, S. 576.

${ }^{521}$ § 1304a Abs. 6 RVO, § 83a Abs. 6 AVG.

${ }_{522} \$ 58$ Beamtenversorgungsgesetz.
} 
chen Probleme wenn auch in abgeschwächter Form wie schon unter Punkt 2 beschrieben.

4. Erwirbt der Ausgleichsberechtigte neben den Versorgungsanrechten aus dem Wertausgleich keine weiteren Anrechte auf eine Altersversorgung, ist die daraus resultierende Rentenzahlung häufig so gering, daß sie durch weitere Sozialleistungen ergänzt werden muß (Sozialhilfe). Dies ist jedoch genau die Situation, die durch den Aufbau einer eigenständigen sozialen Sicherung vermieden werden soll.

\subsubsection{Die Erziehungsrente}

Das neue Scheidungsrecht hatte nicht nur den Versorgungsausgleich zur Folge, sondern führte für die nach neuem Recht Geschiedenen die Erziehungsrente ein, ${ }^{523}$ die eine Versorung aus der GRV für den Fall vorsieht, daß ein geschiedener Ehepartner nach dem Tod des anderen durch Kindererziehung an einer Erwerbstätigkeit gehindert wird. ${ }^{524}$ Der Bezug dieser Sozialleistungen knüpft jedoch an mehrere Voraussetzungen an:

1. Die Ehe muß nach dem 30.6.1977 geschieden worden sein.

2. Der kindererziehende Partner darf nicht wieder geheiratet haben.

3. Der geschiedene Ehegatte muß verstorben sein.

4. Der kindererziehende Partner muß mindestens ein minderjähriges waisenrentenberechtigtes Kind erziehen, oder ein volljähriges Kind betreuen, das körperlich oder geistig behindert ist.

5. Der überlebende Ehepartner muß vor dem Tod des früheren Ehegatten eine Versicherungszeit von 60 Monaten zurückgelegt haben.

6. Vom kindererziehenden Ehepartner kann eine Erwerbstätigkeit wegen der Kindererziehung nicht erwartet werden.

\footnotetext{
${ }^{523}$ Vgl. § 47, Absatz 1 SGB VI, 42a AVG.

${ }^{524}$ Vgl. Münch, E.M.v., a.a.O., S. 111.
} 
Die vorausgesetzte Versicherungszeit von 60 Monaten kann auch durch im Versorgungsausgleich übertragene Anwartschaftsrechte erworben werden, so daB diese Mindestzeit von fast allen geschiedenen Frauen erfüllt wird. Die genannten Voraussetzungen können natürlich auch von einem Mann nach dem Tod seiner geschiedenen Frau erfüllt werden. Da diese Regelungen der Geschiedenenwitwenrente auf das Wohl des Kindes oder der Kinder abziehen, liegt in der Forderung nach einer Anwartschaft für den Erziehenden in der GRV ein Systemfehler vor.

Geringe Modifikationen in der Ausgestaltung dieser Rente gingen mit der Rentenreform 1992 einher: So besteht ein Anspruch auf Erziehungsrente unabhängig von der Einkommenshöhe. Da es sich in der Systematik des Rentenrechts aber um eine Versichertenrente handelt, kann die Rentenhöhe gegebenenfalls durch Einkommensanrechnung gemindert werden. Außerdem wird nach neuem Recht nicht mehr geprüft, ob eine Beschäftigung oder Erwerbstätigkeit zumutbar ist. Darüber hinaus wird auch keine Unterscheidung sogenannter kleiner und großer Erziehungsrenten mehr vorgenommen. Der Anspruch auf eine Erziehungsrente endet entweder dann, wenn eine der genannten Voraussetzungen wegfällt oder spätestens mit der Vollendung des Lebensjahres, in dem die Regelaltersrente in Anspruch genommen wird. ${ }^{255}$

Insgesamt ist festzustellen, daB die Bedeutung dieser Rentenart eher gering ist, nach der Rentenbestandsstatistik 1994 wurden im ursprünglichen Bundesgebiet 3.105 Renten mit einem durchschnittlichen Betrag der Rente von 1091,05 DM und in den neuen Bundesländern 2.654 Renten mit einem durchschnittlichen Rentenbetrag von 931,14 DM ausgezahlt. Dabei entfielen 3.021 Renten (alte Bundesländer) auf Frauen und lediglich 84 Renten auf Männer. In den neuen Bundesländern einschließlich Ost-Berlins waren 2.509 Frauenrenten und 145 Männerrenten. ${ }^{526}$

\footnotetext{
${ }^{525}$ Schmidt, M., Die Erziehungsrente - eine (leider) fast unbekannte Rente, in: Die Sozialversicherung, 48. Jg. 1993, S. 257.

${ }^{526}$ Verband Deutscher Rentenversicherungsträger, Rentenbestand am 31.12.1994.
} 


\subsubsection{Schuldrechtlicher Versorgungsausgleich}

Im Gegensatz zum öffentlich-rechtlichen Versorgungsausgleich erwirbt der Ausgleichsberechtigte beim schuldrechtlichen Versorgungsausgleich ${ }^{527}$ keine eigenständigen Versorgungsanrechte bei einem Träger der GRV, sondern er bekommt lediglich einen Geldanspruch gegen den geschiedenen ausgleichspflichtigen Ehepartner. Der Unterschied liegt vor allem darin, daß der Wertausgleich von Amts wegen (öffentlich-rechtlich), der schuldrechtliche Versorgungsausgleich indessen nur auf Antrag vom Familiengericht durchgeführt wird ${ }^{528}$.

Der Ausgleichsberechtigte erhält einen schuldrechtlichen Anspruch auf Gewährung einer Ausgleichsrente ${ }^{529}$, der jedoch erst nach Eintritt der Versorgungsberechtigung beider Ehepartner geltend gemacht werden kann. ${ }^{530}$ Da die Zielsetzung des Gesetzgebers war, möglichst viele Versorgungsanwartschaften der Ehegatten im Wertausgleich zu bilden, um dem ausgleichsberechtigten Ehepartner einen vom ausgleichsverpflichteten Ehepartner unabhängigen Anspruch zu garantieren, kommt es nur in folgenden Ausnahmefällen zum schuldrechtlichen Versorgungsausgleich: ${ }^{531}$

a) Wenn die Begründung von Rentenanwartschaften nicht mehr möglich ist, weil der Ausgleichsberechtigte bereits ein bindend festgestelltes Altersruhegeld aus der GRV bezieht (§ 1587b, Abs. III, Ziffer 6c).

b) Wenn die Übertragung oder Begründung von Rentenanwartschaften in der GRV unmöglich ist, weil der Höchstbetrag nach $\S 1587 \mathrm{~b}$, Abs. V BGB bereits überschritten ist. Der Versorgungsausgleich in der GRV unterliegt damit einer Begrenzung auf den Unterschiedsbetrag zwischen den von dem Versicherten in der Ehezeit selbst erworbenen Rentenansprüchen und dem Höchstbetrag.

c) Wenn der Ausgleichsverpflichtete die als Beitragsentrichtung zu leistenden Zahlungen nicht erbracht hat.



${ }_{528}$ Vgl. Gümpel, U., a.a.O., S. 134.

${ }^{529} \S 1587 \mathrm{~g} \mathrm{BGB}$.

${ }^{530}$ Vgl. Gümpel, U., a.a.O., S. 134.

531 Vgl. Gümpel, U., a.a.O., S. 134ff.
} 
d) Wenn in den Ausgleich auch Leistungen der betrieblichen Altersversorgung, die noch nicht unverfallbar waren und deshalb nach § 1587a, Abs. II, Ziffer 3 nicht berücksichtigt werden konnten, einzubeziehen sind.

e) Wenn das Familiengericht nach $\S 1587 \mathrm{~b}$, Abs. IV auf Antrag eines beteiligten Ehepartners eine Regulierung in Form des schuldrechtlichen Versorgungsausgleichs angeordnet hat, weil sich eine Übertragung oder Begründung von Rentenanwartschaften voraussichtlich nicht zugunsten des Ausgleichsberechtigten auswirken würde oder unwirtschaftlich wäre.

f) Wenn die Ehepartner den schuldrechtlichen Versorgungsausgleich nach $\$ 15870$ vereinbart haben.

g) Wenn der Ausgleich "sonstiger Anwartschaften" weder durch Splitting, noch durch Quasi-Splitting noch durch Realteilung oder erweitertes Splitting erfolgen konnte.

Da in vielen Fällen die Entscheidung über den schuldrechtlichen Versorgungsausgleich erst längere Zeit nach der Scheidung erfolgt, hat der Gesetzgeber für den Ausgleichsberechtigten einen Abfindungsanspruch vorgesehen, falls der Ausgleichsverpflichtete dadurch nicht unbillig belastet wird. ${ }^{532}$ Diese Abfindung darf nicht in der Zahlung eines Kapitalbetrages bestehen, der Ausgleichsberechtigte soll lediglich "in die Lage versetzt werden, die Abhängigkeit von der Sicherung des anderen Ehegatten endgültig zu lösen und eine eigenständige Sicherung für den Fall des Alters, der Berufs- und der Erwerbsunfähigkeit aufzubauen oder auszubauen"s33, deshalb kann sie nur in Form der Zahlung von Beiträgen zu einer privaten Versicherung oder zur GRV erfolgen. ${ }^{534}$

Gemeinhin erfolgt jedoch der schuldrechtliche Versorgungsausgleich durch Zahlung einer Geldrente, welche fällig wird, wenn beide Ehepartner Versorgungsempfänger sind. ${ }^{335}$ Gemäß $§ 1587$ i BGB kann der Ausgleichsberechtigte die Abtretung der Rentenansprüche in Höhe der laufenden Aus-

\footnotetext{
${ }^{532}$ Vgl. Münch, E.M.V., a.a.O., S. 168f.

${ }^{533}$ BT-Drucksache 7/650, S. 169.

s4 Vgl. § 1587l, Abs. III BGB.

${ }^{535}$ Vgl. § 1587g, Abs. I BGB.
} 
gleichsrente verlangen, d.h. der abgetretene Betrag wird dann direkt vom Versorgungsträger an den ausgleichsberechtigten Ehepartner ausbezahlt. Der Vergleich zwischen öffentlich-rechtlichem und schuldrechtlichem Versorgungsausgleich zeigt deutliche Unterschiede hinsichtlich des Charakters und des Sicherheitsgrades der Ansprüche, so daß der Berechtigte eine Abtretung nach § 1587i BGB oder eine Abfindung nach § 15871 BGB verlangen sollte. So bleibt der Ausgleichsberechtigte auch nach der Entscheidung über den schuldrechtlichen Versorgungsausgleich ungesichert, wenn bei ihm der Versorgungsfall eintritt, bevor der Ausgleichsverpflichtete die Voraussetzungen für den Bezug der Versorgungsleistung erfüllt. Weiterhin bleibt der Berechtigte ungesichert, wenn der Ausgleichsverpflichtete zuerst stirbt, und eine Hinterbliebenenversorgung nicht vorgesehen ist. ${ }^{536} \mathrm{Zwar}$ ist dies nicht ausdrücklich im Gesetz geregelt, es wird jedoch davon ausgegangen, daß der Rechtsnatur des schuldrechtlichen Versorgungsausgleich als einer Beteiligung des Ausgleichsberechtigten an der Versorgung des Ausgleichspflichtigen am ehesten entsprochen wird, wenn mit dem Tode des Ausgleichspflichtigen auch der Ausgleichsanspruch entfällt. ${ }^{537}$

Der Tod des Ausgleichsberechtigten hat - anders als nach einem öffentlichrechtlichen Versorgungsausgleich - zur Folge, daß die abgetretenen Rentenanteile wieder an den Ausgleichsverpflichteten zurückfallen, er also wieder seine volle Rente bekommt. ${ }^{538} \mathrm{Um}$ die oben beschriebenen Nachteile wenigstens teilweise abzumildern und eventuell entstehenden Versorgungslücken vorzubeugen, besteht seit dem 1.1.1987 die Möglichkeit, den schuldrechtlichen Versorgungsausgleich über den Tod des Ausgleichspflichtigen hinaus zu verlängern, wenn der Verstorbene bis zu seinem Tod unterhaltspflichtig war und der Versorgungsträger darüber hinaus eine solche Versorgung für den/die Hinterbliebene(n) vorsieht. Dies ist dann der Fall, wenn bei Weiterbestehen der Ehe eine Hinterbliebenenrente zu zahlen gewesen wäre. Dieser sogenannte "verlängerte" schuldrechtliche Versorgungsausgleich kann durch vertragliche Abreden der Ehegatten eingeschränkt, allerdings nicht über den vom Gesetzgeber vorgesehenen Umfang. ${ }^{539}$

\footnotetext{
${ }^{536}$ Vgl. § 1587k BGB, § 3a, Abs. I VAHRG.

${ }^{537}$ Vgl. Maier, M., Versorgungsausgleich in der Rentenversicherung.

${ }_{538}$ Vgl. § 1587k, Abs. II BGB.

539 Vgl. § 1587 o BGB.
} 
In Anlehnung an den öffentlich-rechtlichen Versorgungsausgleich gilt auch für den schuldrechtlichen Versorgungsausgleich eine Härteklausel ${ }^{500}$, die einen Anspruch ausschliebt, wenn "der Berechtigte den nach seinen Lebensverhältnissen angemessenen Unterhalt aus seinen Einkünften und seinem Vermögen bestreiten kann und die Gewährung des Versorgungsausgleichs für den Verpflichteten bei Berücksichtigung der beiderseitigen wirtschaftlichen Verhältnisse eine unbillige Härte bedeuten würde" ${ }^{1541}$. Es wird hier also eindeutig und allein auf die wirtschaftlichen Verhältnisse des Ausgleichsberechtigten abgestellt, persönliche Umstände bleiben unberücksichtigt. Dies kann im Einzelfall zu solch skurrilen Ergebnissen führen, daß einem Ehegatten, der seinen Partner schwer mißhandelt, der öffentlich-rechtliche Wertausgleich gestrichen wird, der schuldrechtliche aber bestehen bleibt. ${ }^{542}$

\section{Die Stellung der verwitweten Frau in der gesetzlichen Rentenversicherung}

\section{Die Entwicklung der Witwen-, bzw. Witwerrenten bis zur Ent- scheidung des Bundesverfassungsgerichts 1975}

Ihren gesetzlich fixierten Ursprung hat die Hinterbliebenenversorgung - wozu auch die Versorgung hinterbliebener Waisen gehört - in der sozialen Unfallversicherung von 1884. Von Anfang an sind die Leistungen als Unterhaltsersatzleistungen konzipiert und stützen sich im wesentlichen auf die Grundnorm § 3 des Reichshaftpflichtgesetzes von 1871, in dem es heißt: "War der Getödtete zur Zeit seines Todes vermöge Gesetzes verpflichtet (Anm. des V.: in diesem Fall einer rechtsgültigen Ehe), einem anderen Unterhalt zu leisten, so kann dieser insoweit Ersatz fordern, als ihm infolge des Todesfalles der Unterhalt entzogen worden ist."

Das Unfallversicherungsgesetz von 1884 formte diesen zivilrechtlichen Schadensersatzanspruch in einen sozialrechtlichen Anspruch auf eine typi-

\footnotetext{
$\$_{400}$ Vgl. § $1587 \mathrm{~h} \mathrm{BGB}$.

${ }^{541} \S 1587 \mathrm{~h}$, Ziffer 1 BGB.

542 Vgl. Münch, E.M.v., a.a.O., S. 171.
} 
sierte Witwenrente um, deren Ausgestaltung im wesentlichen bis in neuere Zeiten erhalten blieb. Bemessungsgrundlage der Leistung war der Arbeitsverdienst des Verstorbenen, von dem dann ein bestimmter Prozentsatz als Witwenrente gezahlt wurde. Die Begründung für die sich ergebenden, im Vergleich mit den Versichertenrenten niedrigeren, Hinterbliebenenrenten lag unter dem Aspekt der Unterhaltsersatzfunktion der Leistung im Wegfall des Unterhalts durch den Verstorbenen. $\mathrm{Zu}$ bemerken sei in diesem $\mathrm{Zu}$ sammenhang die Tatsache, daß die Leistung nicht den Bedarf der Hinterbliebenen zu decken vermochte, da der Gesetzgeber unterstellte, daß der Unterhalt in Arbeiterfamilien schon zu Lebzeiten auch von der Frau und sogar teilweise von den vorhandenen Kindern erbracht wurde, so daß ein bedarfsgerechter Ausgleich nicht angestrebt wurde.

Eine Weiterentwicklung des Gedankens der Hinterbliebenenversorgung erfolgte im Gewerbeunfallversicherungsgesetz von 1900 insofern, als nun auch der Witwer einen Rentenanspruch erwerben konnte, jedoch nur, wenn die verstorbene Ehefrau nachweislich den Unterhalt des Ehepaares überwiegend bestritten hatte und der Witwer bedürftig war. Die gesetzliche Rentenversicherung schloB sich dieser Regelung nicht an, sie eröffnete im Invaliden-- und Alterssicherungsgesetz von 1889 der Witwe lediglich einen Beitragserstattungsanspruch, wenn der Verstorbene noch keine eigene Rente bezogen hatte. Die Witwe war also faktisch ungesichert und auf ein Einkommen aus eigener Erwerbstätigkeit angewiesen. Erst 1911 wurde eine Witwenrente als beitragsfinanzierte Versicherungsleistung - allerdings ohne jegliche Beitragsdifferenzierung gegenüber Ledigen - in die Reichsversicherungsordnung (RVO) und das Versicherungsgesetz für Angestellte aufgenommen. Die Beiträge wurden so festgesetzt, daB nach den versicherungsmathematischen Berechnungen die abgeleiteten Hinterbliebenenrenten abgedeckt waren. Die gleiche Beitragsleistung der Ledigen wurde mit Hinweis auf die Heiratswahrscheinlichkeit legitimiert, denn egal, zu welchem Zeitpunkt der Versicherte eine Ehe einging, er erwarb sofort mit Eheschließung den Anspruch auf Hinterbliebenenversorgung.

Besonders bemerkenswert und aus heutiger Sicht äußerst diskriminierend war die ungleiche Behandlung der Witwen in der Arbeiter- und Angestelltenversicherung. In der Arbeiterrentenversicherung erhielt die 
Witwe nur dann eine Rente, wenn sie selbst erwerbsunfähig war, während in der Angestelltenrentenversicherung eine unbedingte Witwenrente gezahlt wurde. Leitbild dieser Regelung war die Unterstellung des Gesetzgebers, daß die Ehefrauen von Angestellten generell nicht erwerbstätig waren, sie eine entsprechende Ausbildung für eine Erwerbstätigkeit nicht hatten, so daB sie sich beliebigen Erwerbsformen nicht so leicht anpassen konnten wie Arbeiterwitwen. Dahingestellt sei, inwiefern Arbeiterinnen eine Ausbildung für ihre Arbeit erwerben konnten, wenn ihre Entscheidung zur Erwerbstätigkeit aus der Not heraus erfolgte, zum Familieneinkommen beitragen zu müssen, da das Einkommen des Mannes in den meisten Fällen nicht ausreichte, um den Bedarf der Familie zu decken.

Zusammenfassend kann an dieser Stelle festgestellt werden, daB damit folgendes Risiko versichert war:

- Der versicherte Ehegatte muBte verstorben,

- der Hinterbliebene erwerbsunfähig und

- der Verstorbene mußte der überwiegende Verdiener gewesen sein.

Zwischen den einzelnen Gruppen der Hinterbliebenen - den Arbeiterwitwen in der Arbeiterrentenversicherung und den Angestellten in der Angestelltenversicherung - fand unter den oben beschriebenen Voraussetzungen kein spezieller UmverteilungsprozeB zwischen den Witwen statt.

Die Arbeiterrentenversicherung mit ihren stark restriktiven Bestimmungen zum Bezug der Hinterbliebenenrente weitete die Versicherungsfälle schrittweise aus, 1927 führte sie die Witwenrente wegen vorgerückten Alters ein, damit war die Arbeiterwitwe wenigstens im fortgeschrittenen Alter vom Zwang zur Erwerbstätigkeit befreit, und ab 1937 konnte eine Witwenrente auch wegen der Erziehung von Kindern bezogen werden. Hier findet sich erstmals ein Element der Berücksichtigung von Kindererziehungszeiten im Rentenrecht. 
Das Sozialversicherungsanpassungsgesetz von 1949 schließlich vereinheitlichte die Witwenrentenregelung ${ }^{543}$, weiterhin galt jedoch das familienpolitische Leitbild, daß der Mann der Haupternährer der Familie sein sollte. In der Konsequenz institutionalisierte diese neue Regelung eine neue Ungleichbehandlung unter den hinterbliebenen Frauen, es galt nicht mehr die Trennung zwischen Arbeiter- und Angestelltenwitwen, wohl aber zwischen Arbeiterwitwen, deren Ehemann bereits vor dem 1.6.1949 verstorben war und allen anderen hinterbliebenen Frauen ${ }^{544}$. So blieben weiterhin eine große Anzahl von Witwen vom Rentenbezug und damit von rechtlicher und sozialer Gleichstellung ausgeschlossen ${ }^{545}$. Diese Situation blieb auch in den ersten beiden Legislaturperioden des Bundestages bestehen, obwohl "die gesellschafts- und sozialpolitische Relevanz der Regelung von keiner Seite in Frage gestellt" ${ }^{156}$ wurde.

Angesichts einer Zahl von etwa $\mathbf{4 0 0 . 0 0 0}$ Witwen, die von der Invalidenversicherung vom Bezug einer Witwenrente ausgeschlossen waren, wäre bei einer Gesamtzahl von rd. 1,62 Mio anspruchsberechtigten Witwen das Volumen der zu zahlenden Witwenrenten um $25 \%$ gestiegen $^{547}$. Daher gab es natürlich erhebliche Differenzen innerhalb und zwischen den beteiligten Fraktionen bis ein den untragbaren Zustand beseitigendes Gesetz am 6. Oktober 1955 im Bundesgesetzblatt erschien ${ }^{548}$. Durch Herabsetzen der Altersgrenze waren weitere Frauen anspruchsberechtigt geworden, eine vollständige Gleichbehandlung aller Witwen war damit aber noch nicht erreicht.

\footnotetext{
543 § 3 Abs. 1 SVAG: "Die Witwenrente wird einheitlich nach dem Tode des versicherten Ehemannes gewährt. Die bisherigen einschränkenden Vorschriften des $\S 1256$ Abs. 1 bis 3 und 5 der Reichsversicherungsordnung sind nicht mehr anzuwenden".

${ }_{544}$ Vgl. $§ 21$ Abs. 4 (= $§ 21$ Abs. 5 i.d.F. vom 10.8.1949) Sozialversicherungsanpassungsgesetz: "Der $\S 3$ Abs. 1 gilt nur für Todesfälle, die nach dem 31. Mai 1949 eingetreten sind. Für Ehefrauen von Versicherten, die vor dem 1. Juni 1949 Witwen geworden sind, gilt diese Einschränkung nicht, sobald sie das 60 . Lebensjahr vollendet haben".

${ }^{545}$ Vgl. Hermann, Christopher, Gleichstellung der Frau und Rentenrecht, Sozialpolitische Schriften Heft 51, Berlin 1984, S. 61.

${ }^{546}$ Vgl. Hermann, Christopfer, Gleichstellung der Frau und Rentenrecht, a.a.O., S. 62.

547 Vgl. die Aussage des Abg. Schüttler (CDU/CSU) bei der 1. Beratung der Änderungsvorlagen zum SVAG: 2. Wp., Stenogr. Ber. der 83. Sitzung (26.5.1955; Bd. 24), S. 4568.

${ }^{5+8}$ Vgl. BGBL I, S. 653.
} 
Der durch die Novellierung neu anspruchsberechtigte Kreis von Frauen sollte aber fast unmittelbar nach Gesetzesverkündung durch einen Änderungsentwurf der Koalitionsparteien ${ }^{549}$ wieder eingeengt werden.

Intention des Änderungsentwurfs war, die Einbeziehung der Witwen mit Kindern auf waisenrentenberechtigte Kinder zu begrenzen, was offensichtlich eine Diskriminierung von Müttern nichtehelicher Kinder darstellte. Damit sollte auch über die Gestaltung des Sozialrechts eine Stabilisierung der traditionell-bürgerlichen Familienform erreicht werden. Auch hier wird wieder einmal deutlich, daß die materielle Gleichstellung alleinerziehender Mütter davon abhängig gemacht wurde, ob sich die Witwe dem herrschenden Frauen- und Familienleitbild angepaßt verhalten hat ${ }^{s s 0}$. Dessen ungeachtet erhielt der Änderungsentwurf die Zustimmung des Bundestages ${ }^{551}$ und trat in Kraft. Schätzungen gingen davon aus, daB dadurch ca. 20.000 Witwen, also etwa jede zehnte der neu einbezogenen, vom Rentenanspruch wieder ausgeschlossen wurde ${ }^{552}$.

Mit der großen Rentenreform von $1957^{553}$ wurde in einem Neuregelungsgesetz der Hinterbliebenenversorgung die Fiktion fallengelassen, daß die Witwe erwerbsunfähig sein müsse. Jede Witwe erhielt die sogenannte "kleine" Witwenrente, die $60 \%$ der Berufsunfähigkeitsrente betrug, als Grundbetrag. Bei tatsächlicher Erwerbsunfähigkeit oder Kindererziehung oder wenn sie im vorgerückten Alter stand, wurde die Rente zur "großen" Witwenrente (60\% des Altersruhegeldes). Es galt jedoch - auch gemäB BGB (§ 1357) - weiterhin das Leitbild der Hausfrauenehe. Ausschlaggebend für den Bezug der Rente war - sofern der verstorbene Ehemann die versicherungsmäßigen Voraussetzungen erfüllt hatte - allein der Tod des Man-

\footnotetext{
${ }^{549}$ Vgl. Entwurf eines Gesetzes über die Änderung des Dritten Gesetzes zur Änderung des SVAG, Antrag der Fraktionen von CDU/CSU, FDP und DP vom 6.10.1955; Bt., 2. Wp., Ders. 1742 (Anl.-Bd. 37).

${ }_{550}$ Vgl. Temme, Willi, Mangelhafte Gleichstellung der Arbeiterwitwen, in: Soziale Sicherung 1955, S. 373f.

${ }^{551}$ Vgl. BGBL. I (1956), S. 16.

552 Vgl. Temme, Willi, Mangelhafte Gleichstellung der Arbeiterwitwen, a.a.O., S. 373.

553 Vgl. Gesetz zur Neuregelung des Rechts der Rentenversicherung der Arbeiter vom 23.2.1957, BGBL. I, S. 45; Gesetz zur Neuregelung des Rechts der Rentenversicherung der Angestellten vom 23.2.1957, BGBL. I, S. 88. Beide Gesetze traten rückwirkend zum 1.1.1957 in Kraft.
} 
nes; dieser löste also - dem Kausalprinzip folgend - allein Unterhaltsersatzleistungen an die Frau aus ${ }^{54}$.

Die zunehmende Erwerbstätigkeit der Frauen (siehe Teil B, Punkt 1.) nahm der Witwenrentenregelung im Laufe der Zeit ihre Basis. Darüber hinaus hat das Bundesverfassungsgericht am 12. März 1975 entschieden, daß die Diskriminierung der Witwer - er mußte nachweisen, daß er überwiegend unterhalten worden ist, während bei der Witwe ein Unterhaltsbedarf unbedingt unterstellt wurde - auf Dauer nicht aufrechterhalten werden könne. Das Duisburger Sozialgericht stellte nach Klage mehrerer Witwer auf eine Hinterbliebenenrente fest, daß das Gleichberechtigungsgebot des Grundgesetzes verletzt sei, "weil bei gleichen Beitragsleistungen der versicherten Frau aus ihren Beiträgen ein geringerer Versicherungsschutz zuteil werde als dem versicherten Mann" ${ }^{155}$.

Noch 1963 sah das BVerfG keine Diskriminierung, denn es entschied, daß diese unterschiedlichen Regelungen an die typische eheliche Arbeitsteilung anknüpften und von daher gerechtfertigt seien. Da der Verlust der von der Ehefrau erbrachten Haushaltsleistungen in etwa durch den Wegfall ihrer Unterhaltskosten ausgeglichen werde, ergäbe sich im Hinterbliebenenfall beim Ehemann keine Bedarfsänderung. Die Witwe hingegen müsse durch den Fortfall der materiellen Unterhaltsleistungen des verstorbenen Ehemannes immer eine erhebliche wirtschaftliche Einbuße hinnehmen, die durch eine unbedingte Witwenrente teilweise ausgeglichen werden müsse ${ }^{556}$.

12 Jahre später scheint die bis dahin apostrophierte Typisierung der Rollenverteilung in Ehe und Familie auch dem Gericht nicht mehr haltbar, denn "die Entscheidung ergehe zu einer Zeit, in der sich das frühere Ver-

${ }^{554}$ Bei erneuter Heirat der Witwe entfällt die Witwenrente konsequenterweise, $(\$ 1302$ Abs. 1 RVO), um jedoch bei Scheidung dieser Ehe wieder aufzuleben ( 90 SGB VI, 68 Abs. 1 und 2 AVG). Außerdem hat die Witwe die Möglichkeit eine Abfindung zu bekommen, wenn sie eine neue Ehe eingeht ( 81 Abs. 1 AVG).

${ }^{555}$ Brück, D., Karlsruhe sprach nicht Recht, sondern machte Politik, in: Sozialer Fortschritt 7/1975, S. 147.

556 Vgl. Entscheidungen des Bundesverfassungsgerichtes von 1965, Bd. 17, Tübingen 1965, S. 19ff. 
ständnis der Rolle der Frau in Ehe und Familie zu verändern begonnen habe" ${ }^{1557}$.

Das BVerfG forderte deshalb, daß eine gesetzliche "Neuordnung bis zum Ende der übernächsten Legislaturperiode in Kraft gesetzt werden müBte $^{\text {"ss8 }}$, das bedeutete zum damaligen Zeitpunkt bis zum Herbst 1984. Diese lange Frist von immerhin fast zehn Jahren räumte das Gericht deshalb ein, weil nicht nur die Verfassungswidrigkeit der Witwerrenten-Regelung beseitigt werden sollte, sondern gleichzeitig eine unumgängliche Neuordnung des Hinterbliebenenrentenrechts unter dem Aspekt, eine eigenständige soziale Sicherung der Frau auszubauen, realisiert werden sollte.

Diese Situation war nun Ausgangspunkt einer im Vorfeld als "Jahrhundert-Reform" bezeichneten Rentenreform, die letztlich auch wieder zusammenschrumpfte zu einer Reform, die an Symptomen kuriert, aber keine Ursachen beseitigt hat und schlieblich erst 1986 und nicht 1984 verwirklicht wurde.

\section{2. Überlegungen der '84er Kommission zur Reform der Hinterblie- benenrenten}

Neben der Entscheidung des Bundesverfassungsgerichts, die unterschiedlichen Voraussetzungen für den Bezug der Witwer- und Witwenrenten zu beseitigen, gab es weitere Aspekte, die eine Reform des Hinterbliebenenrechts dringend notwendig machten, so

1. die niedrigen Witwenrenten, die den Bedarf zur Aufrechterhaltung des ursprünglichen Lebensstandards nicht mehr sicherstellen konnten. Es kann als wenig befriedigend angesehen werden, wenn die Witwe eines Arbeiters, "der voll erwerbstätig war, aber einen niedrigen Lohn bezogen hat, auf die Sozialhilfe verwiesen wird"ss9, weil die Witwenrente ihre Existenz nicht sichert und sie nur in geringem AusmaB eigene Rentenansprüche aufbauen konnte, da sie mehrere Kinder aufgezogen hat und deshalb nicht erwerbstä-

\footnotetext{
${ }^{557}$ Vgl. BVerfGE 39.169 (187; auch 193), zitiert nach Hermann, Christopher, Gleichstellung der Frau und Rentenrecht, a.a.O., S. 127.

${ }_{558}$ BVerfGE 39.169 (195).

${ }^{559}$ Albers, Willi, Soziale Sicherung..., a.a.O., S. 106.
} 
tig sein konnte ${ }^{s 60}$. Hier wird also neben den niedrigen Löhnen für Frauen und der schlechten Ausbildung in der Vergangenheit die Nichtberücksichtigung von Erziehungszeiten wirksam,

2. führten zunehmende Emanzipationsbestrebungen zu einer eigenständigen Sicherung der Frau, die auch unter ökonomischen Gesichtspunkten notwendig wurde, denn eine vom Manne abgeleitete Sicherung entsprach nicht mehr den wirtschaftlichen und gesellschaftlichen Verhältnissen, wenn die Frau nach der EheschlieBung erwerbstätig blieb und sich das eheliche Verhältnis von einem patriarchalischen $z u$ einem partnerschaftlichen verwandelte. Langjährige Erwerbstätigkeit ist die Basis für eine eigene Versichertenrente, zu der dann unter Umständen eine Witwenrente hinzukommt, so daß diese Rentenkumulation zu einer "Übersicherung" führt, die unter sozialpolitischen Aspekten auch nicht begrüßenswert erscheint. Da der Kreis der Pflichtversicherten unter allen Frauen im erwerbstätigen Alter ständig zunimmt, wird weiterhin aus den Bevölkerungsgruppen, die jeweils die Altersgrenze erreichen, eine zunehmende Zahl von Frauen mit eigenen Rentenansprüchen hervorgehen. Mit steigendem Gewicht des Mehrfachbezuges von Leistungen der gesetzlichen Rentenversicherung aber erhöht sich auch die Wahrscheinlichkeit, daB die Verwirklichung bisher geltender Ziele vereitelt wird, so daß dabei sozialpolitisch unbefriedigende Ergebnisse auftre$\operatorname{ten}^{561}$.

Um dem Verfassungsgerichtsurteil Folge leisten zu können, setzte die Bundesregierung eine Sachverständigenkommission ein (die sogenannte 84er-Kommission), deren Aufgabe war, Vorschläge für den Aufbau einer eigenständigen sozialen Sicherung der Frau zu erarbeiten, wobei

- die Gleichbehandlung von Mann und Frau in der Hinterbliebenenrente realisiert werden sollte,

- eine Neuordnung der sozialen Sicherung der Frau zum Ausbau eigener Sicherheitsansprüche für Alter und Invalidität angestrebt wurde,

\footnotetext{
${ }^{560}$ Albers, Willi, Die soziale Sicherung der Frau im Alter, in: Gitter, W., Thieme, W. und F. Zacher (Hrsg.), Im Dienst des Sozialrechts, Festschrift für Georg Wannagat, Köln, u.a.O. 1981, S. 1 .

${ }^{561}$ Vgl. Wochenbericht 14/79 des Deutschen Instituts für Wirtschaftsforschung, Gleichberechtigung von Mann und Frau - ein Problem für die gesetzliche Rentenversicherung, S. $163 f$.
} 
- sowie letztlich unter dem Gesichtspunkt der Beitragsäquivalenz soziale Ungerechtigkeiten zu korrigieren ${ }^{562}$.

Die erarbeiteten Vorschläge sollten zudem breiten Spielraum für politische Entscheidungen bieten und Lösungen zulassen, die der Forderung nach Kostenneutralität gerecht werden.

Die Kommissionsmitglieder haben unter diesem Gesichtspunkt ihren Auftrag eher restriktiv interpretiert, d.h. sie sahen die Begrenzung in der Forderung, die soziale Rentenversicherung weiterzuentwickeln, also kein gänzlich neues System zu konstruieren ${ }^{56}$. Dies führte zu Reformvorschlägen, die in vier Grundformen unterteilt werden können: ${ }^{564}$

Grundform 1: Die Neugestaltung der Witwen- und Witwerrenten in Anlehnung an das bisher geltende Recht, also für beide Ehegatten eine unbedingte abgeleitete Hinterbliebenenversorgung

Grundform 2: Die Teilhabe des überlebenden Ehegatten an der Gesamtversorgung aus der Ehe (Teilhaberente)

Grundform 3: Ein laufendes Splitting von Rentenanwartschaften während des Bestehens der Ehe

Grundform 4: Die Hausfrauenpflichtversicherung, d.h. also die Mitversicherung für den haushaltsführenden Ehegatten.

Übereinstimmend ist die Kommission dann zu dem Ergebnis gekommen, daß die Grundform 2, also die sogenannte Teilhaberente, am ehesten geeignet erscheint, die existierenden Probleme zu lösen. Danach ergibt sich folgendes:

\footnotetext{
562 Vgl. Beschluß der Bundesregierung über die Bildung einer Sachverständigenkommission für die soziale Sicherung der Frau und der Hinterbliebenen vom 17. August 1977, Zf. 1.

\$63 Vgl. Sachverständigenkommission für die soziale Sicherung der Frau und der Hinterbliebenen: Vorschläge zur sozialen Sicherung der Frau und der Hinterbliebenen. Gutachten der Sachverständigenkommission vom 21. Mai 1979, S. 14, Zf. 8.

${ }^{56+}$ Vgl. Vorschläge zur Sozialen Sicherung der Frau..., a.a.O., S. 33ff.
} 
In der Erwerbsphase, also in der Phase, in der die Witwe bzw. der Witwer die Voraussetzungen für eine eigene Rente noch nicht erfüllen, sollen sie - jedoch nur im Fall der Invalidität oder wenn sie bei Tod des anderen Ehegatten bereits 45 Jahre alt sind oder wenn sie Kinder erziehen - eine aus den Anwartschaften des Verstorbenen abgeleitete Hinterbliebenenrente erhalten. Hinsichtlich der Frage der Anrechnung von Einkommen auf die Hinterbliebenenrente ist im Kommissionsgutachten folgendes zu lesen: ${ }^{565}$

"Bei der Rente wegen Kindererziehung soll nach Meinung der Mehrheit der Kommission ein unbeschränkter Hinzuverdienst möglich sein. Bei der Rente wegen vorgerückten Alters soll ein Hinzuverdienst bis zu einer gewissen dynamischen Grenze rentenunschädlich sein; überschreitet der Hinzuverdienst diese Grenze, so soll der überschreitende Betrag teilweise und zwar mit gleitender Skala - auf die Rente angerechnet werden; überschreitet der Hinzuverdienst eine Höchstgrenze, so soll die Rente wegfallen".

In der Rentenphase schließlich soll aus den eigenen Anwartschaften des Hinterbliebenen und den Anwartschaften des Verstorbenen eine Gesamtversorgungsrente (Teilhaberente) gebildet werden. Wie diese Rente im Detail hinsichtlich der Anwartschaften beider Ehegatten ausgestaltet sein sollte, gab es drei unterschiedliche Vorschläge von drei Gruppen der Kommission: ${ }^{566}$

1. $75 \%$ der von beiden Ehegatten in der Ehe erworbenen Anwartschaften zuzüglich $100 \%$ an eigenen, außerhalb der Ehe erworbenen Anwartschaften. Gegen diese Lösung wurde jedoch eingewandt, daß zum einen $75 \%$ der ehebezogenen Anwartschaften weniger sein könnten als $60 \%$ der vor und in der Ehe erworbenen Anwartschaften, was gegen die Bestandsgarantie des Gesetzgebers verstößt, zum anderen insbesondere Verheiratete gegenüber den Ledigen benachteiligt würden. Ein Witwer würde - gesetzt dem Fall, seine verstorbene Frau habe keine eigenen Anwartschaften - neben seinen vorehelichen nur $75 \%$ seiner ehelichen Anwartschaften erhalten, während dem Ledigen die eigene Rente ungekürzt verbliebe. Diese Einwände führten nun zur Modellvarianten 2-3:

\footnotetext{
${ }^{565}$ Vorschläge zur sozialen Sicherung der Frau..., a.a.O., Zf. 124, Zf. 191, Zf. 196-199.

${ }^{566}$ Vgl. Vorschläge zur Sozialen Sicherung der Frau..., a.a.O., S. 47.
} 
2. $75 \%$ der von beiden Ehegatten insgesamt - also vor und während der Ehe - erworbenen Rentenanwartschaften.

3. $70 \%$ der von beiden Ehegatten insgesamt erworbenen Rentenanwartschaften, verbunden mit der Garantie des selbsterworbenen Anspruchs des überlebenden Ehegatten in Höhe von $100 \%$.

Letztere Variante stand schließlich auch Pate bei der Konstruktion des im Gesetz zur Neuordnung der Hinterbliebenenversorgung (HEZG) fixierten "Anrechnungsmodells".

Eines aber wird nach diesen kurzen Ausführungen deutlich, bereits durch die Formulierung der vier Grundformen hat die 84er Kommission die Möglichkeit verworfen, ein vollständiges System für eine eigenständige Sicherung der Frau zu entwickeln ${ }^{567}$. An der Situation der verheirateten Frau würde sich nach den Vorschlägen der Kommission nichts ändern; waren sie wegen Kindererziehung nicht erwerbstätig, haben sie auch im Alter keine unmittelbaren Ansprüche an die Sozialversicherung ${ }^{568}$. Die Modellvarianten 2 und 3 der Teilhaberente führen bei irregulären Eheverläufen zu unplausiblen Ergebnissen und angesichts der relativ hohen aktuellen Scheidungshäufigkeitsziffern ist bei Realisierung dieser Varianten mit zunehmender Häufigkeit mit problematischen Fällen bei der Hinterbliebenenversorgung zu rechnen. So entsteht beispielsweise die Frage, "welcher(m) Witwe(r) solche Anwartschaften bei mehrfacher Heirat angerechnet werden, die ein Mann (eine Frau) vor der Ehe erworben hatte"s69.

Ohne daß diese Überlegungen explizit in die Zielsetzungen der Reform aufgenommen wurden, ist es unumgänglich einmal zu erarbeiten, welche Verteilungseffekte das Modell der Teilhaberente mit sich bringt.

Die Regelung der abgeleiteten Witwenrenten bewirkte Umverteilungseffekte, die nach Veränderung des Leitbildes einer Hausfrauenehe keinerlei sozialpolitische Berechtigung zu haben scheinen. Den Hinterbliebenenrenten standen keine Beitragszahlungen gegenüber, die Witwenrenten werden also aus dem Beitragsaufkommen aller Versicherten finanziert, d.h.

\footnotetext{
${ }^{567}$ Vgl. Wochenbericht 40/41/1979, Deutsches Institut für Wirtschaftsforschung Berlin 1979, Rentenreform 1984: Neue Probleme schaffen, ohne die alten zu lösen? S. 417-424, hier: S. 419.

${ }^{568}$ Vgl. Wochenbericht 40/41/1979, a.a.O., S. 419.

${ }^{569}$ Vgl. Wochenbericht 40/41/1979, a.a.O., S. 421.
} 
sowohl aus den Beitragszahlungen von Ledigen, als auch von erwerbstätigen verheirateten Frauen, die für ihre Ehemänner nach altem Recht keine Hinterbliebenensicherung aufbauen konnten. Daraus folgte für die verheirateten Frauen eine Umverteilung von Ledigen zu Verheirateten, und von der erwerbstätigen Ehefrau zur Alleinverdienerehe ${ }^{570}$.

Wird darüber hinaus das Erwerbsverhalten betrachtet, zeigt sich, daB die Erwerbsbeteiligung von Ehefrauen mit zunehmendem Einkommen des Ehemannes abnimmt (siehe P. 1.2.1.). Die Frau also, die trotz und wegen der Kinder erwerbstätig sein muß, trägt also mit ihren Beiträgen zur Finanzierung der Alterssicherung kinderloser, gut situierter Hausfrauen bei, "denn die Umverteilungswirkungen der Hinterbliebenensicherung knüpfen lediglich an Ehestand und Erwerbsbeteiligung, nicht aber daran an, ob Kinder vorhanden sind"s71.

Diese versicherungsimmanente Bevorzugung der Hausfrauenehe führt also letztlich zu einer Umverteilung von den unteren zu den oberen Einkommensschichten ${ }^{572}$.

Der laut Bundesverfassunggericht auferlegte Auftrag die Ungleichbehandlung der Witwer in der Hinterbliebenenversorgung zu beseitigen, ist erfüllt worden.

Der Tod der Ehefrau nach dem 31.12.1985 berechtigt den Ehemann zum Bezug einer unbedingten Witwerrente, d.h. es muß nicht mehr nachgewiesen werden, daB die verstorbene Ehefrau den Unterhalt der Familie überwiegend bestritten hat ( $\$ 1264$ RVO). Selbstverständlich müssen aber die geltenden versicherungsrechtlichen Voraussetzungen einer Mindestversicherungszeit von 60 Kalendermonaten des verstorbenen Ehepartners nachgewiesen werden. Details zum sogenannten "Anrechnungsmodell" werden im folgenden Abschnitt behandelt.

\footnotetext{
${ }^{570}$ Vgl. Ruby, Andrea, Brigitte Göttgens, Sigrid Koeppinghoff, Rentenreform '84: Frauen bleiben diskriminiert, in: Prohla 12. Jg. 1982, Nr. 4, S. 77-89, hier: S. 81.

${ }^{571}$ Ruby, Andrea, Brigitte Göttgens, Sigrid Koeppinghoff, Rentenreform '84, a.a.O., S. 81.

${ }^{572}$ Vgl. Ruby, Andrea, Brigitte Göttgens, Sigrid Koeppinghoff, Rentenreform '84, S. 81.
} 
3. Das "Anrechnungsmodell" im Gesetz zur Neuordnung der Hinterbliebenenversorgung (HEZG)

Die vom Bundesverfassungsgericht mit Urteil vom 12. März 1975 geforderte Gleichstellung von Witwen und Witwern bei den Hinterbliebenenrenten führte zu einer nachhaltigen Diskussion und Erarbeitung von Rentenreformvorschlägen (siehe 84' Kommission), da nicht nur die festgestellte Ungleichheit von Witwen und Witwern beseitigt, sondern darüber hinaus die eigenständige soziale Sicherung der Frau als umfassendes und umsetzbares Konzept erarbeitet und der Bundesregierung zur Entscheidung vorgelegt werden sollte. Da die relevanten Vorschläge bereits in Punkt 2 vorgestellt wurden, soll im folgenden der realisierte Entwurf des ab 1986 geltenden „Hinterbliebenenrenten- und Erziehungszeiten-Gesetz (HEZG) dargestellt und analysiert werden. Das Gesetz hatte zwei Schwerpunkte, wovon der zweite, die Anrechnung der Kindererziehung in der gesetzlichen Rentenversicherung bereits an anderer Stelle behandelt wurde. Ohne wesentliches bereits vorweg zu nehmen, sei an dieser Stelle vermerkt, daB das Anrechnungsmodell dem Ziel einer eigenständigen sozialen Sicherung der Frau nicht gerecht wird, es kann auch nicht als neue, wegbereitende Reform bezeichnet werden, denn es knüpft an die bewährten Strukturen der Rentenversicherung an und beseitigt die vom Bundesverfassungsgericht beanstandete Sachlage.

Das Modell sieht grundsätzlich vor, daB die bis dahin geltende Versorgungsregelung für Witwen auf Witwer übertragen wird, beide also einen unbedingten Anspruch auf Hinterbliebenenrente unter der Voraussetzung haben, daß der verstorbene Ehegatte mindestens 60 Versicherungsmonate zurückgelegt hat. Da das Anrechnungsmodell lediglich für die gesetzliche Renten- und Unfallversicherung gilt, also kein systemübergreifendes Modell ist, wird damit kein Beitrag zur Harmonisierung der Alterssicherungssysteme geleistet. D.h. die Frau eines verstorbenen Beamten, die eine Witwenpension bezieht, braucht sich hierauf ihre eigene Rente aus der gesetzlichen Rentenversicherung nicht anrechnen zu lassen ${ }^{573}$ wie die Witwe eines verstorbenen Arbeiters oder Angestellten. In der Kriegsopferversorgung er-

${ }^{573}$ Vgl. $§ 55$ Abs. 3, Nr. 2 Beamt VG. 
folgt eine Berücksichtigung des eigenen Einkommens nur beim Berufsschadensausgleich. ${ }^{574}$

Die Neuregelung sieht vor, daß nach dem Tode des versicherten Ehegatten der überlebende Ehegatte eine abgeleitete Witwen- oder Witwerrente erhält, ohne daß es einer Prüfung der überwiegenden Unterhaltsbestreitung bedarf. Damit wird der Charakter der Hinterbliebenenversorgung als Leistung mit überwiegender Unterhaltsfunktion beibehalten. Auch die Unterscheidung in eine „kleine“ und eine "große“ Witwen- bzw. ab jetzt dann auch Witwerrente bleibt unverändert. Neu in der Konzeption und damit auch der Kern des Anrechnungsmodells ist die Berücksichtigung eigenen Einkommens, soweit es mit der Hinterbliebenenrente zusammentrifft. Je nach Höhe des eigenen Einkommens „ruht“ ein Teil der Rente oder im Extremfall sogar die gesamte Rente ${ }^{575}$. In der Gesetzesbegründung heißt es dazu: „Der überlebende Ehegatte hat bei einer Saldierung der beiderseitigen Unterhaltsleistungen zu Lebzeiten des anderen Ehegatten im Ergebnis weniger an Unterhaltsleistungen erhalten als ein Ehegatte, der keinerlei eigenes Erwerbs- oder Erwerbsersatzeinkommen hatte ${ }^{6576}$. Die Unterhaltsfunktion der Witwen- und Witwerrente wird damit zweimal berücksichtigt, einmal über die Fortsetzung der $\mathbf{6 0 \%}$ Quote und darüber hinaus in individualisierter Form über die Anrechnung des eigenen Einkommens. ${ }^{577}$ Um unnötige Härten zu vermeiden, wird eigenes Einkommen nur insoweit angerechnet, als es einen dynamisierten Freibetrag übersteigt, ${ }^{578}$ der zu Beginn der Regelung als Prozentsatz der allgemeinen Bemessungsgrundlage ausgedrückt wurde und inzwischen am aktuellen Rentenwert gemessen wird. 1996 beträgt er 1.220,47 DM in den alten und 1.001,09 DM in den neuen Bundesländern. Er orientiert sich „an der Höhe des notwendigen Selbstbehalts eines unterhaltsverpflichteten Ehegatten ${ }^{6579}$ und ist eine Ausprägung des Sozial-

\footnotetext{
${ }^{574}$ Vgl. $\S \S 42$ Abs. 1, 43, 44 Abs. 5 und 6, 48 Abs. 4, 48a BVersG.

575 Vgl. § 46 SGB VI und § 97 SGB VI.

576 BR-Drucks. 500/84, S. 24.

577 Vgl. W. Heine, Die Neuregelung der Witwen- und Witwerrenten in der gesetzlichen Rentenversicherung. Zur Problematik einer Einkommensanrechnung bei beitragsfinanzierten Leistungen der Sozialversicherung, in: Zeitschrift für das gesamte Familienrecht, 33. Jg. 1986, Heft 2, S. 115.

578 §97 SGB VI.

579 BR-Drucks. 500/84, S. 24.
} 
staatsprinzips, da die Bezieher kleinerer Einkommen von der Neuregelung nicht berührt werden. Erzieht die Witwe/der Witwer ein waisenrentenberechtigtes Kind, erhöht sich der Freibetrag um einen „Kinderzuschlag“, so daß die besondere wirtschaftliche Belastung des überlebenden Ehegatten, der Kinder zu unterhalten hat, Berücksichtigung findet und die soziale Ausgleichsfunktion des Freibetrages verstärkt wird..$^{500}$

Das den jeweiligen Freibetrag übersteigende Einkommen wird zu $40 \%$ auf die Witwen- oder Witwerrente angerechnet, sie ruht in Höhe dieses Betrages. Fällt das anzurechnende Einkommen weg, kommt das bestehende Stammrecht wieder zum Tragen und die Witwen-/Witwerrente wird in voller Höhe ausgezahlt, d.h. die ruhende Hinterbliebenenrente kann jederzeit bei Vorliegen der entsprechenden Voraussetzungen in voller Höhe wieder aufleben. Jedoch ist auch die ruhende Rente noch wirksam, da durch sie der Krankenversicherungsschutz der jeweiligen Rentner/in gesichert bleibt. Auch in den ersten 3 Monaten nach Rentenbeginn wird die Rente in voller Höhe ausgezahlt (Sterbevierteljahr). Angerechnet werden grundsätzlich alle Erwerbs- und Erwerbsersatzeinkommen des Rentenberechtigten, ${ }^{581}$ besonders letzteres läBt erkennen, daB die Abgrenzung dessen, was als Einkommen anzusehen ist z.T. nur unbefriedigend gelöst ist. Die folgende Tabelle zeigt, welche Einkommen auf die Hinterbliebenenrente angerechnet werden und in welchem AusmaB diese Einkommen gekürzt werden.

Anrechnungsfrei bleiben demgegenüber ${ }^{582}$ :

- Zusatzleistungen öffentlich-rechtlicher Systeme,

- Leistungen mit Zusatzsicherungsfunktion aufgrund Tarifvertrages (betriebliche Altersversorgung),

- Leistungen mit Ausgleichs- und Entschädigungscharakter,

- Leistungen mit subsidiärem, fürsorgerechtlichem Charakter kindbezogene Leistungen,

- Leistungen privater Vorsorge,

\footnotetext{
580 Vgl. BT-Drucks. 10/3519, S. 14.

s81 § 18a Abs. 1 SGB VI.

${ }_{582}$ § 18a Abs. 1 Nr. 2, Abs. 3 Nr. 8, Abs. 4 SGB IV.
} 
- Einkünfte aus Kapitalvermögen einschließlich Vermietung und Verpachtung.

Tabelle 55: Anrechenbares Einkommen auf die Hinterbliebenenrente

\begin{tabular}{|c|c|}
\hline Art des Einkommens & Abzüge \\
\hline \multicolumn{2}{|l|}{ Erwerbseinkommen: } \\
\hline Arbeitseintgelt & $35 \%$ \\
\hline Bezüge von Beamten, Richtern, Berufssoldaten, Soldaten auf Zeit, DO-Angestellten & $27,5 \%$ \\
\hline Arbeitseinkommen & $35 \%$ \\
\hline Bezüge der Minister und parlam. Staatssekretäre & $27,5 \%$ \\
\hline Entschädigungen der Abgeordneten & $27,5 \%$ \\
\hline Vorruhestandsgelder & $35 \%$ \\
\hline Überbrückungsgelder vom Arbeitgeber & $35 \%$ \\
\hline \multicolumn{2}{|l|}{ Kurzfristiges Erwerbsersatzeinkommen: } \\
\hline \multicolumn{2}{|l|}{$\begin{array}{l}\text { Krankengeld } \\
\quad \text { Beitr.anteil' }{ }^{1} \text { ) }\end{array}$} \\
\hline \multicolumn{2}{|l|}{$\begin{array}{l}\text { Verletztengeld } \\
\quad \text { Beitr.anteil }{ }^{1} \text { ) }\end{array}$} \\
\hline Versorgungskrankengeld & - \\
\hline Erziehungsgeld & - \\
\hline Übergangsgeld & - \\
\hline Unterhaltsgeld, Arbeitslosengeld, Konkursausfallgeld & - \\
\hline Kurzarbeitergeld, Schlechtwettergeld & $35 \%$ \\
\hline \multicolumn{2}{|l|}{$\begin{array}{l}\text { Überbrückungsgeld der Seemannskasse } \\
\text { Beitr.anteil }{ }^{2} \text { ) }\end{array}$} \\
\hline Ūbergangsleistungen bei Maßnahmen gegen Berufskrankheiten & - \\
\hline \multicolumn{2}{|l|}{ Dauerhaftes Erwerbsersatzeinkommen: } \\
\hline \multicolumn{2}{|l|}{$\begin{array}{l}\text { Renten aus eigener Versicherung aus der RV der Angestellten und Arbeiter } \\
\text { Beitr.anteil }{ }^{2} \text { ) }\end{array}$} \\
\hline \multicolumn{2}{|l|}{$\begin{array}{l}\text { Renten aus eigener Versicherung } \\
\text { Beitr.anteil }{ }^{2} \text { ) }\end{array}$} \\
\hline Aus der knappschaftlichen Rentenversicherung & und $25 \%$ \\
\hline $\begin{array}{l}\text { Altersgelder der landwirtschaftlichen Altersklasse } \\
\text { Beitr.anteil') }\end{array}$ & \\
\hline
\end{tabular}


Verletztenrente aus der gesetzlichen Unfallversicherung

Ruhegehalt und vergleichbare Bezüge sowie Bezüge aus d. Versorgung d. Abgeordneten $\quad 37,5 \%$ Unfallruhegehalt und vergl. Bexüge sowie vergl. Bexüge aus d. Versorgg. d. Abgeordneten 37,5\%

Renten der berufsständischen Versorgung $27,5 \%$

Berufsschadensausgleich nach dem Bundesversorgungsgesetz und anderen Gesetzen

1) Anteil der vom Rentenberechtigten zu tragenden Beiträge zur Sozialversicherung und BA.

2) Beitrag des Rentenberechtigten zur Krankenversicherung abzüglich Zuschuß des RV-Trägers zu den Aufwendungen für die Krankenversicherung.

Quelle: Übersicht über die Soziale Sicherheit, Bonn 1991, S. 184

Da das Anrechnungsmodell wegen der Einkommensanrechnung dazu führen konnte, daß Frauen sich gegenüber dem bis 1986 geltendem Recht verschlechtern konnten, eröffnete der Gesetzgeber Ehepaaren, die sich in ihrer Lebensplanung auf das alte Recht eingestellt hatten und die sich aufgrund ihres Alters nicht ohne weiteres auf das neue Recht einstellen konnten, die Option, sich für das alte oder das neue Recht zu entscheiden. ${ }^{533}$ Voraussetzung war, daß beide Ehegatten vor dem 1.1.1936 geboren waren, die Ehe vor dem 1. Januar geschlossen wurde und die Erklärung vor dem Tode eines Ehegatten abgegeben worden ist. Die Erklärung mußte von beiden Ehegatten gemeinsam und übereinstimmend gegenüber dem zuständigen Rentenversicherungsträger abgegeben werden und muBte spätestens bis zum 31.12.1988 erfolgt sein. Die Entscheidung konnte nicht widerrufen werden. Wurde nichts besonderes vereinbart, galt automatisch das neue Recht.

Das im Vorfeld der Diskussionen nicht zur Debatte stehende Anrechnungsmodell konkurrierte in der Entscheidungsphase stark mit dem Modell der Teilhaberrente auf der Basis von 70 \%, das von der Sachverständigenkommission für die soziale Sicherung der Frau und der Hinterbliebenen in ihrem Gutachten von 1979 vorgeschlagen wurde. Eine Stichprobenerhebung durch den Verband Deutscher Rentenversicherungsträger in den Jahren 1980/81 ergab dann aber, daB das Modell der Teilhaberrente Mehrkosten in Höhe von 1,5\% verursachen würde, die eine Beitragssatzanhebung unumgänglich werden lieb. Eine Absenkung des Teilhabesatzes auf $65 \%$ wieder-

$\$ 83 \S 18$ Abs. 3,19 Abs. 4 ArVNG. 
um hätte zur Folge gehabt, daß sich sämtliche Frauen mit einer eigenen Versichertenrente im Verhältnis zum bis 1986 geltendem Recht bereits dann schlechter gestellt hätten, wenn ihre Anwartschaften mehr als $14 \%$ der Anwartschaften des Verstorbenen ausmachten. ${ }^{584}$ Damit war diese Variante nicht durchsetzungsfähig, so daß nun das Modell der Hinterbliebenenrente mit Freibetrag favorisiert wurde. Es traf nur etwa $10 \%$ der erwerbstätigen Frauen, bei $90 \%$ blieb es dabei, daB ihre Witwenrente in voller Höhe gezahlt werden würde, und es war zudem kostenneutral, denn die damalige angespannte Haushaltslage ließ ein Reformvorhaben, daß zusätzliche Kosten mit sich brachte, nicht zu.

Mit dem Anrechnungsmodell wurde dem Auftrag des Bundesverfassungsgerichtes Rechnung getragen und es verursachte keine Mehrkosten. Dem Ziel, eine eigenständige soziale Sicherung der Frau zu schaffen, ist die Bundesregierung mit der Entscheidung für das Anrechnungsmodell nicht näher gekommen. Zudem gab das Modell Anlaß zu grundlegenden Fragen ${ }^{585}$ und Kritik:

1. Ist die Einkommensanrechnung mit dem in Art. 3 GG postulierten Gleichheitsgrundsatz vereinbar?

2. Ist das Anrechnungsmodell mit dem Versicherungsprinzip und hier speziell mit dem Äquivalenzprinzip - vereinbar?

3. Wirkt sich das Anrechnungsmodell leistungshemmend aus?

4. Inwieweit ist das Anrechnungsmodell mit dem Versorgungsausgleich vereinbar?

Zu 1. Probleme ergeben sich in diesem Modell bei der Abgrenzung der anrechnungsfreien zu den anzurechnenden Einkommen. Die systemgerechte Abgrenzung müBte sich aus dem Unterhaltsersatzprinzip ergeben, da dieses der Grundgedanke für die Hinterbliebenenversorgung ist. Diese Funktion wird gemeinhin nicht in Frage gestellt, zumal auch das Bundesverfassungs-

\footnotetext{
584 Vgl. H. Kaltenbach, Irrwege und Fehleinschätzungen, Zur Reform des Hinterbliebenenrechts, Berlin 1984, S. 17.

585 Vgl. A. Bokeloh, Die Neuregelung der Hinterbliebenenversorgung nach dem System der Hinterbliebenenrente mit Freibetrag, in: Zeitschrift für Sozialreform, 31. Jg. 1985, S. 279.
} 
gericht in seiner Rechtsprechung mehrfach darauf verwiesen hat. GemäB § 1360 BGB sind beide Ehepartner verpflichtet, die Familie angemessen zu unterhalten. Stirbt einer der Ehegatten, so fällt seine Unterhaltsleistung weg und der überlebende Ehepartner bedarf hierfür eines Ersatzes; dieser wird ihm mit der Witwen- bzw. Witwerrente gewährt. Unterstrichen wird die Unterhaltsersatzfunktion der Witwen- und Witwerrenten noch dadurch, daB sie wegfallen, wenn der überlebende Ehegatte wieder heiratet. Durch das Anrechnungsmodell wird die Unterhaltsersatzfunktion der Hinterbliebenenrente gegenüber dem alten Recht eher noch konkretisiert. „Für die Witwe wird nicht mehr generell davon ausgegangen, daB sie immer eines Ersatzes für die vollen Unterhaltsleistungen bedarf, die durch den Tod des Mannes weggefallen sind. Verfügt sie nämlich über eigenes Erwerbs- oder Erwerbsersatzeinkommen in einem ins Gewicht fallendem Umfang, so hat sie bereits zu Lebzeiten des Mannes bei einer rechnerischen Gegenüberstellung der Unterhaltsleistungen, die sie erbracht und die sie erhalten hat, weniger erhalten als eine Frau, die keinerlei eigenes Einkommen hatte. Daher ist es nur konsequent, wenn sich die Witwenrente bei Vorhandensein eines ins Gewicht fallenden eigenen Erwerbs- oder Erwerbsersatzeinkommens verringert".ss6

Nicht zu leugnen ist allerdings, daß das Anrechnungsmodell vom Prinzip des Vorrangs der eigenen Sicherung geprägt ist, ${ }^{587}$ denn ist der Unterhalt des überlebenden Ehepartners im Sinne des Gesetzgebers gesichert, erlischt der Unterhaltsanspruch gegen den Versicherungsträger und damit gegen die Gesamtheit der Versichertengemeinschaft, dieses entspricht auch weitgehend dem Grundgedanken des Subsidiaritätsprinzips.

Die Nichtanrechnung privater Vorsorgeleistungen und der Leistungen aus der betrieblichen Altersversorgung führt immer wieder zu Kritik, da sie ihrem Charakter nach Erwerbsersatzeinkommen sind, was dafür sprechen könnte, sie in den Katalog der anzurechnenden Einkommensarten aufzunehmen. Dagegen wird allerdings eingewandt, daß sie aus versteuertem Einkommen entrichtet werden und die Funktion haben, zusätzlich zu Rentenleistungen aus der Rentenversicherung zur Verfügung zu stehen. An-

\footnotetext{
${ }_{586}$ A. Bokeloh, Die Neuregelung..., a.a.O., S. 289.

587 Vgl. W. Heine, a.a.O., S. 119.
} 
rechnungsregelungen könnten zudem die Bereitschaft der Unternehmen senken, die betriebliche Altersversorgung einzurichten bzw. auszubauen. ${ }^{588}$ Gerade im Hinblick auf die zukünftige Entwicklung der Rentenversicherung dürfen private Aktivitäten in keiner Weise gehemmt werden.

Zu 2. Die Diskussion, ob die Hinterbliebenenrenten Versicherungsleistungen oder versicherungsfremde Leistungen aufgrund des Fürsorgeprinzips sind, flammt in Zeiten finanzieller Notlagen der gesetzlichen Rentenversicherung immer wieder auf, wobei festzustellen ist, daB die Hinterbliebenenrenten sowohl beitragsfinanzierte als auch bedarfsorientierte Versicherungsleistungen sind. ${ }^{599}$ Das Bundesverfassungsgericht betont, daß die Hinterbliebenenrenten mehr als die Versichertenrenten vom fürsorgerischen Charakter geprägt seien. Dies ergebe sich schon daraus, daß Verheiratete keine höheren Beiträge zahlen als Ledige und die Rentenempfänger ihrerseits keinen eigenen Beitrag entrichteten. Gleichwohl wird auch der Beitrag in der Rentenversicherung nach versicherungsmathematischen Regeln so kalkuliert, daß er auch das Risiko der Hinterbliebenenrente mit abdeckt, der Globaläquivalenz wird damit in diesem Zweig der Sozialversicherung gefolgt. Das durch die Anrechnung eigenen Einkommens Elemente der Bedürftigkeitsprüfung in die gesetzliche Rentenversicherung hineingebracht worden sind, führt zu einer Modifizierung des Versicherungsprinzips, allerdings grenzt sich die Sozialversicherung ganz bewußt vom reinen, in der Privatwirtschaft geltenden, Versicherungsprinzip ab, ohne jedoch die Grundidee als solche zu verletzen. Von einer realisierten Beitragsäquivalenz kann im Hinblick auf die Witwen-/Witwerrenten sicherlich nicht gesprochen werden, dennoch findet das Äquivalenzprinzip Eingang in das System der gesetzlichen Rentenversicherung, wenn darunter das Verhältnis zwischen den Beiträgen, die der Versicherte an die Rentenversicherung entrichtet hat, und den Leistungen, die mit diesen Beiträgen begründet wurden, verstanden wird. Daraus folgt dann lediglich, daß höheren Beiträgen auch höhere Leistungen entsprechen, was durch die gegenwärtig geltende Rentenformel sichergestellt wird. Auch für die Hinterbliebenenrente gilt, daß sich aus einer

\footnotetext{
588 Vgl. A. Bokeloh, Die Neuregelung..., a.a.O., S. 280.

589 Vgl. G. Wannagat, Verletzt das Anrechnungsmodell in der Hinterbliebenenrentenreform das Versicherungsprinzip?, in: Die Angestelltenversicherung, 32. Jg. 1985, Heft 3, S. 103.
} 
höheren Versichertenrente eine höhere Witwen-/Witwerrente ergibt, ohne daß hier die Bedürftigkeit des Hinterbliebenen relevant wird. Das Anrechnungsmodell bewirkt einen deutlichen Gewinn an Beitragsäquivalenz gegenüber der alten Regelung. Diese verstieß insofern gegen den Grundsatz der Beitragsäquivalenz, als die Beiträge der Versicherten für die Begründung einer Witwen- oder Witwerrente unterschiedlich bewertet wurden und zwar je nachdem, ob der Ehegatte des Versicherten oder der Versicherte selbst im letzten wirtschaftlichen Dauerzustand den Unterhalt der Familie überwiegend bestritten hat. ${ }^{590}$ Das Anrechnungsmodell bewertet demgegenüber die Beiträge von Frauen und Männer völlig gleich.

zu 3. Das alte Rentenrecht gestattete die vollständige Kumulation von Witwenrente und eigenem Einkommen, dadurch wurde der Anreiz, eigenes Einkommen zu erzielen, nicht beeinträchtigt, so daB die Regelung allgemein als „leistungsfreundlich“ eingestuft wurde. Da - wie oben schon erwähnt eigene Vorsorgeleistungen aus der Einkommensanrechnung herausgenommen sind, wird die Eigenverantwortung und Eigenvorsorge für das Alter in keiner Weise beeinträchtigt, so daB sich die Betrachtung auf die Erwerbstätigkeit des überlebenden Ehegatten beschränken kann. Es scheint nicht plausibel anzunehmen, daß der hinterbliebene Ehepartner eine von ihm bis zum Tode des Ehegatten ausgeübte Tätigkeit aufgibt: Ist das mit der Erwerbstätigkeit erzielte Einkommen so gering, daß der Freibetrag nicht überschritten wird, sind die Auswirkungen auf die Hinterbliebenenversorgung sowieso gleich null. Wird mit der Erwerbstätigkeit ein höheres Einkommen erzielt, so daß es zu einer Absenkung der Hinterbliebenenrente käme, müßte für den überlebenden Ehegatten allein der finanzielle Aspekt ausschlaggebend für das Ausüben der Erwerbstätigkeit sein, wenn er sich zur Einschränkung oder Aufgabe der Tätigkeit entschließt. Dies ist mithin unrealistisch, da neben dem Aspekt der Einkommenserzielung vielfältige Gründe (Möglichkeit der Selbstverwirklichung, Kontakte zu anderen Menschen, Kenntniserweiterung u.s.w.) das Ausüben einer Erwerbstätigkeit determinieren und gerade der Tod des Ehepartners führt häufig dazu, in der Er-

${ }^{590}$ Vgl. A. Bokeloh, Die Neuregelung..., a.a.O., S. 283. 
werbstätigkeit noch einen Lebensinn zu sehen, insofern wird der Verzicht auf die Erwerbstätigkeit eher die Ausnahme als die Regel sein.

zu 4. Die Frage nach der Vereinbarkeit mit dem Versorgungsausgleich ergibt sich aus der Tatsache, daß der Versorgungsausgleich zu günstigeren Leistungen führen könne als die Hinterbliebenenrente im Rahmen des Anrechnungsmodells. Wäre dies der Fall, so könne darin eine Verletzung des Art. 6 GG (Schutz von Ehe und Familie) gesehen werden. ${ }^{591}$

Ungereimtheiten ergeben sich in diesem Zusammenhang in der Tat dadurch, daß für den gleichen Tatbestand „Auflösung der Ehe“ unterschiedliche Regelungen gelten. Der Versorgungsausgleich führt zu einer eigenständigen sozialen Sicherung der geschiedenen Frau, die Witwe kann weiterhin nur eine abgeleitete Sicherung beanspruchen. D.h. die Anwartschaften aus einem Versorgungsausgleich werden im eigenen Versicherungsfall der Frau aktiviert, während die Leistung der Witwenrente den Tod des Versicherten voraussetzt. ${ }^{52}$ Die dem ausgleichsberechtigten geschiedenen Ehegatten zugewiesenen Anwartschaften verbleiben ihm in voller Höhe, gleichgültig, welches Einkommen er noch erzielt. Auch im Falle der Wiederheirat der geschiedenen Frau sind ihre Anwartschaften nicht verloren, während bei Wiederheirat der verwitweten Frau die Witwenrente wegfällt. Allerdings kann die Witwe höhere Ansprüche als die geschiedene Frau geltend machen (die Witwenrente beträgt $60 \%$ der Rente des Mannes, die geschiedene Frau erhält lediglich $50 \%$ ), insofern ist sie - gemessen an der Leistung - faktisch bessergestellt als die geschiedene Frau, so daß ein Verstoß gegen Art. 6 GG nicht gegeben ist. ${ }^{593}$

Mit der Einführung des Anrechnungsmodells sollten Konflikte zwischen den einzelnen Gruppen von Rentenbeziehern hinsichtlich veränderter Verteilungswirkungen weitgehend vermieden werden. Dieses scheint realisiert worden sein, angesichts der Tatsache, daß es für die Frauen gegenüber der alten Rechtsregelung keine Verbesserungen bringt, sich aber auch die Verschlechterungen in Grenzen halten, denn durch die Beibehaltung der abge-

\footnotetext{
591 Vgl. ebenda, S. 287.

592 Vgl. ebenda.

593 Vgl. ebenda, S. 288.
} 
leiteten $60 \%$ igen Hinterbliebenenrente unter Berücksichtigung eines Freibetrages wird die Umverteilung zu Lasten der erwerbstätigen Frauen auf ein Minimum reduziert, so da $B$ die Verteilungskonflikte zwischen erwerbstätigen und nichterwerbstätigen Frauen - zumindest gegenwärtig - noch sehr begrenzt sind. Die generelle Beibehaltung der abgeleiteten Sicherung mit dem Hinterbliebenenrentensatz von $60 \%$ vermied und vermeidet eine Konfrontation zwischen alten und neuen Verwitweten, da der soziale Tatbestand „Verwitwung“ jeweils gleich behandelt wird. Eine Betrachtung der gegenwärtigen Situation und der zu erwartenden Entwicklung der gesetzlichen Rentenversicherung läßt vermuten, daß das Institut der abgeleiteten Hinterbliebenenversicherung über kurz oder lang zur Disposition gestellt wird, da es in keiner Weise dem Anspruch einer eigenständigen sozialen Sicherung einer Person gerecht wird. Angesichts der Pluralität der Lebensformen und der desolaten finanziellen Situation der Rentenversicherung werden weitere Reformschritte zur langfristigen Bestandssicherung des Systems unumgänglich sein.

\section{VII. Überlegungen zur systemkonformen Eingliederung}

\section{Alleinerziehender in die Gesetzliche Rentenversicherung}

\section{Allgemeines, Zielsetzungen}

Der materielle Wohlstand breiter Bevölkerungsschichten bewirkt zunehmende Individualisierungstendenzen in unserer Gesellschaft, die sich dahingehend äußern, daß Lebensgenuß und Selbstverwirklichung zum vorrangigen Lebensziel erklärt werden. Dieser Wertewandel im Zuge der Modernisierung des Lebens von Pflicht- und Akzeptanzwerten hin zu Selbstentfaltungswerten findet sein Abbild auch in den Familien. In der Wertehierarchie wird neben der individuellen Freiheit und Unabhängigkeit der materiellen Wohlhabenheit ein hoher Stellenwert zugebilligt, entsprechend gering ist die Präferenz für Kinder. Sie erscheinen weiten Teilen der Gesellschaft kaum den Aufwand wert, den sie verursachen. Übersehen werden von der individualistischen Gesellschaft fatalerweise die mittel- und langfristigen 
Folgen ihres Verhaltens. ${ }^{594}$ So bilden Kinder -gleichgültig, welches System der Alterssicherung die Gesellschaft gewählt hat- nicht nur die Grundlage für die Versorgung der nicht mehr im Erwerbsleben stehenden Personen (Mackenroth-These), sie sind zudem unverzichtbar für den Bestand und die Entwicklung einer Gesellschaft.

Stand früher in erster Linie die Entwicklung der Eigenschaften und Fähigkeiten von Kindern wie Selbständigkeit, Mündigkeit, Opferbereitschaft, Toleranz und Mitverantwortung in der Familie als Gemeinschaft von Mann, Frau und Nachkommen im Mittelpunkt und bildete das Fundament unserer sich ständig wandelnden Gesellschaft, muß heute im Zuge der sinkenden Bereitschaft der Individuen, gesellschaftliche und individuelle Pflichten zu übernehmen und Leistungen zu erbringen, die nicht nur mit Vorteilen für den Einzelnen verbunden sind, im Rahmen der Familienpolitik das Ausmaß des Engagements und der Hilfen für die vielfältigen neuen Lebenslagen der Individuen durch den Staat bestimmt werden.

Dabei bewegen sich staatliche Eingriffe im Spannungsfeld zwischen individuellen und gesellschaftlichen Interessen und müssen insbesondere zwischen dem legitimen Bedürfnis der Kinder nach Geborgenheit in einer Familie, nach persönlicher Zuwendung und Liebe der Eltern und dem verständlichen Streben der Eltern bzw. des Erziehungsberechtigten nach Selbstverwirklichung und Entfaltung abwägen. Neue Lebensformen in der Gesellschaft stellen neue Anforderungen an den Einzelnen und die Solidargemeinschaft und erfordern auf Dauer tragfähige Antworten. Gesellschaftliche Verantwortung und Eigenverantwortung müssen für eine nachhaltige Entwicklung unserer Gesellschaft, gerade auch im Hinblick auf die Erfüllung des Generationenvertrages auch zum Wohle aller Mitglieder in Dekkung miteinander gebracht werden. Dabei ist die Familie einerseits vor staatlicher Bevormundung zu schützen, andererseits ist es die Pflicht des Staates die erzieherischen Kräfte der Familie zu fördern und zu stärken, denn die Entwicklung des Sprach- und Denkvermögens, personale Eigenständigkeit und Gemeinschaftsfähigkeit, Wert- und Verantwortungsbewußtsein hängen wesentlich von der Erziehung in einer Familie, dem ersten und

\footnotetext{
${ }^{594}$ Miegel, Meinhard, Am Ende der Gesellschaft - zerstört uns unsere individualistische Kultur, in: Die Neue Ordnung, 48. Jg 1994, Heft 3, S. 165.
} 
wichtigsten Ort individueller Geborgenheit und Sinnvermittlung, ab. Kindererziehung ist somit eine Leistung, die im Interesse der Allgemeinheit liegt und es ist "heute nicht mehr nur eine Frage der Subsidiarität, an der Familie festzuhalten und sie zu fördern; gerade weil sie der Ort ist, an dem jene Gemeinschaftswerte im Kleinen tagtäglich erlebt und eingeübt werden, die für den Zusammenhalt im Großen so notwendig sind, ist die Stärkung der Familie in unserer Zeit eine staatspolitische Notwendigkeit erster Ordnung"s9s.

Grundlage jeglicher Handlungen des Staates sind die von ihm geschaffenen Gesetze, wobei die behandelte Thematik in erster Linie das Sozialversicherungsgesetz mit seinen Ausführungsgesetzen erfassen wird. Das Sozialversicherungsrecht gründet sich wiederum auf die wesentlichste Rechtsgrundlage eines demokratischen Staates, die Grundrechte.

Gemäß Art. 3 GG, Abs. 1 sind alle Menschen vor dem Gesetz gleich. Diese Gleichheit kann allerdings nur im Zusammenhang mit der Verfassung eines Staates gesehen werden, denn nur wenn ,hinreichend meßbare, justiziable Maßstäbe und Merkmale“" existieren, kann der Gleichheitsgrundsatz angewendet werden, die Gleichheit schlechthin gibt es nicht. Wird der Gleichheitsgrundsatz als oberste Maxime für staatliches Handeln angesehen, gilt diese Gleichheits-Bindung des Gesetzgebers derart, daß wesentlich Gleiches gleich, wesentlich Ungleiches ungleich zu behandeln ist. Es taucht in diesem Zusammenhang unweigerlich die Frage auf, ob die postulierte Gleichheit an absoluten oder relativen Kriterien gemessen werden soll, letzteres erfordert ein Gerechtigkeitsprinzip und die Schaffung einer sich an diesem Prinzip orientierenden Rechtstechnik.

Eine Spezifizierung des allgemeinen Gleichheitsgrundsatzes erfolgt in Art. 3 GG, Abs. 2, der die Gleichberechtigung von Männern und Frauen fordert (dieser Absatz ist am 1. April 1953 in Kraft getreten). Hier wird durch die Verwendung des Begriffes „Gleichberechtigung“ deutlich, daB die natürliche Ungleichheit von Frauen und Männern keineswegs in Frage gestellt werden soll und demzufolge Männer und Frauen nicht ,gleich“ behandelt werden können, sondern lediglich mit den gleichen Rechten ausgestattet werden sollen. Schon aus den Beratungen des Parlamentarischen Rates vor

\footnotetext{
${ }^{595}$ Schäuble, Wolfgang, Und der Zukunft zugewandt, Berlin 1994, S.111.
} 
Einführung dieses Abschnittes geht hervor, daß es nicht darauf ankam eine Gleichheit der Geschlechter zu fingieren, sondern die Gleichwertigkeit von Frauen und Männern zu betonen, so erklärte die Abg. Frau Dr. Selbert (SPD) in der 17. Sitzung des Hauptausschusses des Parlamentarischen Rates am 3.12.1948, die Frau habe ein Recht darauf, „so wie der Mann bewertet zu werden".

Bei näherer Betrachtung des Art. 3 GG läßt sich erkennen, daß dem Merkmal „Geschlecht" eine besondere Bedeutung zugemessen wird, da neben der gesonderten Hervorhebung in Art. 3 GG, Abs. 2 zu Beginn des Abs. 3 desselben Artikels noch einmal das Geschlecht genannt wird, nachdem niemand bevorzugt oder benachteiligt werden soll. Während Art. 3 GG, Abs. 2 also den Charakter einer Generalklausel hat, erfolgt in Abs. 3 eine Spezifizierung der Forderung nach Gleichberechtigung durch das Bevorzugungs- und Benachteiligungsverbot.

Alleinerziehende sind gegenüber Verheirateten und nichtehelichen Lebensgemeinschaften aufgrund ihrer besonderen Lebensumstände häufig nicht in der Lage, die familiären Funktionen vollständig zu erfüllen, so daß es geboten scheint, ihnen eine besondere staatliche Hilfe zuteil werden zu lassen. Herrscht bezüglich der generellen Entscheidung zur Hilfestellung allgemein Einigkeit, so besteht Unsicherheit hinsichtlich der konkreten Ausgestaltung dieser Hilfen. Finanzielle Mittel stehen angesichts leerer Staatskassen nur begrenzt zur Verfügung und eine neue staatliche Aufgabe steht unweigerlich in einem Konkurrenzverhältnis zu allen anderen ausgabewirksamen Funktionen des Staates.

Die o.a. Situation der Alleinerziehenden führt zwangsläufig zu der Forderung, die materielle Lage dieser Personengruppe zu verbessern und damit ihre Erziehungsleistung zu stärken. Eine weitere Verschlechterung der finanziellen und sozialversicherungsrechtlichen Situation dieser Personengruppe würde letztlich zu Lasten der Chancengleichheit der in diesen Familien aufwachsenden Kinder gehen; dies wiederum kann nicht -wie schon oben ausgeführt- familienpolitisches Ziel des Staates sein. Nach Maßgabe zweier Bundesverfassungsgerichtsurteile $(1982,1992)$ ist dem Gesetzgeber die Verbesserung der sozialen Sicherung der Frau auferlegt worden. Bislang ist zwar der Weg hin zu einer eigenständigen sozialen Sicherung der Frau 
angedacht worden, es ist jedoch noch kein sich in die bestehende gesetzliche Rentenversicherung integrierendes geschlossenes Modell realisiert worden.

Ohne das System der gesetzlichen Rentenversicherung in seinen Grundfesten und Prinzipien in Frage zu stellen, müßte der soziale Tatbestand "Erziehung eines Kindes", der seit Einführung der Berücksichtigung von Kindererziehungszeiten bereits Eingang in die Sozialversicherung gefunden hat, zielgerichteter, d.h. mit transparenten Verteilungswirkungen und präziser formuliert, ausgestaltet werden.

Mit der Anrechnung von Erziehungszeiten können eine Reihe relevanter sozialpolitischer Zielsetzungen gleichzeitig verfolgt werden:

1. Eine Leistung, die gesellschaftlich notwendig ist, wird anerkannt und aufgewertet (gesellschaftspolitische Zielsetzung),

2. Es wird auch kindererziehenden Frauen ermöglicht, eine lückenlose „Sozialversicherungsbiografie“ aufzubauen (Erfüllen versicherungstechnischer Voraussetzung)

3. Die Beseitigung von Altersarmut bei Frauen, die wiederum durch das Aufziehen von Kindern den Bestand der Gesellschaft sichern (sozialpolitische Zielsetzung)

4. Der Bestand der Gesellschaft soll langfristig gesichert werden (bevölkerungspolitische Zielsetzung).

Da die gesetzliche Rentenversicherung ohnehin eine Vielzahl von Elementen eines sozialen Ausgleichs enthält, die je nach Zielsetzung von der Versichertengemeinschaft oder aus Mitteln des Bundes bezahlt werden, ist eine Einbeziehung ohne weiteres möglich und sozialpolitisch erwünscht.

Ist es darüber hinaus beabsichtigt, die materielle Situation von Familien während der Expansionsphase (Geburt des ersten Kindes) und der sich anschließenden Phase der Primärsozialisation ${ }^{596}$ zu verbessern, so müssen ergänzend zu den sozialversicherungsrechtlichen Regelungen Transferzahlungen und/oder Steuererleichterungen staatlicherseits gewährt werden. Beide Instrumente sind im Regelwerk der Familienpolitik in Deutschland etabliert, sie bedürfen jedoch ständig der Überprüfung in einer sich immer schneller verändernden Gesellschaft. Auch hier muß weitergehend spezifi-

${ }_{596}$ Vgl. F. Filser, Einführung in die Familiensoziologie, Paderborn u.a.O., 1978, S. 68. 
ziert werden, welche Belastungen der Familien als gravierender empfunden werden: Sollen Eltern ganz oder teilweise von den Unterhaltskosten von Kindern entlastet werden, eignen sich sowohl Steuererleichterungen als auch direkte Transferzahlungen - mit den schon erörterten Vor- und Nachteilen als Instrumente, die allerdings bei kleinen Einkommen und steuerfreien Transfers problematisch sind. Fällt der Ausfall des Einkommens der kindererziehenden Mutter stärker ins Gewicht, kommt nur ein Ausgleich in Form direkter Geldleistungen, wie beispielsweise in Form des Erziehungsgeldes, in Frage.

Die Grundidee des Generationenvertrages, die darauf abzielt, daß der einzelne genausoviel Sozialproduktanteile zurückerhält, wie er in Form von Beiträgen während der Erwerbsarbeit eingezahlt habe, ist als Verteilungsprinzip sozialpolitisch gerechtfertigt. Allerdings nur dann, wenn quasi stillschweigend, ohne eine vertragliche Abmachung, eine zur Bestandserhaltung ausreichende nachwachsende Generation von den jeweils Erwerbstätigen erzeugt und aufgezogen wird. Schon Schreiber selbst und eher noch vehementer Nell-Breuning wiesen auf die Bedeutung dieses dritten Zusammenhangs hinsichtlich der Funktionsfähigkeit eines Umlagesystems hin und sprachen explizit von einem "Drei-Generationen-Vertrag". Demographische Veränderungen wirken sich mit einem time-lag auf ein solches System aus und können zu sozialpolitisch unbefriedigenden Ergebnissen führen, wenn sich das Verhältnis von Beitragszahlern und Rentnern nachhaltig verändert. Wird unterstellt, daß ein echter Transfer von Einkommensteilen in die $\mathrm{Zu}$ kunft nicht möglich ist (Mackenroth-These), ergibt sich daraus, daß die erwerbstätige Bevölkerung stets die Gesamtlasten der Versorgung der nicht mehr aktiven Generation zu tragen hat. ${ }^{597}$ In der Großfamilie konnte das Verhältnis zwischen Güterproduktion und Güterverbrauch noch unmittelbar festgestellt und erlebt werden. Die Verteilung der Leistungen, also der Güterverbrauch, konnte je nach Größe des erwirtschafteten Güterprodukts

\footnotetext{
${ }^{597}$ Vgl. B. Külp, Zur Diskussion um den Generationenvertrag, in: Leitbilder für Familie und Familienpolitik, Festgabe für Helga Schmucker zum 80. Geburtstag, Hrsg. R.v. Schweitzer, Berlin 1981, S. 142.
} 
ständig neu festgelegt und damit angepaßt werden. ${ }^{.98}$ Güterwirtschaftlich gesehen muB die erwerbstätige Generation zwei Leistungen erbringen: ${ }^{599}$

1. die laufenden Betriebskosten aufbringen,

2. eine Investition tätigen, die eine Infrastruktur durch das Aufziehen einer nachwachsenden Generation schafft, die das Sozialprodukt erarbeiten wird, an dem sie zu späterer Zeit teilhaben will.

Die nachwachsende Generation ist damit zwar eine kostspielige, jedoch unentbehrliche Infrastruktur jeder Altersvorsorge.

War es für eine verheiratete Frau in den 50er und 60er Jahren eine beneidenswertes Privileg, nicht erwerbstätig sein zu müssen, so scheint es seit den 70er Jahren eher ein Makel zu sein, auf eine Erwerbstätigkeit zu verzichten und sich völlig dem Haushalt und der Kindererziehung zu widmen. Die Grundlage dieser Meinung ist je nach betrachteter gesellschaftlicher Gruppe unterschiedlich. Während von "emanzipierten" Frauen die fehlende Selbstverwirklichung bei Nichterwerbstätigkeit herausgestellt wird, so erscheint anderen Gruppen die nichterwerbstätige Frau als "Trittbrettfahrer" der Gesellschaft. Auch einige Männer glauben, ihre Ehefrau zu alimentieren. Von Einzelfällen einmal abgesehen, kann keine Rede davon sein, daB der Mann die Frau "versorge", vielmehr besteht zwischen ihnen beiden in einer Lebensgemeinschaft eine klare Arbeitsteilung. ${ }^{600}$

Insofern ist es auch nur systemkonform, wenn mittels Anerkennung von Kindererziehungszeiten der real geleistete Beitrag rentenrechtlich honoriert wird. Dieser Argumentation kann sich offensichtlich der Gesetzgeber anschließen, nichtsdestotrotz hat er im Hinblick auf die Kosten dieser Regelung, Ungereimtheiten und damit in Einzelfällen auch Ungerechtigkeiten produziert.

\footnotetext{
${ }^{598}$ Vgl. Nell-Breuning, O.v., Drei Generationen in Solidarität, Rückbesinnung auf den echten Schreiber-Plan, Köln 1981, S. 31.

${ }^{599}$ Vgl. O.v.Nell-Breuning, Gleichstellung der Frau in der sozialen Rentenversicherung, in: Leitbilder für Familie und Familienpolitik, Festgabe für Helga Schmucker zum 80. Geburtstag, Hrsg. R.v. Schweitzer, Berlin 1981, S. 128.

600 Vgl. O.v. Breuning, Gleichstellung der Frau in der sozialen Rentenversicherung, a.a.O., S. 122.
} 
Ungeachtet der Tatsache, daß die Erziehungsleistung entweder bei allen Müttern gleich (Art. 3 GG) oder überhaupt nicht bewertet werden müßte, führt die derzeitige, aber inzwischen auch vom Bundesverfassungsgericht monierte Lösung dazu, daß je nachdem, ob die Frau gar nicht, teilweise oder ganz beschäftigt ist, die Kindererziehungszeiten zum Teil oder ganz entfallen oder voll angerechnet werden.

Im folgenden sollen nun Möglichkeiten erörtert werden, die bis jetzt eher am Rande stehende Gruppe der Alleinerziehenden in eine umfassendere staatliche Fürsorge einzubinden, sei es durch die Verbesserung der finanziellen Situation einerseits sowie durch die konsequentere Einbindung in das System der Gesetzlichen Rentenversicherung andererseits. Im Hinblick auf die Heterogenität der hier betrachteten Gruppe kann eine für alle gleiche Lösung nicht erarbeitet werden, so daß eine differenzierte Betrachtung der einzelnen Gruppen der Verwitweten, der Geschiedenen, der verheiratet getrennt Lebenden und der Ledigen, die sich weiterhin in Ein-Eltern-Familien und nichtehelichen Lebensgemeinschaften gliedern lassen, vorgenommen wird.

\section{Konzeption}

\subsection{Ledige}

Der Anteil der ledigen Alleinerziehenden an den Alleinerziehenden insgesamt betrug 1991 21,2\%; besonders hoch ist der Anteil Lediger in den neuen Bundesländern mit 33,6\% gegenüber 16,7\% im früheren Bundesgebiet. ErwartungsgemäB handelt es sich überwiegend um jüngere Frauen, gemessen an allen Müttern in der jeweiligen Altersgruppe befinden sich 21,3 $\%$ der ledigen Alleinerziehenden in der Altersklasse unter 25 Jahre, lediglich $4,8 \%$ sind 25 und älter. Dennoch ist es sinnvoll, auf beide Gruppen gesondert einzugehen, zumal da die Anzahl älterer Alleinerziehender langsam aber stetig zunimmt. Offensichtlich trennt aber nicht nur der Altersunterschied die beiden Gruppen, sondern auch eine völlig andersartige Einstellung zum Leben und zur gewünschten Lebensform. Während die überwiegende Zahl der jüngeren Frauen trotz umfassender sexueller Aufklärung 
und freiem Zugang zu allen möglichen Formen der Verhütung mehr oder weniger in ihre Situation ,hineinstolpert“, plant und gestaltet die Gruppe der älteren, ledigen, potentiellen Mütter diese Form des Lebens ganz bewuBt. In einer neueren Untersuchung von Mädje/Neusü $B^{601}$ stellen diese fest, da $B$ die Realisierung eines Kinderwunsches bei einigen Frauen den Wunsch nach einer gemeinsamen Elternschaft dominiert, so daB sich diese Frauen angesichts ihres fortgeschrittenen Alters in einigen Fällen zu einer Entkoppelung der Kinderfrage von der Partnerfrage gezwungen sahen, da sich bislang kein geeigneter Vater für ein Kind finden ließ.602 Die Autorinnen schließen daraus, daß in Zukunft andere Lebensformen als Alternative zur bürgerlichen Kleinfamilie gelebt werden müssen, ${ }^{603}$ „potentiell werden die Männer zu Transitreisenden im Leben der Frauen und Kinder, zu Verweilenden am familiären Rand..." ${ }^{6004}$. Eine derartige Entwicklung würde nicht nur das Bild von der bürgerlichen Familie als anstrebenswerte Lebensform in Frage stellen, sondern hätte erhebliche Auswirkungen auf die Konstruktion und Wirkungsweise des Sozialstaates, mit zunehmender Schwächung der Familie wäre dieser insgesamt in Frage gestellt. Die Rolle des Mannes als lebenslanger Ernährer, Partner und Vater wird von der betrachteten Gruppe Alleinerziehender weder akzeptiert, noch in irgendeiner Weise angenommen. Da aber auch sie entweder nicht in der Lage oder nicht willens sind, ihren Lebensunterhalt allein zu sichern, substituieren sie den familiären Unterhalt durch sozialstaatliche Leistungen und ersetzen die Arbeitsteilung mit einem Mann durch die Arbeitsteilung mit dem Sozialstaat. Wie Mädje/Neusüß bei ihren Befragungen herausfanden, gibt es eine Gruppe von Sozialhilfeempfängerinnen, die die Inanspruchnahme des Sozialstaates nicht als Eingeständnis des Scheiterns oder als Indiz für eine Abhängigkeit sehen, vielmehr erscheint ihnen der Bezug von Sozialhilfe als einklagbares Recht, als eine Selbstverständlichkeit, die ihnen die persönliche Unabhängigkeit garantiert. ${ }^{605}$ Die von der Gesellschaft zur Verfügung gestellten Res-

\footnotetext{
${ }^{601}$ Eva Mädje, Claudia Neusüß, Frauen im Sozialstaat. Zur Lebenssituation alleinerziehender Sozialhilfeempfängerinnen, Frankfurt/M. 1996.

602 Vgl. ebenda, S. 183.

${ }^{603}$ Vgl. ebenda, S. 56.

604 Ebenda, S. 213.

${ }^{605}$ Vgl. ebenda, S. 99.
} 
sourcen, die diese Frauen in Form von Sozialhilfe in Anspruch nehmen, verstehen sie als Lohn, der ihnen für ihre Arbeit als Mütter zusteht, es ist sozusagen ihr legitimes Einkommen. Die befragten Frauen „stellen die Ansprüche, die sie im Prinzip an einen Partner in bezug auf die Verantwortung für die Kinder haben, nun an den Staat. Ihn fordern sie als Versorger ein, der ihnen die ausschließliche Betreuung der Kinder ermöglicht, und/oder als „Partner“, der ihnen verbindlich und zuverlässig die Unterstützung bei der Kinderbetreuung zukommen läßt, die sie sich von den Vätern ihrer Kinder wünschen" ${ }^{\text {6606 }}$.

Diese Frauen gehen sozusagen einen Weg der Arbeitsteilung mit dem Sozialstaat. Gleichheitserwartungen gegenüber Männer ließen sich für sie nicht realisieren, so daß sie diese nun an den Staat und die Gesellschaft richten. Augenscheinlich wird ein quasi individuelles Leben und keine Verantwortung einem gemeinsamen Leben mit gemeinsamer Verantwortung vorgezogen. Übersehen werden in den meisten Fällen von diesen Personen jedoch die neu geschaffenen Abhängigkeiten von den Institutionen des Sozialstaates. Leitmotiv des Handelns ist offenbar ein Wertesystem, das vorgibt, persönlichen Beziehungen zu entfliehen und deren Verlust zugleich zu beklagen, sich aber andererseits in institutionelle Abhängigkeiten zu begeben und den dort erlittenen Verlust an Autonomie nicht wahrzunehmen. ${ }^{607}$

Unter diesem Aspekt scheint die Sozialhilfe für alleinerziehende Frauen nicht nur Folge, sondern auch eine Ursache der Zerstörung der Ehe zu sein. ${ }^{608}$ Gleichwohl kann und darf diese Erkenntnis nun nicht dazu führen, die Sozialhilfe diesem Personenkreis zu verweigern, da dieses notwendigerweise zu einer nicht wünschenswerten Lebenssituation für das Kind führt.

Schwierig gestaltet sich damit die Beantwortung der Frage, ob und inwieweit die soziale Lage dieses Personenkreises durch staatliche Unterstützungszahlungen verbessert werden sollte. Derzeit sind ledige kindererziehende Personen im Regelfall auf die gemäß Bundessozialhilfegesetz gezahlte Hilfe zum laufenden Lebensunterhalt (Sozialhilfe) angewiesen, obwohl seit dem 1.10.1995 der Gesetzgeber die Gesetzeslage über Unterhaltsansprüche

\footnotetext{
606 Ebenda, S. 171.

607 Vgl. A. Schuller, Ernährer, Partner, Vater: Macht der Sozialstaat Ehe und Familie obsolet?, Welt am Sonntag vom 13. Oktober 1996, Nr. 41, S. 37.

${ }^{608}$ Vgl. ebenda.
} 
auch dieses Personenkreises erheblich verbessert hat, indem nun auch die ledige Mutter Unterhaltsansprüche an den Vater des Kindes für ihre Person geltend machen kann. $\S 1615$ BGB besagt, daß bei nachgewiesener Bedürftigkeit der Mutter vom Vater des unehelichen Kindes eine Unterhaltszahlung von mindestens 1 300,-- DM bis maximal dreisiebtel des Einkommens für die Zeit vom 4. Monat vor der Geburt bis 3 Jahre nach der Entbindung des Kindes geleistet werden muß. Aber wie auch schon beim Unterhaltsvorschußgesetz klafft zwischen der juristisch fixierten Gesetzeslage und der tatsächlich zu beobachtenden Situation eine große Lücke, denn ein zugesicherter Anspruch muß auch erst einmal durchgesetzt werden. Die Realität zeigt, daß die Väter entweder keine entsprechenden finanziellen Mittel haben, oder sich dieser Zahlung erfolgreich entziehen können, so daß die finanzielle Lage der Frauen zumeist nach wie vor schlecht ist und staatlicherseits Transferleistungen gewährt werden müssen. Diese sollten jedoch nicht als Regelleistung im System der sozialen Sicherung verankert sein, sondern angepaßt an den Einzelfall und den jeweiligen Bedarf der antragstellenden Person jeweils gesondert bewilligt oder eventuell auch abgelehnt werden. Das soziale Sicherungssystem sollte gesellschaftlich unerwünschte Verhaltensweisen nicht schon ex ante einbeziehen, um diese eventuell dadurch noch zu fördern, sondern sollte Hilfe, wenn sie aus moralischer Sicht unumgänglich sind, außerhalb des Systems gewähren. D.h. wenn die traditionelle Familie als gesellschaftlich gewünschte Maxime angesehen wird, dann sollten andere Lebensformen nicht von vornherein in das System einbezogen werden, sondern als Sonderfall mit eigenen Zielsetzungen behandelt werden.

Im folgenden ausgehend von der Annahme eines mittleren Bildungsabschlußes zuzüglich einer i.d.R. dreijährigen Berufsausbildung der Frau kann vorausgesetzt werden, daß die überwiegende Anzahl der ledigen Alleinerziehenden keine oder nur ungenügende Rentenansprüche vor der Geburt des ersten Kindes erworben hat, es ihr aber noch möglich ist, im Laufe ihrer Versicherungsbiografie solche zu erwerben. Zudem erwirbt sie pro Kind (HEZG) 3 zusätzliche Versicherungsjahre, die -wie schon ausführlich dargestellt- rentenbegründend und rentensteigernd wirken. Der inzwischen realisierte Rechtsanspruch auf einen Kindergartenplatz ab dem 3. Lebensjahr des Kindes läßt zumindest eine Teilzeitarbeit zumutbar erscheinen, so daB 
der Aufbau einer lückenlosen Versicherungsbiografie gewährleistet werden kann. Da die weitaus größte Zahl der Ledigen nur ein Kind erzieht, würde abgesehen von der Problematik, einen geeigneten Arbeitsplatz zu finden, aus rentenversicherungsrechtlicher Sicht nur bedingt Handlungsbedarf bestehen. Faktisch stellt sich die Situation für diese Mütter jedoch sehr viel problematischer dar, denn trotz kollektiver Erziehungseinrichtungen kann die Unterbringung des Kindes häufig nicht so gestaltet werden, daß Berufstätigkeit und Kindererziehung vereinbart werden können. Die Folge ist dann ein Verzicht der Mutter auf das Ausüben einer Erwerbstätigkeit. D.h. nach Auslaufen der Regelung des Kindererziehungszeitengesetz (HEZG) kann die Frau keine oder nur unzureichende (Berücksichtigungszeiten für Kindererziehung) Rentenansprüche aufbauen. Durch das Konzept der abgeleiteten Sicherung, das am Familienstand und nicht am Tatbestand Kindererziehung anknüpft, entsteht hier eine erhebliche Sicherungslücke für alleinerziehende Mütter gegenüber einer verheirateten Frau (sowohl mit als auch ohne Kind), die sozialpolitisch nicht erwünscht sein kann. Zu überlegen ist deshalb, ob die für Kindererziehung angerechnete Versicherungszeit auf 5 Jahre pro Kind ausgedehnt werden sollte, um familienpolitische Zielsetzungen stärker zu berücksichtigen. Allerdings sollte eine solche Regelung von jeder kindererziehenden Person geltend gemacht werden können, unabhängig davon, ob sie in einer vollständigen oder unvollständigen Familie lebt. Die Finanzierung dieser Leistung sollte -geht man vom jetzigen System der Rentenversicherung aus- nicht allein den jetzigen Beitragszahlern aufgebürdet werden, sondern da es sich um einen gesellschaftspolitisch bedeutsamen Tatbestand handelt, sollten alle Mitglieder der Gesellschaft in Form von Steuern ihren Teil dazu beitragen, so daß aus diesen Erwägungen heraus nur eine Steuerfinanzierung in Frage kommen kann. Die bislang geltende Bewertung dieser Zeiten von $\mathbf{7 5 \%}$ des Durchschnittsverdienstes aller Versicherten sollte auf $100 \%$ des Durchschnittsverdienstes angehoben werden. Damit würde der Tatsache Rechnung getragen werden, dab die Erziehung von Kindern eine der Erwerbstätigkeit gleichgestellte Tätigkeit ist. Gilt diese Regelung generell, ist damit ein weiterer Schritt in die Richtung einer eigenständigen sozialen Sicherung der Frau getan. Der Aufbau eigener Ansprüche läßt die bisher geltende Hinterbliebenenversorgung mittel- bis langfristig überflüssig 
werden; schon heute ergibt sich durch das Nebeneinander von eigener und abgeleiteter Sicherung in vielen Fällen eine Überversorgung, die bei Ansatz des Bedarfsprinzips nicht gerechtfertigt erscheint. Rentenversicherungsrechtlich würden damit alle -unabhängig vom Familienstand- gleich behandelt werden, was angesichts der jetzt schon bestehenden Überfrachtung des Systems mit versicherungsfremden Leistungen und den damit verbundenen unüberschaubaren Verteilungswirkungen nur wünschenswert wäre. Für jeden würde die gleiche Beitrags-Leistungsrelation gelten, so daB nicht nur die Tätigkeit der Kindererziehung für alle gleich bewertet ist, sondern auch der Versicherungsgedanke in der gesetzlichen Rentenversicherung gestärkt wird.

Nach Ablauf der fünfjährigen Kindererziehungszeit könnte der Mutter zumindest eine Teilzeitbeschäftigung zugemutet werden, da sich mit zunehmendem Alter des Kindes die Betreuungsproblematik verringert (Vorschule, Schule, Spielgruppen). Da eine Teilzeitbeschäftigung i.d.R. nur zu ungenügenden Ansprüchen führt und der Tatbestand Kindererziehung nach wie vor besteht, wäre es durchaus konsequent, ihn mit $50 \%$ des Durchschnittsverdienstes aller Versicherten zu bewerten, so daß durch die Kombination Teilzeitarbeit und Kindererziehung eine ausreichende soziale Sicherung aufgebaut werden kann. Betragen die durch die Erwerbstätigkeit erworbenen Ansprüche mehr als $50 \%$ des durchschnittlichen Entgelts aller Versicherten, sollte im Zuge der additiven Verrechnung auch ein Gesamtanspruch von über $100 \%$ zur Anrechnung gelangen. Neben der Anerkennung der Doppelbelastung, die die Frau auf sich nimmt, würde diese einen zusätzlichen Anreiz zur Aufnahme einer Erwerbstätigkeit bewirken.

Die erweiterte Anerkennung von Erziehungszeiten führt nicht unmittelbar zu höheren Ausgaben, da entsprechende Geldleistungen erst im Alter oder bei vorzeitigem Eintritt des Versicherungsfalles fällig werden. Bei unverändertem System (Umlageverfahren) würden jedoch die aufgezogenen Kinder die Renten ihrer Mütter finanzieren. Bedenken hinsichtlich der Finanzierung dieser langfristig hohen Zusatzlast in einer Zeit, in der es - nach heutigem dafürhalten - fraglich ist, ob überhaupt die bestehenden Verpflichtungen erfüllt werden können, sind durchaus berechtigt. Finanzieller Spielraum könnte durch die gänzliche Abschaffung der abgeleiteten Hinterblie- 
benenversorgung und durch die erhöhte Inanspruchnahme Kinderloser gewonnen werden. Letzteres wäre gegeben, wenn Erziehungszeiten aus Steuermitteln finanziert würden; damit würden diejenigen stärker belastet werden, die überproportional zum Steueraufkommen beitragen und dieses sind i.d.R. kinderlose Doppelverdiener.

\subsection{Verheiratet Getrennt Lebende}

1991 waren 9,1\% aller Alleinerziehenden (alte Bundesländer) getrennt lebende verheiratete Ehepartner. In diesen Familien lebten 1,9\% aller minderjährigen Kinder. Während die Zahl der Kinder, die bei ihrem Vater leben, leicht zurückging (1981: 0,4\%, 1991: 0,3\%), stiegen sie bei den getrennt lebenden verheirateten Müttern kontinuierlich an (1972: 0,5\%, 1981: 1,3\%, 1991: 1,6\%). Da seit Inkrafttreten des Scheidungsgesetzes 1977 einerseits die Zahl der Frauen zugenommen hat, die die Scheidung einreichen, andererseits in den meisten Fällen ein Trennungsjahr zwingend vorgeschrieben ist, kann vermutet werden, daß diese Kinder in absehbarer Zeit Scheidungswaisen sein werden.

Bei den verheiratet getrennt lebenden Alleinerziehenden handelt es sich im wesentlichen um die Gruppe derjenigen, die aufgrund gesetzlicher Bestimmungen ein bzw. drei Jahre bis zu ihrer endgültigen Scheidung getrennt leben müssen. Vernachlässigbar gering ist die Anzahl der Personen, die dauerhaft getrennt leben und zudem Kinder erziehen.

Im Vergleich zu allen anderen betrachteten Gruppen erfahren diese Personen verhältnismäßig wenig Veränderungen, insbesondere im Bereich der sozialen Sicherung. Während der Zeit des Getrenntlebens ist die Alleinerziehende mit ihren Kindern in die beitragsfreie Familienversicherung der Gesetzlichen Krankenversicherung des Ehepartners eingebunden. In der Gesetzlichen Rentenversicherung erwirbt sie auch ohne eigene Erwerbstätigkeit Versicherungszeiten, entweder aufgrund des Tatbestands Kindererziehung oder durch die Erwerbstätigkeit des Ehepartners, da im Falle einer Scheidung im Rahmen des Versorgungsausgleichs die Hälfte der von ihm erworbenen Anwartschaften ihr zugesprochen werden. 
Wie auch schon für die Gruppe der Ledigen gefordert, sollte der Tatbestand "Kindererziehung" in der GRV durch Anrechnung von 5 Jahren pro Kind stärker Berücksichtigung finden, um vor allem auch keine Ungleichbehandlung beim gleichen sozialen Tatbestand zu konstruieren.

Die verheiratet getrennt lebende Ehefrau mit Kindern hat gemäß 1361 Abs.I BGB während der Dauer des Getrenntlebens einen Unterhaltsanspruch. Maßgeblich für die Höhe dieses Unterhalts ist Bedürftigkeit, die i.d.R. mit minderjährigen Kindern gegeben ist, und die Leistungsfähigkeit des Ehepartners. Im einzelnen sind folgende Kriterien relevant:

- die persönlichen Verhältnisse,

- die frühere Erwerbstätigkeit der

kindererziehenden Person,

- die Dauer der Ehe,

- die wirtschaftlichen Verhältnisse

beider Ehepartner.

Die Inkonsistenz bei der Behandlung der einzelnen Personen in den verschiedenen Gruppen wird besonders deutlich in der Besonderheit, die für diese Personengruppe gilt, weil voreheliche, nicht gemeinsame Kinder ebenso wie eheliche gemeinsame, während der Zeit der Trennung einen Unterhaltsanspruch begründen können.

Liegt der faktisch gezahlte Unterhalt unterhalb der Sozialhilfegrenze, wird von staatlicher Seite Sozialhilfe gewährt.

Wie in allen Lebensformen, in denen Kinder erzogen werden, sollte das Wohl dieser Kinder im Mittelpunkt der Betrachtung stehen und jegliche Leistungen für Alleinerziehende, die die Gesellschaft bereit ist, zur Verfügung zu stellen, sollten dazu führen, daß Kinder, die in unvollständigen Familien aufwachsen nicht schlechter gestellt sind als Kinder, die in einer vollständigen Familie aufwachsen. Die Verbesserung der Lebensbedingungen und der Erhalt gleicher Startchancen der Kinder muß bei der Ausgestaltung der Leistungen an die Personengruppe der Alleinerziehenden in der Zielhierarchie oberste Priorität genießen, da sie für den für sie unbefriedigenden und in hohem Maße seelisch belastenden Zustand nicht noch bestraft werden sollten. Sie, die diesen Zustand i.d.R. weder gewollt noch herbeige- 
führt haben, sind gröBtenteils die Leidtragenden in der Trennungssituation der Eltern.

Sozialpolitisch erwünschte Leistungen an die betrachtete Personengruppe können zwei Zielsetzungen verfolgen: Zum einen kann die soziale Lage der Betroffenen als nicht wünschenswert angesehen werden und eine Verbesserung angestrebt werden, zum anderen kann die Stellung in der Sozialversicherung eine maßgebliche Zielgröße sein. Diese Ziele schließen sich nicht aus, und können infolgedessen auch gleichzeitig realisiert werden.

Wie oben schon angesprochen, bleibt während des getrenntlebens von Ehepartnern die Stellung beider in der Sozialversicherung und auch im Steuerrecht gleich, so daß sich in dieser Zeit keine besonderen Benachteiligungen für die Ehegatten ergeben. Der erwerbstätige Ehepartner ist vollständig in das System der sozialen Sicherung eingebunden ${ }^{609}$, der nichterwerbstätige Ehepartner partizipiert durch eine abgeleitete Sicherung bzw. durch die Einbindung im Rahmen der Familienversicherung an den Leistungen des Systems. Die Ehe besteht offiziell nach dem Gesetz auch in der Zeit des getrenntlebens und dieses ist maßgeblich für die Anwendung des Sozialversicherungsrechts.

Annähernd unproblematisch ist es, wenn beide Ehepartner auch schon zu Zeiten des "Bestands" der Ehe erwerbstätig waren und dies auch nach der Trennung bleiben, da die Erwerbstätigkeit die Einbindung in das Sozialversicherungssystem garantiert. Sichergestellt ist in beiden Fällen (erwerbstätig, nichterwerbstätig) die Absicherung gegen Krankheit, auch für die vorhandenen Kinder. Sind beide Ehepartner erwerbstätig, sind sie auch in das System der Arbeitslosenversicherung eingebunden und können im Falle des Eintretens des sozialen Tatbestands "Arbeitslosigkeit" Leistungen aus diesem Zweig der Sozialversicherung geltend machen. Da dieser Bereich der Sozialversicherung noch am ehesten dem Grundgedanken des Versicherungsprinzips entspricht, sollte es auch in Zukunft vermieden werden, sozialpolitisch eventuell erwünschte, aber das System belastete Leistungen für bestimmte Personenkreise, dort einzubauen, Umverteilungen aus sozialpoli-

\footnotetext{
${ }^{609}$ Generelle Kritikpunkte am System der sozialen Sicherheit in Deutschland finden sich an anderen Stellen in dieser Arbeit und sollen hier nicht weiter erörtert werden.
} 
tischen Erwägungen heraus verfälschen die Idee der Versicherung und führen in vielen Fällen auch nicht unbedingt zu dem gewünschten Ergebnis.

Die seit 1995 eingeführte Pflegeversicherung ist im betrachteten $\mathrm{Zu}$ sammenhang von nachrangiger Bedeutung und soll deshalb an dieser Stelle vernachlässigt werden.

Erwerbstätigkeit führt auch zum Aufbau eigener Rentenansprüche, die bei nachfolgender Scheidung im Zuge des Wertausgleichs bei Durchführung des Versorgungsausgleichs mit dem Partner geteilt werden müssen. War die Frau auch während der Zeit der Kindererziehung ständig erwerbstätig, stellt sich auch hier wieder die Frage, inwieweit eine Bewertung der Zeiten der Erwerbstätigkeit und der Kindererziehung erfolgen soll. Wie schon im Rahmen dieser Arbeit ausgeführt, sollten Kindererziehungszeiten additiv angerechnet werden, eine besondere Regelung für den Kreis der Alleinerziehenden sollte nicht geschaffen werden, da Gleiches (= Kindererziehung) auch Gleich behandelt werden sollte, wozu das Grundgesetz (Art. 3) im übrigen verpflichtet. Die Tatsache, daB für Alleinerziehende erschwerte Bedingungen gelten, soll an dieser Stelle nicht übersehen werden, jedoch könnten außerhalb des Systems der Rentenversicherung Ausgleichsmaßnahmen als Kompensation für diese schwierige Lebenslage gefunden werden, so da $B$ die Rentenversicherung, die in ihrem Kern eine Versicherung sein sollte, nicht zum sozialen Ausgleich genutzt wird.

Schwieriger wird es, die soziale Lage dieses Personenkreises zu beurteilen, da die Datenlage bzgl. der Einkommenssituation äußerst dürftig ist. Da die Ehe theoretisch noch Bestand hat, gelten alle mit ihr verbundenen Rechte und Pflichten weiterhin ohne Einschränkungen, im Prinzip für beide Ehepartner. Faktisch ist dieses jedoch höchst problematisch: GemäB BGB sollen die in einer Ehe und Familie anfallenden Aufgaben partnerschaftlich auf die Ehepartner verteilt werden. Jeder hat dann, dieser Aufgabenteilung zufolge, auch an dem Ergebnis zu partizipieren. Gesetzt den Fall, der Ehemann war während der Zeit des Zusammenlebens erwerbstätig, der Ehefrau oblag die Haushaltsführung und Kindererziehung. Kommt es zur Trennung, ist es relativ unproblematisch, den monetär erbrachten Betrag nach einem vereinbarten Schlüssel zu trennen, die bis dahin erbrachten nichtmonetären Leistungen in der Lebensgemeinschaft können jedoch nur schwer- 
lich beibehalten werden. Es kommt zwangsläufig zu einer Ungleichverteilung der Rechte und Pflichten. Zudem ist zu erwarten, daß das Erwerbseinkommen des Mannes nicht ausreicht, um dann zwei Haushalte zu finanzieren. Eine doppelte Haushaltsführung läBt zwar die variablen Kosten nur unterproportional ansteigen (die Ausgaben für Ernährung und Kleidung werden sich durch die neue Situation nur wenig verändern), führt aber zu einem erheblichen Anstieg der Fixkosten (Miete, Energiekosten, Kosten der Mobilität). Letztendlich führt also der Unterhaltsanspruch der Ehefrau gegenüber dem Ehemann nur dazu, daß beide sich verschlechtern und im Extremfall am Existenzminimum oder sogar darunter leben müssen. Da der Zustand des verheiratet getrenntlebens in den meisten Fällen nur die Vorstufe zu einer beabsichtigten Scheidung darstellt, findet sich dieses Problem auch bei den Geschiedenen, allerdings haben die Betroffenen einen anderen rechtlichen Status, der ihnen beispielsweise im Steuerrecht weitere Kompensationsmöglichkeiten eröffnet. Die vom Gesetzgeber intendierte Prüfung der Trennungsentscheidung von zwei Ehepartnern führt also - zumindest zwischenzeitlich - zu einer juristisch nicht klar abgrenzbaren Konstellation mit wirtschaftlichen und sozialen Problemen für die Betroffenen.

Existiert in der Gesellschaft eine Optionsmöglichkeit für verschiedene Lebensformen, stellt sich die Frage, inwieweit die Gesellschaft die Folgen von Individualentscheidungen, von denen der einzelne meint sie treffen $\mathrm{zu}$ müssen, tragen soll. Zwischen den Extremen, daß jeder die Konsequenzen seines Handels vollständig selbst zu tragen hat und einer gänzlichen Übernahme aller finanziellen Belastungen durch die Gesellschaft, die beide als irrelevant eingestuft werden, liegt dann letztlich die Lösung des Problems. Sind in einer Ehe keine Kinder vorhanden und entscheiden sich beide Ehepartner zu einer Trennung, können sie darauf verwiesen werden, mittels eigener Anstrengung zukünftig ihren Lebensunterhalt zu sichern, auch wenn damit ein Absinken des bisherigen Lebensstandards verbunden ist. Gefordert ist die Gesellschaft nur dann, wenn aus der Ehe Kinder hervorgegangen sind. Ihnen darf aus der Entscheidung der Eltern kein Nachteil entstehen, der ihre Sozialisationschancen mindert. Von humanitären, moralischen und christlichen Gesichtspunkten einmal abgesehen, hat die Unterstützung durch die Gesellschaft auch eine ganz klare ökonomische Komponente. Die unge- 
nügende Sozialisation von Kindern führt häufig zu gesellschaftlich unerwünschten Verhaltensweisen im Erwachsenenalter, deren finanzielle Folgen dann auch von der Gesellschaft getragen werden müßten (Bsp.: Kriminalität) und unter Umständen ein Vielfaches der ursprünglichen Kostenbelastung ergeben. Darüber hinaus sollte eine hochentwickelte Gesellschaft ständig bemüht sein, ihre Ausstattung mit Humankapital zu verbessern und infolgedessen keine Chance ungenutzt lassen, die nachwachsende Generation zu fördern, da der zukünftige Wohlstand in hohem Maße davon abgängt. Daraus folgt, daB die entstehenden Sozialisationskosten von der Gesellschaft im Rahmen der Umverteilung getragen werden sollten, allerdings nur in dem Ausmaß, wie die Eltern selbst dazu nicht in der Lage sind. Die Eigenverantwortung der Eltern muß bestehen bleiben, wenn die individualistischfreiheitliche Gesellschaftsordnung Bestand haben soll.

Da schon das Scheidungsrecht bei der Bemessung der Ansprüche nicht mehr vom Kausalprinzip ausgeht, sollte es auch für die Gruppe der verheiratet getrennt Lebenden keinen Belang haben. Sinnvoll erscheint es dann aus ökonomischer Sicht, das Finalprinzip anzuwenden, welches auf die soziale Lage des einzelnen oder der Familie abstellt und daraus eine Sozialleistung ableitet. Obwohl ihrem Wesen nach das Versicherungsprinzip nicht auf Bedürftigkeit abstellt, sollten für über das Existenzminimum hinausgehende Leistungen deren Dringlichkeit geprüft werden, damit die Mentalität einer „Vollkasko-Absicherung“" vermieden wird.

Auch wenn vielfach behauptet wird, Bedürftigkeitsprüfungen verletzten die Würde der bedürftigen Personen und sollten demzufolge völlig abgeschafft werden, scheint es nur konsequent, daB in diesem Fall die Person, die nicht unverschuldet in Not geraten ist, ihre wirtschaftliche Lage offenlegt, wenn sie Ressourcen von der Gesellschaft beanspruchen will. Zudem sollten, aus der Idee des Subsidiaritätsprinzips heraus, die Rahmenbedingungen so gesetzt werden, daB die Alleinerziehende so bald wie möglich in die Lage versetzt wird, die Situation selbst zu meistern. Konkret heiBt dies, die Betreuungsmöglichkeiten für Kinder dieses Personenkreises zu verbessern, die Wiedereingliederung ins Berufsleben zu ermöglichen und nicht zuletzt für eine ausreichende Anzahl von Arbeitsplätzen zu sorgen, damit eine eigen- 
ständige Versorgung ermöglicht wird und die Gesellschaft aus ihrer Pflicht entlassen werden kann.

\subsection{Geschiedene}

Die Geschiedenen, und hier insbesondere die geschiedenen Frauen, stellen mit 38,6 \% (Mikrozensus 1991, alte und neue Bundesländer) die größte Gruppe innerhalb der Alleinerziehenden. Die Zahl der Ehescheidungen hat seit dem vorigen Jahrhundert in Deutschland bis in die Gegenwart stetig zugenommen. ${ }^{610}$ Unter den gegenwärtigen Verhältnissen werden etwa $30 \%$ der geschlossenen Ehen wieder geschieden, derzeit stehen 400.000 Eheschließungen etwa $\mathbf{1 3 0 . 0 0 0}$ Ehescheidungen gegenüber, d.h. auf jede dritte Eheschließung kommt eine Ehescheidung. Männer sind besonders betroffen im Alter von 30 bis unter 40 Jahren, Frauen im Alter von 25 bis unter 35 Jahren. Die Scheidungshäufigkeit hat seit der Reform des Scheidungsrechts 1977 zugenommen, wobei es bemerkenswert ist, daß die Scheidung in der Mehrzahl der Fälle von den Frauen angestrebt wird.

Abgesehen davon, daß das Scheidungsverfahren beim Übergang vom Schuldprinzip zum Zerrüttungsprinzip erheblich entemotionalisiert wurde und damit reibungsloser durchgeführt werden kann, tragen sicherlich auch die Bestimmungen über die Versorgung des geschiedenen Ehepartners dazu bei, daß eine Scheidung schneller in das Kalkül der Lebensplanung einbezogen wird. Besonders Frauen, die erwarten können, daß ihnen das Sorgerecht für die Kinder zugesprochen wird, haben hinsichtlich des finanziellen Unterhalts „das Recht auf ihrer Seite“.

610 Vgl. Bundesministerium für Familie und Senioren, Familien und Familienpolitik im geeinten Deutschland - Zukunft des Humanvermögens, Fünfter Familienbericht, Bonn 1994, S. 52. 
Tabelle 56: Ehescheidungen 1950 - 1988

\begin{tabular}{|c|c|c|c|c|}
\hline Jahr & Insgesamt & Je 10 & $\begin{array}{l}\text { Bestehende } \\
\text { Ehen }\end{array}$ & $\begin{array}{l}\text { Verhältnis zur } \\
\text { Zahl der Ehe- } \\
\text { schlieBungen (auf } \\
100 \text { geschlossene } \\
\text { Ehen kommen ... } \\
\text { Ehescheidungen) }\end{array}$ \\
\hline $1950 \ldots$. & 84740 & 16,9 & 67,5 & 15,8 \\
\hline $1960 \ldots$. & 48878 & 8,8 & 35,0 & 9,4 \\
\hline $1975 .$. & 106829 & 17,3 & 67,4 & 27,6 \\
\hline $1976 \ldots . .$. & 108258 & 17,5 & 68,8 & 29,6 \\
\hline $1977 \ldots$. & 74658 & 12,2 & 47,7 & 20,8 \\
\hline $1978 \ldots$ & 32462 & 5,3 & 20,8 & 9,9 \\
\hline $1980 \ldots$ & 96222 & 15,6 & 61,3 & 26,6 \\
\hline $1985 \ldots$ & 128124 & 21,0 & 86,1 & 35,1 \\
\hline $1986 \ldots$ & 122443 & 20,1 & 82,6 & 32,9 \\
\hline $1987 \ldots$. & 129850 & 21,2 & 87,6 & 33,9 \\
\hline $1988 \ldots . .$. & 128729 & 21,0 & $\ldots$ & 32,4 \\
\hline
\end{tabular}

Ergebnis der Statistik der natürlichen Bevölkerungsbewegung in Verbindung mit Ergebnissen von Volkszählungen und Bevőlkerungsfortschreibung.

Quelle: Familie heute, Ausgabe 1990, S. 127. 
Tabelle 57: Ehescheidungen nach dem Antragsteller

\begin{tabular}{|c|c|c|c|}
\hline \multicolumn{4}{|c|}{ a) Vor der Reform des Scheidungsrechts 1977 gelöste Ehen } \\
\hline Kläger(in) & 1950 & 1960 & 1970 \\
\hline Mann........ & 41057 & 16199 & 22840 \\
\hline Dar. Widerklage der Frau & 19434 & 7903 & 10469 \\
\hline Frau........ & 44927 & 33052 & 53852 \\
\hline Dar. Widerklage des Mannes & 17186 & 8426 & 14475 \\
\hline Staatsanwaltschaft..... & 357 & 74 & 19 \\
\hline Insgesamt..... & 86341 & 49711 & 76711 \\
\hline \multicolumn{4}{|c|}{ b) Nach der Reform des Scheidungsrechts 1977 gelöste Ehen } \\
\hline Antragsteller(in) & 1980 & 1987 & 1988 \\
\hline \multicolumn{4}{|l|}{ Mann } \\
\hline Ohne Zustimmung der Frau... & 6467 & 6224 & 5913 \\
\hline Mit Zustimmung der Frau..... & 24042 & 37229 & 37902 \\
\hline Zusammen..... & 30509 & 43453 & 43815 \\
\hline \multicolumn{4}{|l|}{ Frau } \\
\hline Ohne Zustimmung des Man- & 13127 & 11773 & 11016 \\
\hline nes..... & 43611 & 62974 & 62127 \\
\hline $\begin{array}{l}\text { Mit Zustimmung des Man- } \\
\text { nes..... }\end{array}$ & & 74747 & 73143 \\
\hline Zusammen..... & 56738 & 11788 & 11927 \\
\hline Beide Ehegatten..... & 21 & 22 & 12 \\
\hline Staatsanwaltschaft..... & 96351 & 130010 & 12889 \\
\hline Insgesamt..... & & & \\
\hline
\end{tabular}

Ergebnis der Statistik der natürlichen Bevőlkerungsbewegung.

Quelle: Familien heute, Ausgabe 1990, S. 135.

D.h. hat der geschiedene Ehemann ein ausreichend hohes Einkommen, ist auch der Unterhalt der geschiedenen Ehefrau mit ihren Kindern gesichert. Die Entscheidung zur Trennung wird unter diesen Umständen sicher- 
lich schneller und leichter gefällt als in Erwartung großer ökonomischer Unsicherheit. In annähernd $50 \%$ aller geschiedenen Ehen sind minderjährige Kinder vorhanden, $31.5 \%$ haben ein Kind, 14,8 \% zwei Kinder und 3,4 \% drei und mehr Kinder. ${ }^{611}$ Die Anzahl der vorhandenen Kinder scheint also ebenfalls die Trennungsentscheidung in nicht unerheblichem Umfang zu beeinflussen. Immer mehr Ehen werden aufgrund einer einvernehmlichen Scheidung nach einjähriger Trennung gelöst, waren es 1980 noch $49 \%$ stieg dieser Anteil im Jahre 1988 auf $65 \%$ an.

Tabelle 58: Geschiedene Ehen nach Art der „Entscheidung in der Ehesache" $^{\text {" }}$

\begin{tabular}{|c|c|c|c|c|c|c|}
\hline \multirow{2}{*}{ Entscheidung in der Ehesache nach BGB } & \multicolumn{2}{|c|}{1980} & \multicolumn{2}{|c|}{1987} & \multicolumn{2}{|c|}{1988} \\
\hline & Anzahl & $\%$ & Anzahl & $\%$ & Anzahl & $\%$ \\
\hline $\begin{array}{l}\text { § } 1565 \text { Abs. } 1 \text { i.V.m. } \S 1565 \text { Abs. } 2 \\
\text { (vor einjähriger Trennung) }\end{array}$ & 7778 & 8,1 & 5875 & 4,5 & 5519 & 4,3 \\
\hline $\begin{array}{l}\text { § } 1565 \text { Abs. } 1 \\
\text { (nicht einverständliche Scheidung nach ein- } \\
\text { jāhriger Trennung) }\end{array}$ & 32574 & 33,9 & 25560 & 19,7 & 25378 & 19,7 \\
\hline $\begin{array}{l}\text { § } 1565 \text { Abs. } 1 \text { i.V.m. § } 1566 \text { Abs. } 1 \\
\text { (einverständliche Scheidung nach einjāhriger } \\
\text { Trennung) }\end{array}$ & 47219 & 49,1 & 83983 & 64,7 & 83057 & 64,5 \\
\hline $\begin{array}{l}\text { § } 1565 \text { Abs. } 1 \text { i.V.m. } § 1566 \text { Abs. } 2 \\
\text { (nach dreijähriger Trennung) }\end{array}$ & 8280 & 8,6 & 14024 & 10,8 & 14174 & 11,0 \\
\hline Aufgrund anderer Vorschriften & 371 & 0,4 & 408 & 0,3 & 601 & 0,5 \\
\hline Scheidungen insgesamt & 96222 & 100 & 129850 & 100 & 128729 & 100 \\
\hline
\end{tabular}

Ergebnis der Statistik der natürlichen Bevölkerungsbewegung.

Quelle: Familien heute, Ausgabe 1990, S. 136.

611 Statistisches Bundesamt, Familien heute, Strukturen, Verläufe und Einstellungen, Ausgabe 1990, S. 134. 
Rückläufig ist die nicht-einvernehmliche Scheidung nach einjähriger Trennung, waren es 1980 noch $34 \%$, so sank dieser Anteil bis 1988 auf 20 $\%$.

Trotz der umfassenden und rechtlich einklagbaren Ansprüche, die diese Gruppe von Alleinerziehenden hat, finden sich auch hier zahlreiche Fälle, in denen eine unzureichende Versorgung eine finanzielle Unterstützung unumgänglich erscheinen läßt.

Tabelle 59: Geschiedene Ehen nach der Zahl der minderjährigen Kinder in der Familie

\begin{tabular}{|c|c|c|c|c|c|c|}
\hline $\begin{array}{l}\text { Gegenstand der } \\
\text { Nachweisung }\end{array}$ & 1950 & 1960 & 1970 & 1980 & 1987 & 1988 \\
\hline \multicolumn{7}{|c|}{ Anzahl } \\
\hline $\begin{array}{l}\text { Geschiedene Ehen } \\
\text { Insgesamt 1)... }\end{array}$ & 84740 & 48878 & 76520 & 96222 & 129850 & 128729 \\
\hline Davon: & & & & & & \\
\hline Ohne Kinder... & 36062 & 20635 & 27764 & 45344 & 63191 & 64741 \\
\hline Mit Kindern... & 48612 & 28238 & 48756 & 50878 & 66659 & 63988 \\
\hline Mit 1 Kind... & 27443 & 16975 & 25819 & 30011 & 42863 & 40581 \\
\hline $\begin{array}{l}\text { Mit } 2 \text { Kindern... } \\
\text { Mit } 3 \text { und mehr }\end{array}$ & 13256 & 7550 & 14551 & 15641 & 19562 & 19091 \\
\hline $\begin{array}{l}\text { Kindern... } \\
\text { Betroffene Kinder }\end{array}$ & 7913 & 3713 & 8386 & 5226 & 4234 & 4316 \\
\hline Insgesamt... & 83296 & 45067 & 86057 & 78972 & 95740 & 92785 \\
\hline $\begin{array}{l}\text { Gegenstand der } \\
\text { Nachweisung }\end{array}$ & 1950 & 1960 & 1970 & 1980 & 1987 & 1988 \\
\hline
\end{tabular}




\begin{tabular}{|l|r|r|r|r|r|r|}
\hline \multicolumn{7}{|c|}{ Prozent } \\
\hline Geschiedene Ehen & & & & & & \\
insgesamt ... & 100 & 100 & 100 & 100 & 100 & 100 \\
& & & & & & \\
Davon: & 42,6 & 42,2 & 36,3 & 47,1 & 48,7 & 50,3 \\
Ohne Kinder... & 57,4 & 57,8 & 63,7 & 52,9 & 51,3 & 49,7 \\
Mit Kindern... & 32,4 & 34,7 & 33,7 & 31,2 & 33,0 & 31,5 \\
Mit 1 Kind... & 15,6 & 15,4 & 19,0 & 16,3 & 15,1 & 14,8 \\
Mit 2 Kindern... & & & & & & \\
Mit 3 und mehr & & & & & & \\
Kindern... & & & & & & \\
\end{tabular}

*) Ergebnis der Statistik der natürlichen Bevőlkerungsbewegung

1) Einschl. der Fălle mit unbekannter Kinderzahl.

Quelle: Familie heute, Ausgabe 1990, S. 134

Für die Ausgestaltung sozialpolitisch motivierter Hilfen muB zuerst einmal wieder klar getrennt werden zwischen der Verbesserung der sozialen Lage dieses Personenkreises und der Eingliederung der geschiedenen Personen mit ihren Kindern in das System der sozialen Sicherung.

GemäB Art. 3 GG müssen gleiche soziale Tatbestände in gleicher Weise behandelt werden, insofern ist es nur konsequent, den Tatbestand „Kindererziehung" in der Weise zu honorieren wie bei allen anderen kindererziehenden Frauen auch. Es wird also auch an dieser Stelle erneut gefordert, die Kindererziehungszeit in erweiterter Form (5 Jahre pro Kind) als Rentenversicherungszeit anzuerkennen, die Bewertung auf $100 \%$ des Durchschnittsverdienstes aller Versicherten anzuheben und die anfallenden Beitragszahlungen auf die Gesellschaft abzuwälzen, indem die Zahlung an den Rentenversicherungsträger aus dem allgemeinen Steueraufkommen erfolgt. Beiträge sollten auch für diese Zeit entrichtet werden, um in der Rentenversicherung möglichst keine weitere Verwässerung des Versicherungsprinzips herbeizuführen. Eine Überfrachtung des Systems mit weiteren beitragsfrei- 
en Elementen würde dem Versicherungsgedanken zuwider laufen und auBerdem die erwünschten Verteilungswirkungen nicht erzielen.

Mit Einführung des Versorgungsausgleichs ist der Gedanke der Zugewinngemeinschaft in der Ehe auch auf das System der Rentenversicherung übertragen worden. Gemeinsame Ehejahre werden, auch ohne daß die Frau durch Erwerbstätigkeit eigene Ansprüche erworben hat, im Versorgungsausgleich anerkannt. Keine andere Gruppe der Alleinerziehenden hat die Möglichkeit auf diese Weise eine eigenständige soziale Sicherung aufzubauen, einmal abgesehen von den Getrenntlebenden, die sich noch in einer Ehesituation befinden, die dann i.d.R. ebenfalls durch eine Scheidung beendet wird. Es leuchtet nicht unmittelbar ein, für eine Gruppe von Versicherten die Möglichkeit einer eigenständigen sozialen Sicherung zu schaffen, sie anderen Gruppen jedoch vorzuenthalten. Gerade der Vergleich mit den Regelungen der Hinterbliebenenversorgung zeigt die unsystematische Behandlung versicherungsmäßig gleicher Tatbestände: In beiden Fällen handelt es sich um den objektiv gleichen Tatbestand „Auflösung der Ehe“, die rentenversicherungsmäßigen Auswirkungen sind jedoch unterschiedlich. Die Witwe erhält $60 \%$ der Ansprüche ihres versicherten Ehepartners gegenüber 50 $\%$ bei Aufteilung der Ansprüche im Versorgungsausgleich, entscheidend ist jedoch, daB es sich bei der Versorgung der Witwe um eine abgeleitete Sicherung handelt, in die zudem Bedarfselemente eingebaut wurden (Anrechnungsmodell), bei Wiederheirat entfällt sie gänzlich. Folgt der Gesetzgeber in diesen Fällen dem Grundsatz der Bedarfsgerechtigkeit, so fließen in die Behandlung der Geschiedenen Elemente des Grundsatzes der Leistungsgerechtigkeit ein. Der Anspruch aus dem Versorgungsausgleich richtet sich sozusagen nach der ,in der Ehe erbrachten Leistung“, unabhängig davon, ob die Geschiedene dieser sozialen Sicherung bedarf oder ob sie anderweitig (privat) gesichert ist. Schon aus dem Grundsatz der Gleichbehandlung gleicher objektiver Tatbestände (Art. 3 GG) kann eine Angleichung der Regelungen für Geschiedene und Witwen gefordert werden, wobei es, angesichts der seit langem geführten Diskussion über die eigenständige Sicherung der Frau, plausibel ist, die Hinterbliebenenversorgung in ihrer jetzigen Form vollständig abzuschaffen. W. Albers ${ }^{612}$ schlägt in diesem Zusammenhang vor,

${ }^{612}$ Vgl. W. Albers, Kindererziehung und Alterssicherung, a.a.O., S. 525. 
daß die Rentenansprüche von Mann und Frau in der Ehe eine Einheit bilden und jedem Partner zu gleichen Teilen zugerechnet werden (dieses ist nichts anderes, als die dem Versorgungsausgleich zugrunde liegende Idee). Im Gegensatz zur Regelung im Falle der Scheidung, fordert Albers einen Anteil von über $50 \%$ der gemeinsamen Rente, „da ein nicht kleiner Teil der Haushaltsausgaben feste Kosten sind, die beim Tod eines Partners nicht wegfallen“.613 Außerdem wäre die Besserstellung Verheirateter gegenüber Geschiedenen durch Art. 6 GG gedeckt, der Ehe und Familie unter besonderen Schutz der staatlichen Ordnung stellt. ${ }^{614}$ Dieses trifft unter Umständen auch im Scheidungsfall zu, allerdings kann dem entgegengehalten werden, daB die Geschiedene ihren Zustand bewuBt herbeigeführt hat und demzufolge auch die Konsequenzen ihrer Entscheidung ganz oder zumindest teilweise tragen sollte. Wird während der Ehe das Familienprinzip angewandt, ist es ohne weiteres möglich, durch ein Splitting der Rentenanwartschaften bei Auflösung der Ehe, die soziale Sicherung auf eine Person zu beziehen, die rentenrechtlich eigenständig ist. Durch die EDV-gestützte Abwicklung der Rentenfälle bei den Rentenversicherungsträgern könnte diese Veränderung ohne großen organisatorischen Aufwand durchgeführt werden.

Neben der kritischen Betrachtung der sozialversicherungsrechtlichen Stellung der geschiedenen Frau, ist die finanzielle Lage dieser Personengruppe ein entscheidendes Kriterium zur Beurteilung der sozialen Gesamtsituation. $70 \%$ der minderjährigen Kinder, die bei Alleinerziehenden leben, stammen aus geschiedenen Ehen $^{615}$, dieses allein sollte Grund genug sein, ein familienpolitisches Augenmerk auf diese Personengruppe zu richten. Theoretisch sollte die Geschiedene, wenn sie Kinder zu erziehen hat, Unterhalt (analog zur Unterhaltsverpflichtung in der Ehe) von ihrem geschiedenen Ehepartner für sich und ihre Kinder bekommen, und dieses in ausreichendem Umfang, so daB die Gesellschaft mit diesen Kosten nicht belastet wird. Die Realität zeigt nun ein völlig anderes Bild: Der Unterhaltsanspruch besteht zwar, wird auch geltend gemacht und durchgesetzt, die Höhe des Unterhalts reicht aber in den meisten Fällen nicht aus, um den Lebensunterhalt

\footnotetext{
${ }^{613}$ Ebenda, S. 525.

${ }^{614}$ Vgl. W. Albers, Die Alterssicherung kindererziehender Mütter und Witwen, in: Sozialer Fortschritt, 47. Jg., Heft 6-7/1997, S. 139.

${ }^{615}$ Siehe Teil C, Punkt I. dieser Arbeit.
} 
der geschiedenen Frau mit ihren Kindern zu bestreiten. In nicht wenigen Fällen entzieht sich der geschiedene Ehemann der Zahlung, indem er sein Arbeitsangebot - soweit es ihm möglich ist - reduziert, womit natürlich auch das zu verteilende Einkommen verringert wird, unter Berücksichtigung des Selbstbehalts sinkt die Verteilungsmasse im Extremfall auf 0, und die Geschiedene steht trotz anerkannten Unterhaltsanspruchs ohne finanzielle Unterstuitzung da. Um eine Benachteiligung der Kinder in dieser Situation abzumildern, ist das Unterhaltsvorschußgesetz am 1.1.1980 in Kraft getreten. Im Rahmen dieses Gesetzes ist es durch den Gesetzgeber ermöglicht worden, die finanzielle Lücke, die bei Alleinerziehenden durch den Ausfall des eigentlich Unterhaltsverpflichteten entstanden ist, zu schließen, allerdings wird der Unterhaltspflichtige dadurch von seinen Verpflichtungen nicht freigestellt, da diese Leistung lediglich als Darlehen gezahlt wird. ${ }^{.16}$ Die zeitliche Begrenzung dieser Leistung führt jedoch dazu, daß die soziale Lage der geschiedenen Frau nur für eine Übergangszeit annähernd gesichert ist.

Unterhaltsvorschußkassen kurieren zwar kurzfristig die Symptome, beseitigen aber nicht das generelle familienpolitische Problem. Eine soziale Sicherung ist eine Sicherung, die durch gesellschaftliche Institutionen erfolgt, die mit einer sozialpolitischen Intention begründet werden, das „Soziale“ kann also nicht immer nur am Resultat, sondern muß auch am Motiv gemessen werden. Sozialpolitische Intention kann es nicht sein, durch eine umfassende Versorgung der Geschiedenen, den Anreiz zur Scheidung (aus individuellen Erwägungen heraus) zu erhöhen. Die vollständige Familie sollte in der Gesellschaft die gewünschte, erstrebenswerte und geförderte (was im übrigen grundsetzlich verankert ist) Lebensform darstellen, die staatlicherseits bei ihrer Funktionserfüllung unterstützt wird, die unvollständige Familie sollte als unvermeidlicher Sonderfall zwar nicht diskriminiert, jedoch auch nicht besonders gefördert werden. Besonders das Scheidungsrecht mit seinen Ausführungsbestimmungen scheint Anreize zu setzen, aus individuellrationalen Erwägungen heraus, die Trennungsentscheidung zu treffen. Sicherlich war das bis 1976 praktizierte Verfahren, nach dem Schuldprinzip zu urteilen, in vielerlei Hinsicht unbefriedigend, so daB aus menschlich moralischer Sicht das Zerrüttungsprinzip für die beteiligten Ehepartner weni-

${ }^{616}$ Näheres dazu in Teil C, III, 4. 
ger entwürdigend ist, es hat jedoch einen großen Nachteil: Da die Schuldfrage für die Bemessung des finanziellen Unterhalts völlig ohne Belang ist, verlagern sich die Auseinandersetzungen auf die Frage, wem das Sorgerecht für das Kind bzw. die Kinder zugesprochen wird, denn gemeinhin kann derjenige, der die Erziehung der Kinder übernimmt, Unterhalt auch vom anderen Ehepartner erwarten. Die Rechtssprechung ging bislang i.d.R. davon aus, daB die Mutter quasi die „bessere“ Erziehungsleistung erbringen könnte und sprachen der Mutter das Sorgerecht für die Kinder zu, so daB der Vater - bis auf ein bescheidenes Besuchsrecht - lediglich als Geldgeber fungieren durfte. Hat die Frau das Sorgerecht für die Kinder und einen juristischen Titel für die Unterhaltsforderung, wird die Qualität ihrer Erziehungsleistung nicht mehr geprüft. Lediglich in Extremfällen, in denen der Vater der kinderbetreuenden Mutter die Vernachlässigung ihrer Pflichten hieb- und stichfest nachweisen kann, besteht für ihn die Möglichkeit, das Sorgerechtsverfahren wieder neu aufleben zu lassen, um das Sorgerecht für sich selbst geltend zu machen und gleichzeitig von den Unterhaltsverpflichtungen an die geschiedene Frau befreit zu werden.

Auch wenn es keine gewünschte gesellschaftliche Entwicklung ist, werden Trennung und Scheidung von Ehepartner mit Kindern auch künftig noch verstärkt gesellschaftlich relevante Phänomene sein, die von der Politik berücksichtigt werden müssen. Jegliche Regelung - sei es ein juristischer Tatbestand wie etwa die momentan geführte Diskussion eines gemeinsamen Sorgerechts, oder eine, die die ökonomischen Rahmenbedingungen verändert - muß sich in erster Linie am Kindeswohl ausrichten. Neben einer positiven emotionalen Beziehung möglichst zu beiden Elternteilen, müssen, mit Blick auf die Lebens- und Entfaltungsbedingungen des Kindes, besonders die wirtschaftlichen und sozialen Lebensbedingungen von Scheidungskindern in den Vordergrund politischer Entscheidungen rücken. Hinsichtlich der ökonomischen Situation nach einer Scheidung, sollten im Interesse der Scheidungskinder ausreichende Familienlastenausgleichsleistungen gewährt werden. Diese sollten allerdings nicht so ausgestaltet sein, daB sie jegliche Eigeninitiative der geschiedenen Ehefrau, sich aus der wirtschaftlichen $\mathbf{A b}$ hängigkeit von ihrem früheren Ehemann oder von den ersatzweise geleisteten staatlichen Transferzahlungen zu befreien, überflüssig machen. „Die be- 
ste Gemeinschaftshilfe ist die Hilfe zur Selbsthilfe; wo immer Gemeinschaftshilfe zu Selbsthilfe möglich ist, soll daher die Selbsthilfe unterstützt, Fremdhilfe dagegen nur dann und insoweit eingesetzt werden, wie Gemeinschaftshilfe zur Selbsthilfe nicht möglich ist oder nicht ausreichen würde" ${ }^{6017}$ Dieses Plädoyer Nell-Breunings für Unterstützungsleistungen für den einzelnen, aber nur dann, wenn er nicht in der Lage ist, sich selbst zu helfen, basiert auf der Grundidee des Subsidiaritätsprinzips, daß auch im Familienlastenausgleich zum Tragen kommen sollte. Konkret bedeutet dies, der alleinerziehenden Geschiedenen finanzielle Mittel nicht vorzuenthalten, sie aber doch auch vermehrt in die Lage zu versetzen, einer Erwerbstätigkeit nachzugehen. Da der Schwerpunkt der Ehescheidungen nach einer Ehedauer von 5 Jahren liegt ${ }^{618}$, ist zu vermuten, daß die aus dieser Ehe stammenden Kinder i.d.R. in die Altersgruppe 0-3 bzw. 0-4 Jahre gehören. Angesichts des geringen Alters und der psychischen Belastung, die diese Kinder durch die Trennung ihrer Eltern erleben, erscheint es nicht wünschenswert, sie in hohem Maße außerhalb der - inzwischen unvollständigen - Familie betreuen zu lassen, so daß in dieser Zeit die finanziellen Leistungen Vorrang haben sollten. Mit dem Institut der Unterhaltsvorschußkassen und der Zahlung von Erziehungsgeld hat der Gesetzgeber bereits versucht, entstehende Notlagen zu beseitigen. Auch die nach dem Fürsorgeprinzip gewährte Sozialhilfe trägt dazu bei, daß der Lebensunterhalt der Familie gesichert ist. Mit zunehmendem Alter der Kinder ist der Mutter zuzumuten, eine Erwerbstätigkeit auszuüben. Daraus ergeben sich folgende Wirkungen:

- die Stärkung der Selbstverantwortung,

- die Freisetzung von staatlichen Mitteln, die dann ihrerseits für andere „Notfälle“ zur Verfügung stehen,

- die Kinder werden in ihrer sozialen Bezugsgruppe nicht mehr stigmatisiert, weil sie als Sozialhilfeempfänger „anders sind“ als die anderen Kinder,

${ }^{617}$ O.v. Nell-Breuning, Gerechtigkeit und Freiheit. Grundzüge katholischer Soziallehre, Freiburg 1985, S. 56.

${ }^{618}$ Statistisches Bundesamt, Familien heute, Ausgabe 1990, S. 129. 
- die geschiedene Frau kann in vermehrtem AusmaB soziale Kontakte knüpfen und pflegen und evtl. neue Lebensziele anstreben,

- die Möglichkeit zur Selbstverwirklichung außerhalb ihrer familiären Situation wird geschaffen.

Da auch mit Beginn der Schulpflicht der Kinder diese lediglich halbtags betreut wären, müBte diesem Personenkreis entweder der Zugang zu Ganztagsschulen vorrangig ermöglicht werden oder sie müßten vermehrt die Gelegenheit zur Teilzeitarbeit bekommen. Letzteres liegt aber weniger im Ermessen der Politik als vielmehr an der Bereitschaft der Tarifpartner, den Arbeitsmarkt insgesamt zu flexibilisieren. So sehr familienpolitische MaBnahmen verstärkt bei besonderen Problemlagen von Familien ergriffen werden sollen, so wichtig erscheint es zugleich, die intakte Familie zu unterstützen und in ihrer Funktionsausübung zu stärken, „sie hat generell im Blick auf alle Familien die bedingenden Voraussetzungen für möglichst gute Aufgabenerfüllung der Familien im Dienste der personalen Entfaltung ihrer Mitglieder wie des größeren gesellschaftlichen Ganzen immer wieder neu zu sichern". .619

\subsection{Witwen/Witwer}

Eine Betrachtung der durchschnittlichen Einkommen sowie der Stellung dieses Personenkreises im System der sozialen Sicherung läßt die Vermutung aufkommen, daB es für diese Personen kaum Probleme, wie sie im Vorherigen beschrieben wurden, gibt. Dennoch ist die Hinterbliebenenversorgung immer wieder in die Rentendiskussion eingeflossen, zum einen durch die katastrophale finanzielle Situation derjenigen Witwen, die in Zeiten des Zweiten Weltkrieges bzw. unmittelbar danach mehrere Kinder vielfach sogar allein- aufgezogen haben und heute aufgrund nur geringer Rentenansprüche den überwiegenden Lebensunterhalt mittels Sozialhilfe bestreiten müssen und nicht zuletzt auch durch die Verfassungsbeschwer-

619 M. Wingen, Zur Theorie und Praxis der Familienpolitik, Frankfurt/Main 1994, S. 323. 
den (1992) mehrerer Beschwerdeführerinnen, die eine Berücksichtigung ihrer Kindererziehung erwirken wollten. Obwohl die Mütter mehrerer Kinder mit ihrer Lebensleistung die Grundlage für die Altersversorgung ihrer Generation schufen, befinden sie sich im Alter an der Armutsgrenze. Neuere Statistiken belegen, daB dieser Tatbestand immer noch zutrifft. So betrug die durchschnittliche Versichertenrente für Frauen am 1.Januar 1992 (altes Bundesgebiet) in der Arbeiterrentenversicherung 579,30 DM und in der Angestelltenversicherung 972,69 DM, während die entsprechenden Werte für Männer etwa doppelt so hoch waren: 1501.49 DM in der Arbeiterrentenversicherung und 2041,27 DM in der Angestelltenversicherung (VDRGeschäftsbericht 1991). Nicht viel besser sieht es bei der Betrachtung der Hinterbliebenenrenten aus: die durchschnittliche Witwenrente in der Arbeiterrentenversicherung betrug am 1.1.1992 853,62 DM und in der Angestelltenversicherung 1181,53 DM. Im gleichen Zeitraum betrug der Eckregelsatz der Hilfe zum Lebensunterhalt durchschnittlich 491,00 DM/Monat. Für einen Alleinstehenden fielen im Jahr 1992 Sozialhilfeleistungen von durchschnittlich 1158,00 DM/Monat an. (Sozialhilfebericht 1992)

Obwohl der Auftrag des Bundesverfassungsgerichts an die Bundesregierung lautete, die Hinterbliebenenversorgung umfassend in ihren Strukturen zu reformieren, besteht sie -abgesehen von der Einbeziehung der Witwer und den Modalitäten der Anrechnung eigenen Einkommens- in der alten Form weiter. Besonders die Existenz der "kleinen" Witwenrente gerät immer wieder in die Kritik verschiedener gesellschaftlicher Gruppen. Folgen beide, die "kleine" und die "große" Witwenrente der Vorstellung, einen Unterhaltsersatz für das nicht mehr vorhandene Einkommen des verstorbenen Ehepartners zu gewährleisten, wird die "kleine" Witwenrente mit dem Hinweis auf die hohe Erwerbsquote (47\% West/60\% Ost) der betroffenen Gruppe als Indiz für eine Überversorgung und damit als nicht mehr zeitgemäß angesehen, während bei der "großen" Witwenrente zusätzliche soziale Tatbestände hinzutreten, die eine Zahlung dieser Rente, auch unter gesellschaftlichen Erwägungen heraus, unumgänglich erscheinen lassen. Einer jungen Witwe ohne Kinder ist es durchaus zuzumuten mittels einer Erwerbstätigkeit für ihren Lebensunterhalt selbst aufzukommen. Allerdings sei an dieser Stelle auch noch einmal erwähnt, daß mit Erreichen des 45. 
Lebensjahres Empfänger von "kleinen" Witwenrenten automatisch in die "große" Witwenrente hineinwachsen, auch ohne das Vorhandensein von Kindern und bei eigener Erwerbstätigkeit. Beide Rentenarten orientieren sich gemäß ihrer Grundidee am Familienprinzip. Auch wenn dieses Prinzip im Hinblick auf Leistungen, die dem Grundsatz der Bedarfsgerechtigkeit folgen sollen sinnvoll und wünschenswert ist, so korrespondiert es nicht mit der Forderung nach einer eigenständigen sozialen Sicherung der Frau. Zudem führte die Anwendung dieses Prinzips angesichts veränderter familialer Lebensformen einerseits zu Überversorgung einiger Personen, andererseits zu bedenklicher Unterversorgung bei anderen Personenkreisen.

Bei der Betrachtung verwitweter Personen stellt sich zunächst einmal die Frage, ob sie mit dem obigen Personenkreis (Punkt 1-3) vergleichbar sind und welche familien- und frauenpolitischen Ziele bezogen auf diesen Personenkreis verfolgt werden sollen. Die strikte Anwendung des Individualprinzips würde die Witwe (den Witwer) auf den Arbeitsmarkt verweisen, um mit Hilfe einer Erwerbstätigkeit nicht nur den Lebensunterhalt für sich und die Kinder, sondern auch die Rentenansprüche für das eigene Alter zu sichern, ungeachtet der Tatsache, ob dieses aufgrund fortgeschrittenen Alters oder der Erziehung von Kindern möglich ist. Gesellschaftlich wünschenswert kann es auf keinen Fall sein, vielmehr obliegt es der Pflicht des Staates, kindererziehende Hinterbliebene in die Lage zu versetzen, ihrer Erziehungsaufgabe ohne materielle Not nachkommen zu können. Da die gegenwärtige Regelung der Hinterbliebenenversorgung diesem Ziel nicht bzw. nur unzulänglich gerecht wird, ist eine Reform der Rentenversicherung dringend erforderlich.

Einzige Voraussetzung für den Bezug der "kleinen" Witwenrente ist die Erfüllung der allgemeinen Wartezeit von fünf Jahren durch den versicherten und verstorbenen Ehegatten ${ }^{620}$. Da die Finanzierung dieser Leistung lediglich durch rentenversicherungspflichtige Personen erfolgt, subventionieren erwerbstätige Familienmitglieder (auch mit Kindern) kinderlose nichterwerbstätige Ehefrauen, die sich zudem noch im leistungsfähigen Alter befinden. War dies in den ersten 15-20 Jahren seit Einführung des Umlageverfahrens unproblematisch, da die Zahl kinderloser Ehefrauen (etwa 10-

${ }^{620}$ Vgl. $§ 49$ Abs. 1 und $\S 50$ Abs. 1 SGB VI 
$15 \%$ aller Ehefrauen) gering war und diese aufgrund eines anderen Eheund Familienleitbildes meist auch nicht einer Erwerbstätigkeit nachgingen, so hat sich in neuerer Zeit ein grundlegender Wandel im Verständnis des ehelichen Zusammenlebens gezeigt. In der Regel gibt die Frau ihre Erwerbstätigkeit nicht bei der Eheschließung, sondern bei der Geburt des ersten bzw. häufig erst des zweiten Kindes auf. Ist die Frau demgemäß während der Ehe erwerbstätig (es wird im folgenden unterstellt, daß es sich um eine Vollzeittätigkeit handelt) und erwirbt ein eigenes Einkommen, dann benötigt sie beim Tod ihres Ehemannes keinen Ersatz für ein "verlorengegangenes" Einkommen. War die Frau nicht erwerbstätig, ist ihr dennoch zuzumuten, eine Erwerbstätigkeit aufzunehmen, um für ihren Lebensunterhalt selbst zu sorgen. Das Problem eventuell nicht vorhandener adäquater Arbeitsplätze wird an dieser Stelle nicht übersehen, jedoch kann es nicht Aufgabe der Rentenversicherung sein, die Arbeitsmarktprobleme zu lösen. Vielmehr müssen flankierend zu einer Reform der Rentenversicherung die Rahmenbedingungen für die Wirtschaft hinsichtlich des Einsatzes von Arbeitskräften verbessert werden. Die einmal gültigen Argumente für die Existenz der "kleinen" Witwenrente können damit nicht aufrechterhalten werden, so daß ein ersatzloses Streichen dieser Leistung auch unter sozialpolitischem Aspekt zu rechtfertigen ist, da allein die Tatsache Witwe zu sein kein besonders schutzwürdiger sozialer Tatbestand sein kann und deshalb keinen Anspruch auf finanzielle Leistungen auslösen sollte. Ehe und Familie stehen zwar laut Grundgsetz Art.6, Abs.1 unter dem besonderen Schutz der staatlichen Ordnung, dennoch kann "wenn es hart auf hart geht zwischen Ehe und Familie," ${ }^{221}$ der Familie der Vorrang gegenüber der Ehe gegeben werden, da die Familie als Grundpfeiler der bürgerlichen Gesellschaft angesehen werden kann. Die Hinterbliebenenrente hat (vgl. auch Urteil des Bundesverfassungsgerichts 1992) ihre ursprüngliche Funktion weitgehend eingebüßt, so daß auch im Falle der "großen" Witwenrente eine gänzliche Beseitigung gefordert werden kann. Die kindererziehende Witwe muB jedoch im Rahmen des Familienlastenausgleichs in das soziale Sicherungssystem eingebunden werden. Sie hat zum einen die besonderen Lasten kinderver-

${ }^{621}$ R. Herzog, Vortrag im Rahmen der Festakademie aus Anlaß des 50. Geburtstages von Frau Ministerin Rönsch. 
sorgender Personen, wie den Entgang von Erwerbseinkommen bei Aufgabe der Erwerbstätigkeit, den Verlust an Sozialleistungsansprüchen und die unentgeltliche Betreuungs- und Erziehungsleistung zu tragen, zum anderen stellt die Kindererziehung in diesem Fall eine außergewöhnliche Belastung dar, die -im Unterschied zu den oben betrachteten Gruppen- von der kindererziehenden Person nicht willentlich herbeigeführt wurde, diese auBergewöhnliche Belastung ist eine deutliche Schlechterstellung dieser Frauen und Mütter gegenüber Verheirateten. Die auf den ersten Blick augenscheinlich gleiche Situation erhält durch diesen Umstand eine gänzlich neue Dimension, der objektiv gleiche Tatbestand "Kindererziehung" ist in allen Fällen gegeben, allerdings ist der Ausgangspunkt der Betrachtung jeweils ein anderer. Entzieht sich die ledige Alleinerziehende dem gesellschaftlichen Rahmen mit den jeweils geltenden Normen und Werten, hat die Witwe diese -dokumentiert durch ihre Verhaltensweise- nicht in Frage gestellt. Sie ist davon ausgegangen, daB ihren Kindern Schutz und Entwicklungsmöglichkeiten zur Verfügung stehen, für die Erfüllung familienpolitischer Aufgaben ist eine soziale Bindung des Vaters an das gesellschaftliche Schicksal von Mutter und Kind wichtig. ${ }^{622}$ Diese fehlende Bindung des Vaters an die Familie, wie sie bei Unehelichkeit des Kindes und bei durch Trennung, Scheidung oder Tod aufgelösten Familien besteht, gefährdet Aufzucht und Sozialisation von Kindern, und führt vielfach zu einer Überbelastung der Mutter, sofern nicht Ersatzlösungen von der Gesellschaft geschaffen werden. ${ }^{623}$

Die in Art. 3 Abs. 1 GG geforderte Gleichbehandlung aller Menschen muB in Verbindung mit Art. 6 Abs.1 GG gesehen werden. Der Gleichheitsgrundsatz will in erster Linie ausschlieBen, "daB eine Gruppe von Normadressaten im Vergleich zu anderen Normadressaten anders behandelt wird, obwohl zwischen beiden Gruppen keine Unterschiede von solcher Art und solchem Gewicht bestehen, daB sie die ungleiche Behandlung rechtfertigen könnten" (BVerfGE 55, 72, 88). Die Gesetzgebung verlangt also lediglich den Vergleich von Lebenssachverhalten, die sich nicht in allen, sondern nur in einzelnen Merkmalen gleichen und insoweit hat der Gesetzgeber

${ }^{622}$ Vgl. F. Neidhardt, Definition und Theorie der Familie, in: Franz Filser (Hrsg.), Einführung in die Familiensoziologie, Paderborn u.a.O. 1978, S. 264.

${ }^{623}$ Vgl. F. Neidhardt ,a.a.O., S. 264. 
grundsätzlich die Freiheit zu entscheiden, welche dieser Merkmale er als maßgeblich für eine Gleich- oder Ungleichbehandlung ansieht, er darf nur nicht Art und Gewicht der tatsächlichen Unterschiede sachwidrig außer acht lassen. Einzig den besonderen Schutz der Familie nach Art. 6 Abs. 1 GG hat er bei der konkreten Ausgestaltung eines wirksamen Familienlastenausgleichs in seine Betrachtung einzubeziehen.

Die Familie, hier verstanden als Kernfamilie (Eltern mit ihren Kindern), ist das Rückgrat unserer Gesellschaft und bildet zugleich die beständigste Form des Zusammenlebens. Letzteres schließt nicht aus, daß sich die Positionen der einzelnen Mitglieder des Gebildes "Familie" im Laufe der Zeit verändern können und auch verändert haben, ihre Zusammensetzung, die Art der sie begründenden Eheordnung, ihre Stabilität und Leistung sowie ihre gesellschaftliche Stellung waren von jeher Teil eines sich verändernden gesellschaftlichen Prozesses, bedingt durch Veränderungen und Fortschritte in Wirtschaft, Technik, Religion, Kultur etc. ${ }^{624}$

Rentenversicherungsrechtlich sollten Kindererziehungsjahre zum Aufbau einer eigenen sozialen Sicherung weiterhin bestehen bleiben, wobei gute Gründe für eine Ausdehnung dieser Zeit auf 5 Jahre pro Kind sprechen. ${ }^{625}$ Erstens hat dieser Personenkreis besondere Lasten zu tragen, da er die Betreuungs- und Erziehungsleistung ohne Ehepartner zu erbringen hat. Zweitens wird der kindererziehenden Person die Möglichkeit eröffnet, die Erziehung des Kindes bis zu Beginn der Vorschule zu leisten, ohne dem Zwang ausgesetzt zu sein, das Kind in einem Kindergarten unterzubringen, mit den bekannten Nachteilen einer Kollektiverziehung.

Die rentenrechtliche Bewertung der Kindererziehungszeiten sollte, wie schon mehrfach erwähnt, $100 \%$ des Durchschnittsentgelts aller Versicherten betragen. Damit bewirkt diese Bewertung eine wertmäßige Gleichstellung von Erwerbstätigkeit und Kindererziehung auf dem Niveau des Durchschnittsverdienstes der Versicherten, so daß zumindest aus sozialversicherungsrechtlicher Sicht eine "echte" Wahlfreiheit zwischen Kindererziehung und Erwerbstätigkeit geschaffen wird. Im Zuge der Typisierung werden El-

\footnotetext{
${ }^{624}$ Vgl. F. Neidhardt, a.a.O., S.258.

${ }^{625}$ Vgl. W. Albers, Auf die Familie kommt es an, Bonn 1986, S. 108. Albers fordert in dem Zusammenhang, die Versicherungszeit bei zwei Kindern auf vier und vom dritten Kind auf fünf Jahre je Kind zu erhöhen.
} 
ternteile mit ansonsten höher bewerteten Zeiten schlechtergestellt, dies ist aber verfassungsrechtlich nicht $\mathrm{zu}$ beanstanden, da Kindererziehung und Beitragszahlung nicht gleichartig sind, ${ }^{626}$ "der Beitrag zur Aufrechterhaltung der Rentenversicherung, der in Form von Kindererziehung geleistet wird, kann im Unterschied zu den monetären Beiträgen der Erwerbstätigen nicht sogleich wieder in Form von Rentenzahlungen an die ältere Generation ausgeschüttet werden"627, so daß eine Ungleichbehandlung bei der Begründung von Rentenanwartschaften gerechtfertigt werden kann.

Das Bundesverfassungsgericht fordert zwar, dab die Benachteiligung in der Alterssicherung im Rentenrecht behoben werden sollte, durch den Gebrauch des Wortes „vornehmlich“ muß dies aber nicht ausschließlich innerhalb des Rentenrechts erfolgen, vielmehr können auch andere Instrumente des Familienlastenausgleichs zum tragen kommen, wenn mit ihnen systemkonform und zielgerichtet Benachteiligungen abgebaut werden können.

Insofern könnte anstelle der "großen" Witwenrente eine Transferzahlung aus allgemeinen Steuermitteln an alle kindererziehenden Witwen gezahlt werden, ähnlich des Erziehungsgeldes. Damit steht das Kindeswohl im Mittelpunkt und nicht die Abhängigkeit von einer vorhandenen Versicherung des verstorbenen Vaters. Durch diese Finanzierungsmodalität wird außerdem gewährleistet, daß nicht nur die in das System der Rentenversicherung eingebundenen Versicherten die Finanzmasse aufbringen müssen, sondern die Gesellschaft in Form aller Steuerzahler herangezogen wird. Da im Hinblick auf das geltende Steuersystem davon ausgegangen werden kann, daB kinderlose Erwerbstätige überproportional zum Steueraufkommen beitragen, findet eine -durchaus erwünschte- Umverteilung von den Kinderlosen zu den Kindererziehenden statt.

Die Höhe dieser Transferzahlung könnte sich am sozialkulturellen Existenzminimum der Sozialhilfe orientieren, wünschenswert wäre jedoch eine höhere Leistung, um die besondere Belastung dieses Personenkreises zu berücksichtigen und ein Absinken aus der gesellschaftlichen Schicht, in die diese Familie bislang einzuordnen war, möglichst zu vermeiden.

\footnotetext{
${ }^{626}$ Vgl. Urteil Bundesverfassungsgericht vom 7.7.1992, S. 59.

${ }^{627}$ Urteil des Bundesverfassungsgerichts vom 7.7.1992, S. 59.
} 


\section{SchluBbemerkungen}

Die Diskussion um die Reformbedürftigkeit des sozialen Sicherungssystems und hier insbesondere um die Finanzierbarkeit der gesetzlichen Rentenversicherung will nicht verstummen. Konjunkturzyklenartig ist sie einige Zeit Randthema, um dann wieder vehement alle anderen Themen in den Schatten zu stellen. Letzteres kennzeichnet die gegenwärtige Situation, denn massive Finanzierungsprobleme im System der sozialen Sicherung zwingen zum Handeln und dies möglichst schnell. Wohltaten der Vergangenheit und mangelnde Systematik rächen sich heute, so daß die Beseitigung der Ungereimtheiten oberste Aufgabe der Politik ist. Wenn „Häkelkurse“ als Bildungsurlaubs von der Gesellschaft (über die entsprechende Institution des sozialen Sicherungssystems) bezahlt werden und bewußte Kinderlosigkeit in hohem Ausmaß nicht dazu führt, daß dieser Personenkreis in irgendeiner Weise die Konsequenzen dieser Entscheidung trägt, sondern ebenso an den Vorteilen des Rentenversicherungssystems partizipiert wie derjenige, der Kinder aufzieht, dann sind dies klare Indizien für Fehlallokationen im System, was jedoch nicht gleichbedeutend mit der völligen Funktionsunfähigkeit des Systems ist, wie von einigen Gruppen gern behauptet wird. Ähnlich einer Hekke, die lange Zeit nicht geschnitten wurde und nun an einigen Stellen Auswüchse besonders kräftiger Zweige hat, hat das deutsche Sozialversicherungssystem in einigen Bereichen Dimensionen angenommen, die dem eigentlichen Grundgedanken zuwider laufen und über längere Zeit nicht finanzierbar sind. Unterstützt wird dieses von einer gesellschaftlichen Entwicklung, in der die Wertvorstellungen über das Zusammenleben von Menschen in eine neue Richtung drängen: Wenn es um die Verwirklichung persönlicher Bedürfnisse geht, wird die Individualisierung respektive die Selbstverwirklichung in den Vordergrund gestellt, zur Finanzierung sollen dann allerdings alle Mitglieder der Gesellschaft, im Rahmen der Solidarität, beitragen.

Anknüpfungspunkt für jegliche Reformschritte muß das klare Bekenntnis zu einem der beiden kollidierenden Ziele „mehr Freiheit“ oder „mehr Sicherheit" sein, beides zusammen ist nun einmal schwer zu realisieren, und die ausschließliche Konzentration auf eines dieser beiden Ziele führt im Endef- 
fekt zu Wirtschafts- und Gesellschaftsordnungen, die wohl kaum im Extrem gewünscht werden. Insofern sollten sich die Entscheidungsträger vor Augen halten, daß der einzelne Staatsbürger durchaus mündig ist und seine Präferenzen äußern kann, so daß das System der Sozialen Sicherheit den Rahmen vorgeben - also eine Mindestsicherung für alle garantieren - sollte, aber dem einzelnen die Freiheit läßt, entsprechend seiner Präferenzen zu agieren. Dieses könnte eine zukunftsgerichtete Überlegung sein, die nicht dazu führen muß, daß das System der sozialen Sicherung insgesamt an Relevanz verliert, sondern im Gegenteil im Bestand gefestigt wird, um die tatsächlich Bedürftigen in unserer Gesellschaft im Sinne der Sozialethik und des Christentums unterstützen zu können, damit auch sie ihre Funktionen in Gesellschaft und Familie erfüllen können. 



\section{LITERATURVERZEICHNIS}

Abelshauser, W. (1987): Die Weimarer Republik als Wohlfahrtsstaat, Wiesbaden.

Abild-Schindler, Gabriele (1985): "Mehr Chancengleichheit", in: Bundesarbeitsblatt, Heft 4, S. 11-14.

Abteilung Frauen im Bundesvorstand des Deutschen Gewerkschaftsbundes (Hrsg.) (1979): "Studie zur Lage Alleinstehender mit Kindern", in: Frauen und Arbeit, Heft 2/3, S. 14-15.

Adami, Manfred (1987): "Der Versorgungsausgleich in der gesetzlichen Rentenversicherung - Überblick über die gesetzlichen Regelungen ab 1.1.1987", in: Deutsche Rentenversicherung, Heft 7, S. 121-125.

Adamy Wilhelm und Sigrid Koeppinghoff (1983): „Reform der Reformen - oder das Ende der 84'er Reform?“, in: Vierteljahresschrift für Sozialrecht, 11. Jg., S. 315-335.

Adamy, Wilhelm (1985): "Rentenpolitik in der Sackgasse - Zum Konzept der Koalition", in: Soziale Sicherheit, 34.Jg., Heft 2, S. 45-51.

Adamy, Wilhelm und Bäcker, Gerhard (1985): "Der Maschinenbeitrag ein Allheilmittel für Rentenfinanzen und Arbeitsmarkt?", in: WSIMitteilungen, 38.Jg., Heft 1, S. 24-33.

Adamy, Wilhelm und Steffen, Johannes (1985): "Ein Konzept gegen die ,Neue Armut'", in: Wirtschaftsdienst, 65. Jg., Heft 7, S. 353-359.

Albers, Willi (1967): "Zur Reform des Familienlastenausgleichs in der Bundesrepublik Deutschland", in: Sozialer Fortschritt, 16. Jg., Heft 9, S. 199-204. 
Albers, Willi (1968): "Soziale Sicherheit durch individuelle Vorsorge oder durch kollektive Maßnahmen?", in: Finanzarchiv, N. F., 27. Jg., Heft 1-2, S. 68-86.

Albers, Willi (1971): "Überlegungen zur sozialen Sicherung der Frau", in: Sozialer Fortschritt, 20. Jg., Heft 12, S. 265-272.

Albers, Willi (1973): "Zum Streit um die Rentenreform", in: Sozialer Fortschritt, 22. Jg., Heft 5, S. 107-112.

Albers, Willi (1976): Möglichkeiten einer stärker final orientierten Sozialpolitik, Kommission für wirtschaftlichen und sozialen Wandel, Bd. 119, Göttingen.

Albers, Willi (1977): "Die soziale Sicherung der Frau", in: Hauswirtschaft und Wissenschaft, 25. Jg., Heft 1, S. 9-11.

Albers, Willi (1978): "Einkommensverteilung durch Transferzahlungen", in: Wirtschaftsdienst, 58. Jg., Heft 12, S. 598-603.

Albers, Willi (1981a): „Probleme der westdeutschen Familienpolitik“, in: Leitbilder für Familie und Familienpolitik, Festgabe für Helga Schmucker zum 80. Geburtstag, Hrsg.: R. v. Schweitzer, Berlin, S. 41-61.

Albers, Willi (1981b): „Die soziale Sicherung der Frau im Alter", in: Gitter, W., Thieme, W. und F. Zacher (Hrsg.), Im Dienst des Sozialrechts, Festschrift für Georg Wannagat, Köln.

Albers, Willi (1982): Soziale Sicherung. Konstruktion für die Zukunft, Stuttgart.

Albers, Willi (1983a): "Perspektiven der Sozialpolitik", in: Wirtschaftsdienst, 63. Jg., Heft 6, S. 280-286. 
Albers, Willi (1983b): "Beurteilungskriterien für ein System der Sozialen Sicherheit", in: Pfaff, M. (Hrsg.), Effizienz und Effektivität staatlicher Transferpolitik in der Wirtschaftskrise, Schriften des Internationalen Instituts für Empirische Sozialökonomie, Bd.7/I, Berlin, S. 43-60.

Albers, Willi (1984a): "Harmonisierung der Sozialleistungen im Alter. Eine Stellungnahme zum Bericht der Sachverständigenkommission Alterssicherungssysteme", in: Finanzarchiv, N.F., Bd.42, Heft 2, S. 210-223.

Albers, Willi (1984b): "Ungereimtheiten im System der Sozialen Sicherheit in der Bundesrepublik Deutschland: Ursachen und Reformmöglichkeiten", in: Finanzarchiv, N.F., Bd.42, Heft 3, S. 613-629.

Albers, Willi (1985a): "Harmonisierung von Sozialleistungen", in: Hampe, Peter (Hrsg.), Renten 2000 - Längerfristige Finanzierungsprobleme der Alterssicherung und Lösungsansätze, München, S. 97-108.

Albers, Willi (1985b): „Die Strukturreform der sozialen Sicherung - eine sozialpolitische Aufgabe“, in: Wirtschaftsdienst, 65. Jg., Heft 12, S. 601-608.

Albers, Willi (1986): Auf die Familie kommt es an: Familienpolitik als zentrale Aufgabe, Stuttgart.

Albers, Willi (1987a): "Langfristige Anpassungen der gesetzlichen Rentenversicherung", in: Wirtschaftsdienst, 67. Jg., Heft 1, S. 26-33.

Albers, Willi (1987b): "Freiheit und Sicherheit in der Sozialpolitik", in: Die Sozialversicherung, 42. Jg., Nr. 1, S. 1-8.

Albers, Willi (1987c): „Individual- oder Familienprinzip in der gesetzlichen Rentenversicherung?, in: Wirtschaftsdienst, 67. Jg., Heft 6, S. 293-299.

Albers, Willi (1988): "Die Beeinflussung der Verhaltensweisen der Familie mit ökonomischen Mitteln", in: B. Felderer (Hrsg.), Familienlastenausgleich 
und demographische Entwicklung, Schriften des Vereins für Socialpolitik, Bdl. 175, Berlin, S. 53-65.

Albers, Willi (1989): „Grundsatzfragen der Familienpolitik“, in: Wirtschaftsdienst, 69. Jg. Heft 7, S. 338-344.

Albers, Willi (1990): Die Anpassung des Systems der gesetzlichen Rentenversicherung an demographische Änderungen, in: Finanzierungsprobleme der sozialen Sicherung I, Hrsg.: Kurt Schmidt, Schriften des Vereins für Socialpolitik, Neue Folge Band 194/I, S. 9-40.

Albers, Willi (1992): "Kindererziehung und Alterssicherung", in: Wirtschaftsdienst, 72. Jg., Heft 10, S. 520-525.

Albrecht, Günter (1996): "Die geplanten Neuregelungen in der Rentenversicherung nach dem Sparpaket der Bundesregierung", in: Die Sozialversicherung, 51. Jg, Heft 8, S. 197-205.

Almsick, Josef van und Niemeyer, Werner (1988): "Staffelung des Beitragssatzes nach der Kinderzahl - mögliches Element der Strukturreform der gesetzlichen Rentenversicherung?", in: Deutsche Rentenversicherung, Heft 1-2, S. 41-48.

Anthes, Jochen (1979): "Vorurteile gegenüber ledigen Müttern", in: Neumann, Lothar F. (Hrsg.), Sozialforschung und soziale Demokratie, Festschrift für Otto Blume zum 60. Geb., Bonn, S. 157-165.

Bach, Hans-Uwe und Reyher, Lutz (1985): "Strukturen und Entwicklung der Erwerbstätigkeit, Frauen auf dem Arbeitsmarkt", in: Mitteilungen aus der Arbeitsmarkt- und Berufsforschung, 18. Jg., Heft 1, S. 11-14.

Bäcker, Gerhard (1979): "Wirtschaftskrise und Rentenversicherung. Anmerkungen zu den Finanzierungsproblemen und den Konsolidierungsmaßnahmen in der Gesetzlichen Rentenversicherung", in: Neumann, Lothar F. 
(Hrsg.), Sozialforschung und soziale Demokratie, Festschrift für Otto Blume zum 60. Geb., Bonn, S. 351-359.

Bäcker, Gerhard (1980): "Familienpolitik durch soziale Transfers", in: WSI-Mitteilungen, 33. Jg., Heft 1, S. 43-53.

Bäcker, Gerhard (1982): "Die Entwicklung der Alterssicherung: Auf dem Weg zur Aushöhlung des Sozialstaates. Hintergründe und Folgen der Finanzkrise in der Rentenversicherung", in: Gewerkschaftliche Monatshefte, 33. Jg., Heft 11, S. 713-728.

Bäumer, Gertrud (1933): Familienpolitik, Berlin.

Becker, Gary S. (1957): The Economics of Discrimination, Chicago/London.

Beck-Gernsheim, Elisabeth (1976): Der geschlechtsspezifische Arbeitsmarkt. Zur Ideologie und Realität von Frauenberufen, Frankfurt a. Main.

Beck-Gernsheim, Elisabeth (1983): "Vom ,Dasein für andere' zum Anspruch auf ein Stück ,eigenes Leben'- Individualisierungsprozesse im weiblichen Lebenszusammenhang", in: Soziale Welt, 34. Jg., Heft 3, S. 307-340.

Bedau, Klaus Dietrich (1985): "Aspekte der Einkommensverteilung", in: Wirtschaftsdienst, 65. Jg., Heft 7, S. 359-364.

Beer, Ursula (1984): "Unentgeltliche Arbeit im Lebenszusammenhang von Frauen und deren Reflexion in den Sozialwissenschaften", in: Sektion Frauenforschung in den Sozialwissenschaften in den DGS (Hrsg.), Frauenforschung, Beiträge zum 22. Deutschen Soziologentag, S. 22-39.

Behr, Sopie (1978): "Familien zweiter Klasse", in: Kühn, E. und Tourneau, Ingrid (Hrsg.), Familienrechtsreform - Chance einer besseren Wirklichkeit, Bielefeld, S. 251-263. 
Bergner, Ludwig (1985): "Weitere Korrekturen, völlige Umgestaltung oder Abschaffung des Versorgungsausgleichs?", in: Deutsche Rentenversicherung, Heft 10/11, S. 636-661.

Berntsen, R./BloBfeld, D. (1995): "Trotz hoher Lasten solide", in: Bundesarbeitsblatt 9/1995, S. 13-23.

Bertsch, Frank (1994): "Kinderkosten-Private Kosten-Öffentliche Kosten?!" in: Wie privat sind Kinder in unserer Gesellschaft?, Dokumentation der Tagung in Bad Honnef 26./27. November 1993, Hrsg. Bundesverband Neue Erziehung e.V., Grafschaft, S.47-56.

Beschluß der Bundesregierung über die Bildung einer Sachverständigenkommission für die Soziale Sicherung der Frau und der Hinterbliebenen vom 17. August 1977.

von Bethusy-Huc, Viola (1987): Familienpolitik, Tübingen.

Bieback, Karl-Jürgen (1996): "Familienleistungen und Familienlastenausgleich in der Sozialversicherung", in: Vierteljahresschrift für Sozialrecht, 24. Jg., Heft 2, S. 73-78.

Bley, Helmar (1979): "Die Reform der sozialen Sicherung von Ehegatten", in: Zeitschrift für Sozialreform, 25. Jg., Heft 8, S. 456-468 und Heft 9, S. 523-540.

Bley, Helmar (1980): "Die Reform der sozialen Sicherung von Ehegatten", in: Deutsche Rentenversicherung, Heft 3, S. 185-193.

Bogs, W. (1981): Die Sozialversicherung in der Weimarer Demokratie, München.

Bokeloh, Arno (1982): Die soziale Sicherung der Frau im Rentenrecht: Rechtslage und Reformmöglichkeit, Sankt Augustin. 
Bokeloh, Arno (1985a): "Ausgestaltung (Hinterbliebenenrenten)", in: Bundesarbeitsblatt, Heft 10, S. 10-14.

Bokeloh, Arno (1985b): „Die Neuregelung der Hinterbliebenenversorgung nach dem System der Hinterbliebenenrente mit Freibetrag", in: Zeitschrift für Sozialreform, 31. Jg., Heft 5, S. 276-295.

Borchardt, K. (1982): Wachstum, Krise, Handlungsspielräume der Wirtschaftspolitik, Göttingen.

Borchert, Ernst-Jürgen (1981): Die Berücksichtigung familärer Kindererziehung im Recht der gesetzlichen Rentenversicherung, Berlin.

Borchert, Ernst-Jürgen (1984): "Rentenreform und Kindererziehung", in: Zeitschrift für Sozialreform, 30. Jg., Heft 7, S. 393-411.

Borchert, Ernst-Jürgen (1988a): "Operation ohne Diagnose? Rentenstrukturreform ohne Kinder? - Zur Frage der Berücksichtigung der Kindererziehung in der aktuellen Rentenreformdebatte", in: Zeitschrift für Sozialreform, 34. Jg., Heft 6, S. 321-341.

Borchert, Ernst-Jürgen/Ferdinand Oeter (1988b): "Familienpolitik und Steuerreform", in: Orientierungen zur Wirtschafts- und Gesellschaftspolitik, 35.Jg. Heft 1, S. 58-63.

Borchert, Ernst-Jürgen (1993): Renten vor dem Absturz, Frankfurt a.M.

Breuer, W. (1979): "Empirische Lebenslagenforschung und ,neue soziale Frage'", in: Neumann, Lothar F. (Hrsg.), Sozialforschung und Soziale Demokratie, Festschrift für Otto Blume zum 60. Geburtstag, Bonn, S. 149-156.

Breuer, W., Engels, D. (1994): Otto-Blume-Institut für Sozialforschung und Gesellschaftspolitik e.V. im Auftrag des Bundesministeriums für Famile und Senioren, Grundinformationen und Daten zur Sozialhilfe, Köln. 
Brück, D. (1975): „Karlsruhe sprach nicht Recht, sondern machte Politik“, in: Sozialer Fortschritt, 24. Jg., Heft 2.

Brückner, Erika (1996): „Lebenslagen alleinstehender älterer Frauen in Brandenburg, in: Gesellschaften im Umbruch, Verhandlungen des 27. Kongresses der Deutschen Gesellschaft für Soziologie in Halle an der Saale 1995, Hrsg. Lars Clausen, Frankfurt/Main, S. 916-929.

Buchhofer, B. (1980): Die soziale Lage der Ein-Elternteil-Familie, Eine Sekundäranalyse der Einkommens- und Verbraucherstichprobe bei „unvollständigen" Familien und alleinlebenden Frauen, Bericht der Sozialwissenschaftlichen Forschungsgruppe am Max-Planck-Institut für ausländisches und internationales Privatrecht, Weinheim/Basel.

Buchner, H. (1979): "Der Mutterschutz auf dem Wege vom Arbeitsrecht zur Familienpolitik", in: Neue Juristische Wochenschrift, 32. Jg., Heft 36, S. 1793-1802.

Bundesministerium für Arbeit und Sozialordnung (1954/55): Die Frau im Erwerbsleben - Ein Zahlenbericht (1939-1950), 2. Auflage, Bonn.

Bundesministerium für Arbeit und Sozialordnung, Drucksache 5/909 vom 14.9.1966: Bericht der Bundesregierung über die Situation der Frauen in Beruf, Familie und Gesellschaft.

Bundesministerium für Arbeit und Sozialordnung (1972): Kennzeichen sozial, Bonn.

Bundesministerium für Arbeit und Sozialordnung (Hrsg.) (1979): Vorschläge zur sozialen Sicherung der Frau und der Hinterbliebenen. Gutachten der Sachverständigenkommission vom 21.5.1979. Sachverständigenkommission für die Soziale Sicherheit der Frau und der Hinterbliebenen, Anlage Bd. 1 und 2, Bonn. 
Bundesministerium für Arbeit und Szialordnung (1991): Übersicht über die Soziale Sicherung, Bonn.

Bundesministerium für Arbeit und Sozialordnung (1994), Alterssicherung in Deutschland 1992 (ASID '92), Bd. I Strukturdaten zur Einkommenssituation von Personen und Ehepaaren ab 55 Jahren, München.

Bundesministerium für Arbeit und Sozialordnung (Hrsg.) (1997), „Eckpunkte für die Gesetzgebung beschlossen“, in: Sozialpolitische Informationen, 31. Jg., Heft 5, S. 1-3.

Bundesministerium für Familie und Jugend (1969): Mütter und Kinder in der Bundesrepublik Deutschland. Ergebnisse einer Stichprobe über die Situation erwerbstätiger und nicht erwerbstätiger Mütter sowie der ihrer Kinder, 1. Tabellen, 2. Analysen, Bad Godesberg.

Bundesministerium für Jugend, Familie und Gesundheit (Hrsg.) (1969): Bericht über die Lage der Familien, Erster Familienbericht, Bonn.

Bundesministerium für Jugend, Familie und Gesundheit (Hrsg.) (1970): Alleinstehende Elternteile mit abhängigen Kindern. Antworten auf einen Fragebogen zur Vorbereitung der 12. Tagung Europäischer Minister für Familienfragen - Stockholm 1971, Bonn-Bad Godesberg.

Bundesministerium für Jugend, Familie und Gesundheit (Hrsg.) (1975): Familie und Sozialisation - Leistungen und Leistungsgrenzen hinsichtlich des Erziehungs- und Bildungsprozesses der jüngeren Generation, Bonn.

Bundesministerium für Jugend, Familie und Gesundheit (Hrsg.) (1979): Bericht über die Lage der Familie in der Bundesrepublik Deutschland, Dritter Familienbericht, Bonn. 
Bundesministerium für Jugend, Familie und Gesundheit (1984): Familie und Arbeitswelt, Gutachten des wissenschaftlichen Beirats für Familienfragen beim BMJFG, Stuttgart u.a.O.

Bundesministerium für Jugend, Familie und Gesundheit (Hrsg.) (1985): Nichteheliche Lebensgemeinschaften in der Bundesrepublik Deutschland, Schriftenreihe des Bundesministers für Jugend, Familie und Gesundheit, Bd. 170, Stuttgart.

Bundesministerium für Jugend, Familie, Frauen und Gesundheit (1989): Erziehungsgeld, Erziehungsurlaub und Anrechnung von Erziehungszeiten in der Rentenversicherung, Gutachten des Wissenschaftlichen Beirats für Familienfragen, Schriftenreihe des Bundesministeriums für Jugend, Familie, Frauen und Gesundheit, Bd. 243, Stuttgart u.a.O.

Bundesministerium für Familie und Senioren (Hrsg.) (1994): Optionen der Lebensgestaltung junger Ehen und Kinderwunsch, Zweiter Projektbericht, Schriftenreihe des Bundesministeriums für Familie und Senioren, Bd. 9,1, Stuttgart.

Bundesministerium für Familie und Senioren (1994): Gesetz über die Gewährung von Erziehungsgeld und Erziehungsurlaub (Bundeserziehungsgeldgesetz-BErzGG) vom 31. Januar 1994.

Bundesministerium für Familie und Senioren (1994): Familien und Familienpolitik im geeinten Deutschland - Zukunft des Humanvermögens, Fünfter Familienbericht, Bonn.

Bundesministerium für Familie, Senioren, Frauen und Jugend (1995): Lebenshaltungsaufwendungen für Kinder, Schriftenreihe des Bmf FSFJ, Bd. 43, Stuttgart.

Bundeszentrale für politische Bildung (Hrsg.) (1985): Die Familie in der Bundesrepublik Deutschland Informationen zur Politischen Bildung, Nr. 206, Bonn. 
Burkart, Günter (1995): "Zum Strukturwandel der Familie, Mythen und Fakten", in: Aus Politik und Zeitgeschichte, Heft 52-53, S. 3-15.

Burkart, G./M. Kohli (1992): Liebe, Ehe, Elternschaft: die Zukunft der Familie, München/Zürich.

Buttler, G. (1985): "Vorschläge für eine Umgestaltung der Alterssicherung", in: Sozialer Fortschritt, 34. Jg., Heft 1, S. 11-14.

Buttler, G, und Winterstein, Helmut (1984): "Überlegungen zur Ausgestaltung der Alterssicherung in der Bundesrepublik", in: Herder-Dorneich, P., Klages, H. und Schlotter, H.G. (Hrsg.), Überwindung der Sozialstaatkrise, Baden-Baden, S. 265-312.

Christopher, Hermann (1984): Gleichstellung der Frau und Rentenrecht, Sozialpolitische Schriften, Heft 51, Berlin.

Cramer, A. (1982): Familie und Familienpolitik in der Bundesrepublik Deutschland, Opladen.

Deutscher Bundesrat, BR-Drucksache 500/84.

Deutscher Bundestag, Drucksache 6/3689 vom 01.08.1972: Bericht der Bundesregierung über die MaBnahmen zur Verbesserung der Situation der Frau.

Deutscher Bundestag, Drucksache 7/4947 vom 31.03.1976: Zur Lage der alleinstehenden Elternteile im Sinne des §23 Abs. 2, BSHG.

Deutscher Bundestag, Drucksache 7/5866 vom 11.11.1976: Zwischenbericht der Enquete-Kommission Frau und Gesellschaft.

Deutscher Bundestag, Drucksache 8/1952 vom 22.06.1978: Entwurf eines Gesetzes zur Sicherung des Unterhalts von Kindern alleinstehender Mütter 
und Väter durch Unterhaltsvorschüsse oder -ausfalleistungen (UnterhaltsvorschuBgesetz).

Deutscher Bundestag, Drucksache 9/34 vom 05.12.1980: Entwurf eines Gesetzes zur Ergänzung von Regelungen über den Versorgungsausgleich.

Deutscher Bundestag (1981): Frau und Gesellschaft, Bericht 1980 der Enquete-Kommission und Aussprache 1981 im Plenum des Deutschen Bundestages, Bonn.

Deutscher Bundestag, Drucksache 9/562 vom 11.06.1981: Entwurf eines Gesetzes zur Vereinfachung und Verbesserung des Versorgungsausgleichs.

Deutscher Bundestag, Drucksache 9/632 vom 03.07.1981: Gutachten des Sozialbeirats über langfristige Probleme der Alterssicherung in der Bundesrepublik Deutschland.

Deutscher Bundestag, Drucksache 10/2608 vom 12.12.1984: Gesetzentwurf der Fraktion der SPD, Entwurf eines Gesetzes zur Reform der gesetzlichen Rentenversicherung (Rentenreformgesetz 1985-RR6 1985).

Deutscher Bundestag, Drucksache 10/2677 vom 28.12.1984: Entwurf eines Gesetzes zur Neuordnung der Hinterbliebenenrenten sowie zur Anerkennung von Kindererziehungszeiten in der gesetzlichen Rentenversicherung (Hinterbliebenen- und Erziehungszeiten-Gesetz-HEZ 6).

Deutscher Bundestag, Drucksache 10/5332 vom 16.04.1986: Gutachten des Sozialbeirats über eine Strukturreform zur längerfristigen finanziellen Konsolidierung und systematischen Fortentwicklung der gesetzlichen Rentenversicherung im Rahmen der gesetzlichen Alterssicherung.

Deutscher Bundestag, Drucksache 10/5447 vom 07.05.1986: Entwurf eines Gesetzes über weitere Maßnahmen auf dem Gebiet des Versorgungsausgleiches, Bonn. 
Deutscher Bundestag (1987): Reform oder Revolution? - Diskussion um die Änderung der Struktur in der gesetzlichen Rentenversicherung 1990, Wissenschaftliche Dienste, Materialie Nr. 98, Bonn.

Deutscher Bundestag, BT-Drucksache 12/5052 vom 28.5.1993, Bonn.

Deutscher Bundestag (1993), BT-Drucksache 12/5168, Bonn.

Deutscher Bundestag, BT-Drucksache 10/2677, Bonn.

Deutscher Bundestag, BT-Drucksache 10/3519, Bonn.

Deutscher Bundestag, BT-Drucksache 11/4124, Bonn.

Deutsches Institut für Wirschaftsforschung (1977): "Längerfristige Aspekte des Defizits in der gesetzlichen Rentenversicherung", in: DIWWochenbericht, 44. Jg., Nr. 21, S. 175-180.

Deutsches Institut für Wirschaftsforschung (1980): "Das Einkommen der Familien in der Bundesrepublik Deutschland im Jahr 1979", in: DIWWochenbericht, 47. Jg., Nr.38, S.401-411.

Deutsches Institut für Wirtschaftsforschung (1984): "Ehegattensplitting versus Familientarif - Eine Analyse der Einkommensbesteuerung", in: DIW-Wochenbericht, 51. Jg., Nr. 49, S. 587-593.

Dieckmann, Albrecht (1987): "Nachehelicher Unterhalt und Wiederaufleben von Witwen- und Witwerrenten - \$1291 II RVO, §83 III RKG, §44 II BVG", in: Zeitschrift für das gesamte Familienrecht, 34. Jg., Heft 3, S. 231239.

Dinkel, Rainer (1981): "Kinder- und Alterslastenausgleich bei abnehmender Bevölkerung", in: Finanzarchiv N.F. Bd.39, S. 134ff. 
Dinkel, Rainer (1983): "Werden Frauen durch die gesetzliche Rentenversicherung benachteiligt?", in: Finanzarchiv, N.F., Bd.41, S. 60-72.

Dinkel, Rainer (1987): "Familienlastenausgleich: Reformen und kein Ende", in: Wirtschaftsdienst, 67. Jg., Heft 2, S. 91-96.

Döring, D. (1980): Das System der gesetzlichen Rentenversicherung, Eine sozialpolitische Einführung, Frankfurt/M., New York.

Doetsch, Werner (1979): "Zum Gutachten der 84'er Kommission", in: Die Angestelltenversicherung, 26. Jg., Heft 7, S. 273-777.

Dornbusch, H.-L. (1982): "Ein Vorschlag zur Neugestaltung des Kinderlastenausgleichs", in: Wirtschaftsdienst, 62. Jg., Heft 11, S. 544-548.

Dreher, W. (1978): Die Entstehung der Arbeiterwitwenversicherung in Deutschland, Berlin.

Dreier, Wilhelm (1960): Das Familienprinzip - Ein Strukturelement der modernen Wirtschaftsgesellschaft, Münster.

Dünnwald, M./Kuhn, M./Löffler, M. (1995): Statistische Aussagen verbessert, in: Bundesarbeitsblatt 9/1995, S. 24-28.

Ebert, Thomas (1993): Frauen, Kinder, Renten, in: Soziale Sicherheit, 42. Jg., Heft 4, S. 97-104.

Ebsen, Ingwer (1993): „Das Kindererziehungsurteil des BVerfG vom 7. Juli 1992 - verfassungspolitischer Kontext, Entscheidungsduktus, Konsequenzen für den Gesetzgeber“, in: Die Sozialversicherung, 48. Jg., Nr. 6, S. 144-147.

Egner, Erich (1966): „Epochen im Wandel des Familienhaushalts“, in: Familie und Gesellschaft, Tübingen, S. 57-93. 
Ellger, Wolfgang (1985): "Versorgungsausgleich in der Privatversicherung", in: Deutsche Rentenversicherung, Heft 10/11, S. 624-630.

Engel, B. und Rolf, Gabriele (1985): "Soziale Lage von Frauen: Kindererziehung und Versorgung im Alter", in: Hauser, Richard und Engel, B. (Hrsg.), Soziale Sicherung und Einkommensverteilung, Frankfurt am Main/New York, S. 381-420.

Engelbrech, Gerhard (1987): "Erwerbsverhalten und Berufsverlauf von Frauen: Ergebnisse neuerer Untersuchungen im Überblick", in: Mitteilungen aus der Arbeitsmarkt- und Berufsforschung, 20. Jg., Heft 2, S. 181-196.

Engelbrech, Gerhard (1989): "Erfahrungen von Frauen an der ,dritten Schwelle' - Schwierigkeiten bei der beruflichen Wiedereingliederung aus der Sicht der Frauen", in: Mitteilungen aus der Arbeitsmarkt- und Berufsforschung, 22. Jg., Heft 1, S. 100-113.

Engelbrech, G./Kraft, H. (1992): Sind Frauen das zukünftige Innovationspotential? Gegenwärtige Hemmnise und berufliche Möglichkeiten von Frauen - Ergebnisse einer Betriebsbefragung, in: Mitteilungen aus der Arbeitsmarkt- und Berufsforschung, Heft 1, S. 13-26.

Engelen-Kefer, Ursula (1992): "Aktuelle Probleme der gesetzlichen Rentenversichung - Finanzielle Situation der Rentenversicherung - Reform der Kindererziehungszeiten, in: Verband Deutscher Rentenversicherungsträger (Hrsg.), Aktuelles Presseseminar des VDR 12./13. November 1992 in Würzburg, S. 7-29.

Erbe, Rainer (1986): "Familienlastenausgleich über die gesetzliche Rentenversicherung?", in: Wirtschaftsdienst, 66. Jg., Heft 4, S. 194-202.

Erbe, Rainer (1987): "Rentenreform, aber wie?", in: Wirtschaftsdienst,67.Jg., Heft 10, S. 486-487. 
Esenwein-Rothe, Ingeborg (1984): "Demo-ökonomische Aspekte einer staatlichen Familienpolitik", in: Jahrbuch für Sozialwissenschaften, 35. Jg., S. 265-281.

Euler, Manfred und Klanberg, F. (Hrsg.) (1983): Haushalte mit ausgewählten staatlichen Transferzahlungen. Ergebnisse der Einkommens- und Verbrauchsstichprobe 1978 ergänzt durch Ergebnisse des Mikrozensus 1979, Stuttgart u.a.

Faupel, G. (1985): "Strukturreform in der gesetzlichen Rentenversicherung: Herauf mit den Altersgrenzen (Kritische Anmerkung zum Aufsatz ,Umverteilung in der gesetzlichen Rentenversicherung' von G. Wagner)", in: Soziale Sicherheit, 34. Jg., Heft 2, S. 55-56.

Filser, Franz (1978): Einführung in die Familiensoziologie, Paderborn u.a.O.

Finanzwissenschaftlicher Beirat beim Bundesministerium für Wirtschaft und Finanzen (1971): Alterssicherung und Familienlastenausgleich, Gutachten zur Neugestaltung und Finanzierung, Bonn.

Finke, H., Francke, K. und Heller, B. (1985): "Erziehungszeiten in der gesetzlichen Rentenversicherung", in: Die Angestelltenversicherung, 32. Jg., Heft 7/8, S. 300-320.

Fischer, W. (1985): Deutschland 1815-1914, in: W. Fischer (Hrsg.), Europäische Wirtschafts- und Sozialgeschichte von der Mitte des 19. Jahrhunderts bis zum Ersten Weltkrieg. Stuttgart, S. 357-442.

Friedmann, Petra und Pfau, Birgit (1985): "Frauenarbeit in der Krise Frauenarbeit trotz Krise?", in: Leviathan, Zeitschrift für Sozialwissenschaft, 13. Jg., Heft 2, S. 155-186.

Fuchs, Anke (1980): "Perspektiven der sozialen Sicherung der Frau", in: Schenke, Klaus und Schmähl, Winfried (Hrsg.), Alterssicherung als Aufgabe 
für Wissenschaft und Politik, Helmut Meinhold zum 65. Geburtstag, Stuttgart/Berlin u.a., S. 486-500.

Fuchs, Anke (1984): "Das SPD-Konzept zur Rentenreform", in: Wirtschaftsdienst, 64. Jg., Heft 11, S. 525-527.

Grandi, Werner (1990): "Die rentenrechtlichen Zeiten und die Wartezeit", in: Handbuch der gesetzlichen Rentenversicherung, Hrsg. F. Ruland, Frankfurt, S. 645-694.

Gärtner, H. (1978): Das nichteheliche Kind in Schule, Lehre und Beruf, Tübingen.

Geissler, Birgit/Pfau, Birgit (1988): "Geschützte Teilzeitarbeit für Eltern - ein Regulierungsmodell. SAMF-Arbeitspapier 1988-12.

Gerlach, Irene (1996): Familie und staatliches Handeln, Ideologie und politische Praxis in Deutschland, Opladen.

Glatzel, E. (1971): "Zur sozialrechtlichen Sicherung der nichterwerbstätigen Frau", in: Die Neue Ordnung in Kirche, Staat, Gesellschaft, Kultur, 25. Jg., Heft 2, S. 112-123.

Götting, Ulrike (1992): "Die Politik der Kindererziehungszeiten - Eine Fallstudie" - ZeS - Arbeitspapier Nr. $2 / 92$.

Grohmann, Heinz (1980): "Ist die Rentenformel reformbedürftig?", in: Schenke, Klaus und Schmähl, Winfried (Hrsg.), Alterssicherung als Aufgabe für Wissenschaft und Politik, Helmut Meinhold zum 65. Geburtstag, Stuttgart/Berlin u.a., S. 413-439.

Grohmann, Heinz (1985): "Demographische Entwicklung und Finanzierung der Alterssicherung", in: Hampe, Peter (Hrsg.), Renten 2000 - Längerfristige Finanzierungsprobleme der Alterssicherung und Lösungsansätze, München, S. 27-53. 
GroBjohann, Klaus (1984): "Unfallversicherungsträger lehnen Regierungsentwurf zur Neuregelung der Hinterbliebenenrente ab", in: Sozialer Fortschritt, 33. Jg., Heft 12, S. 289-290.

Gümpel, Udo (1988): Versorgungsausgleich im Scheidungsfall. Ein Ratgeber mit den gesetzlichen Neuerungen, Frankfurt am Main.

Hadler, Antje/Michel E. Domsch (1994): "Frauen auf dem Weg in Spitzenpositionen der Wirtschaft? Eine Bestandsaufnahme für die Bundesrepublik Deutschland", in: Aus Politik und Zeitgeschichte, Hrsg. Bundeszentrale für politische Bildung, Bonn, S.3-15.

Hahne, Meo Micaela (1987): "Die Abänderung rechtskräftiger Versorgungsausgleichsentscheidungen gemäß §10a VAHRG n. F.", in: Zeitschrift für das gesamte Familienrecht, 34. Jg., Heft 3, S. 217-231.

Hampe, Peter (1985): "Langfristige Alterssicherung - aber wie? - Ein einleitender Überblick", in: Hampe, Peter (Hrsg.), Renten 2000 - Längerfristige Finanzierungsprobleme der Alterssicherung und Lösungsansätze, München, S. 9-14.

Hampel, Herbert (1986): "Zu den geplanten gesetzgeberischen Maßnahmen auf dem Gebiet des Versorgungsausgleichs - Stellungnahme zum Entwurf des Bundesministers der Justiz", in: Zeitschrift für das gesamte Familienrecht, 33. Jg., Heft 3, S. 218-226.

Hansen-Blanke, Dora (1960): "Erwerbstätigkeit und Mutterschaftsleistung als Grundlage für eine selbständige Sozialversicherung für jede Frau", in: Die ökonomischen Grundlagen der Familie in ihrer gesellschaftlichen Bedeutung, Berlin, S. 292-295.

Hartmann, Helmut (1979): "Standort und Perspektiven der Sozialhilfe im System sozialer Sicherung", in: WSI-Mitteilungen, 32. Jg., Heft 12, S. 659669. 
Hase, Friedhelm (1992): "Benachteiligung der Familie durch die Rentenversicherung?", in: Wirtschaftsdienst, 72. Jg., Heft 10, S. 526-530.

Hase, Friedhelm (1995): "Anrechnung von Kindererziehungszeiten in der Rentenversicherung: Element eines sozialen Ausgleichs neuer Art?", in: Vierteljahresschrift für Sozialrecht, 23. Jg., Heft 1, S. 25-49.

Hase, Friedhelm (1996): "Sozialversicherung und Familie - verfassungsrechtliche Vorgaben für die Ausgestaltung der sozialen Sicherung?", in: Vierteljahresschrift für Sozialrecht, 24. Jg., Heft 2, S. 79-101.

Hauck, Karl und Bokeloh, Arno (1984): "Die Neuordnung der Hinterbliebenenversorgung in der gesetzlichen Rentenversicherung", in: Deutsche Rentenversicherung, Heft 11, S. 650-661.

Hauser, Richard (1983): "Zur Diskussion um die Witwenrenten. Ökonomische und sozialpolitische Aspekte der ,Rentenreform '84'", in: IfoStudien, 29. Jg., S. 139-161.

Hauser, Richard (1984): "Probleme des Anrechnungsmodells in der Hinterbliebenensicherung. Ein Vergleich mit einer allgemeinen bedingten Hinterbliebenenrente und dem Teilhabemodell", in: Ifo-Studien, 30. Jg., Heft 4, S. 107-138.

Hauser, Richard, Cremer-Schäfer, H. und Nouvertué, U. (1981): Armut, Niedrigeinkommen und Unterversorgung in der Bundesrepublik Deutschland. Bestandsaufnahme und sozialpolitische Perspektiven, Frankfurt am Main/New York.

Heier, Dieter (1986): "Grundrente statt Lebensstandardisierung - Wiederbelebung oder Überspannung des Subsidiaritätsprinzips?", in: Sozialer Fortschritt, 35. Jg., Heft 5/6, S.137-142.

Heine, Wolfgang (1986): "Die Neuregelung der Witwen- und Witwerrenten in der gesetzlichen Rentenversicherung. Zur Problematik einer Ein- 
kommensanrechnung bei beitragsfinanzierten Leistungen der Sozialversicherung", in: Zeitschrift für das gesamte Familienrecht, 33. Jg., Heft 2, S. 113-122.

Heine, Wolfgang (1986): "Hinterbliebenenfürsorge statt Hinterbliebenenversicherung", in: Zeitschrift für Sozialreform, 32. Jg., Heft 2, S. 82-104.

Heinsolm, Gunnar und Knieper, Rolf (1974): Theorie des Familienrechts. Geschlechtsrollenaufhebung, Kindesvernachlässigung, Geburtenrückgang, Frankfurt am Main.

Helberger, Christof (1984): "Zahlreiche Probleme bleiben ungelöst", in: Wirtschaftsdienst, 64. Jg., Heft 11, S. 528-532.

Helberger, Christof (1985): "Konkunturelle Haushaltsrisiken in der Rentenversicherung", in: Wirtschaftsdienst, 65. Jg., Heft 2, S. 72-78.

Helberger, Christof (1986): "Arbeitslosigkeit als finanzielles Problem des sozialen Sicherungssystems", in: Sozialer Fortschritt, 35. Jg., Heft 1/2, S. 1321.

Helberger, Christof (1988): "Frauenerwerbstätigkeit und die Entwicklung der sozialen Sicherungssysteme im internationalen Vergleich", in: Zeitschrift für Sozialreform, 34. Jg., Heft 11/12, S. 735-749.

Hentschel, V. (1983): Geschichte der Sozialpolitik in Deutschland von 1880-1980, Frankfurt/M.

Hermann, Franz (1976): "Eigenständige soziale Sicherung der Frau", in: Die neue Gesellschaft, 23. Jg., Heft 8, S. 640-642.

Herzog, Roman, Vortrag im Rahmen der Festakademie aus Anlaß des 50. Geburtstages von Frau Ministerin Rönsch. 
Hilzenbecher, Manfred (1985): „Die Richtigstellung des DreiGenerationenvertrages in der gesetzlichen Rentenversicherung durch eine Beitragsstaffelung nach der Kinderzahl“, in: Sozialer Fortschritt, 34. Jg., Heft 12, S. 281-288.

Hohmann-Dennhardt, Christine (1988): "Soziale Sicherung der Frau im Widerspruch von Familien- und Sozialrecht", in: Zeitschrift für Sozialreform, 34. Jg., Heft 11/12, S. 673-677.

Hoppenz, Rainer (1987): "Zum isolierten Versorgungsausgleichsverfahren - Verfahrensfragen auf Grund des Gesetzes über weitere MaBnahmen auf dem Gebiet des Versorgungsausgleichs", in: Zeitschrift für das gesamte Familienrecht, 34. Jg., Heft 5, S. 425-429.

Höhn, Charlotte (1980): "Rechtliche und demographische Einflüsse auf die Entwicklung der Ehescheidungen seit 1946", in: Zeitschrift für Bevölkerungswissenschaft, 6. Jg., Heft 3/4, S. 335-371.

Höhn, Charlotte (1983): "Frauenerwerbstätigkeit und soziale Sicherheit", in: Zeitschrift für Bevölkerungswissenschaft, 9. Jg., Heft 4, S. 475-486.

Höpfinger, Stefan (1984): "Der Durchbruch ist geschafft!", in: Wirtschaftsdienst, 64. Jg., Heft 11, S. 523-525.

Husmann, Jürgen: „Die Lage der Rentner in den neuen Bundesländern“, in: Aktuelles Presseseminar des VDR, 12./13. November 1992 in Würzburg.

Jacobsen, C. (1961): Familiengerechte Frauenarbeit, ein gesamtwirtschaftliches Zeitproblem, Berlin.

Jaeger, Renate (1996): "Familienleistungen in der Rentenversicherung", in: Vierteljahresschrift für Sozialrecht, 24. Jg., Heft 2, S. 125-134.

Kahn, A.J. und Kamerman, Sheila B. (1982): "Einkommenstransfers, Arbeit und das wirtschaftliche Wohlergehen von Familien mit Kindern: Ei- 
ne vergleichende Studie", in: Internationale Revue für Soziale Sicherheit, 35. Jg., Heft 3, S. 376-417.

Kaltenbach, Helmut (1978): "Soziale Sicherung der Frau und der Hinterbliebenen.", in: Die Angestelltenversicherung, 25. Jg., Heft 12, S. 4-27.

Kaltenbach, Helmut (1980): "Vorschläge zur 84er Reform, Synopse", in: Die Angestelltenversicherung, 27. Jg., Heft 8, S. 263-284.

Kaltenbach, Helmut (1984): Irrwege und Fehleinschätzungen, Zur Reform des Hinterbenenrentenrechts, Berlin.

Kaltenbach, Helmut/ Clausing, Peter (1985): "Das neue Rentenrecht 1986, Rentenrecht für Hinterbliebene und Anrechnung von Kindererziehungszeiten nach dem HEZG", München.

Kaltenbach, Helmut (1988): "Ein Kommentar zur Alterssicherung der Frau", in: Zeitschrift für Sozialreform, 34. Jg., Heft 11/12, S. 728-734.

Kerschreiter, M. (1983): "Zusammenfassung der Diskussion (zu Pfaff und Voskuhl)", in: M. Pfaff (Hrsg.), Effizienz und Effektivität staatlicher Transferpolitik in der Wirtschaftskrise, Schriften des Internationalen Instituts für Empirische Sozialökonomie, Bd. 7/I, Berlin, S. 351-256.

Kirner, Ellen (1980): "Verteilungs- und familienpolitische Aspekte der Pläne zur Rentenreform 1984. Ein Plädoyer für die ausreichende Anerkennung von Zeiten der Kindererziehung bei der Teilhaberrente", in: DIWWochenbericht, 47. Jg., Nr. 20, S. 209-216.

Klanberg, Frank (1983): "Die Kumulation von Renten und anderen staatlichen Transferzahlungen: eine Synopse", in: Deutsche Rentenversicherung, Heft 5, S. 295-315.

Klanberg, Frank (1985): "Sozialhilfebedürftigkeit unter Rentenempfängern", in: Deutsche Rentenversicherung, Heft 6/7/8, S. 437-448. 
Klanberg, Frank und Prinz, Aloys (1985): "Vexierbilder der neuen Familienpolitik", in: Wirtschaftsdienst, 65. Jg., Heft 9, S. 456-463.

Kleinhenz, Gerhard (1981): "Soziale Sicherung bei Mutterschaft", in: HdWW, Bd. 6, S. 629-635.

König, René (1974): Die Familie der Gegenwart. Ein interkultureller Vergleich, München.

Koeppinghoff, Sigrid (1982): Einkommenssicherung von Frauen im Alter. Perspektiven der Rentenreform 1984, Frankfurt/New York.

Kolb, Rudolf (1984a): "Hinterbliebenenversicherung oder Hinterbliebenenversorgung?", in: Deutsche Rentenversicherung, Heft 11, S. 635649.

Kolb, Rudolf (1984b): "Die Bedeutung des Versicherungsprinzips für die gesetzliche Rentenversicherung", in: Deutsche Rentenversicherung, Heft 4, S. 177-187.

Kolb, Rudolf (1985a): "Die gesetzliche Rentenversicherung", in: Hampe, Peter (Hrsg.), Renten 2000 - Längerfristige Finanzierungsprobleme der Alterssicherung und Lösungsansätze, München, S. 55-67.

Kolb, Rudolf (1985b): „Die Bedeutung des Versicherungsprinzips für die gesetzliche Rentenversicherung ${ }^{\star}$, in: W. Schmähl (Hrsg.), Versicherungsprinzip und soziale Sicherung, Tübingen, S. 120-139.

Kolb, Rudolf (1989): "Die geplante Neuregelung des Bundesanteils an der gesetzlichen Rentenversicherung", in: Wirtschaftsdienst, 69.Jg.,Heft 2, S. 74-82.

Kolb, Rudolf (1990): „Die Auswirkungen des Rentenreformgesetzes auf die weitere Entwicklung der Rentenversicherung“, in: Sozialer Fortschritt, 39. Jg., Heft 5, S. 102-108. 
Kollenberg, Udo (1978): Partnerschaft im Rentenrecht. Zur eigenständigen sozialen Sicherung der Frau, Beiträge zur Gesellschafts- und Bildungspolitik, Nr. 31, 2. erweiterte Auflage, Köln.

Krause, P. und Ruland, F. (1969): "Unvollständige Familie und Auflösung der Ehe im Sozialrecht", in: Zeitschrift für Sozialreform, 15. Jg., Heft 3, S. 129-148, Heft 4, S. 200-210, Heft 5, S. 260-274.

Krause-Brewer, F. (1980): Das Rentenrisiko, Stuttgart.

Kreikebohm, Ralf (1988): "Frauenarbeit und ihre Folgen für die soziale Sicherung: ein Kommentar", in: Zeitschrift für Sozialreform, 34. Jg., Heft 11/12, S. 687-695.

Kruber, Klaus-Peter (1988): "Die Lebenssituation von alleinerziehenden Müttern und Vätern - Bericht über eine empirische Studie in SchleswigHolstein", in: Zeitschrift für Sozialreform, 34. Jg., Heft 2, S. 89-103.

Krupp, Hans-Jürgen (1980): "Frauen-Erwerbstätigkeit und Ziele der Alterssicherung", in: Schenke, Klaus und Schmähl, Winfried (Hrsg.), Alterssicherung als Aufgabe für Wissenschaft und Politik, Helmut Meinhold zum 65. Geburtstag, Stuttgart/Berlin u.a., S. 501-521.

Krupp, Hans-Jürgen (1982): "Konsequenzen alternativer Vorschläge zur Rentenreform", in: Jahrbuch für Sozialökonomie und Gesellschaftstheorie, Verteilungsprobleme in Industriegesellschaften, Hamburg-Opladen, S. 82105.

Krupp, Hans-Jürgen (1984): "Sozialpolitische Ziele und der empirische Vergleich der Alterssicherungssysteme für abhängig Beschäftigte", in: Sozialer Fortschritt, 33. Jg., Heft 3-4, S. 57-65.

Krupp, Hans-Jürgen (1985): "Bestandsaufnahme und Perspektiven der Finanzierung des Sozialversicherungssystems", in: Wirtschaftsdienst, 65. Jg., Heft 2, S. 64-72. 
Krüger, Ellen (1981): Ein Vergleich der sozialen Sicherung alleinstehender Mütter durch die gesetzliche Rentenversicherung - Zur Auswirkung ehestatusgebundener Sicherung, Europäische Hochschulschriften, Reihe 5, Volksund Betriebswirtschaft, Bd. 331, Frankfurt am Main/Bern.

Külp, Bernhard (1981a): "Soziale Sicherung bei Ausfall und Tod des Ernährers", in: HdWW, Bd. 6, S. 611-617.

Külp, Bernhard (1981b): „Zur Diskussion um den Generationenvertrag“, in: Leitbilder für Familie und Familienpolitik, Festgabe für Helga Schmukker zum 80. Geburtstag, Hrsg. R.v. Schweitzer, Berlin, S. 131-143.

Lampert, Heinz (1982): "Sozialpolitik, I: staatliche", in: HdWW, Bd. 7, S. 60-76.

Lampert, Heinz (1984): "Das Transfersystem in der Bundesrepublik Deutschland - Bericht über das Gutachten der Transfer-EnqueteKommission", in: Finanzarchiv, N.F., Bd. 42, Heft 1, S. 475-504.

Lampert, Heinz (1986): Ordnungspolitische und verteilungspolitische Aspekte der Familienpolitik in der Bundesrepublik Deutschland, in: $\mathbf{H}$. Lampert, M. Wingen, Familie und Familienpolitik - Bestandsaufnahme und Perspektiven, Walter-Raymond-Stiftung, Kleine Reihe, Heft 41, Köln.

Lampert, Heinz und Beierl, Marianne (1983): "Reform der Altersrentenversicherung durch Nettolohnorientierung", in: WIST, 12. Jg., Heft 9, S. 455-461.

Langenheim, Hermann (1985): "Die Neuordnung der Hinterbliebenenrenten", in: Deutsche Rentenversicherung, Heft 9, S. 507-523.

Liefmann-Keil, Elisabeth (1961): Ökonomische Theorie der Sozialpolitik, Berlin u.a.O. 
Liegle, Ludwig (1978): "Familien mit alleinerziehenden Eltern - eine nach wie vor vergessene Minderheit", in: Neue Sammlung, 18. Jg., Heft 6, S. 583603.

Linke, W. (1981): "Auswertung der Mikrozensen für Aussagen über den Zusammenhang zwischen Kinderzahl und Erwerbstätigkeit verheirateter Frauen", in: Alte und neue Themen der Bevölkerungswissenschaft, Festschrift für Hans Harmsen, Boppard/Rh., S. 31-43.

Littmann, Konrad (1984): "Bericht und Anmerkungen zum Gutachten der Sachverständigenkommission Alterssicherungssysteme", in: Finanzarchiv, N.F., Bd. 42, Heft 2, S. 193-209.

Lohkamp-Himmighofen, Marlene (1994): "Vereinbarkeit von Familie und Beruf: Die Situation in den zwölf Ländern der EG", in: Aus Politik und Zeitgeschichte, B 7-8/94, S. 3-13.

Lohmann, Friedrich (1985): "Reform des Versorgungsausgleichs?", in: Deutsche Rentenversicherung, Heft 10/11, S. 577-585.

Lohr, Bernhard (1985): "Stand der Arbeiten zur Änderung des Versorgungsausgleichs", in: Deutsche Rentenversicherung, Heft 10/11, S. 631-635.

Luckert, H. und Rehfeld, U. (1989): "Die versicherungsfremden Leistungen der Rentenversicherung - Eine Schätzung von Häufigkeiten und Volumen", in: Deutsche Rentenversicherung, Heft 1/2, S. 42-71.

Lüscher, Kurt/Fisch, Rudolf/Pape, Thomas (1983): "Die Lebenssituationen junger Familien im Urteil der Eltern", in: Soziale Welt, 34. Jg., Heft 4, S. 450-470.

Mackscheidt, Klaus (1984): "Grundsätzliche Überlegungen zur Gestaltung von Harmonisierungschritten. Anmerkungen zum Bericht der Sachverständigenkommission Alterssicherungssysteme", in: Finanzarchiv, N.F., Bd. 42, Heft 2, S. 237-251. 
Mackscheidt, Klaus (1990): FinanzausgleichsmaBnahmen zwischen dem Bund und den Trägern der Sozialen Sicherung und zwischen den Trägern der Sozialen Sicherung untereinander, in: Finanzierungsprobleme der sozialen Sicherung I, Hrsg.: Kurt Schmidt, Schriften des Vereins für Socialpolitik, Neue Folge Band 194/I, S. 145-182.

Mådje, Eva/Claudia Neusü6 (1996): Frauen im Sozialstaat, Zur Lebenssituation alleinerziehender Sozialhilfeempfängerinnen, Frankfurt, New York.

Maier, Kurt (1988): "Die Rente im Jahr 2000 - Ziele und Vorstellungen einer Strukturreform der gesetzlichen Rentenversicherung im Blickwinkel der demographischen Entwicklung", in: Zeitschrift für Sozialreform, 34. Jg., Heft 7, S. 385-423.

Maydell, Bernd von (1980a): "Die Absicherung der Frau im System der sozialen Sicherung", in: Gesamtbericht über den 69. Deutschen Fürsorgetag 1980 in Frankfurt/M. 23-25.4. 1980: Soziale Arbeit, soziale Sicherheit, Aufgaben, Probleme, Perspektiven, Schriften des Deutschen Vereins für öffentliche und private Fürsorge, Nr. 261, S. 80-95.

Maydell, Bernd von (1980b): "Die Neuordnung der sozialen Alterssicherung der Frau", in: Zeitschrift für Sozialreform, 26. Jg., Heft 5, S. 270-278.

Maydell, Bernd von (1982): Die Neuordnung der sozialen Alterssicherung der Frau, Heidelberg.

Maydell, Bernd von (1984a): "Eine Alternative zum Regierungsentwurf", in: Wirtschaftsdienst, 64. Jg,.Heft 4, S. 532-534.

Maydell, Bernd von (1984b): "Hinterbliebenenrente mit Einkommensanrechnung - eine geglückte Reformkonzeption?", in: Deutsche Rentenversicherung, Heft 11, S. 662-676.

Mayntz, Renate (1955): Die moderne Frau, Stuttgart. 
Meinhold, Helmut (1984): "Ergebnisse der Sachverständigenkommission "Alterssicherungsprobleme" - Vergleichbarkeiten und Funktionsweisen", in: Sozialer Fortschritt, 33. Jg., Heft 3-4, S. 49-57.

Meinhold, Helmut (1985a): "Langfristprobleme der gesetzlichen Rentenversicherung", in: Hampe, Peter (Hrsg.), Renten 2000 - Längerfristige Finanzierungsprobleme der Alterssicherung und Lösungsansätze, München, S. 15-26.

Meinhold, Helmut (1985b): „Die ordnungspolitische Bedeutung des Versicherungsprinzips in der deutschen Sozialpolitik“, in: W. Schmähl (Hrsg.), Versicherungsprinzip und soziale Sicherung, Tübingen, S. 13-26.

Michaelis, Klaus (1996): "Familienlastenausgleich in der Rentenversicherung", in: Vierteljahresschrift für Sozialrecht, 24. Jg., Heft 2, S. 135-143.

Michalsky, H. (1984): "Parteien und Sozialpolitik in der Bundesrepublik Deutschland", in: Sozialer Fortschritt, 33. Jg., Heft 6, S. 134-142.

Miegel, Meinhard (1985): "Grundversorgung und private Alterssicherung - Eine Alternative zum bestehenden Rentenkonzept", in: Hampe, Peter (Hrsg.), Renten 2000 - Längerfristige Finanzierungsprobleme der Alterssicherung und Lösungsansätze, München, S. 83-92.

Miegel, Meinhard und Wahl, Stefanie (1986): "Wie reformbedürftig ist die gesetzliche Alterssicherung?", in: Die Sozialversicherung, 41. Jg., Nr. 4, S. 91-97.

Miegel, Meinhard (1994): "Am Ende der Gesellschaft-zerstört uns unsere individualistische Kultur", in: Die Neue Ordnung, 48.Jg., Heft 3, S.164-176.

Minz, Hubert (1985): "Reform oder Korrektur des Versorgungsausgleichs in der Beamtenversorgung", in: Deutsche Rentenversicherung, Heft 10/11, S. 596-602. 
Müller, Horst-Wolf (1988): "Zur langfristigen Finanzierung der Rentenversicherung unter demographischen und ökonomischen Aspekten", in: Zeitschrift für Sozialreform, 34. Jg., Heft 5, S. 270-283.

v. Münch, Eva Marie (1996): Die Scheidung nach neuem Recht, 9. Auflage, München.

Musgrave, Musgrave, Kullmer (1990): Die öffentlichen Finanzen in Theorie und Praxis, Bd. 1, 5. überarbeitete Auflage, Tübingen.

Myrdal, A./Klein, V. (1981): Die Doppelrolle der Frau in Familie und Beruf, Köln/Berlin.

Nahnsen, Ingeborg (1988): "Sozialpolitik im Spannungsfeld von Ungleichheit und Existenznot", in: Zeitschrift für Sozialreform, 34. Jg., Heft 10, S. 643-654.

Napp-Peters, A. (1985): Ein-Eltern-Familien, Weinheim, München.

Nave-Herz, Rosemarie (1988): Kinderlose Ehen, Weinheim.

Nave-Herz, Rosemarie/Krüger, Dorothea (1992): "Ein-Eltern-Familien." Eine empirische Studie zur Lebenssituation und Lebensplanung alleinerziehender Mütter und Väter. Materialien zur Frauenforschung, Band 15, Schriftenreihe des Instituts Frau und Gesellschaft, Bielefeld.

Nave-Herz, Rosemarie (1993): "Ledige Mutterschaft. Eine alternative Lebensform", in: Einblicke. Wissenschaft und Forschung an der Carl von Ossietzky Universität Oldenburg. Universität Oldenburg. Nr. 17, S.4-8.

Nave-Herz, Rosemarie (1996): "Zeitgeschichtliche Differenzierungsprozesse privater Lebensformen - am Beispiel des veränderten Verhältnisses von Ehe und Familie -", in: Gesellschaften im Umbruch, Verhandlungen des 27. Kongresses der Deutschen Gesellschaft für Soziologie in Halle an der Saale 1995, Hrsg.: Lars Clausen, Frankfurt/Main, S. 60-77. 
Neidhardt, Friedhelm (1975): Die Familie in Deutschland, Gesellschaftliche Stellung, Struktur und Funktion, Opladen.

Neidhardt, Friedhelm (1978): "Definition und Theorie der Familie", in: Filser, Franz (Hrsg.), Einführung in die Familiensoziologie, Paderborn u.a.O.

Nell-Breuning, Oswald von (1981a): "Gleichstellung der Frau in der sozialen Rentenversicherung", in: Leitbilder für Familie und Familienpolitik. Festgabe für Helga Schmucker, Berlin, S. 121-130.

Nell-Breuning, Oswald von (1981b): Drei Generationen in Solidarität, Rückbesinnung auf den echten Schreiber-Plan, Köln.

Nell-Breuning, Oswald von (1985): Gerechtigkeit und Freiheit. Grundzüge katholischer Soziallehre, Freiburg.

Nell-Breuning, Oswald von (1986): "Gespräch mit Dr. Jürgen Borchert: ,Die Alterssicherung hängt in der Luft"', in: Zeitschrift für Sozialreform, 32. Jg., Heft 4, S. 205-215.

Netzler, Andreas (1985): Soziale Gerechtigkeit durch Familienlastenausgleich. Eine normative Analyse unter besonderer Berücksichtigung der Rechtsphilosophie von Leonard Nelson, Sozialpolitische Schriften, Heft 53, Berlin.

Netzler, Andreas (1993): Familie als Risiko? Zur Anerkennung von Erziehungszeiten in der gesetzlichen Rentenversicherung, Konsequenzen aus dem Urteil des Bundesverfassungsgerichtes, Grafschaft.

Neumann, L.F., K. Schaper (1990): Die Sozialordnung der Bundesrepublik Deutschland, Frankfurt, New York. 
Neubauer, Erika (1994): "Alleinerziehende in den zwölf Ländern der EG, Familienform mit wachsender Bedeutung", in: Aus Politik und Zeitgeschichte, B 7-8/94, S. 14-21.

Niemann, Herbert (1981): "Nochmals: Versorgungsausgleich, Neuordnung der Hinterbliebenenversorgung und Kindererziehungsjahre - Lösung zu Lasten berufstätiger Mütter und geschiedener Eheleute?", in: Die Sozialversicherung, 36. Jg., Heft 2, S. 35-43.

Niemann, Herbert (1985): "Zur Zukunft und Sicherheit von Renten- und Versorgungsansprüchen - Teil I", in: Die Sozialversicherung, 40. Jg., Heft 9, S. 225-229.

Niemeyer, Frank (1994): "Nichteheliche Lebensgemeinschaften und Ehepaare-Formen der Partnerschaft gestern und heute", in: Wirtschaft und Statistik Heft 7, S. 504-517.

Niemeyer, Werner (1990): „Die Rentenversicherung anch der Reform rechtlich, sozialpolitisch, finanziell“", in: Sozialer Fortschritt, 39. Jg., Heft 5, S. 98-102.

Nullmeier, F./F.W. Rüb (1994): "Erschöpfung des Sozialversicherungsprinzips? Gesetzliche Rentenversicherung und sozialstaatlicher Republikanismus", in: Barbara Riedmüller, Thomas Olk (Hrsg.), Grenzen des Sozialversicherungsstaates, Leviathan, Sonderheft 14, S. 59-80.

Oberhauser, Alois (1985): "Die Ungereimtheiten des dualen Systems", in: Sozialer Fortschritt, 34. Jg., Heft 1, S. 14-20.

Oeter, Ferdinand (1954): Familienpolitik - Ziele, Wege und Wirkungen, Paderborn.

Oeter, Ferdinand (1985a): "Ungereimtheiten des dualen Systems - zum Aufsatz von Prof. Dr. Alois Oberhauser", in: Sozialer Fortschritt, 34. Jg., Heft 5, S. 110-112. 
Oeter, Ferdinand (1985b): "Ein sicher gefügtes System der Altersversorgung", in: Die Sozialversicherung, 40. Jg., Heft 6, S. 142-144.

Oeter, Ferdinand (1987): „Die Familienpolitik in den Steuersenkungsgesetzen der Regierung Kohl“, in: Zeitschrift für Sozialreform, 33. Jg., Heft 7, S. 431-441.

Oeter, Ferdinand (1995): „Benachteiligung der Familie in der Rentenversicherung!“‘, in: Die Angestelltenversicherung, 42. Jg., Heft 6, S. 202-206.

Ohsmann, Sabine und Ulrich Stolz (1997): Renteneinkommen von Witwen, Vortrag anläßlich der Tagung der Gesellschaft für Sozialen Fortschritt und der Bundesversicherungsanstalt für Angestellte (BfA) am 30.10.1997 in Berlin zum Thema: Die Alterssicherung von Frauen.

Osterloh, Margit/Karin Oberholzer (1994): "Der geschlechtsspezifische Arbeitsmarkt: Ökonomische und soziologische Erklärungsansätze", in: Aus Politik und Zeitgeschichte, Hrsg. Bundeszentrale für politische Bildung, Bonn, S. 3-10.

Pelikan, Wolfgang (1988): Rentenversicherung mit Versorgungsausgleich im Scheidungsfalle, 7. neubearbeitete Auflage, München.

Petersen, H.-G. (1981): Sicherheit der Renten? Die Zukunft der Altersversorgung, Würzburg, Wien.

Petersen, J. (1907): Die öffentliche Fürsorge für die hilfsbedürftige Jugend, Leipzig.

Pfaff, Anita B. (1980): "Erwerbsverhalten von Männern und Frauen im Lebenszyklus als Determinanten der Alterssicherung", in: Zeitschrift für Sozialreform, 26. Jg., Heft 5, S. 288-306.

Pfaff, Anita B. (1980): "Zur Sozialen Sicherung der Frau", in: Zeitschrift für die Gesamte Staatswissenschaft, 136. Jg., Heft 4, S. 694-704. 
Pfaff, Anita B. (1983): "Soziale Sicherung der Frau: Familienbezogene oder Personenbezogene Sicherung", in: Pfaff M. (Hrsg.), Effizienz und Effektivität staatlicher Transferpolitik in der Wirtschaftskrise, Schriften des Internationalen Instituts für Empirische Sozialökonomie, Bd. 7/, Berlin, S. 317-339.

Pfaff, Anita B. und Kerschreiter, Manfred (1982): "Die Familie im UmverteilungsprozeB: Monetäre Leistungen für Ehegatten und Kinder", in: Kaufmann, Franz-Xaver (Hrsg.), Staatliche Sozialpolitik und Familie, München/Wien, S. 131-164.

Plaschke, Jürgen (1984): "Zwischen sozialen Transfers und „unzumutbarer" Erwerbsarbeit: Zum Stand der Einkommenssicherung von Einelternfamilien in der Bundesrepublik und im internationalen Vergleich", in: Sozialer Fortschritt, 25. Jg., Heft 7, S. 154-164.

Pohmer, Dieter (1985): "Einige finanzpolitische Aspekte der Familienpolitik unter besonderer Berücksichtigung von Problemen de Familienbesteuerung", in: Hanusch, H., Roskamp, K.W. und Wisenau, J. (Hrsg.), Staat und Politische Ökonomie heute - Public Sector and Political Economy Today: Horst Claus Recktenwald zunn 65. Geb., Stuttgart/New York, S. 237-260.

Poshe, Dieter (1981): "Die Rechtsprechung des Bundesverfassungsgerichts zur Gleichstellung von Mann und Frau im Deutschen Rentenversicherungsrecht", in: Internationale Revue für Soziale Sicherheit, 34. Jg., Heft 2, S. 194-203.

Rauscher, Anton (1981): "Die Familie als Träger intertemporaler Ausgleichsprozesse", in: Herder-Dorneich, P. (Hrsg.), Dynamische Theorie der Sozialpolitik, Schriften des Vereins für Socialpolitik, Bd. 123, Berlin, S. 81111.

Reimann, Axel und Axel Teubusch (1990): „RRG 1992: Auswirkungen auf die Anwartschaftsstruktur der Versicherten", in: Die Angestelltenversicherung, 37. Jg., Heft 2, S. 93-104. 
Rerrich, Maria S. (1990): Balanceakt Familie, Zwischen alten Leitbildern und neuen Lebensformen, Freiburg im Breisgau.

Resch, Johannes und Knipping, Wolfgang (1982): "Die Auswirkungen des in der Bundesrepublik Deutschland bestehenden gesetzlichen Alterssicherungssystems auf die wirtschaftliche Situation der Familie", in: Jahrbuch für Sozialwissenschaft, Bd. 33, S. 92-122.

Richter, Wolfram F. und Weimann, Jochen (1987): „Kinderjahre: ein Vorschlag zur Rentenreform“, in: Wirtschaftsdienst, 67. Jg., Heft 5, S. 260262.

Riedmüller, Barbara (1985a): "Armutspolitik und Familienpolitik. Die Armut der Familie ist die Armut der Frau", in: Leibfried, Stephan und Tennstedt, Florian (Hrsg.), Politik der Armut und die Spaltung des Sozialstaats, Frankfurt am Main, S. 311-335.

Riedmüller Barbara (1985b): "Probleme mit der Frauenarbeit", in: Leviathan, Zeitschrift für Sozialwissenschaft, 13. Jg., Heft 2, S. 151-154.

Rieker, Karl (1987): "Neuordnung im Hinterbliebenen-Rentenrecht", in: Deutsche Rentenversicherung, Heft 7, S. 125-128.

Ritter, G.A. (1983): "Die Sozialversicherung in Deutschland 1881-1914", in: Aus Politik und Zeitgeschichte, Nr. B34, S. 30-38.

Rolf, Gabriele (1980): "Konjunkturelle Aspekte der Nettoanpassung", in: Schenke, Klaus und Schmähl, Winfried (Hrsg.), Alterssicherung als Aufgabe für Wissenschaft und Politik, Helmut Meinhold zum 65. Geburtstag, Stuttgart/Berlin u.a., S. 440-454.

Rolf, Gabriele und Wagner, Gert (1988): "Altersvorsorge von Frauen Probleme und Reformmöglichkeiten", in: Zeitschrift für Sozialreform, 34. Jg., Heft 11/12, S. 709-728. 
Ruby, A., Göttgens, B. und Koeppinghoff, S. (1982): "Rentenreform '84: Frauen bleiben diskriminiert", in: Prokla, 12. Jg., Heft 49, Nr. 4, S. 77-89.

Rudolph, Hedwig (1982): ",Neue Arbeitszeitpolitik' - schlechte Zeiten für Frauen", in: Prokla, 12. Jg., Heft 49, Nr. 4., S. 90-98.

Ruland, Franz (1975): "Die Stellung der Frau in der Sozialversicherung", in: Zeitschrift für das gesamte Familienrecht, 22. Jg., Heft 3, S. 144-155.

Ruland, Franz (1984a): "Die Vorschläge der Alterssicherungskommission zur Harmonisierung von Beamtenversorgung und Rentenversicherung", in: Sozialer Fortschritt, 33. Jg., Heft 3-4, S. 74-87.

Ruland, Franz (1984b): "Der Korrekturbedarf des Versorgungsausgleichsrechts", in: Deutsche Rentenversicherung, Heft 8, S. 415-428.

Ruland, Franz (1985a): "Reform oder Korrektur des Versorgungsausgleichs? - Eine gemeinsame Tagung des Verbandes Deutscher Rentenversicherungsträger (VDR) und der Gesellschaft für Versicherungswissenschaftund -gestaltung e.V. (GVG)", in: Deutsche Rentenversicherung, Heft 10/11, S. 573-576.

Ruland, Franz (1985b): "Sozialpolitische und verfassungsrechtliche Bedenken gegen das Anrechnungsmodell", in: Deutsche Rentenversicherung, Heft 5, S. 278-287.

Ruland, Franz (1987): "Die Verpflichtungen des Bundes gegenüber der Rentenversicherung", in: Wirtschaftsdienst, 67. Jg., Heft 12, S. 607-614.

Ruland, Franz (1992): „Reform der sozialen Sicherung der Frau, Analyse des Ist-Zustandes und Bericht über die noch in der Diskussion befindlichen Lösungsvorschläge“, in: Deutsche Rentenversicherung, Heft 2-3, S. 68-105. 
Ruland, Franz (1993): "Soziale Sicherung der Frauen - Bedarf, Ziele und Elemente einer Reform", in: Deutsche Rentenversicherung, Heft 6, S. 337 357.

Rürup, Bert (1981): "Der Bundeszuschuß an die Rentenversicherung. Vorschläge für eine Reform", in: Wirtschaftsdienst, 61. Jg., Heft 6, S. 276-282.

Rürup, Bert (1986): "Die Bedeutung des Bundeszuschusses zur gesetzlichen Rentenversicherung", in: Wirtschaftsdienst, 66. Jg., Heft 9, S. 458-460.

Rust, Ursula (1996): „Historische Entwicklung und gegenwärtige Bedeutung von Familienleistungen in der Sozialversicherung“, in: Vierteljahresschrift für Sozialrecht, Heft 2, S. 103-123.

Sachverständigenkommission für die soziale Sicherung der Frau und der Hinterbliebenen: Vorschläge zur sozialen Sicherung der Frau und der Hinterbliebenen. Gutachten der Sachverständigenkommission vom 21. Mai 1979.

SachBe, Ch. und Tennstedt, Florian (1982): "Familienpolitik durch Gesetzgebung: Die juristische Regelung der Familie", in: Kaufmann, F.X. (Hrsg.), Staatliche Sozialpolitik und Familie, München/Wien, S. 87-130.

Saul, K. (1980): Industrialisierung, Systemstabilisierung und Sozialversicherung. Zur Entstehung, politischen Funktion und soziale Realität der Sozialversicherung des kaiserlichen Deutschland, in: Zeitschrift für die gesamte Versicherungswirtschaft, Jg. 69, S. 177-198.

Schäuble, Wolfgang: "Und der Zukunft zugewandt", Berlin 1994.

Schaub, H.A. und Schaub-Harmsen, F. (1984): "Einelternfamilien", in: Familiendynamik, 9. Jg., Heft 1, S. 20-32.

Schäfer, Dieter (1988): "Alterssicherung in der sozialen Marktwirtschaft", in: Zeitschrift für Sozialreform, 34. Jg., Heft 5, S. 291-317. 
Schelsky, Helmut (1953): Wandlungen der deutschen Familie in der Gegenwart, Dortmund.

Scherf, Wolfgang (1994): "Familienbesteuerung und Familienlastenausgleich, Ansatzpunkte einer Reform des dualen Systems", in: Sozialer Fortschritt, 43.Jg., Heft 11; S. 259-265.

Schewe, Carola (1996): "Zur Zahlungsmoral von unterhaltspflichtigen Elternteilen", in: Sozialer Fortschritt, 45. Jg., Heft 9, S. 225-226.

Schlotter, Hans-Günther (1984): "Soziale Alterssicherung in ordnungspolitischer Sicht", in: Herder-Dorneich, P., Klages, H. und Schlotter, H.-G. (Hrsg.), Überwindung der Sozialstaatskrise, Baden-Baden, S. 199-240.

Schmähl, Winfried (1980a): "Die Kumulation von Versicherten- und Witwenrenten aus der gesetzlichen Rentenversicherung und ihre einkommensmäßige Bedeutung", in: Vierteljahresschrift für Sozialrecht, 8 Jg., S. 209-227.

Schmähl, Winfried (1980b): "Alterssicherung von Frauen und die langfristige finanzielle Entwicklung der Rentenversicherung", in: Zeitschrift für Sozialreform, 26. Jg., Heft 5, S. 306-329.

Schmähl, Winfried (1983): "Effektivität und Effizienz staatlicher ,Transferpolitik"', in: Pfaff, M. (Hrsg.), Effizienz und Effektivität staatlicher Transferpolitik in der Wirtschaftskrise, Schriften des Internationalen Instituts für Empirische Sozialökonomie, Bd. 7/I, Berlin, S. 61-101.

Schmähl, Winfried (1984a): "Ziele der Alterssicherungspolitik und Alternativen der Besteuerung von Alterseinkünften. Anmerkungen zum Bericht der Sachverständigenkommission!, in: Finanzarchiv, N.F., Bd. 42, Heft 2, S. 252-273.

Schmähl, Winfried (1984b): "Probleme der Zielformulierung in der Alterssicherungspolitik: zum Grundsatz einer, Gleichgewichtigen Entwicklung 
von Renten und verfügbaren Arbeitsentgelten' - Anmerkungen zur Neufassung des $₫ 1272$ Abs. 2, RVO", in: Sozialer Fortschritt, 33. Jg., Heft 9, S. 217-220.

Schmähl, Winfried (1985a): "Neuregelung der Hinterbliebenenversorgung in längerfristiger Perspektive", in: Deutsche Rentenversicherung, Heft 5, S. 288-296.

Schmāhl, Winfried (1985b): "Versicherungsgedanke und Sozialversicherung - Konzept und politische Bedeutung", in: Schmähl, Winfried (Hrsg.), Versicherungsprinzip und soziale Sicherung, Tübingen, S. 1-12.

Schmähl, Winfried (1985c): „Zur Bedeutung des Versicherungsgedankens für die weitere Entwicklung der gesetzlichen Rentenversicherung“, in: W. Schmähl (Hrsg.), Versicherungsprinzip und soziale Sicherung, Tübingen, S. 204-234.

Schmeiduch, Dietmar (1985): "Reform oder Korrektur des Versorgungsausgleichs? - Der Versorgungsausgleich in der gesetzlichen Rentenversicherung", in: Deutsche Rentenversicherung, Heft 10/11, S. 586-595.

Schmidt, Alfred (1988): „Alterssicherung und Familie, Probleme, Zusammenhänge, Lösungsperspektiven“, in: Die Angestelltenversicherung, 35. Jg., Heft 12, S. 477-492.

Schmidt, Henning/Frank, Udo/Müller-Rohr, Iris (1985): "Kritische Bemerkungen zum System des Kinderlastenausgleichs - zugleich ein Vorschlag zur Neugestaltung der gesetzlichen Rentenversicherung", in: Finanzarchiv, N.F., Bd. 43, Heft 1, S. 28-66.

Schmidt, M.G. (1988): Sozialpolitik - Historische Entwicklung und internationaler Vergleich, Opladen.

Schmidt, Michael (1993): "Die Erziehungsrente - eine (leider) fast unbekannte Rente", in: Die Sozialversicherung, 48. Jahrgang, S. 257-258. 
Schmidt, Michael (1996): „Verbessern Modelle der eigenständigen Sicherung wirklich die Altersvorsorge der Frauen?“, in: Sozialer Fortschritt, 45. Jg., Heft 10, S. 249-255.

Schöffel, Luise (1974): "Der soziale Status der alleinstehenden Mutter", in: Vorgänge Nr. 8, 13. Jg., Heft 2, S. 96-99.

Schönbauer, Gina (1969): "Soziale Sicherung der, nicht berufstätigen' Frau in zeitgemäBer Sicht", in: Zeitschrift für Sozialreform, 15. Jg., Heft 8, S. 449-461.

Schöningh, Insa/Monika Aslanidis/Silke Faubel-Diekmann (1991): Alleinerziehende Frauen, Zwischen Lebenskrise und neuem Selbstverständnis, Opladen.

Schreiber, Wilfrid (1955): Existenzsicherheit in der industriellen Gesellschaft, Vorschläge des Bundes katholischer Unternehmer zur Reform der Sozialversicherung, Köln.

Schubert, Renate (1993): Ökonomische Diskriminierung von Frauen, Frankfurt a. Main.

v. Schuller, Alexander (1996): Ernährer, Partner, Vater: Macht der Sozialstaat Ehe und Familie obsolet? Welt am Sonntag vom 13. Oktober 1996, Nr. 41, S. 37.

Schumacher, Helga (1961): "Das Kind als Kostenfaktor", in: Die ökonomische Lage der Familien in der Bundesrepublik Deutschland, Stuttgart, S. 267-304.

Schumacher, Harald (1982): "Der soziale Ausgleich in der Sozialversicherung. Anspruch und Wirklichkeit", in: Jahrbuch für Sozialökonomie und Gesellschaftstheorie, Verteilungsprobleme in Industriegesellschaften, S. 121136. 
Schurz, Eberhard (1985): "Große Rentenreform", in: Bundesarbeitsblatt, Heft 3, S. 24-27.

Schwarz, W. (1974): „Die Familie im sozialen Wandel“, in: Material zu Problemen der Familienpolitik, Konrad-Adenauer-Stiftung (Hrsg.), Bonn, S. 9-11.

Schweitzer, Rosemarie von (1976): "Entwicklungstendenzen der Haushalts- und Familienstruktur sowie der Erwerbstätigkeit der Frau", in: Schweitzer, Rosemarie von und Pross, Helge (Hrsg.), Die Familienhaushalte im wirtschaftlichen und sozialen Wandel, Göttingen, S. 79-101.

Sell, Stefan (1994): "Frauen in der Arbeitslosenversicherung und Arbeitsmarktpolitik, Theoretische und empirische Aspekte der Benachteiligung von Frauen", in: Sozialer Fortschritt, 43.Jg., Heft 5, S.116-120.

Seidl, Christian (1990): The Wish for a Son is the Father of Many Daughters - A Paradox in Population Economics, Manuskript, Institut für Finanzwissenschaft, Universität Kiel.

Sonderforschungsbereich 3 (Universität Ffm. und Mannheim) (1990): "Wird Alterssicherung von Frauen gesellschaftlichem Strukturwandel gerecht?", in: Die Sozialversicherung, 45. Jg., Heft 4, S. 90-91.

Stahl, Thomas und Zängle, Michael (1984): Die Legende von der Krise des Sozialstaats, Frankfurt am Main/New York.

Standfest, E. (1979): "Zur Diskussion um die soziale Sicherung der Frau und die Reform der Hinterbliebenenversorgung", in: WSI-Mitteilungen, 32. Jg., Heft 12, S. 682-687.

Statistisches Bundesamt (Hrsg.) (1983): Frauen in Familie, Beruf und Gesellschaft, Wiesbaden. 
Statistisches Bundesamt (Hrsg.) (1990): Familien heute, Strukturen, Verläufe und Einstellungen.

Statistisches Bundesamt (Hrsg.) (1995): Im Blickpunkt: Familien heute, Wiesbaden.

Statistisches Bundesamt (Hrsg.) (1996): Statistisches Jahrbuch für die Bundesrepublik Deutschland, Wiesbaden.

Stier, Günter (1982): "Ungelöste Basisprobleme der Rentenreform (1. + 2. Teil)", in: Soziale Sicherheit, 31. Jg., S. 20-25 und S. 43-49.

Stutzer, Erich/Wingen, Max (1989), Alleinerziehende in der Bundesrepublik Deutschland, Eine datenorientierte Analyse demographischer und sozioökonomischer Strukturen, „Materialien und Berichte“ der Familienwissenschaftlichen Forschungsstelle, Heft 21, Stuttgart.

Sudmann, Heinrich (1986): "Für Familie und Arbeitswelt (Erziehungsgeldgesetz)", in: Bundesarbeitsblatt, Heft 2, S. 5-7.

Susteck, Herbert (1995): "Das gesellschaftliche Verständnis der Familie in der Bundesrepublik Deutschland", in: Aus Politik und Zeitgeschichte, Heft 52-53, S. 16-25.

Swientek, Christine (1984): Alleinerziehende - Familien wie andere auch ? Zur Lebenssituation von Ein-Eltern-Familien, Bielefeld.

Temme, Willi (1955): "Mangelhafte Gleichstellung der Arbeiterwitwen", in: Soziale Sicherung, S. 373.

Tennstedt, F. (1976): Sozialgeschichte der Sozialversicherung, in: Maria Blohmke u.a. (Hrsg.), Handbuch der Sozialmedizin, Bd. 3, Stuttgart, S. 385492. 
Thiede, Reinhold (1994): „Benachteiligung der Familie in der Rentenversicherung? Anmerkungen zur Forderung nach einem verstärkten Familienbezug im Rentenrecht“, in: Die Angestelltenversicherung, 41. Jg., Heft 11, S. 401-409.

Thiede, Reinhold (1995): „Benachteiligung der Familie in der Rentenversicherung? - Eine Erwiderung auf den Artikel von Dr. Ferdinand Oeter - ," in: Die Angestelltenversicherung, 42. Jg., Heft 6, S. 207-210.

Tophoven, Christina und Wasem, Jürgen (1984): "Bevölkerungspolitische Steuerung als Aufgabe einer familienpolitisch orientierten Sozialpolitik?", in: Sozialer Fortschritt, 33. Jg., Heft 2, S. 25-29.

Ulshoefer, Helgard (1984): "Sozialpolitik und Familie, oder: Wie finden die neuen familialen Lebensformen Eingang in die staatliche Familienpolitik? Ko-Referat zum Referat von K. Lüscher: Neue familiale Lebensformen als Herausforderung der Soziologie", in: Sektion Frauenforschung in den Sozialwissenschaften in den DGS (Hrsg.), Frauenforschung. Beiträge zum 22. Deutschen Soziologentag, Dortmund, S. 19-21.

Veil, Mechthild/Karin Prinz/Ute Gerhard (1992): Am modernen Frauenleben vorbei, Verliererinnen und Gewinnerinnen der Rentenreform 1992, Berlin.

Verband Deutscher Rentenversicherungsträger (Hrsg.) (1993): Verbesserung der sozialen Sicherung der Frauen, Stellungnahme der Kommission des Verbandes Deutscher Rentenversicherungsträger zur Reform der Kindererziehungszeiten, DRV-Schriften, Band 1.

VDR: Statistik Rentenbestand am 31. Dezember 1994, Frankfurt, April 1995.

Voskuhl, Ursula (1979): "Bedeutung des Versorgungsausgleichs für die Neuordnung der Hinterbliebenenversorgung und der sozialen Sicherung der Frau", in: Zeitschrift für Sozialreform, 25. Jg., Heft 9, 348-356. 
Voskuhl, Ursula (1980a): "Die Reform der sozialen Sicherung von Ehegatten - Das Reformmodell und seine Begründung", in: Deutsche Rentenversicherung, Heft 3, S. 174-185.

Voskuhl, Ursula (1980b): "Auf dem Weg zur Reform der sozialen Sicherung der Frau und der Hinterbliebenen im Rentenrecht", in: Schenke, Klaus und Schmähl, Winfried (Hrsg.), Alterssicherung als Aufgabe für Wissenschaft und Politik, Helmut Meinhold zum 65. Geburtstag, Stuttgart/Berlin, S. 522-538.

Voskuhl, Ursula (1983): "Soziale Sicherung der Frau: Familienbezogene oder Personenbezogene Sicherung? Korreferat", in: Pfaff, M. (Hrsg.), Effizienz und Effektivität staatlicher Transferpolitik in der Wirtschaftskrise, Schriften des Internationalen Instituts für Empirische Sozialökonomie, Bd. 7/I, Berlin, S. 340-349.

Voskuhl, Ursula (1985): "Für Mütter und Väter", in: Bundesarbeitsblatt, Heft 10, S. 24-27.

Wagner, Gert (1985a): "Umverteilung in der gesetzlichen Rentenversicherung", in: Soziale Sicherheit, 34. Jg., Heft 2, S. 51-54.

Wagner, Gert (1985b): "Eine Dimension der Versicherungsfunktion in der gesetzlichen Rentenversicherung: Strukturelle Beitragsäquivalenz", in: Die Sozialversicherung, 40. Jg., Nr. 8, S. 197-203.

Wagner, Gert (1988): "Bedarfs- oder beitragsorientierte Grundsicherung in der Rentenversicherung?", in: Klanberg, Frank und Prinz, Aloys (Hrsg.), Perspektiven sozialer Mindestsicherung, Berlin, S. 59-94.

Wannagat, Georg (1985): „Verletzt das Anrechnungsmodell in der Hinterbliebenenreform das Versicherungsprinzip?“, in: Die Angestelltenversicherung, 32. Jg., Heft 3, S. 101-104. 
Weck-Hannemann, Hannelore/Bruno S. Frey (1988): "Die Frau in der Wirtschaft. Die Sicht der Nationalökonomie", in: Wirtschaft und Recht, Jg. 40.

Weg, Marianne (1982): "Vom Mutterschaftsurlaub zum Elternurlaub: Unter welchen Vorzeichen steht eine Reform?", in: WSI-Mitteilungen, 35. Jg., Heft 6, S. 467-481.

Weg, Marianne (1988): "Frauenarbeit und ihre Folgen für die soziale Sicherung", in: Zeitschrift für Sozialreform, 34. Jg., Heft 11/12, S. 677-687.

Wegehaupt-Schneider, Ingeborg (1982): "Von Konkurrenz kann keine Rede sein! Zur Bedeutung von familien- und sozialpolitischen Maßnahmen im historischen Verlauf der Frauenindustriearbeit in Deutschland", in: Prokla, 12. Jg., Heft 49, Nr. 4, S. 44-59.

Weidacher, Alois (1992): "Kritische Anmerkungen zum Familienlastenausgleich, Eine Bestandsaufnahme", in: Hauswirtschaft und Wissenschaft, 40. Jg. Heft 3, S. 131-136.

Willgerodt, H. (1956): "Der Familienlastenausgleich im Rahmen der Sozialreform", in: Ordo, Jahrbuch für die Ordnung von Wirtschaft und Gesellschaft, 8. Bd., S. ???

Wingen, Max (1964): Familienpolitik - Ziel, Wege und Wirkungen, Paderborn.

Wingen, Max (1980): "Familienlastenausgleich", in: HdWW, Bd. 2, S. 583599.

Wingen, Max (1984a): "Aspekte einer demographischen akzentuierten Gesellschaftspolitik", in: Herder-Dorneich, P., Klages, H. und Schlotter, H.G. (Hrsg.), Überwindung der Sozialstaatskrise, Baden-Baden, S. 169-197. 
Wingen, Max (1984b): Nichteheliche Lebensgemeinschaften, FormenMotive-Folgen, Osnabrück.

Wingen, Max (1989): "Verteilungspolitische Aspekte eines wirklichen Familienlastenausgleichs", in: A. von Mutius (Hrsg.), Ausbildungsförderung und Familienlastenausgleich, Dokumentation der Fachtagung des Deutschen Studentenwerks am 25. und 26. Mai 1988, Lorenz-vonStein-Institut, Schriftenreihe Bd.12, Heidelberg, S. 47-62.

Wingen, Max (1994a): Zur Theorie und Praxis der Familienpolitik, Stuttgart u.a.O.

Wingen, Max (1994b): „Nichteheliche Lebensgemeinschaften: Formen, Bedingungen und familienpolitische Forderungen", in: Wingen, M., Zur Theorie und Praxis der Familienpolitik, Stuttgart u.a.O., S. 349-364.

Wingen, Max (1995): "Familienpolitik als Gesellschaftsform", in: Aus Politik und Zeitgeschichte, Heft 52-53, S. 26-39.

Wunderlich, Klaus (1990): „Kein Anspruch auf Witwenrente, weil ein Anspruch auf Hinterbliebenenrente für eine Witwe besteht", in: Die Sozialversicherung, 45. Jg., Heft 7, S. 182-185.

Zimmermann, Horst (1989): "Kindergeld, Kinderfreibetrag oder Familiensplitting?", in: Wirtschaftsdienst, Jg. 69, Heft 3, S. 149-153.

Zimmermann, K.F. (1984): "Staatliche Incentives und intertemporale Ressourcenallokation im Lebenszyklus der Frau: Zeitallokation zwischen Markt- und Haushaltsproduktion und FamiliengröBe", in: Siebert, H. (Hrsg.), Intertemporale Allokation, Bern/New York/Nancy, S. 81-132.

Zimmermann, Klaus (1984): "Grenzen einer Bevölkerungspolitik durch Familienpolitik", in: Wirtschaftsdienst, 64. Jg., Heft 4, S. 180-185. 
426

Zöllner, D. (1981): Ein Jahrhundert Sozialversicherung in Deutschland, Berlin. 


\section{ZEITUNGSARTIKEL UND NACHSCHLAGEWERKE}

Süddeutsche Zeitung vom 13.3.1995

Der große Duden (1971): Fremdwörterbuch, Band 5, Mannheim/Wien/Zürich

Freiheit in Verantwortung, Grundsatzprogramm der Christlich Demokratischen Union Deutschlands, Beschlossen vom 5. Parteitag, Hamburg, 20.-23. Februar 1994.

Gesetz zur Sicherung des Unterhalts von Kindern alleinstehender Mütter und Väter durch Unterhaltsvorschüsse oder -ausfalleistungen vom 19. Januar 1994. 


\section{FINANZWISSENSCHAFTLICHE SCHRIFTEN}

Band 1 Werner Steden: Finanzpolitik und Einkommensverteilung. Ein Wachstums- und Konjunkturmodell der Bundesrepublik Deutschland. 1979.

Band 2 Rainer Hagemann: Kommunale Finanzplanung im föderativen Staat. 1976.

Band 3 Klaus Scherer: Maßstäbe zur Beurteilung von konjunkturellen Wirkungen des öffentlichen Haushalts. 1977.

Band 4 Brita Steinbach: "Formula Flexibility" - Kritische Analyse und Vergleich mit diskretionärer Konjunkturpolitik. 1977.

Band 5 Hans-Georg Petersen: Personelle Einkommensbesteuerung und Inflation. Eine theoretisch-empirische Analyse der Lohn- und veranlagten Einkommensteuer in der Bundesrepublik Deutschland. 1977.

Band 6 Friedemann Tetsch: Raumwirkungen des Finanzsystems der Bundesrepublik Deutschland. Eine Untersuchung der Auswirkungen der Finanzreform von 1969 auf die Einnahmenposition der untergeordneten Gebietskörperschaften und ihrer regionalpolitischen Zieladäquanz. 1978.

Band 7 Wilhelm Pfähler: Normative Theorie der fiskalischen Besteuerung. Ein methodologischer und theoretischer Beitrag zur Integration der normativen Besteuerungstheorie in der Wohlfahrtstheorie. 1978.

Band 8 Wolfgang Wiegard: Optimale Schattenpreise und Produktionsprogramme für öffentliche Unternehmen. Second-Best Modelle im finanzwirtschaftlichen Staatsbereich. 1978.

Band 9 Hans P. Fischer: Die Finanzierung des Umweltschutzes im Rahmen einer rationalen Umweltpolitik. 1978.

Band 10 Rainer Paulenz: Der Einsatz finanzpolitischer Instrumente in der Forschungs- und Entwicklungspolitik. 1978.

Band 11 Hans-Joachim Hauser: Verteilungswirkungen der Staatsverschuldung. Eine kreislauftheoretische Inzidenzbetrachtung. 1979.

Band 12 Gunnar Schwarting: Kommunale Investitionen. Theoretische und empirische Untersuchungen der Bestimmungsgründe kommunaler Investitionstätigkeit in NordrheinWestfalen 1965-1972. 1979.

Band 13 Hans-Joachim Conrad: Stadt-Umland-Wanderung und Finanzwirtschaft der Kernstädte. Amerikanische Erfahrungen, grundsätzliche Zusammenhänge und eine Fallstudie für das Ballungsgebiet Frankfurt am Main. 1980.

Band 14 Cay Folkers: Vermögensverteilung und staatliche Aktivität. Zur Theorie distributiver Prozesse im Interventionsstaat. 1981.

Band 15 Helmut Fischer: US-amerikanische Exportförderung durch die DISC-Gesetzgebung. 1981.

Band 16 Günter Ott: Einkommensumverteilungen in der gesetzlichen Krankenversicherung. Eine quantitative Analyse. 1981.

Band 17 Johann Hermann von Oehsen: Optimale Besteuerung. (Optimal Taxation). 1982.

Band 18 Richard Kössler: Sozialversicherungsprinzip und Staatszuschüsse in der gesetzlichen Rentenversicherung. 1982.

Band 19 Hinrich Steffen: Zum Handlungs- und Entscheidungsspielraum der kommunalen Investitionspolitik in der Bundesrepublik Deutschland. 1983.

Band 20 Manfred Scheuer: Wirkungen einer Auslandsverschuldung des Staates bei flexiblen Wechselkursen. 1983. 
Band 21 Christian Schiller: Staatsausgaben und crowding-out-Effekte. Zur Effizienz einer Finanzpolitik keynesianischer Provenienz. 1983.

Band 22 Hannelore Weck: Schattenwirtschaft: Eine Möglichkeit zur Einschränkung der öffentlichen Verwaltung? Eine ökonomische Analyse. 1983.

Band 23 Wolfgang Schmitt: Steuern als Mittel der Einkommenspolitik. Eine Ergänzung der Stabilitätspolitik? 1984.

Band 24 Wolfgang Laux: Erhöhung staatswirtschaftlicher Effizienz durch budgetäre Selbstbeschränkung? Zur Idee einer verfassungsmäßig verankerten Ausgabengrenze. 1984.

Band 25 Brita Steinbach-van der Veen: Steuerinzidenz. Methodologische Grundlagen und empirisch-statistische Probleme von Länderstudien. 1985.

Band 26 Albert Peters: Ökonomische Kriterien für eine Aufgabenverteilung in der Marktwirtschaft. Eine deskriptive und normative Betrachtung für den Allokationsbereich. 1985.

Band 27 Achim Zeidler: Möglichkeiten zur Fortsetzung der Gemeindefinanzreform. Eine theoretische und empirische Analyse. 1985.

Band 28 Peter Bartsch: Zur Theorie der längerfristigen Wirkungen 'expansiver' Fiskalpolitik. Eine dynamische Analyse unter besonderer Berücksichtigung der staatlichen Budgetbeschränkung und ausgewählter Möglichkeiten der öffentlichen Defizitfinanzierung. 1986.

Band 29 Konrad Beiwinkel: Wehrgerechtigkeit als finanzpolitisches Verteilungsproblem. Möglichkeiten einer Kompensation von Wehrungerechtigkeit durch monetäre Transfers. 1986.

Band 30 Wolfgang Kitterer: Effizienz- und Verteilungswirkungen des Steuersystems. 1986.

Band 31 Heinz Dieter Hessler: Theorie und Politik der Personalsteuern. Eine Kritik ihrer Einkommens- und Vermögensbegriffe mit Blick auf die Leistungsfähigkeitstheorie. 1994.

Band 32 Wolfgang Scherf: Die beschäftigungspolitische und fiskalische Problematik der Arbeitgeberbeiträge zur Rentenversicherung. Eine Auseinandersetzung mit der Kritik an der lohnbezogenen Beitragsbemessung. 1987.

Band 33 Andreas Mästle: Die Steuerunion. Probleme der Harmonisierung spezifischer Gütersteuern. 1987.

Band 34 Günter Ott: Internationale Verteilungswirkungen im Finanzausgleich der Europäischen Gemeinschaften. 1987.

Band 35 Heinz Haller: Zur Frage der zweckmäßigen Gestalt gemeindlicher Steuern. Ein Diskussionsbeitrag zur Gemeindesteuerreform. 1987.

Band 36 Thomas Kuhn: Schlüsselzuweisungen und fiskalische Ungleichneit. Eine theoretische Analyse der Verteilung von Schlüsselzuweisungen an Kommunen. 1988.

Band 37 Walter Hahn: Steuerpolitische Willensbildungsprozesse in der Europäischen Gemeinschaft. Das Beispiel der Umsatzssteuer-Harmonisierung. 1988.

Band 38 Ulrike Hardt: Kommunale Finanzkraft. Die Problematik einer objektiven Bestimmung kommunaler Einnahmemöglichkeiten in der gemeindlichen Haushaltsplanung und im kommunalen Finanzausgleich. 1988.

Band 39 Jochen Michaelis: Optimale Finanzpolitik im Modell überlappender Generationen. 1989.

Band 40 Bernd Raffelhüschen: Anreizwirkungen der sozialen Alterssicherung. Eine dynamische Simulationsanalyse. 1989.

Band 41 Berend Diekmann: Die Anleihe- und Darlehenstransaktionen der Europäischen Gemeinschaften. 1990.

Band 42 Helmut Kaiser: Konsumnachfrage, Arbeitsangebot und optimale Haushaltsbesteuerung. Theoretische Ergebnisse und mikroökonometrische Simulation für die Bundesrepublik Deutschland. 1990. 
Band 43 Rüdiger von Kleist: Das Gramm-Rudman-Hollings-Gesetz. Ein gescheiterter Versuch der Haushaltskonsolidierung. 1991.

Band 44 Rolf Hagedorn: Steuerhinterziehung und Finanzpolitik. Ein theoretischer Beitrag unter besonderer Berücksichtigung der Hinterziehung von Zinserträgen. 1991.

Band 45 Cornelia S. Behrens: Intertemporale Verteilungswirkungen in der gesetzlichen Krankenversicherung der Bundesrepublik Deutschland. 1991.

Band 46 Peter Saile: Ein ökonomischer Ansatz der Theorie der intermediären Finanzgewalten Die Kirchen als Parafisci. 1992.

Band 47 Peter Gottfried: Die verdeckten Effizienzwirkungen der Umsatzsteuer. Eine empirische allgemeine Gleichgewichtsanalyse. 1992.

Band 48 Andreas Burger: Umweltorientierte Beschäftigungsprogramme. Eine Effizienzanalyse am Beispiel des "Sondervermögens Arbeit und Umwelt". 1992.

Band 49 Jeanette Malchow: Die Zuordnung verteilungspolitischer Kompetenzen in der Europäischen Gemeinschaft. Eine Untersuchung aufgrund einer Fortentwicklung der ökonomischen Theorie des Föderalismus. 1992.

Band 50 Barbara Seidel: Die Einbindung der Bundesrepublik Deutschland in die Europäischen Gemeinschaften als Problem des Finanzausgleichs. 1992.

Band 51 Ralph Wiechers: Markt und Macht im Rundfunk. Zur Stellung der öffentlich-rechtlichen Rundfunkanstalten im dualen Rundfunksystem der Bundesrepublik Deutschland. 1992.

Band 52 Klaus Eckhardt: Probleme einer Umweltpolitik mit Abgaben. 1993.

Band 53 Oliver Schwarzkopt: Die Problematik unterschiedlicher Körperschaftsteuersysteme innerhalb der EG. 1993.

Band 54 Thorsten Giersch: Bergson-Wohlfahrtsfunktion und normative Ökonomie. 1993.

Band 55 Li-Fang Chou: Selbstbeteiligung bei Arzneimitteln aus ordnungspolitischer Sicht. Das Beispiel der Bundesrepublik Deutschland. 1993.

Band 56 Harald Schlee: Einkommensteuerliche Behandlung von Transferzahlungen. Zur Neuordnung der Familienbesteuerung sowie der Besteuerung von Versicherungsleistungen und Sozialtransfers. 1994.

Band 57 Alexander Spermann: Kommunales Krisenmanagement. Reaktionen baden-württembergischer Stadtkreise auf steigende Sozialhilfekosten und Einnahmenausfälle (198092). 1993.

Band 58 Otto Roloff / Sibylle Brander / Ingo Barens / Claudia Wesselbaum: Direktinvestitionen und internationale Steuerkonkurrenz. 1994.

Band 59 Claudia Wesselbaum-Neugebauer: Internationale Steuerbelastungsvergleiche. 1994.

Band 60 Stephanie Miera: Kommunales Finanzsystem und Bevölkerungsentwicklung. Eine Analyse des kommunalen Finanzsystems vor dem Hintergrund der sich abzeichnenden $\mathrm{Be}$ völkerungsentwicklung am Beispiel Niedersachsens unter besonderer Berücksichtigung des Landkreises Wolfenbüttel und seiner Gemeinden. 1994.

Band 61 Wolfgang Scherf: Die Bedeutung des kaldorianischen Verteilungsmechanismus für die gesamtwirtschaftlichen Wirkungen der staatlichen Neuverschuldung. 1994.

Band 62 Rainer Volk: Vergleich der Vergünstigungseffekte der verschiedenen investitionsfördernden Maßnahmen. 1994.

Band 63 Hans-Georg Napp: Kommunale Finanzautonomie und ihre Bedeutung für eine effiziente lokale Finanzwirtschaft. 1994. 2., unveränderte Auflage 1994.

Band 64 Bernd Rahmann / Uwe Steinborn / Günter Vornholz: Empirische Analyse der Autonomie lokaler Finanzwirtschaften in der Europäischen Gemeinschaft. 1994. 
Band 65 Carsten Kühl: Strategien zur Finanzierung der Altlastensanierung. 1994.

Band 66 Stephan Boll: Intergenerationale Umverteilungswirkungen der Fiskalpolitik in der Bundesrepublik Deutschland. Ein Ansatz mit Hilfe des Generational Accounting. 1994.

Band 67 Karl Justus Bernhard Neumärker: Finanzverfassung und Staatsgewalt in der Demokratie. Ein Beitrag zur konstitutionellen Finanztheorie. 1995.

Band 68 Christian Haslbeck: Zentrale versus dezentrale Internalisierung externer Effekte bei unvollständiger Information. 1995.

Band 69 Regina Müller: Horizontale oder vertikale Transfers zur Durchsetzung eines horizontalen Finanzausgleichs. 1995.

Band 70 Christian Hockenjos: Öffentliche Sportförderung in der Bundesrepublik Deutschland. Darstellung und finanztheoretische Analyse. 1995.

Band 71 Manfred Rosenstock: Die Kontrolle und Harmonisierung nationaler Beihilfen durch die Kommission der Europäischen Gemeinschaften. 1995.

Band 72 Christian Rüsch: Wohnungsbau- und Wohneigentumspolitik im Rahmen der Einkommensteuer. Eine Analyse unter steuersystematischen, verteilungspolitischen und fiskalischen Aspekten. 1996.

Band 73 Stephan Winters: Die kollektive Vorsorge für den Pflegefall im Alter. Eine Untersuchung am Beispiel der gesetzlichen Pflegeversicherung in den Niederlanden. 1996.

Band 74 Knut Blind: Allokationsineffizienzen auf Sicherheitsmärkten: Ursachen und Lösungsmöglichkeiten. Fallstudie: Informationssicherheit in Kommunikationssystemen. 1996.

Band 75 Barbara Petrick-Rump: Ökonomische Wirkungen von Steueramnestien. Untersuchung konkreter Erfahrungen ausgewählter Länder mit dem Einsatz von Steueramnestien anhand eines effizienten Steueramnestieprogramms. 1996.

Band 76 Georg Hirte: Effizienzwirkungen von Finanzausgleichsregelungen. Eine Empirische Allgemeine Gleichgewichtsanalyse für die Bundesrepublik Deutschland. 1996.

Band 77 Ulrike Kirchhoff: Die rheinland-pfälzischen Gemeinden im System des Finanzausgleichs. 1996.

Band 78 Kerstin Keil: Der soziale Mietwohnungsbau: Mängel und Alternativen. 1996.

Band 79 Bernhard Manzke: Kinderlastenausgleich versus verstärkte Einwanderung. Alternative Ansätze zur langfristigen Sicherung der Gesetzlichen Rentenversicherung. 1997.

Band 80 Hariolf $M$. Wenzler: Institutionenökonomik und öffentliche Finanzkontrolle. Eine Analyse am Beispiel der Europäischen Union. 1997.

Band 81 Joachim Nagel: Supply-Side Policy in den USA. Eine theoretische und empirische Analyse der angebotsorientierten Wirtschaftspolitik Reagans unter besonderer Berücksichtigung steuerlicher Aspekte. 1997.

Band 82 Heinz Lampert: Krise und Reform des Sozialstaates. 1997.

Band 83 Monika Hanswillemenke / Bernd Rahmann: Zwischen Reformen und Verantwortung für Vollbeschäftigung. Die Finanz- und Haushaltspolitik der sozial-liberalen Koalition von 1969 bis 1982. 1997.

Band 84 Berthold Fürst: Die Maastrichter Budgetkriterien im Konflikt mit der Verschuldungsautonomie der deutschen Gebietskörperschaften. 1997.

Band 85 Burkhard Pahnke: Einkommensorientierte Förderung des sozialen Mietwohnungsbaues. Bestandsaufnahme und Kritik. 1998.

Band 86 Judith Safford: Staatsverschuldung im Vereinigten Königreich. Die öffentliche Verschuldung unter der Konservativen Regierung von 1979-1994. Ursachen und Auswirkungen. 1998. 
Band 87 Ralf Oberheide: Die Bekämpfung der Steuerumgehung. 1998.

Band 88 Achim Truger: Die neue Finanzwissenschaft zwischen Realitätsferne und Irrelevanz der Annahmen. Eine methodologische Analyse potentieller Verteidigungsstrategien der neuen Finanzwissenschaft gegen den Vorwurt der Realitätsferne ihres entscheidungstheoretischen Fundamentes. 1998.

Band 89 Karin Bickel: Familienbezogene Elemente im System der gesetzlichen Rentenversicherung. Unter besonderer Berücksichtigung von Ein-Eltern-Familien. 1999.

Band 90 Wolfgang Scherf: Schlüsselzuweisungen und Kreisumlage. Die Problematik der Finanzierung der Landkreise am Beispiel des kommunalen Finanzausgleichs von RheinlandPfalz. 1998.

Band 91 Sandra Ehmann: Familienpolitik in Frankreich und Deutschland - ein Vergleich. 1999.

Band 92 Hendrik Suermann: Einkommensteuerliche Behandlung von Währungsgewinnen und -verlusten. Eine finanzwissenschaftliche Analyse des Steuerrechts in den USA und in Deutschland. 1999.

Band 93 Rolf Bösinger: Die Neuordnung des bundesstaatlichen Finanzausgleichs 1995. Eine theoretische und empirische Analyse unter Berücksichtigung von allokationstheoretischen und polit-ökonomischen Gesichtspunkten. 1999.

Band 94 Ulrich Ermschel: Finanzwirtschaftliche Konsequenzen beim Übergang auf das Ursprungslandprinzip im Europäischen Binnenmarkt. Eine Untersuchung am Beispiel des unvollkommenen oligopolistischen Neufahrzeugmarktes. 1999. 